

$$
\gamma
$$






'THE FloraL WORLD begins its life in a modest way, and with an humble aim. It seeks only to be a reliable and practical guide to home floriculture. All our space and effort will be devoted to this end.

Interest in flowers is greater today than ever before. There are few homes worthy the name in which they are not grown to some extent. People are learning more and more to appreciate the beauty and fragrance which flowers afford.

We shall do our best to make THE FLORAL WORLD of real service to all who love flowers. It will be edited by men and women who cultivate plants under ordinary conditions. Their great desire is that this may be the people's floral magazine-simple, accurate and to the point.

IVe make no extravagant promises as to the future. Our readers will be given the best advice and the most reliable information we can gather from those who have success with flowers. We have no higher ambition than to have THe Floral WORLD a complete and practical flower journal-one which will tell you what you want to know. If our plan suits you, let us have your subscription and kindly tell your neighbors what we propose to do. Address us as

The Floral IVorld, Springfield, Ohio.

\section{A Word As To Our Prize Awards}

Some weeks ago the publishers of THE FLORAL WORLD advertised an offer of $\$ 100.00$ in cash prizes for the best articles on home flower growing submitted them before September 30, 1901. The response has been so great that it will require two numbers of the paper in order to publish all the contributions. The articles which appear this month, therefore, and those which we shall give place in our November number, all have been entered in this prize contest.

The prizes are to be awarded by our subscribers. In the November issue we shall print a coupon, or blank ballot, on which you may vote as to the best articles. There will be spaces on the coupon wherein you may indicate your selection of the best article, the second best, and so on through the list of prizes offered. The writer of the article which is roted to be the best by the largest number of subscribers will be awarded first prize, and the other awards will be made in the same manner. Only subscribers will be allowed to vote.

We now invite from our friends articles suitable for publication in the December number of THE FLORAL WORLD. These should be of timely interest and must be short-hereafter we will receive no article that contains more than 300 words. Only contributions from subscribers will be received. All the articles intended for this competition must reach us by Norember 10. For the best article we will give a prize of $\$ 25.00$; for the second best, $\$ 15.00$; for the third best, $\$ 10.00$; for the fourth best, $\$ 3.00$, and for the fifth best, $\$ 2.00$. The prizes will be awarded by rote of our subscribers and announced in the February, 1902, issue.

Address your letters to

THE Floral WORLD, Springfield, Ohio 


\section{The Floral World A Fournal For Home Floriculture}

Vol. I, No. I

Springfield, Ohio, October, 1901

25 Cents a Year

\section{GERANIUMS FOR WINTER}

If one wishes nice plants for winter blooming they must begin in the spring and pinch out all buds and also the new shoots, so the plants will be in a strong, healthy condition and do their best in the dull days of winter. A little fertilizer worked into the earth will greatly benefit them, and with care they should give an abundance of blossoms. Don't use too large pots or there will be more leaves than flowers.

Mrs. E. E. CADY.

Vermont.

\section{HANDY WINTER PROTECTION}

For tender roses, carnations, verbenas and chrysanthemums left in the ground before freezing weather comes, invert a small box or barrel, according to size of plant, over each. Before severe weather comes on bank up the earth around the box. In the spring the cover should be left off on sunny days only, until all danger of freezing weather is past. I have kept plants nicely in this way. Gladiolus bulbs I dry and put in the cellar in a box. Dahlia and madeira vine roots keep best in a box of dry sand. Last winter I set my bedding geraniums in small boxes of dirt, crowding several in each box, and set the boxes upstairs in a cool room and watered them once in two weeks until spring. The larger geraniums I dug up by the roots and hung in a damp cellar. All of my plants did well. Mrs. A. A. Sigler.

Indiana.

\section{AUTUMN HINTS ABOUT CACTI}

Early in September, and not later than October, is the best time to order cactus. The cactus is indigenous in the Southwest and tropical climates, and naturally begins to blossom in its native haunts very early in the spring.

Many cacti lovers have been disappointed in their culture owing to this fact, as they begin to order cactus after blossoming time, and become discouraged before the next year, and discard them in disgust.

Echino cacti in its numerous genera lends, itself to the many drawbacks of window culture more readily than any variety I know of. It is quite hardy, has beautiful spines, and blooms brilliantly as well as profusely. Needs little attention till January, then water with lukewarm water copiously till after flowering.

There are no plants or bulbs that will withstand the neglect that the family of cactus will.

All lovers of the curious and beautiful in plant life should try a few Echino cactus. E. Wislizenii is a very hardy variety, has strange, hooked spines like a fishhook, and blooms readily with the simplest of care. Cut off roots close to plant, pot in sandy soil, well drained; water well in early spring till after blooming, then gradually withhold water, giving water only when soil seems very dry. Sunlight is the cacti's greatest need.

Mrs. Sudie L. Patterson.

New Mexico. 


\section{HOW I PLANT BULBS}

I have a bank. against a piazza and another where the ground is terraced off. Four years ago the last of October I dug some well rotted manure in, made a trench four inches wide and six deep, put in one inch of sand, set the bulbs on the sand, put a little around them, then filled in the earth and rounded it to keep out water after the ground froze. I covered with leaves and laid on pine boughs to keep the leaves from blowing away. I set out a few new ones every fall, spread on dry the manure and mix it a little with the earth. I do not think that I ever lost a bulb. Every spring they are full of blossoms, double and single. After they are done blooming I set out petunias or any plants that do not have deep roots, and have Howers the rest of the summer.

Mrs. J. M. Fowle.

Massachusetts.

\section{HYACINTH CULTURE}

If those who are debating in their minds whether or not to plant hyacinths this fall could only once see my hyacinth bed in bloom, and know how easily it is managed, I am sure they would hesitate no longer. My bed is twenty-four feet long by eighteen feet wide, and it was planted more than eight years ago. In all that time the bulbs have never been taken up nor reset, and their wealth of fragrant, beautiful blossoms grows, if possible, more abundant and gorgeous with each returning spring. Before planting the soil was well forked up and gotten into fine condition. The bed was then laid off in rows four inches deep and eighteen inches apart. The last of October the bulbs were planted, each one placed firmly in the rows nine inches apart, the soil drawn over them and slightly packed. Later on, just before freezing weather, a compost of hen house manure and wood ashes-one- third ashes and two-thirds manurewas spread thickly over the bed. The following spring this dressing was well worked into the soil, care being taken to hoe between the rows in order not to disturb the plants that were just beginning to peep above the ground. Every fall I give my bed this dressing, following it in the spring with the working, and this is all the attention it receives for its thousands of handsome stalks of beautiful flowers that delight all who see them. For year's I have had growing side by side the double purple, double pink, double white and single yellow, and they are just as perfect in color and size as when first planted.

Tennessee.

Mrs. H. C. Ryall.

\section{EXPERIENCE WITH HYACINTHS}

My first experience with hyacinths was in the ' 80 's, and was almost a failure, as some of the blossoms had stems an inch or two long, while others blossomed close to the dirt. I did not get discouraged, but kept trying, and for years I have had lovely blossoms with long stems. I used to think the flowers pictured in catalogues were exaggerated, but I know they were not from experience, as I have had them equally as nice. Plant the bulbs in September or the first of October, in good garden soil and chip dirt, equal parts. Fill the pots with dirt, leaving room at the top to place the bulbs, then cover, leaving the center of the bulb uncovered; never press the bulbs in the dirt, as when they sprout they will be apt to throw the bulbs on top of the pots. After planting place the pots in a pail of water, with the water just at the rim of the pots; leave them till the water has penetrated the dirt on the top of the pots, take out and drain, then place in a dark place in the cellar, leave there till the sprouts are an inch long, no matter if you can see the buds, bring them upstairs, place them back from 
the light for a few days until the leaves turn a dark green, then give them sunshine and plenty of water. If they should become dry when down cellar, water them. Sometimes I have to water, at other times I do not. The reason people fail with hyacinths is because they do not give them time enough to make root growth before bringing to the light. There can be no specified time, as some cellars are much warmer than others, and some bulbs are more mature than others.

Connecticut.

R. J. BRAdLEy.

\section{OXALIS CULTURE}

If all flower lovers could grow oxalis as some of us do, the homes of many, at almost no expense, could be made cheering and cultivating. We have been trying it for some years and speak from experience. The way to do it is very simple.

Get the best bulbs you can from a florist. Give them careful attention, enjoy them when they bloom, but remember to give the plants full opportunity to mature their bulbs. Because they become faded in leaf and no longer bear flowers, don't cast them away. When leaf and stem are dying cut them off and put aside the box or jar and let it alone. In about two months you will find beautifully dried bulbs in the bottom. Select the finest of these for your next planting, give some of the remaining to cheer a neighbor, and throw away the small ones. Do this every year. Now you may be said to be on your feet, and can follow my plan if you wish. In September take a box (with holes in bottom for drainage) eighteen inches long, six wide and four deep. Fill it with good garden earth mixed onethird with decomposed cow manure. Put in your bulbs, in two rows, five inches apart in the row. See that the point of bulb is well up and the bulb itself an inch and a half below the sur- face. Press the earth firmly in the box so as to force it an inch below edge of box. (You will have space here for more enriching if needed.) Set the box in the shade and water thoroughly. If the weather be dry, water again when the surface earth shows dryness. When your plants are up keep them well watered. Give them all the light (not sun always) you can, and in a month or two you will have something to be proud of.

Pursuing this plan, I have now bulbs of the large trailing pink oxalis (which flowers in clusters) measuring over two inches in length by one-half inch through; the leaves measure six inches across or three inches to each lobe, and the flowers are larger than a silver dollar. My Grand Duchess and single white have flowers. even larger.

South Carolina. JoHN GADSDEN.

\section{WINTER PROTECTION OF ROSES}

I prune out all weak branches, cut back old tops and allow frost to attack them well into December, then mulch them well with rotted manure and straw, tie down the tops, put light litter over them that will not pack or smother them. Put old boxes or barrels over them, leave air holes in them, but not large enough for the sun to get in. In the spring, about April 20th, take off barrels. In a few days let the tops up. Now when there is no more danger of the ground freezing nights, remove the light litter and spade the manure in the ground around the plants. This proves very successful here in the Northwest. Many are afraid to try the culture of flowers of any kind here in South Dakota on account of the wind and cold, but I have found no trouble, and write this to help my Western sisters. Protect your roses in this manner and you will save them in any winter weather. J. A. Eves.

South Dakota. 


\section{THE SUMMER OR WINTER GARDEN}

There are two things that make a success. One is to puddle the roots of every transplanted flower or shrub. To puddle means to prepare a batter of clay or firm, heavy soil and water. Dip the roots in this, then place in the ground or pot and press the earth firmly around the plant. It is an ideal treatment, as the roots are at once coated round about with soil. The other is to place powdered charcoal around bulbs of every description. Place it under, around and over every bulb you plant. It insures against rot. Let everyone try these two simple helps to floriculture. I have proved their worth for fifteen years, with never a failure. Try the puddling for your transplanted roses that come two thousand miles, and other plants also. Try the charcoal for the bulbs when they seem soft. Try it for the tuberous begonias when they start to rot.

California. Mrs. AnNa Schuler.

\section{OUR BEST BLOOMING}

As freesias are one of our best winter flowering bulbs, I want to give my experience in raising them.

If wanted to bloom in December, I plant not later than August 1st, and for a succession of blooms, every two or three weeks until the last of October. Last year I took a cheese box, put plenty of charcoal at the bottom for drainage, and used ordinary garden soil with a little manure, and put about fifteen or twenty bulbs in it about an inch deep, watered well, and set away under the porch. As soon as I noticed the tender shoots I removed them to the sunny corner of the porch, kept watered well until cold weather, when I took them into my dining room at the east window, where they bloomed profusely.

After the blooming season was over I gradually left off watering until the foliage was dead, then I put them, box and all, under the porch. The first of August I took out the bulbs, sorted them, put the small ones in a pot to themselves to make blooming bulbs for next season, and the large ones gave the same treatment as at the start. Mrs. HARRY GodBER.

Texas.

\section{LILIES}

The growing of the lily is easy if certain rules are observed. First, procure good bulbs as early in the fall as possible. Place them in shallow dishes in lukewarm water, but do not cover crowns; let them remain twenty-four hours. In the second place, get the right kind of soil. A good one consists of two parts garden soil, one part sand, one part well rotted cow manure, mixed thoroughly. For a large sized bulb take an eight-inch pot, put in two inches of drainage, then a layer of moss to prevent soil washing down; fill up with compost, leaving two inches at top. Make a cavity a little larger than bulb, line with sand to prevent bulb coming in contact with soil. Put bulb in place and cover it, having half an inch of soil over crown. Water thoroughly, then invert saucer over it to protect from mice and to darken it. Put in dark corner of cellar. Examine in four weeks. Water it if dry. Examine again in two or three weeks, when you may begin to see signs of growth. When the stalk is half an inch begin by removing cover in day and replacing at night. Bring gradually to light and sunshine, which will take about two weeks. Then give plenty of sunlight, but not much artificial heat, as they like a low temperature. After the plants reach a height of eight or ten inches fill in with soil for nourishment and support laterals which are thrown out at base of stalk. Keep moist, but not too wet. Mrs. Candace Powell. 


\section{PEONIES}

The situation should be open, the soil deep, at least two feet, well drained, and the richer the better.

Peonies delight in a light, rich soil, and object to heavy clay. The bed should be made in September or October, and the roots planted from two and one-half to three feet apart. Set fairly deep so they will not suffer badly if thrown up by the frost. A good cover of leaves before the ground freezes is important. Remove this in early spring and replace with a thick layer of good manure, which leave on all summer. At no time let them suffer for water. Peonies love water, and upon a free use of it depends the quality of the blooms. Some form of support must be used, or a heavy shower at the time of blooming will result in the ruin of the blooms. If you make your bed well in the beginning it will not need to be disturbed for several years. You will want both double and single varieties.

Mrs. Annie E. Craft.

Missouri.

\section{PANSIES IN MIDWINTER}

In October I potted some young pansy plants in a large tin dishpan, about four inches in depth. The soil was composed of very rich leaf mold, sand and common garden soil, with a little well rotted cow manure chopped very fine. When the plants were well settled they were given an eastern window, but after it became very cold they were changed to a southern window in a frost-proof room, but where no fire was ever used. They were sprayed with a very fine spray daily, the soil was stirred and kept very loose and always moist. A liquid fertilizer of a few drops of ammonia in water was given them twice a week, but this was never allowed to touch the foliage. 'I had quantities of the large, dark, velvety pansies measuring
- three inches across. No seed pods were allowed to form, so I had quantities of bloom for the greater part of the winter.

Spraying with a very fine spray kept down the insects, and on very cold nights the pan was wrapped in several thicknesses of newspaper and placed in a room where there was no fire.

Kentucky. MIss LAURA Jones.

\section{ROMAN HYACINTHS}

I would like to tell others the success I have with Roman hyacinths. I always have them in bloom for Christmas, and from that until spring. I plant in small grape baskets; for me they grow and bloom better in these than in pots. I always keep good soil for my pot plants, a mixture of leaf mold, sand, garden soil and well rotted manure. First I break up old pieces of pots and cover the bottom of basket for drainage, then fill with soil and plant ten bulbs in each basket, four on each side and one at the ends, cover lightly and pack down, put in a dark place, where there will be no danger of mice, and let them remain for six weeks. During this time the roots will grow, and when brought to the light will come along rapidly, form buds and soon be in bloom. I plant my first bulbs the last week in September, then every three weeks until the last of November, keeping them moist, but not too wet. When in bud I take green crinkle paper and arrange nicely around the basket, and when in bloom they are indeed a thing of beauty. Do not keep them too warm and they will bloom longer and more luxuriantly. Then your friends will exclaim at their loveliness, and want to know when and how to plant-and forget all about it until they see them again, when it is too late. I have success with 'other bulbs, but none give me such pleasure as my hyacinths.

MRs. B. G. WARD.

North Carolina. 


\section{KEEPING BULBS}

Our bulbs and roots coming from so many different climates require different treatment and surroundings to keep successfully through the long winters of the North. Cannas, caladiums, tuberoses and many other's if kept cool and damp will rot or become blind; that is, the eye will be dead, though the bulb may appear sound. Dahlias, spotted calla, gladiolus and others, if kept dry and warm will dry up. Under the benches of a greenhouse is an ideal place to keep cannas, Caladium esculentum and dahlias. Gladiolus and spotted calla, zephyranthes, can be kept as easily as potatoes, but tuberoses, gloxinias, tuberous begonias, fancy caladiums, must be kept in dry sand in the warmest place, not lower than fifty degrees. Those who have only a cellar for their treasures will have lots of trouble and many losses even with the best of care. After the frost kills the tops of cannas and dahlias dig and set the clumps in boxes and fill in with soil about as they grew. Gladiolus, tuberoses, spotted calla and zephyranthes should be dug and dried and put in boxes, the tuberoses in a warm place, the others in any place free from frost. Tuberous begonias, fancy caladiums, gloxinias, in dry sand in a warm closet. A watchful eye should be kept on all bulbs and plants while in their winter quarters that they do not become too wet or too dry, too hot or too cold, for either extreme is fatal to some. Experience is the best teacher.

Ohio.

S. J. GALLOWAY.

\section{BIBLE CROCUS BED}

Mark off a rectangle eight by five feet. Spade the bed in small, deep spades, so the ground will be in a fine, mellow condition, and it must have a reworking to fine the surface, and not be grassy nor trash on it, and ready to plant in October or November. bought seven hundred crocus bulbs of the Mammoth Yellow, but did not use the small ones, and one hundred and fifty early Duc Van Thol scarlet tulips.

Set the tulips very close in two rows around the edge. Now mark in the bed "Holy Bible" in plain letters, and set close, nearly touching the crocus bulbs in the letters. Make the capitals in a solid chain and the corners fill in, but not touching the letters, and three rows around the margin by the tulips.

Be sure the bed drains and has no manure touching on the bulbs. But cover with two inches of good garden soil. Mulch with leaves and cover with brush to keep the leaves from blowing away.

The crocus blooms first, and a little later the golden Bible will be bordered with a deep crimson, and these two colors blend so pretty. Notice the bed early and remove the mulch as soon as they commence to green and grow.

Illinois.

ANNIE J. PADDICK.

\section{THE FLOWER FOR THE MILLION}

Since the peony is crowned "flower queen," as loyal subjects we should give it a royal reception by preparing a bed which will foster a noble and worthy sovereign, requiring no change during life if but accorded one new coverlet each winter. Their flowers will be more lasting if the hottest sun cannot strike them. Excavate a tenfoot circle two feet deep, carting half away, incorporating rotted manure with the balance. Plant double white in the center, with six Rosea Fragrans two feet distant and twelve double white around these, two feet away. Fill vacancies with cup daffoails and Narcissus poeticus mixed. Mulch heavily with rough manure every winter. The size, shape and number of beds and the colors employed may vary indefinitely. Remove faded flowers, keep grass edged, and when they crowd divide, making new beds.

Indiana. SARAH A. PleAs. 


\section{HOW TO KILL THE BLACK FLY}

For several years I have tried various means to conquer the tiny black fly, a great enemy of house plants.

In the fall when potting and repotting I either bake or scald the earth to destroy animal life. When plants are placed for winter, every week I examine saucers and top of pots for the eggs of the fly. They are white and as small as a pin point and soon hatch into very lively grubs and grow as large as a small pin, and then breed flies again. A few hundred worms will soon destroy the finest plant. At the first sign of eggs I take plants to the kitchen sink, wash the saucer's and bottoms of pots, fill top with water and pour off quickly, and the eggs and worms float off. I take a fork and loosen the earth, and if I see any worms I sink the pot in water to cover it and let it stand ten minutes. What do not rise will drown. It is the most effective plan I ever tried.

About once a month I put a teaspoonful of ammonia in a quart of water and water freely, and give a little fertilizer.

To be successful with house plants, unless one's eyes are very strong, a small magnifying glass is almost a necessity to examine leaves and earth. Black flies' and red spiders' eggs are so tiny they can easily get the start of one. Glasses can be bought from twenty-five cents up.

Illinois.

Mrs. S. E. Browne.

\section{FALL WORK AMONG THE ROSES}

At the North I would not advise the planting of roses in the fall, unless you find that you realize success by so doing. Only the hardiest sorts should be planted at this season. Teas and hybrid teas will generally disappoint if planted now. It will soon be time to administer protection to such roses as you care to save. By the first of December go over the rose plot and see that each bush is left in suitable condition for withstanding the rigors of winter. Choose a day when the ground is frozen. Alternate freezing and thawing do much harm to a plant; and you want to aim to have the ground remain frozen throughout the winter. This may generally be accomplished by administering protection when the soil is in a frozen state. Put a liberal mulch of decomposed manure around each plant, and trim back the tallest branches. Then set a topless and bottomless box snugly over the bush, filling it full of dry leaves, but not packing them tight. Provide a top of boards which will shed rain, and try to fix it so that a certain amount of air and light can find ingress.

New York. BenJamin B. KeEch.

\section{PLANTS FOR INDOOR CULTURE}

Your window garden may be a complete success this winter, and again it may not. It will all depend on the care you give it, and on the plants themselves. We will suppose that your cultivation is to be of the best; what needs the most consideration is the plants you intend to grow. In the first place, discard all scraggly fuchsias, heliotropes and lantanas; put them down cellar, where they belong. Go to a florist and invest in a half dozen of thrifty young primroses and cinerarias; these will blossom more or less continuously, and prove a source of much delight. If you cannot procure them, buy some bulbs; hyacinths, crocuses, Chinese lilies and tulips are sure to do well in almost any room, under almost any treatment. Plant in good soil and put away in the dark. Do not bring to the light until they have sprouted well. November is not too late to start your winter flower garden. Twelve or fifteen thrifty plants are enough for an ordinarily large window.

New York. BenJamin B. KeECH. 


\section{The Floral World}

$\approx$ : Published Monthi,y at Springfield, Ohio : Subscription Price, 25 Cents a Year

Correspondence invited from all persons interested in flowers. Write us yomr experiences with plants

\section{OUR EDITORIAL PLAN}

We propose to make THE FLorAL WoRLD practical in every sense of the word. It will contain only matter about the culture of flowers. Every article will be for the amateur.

You can help us-and help our readers-by giving us your experience in growing flowers. Write us, therefore, about t.ue plants with which you have succeeded and the methods you follow.

Each month we will award $\$ 50.00$ in cash prizes for the best contributions that reach us. The first prize will be $\$ 25.00$; second, $\$ 15.00$; third, $\$ 10.00$; fourth, $\$ 3.00$, and fifth, $\$ 2.00$.

Our subscribers will award the prizes. Each one can vote-blank coupons or ballots will appear in every issue, beginning with November. The amounts offered will be paid to the persons whose articles receive the greatest number of votes.

The ballots in our November issue will be for a vote on the articles it contains and those which appear in this issue. As previously advertised, $\$ 100.00$ in prizes are to be awarded for the contributions in these two numbers. The winners will be announced in the January FLoR.AL WorLd.

We now request articles for publication in December. These must not exceed three hundred words in. length, and must be in our hands by November 10. Ballot for vote on December articles will appear in that issue, the awards to be made public in February number.

The editorial plan of THE FLoraL WORLD is absolutely new and unique, you will see, and we hope that it meets your approval. Our aim is to make a floral paper for the people, and your help is needed. Let us have it both in the form of subscriptions and of contributions that give your experience in floriculture.

\section{A FLORAL BALL}

We want to encourage interest in flowers. Their influence for good is great, and no one can know too much about them. Here is a clever set of questions about a floral ball-every question answered by the name of a plant or flower. For a correct set of answers to these questions from a subscriber for THE FLORAL WORLD we will give a prize of $\$ 10.00$. For the nearest correct answer a prize of $\$ 5.00$ will be awarded. For the next two nearest correct answers prizes of $\$ 3.00$ and $\$ 2.00$ will be given.

To be entitled to tne first prize a hist of answers must exactly correspond with the one we have prepared and have on file in the safe of the publishers of THE FLoral WorLd, where no competitor in this contest can have access to it. In our solution of the puzzle each question is answered by the name of a plant or flower given on pages $840,841,842,843$ of Wood's Class Book of Botany. The questions in "The Floral Ball" are as follows:

1. In popular language what was the ball called?

2. What name was applied to the bashful ones who sat around the room?

3. What did a bad boy throw through the window?

4. What old-fashioned article of dress worn by the host was struck by the missile?

5. What did he threaten to do to the young rascal if he could catch him?

6. What were the given names of his three charming daughters who were laughing at him behind his back?

7. By what pet name did they call him when about to ask a favor of him?

8. With what salutation did he bid good-night to his parting guests? 


\section{PLANTS FOR WINTER FLOWERS}

If you wish plants that will bloom in winter, try begonia McBethii, oxalis ortgiesi, ageratum blue and white, Chinese primrose, Impatiens sultani, abutilon, and for a vine smilax. For bulbs, try hyacinth, alliums, narcissus Von Sion, tritilea and grape hyacinth.

Pot in rich garden soil and chip dirt equal parts, the last of September or tirst of October. Fill the pots, leaving room to place the bulbs, then fill - in the dirt about the bulbs, leaving the hyacinths and narcissus tops bare; water thoroughly, place in the cellar where it is perfectly dark, leave till sprouted, and the hyacinths till the sprouts are an inch or more long, then bring them gradually to the light. If the dirt gets dry in the cellar, water them. Place in a five-inch pot three hyacinth bulbs, and for the smaller bulbs from five to eight, according to the size of the bulbs. Have the plants nice and thrifty in September.

Once in two weeks put one teaspoonful of ammonia in one quart of water for fertilizing. The ageratum is a thirsty plant. I think water for plants is better if it is warmed a little.

Connecticut.

R. J. Bradley.

\section{FOR GREENHOUSE CULTURE}

What shall be done with the plants that have given service all summer, in the open ground? If you have a greenhouse, potting soil, composed of rich earth, leaf loam and sand, make a light, porous compost adapted to the majority of plants. With this and clean pots the problem is solved, and progress made easy, pleasant and remunerative. Any time in early fall lift and pot the plants, removing all superfluous branches. Trim into neat shape and place aside to recover. In two weeks they are ready for their permanent quarters. Give geraniums the sunniest place, as their wonderful vitality for winter blooming demands favoritism. Sow sweet alyssum in the pots, as it is easily grown, fragrant and pretty. The callas are favorites always. Give them a throne in the kingdom of flowers. Of ageratum, vinca, salvia, cosmos, oxalis, petunia, take slips to come after the parent plant is exhausted. Carnations, cinerarias, calceolarias, primulas, (primroses), are sure to reward. This list might be greatly extened.

Louisiana. Mrs. W. N. White.

\section{HOW I CARE FOR BULBS AND TUBERS}

Plant hyacinths, tulips and crocuses in the house or outdoors in October; if one waits longer the bulbs deteriorate. Success will be in proportion to the time one waits.

Pot cyclamen in October. Use soil one-third leaf mold, two-thirds sandy loain. Leave top of the corymb exposed. The dainty blossoms will appear in about ten weeks.

Pot freesias in August or September in rich loam, give plenty of light and moisture; six bulbs to a six-inch pot.

Let Amaryllis Jonsonii rest with but little moisture until February. Water freely during spring and summer. It will bloom in May.

Leave the spotted calla in the pot and keep in the cellar during the winter without water.

When gloxinias drop their leaves set away in the pots were they will not freeze. Moisten occasionally during the winter.

Dry house-grown caladiums and cannas off in the pots. Dig those outdoors when the soil is wet, et a portion adhere, dry and store where the temperature is about fifty degrees.

When tuberous begonias unjoint and go to sleep set away in pots in a frostproof room.

- Dig gladiolus in October, remove the tops, dry and store in cellar free from frost. Mrs. E. R. B. BARBER.

Michigan. 


\section{CONVENIENT PLACE FOR FLOWERS}

All cannot afford a bay window or a conservatory, and to those I will tell how I manage. On the south side of my dining room I had a little room built which contains four windows, cne on each end and two on the side, and a door opening from the dining room which may be only curtained to keep out the dust. In the center I have a good, solid table, and on this I keep an oil heater. On the heater I have a pan of water, which supplies the necessary moisture. Through the day the heat from the dining room is enough. I have a shelf two feet wide on which I nailed strips two inches wide. This is lined with tin and painted to keep it from rusting. In this I set my pots, putting the lowest ones next to the window, and fill the tin with water, which will both water and catch the drainage. About half way up I have another shelf one foot wide finished the same way. Here I keep my pots of bulbs and low-growing plants. I have dark green shades, and if the sun gets too hot I lower the shades. On one end and in the hottest place I keep my cacti, and they do well. I do not give them much water. I turn my plants about once a week.

California. Mrs. N. R. Anderson.

\section{NOTES ON THIS AND THAT}

A touch of frost will weaken your house plants for the entire winter. Get them into the house early, and keep the newly potted plants in some sheltered place for awhile before you take them in. An immediate change from the garden to the house will have a bad effect on them, but aim to get them all in before you need to have a fire.

Do not forget to have a big box of good soil set away where it will not freeze. You will need it before the winter is over.
Do not manure hard-wooded shrubs until the ground freezes, else they will start a second growth that will winter kill.

Take up that Nicotiana affinis that is full of buds and pot for winter. It will bloom till spring, and if kept partly shaded the blooms will remain open all day. In spring cut well back, set out in the garden, and it will be mucn better the next winter.

The foliage of heliotrope will turn black when the soil gets too dry. They require more frequent watering than most plants. Give soot water once a week.

A. Elizabeth Badger.

Missouri.

\section{VIOLETS IN COLD FRAMES}

The simplicity of violet culture and their value as cut flowers should make violets general favorites with amateurs. Through the middle South they may be grown most perfectly in cold frames.

Dig the pit two feet deep, sloping and facing south; fill six or eight inches with loose, rich soil and set in the plants, which may be had of any good florist as early as September, though it is better to buy small plants in the spring and give them the summer to grow in, being careful to keep all runners pinched off. The glass need not be put over the frames until frost comes, and should be opened every bright day through the warm part of the day. The soil should be kept rather moist. In rainy or snowy weather a board covering to turn water will be necessary, and in severely cold weather an old piece of carpeting thrown over the glass will insure against frost creeping in.

California, Luxonne, Lady Campbell and Swanley White are fine varieties. With moderate care these will furnish an abundance of blooms.

Miss Marguerite Caldwell.

Tennessee. 


\section{WINTER-BLOOMING BULBS}

First and best of all comes the hyacinth. And the best of these are the single named ones, as follows: White, Marie Stuart, Alba Superbissima, Mont Blanc and La Pucelle de Orleans; blue, Charles Dickens, La Perouse and King of Blues; red, Gertrude, William the First and Fire Ball; yellow, Ida, Anna Carolina and Hermann; pink, Florence Nightingale, Gigantea and Sultan's Favorite.

For a succession of bloom pot them from the first of September to the last of November in a soil composed of good sandy loam and well rotted cow manure. This is the soil for all winter blooming bulbs. Place one bulb in a four-inch pot or three in a six-inch, with the tip of the bulb protruding from the soil. Water well and place in any cool, dark place to form roots. In six or eight weeks bring gradually to light and warmth, keep well watered, and they will do the rest.

Give tulips the same treatment as hyacinths, except cover all the bulb with soil. The best for winter blooming are: Double, Blue Flag, Duke of York and La Candeur; single, Cardinal's Hat, Yellow Prince, La Reine, Cottage Maid and Brutus.

To succeed with freesias they must be planted early, six to eight in a six-inch or twelve in an eight-inch pot. The Bride, Leichtlinii Major and Mammoth French are some of the newer sorts.

Narcissus and daffodils are old stand-bys. Plant Von Sion, Paper White, Trumpet Major, Incomparable, Poeticus and, of course, the Chinese sacred lily.

Oxalis, all kinds, Scilla sibirica, chionodoxa, luciliæ, Tritilea uniflora, snowdrops, brodiœas, are all fine. Three bulbs of any of them in a fourinch pot will make a fine display.

Everyone with a collection of winter blooming plants wants a white calla and an Easter lily. Get large bulbs and the results will be satisfactory.

And if you want something that will attract attention, something in all probability that your neighbor has not, get a dozen named crocus bulbs and plant in water with a little sand to hold the bulbs in place. The effect will be charming. VALTon G. DAvis.

Texas.

\section{PROTECTION FOR CHRYSANTHEMUM}

In the corner of a netting fence I had two wire panels made, forming a pen eight feet square. From the center of two opposite panels I have an upright piece joining the two at the top with a slat. This is to support the canvas and form the highest part of tne tent. Though early, I am lifting my chrysanthemums, and have about twenty in boxes and buckets in this pen. Still there is room for me to attend them. At one corner and near the hydrant is a gate through which I can go and to which the hose reaches.

I am beginning to disbud, and as yet have used no covering except for a few days after lifting, then I took it off at night and during a rain. When the buds show color I will put up canvas to stay and protect bloom from water. Before frost I will extend the canvas to bottom of pen, protecting from both frost and high winds. Keeping the blooms from the sun helps preserve the color; the pink ones fade quickly if exposed. I kept a beautiful pink, Mrs. Murdock, till the last of November in this way, and then sold the blooms at fifteen cents apiece.

Autumn Glory was slow in opening, so I put it in the greenhouse under glass, and the warmth helped to force it, but when open put in the hall where it was darker in order to preserve the color. Except in such cases the pen meets all needs, requiring no moving after lifting them from the bed.

Mississippi.
Mrs. W. B. BYrd. 


\section{MUUCH PLEASURE AT LITTLE COST}

In the fall several years ago, knowing I had but little time to devote to plants during the coming winter, I planned how I might enjoy a few simple plants and yet take up little of my time in caring for them.

I had a cast-off dining table of the old-fashicned kind, with six legs and two "leaves" which were lowered or raised at pleasure by the two extra legs, but now the "leaves" were warped and the hinges loose.

I had the extra legs and the leaves removed and the oblong frame fitted with a zinc pan some ten inches deep. In the center of the pan was a small tube to carry off the surplus moisture. I put in the bottom of the pan a good, thick layer of broken pots and bits of brick, over this a layer of charcoal, and then a thin layer of dried moss and grass roots taken from partly rotted sod. Then I placed, at equal distance apart and along the lengthwise center of the pan, fine, common earthen flower pots of the six-inch size, and in the bottom of each of these I placed the same mixture of shredded pots, charcoal and moss as I had placed in the pan. I now prepared a mixture of sand, well rotted cow manure, leaf mold and good garden soil, and filled the zinc pan and pots with this. In each of the two end pots of the stand I placed a bright coleus, four different varieties in all, and in the center pot a fine rose geranium. Around the outer edge of the zinc pan I put a row of fine moss, such as is used for vases and hanging baskets, then a few inches further in a row of small, silver-leaved geraniums. I now gave the plants a good showering and placed the stand on an east porch, where they would get the morning sun, but no cool winds, and let it remain there until the nights began to get too cool for the coleus, when I removed the stand to the east window of my dining room.
I never saw plants grow better or have finer color, and long before Thanksgiving the bright colors of the coleus and the bright green and silver of the geraniums, with the moss hanging over and entirely hiding the edge of the stand, made a pleasing sight.

It grew and thrived all winter, and I received many compliments.

Kansas. Mrs. R. C. HARRIngton.

\section{BULB CULTURE IN NEW YORK}

Hyacinths, tulips, crocus and narcissus should now be chosen for the early bulb bed and winter blooming. For the bulb bed have a rich, mellow soil prepared and place the bulbs as desired any time before the ground is frozen. Give a slight covering of leaves or hay, but avoid heating manure as a protection. Put bulbs for house blooming into good potting soil (I use one pail of leaf mold, one pail of well rotted cow manure, two pails of garden soil and scant half pail of sand), and place in cool cellar or dark corner and water occasionally. When growth commences bring to the light and force in the sunniest windows.

I consider geraniums of all kinds, oxalis, begonias, smilax, abutilon, primroses, hyacinths, freesias, fuchsias, swanflower, asparagus fern and Kenilworth ivy the best plants for winter gardening. Plants should be brought into the house before cold weather and gradually become acclimated.

Plant freesias now for late winter blooming. A neat support for freesias inay be made by taking a small piece of fine wire poultry netting and fasten to two wires about three inches long to two wires, which stick into the pot. As the freesias grow train eacı sprout through a mesh, and there will be no drooping.

A pretty and quaint frame for smilax is a Japanese palm fan from which the paper has been removed. Stick the 
end into the smilax pot and train as desired.

Make notes on improvements for next year's gardening, as to arrangement and choice of flowers. After frost has visited you, your sweet williams would like a slight covering of leaves. Cover your peonies with a pailful of well rotted cow manure and allow them to grow up through it in the spring. Don't fail to put a liberal supply of well rotted cow manure around young pansy plants, and cover well with leaves until early spring, then remove and cover with a cold frame, or let nature take her own time, and the beautiful faces, much larger than last year, will greet you.

Do not cover your tender rose bushes too early. Be sure the sap has run down and the foliage is well browned. Take a good handful of straw and place around the bush, and tie securely to a stake, previously placed as a support. Every bush I covered last year lived through the winter. Sow poppy and verbena seeds now for next year's blooming.l Thin the poppies out severely as soon as the frost leaves the ground. Mrs. Charles L. Tuthill.

New York.

\section{KEEP YOUR PLANTS BREATHING}

Consult your own taste and ability as to the kind of plants you keep, but prepare to keep them with as little labor and trouble as possible. While the busy housewife is trying to find time to remove the window plants to the kitchen or tub to wash them, they are dusty and unsightly and insects have obtained such foothold that the plants are permanently injured.

Try my plan. On the wall each side of the window tack white or dainty colored oilcloth. Let it extend under the window and down over the mop board to floor. Take up the carpet for three feet of window and two or three feet on either side, putting oilcloth in its place, with a lath just under the edge wherever necessary to prevent water running off in any direction. Use hanging baskets and swinging brackets rather than shelves half way up the window. They are more cleanly, obstruct the light less and swing out of the way of the blinds. There should be no curtains. Make a bench two inches higher and a foot longer than the lower casing and fifteen to eighteen inches wide. Use wide, square legs large enough to insert casters, and three inches from the floor put in a second shelf. Tack oilcloth closely around top and let it fall below bottom shelf, and you have a "cool, dark place" to keep your potted bulbs before "bringing to the light" or to finish "ripening off." You have a stand that is easily rolled into a warmer place. It is easily kept clean or removed altogether, and will hold all the plants your window will grow.

Gather the branches of a plant loosely in one hand and with a spray or very small sprinkler spray the plants where they stand. The floor is easily wiped up, and the rest of the water will be beneficial.

In this way five minutes' brisk work each morning-aside from repottingwill keep your plants free from insects and clean and attractive all the time. It must be done every day, however, not attended to. a few days and then neglected a few, as this amount of work is not sufficient to dislodge insect pests once started.

If you have extra choice or tender plants try setting them on a box and putting your steam bath cabinet over them on cold nights. Lay a folded towel over the opening in the top. This is also the best thing I have found in which to smoke plants for aphis, or to put your begonias to dry in the dark after you have washed them.

I have not attempted to tell you anything of the care of plants except how to keep them from frost and to keep them clean with little trouble.

Iowa.
Eva I. Griffith. 


\section{OREGON BULB NOTES}

To grow bulbs that are sure to bloom in winter, deal only with reliable florists; otherwise with the best of care your window garden will probably be a failure. Use deep pots to give room for plenty of strong roots, without which a bulb cannot produce fine blossoms.

For potting material use a mixture of sand and leaf mold, first putting in charcoal and burnt bones overlaid with sphagnum moss to insure perfect drainage.

Plant hyacinths and narcissus with the tops of the bulbs even with the surface.

Tulips, freesias, ixias, sparaxis, Scilla sibirica and Tritilea uniflora should be planted one inch below the surface, as they make a sturdier growth when so treated.

Press the soil firmly around the bulbs, and after saturating with water set away in the dar.. for six weeks.

Bring to the light very gradually, and water only when the soil looks dry.

After the buds appear use "Bowker's ammoniated food for flowers" according to directions. A tin of hot water placed on the flower stand each morning helps to furnish the moisture the plants require.

Remove faded flowers and gradually withhold water until the foliage turns yellow, then put them away to rest.

Oregon.

Bertha M. Gibson.

\section{A LITTLE GREENHOUSE}

My flowers have always been more of a pleasure to me in winter than in summer; the blossoms then are daintier, the foliage richer, and under proper conditions the plants are altogether more to be depended upon for good results than outdoor plants which make our gardens beautiful. Drouth and excessive rains are to be struggled against out-of-doors, and if one has a large garden the care of it will draw heavily upon one's strength and purse, but with a little conservatory one can regulate moisture and with an incredibly small amount of labor these will be a spot of summer and blooming flowers all winter. The one I have in mind is in the form of a lean-to against the eastern side of a dwelling house, and is some eighteen feet long by twelve wide. The roof is of glass, and there are three windows on the eastern side, one towards the south, and a door opening from the north. On the side next the dwelling is a long flight of steps to hold pots; across the eastern windows is a platform the length of the conservatory, on which the handsome specimens are placed. Shelves and brackets placed here and there in convenient places give additional pot room, and are especially nice for trailing plants. This little greenhouse is in south Georgia, and rarely requires any heat except that which it gathers from the sun.- Its floor is about two feet below the level of the ground, which fact insures a good deal of moisture, but for extra occasions there is a small oil heater, which with a can of water on top, answers its purpose admirably. The entire cost of glass, lumber and heater was not more than thirty dollars, and carpenter's work was less than ten.

Now, as to plants for winter bloom, nothing is better than the geranium in variety. The abutilons are good, as also are heliutropes, oxalis Bowii and Bermuda Buttercup.

Little plants of the Bowii will bear large clusters of their elegant pink blossoms, and the handsome foliage never fails to please. The showiest plant I had last winter was a large linum, and at Christmas time it had hundreds of golden blossoms on it. Freesias and Dutch hyacinths in pots, callas and Easter lilies, are all perfectly dependable, and once started will almost care for themselves. Quite 
as lovely as the flowers are the decorative plants, palms, ferns and begonias, and all are at their best in the gentle warmth and moisture of the greenhouse. Mrs. HenRY Wight.

Georgia.

\section{TEXAS FLOWER GARDENS}

In fixing my garden for winter I use old hay and straw as a mulch, combined with plenty of well rotted manure. The ground should be loosened around the plants before putting the manure on, especialiy the roses. You cannot make the soil too rich for roses.. In this locality (southwest Texas) roses should be planted in the fall, any time from October to December, when the weather is favorable. Always have some clay mixed with the soil in which they are planted, and when they commence to bud put plenty of well rotted manure around them. By planting in the fall the small roots have ample time to grow before blooming, which insures vigorous bushes and fine flowers early in March. With proper care we can have roses the year round with the exception of the months of January and February. When the winter is mild it is not unusual to find a few blossoms during these months on the hardy bushes.

Violets should be separated and transplanted in the fall to insure an abundance of early blossoms. With us they bloom in the open ground all winter.

Sweet peas should be planted in September or October at the latest, protected during cold weather with straw and manure, and also by drawing the earth up around them. The treslis for them to run on should be placed as soon as they begin to run.

I pot my geraniums for winter blooming during the month of August. They thrive, however, and bloom nicely until late in the fall in the open ground. Before the first frost I bring my pots into the sitting room, where they remain during the winter. . On mild days I put them out on an east gallery and give shower bath before bringing them in for the night.

I have never had any success with bulbs except the common lily. With great care I have succeeded in making a few hyacinths bloom, but have quit entirely the cultivation of bulbs.

Texas.

Mrs. A. Crain.

\section{WINTER-BLOOMING PLANTS}

During late August or early September I would advise giving plants which are to be taken through the winter whatever care may be needed by them. Most plants will need pots of larger size in order that they may develop roots for active work later on. They will require fresh soil, but don't make the mistake of having it too rich. Use no manure in it when repotting, but later on when the plants have become accustomed to their new quarters and growth begins, some reliable fertilizer can be applied when needed. It is a common mistake among amateur florists to think that all a plant needs to make $i$ grow is a rich soil. Fertility is of great importance if given at the right time; apply it when the plants are ready and begin to make strong, healthy growth.

Provide good drainage. It pays to drain any plant well. Be sure to see that your plants are perfectly clean before taken into the house. We can fight insect enemies effectively before they arrive. Keep them away, and you will have no trouble. Shower plants daily. Give plenty of fresh air. The motto of the amateur florist should be "The best possible and you will succeed."

Mrs. R. A. Hour.

Indiana.

\section{HYACINTH CULTURE}

Dig down about fifteen inches, put in sandy loam with some well rotted stable manure, mix and pulverize thor- 
oughly. Have the bed three inches higher in the middle. Set bulbs about three inches apart and three inches deep, make smooth on top and cover with coarse litter four inches deep. Notice in the spring when they are coming up, and then remove the litter so they will have room, but do not take it all off until they commence blooming.

I never put double and single ones together. I put each kind in a bed together so each bed will be a mass of bloom at the same time. When done blooming and tops die down, I take them up and cure them as you would onions, and store them away in a cool dark place until the middle of October, when I put them out again. I have larger and finer blooms by this method than to leave them undisturbed for years, as some recommend. I have tried both ways. Mrs. L. E. Jones.

Missouri.

\section{TUB PLANTS}

Most of my choice plants and shrubs are grown in "tubs." I like to change the appearance of my lawn once in a while, and it is easy to do it with plants in tubs. The altheas are fine grown in this way; they are easy to keep moist, without which an althea does not thrive, but kept wet they rival the tree roses. Bignonias, acacias, alocassia, tree roses, crape myrtle, oleanders, ferns (I have two that are three feet across), cannas, brugmansias, all do well as tub plants. I am partial to climbers, and when trained on a large trellis they break the line and make a fine display. Solanum Wendlandii is beautiful, so is a large plant of cobea, tecomas, ipomeas, bignonias, hedychiums, crinums, alpinias; but the nicest is a large plant of cassia floribunda, deep green foliage, topped with great bunches of golden, pea-shaped flowers. Rich soil, lots of water and rest in winter is all it requires. Will stand a little frost without hurt. Keep in winter as you do the oleanders.

\section{Nebraska. MRs. O. H. HEREFORD.}

\section{Rescued

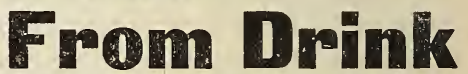

by a new discovery, odorless and tasteless. which any lady can give in tea. coffee or food. It does its work so silently and surely that while the devoted wife, sister or daughter looks on. the drunkard is reclaimed even against his will and without his knowledge or co-opera tion Send name and address to Dr. J. W. Haines, 1480 Glenn Bldg..Cincinnati.O..and he will mail enough of the Glenn Bldg.. Cincinnati.O...and he will mail enough of the
remedy free to show how it is used in tea, coffee or food

17 2 and malignant growths

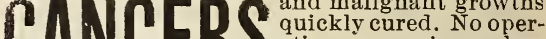
42 ation, no pain or loss My home treatment will not disappoint you. No cure, no pay. Herald of information free. E. M. Boynton, M.D. . 262B B'way, Lawrence, Mass

DEAF NESS and Head Noises permanently cured. Illustrated book and month's treatment free. DR. POWFLL, 23B Huntinginn Avenue, Boston, Mass.

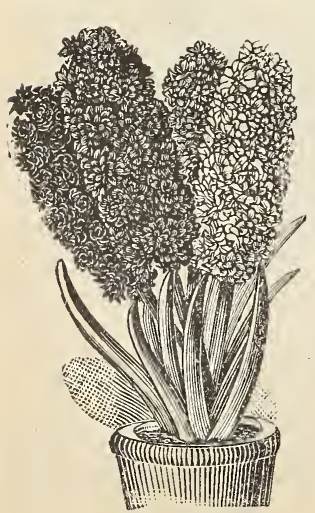

If You Want the Best Bulbs for the Least Money Send for Our Catalogue

\section{OUR “JEWEL" SET OF HYACINTHS.}

\section{THE ENTIRE SET OF TWELVE FOR 60 CENTS, POSTPAID.}

Amethyst.-Splendid, rich, dark purple; simply grand; extra large.

Garnet.-Fine, deep red; very fine.

Alabaster.-Pure waxy white; fine large spike.

Dia mond.-Blush white, with rosy center.

Tourmaline.-Beautiful waxy blush; fine large bells and spikes.

Ruby. - Rich blood red; very fine.

Pear1.-Pure snowy white; extra large and fine.

Opa1.-Rich creamy white; magnificent bells and spike.

Turquois. - Silvery blue; one of the finest of all; large bells.

Sapphire.-Beautiful rich blue; magnificent color and very large spike.

Topaz.-Pure yellow; extra fine in every respect.

Cora1.-Delicate rose color; extra fine large spike and bell.

The finest set of Hyacinths for pot culture in the house or garden ever offered. A magnificent assortment of varieties which are properly named after the "Jezuels" or "Gems," embracing every known shade of color"; strong growing, producing exceedingly large, beautiful bells and spikes of bloon.

Address THE C. A. REESER CO., Urbana, Ohio. 


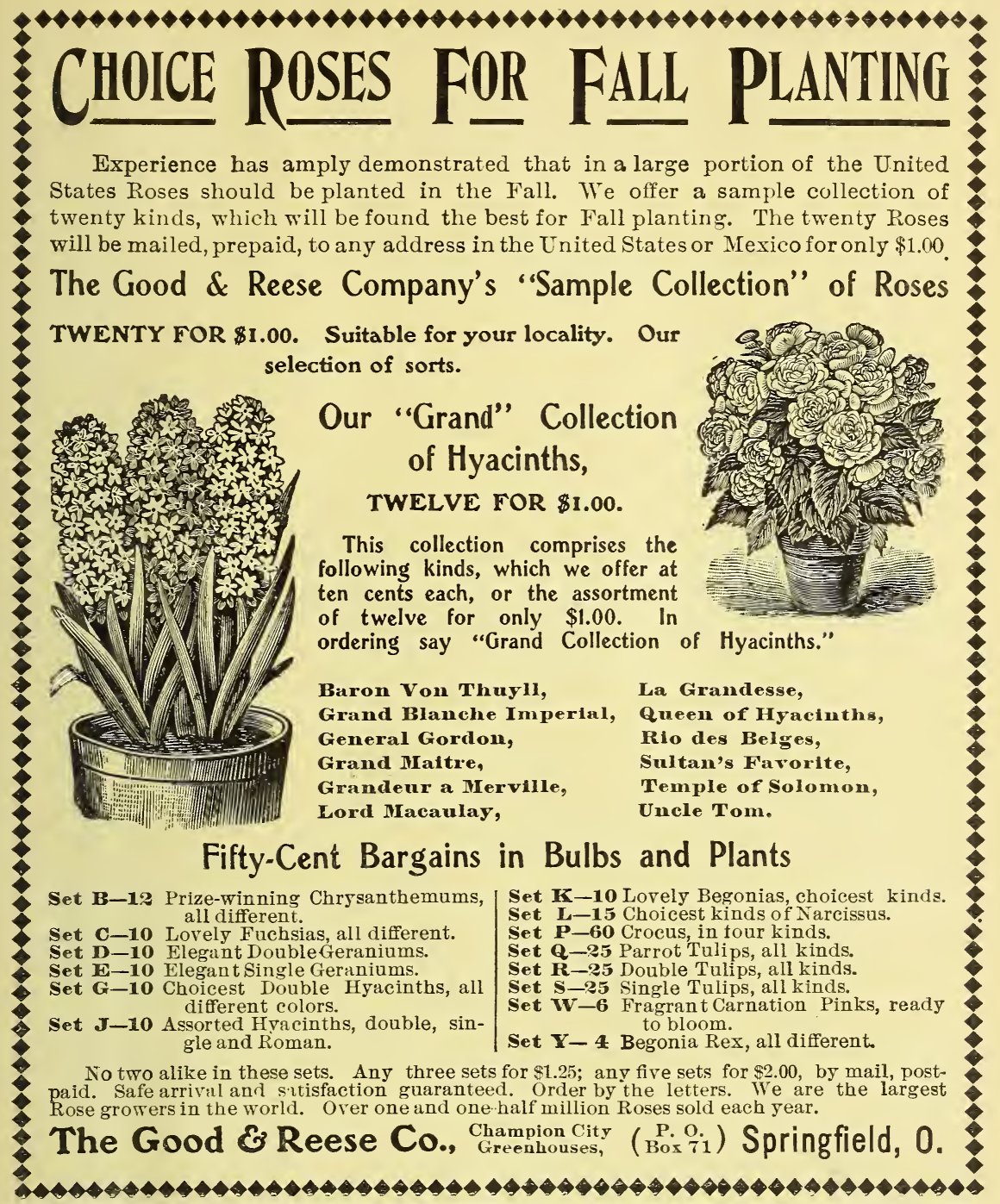

\section{History of Domestic Animals}

In the September number of Pros Axp Axumas was begum the mublication of a series of articles by Ernest lugersoll, the well known maturalist. which in themselves will be wortl many times the price of a yem's subscription. This series of articles will extend thromgh twelve numbers and will be called a "History of the Dumestic Animals of the World." It will tell the origin of each species. its native country, the part its domestication lass played in the rise of mankind from savarely throl:gh barbarism to cirilization. and something as to the different breeds and th ir nst fulntss. These articles will present a vast amount of unfumilias information m respect to the most familiar subject-. They will be written in a popular style, easily unlerstood and handsmely illustrated. The series will trat, in rotation, the dog; horse; iss and mule; the cattle; sheep and griats: camels: llama and alpaca: swine: poultry; the elephant; the cat; caged birds: fishing cormorant, etc; reindeer. Yalk. etc.

THREE MONTHS ON TRIAL ONLY 10 CENTS-SUBSCRIBE AT ONCE

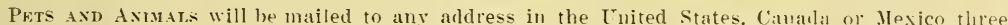
months on trial for only 10 cents. The regular subscription price is 50 cents a year. Adhress

PUBLISHEIRS PETS AND ANIMALS, Springfield, Ohio. 
We have on hand a few hundred collections of winter and spring blooming bulbs which we will close out at bargain figures. Order at once and get choice of our stock. A11 bulbs will be sent by mail, postage prepaid and safe delivery guaranteed. Do not order a part of a collection each one must be supplied complete. No changes can be made under any circumstances.

\section{Choice Holland Bulbs-Two Cents Each}

\section{(Collection C-Twenty=Five Bulbs for Fifty Cents)}

This collection consists of bulbs of fine quality, grown especially for us by a leading Holland house, under contract to furnish only stock sure to bloom.

It contains Five Assorted Hyacinths,

Ten Selected Tulips, Ten Choice Narcissus.

No bigger bargain was ever offered than this collection for fifty cents. At the usual prices for bulbs it would cost you two or three times the money. Order by "Collection C." The twenty-five bulbs, postpaid, for only fifty cents, remember.

\section{American Grown Bulbs-One Cent Each}

(Collection 67-Fifty Bulbs for Fifty Cents)

All the bulbs in this collection are American grown. These bulbs will give best results if planted at once.

\section{Twenty-Four Freesias}

This is one of the most popular and charming bulbs for pot culture, flowering in winter or spring in the conservatory or window garden. Six or eight bulbs should be planted in a four-inch pot.

Twelve Bermuda Buttercup Oxalis An unrivaled winter-flowering pot plant of easy culture. It is a strong and luxuriant grower. Properly treated the plants will flower in six weeks from the time the bulbs are set out.

Six Amary 11 is Atamasco Zephyranthes !

"Zephyr Flowers." or " Flowers of the West Wind," are among our most beautiful bulbous pot plants. The six bulbs elustered in a six-inch pot will give a fine display of bloom during the winter.

Four Montbretias, Crocosmaeflora

A rery desirable acquisition. If not desired for winter blooming. these lubs may be kept for summer flowering. Four Callas

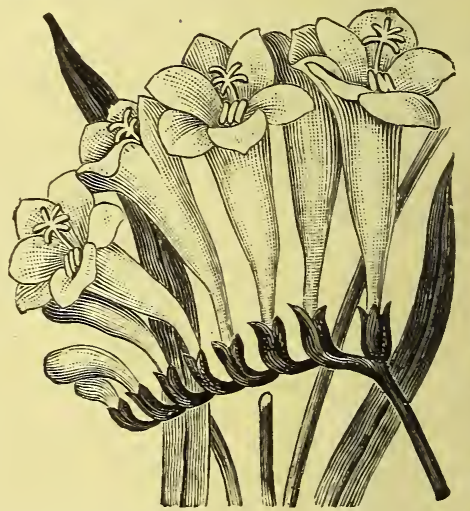

The old favorite Calla Lily is too well known to require extenclerl description.

Collection 67 is we1l worth a dollar. but we will send it postpaid for on 50 cents.

\section{Cheaper Holland Bulbs-One=Half Cent Each}

\section{(Collection A-One Hundred Bulbs for Fifty Cents)}

This is a splendid offer. Collection A is made of the best grade of the bulbs usually furnished in cheap collections. While small, they have been grown with great care and most of them will bloom freely. Of course we cannot recommend these bulbs like those in Collection $\mathrm{C}$, but they are so cheap and we offer such an assortment that you can make no mistake in ordering this lot. The cullection contains

Two Hyacinths,

Six Tulips,

Six Narcissus,

Ten Crocus,
Teu Sparaxis,

Ten Tritilea Uniflora,

Six Scilla Sibirica,

Ten Spanish Iris,
Ten Grape Hyacinths,

Ten Saxifragas,

Ten Star of Bethlehem,

Ten A11ium Neapolitanum,

The one liundred bulbs in Collection A by mail, postpaid, for only 50 cents.

All three collections to one address for $\$ 1.25$. Order quickly.

Address THE FloRal PUBLishing Co., Springfield, Ohio. 


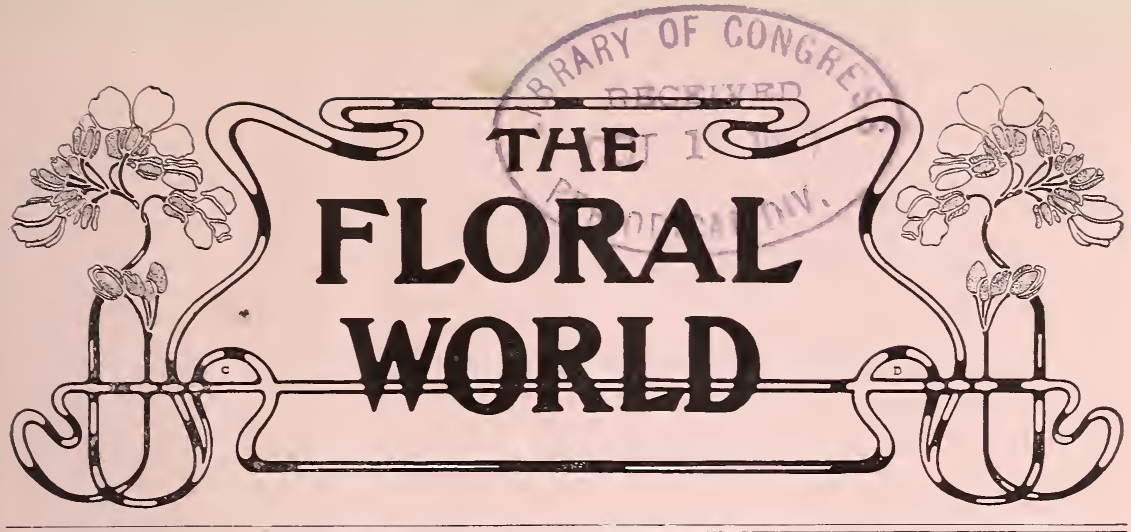

Vol. I, No. 2

Springfield, Ohio, November, 1901

25 Cents a Year

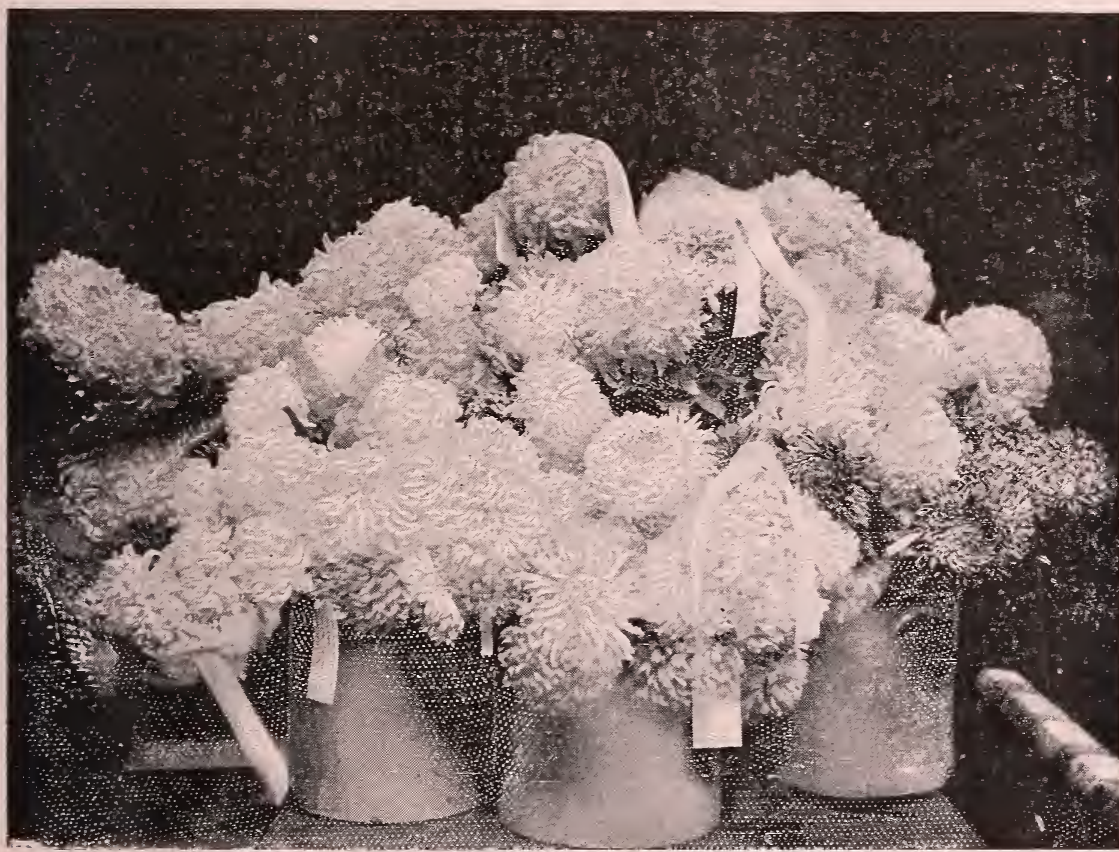

\section{Three Years for Fifty Cents}

Send us half a dollar and we will mail THE FLORAL WORLD regularly to your address for three years. Get two of your friends to accept this offer, sending us one dollar for the two, and we will give you our journal free for three years. Always address

THE FLORAL WORLD, Springfield, Ohio. 


\section{OUR BEST THANKS AND A WORD OF PROMISE}

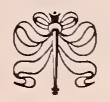

The first issue of The Floral World was warmly welcomed. We take this means of thanking you, one and all, for the kind words of encouragement that we have received. It is evident that we were correct in thinking the people want a practical and inexpensive paper devoted to home flower growing. The response to our first number has been so cheering that we shall put forth every effort to make our little publication an ideal floral journal. Our aim is to render it absolutely invaluable to every person who loves or grows flowers-a paper which will find a place in every home.

You can help us in many ways. First, of course, we need your own subscription. Second, should be a small club of your friends and neighbors. It takes a lot of money to get out a paper like ours, and many small sums are required to make up the amount it costs to print a single issue. Third, send us your experience in flower growing for the help of our other readers, and perhaps you will win one of our prizes. And last, but not least, write us a friendly letter giving your advice as to how The Floral World may be made most helpful and valuable to its readers.

Some one has suggested that we have a department devoted to floral puzzles. What do you think about it? Another friend suggests that no article longer than two hundred words be published-that in this space one can tell all about the culture of any plant. Shall we limit contributions to two hundred words then? The shorter the articles the more of them we can publish, you know. Tell us what you would do in regard to both these matters, and be sure to make some suggestions of your own.

The Floral World is published for the benefit of its subscribers-not for the profit of its owners. Every cent received from subscriptions will be spent on the journal. This is our platform-and we hope it meets your approval. 


\section{The Floral World A Fournal of Home Floriculture}

Vol. I, No. 2

Springfield, Ohio, November, 1901

25 Cents a Year

\section{WINTER PROTECTION OF ROSES}

About the middle of November or later if the fall is late, I cover my roses with leaves, then knock the end from a box of suitable size to cover the plant well. Place upside down over the plant, turning the open end towards the north. Leave covered until the middle of April or all danger of freezing is over. This way keeps the plant and leaves around it dry, as well as protects from sun and cold. I have used this method three or four winters, and have never had a rose winter killed. Miss Nancy MoKeE.

Illinois.

\section{ABOUT GERANIUMS}

About the last of September get your small geraniums in pots ready for winter. I take slips from the large plants in June or July, setting them where they will be partially shaded by the large plants. Some prefer to take them off in August and root the slips in the pots they are to remain in, but of course you will get blossoms earlier if taken off in June, and, what is still better (if one has room), is to keep the buds nipped from the old plants during the summer; cut them back to make them shapely, mix good garden soil with leaf mold (equal parts), and about once in two weeks fertilize with some good plant food. You will be surprised at the result. Save at least a few of the old plants. Keep them free from dust, dead leaves and faded flowers, and you will get more satisfaction from a few well kept plants iwan from a houseful of neglected ones.

For begonias, use leaf mold and a little sand. Give fertilizer as you do geraniums, and they will repay you with an abundance of bloom.

New York. Mrs. L. H. Jennings.

\section{WHERE BULBS ARE BEST}

For winter blooming I think bulbs are the best. They are sure to bloom, and will even endure a light freeze without injury. Pot in leaf mold and sand, with good charcoal drainage. Put away in a dark, cool place for six weeks, then bring gradually to the light, leaving some till later to prolong the blooming season. Roman hyacinths, both white and colored, are the best. Select as many others as you may want.

Tulips should have only harmonizing colors in one pot, say pink and white, yellow and white, blue and white, planting three bulbs in a small pot.

Freezias should not be hurried, but give them a cool place. Ornithogalum arabicum, pot so two-thirds of bulb is above ground. It is a grand plant when in bloom, but don't be impatient; it takes longer to come into bloom than the others. Have several pots of narcissus to give yellow flowers, and if you plant them in dirt they will be more likely to do well.

Harrisii, the Easter lily, needs a large pot, and gives huge, fragrant blossoms. Candidum does well in the house. They both need early starting.

Oregon. 


\section{HOW TO GROW VIOLETS}

Lovers of the violet, English or any other variety, should procure plants the latter part of September or October if they wish an abundance of bloom during February and March. Set plants about six inches apart each way in any good garden soil in some slightly protected spot. If you have old plants, dig up, pull apart, cut off all but two or three of the new leaves, also prune the roots, or plant the runners that are not rooted, but the latter will not bloom nearly so early unless started a month before. On the $\mathrm{Pa}$ cific coast no protection is required, especially on Puget Sound violets often bloom all winter. But in the East a thin covering of straw or barnyard litter should be spread over the plants as soon as the ground begins to freeze.

I believe my great success lies in planting all plants the first or second day of the new moon. Nine years ago I read an article in regard to the influence of the moon on plants, thought it silly, but followed directions, and had such quantities of bloom that I have never since planted any sort of flower at any other time in the month. I plant my cuttings of roses, such as the Queen, Caroline Testout, La France, Marechal Niel and many others at the first of the new moon in September or October. I put cuttings, good, strong ones, in the ground five or six inches deep where I expect plants to remain if possible, press the soil very firmly around them and the following spring do not cuitivate, only pull all weeds very carefully around cuttings, and by June or July they will bud, but I pinch off all buds until late in summer. If started at any other time you must wait two or three years before a single bud appears.

Sweet peas planted according to the above directions will not go to seed so readily; seed pods will form, but seed will be scarcely larger than a pin head.
Try the experiment and be convinced. Washington. Mrs. L. J. FILLEY.

\section{AN EXPERIENCE WITH FREESIAS}

With no experience, and very little information, I very hesitatingly undertook to grow a few freesias for winter blooming. I decided to plant my bulbs in the last week of August. In a fiveinch pot I planted five about an inch apart and an inch from the surface. Experience has taught me to plant them a little deeper to keep them from coming up so soon, insuring strong, healthy plants. I filled the pots with rich wood dirt, being careful to have good drainage through the pot. I watered them thoroughly, and then set them in the shade for several days. After that I never gave them water unless the surface was decidedly dry. In about ten days my persistent watching was rewarded by several little green blades shooting up. After growing too tall to support themselves I stuck four thin sticks in the dirt against the side of the pot, then wound a cotton string around these, thus keeping the long stalks from breaking. When winter came I set them in a southeast window in a room heated by a furnace. Every morning I opened the windows of the next room, letting the fresh air circulate freely in the room with the plants, but not blowing directly on them. In less than five months from the time I planted my bulbs I had the most beautiful and luxuriant wooms anyone could desire. After they quit blooming and the leaves turned brown I stopped watering them, cut the tops off, labeled the pots, and set them away, and when I opened the pots the latter part of August my bulbs had twice doubled themselves.

There is nothing so sweet and fresh as this lovely, innocent-looking flower, and it certainly will more than pay the amateur for the little trouble it is.

Tennessee. 


\section{HINTS FOR LATE FALL}

When the frost kills the tops of gladioli, cannas and dahlias, cut them off five or six inches from the ground, and leave them a week or two to ripen. Dig on a dry day, and expose to the sun and air; when dry put gladioli in paper sacks or boxes. Keep free from frost. Cannas, caladiums and dahlias should be kept in sand or dry earth in the cellar.

The best protection for hardy roses, I find, is banking the dirt up around them, removing gradually as spring advances. Old geraniums I keep piled up on a shelf in the cellar, but they must be at least one year old or they will not keep that way.

It has been said that plants would not thrive where gas was used for heating or lighting purposes, but I have been very successful with coleus and begonias in a room heated in that way. Small jardinieres filled with water are placed on the mantel and hearth to supply the necessary moisture. I don't water my plants every day unless they really need it, then giving them a generous amount. I aim to keep the temperature at about seventy degrees, admitting fresh air daily, when the weather is not too cold, but avoiding draughts.

The Boston fern does well in a room warmed only from the heater in the sitting room; it gets the afternoon sun, and is a thing of beauty all winter. Towards spring, when growth seems to weaken, apply some good commercial fertilizer, according to directions, in preference to liquid manure, which breeds insects in the soil.

Spray your plants often, especially the under sides of the leaves, to keep down the red spider. For earth worms use lime water prepared by dissolving a lump of fresh lime, the size of your fist, in a pailful of water. Let the soil in the pots get rather dry, then give enough to wet the whole ball of earth. The lime must be fresh, for slaked lime is of no use whatever. Two or three applications are generally sufficient. For aphis I use white hellebore, applied with a powder gun, while the foliage is wet.

Ohio. Mattie B. Poe.

\section{THE TWO HOMES}

As I travel around from place to place I am often called to notice the homes. In one I find the yard all bare, dusty and dirty through neglect. There is nothing in this yard for us to admire. The bright labels on the many empty fruit cans may attract our attention. They might be used for flower pots and have lovely flowers in them to ornament the home. We enter that home. We cast our eyes around. How dreary and dark. We see no flowers or pictures. I think we have great need of flower misionaries in such homes. But all homes are not alike. An education will elevate a man or woman. So it will the home, and that which is developed in the home is the best and most abiding. How important then that it be good. The most refining and elevating of all things are flowers in the home. They cheer and charm us in the winter, and these vines and flowers will shade and sweeten the heat of summer. Let us turn now to nis other home for a moment. See the beautiful flowers along the walk. How we love to tarry and admire and inhale the sweet fragrance as we pass along. See the beautiful carpet of green between the flowers, making such a lovely background for the roses and the many other flowers Mrs. M. J. Hopps.

Arizona.

Tell your friends about The Floral WORLD and ask them to subscribe for it. Our little journal is just what hundreds of people want. Write us for a list of our club premium offers, and state whether you wish sample copies for distribution. 


\section{CANNA CULTURE}

Several years ago I set out a Ehemanni canna in my south yard; it is protected on the north by the house. I made a circle four feet across, dug down two feet, put in a bushel of rich dirt and dry stable manure, and mixed it thoroughly. I set my canna in the center and watered it well and kept it so all through the season. It grew very tall and bloomed profusely. After it was killed by frost I cut off the top, put on dry stable manure, and rounded up like a potato hill, put leaves on top and sides and boards on them to weight them down and keep off rain and snow. I saved my cannas this way three years ago when it was twenty degrees below zero. I repeat this process every fall. My canna bed has not been disturbed for years, only to thin out when too thick.

Missouri. Mrs. L. E. Jones.

\section{THE CULTURE OF OXALIS}

Plants, since the memory of man, have been designated as useful, beautiful and injurious; hence it was a belief of the superstitious that good and evil spirits dwelt in them respectively. In a very ancient work on the art of simpling we are told that every shrub and herb has a mission with a particular signature by which its properties may become known. This same treatise unfortunately fails to indicate how such mythical nature lore may be deciphered.

The word oxalis signifies soursalt from the oxalates contained in the juice. It is cultivated with a twofold object; as a remedy for the diseases of man, and for adornment. In the medical cult it was for many years used as a secret cure for cancer. Some writers endeavor to prove that the obcordate leaves represent the "three in one" of the shamrock used by St. Patrick as an object lesson in his famous sermon on the trinity. In flower language, oxalis denotes joy, its ancestor being called fairy bells,

Quite recently in Wales a legend was popular that the tiny golden umbels sounded chimes of flower music to summon Titania and her train to moonlight revelry.

If you wish to grow these delicate blooms successfully procure early in November a six-inch pot or a hanging basket of the same size with a deep saucer. Place in the bottom of this receptacle four or five small stones. Over these sift two tablespoonfuls of powdered charcoal. Fill with leaf mold. Moisten the whole thoroughly before planting the seven bulbs, which is the proper number for this space. Hang or adjust on a bracket in the sunniest nook possible. Water every morning. As the leaflets appear insert in the mold two or three matches an inch deep. These will discourage insects. When the blossoms open be sure to snip with sharp scissors those that have faded. They may be easily distinguished from the fresh buds, as the whorls are twisted in an opposite direction. Occasionally stir the earth.

If these simple directions are followed elfin bells will ring a joyous welcome to every beholder.

\section{Josephine A. CheEseman.}

Colorado.

\section{GERANIUMS AS WINTER ELOOMERS}

There is no more satisfactory winter L.ooming plant than the geranium. Having grown all kinds of plants for several years, wıh varied success, I recommend the geranium for all who desire flowers for winter.

They will do well in the ordinary sitting room window or in the small hothouse of the amateur. What is more beautiful than the lovely double varieties, glowing in every color, from the deepest crimson to the softest pink, or what is brighter than the many colored, delicately shaded sorts?

Get strong, bushy plants or cuttings, 
started this spring or summer. If they are already growing in pots in good soil, they will need nothing except to keep the blooms picked off for a month or two. This helps the plants to grow bushy and vigorous. Keep them in a cool place and do not over water.

If you want to use the plants that have been growing in the yard, do not take up until cool weather. The later the better, so that they do not freeze. Lift carefully on a rainy day, if possible, and place in large pots or boxes. Take them to their winter quarters, and they will continue to bloom.

Geraniums are not at all particular about the soil, although a little care in this line is well repaid. If you want large plants and luxuriant foliage give them a compost of leaf mold and well rotted manure. If wanted especially for flowers, give them a lighter, sandy soil, and they do not care what kind of a vessel they grow in-a tin can, box, flower pot or anything that is convenient. Some of the finest plants were grown in gaı,on paint buckets.

If you should be so unfortunate as to have them freeze they are easily saved by allowing them to thaw in the dark. Pour warm water over the roots and exclude the light. They will thaw out gradually and will not be injured. Here in the South the temperature does not stay below the freezing point very long. During a very cold spell I do not water my plants very much. They are so much easier injured by cold if very wet. Sprinkle the leaves often, and give them plenty of sunshine and regular watering.

$$
\text { Texas. Mrs. D. B. HiLL. }
$$

\section{BULBS FOR THE WINDOW GARDEN}

Selecting from the extended list of the catalogues, a very handsome display may be had for a modest expenditure. These properly cared for will yield a profusion of bloom the entire winter. All bulbs should be ordered early, and only the largest ones se- cured, as the smaller ones will only bring disappointment. First among all collections should be the freesias. They are of easy culture, and their flowers are borne freely. Order them early and plant as soon as received, as they are injured by being allowed to dry out. For a succession of bloom they should be planted at intervals of three weeks until October; you are then assured of flowers for the Eastertide. An excellent soil for them is composed of wood's earth, sand and loam, with a little well rotted manure. Allow six for a five-inch pot, covering with an inch of soil. When growth begins bring to the light gradually. Keep well watered, with plenty of fresh air, and you are assured of a sturdy growth. Gradually bring into full sunshine, for to this is due that rare fragrance which characterizes the freesia. When the blooming season is over water sparingly until the foliage dies, then set away until planting time again, when repot in fresh soil, sorting out the smallest for blooming bulbs another season.

Hyacinths come next in the list. With ordinary treatment they will be a success, and are most desirable plants for a beginner. They delight in a cool atmosphere and a light, rich soil. The Roman hyacinths differ from the Dutch hyacinths in yielding several spikes of bloom to each bulb, and they also bear closer planting, a sixinch pot being large enough for three or four bulbs, and for a mass of bloom several planted in a pan or basket make a beautiful display. A fourinch pot holds enough soil for one bulb of the Dutch hyacinths. The crowns should be just above the surface and the soil pressed down firmly around the bulb. Then water freely and set away in a cool cellar for five or six weeks, then bring into strong light and gradually into the sunlight. The method which gives finest freesias will also apply to hyacinths.

Michigan. Mary Ferguson. 


\section{A FEW HINTS FOR AMATEURS}

If fuchsias are to be kept in the cellar over winter in rather a dormant state, they must be old enough to have woody stems; young plants will die.

You cannot do better than to select the English ivy if you want an "all around" good vine for the house. It will thrive with little heat and very little sun. Give rich soil, and an abundance of water.

If you do not like the looks of ashes on the soil of your pot plants, you can give it in liquid form. Make the lye weak, half quart to three gallons of water. This is grand for potted plants, and mix charcoal either powdered or in small bits in the soil you use for either bulbs or plants. It keeps the soil pure and gives brighter hues to the flowers.

The time to plant lily-of-the-valley is in November or December. They always bloom well in a rather sandy soil, partially shaded. Nothing prettier can be had than a bed of these in spring.

Keep water on the heating stove this winter. It will help the health of the plants as well as yourself. Where plants thrive people will also.

Heliotropes are fine winter bloomers for me. I plant them out in the yard in a rich soil, partly' shaded, and grow them well into September. I wait for a cloudy, rainy day, and lift them carefully and plant in whatever I intend them to remain in through the winter. Sometimes it is a big, round flower stand, sometimes a long window box. Keep them shaded and moist till all danger of wilting is over. I seldom have to cut them back if I use care. Treated thus they bloom all winter in a south window. They enjoy plenty of sun and plenty of moisture to bring out their fragrant blooms. It is good to syringe their foliage once a day when the sun does not strike them till dry. Give rich soil; you cannot have it too rich.
Pot your primroses in September in good, rich soil. Keep them in a cool, shady place till it gets cold enough to bring them into the house. Give them a light place with a little sun once a day. Your flowers will be large and plentiful.

Special care should be taken to have your bulbs well rooted before bringing them to the windows to bloom. Neglect of this will result in failure. Give them a cool temperature when you bring them to the light. A warm, dry atmosphere will cause the buds to blight.

"Vinca rosea" will bloom almost forever, and is fine for either bedding out in summer or pot culture in winter. It likes heat, and in a warm, sunny place and watered freely, it is satisfactory for winter blooming.

$$
\text { Mrs. O. H. Hereford. }
$$

\section{Nebraska.}

\section{THE CHINESE SACRED LILY}

While visiting a Chinese store I noticed a box of bulbs, and inquired what they were.

"They are the Shuey Seen Fah."

This I knew to be the Chinese name for their "sacred lily." Wishing to add this flower to my collection of window plants, I requested the young Chinaman to select for me half a dozen double flowering bulbs.

"Can't tell the double ones. In China pack both kinds in one box. You take these," placing before me half a dozen good sized, solid bulbs. "Some of them will be double."

The Chinese sacred lily is a variety of the narcissus. It will grow in damp sand, soil or among pebbles in water. The Chinese cultivate this lily to bloom on their New Year (which occurs sometime between the 21st of January and 19th of February), and the last named is their favorite method of culture.

Preferring this method, I placed each bulb about half its depth in a 
bowl of well washed pebbles, filled the bowl with water, and placed it in a sunny window. Nearly every day the water was replenished to keep it fresh and at its original height. In a few days thread-like roots found their way into the water, and a bit of grees was showing in the center of each bulb. At this time the young Chinaman came to the house and noticed the bulbs.

"They doing fine. You got a sharp knife?"

I gave him a pocketknife. Taking each bulb, he made six or eight perpendicular slashes about the bulb; cutting nearly half way to the center. As he replaced the last one he said:

"A stem will come out of every cut. New Year you have lots of flowers."

"That is not possible," I replied, "for it now is the 24th of December."

He only laughed.

January 29th was "Chinese New Year." Now I knew the young man referred to that time, for my lilies each had six or eight bright green spikes, bearing clusters of fragrant, lily-shaped, waxy, white flowers, with a small golden crown in the center. Two of them produced double flowers.

Having had repeated success with this lily, I recommend the above method of cultivating it. By planting bulbs a few days apart one may have the "sacred lily" in bloom all through the winter. Mrs. A. B. Mitchell.

Arizona.

\section{THE ROMAN SACRED LILY}

A few autumns ago I subscribed for a floral magazine and received some bulbs as a premium. Having never tried bulb culture before, I closely followed instructions as to soil and treatment. Among the bulbs was a fat, healthy one labeled "Roman sacred lily." I assigned it to a glass pitcher holding more than a quart and having a hole in the bottom. After putting in an inch and a half of charcoal and bits of broken pottery to insure good drain- age, I filled the pitcher within an inch of the top with soil composed of onefourth fine sand, one-fourth black garden soil and half coarse wood earth. The bulb was then pressed in tight, about an inch and a half deep. The directions said, "Keep all bulbs in the dark six weeks." But every time I peeped into the tolerably dark closet I could see tender white roots had grown further and further down the glass sides of the pitcher, and when two weeks had passed and a green tip appeared above the soil I could stand it no longer, and deliberately brought it out into the light (not sunlight at first; indeed it never had much sunshine). It was a very thirsty plant, and I gave it all the water it wanted.

Long, narrow, waxy leaves galore grew, and the rootlets had formed a white network all around the pitcher and doubled and twisted and folded up among the charcoal at the bottom. Then two green, succulent stems shot up from the mass of leaves to a height of more than a foot and began to send out branches clustered with flowersand such flowers, each nearly an inch across, the daintiest, waxy white, with golden cups, for this was a member of the narcissus family. It continued to send up stalks and branch and bloom and fill the house with the fragrance peculiar to its kind, pouting not whether assigned to the dining room, parlor or sitting room, and it did duty in all of these until a "norther" caught us napping, and it froze.

Some of the other bulbs rotted, for all bulbs will not stand the same treatment; others died of pure neglect, inflicted because of their tardiness to respond to good treatment. Since that time I have never had reason to change or alter the opinion then formed that the narcissus, especially the varieties of sacred lily, are the most satisfactory bulbs for amateurs, and for me they yield better results when grown in soil than in water.

Texas.

LOUISE VARNELL. 


\section{The Floral World}

๑: Published Monthiy at Sringfield, Ohio :

Subscription Price, 25 Cents a Year

Correspondence invited from all persons interested, in flowers. Write us your experiences with plants.

\section{OUR EDITORIAL PLAN}

We propose to make The Floral WorLD practical in every sense of the word. It will contain only matter about the culture of flowers. Every article will be for the amateur.

You can help us-and help our readers-by giving us your experience in growing flowers. Write us, therefore, about t.e plants with which you have succeeded and the methods you follow.

Each month we will award $\$ 50.00$ in cash prizes for the best contributions that reach us. The first prize will be $\$ 25.00$; second, $\$ 15.00$; third, $\$ 10.00$; fourth, $\$ 3.00$, and fifth, $\$ 2.00$.

Our subscribers will award the prizes. Each one can vote-blank coupons or ballots will appear in every issue. The amounts offered will be paid to the persons whose articles receive the greatest number of votes.

We now request articles for publication in January. These must not exceed three hundred words in length, and must be in our hands by December 10. Ballot for vote on January articles will appear in that issue, the awards to be made public in March number.

The editorial plan of THE FLORAL WORLD is absolutely new and unique, you will see, and we hope that it meets your approval. Our aim is to make a floral paper for the people, and your help is needed. Let us have it both in the form of subscriptions and of contributions that give your experience in floriculture.

\section{A FLORAL BALL}

We want to encourage interest in flowers. Their influence for good is great, and no one can know too much about them. Here is a clever set of questions about a floral ball-every question answered by the name of a plant or flower. For a correct set of answers to these questions from a subscriber for THE FLORAL WORLD we will give a prize of $\$ 10.00$. For the nearest correct answer a prize of $\$ 5.00$ will be awarded. For the next two nearest correct answers prizes of $\$ 3.00$ and $\$ 2.00$ will be given.

To be entitled to tne first prize a list of answers must exactly correspond with the one we have prepared and have on file in the safe of the publishers of THE FLORAL WorLd, where no competitor in this contest can have access to it. In our solution of the puzzle each question is answered by the name of a plant or flower given on pages $840,841,842,843$ of Wood's Class Book of Botany. The questions in "The Floral Ball" are as follows:

1. In popular language what was the ball called?

2. What name was applied to the bashful ones sitting around the room?

3. What did a bad boy throw through the window?

4. What old-fashioned article of dress worn by the host was struck by the missile?

5. What did he threaten to do to the young rascal if he could catch him?

6. What were the given names of his three charming daughters who were laughing at him behind his back?

7. By what pet name did they call him when about to ask a favor of him?

8. With what salutation did he bid good-night to his parting guests?

This contest will close on December 1 , by which date all solutions of the puzzle must be in our hands. The prize winners will be announced in the January Floral WorLd. Bear in mind that any subscriber may compete for the prizes offered-and no other persons. Read the terms as given above with care, and mail your answers to the questions so they will reach us on or before December 1 . 


\section{HOUSE PLANTS AND THEIR NEEDS}

House plants are like babies; to grow healthy and beautiful they require daily care. They should be brought into the house early so as to become accustomed to the change before artificial heat is needed. Arrange them according to their needs, sun-loving plants in the sunshine and shade-loving plants in a shaded or north window. Before bringing in I spray with kerosene emulsion; this destroys all softbodied insects, but for scale and others I use an old toothbrush and soapsuds, always rinsing in clear tepid water afterward; then if I spray in clear water every day and keep a basin of water on the radiator they are seldom bothered with insects. Plants must have fresh air daily, but must not be in a draft, so before cold weather I take strips of paper and mucilage and cover all the crevices about the windows. The top soil should be stirred frequently. When watering I use warm water, and water when needed; some require much more than others. When plants are chilled or frozen never place in a warm room; it is sure death to them; but immerse in fresh spring water to thaw gradually.

Ohio.

Anvice Bodey Calliatio.

\section{THE WINDOW GARDEN}

In preparing for my window garden this fall I am trying to profit by my former experiences, and avoid former mistakes. Early in September I began to prepare for potting the plants which had been growing in the open ground through the summer, as they should have three or four weeks in which to become established before removing indoors. With a sharp spade I cut to the depth of the blade a circle around each plant about the size of the pot in which to put it. At the end of a week or ten days I choose a damp, cloudy day, and after watering the plants will lift them with the spade and place them in pots already prepared by a good soaking and a supply of drainage material. Then fill in if necessary between the ball of dirt and pot with fine soil, water the plants well, set in the shade where the air circulates freely, shower daily, prune into good shape, removing all weak branches and dead leaves, and stake if necessary. My windows must be examined to see if panes are all whole and perfectly puttied. If any crevices are found to let in the wind I shall crowd in strips of paper with a thinbladed knife. For the bay window I am having a shallow sink made to fit. It is to be lined with zinc, with outlet at one corner stopped with a cork. Each morning after drawing off the water left the day before I shall turn in a pailful of boiling water. At $m y$ north window I shall have a shelf at the sill and another half way up, with brackets at the sides and near top. I cover my shelves with oilcloth, which is so easily wiped clean of dust and water. Previous winters I have made the mistake of trying to keep too many plants, but now I have a pit into which I shall put many and so avoid crowding my windows to the great detriment of the plants. A dozen fine plants are better than thrice as many dwarfed or spindling ones. In order to keep an even temperature of forty-five degrees at night and sixty-five through the day I make use of an oil heater. Especially cold nights I move the plants from the windows to a table and cover with newspapers. Through the winter, as plants grow but slowly, they require less water than at other seasons. I wait till the surface soil looks dry and baked, then give water, and plenty, till it runs through into the saucer. For fertilizer I use well rotted cow manure. Pour over it hot water four parts to one part manure. Dilute till it looks like weak tea, and apply once in two weeks.

Mrs. Meltia M. S. Stoddard.

Kansas. 


\section{FROM SOUTHERN ARIZONA}

Knowing that failures as well as successes are instructive, I will write of my garden, as the conditions prevailing make failures common. It is fifty feet square, and contains ten trees of good size, so that constant enriching of the soil is a necessity. The air is so dry and the rains are so infrequent that an almost daily use of the hose is an absolute necessity also.

The treatment of bulbs and the results here in southern Arizona are, perhaps, different from their care and growth in the North, and my experience may possibly help others, as every article on the subject deals with their care in places of lower temperature and more moisture than this.

Gladioli cannot compare with those North. I have tried them in sunshine and shade, and find the flowers rather inferior-just as bright in color, perhaps; but I think the heat opens the buds too quickly. Hyacinths do very well. I plant in October, not more than three inches deep, and they bloom in February. The small bulbs bloom year after year, but are hardly so large as at first. Tulips are failures. I have never seen here a tulip stem longer than four inches, and very few of the flowers have any color. Out of two dozen of the bulbs most of the flowers were the same green color as the leaves, and only half opened. The only one that had color had a stem one inch long, too short for even a buttonhole bouquet. They were next to the hyacinths, and received the same care.

I have had freesias in the house that were very beautiful to me, as they were the first I had ever seen, but after seeing some that came from California, I realized how much larger they might have been. Lilies-of-thevalley have done well for me in the house by planting half a dozen in a deep pot, as I find the roots are the larger part of the plant.
Easter lilies and callas do extreme. ly well either in the house or in open ground by protecting the callas on very cold nights. Mine bloomed outof-doors last winter. The narcissus does well also, and the bulbs multiply very rapidly. This is the paradise of the tuberose. I had a bed of them ten feet in diameter containing three rows, and the third year after planting, the bulbs having been undisturbed, I cut 550 beautiful stalks of that beautiful flower.

This year I have put up a small greenhouse for pleasure and experiment. The temperature with door and ventilators open reached 120 degrees many August days, but I can keep the air damp, which is what I want. I may have some interesting experiences to relate later in regard to it, but will leave that till another time.

Mrs. Thos. D. SATterwhite.

\section{Arizona.}

\section{FLOWERS FOR THE HOLIDAYS}

Who does not love to have a bright window of flowers at the Christmas holidays or Easter? To make a window attractive it is necessary to use some care in the selection and arrangement of varieties, and also to have the plants clean and healthy. If it is convenient to have a window box it may be made a source of continual pleasure. A point necessary in the culture of plants, if you would have them healthy, is good drainage. This may easily be obtained in a window box. In one end of the box bore a hole of moderate size to carry off all superfluous water. Under this may be placed a cup, or better, a fruit jar. Slope the box very slightly so that the water will drain toward the hole. Put in a layer of broken bricks and fill the box with soil suitable for the plants.

For a mixed window box the following suggestions may prove useful. Have a row of coleus at the back, i. e., 
the side toward the window, for they are effective from the outside. At one end have a heliotrope and at the other a climbing rose or geranium, which may be trained up over the window. Next to the coleus, geraniums or azaleas may be planted, and along the edge a row of oxalis. If bulbs are preferred the box may be made a bed of hyacinths or tulips, with the tall varieties toward the window, that they may be seen from the outside. The freesia is another excellent bulb for the window box.

If it is convenient to have a shelf instead of a box, there are innumerable plants and bulbs suitable for pot culture in winter. Perhaps the most desirable class of plants cultivated for their foliage is the palm. Latania borbonica, Cycas revoluta and Washingtonia filifera are all very decorative, and the umbrella plant is also a good decorative plant and does not need to be grown in water, as I have several fine specimens growing in common garden soil and sand.

I highly recommend the aspidistra as a house plant. I have one in a twelve inch pot with fifty-four leaves. Most are variegated, and two are pure white. Keep the leaves clean and shiny. Soap and water will not hurt.

The rubber plant is another desirable plant, as it will stand more neglect than any other plant I know of. By all means have one Easter lily, if not more, in the window garden. They do not need a greenhouse, but can be grown to perfection in any window, with moderate care. A pot of liliesof-the-valley will fill a whole room with their fragrance, and are such dainty little flowers that everyone loves to see them.

California. P. R. FAYMoNviLLE.

\section{SUCCESS WITH WINDOW PLANTS}

Plants should not be put in their permanent quarters until everything has been made ready for them. If your window is fully exposed to cold winds be sure to stop up every nook and cranny with cloth or paper. Also see that the panes are whole and perfectly puttied. Tack linoleum to your plant shelves; it is more durable than paper. Do not have so many plants that you will have to crowd them. By doing so you lose the individual beauty of each one. Arrange them so that each may display itself to advantage. Have plenty of room for the circulation of air and light. Plants that can stand the most warmth should be placed on the top shelf.

Give your window garden daily attention. Water only when needed. In most cases let the soil appear dry on top; then pour water in the saucers until the soil is thoroughly saturated. Most plants do not need so much water in winter as at other seasons. In no case should a plant be given stimulants when it is not growing actively; to do so is harmful. On the other hand, a thrifty plant which is unfolding flowers should be fertilized every other week at least. Turn your plants whenever they begin to grow onesided. All parts of a plant should develop equally. Use judgment in changing a plant from a shaded window to a bright one, or vice versa, as unopened buds of callas, double geraniums and double primroses sometimes bloom imperfectly unless managed with care. Single flowers, however, rarely disappoint. Keep your plants trim and neat by picking off the dead leaves, and training into pleasing shapes. Keep the atmosphere moist.

$\mathrm{Be}$ on the lookout for scale and mealy bugs on your plants; they multiply rapidly unless fought with diligence. Keep a can of fir-tree oil soap on hand, and use it on infected palms. It is harmless to plants, and insects cannot flourish where it is used. Spray your plants once a week, at least, and let the application be thorough. Administer the water with 
force. It is necessary that every speck of dust should be dislodged, so that the pores of a plant may not be clogged by foreign substances. The cleaner you keep your plants the better ones you will have to admire during the bleak days of winter.

Fresh air is essential. Open the door farthest from your window and let the outside air gradually circulate through the room. It should not strike on the plants directly, lest they become chilled. Let most plants have as much light as possible, especially the sun-loving ones. Keep the shade up to the top of the window, and do away with lace curtains. Take great care to guard against sudden cold snaps. Put papers back of the plants at night, and if the fire goes down burn an oil heater or large lamp. Chilled or frozen plants should be immersed in a tub of cold water until revived.

New York. Benjamin B. Keech.

\section{THE LILY-OF-THE-VALLEY}

This flower is equally well adapted to the open border, the greenhouse or window. It grows upon rhizomes or running root stocks, and all such plants multiply rapidly. Bedded out in a moist, shaded position, lily-of-thevalley will need no further culture than a top dressing of rich compost every fall.

The most profuse and beautiful bed of this exquisite flower I can recall has rambled for twenty years under a broad-spreading apple-tree, in Richmond, Va. Every spring the light green, oblong-ovate leaves cover the surface of the soil, and from their midst the flower scapes rise, covered with bell-shaped, snowy white blossoms, from base to tip. The flowers are so profuse the earth seems under a light fall of white snowflakes where they bloom. If, however, these lovely flowers are wanted for winter, the greenhouse or wirıdow culture must be conducted on different lines. It must be borne in mind that the lily-ofthe-valley loves a freeze. The "pips" or crowns must remain outside until frozen and then be forced into bloom. For this purpose it is better to patronize the florist than to depend upon home-grown stock. The pips or crowns may be bought in December or January, and the florist having duly subjected them to cold, bringing them into a temperature of about seventy degrees will force the blooms like magic. When put into boxes or pots cover the roots lightly with fibrous soil, but over the tops only strew sphagnum or fiber. Water and set in a darkened place until the green leaves appear. Then bring to gradual light and heat, increasing as growth proceeds. Preserve the humidity by moderate water upon the roots, and an occasional spray upon the foliage. The crowns hold the embryo bloom in readiness, and no plant is more active and responsive, none more sure to bloom. Strong sunlight is rather to be avoided, as lily-of-the-valley blooms profusely in partial shade. The tempered light of indoor apartments suits the plants exactly. Ordinarily the window plants can have only a few hours of direct exposure to the sunshine per day. If possible, let these plants have tne window with several hours of morning sunshine. In the greenhouse give lilies-of-the-valley some place that will be shaded part of the day. Directly under the glass is not as favorable as partial shade.

For cut flower purposes lily-of-thevalley is one of the exquisites. For buttonhole bouquets, with a violet, a rosebud and maiden-hair frond, all winter, on up till Easter, it blooms its best. Baskets of Marechal Niel or Bridesmaid rosebuds, interspersed ana fringed with lily-of-the-valley and fern fronds, are ideal for Easter decorations.

Mrs. G. T. Drennan.

Louisiana. 


\section{FLORAL BEAUTY INDOORS}

We can scarcely realize that another seed time and harvest has gone by, so swift is the passage of time. And now, today, we are preparing to stand face to face, shortly, with King Winter.

It is an easy matter to have floral beauty in our rooms when the outside world is in its long winter's sleep. We often wonder how people, especially who are in the country, can pass the dreary months away without a single flower or bit of leaf growing in their windows. Every home needs the cheer and brightness that plants and flowers bring into it. Flowers help us to tide over the wintry days; their beauty and sweetness fills into our lives and keeps the heart fresh and green.

To secure the best results in a window collection much depends upon the choice made. Aim to secure plants that bloom long and freely, and be careful about adding novelties. I am satisfied with common plants. Among my list are the snowdrops, single and double; the crocuses, daffodils, narcissus, hyacinths. I have found all these good winter bloomers, if potted in the fall and put into the cellar. Tulips I will not recommend; living rooms are too warm for them.

The Chinese primroses or primulas are almost constant bloomers. By all means have two varieties at least of these admirable plants.

Oxalis ortgiesi, a native of Brazil, is a choice plant. A dozen bulbs in a hanging basket, an eight-inch size, will be perfectly gorgeous in bud and bloom, producing hundreds of flowers. The bulbs should be rested in the summer for winter flowering.

The amaryllis is a beautiful plant. It is said to have but one rival, and that is the lily. Even with this queen of flowers it may vie for regal honors. These bulbs commonly have their rest in November, December and January.
When they begin to show signs of new life they come into flower in an incredibly short time.

Rex begonias give a wide range of beauty. Those who admire begonias try the three varieties, Grandis, Clementina and Louise Erdody. Care should be taken not to wet the leaves or stalk of the plant when watering.

Crassula perfoliata claims a share of our attention. Although its foliage is rather coarse, it has beautiful spikes of star-shaped flowers, white as the drifting snow. They form a fitting crown for the brow of the dying year, cold December.

The cyclamen is another winter plant, pretty in foliage and flower. There are other pot plants we cannot now mention for want of room. One secret of success with window plants is in proper watering. Too much water is just as deleterious as too little. Good soil is essential, sunlight is most desirable, but proper watering can make or mar the beauty of plants.

Nebraska. HARRIET W. Leightor.

\section{PARLOR PLANTS}

I have had a great deal of admiration bestowed on my collection of plants for winter every season, and I think no finer lot can be seen in expensive homes even.

I have been so discouraged with the common, spindling plants usually carried through our long, tedious winters that I feel confident in saying I have found a collection that will give universal satisfaction.

We can have flowers in winter as well as summer if one is only careful in making a choice. Keep the house warm and air moist. A common fault amateurs are apt to make is to keep the air too dry. A tiny kettle kept on the stove corrects all that. I have a south bay window which is the nicest place for plants, although I used a common window formerly and had good success by just putting up a row 
of shelves and covered with white oilcloth. I made a frame of woven wire in front of the window to look like a bay window, and had it covered with vines; nothing prettier could be had. I have a flower stand sitting in the bay window, with the shelves facing the window.

I began with plants from seed, and soon had a choice lot of them. I now manage to buy a nice plant every year. Palms are easily grown, and I have the tallest one sitting on top. Swainsonia alba is beautiful. Choice geraniums can all be started from seed, too. Cacti are the loveliest and easiest grown flowers, and grow fast from seed. Primroses are beautiful, and so easy to carry through. Storm King fuchsia is always in bloom. I have a large Chinese lantern plant that I started from seed. Perpetual abutilon is a flower which is ornamental in both leaf and flower, and has large, double, bell-shaped flowers of lovely colors. I have two passifloras which are elegant. Giant ghost flower is pretty, too. Callas are lovely, and cinerarias are showy flowers. Zamia is a beautiful plant, and it seems a flower lover ought to curtail her toilet luxuries in order to obtain one of these beauties. Petunias are now grown to perfection, and should be in every window.

I have a comet plant at which every passer-by stops to gaze. It is the easiest thing in the world to grow. Chrysanthemums are not to be slighted, either. This makes a good guide now, and no one need be without flowers nowadays. To all those who cannot keep fires at nighi I would say, make a tight double box with legs on and lid to fit so that nights the plants can be put in. Excelsior makes a good filling for the box. I have often set a lantern in the center when we lived on the ranch and could not afford a furnace.

Mrs. Klevance Parkinson.

Wyoming.

\section{A BAY WINDOW FULL OF PLANTS}

"How lovely!" was often heard during tne winter of 1900 , as people admired my south bay window of plants. There were over sixty. The large geraniums were three years old, cut back sharply in spring, not allowed to bloom in summer. Those from summer slips have but one or two branches. Madame Salleroi, Rose, Balm and Skeleton in large pots of rich soil are perfect trees. Of thirteen roses, Clothidle Soupert and Little Pet bloomed best; I cut sprays of seven from Pet.

Double and single petunias from August slips were always in bloom, also salvia. Justicia flava and Buttercup oxalis gave a touch of yellow. Heliotrope from seed was "nothing but leaves," but such big ones! Swainsonia with its sprays of white was lovely. Gloxinias bloomed all winter (out of season), also Ruellia makoyanna and impatiens. Pelargoniums bloomed towards spring, but the queen of my flowers was scarlet hibiscus. Several pots of coleus-a large one contained three varieties-were magnificent. Bougainvillea was large and grew like "Finney's turnip." I watched in vain for bloom. Solanum jasminoides grandiflorum covered a large trellis, scarlet passion vine climbed over the window, Madeira and ivy draped pictures. Two plumbagos, ardisa, orange, jasmine and other small plants received by mail in August proved it too late for winter bloom. Speciosa is the best winter fuchsia. On a bra?ket is trailing queen, ginger plant, weeping lantanas and asparagus Sprengeri; had also plumosus nanus, several small ferns; an immense Boston and Australian fern in jardinieres each occupy a stand.

At an east window are several begonias, two kentia palms, with perfect leaves, although small. A two-year-old pink Chinese primrose had twelve large clusters of bloom, while one-year- 
old white had but three. Baby has tier upon tier of its dainty bloom. Cyclamen also in bloom.

They are a care. Being an invalid it is about all I do. Get your plants early, keep in pots all summer. Give rich soil, not too big pots for blooming. Plenty of fresh air, wash or shower often. Keep watch for insects; soapsuds will kill them, but use it as a preventative, especially on roses.

In the fall, if you can afford it, plant a lot of bulbs for house and garden. Get a catalogue from a reliable florist, and it will give full directions. Look ovel your garden (hope it is as fine as mine), carefully take up stocks, snapdragons, asters, pinks and such annuals; they will flower all winter; also slips of verbenas. If there are no seedlings of sweet alyssum, browallia or quick bloomers, sow seed in the fall. Remember such plants must be kept cool; just above freezing will suit them. Be sure to keep water on the stove or radiator evaporating for yourself as well as the plants. Last, but not least, take a good floral magazine. I take six.

Maine. Mrs. Aroline P. Adams.

\section{ABOUT THE BULB GARDEN}

Now is the time to be preparing our bulb garden. Bulbs are cheap and should be planted liberally, and in spring we can enjoy a rich harvest of flowers. Do not fail to order early, since you are then sure of getting what you want in fine, large bulbs, before the florist's stock is all picked over. Scillas, snowdrops and crocus appear as soon as the snow is away, and are quickly followed by hyacinths, narcissus and tulips.

Tulips are the most brilliant of all bulbous flowers, and will grow in almost any soil unless there is too much moisture. The bulbs should be planted about six inches apart and covered to a depth of three or four inches. Plant in October, which is the best month for all garden bulbs. As a protection against severe frost, a layer of leaves about six inches deep, with other coarse litter to weight them down, will be effective. This covering should of course be removed early in the spring. Hyacinths are among the first to make their appearance out of doors in the spring, and gladden the earth with their bright bloom.

In preparing a bed or box for the bulbs, special care should be exercised, as their fleshy substance renders them an easy prey to disease, and subjects them to the attacks of rats, mice and other enemies. The best soil for them is a very sandy loam well mixed with leaf mold and old cow manure. Set in rows four inches apart each way and cover five inches deep with soil. A handful of sand placed under each bulb will help to prevent decay. Plant in October and cover as directed for tulips. Narcissus will thrive under about the same treatment except that they will be all the better for having a shaded situation.

Don't forget to give outdoor bulbs some protection during winter. No matter how hardy they are, they will bloom much better for care. Continual freezing and thawing during a mild winter weakens the vitality of a bulb. No matter how mild the winter, some covering is a necessity.

After the flowers and leaves have died down the buibs should be taken up and stored away in a cool place not subject to dampness.

I will give a list of bulbs that I grow in the window garden: Freesias, Roman hyacinths, alliums, oxalis, tritilea, sacred lily, ornithogalum, winter aconite. Their culture is very simple. They can be potted in September, October or November, watered well and set away in a dark cellar, or any cool, dark place, to make roots. After remaining four or five weeks they can be brought out to the light, where they will grow and bloom profusely.

Indiana.

Mrs. R. A. Houk. 


\section{CONSERVATORY SUGGESTIONS}

In a $4 \times 12$ room, all windows on the south, east and west, opening from a room heated by a furnace, I grow successfully the geranium, primrose, fuchsia, begonia, heliotrope, cineraria, pelargonium, freesia, hyacinth, calla, hibiscus, hydrangea, Swainsonia, hoya, cobea, Asparagus plumosa and Sprengeri, besides many others. Some are plants to be carefully carried through tue winter for summer blooming, the rest are my winter blooming plants. Most of my plants are raised from seed or slips. About thirty geraniums rooted in May will give me an abundance of bloom all winter. Considered from all points, geraniums are most satisfactory; they give so much for so little.

Sow primrose and cinéraria seed under glass in the spring in fine soil. Careful repotting in rich, sandy loam, with good drainage, during summer, gives blooming plants for winter. Do not set primroses too deep; keep water from leaves and center of stalk. Watch cinerarias for red spider.

Pot hyacinths early in October, water and set in cool, dark place for six weeks; roots will then be sufficiently grown to bring pots to the light. Leaves will soon appear, and later the flower stalks. Keep quite cool if you wish good blooms. Roman hyacinths will bloom by Christmas.

The hibiscus requires good soil and generous sized pots; water freely in summer, sparingly in winter. After warm weather comes place outdoors, where their large, brilliant blooms will prove attractive. Hydrangeas must rest until February, when they should be pruned, repotted and watered.

Cobea scandens is a good vine for the house; is easily raised from seed. I have a clerodendron growing finely, and four antigonon vines raised from seed. I am anticipating great pleasure from them.

For ornamental plants I grow Boston fern, palms and asparagus. The Sprengeri is very graceful, with long, trailing branches.

Late chrysanthemums with immense blossoms fill every spare corner through November; some last until Christmas.

Flowers have expression and individuality as well as people. Learn their individual needs and you will soon see their gratification expressed in additional growth and blossom, and be surprised at the variety of plants you can cultivate under the same conditions. Mrs. E. R. B. BARber.

Michigan.

\section{Now for A Vote On the Prize Contributions}

The publishers of THE FLORAL WORLD some time ago offered a set of prizes, aggregating $\$ 100.00$, for the contributions from subscribers which were contained in the October issue and those that appear in this number. Some of the articles submitted in competition for these prizes could not be used on account of their length. The prizes were to be as follows:

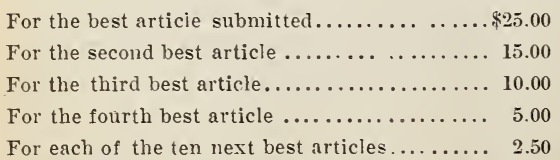
For the best article which does not exceed two hundred words...................\$10.00 For the second best article which does not exceed two hundred words .............. 5.00 For each of the five next best articles which do not exceed two hundred words.......... 1.00

The selection of the prize winners in this contest is to be made by those who are subscribers for THE FLORAL WORLD. You must use the coupon at the bottom of next page in casting your vote. Be sure to fill out all the blanks, writing opposite each prize the name and state of the person whom you think 
entitled to it. No vote will be counted unless the name and address of the subscriber forwarding it is plainly written in the spaces at the top of the coupon. Every paid-in-adrance yearly subscriber for THE FLORAL WORLD may votecoupons sent in by non-subscribers will not be honored. The prize winners will be announced in our January number.

We now invite from our friends articles suitable for publication in the January number of TuF Fuonar. WORI.D. These should be of timely interest and must be short-hereafter we will receive no article that contains more than 300 words. Only contributions from subscribers will be received. All the articles intended for this competition must reach us by December 10 . For the best article we will give a prize of $\$ 25.00$; for the second best, $\$ 15.00$; for the third best, $\$ 10.00$; for the fourth best $\$ 3.00$, and for the fifth best, $\$ 2.00$. The prizes will be awarded by vote of our subscribers and announced in the March, 1902, issue.

Address your letters to

The Fromal, Worid. Springfield, Ohio.

Prize CO

THE PRIZE

YOU VOTE FOR ITS AWARD TO

First

$\$ 25.00$

Name

State.

Second

15.00

Name

...state.

Third

10.00

Name

State

Foneth

5.00

Name

State

Fifth

2.50

Name.

State

Sixth

2.50

Name

State

Seventh

2.50

Name

State

Eighth

2.50

Name

State

Ninth

2.50

Name.

State

Tenth

2.50

Name.

State

Eleventh

2.50

Name.

State

Twelfth

2.50

Name.

State

Thirteenth

2.50

Name

State

Fourteenth ........

2.50

Name.

State

Fixst Special..... 10.00

Name.

State

Second Special... $\quad 5.00$

Name.

State.

Third Special .... 1.00

Name.

State

Fourth Special... 1.00

Name.

State

Fifth Special.....

1.00

Name

State

Sixth Special ..... 1.00

Name

State

Seventh Special .

1.00

rame.

State

Bear in mind that you are to consider all the articles which appear in both October and November issues before casting your vote. Each prize will be awarded to the person for whom the largest number of subscribers vote as entitled to that particular sum. In cases of a tie, the Prize will be divided. NULL AND VOID UNLESS SENT IN BY A SUBSCRIBER. 


\title{
The Biggest Bargain
}

\author{
OF THE SEASON IN PERIODICALS \\ FOR FAMILY READING
}

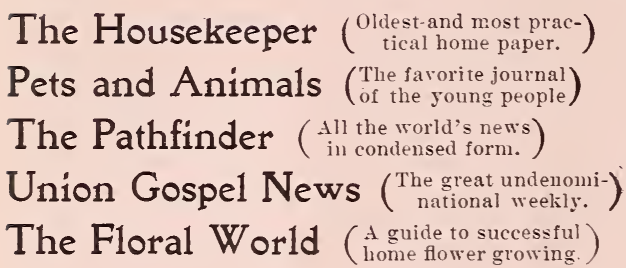

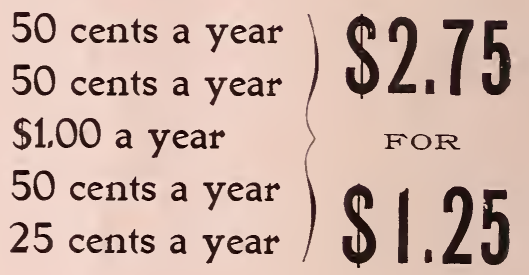

Through a special arrangement with leading publishers we offer for a limited time only this splendid combination of five papers for family reading, covering every phase of home interest. The price when subscribed for singly is $\$ 2.75$ a year; we offer all five publications for only $\$ 1.25$.

"The Houselieeper, $" 36$ page monthly, is the oldest and one of the very best of the domestic periodicals. The progressive housekeeper will find this magazine invaluable, for it tells the best and easiest way 10 dn all necessary work, and helps her to economize, not only in money, hut in time and strength as well. It keens her-informed, and furnishes interesting reading for her entertainment when she is too tired tu care for anthing excent fiction. The departments of Fashions, Fancy Work, Household Helps, Iother's Comcil, The Door-rard. Our Young Folks, are all carefully edited, bright, original and up to date.

"Pets and Animals" is a journal for the whole fanily, of interest to every nember, especially the children. It appeals to all whose hearts are young. Clever stories, attractive illustrations and articles of an instructive character are blended in most readable form. It teaches thoughtfulness, kindness and mercy, and uses the literature of the animal kingdom, always of absorbing interest to young people, as a means of illustrating these great lessons. There is no publication like it. One subscriber writes: "It seems as if it were edited by inspiration." A business man says: "It has stinulated the entire household in the study of natur:il history, in which we have all learned many wonderful things not known before."

"The Pathfinder" gives you every week, in classified, condensed, get-at-able form, all the important news of the world, stated clearly and without bias. It is the only new's review that is trulv comprehensive; and it is at the same time not padded or bulky. It gives the wheat without the chaff, and is a time-saver for all busy people. In purpose it is high-toned, healthy and inspiring. A protest against sensational journalism. It takes the phace of periodicals costing 82.50 and ș.00. Pıice. ş1 a year.

"The Union Gospel News" is a weekly religious paper of sixteen pages. Thoroughly undenominational and evangelistic. Taken by members of all denominations. Many who take several religious papers say it is best of all. Its list of special contributors include the leading writers of the world on religious subjects. Each issue contains among other things a sermon by Dr. J. Wilbur Chamman and notes on the International S. S. Lessons by Dr. James M. Gray of Boston. Dr. Gray is also contributing a two year's' course in Dispensational Bible study. The entire Bible is to be studied by Epochs or Dispensations. Dr. Gray is conceded to be without a peer as a Bible teacher.

"The Floral World" is the people's floral magazine. It contributors are persons who grow flomers successfully in their homes. No professional florists or authors have anything to do with the matter which appears in the jourual. It is published for the benefit of those who can grow only a limited number of plants, hut who wish to get the best results from the home flower garden, whether indoor or outloor. The best varieties for genf ral culture will be treated in their season. Wiery article which is contained in THE FloRaL WorLD is simply witlen, brief and to the point. Liberal prizes are awarled to subscribers for the best contributions furnished ly them.

No offer so liberal as this one will be made by any other publishing house. Send in your order at once-we can give these liberal terms for a short time only. All subscriptions must be new-renewals not received. 


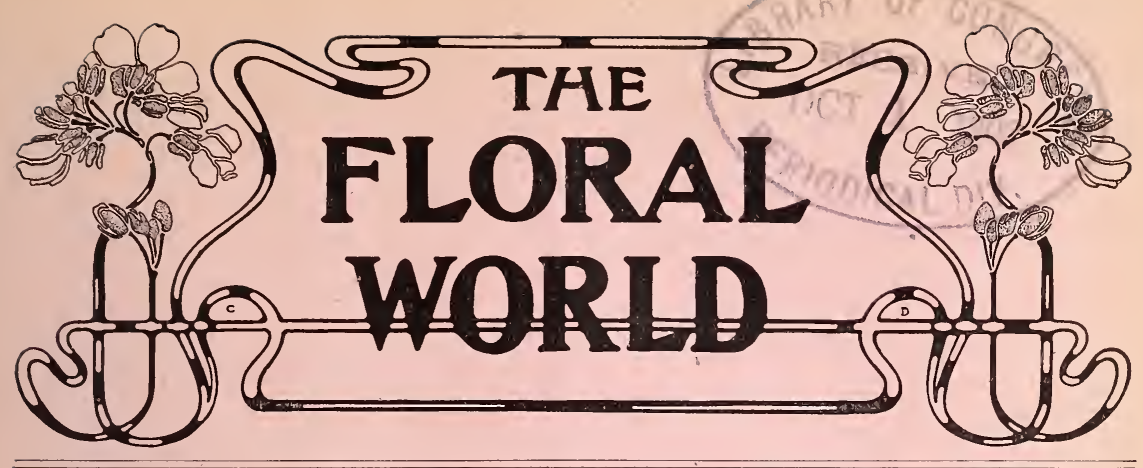

Vol. I, No. 3 Springfield, Ohio, December, 1901 25 Cents a Year

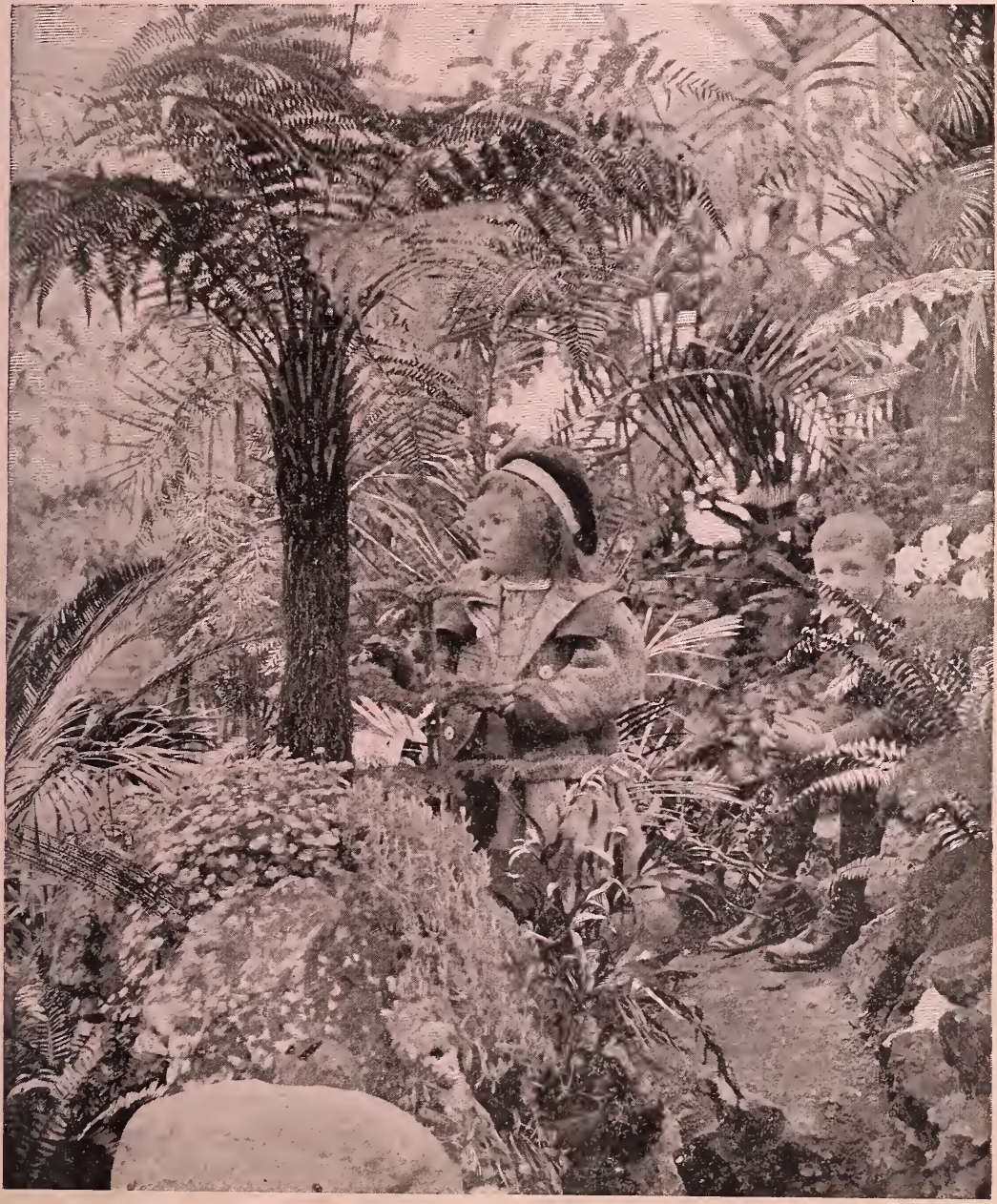




\section{ABOUT OUR PLANS FOR THE NEW YEAR}

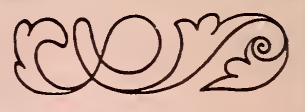

The reception given THE FLORAL WORLD has been so cordial and so encouraging that the publication will take its place as a permanent factor in the world of periodicals. We have been greatly pleased to note the evidences of an increasing interest in home flower growing that are contained in the letters we receive. Our idea of a "people's floral magazine," one devoted wholly to flowers and how to grow them, has been approved by the many hundreds of subscriptions which have been sent in, and of course we like this, too.

Our plans as set forth in the first issue of THE FLORAL WORLD will be carried out. We will continue to publish only practical matter-articles written by persons who succeed with flowers and whose advice will help amateurs. Above everything, we want to make our little journal practical and helpful. No professional florist or gardener will be permitted to write for it. The conditions under which they grow plants are very different from those in the average home.

And it is flower growing in the home we desire to promote. Nothing else will do more to make men and women better or will add so much to their enjoyment of life. That THE FLORAL WORLD, with this aim and purpose, is welcome, has been proved already. It will grow and become better as new friends give it their support, but its object will always remain the same as now.

Every cent we spend for matter to be published in THE FLORAL WORLD will go to our subscribers. They know the things which we want to print, and for writing about these we offer liberal reward. For fuller particulars see offer of prizes for contributions made on page 8. Our readers award these prizes, and in this way the money goes to those who forward the most timely and valuable articles - the ones which help in growing flowers. Let us have your co-operation, both in the form of brief letters for publication and by telling your friends of THE FLORAL WORLD and asking them to subscribe for it. 


\section{A Fournal of Home Floriculture}

Vol. 1, No. 3

Springfield, Ohio, December, 1901

25 Cents a Year

\section{THEY LIKE THE FLORAL WORLD}

I received the sample copy of your little magazine last night, and it seems to be just what I am in need of. I take two floral magazines, but we amateurs need a paper that gives the experience of other beginners, if we are to be really benefited. Wishing you success, I am, yours truly,

Kansas. Mrs. J. J. Overstreet.

Let us who are subscribers to The Floral World co-operate with the editor in making it one of the best publications of the kind. It is just now in its infancy, and a little effort on our part in its behalf will help wonderfully in making it a success. Its subscripticn price is so low that I am sure we each can get for it one or more subscribers. None of us who have grown flowers at all but have learned something about them that others would like to know. Then through the columns of the magazine let us give them the benefit of our experience. There is a sweet affinity between all flower-loving persons, a congeniality that seems to draw us together. Would it not be pleasant for us to have a magazine we can call our own, and through it help each other, feeling tnat whatever concerns one, whatever promotes the success of any, is of interest to all? With pride and pleasure then, we will watch the growth and development of our magazine, The Floral World.

Tennessee. Mrs. M. C. Ryall.

\section{WINTER PROTECTION OF ROSES}

The above caption implies something to protect-that is, strong healthy roses; not weak, sickly things that have battled all summer with drouth, worms and an impoverished soil, leaving them little vitality with which to exist in mild weather, to say nothing of the rigors of winter. If we mothers want our babies plump and rosy, we are careful to see that they are cared for and nourished.

First prepare the bed either in spring or fall, by digging two feet deep. Now, my sisters, let me tell you a secret-this is an opportunity to utilize all the old shoes, bones, stones and any such rubbish that may be in the way. Put in six inches of this for drainage. If the soil removed is not clay, add one-fifth clay, with sand enough to make friable. Add two parts well rotted cow manure. Mix and return to the bed. Set plants two feet apart and a little deeper than they were before, adding soil and water alternately, priming the soil well each time. Shade for a few days and keep moist. As cold weather approaches apply three or four inches of coarse manure. When cold and the ground is hard frozen, put on six inches of excelsior. Mine is held in place by woven wire around the bed a foot high. This is much neater than barrels, boxes and leaves for protection. I have never tried anything so good as the excelsior.

Missouri. Mrs. Candace Powell. 


\section{CAPE JASMINES}

I have just finished planting one dozen cape jasmines, which I rooted in a jar of water. They grow nicely with us in the open ground the year round. From experience. I find the quickest and safest irethod of propagating this beautiful flower is to break the flower with a long stem, pinch off the flower, and place the branch in a glass jar filled with water. Put the jar wnere the sun will shine on $1 t$, and as the water evaporates, fill with fresh water. In a week or ten days little white roots will begin to form. As soon as the roots are large enough, which will be in a few weeks, transplant in a box of coarse white sand. When they commence to put out new leaves, add a little earth and manure. After a week or so (the first rainy day) transpıant in the garden where you want it to grow, giving plenty of water and protection from the sun, for a few days.

Texas. Mrs. A. Crain.

\section{PALMS}

Of all house plants, palms are the least disappointing. They have no flowers, therefore you expect none. I have several of different kinds, the largest a filifera," being twelve years old and having immense leaves and large trunk. It is now in a half barrel. It has set out doors in all the intense heat of last summer, borne all the winds and even endured frosts and a severe hail storm, but is all right to adorn any room it may occupy this winter, though too large for my plant window. The "latania" comes next in my estimation, but is of slower growth. After tıat come the Kentias.

In resetting a palm, choose a deep vessel rather than a large one. They do better when the roots can run down. They like good, rich, porous soil, plenty of drainage, and not too much sun and water in the winter.

Nebraska.

Grace A. Flory.

\section{THE WINTER WINDOW GARDEN}

Arrange your winter window garden as early in September as possible, or as late as December if impossible to do so earlier. Twelve to sixteen plants are enough for an ordinary one. Were my space limited to sixteen plants, they would be: Ficus, Boston fern, cyperus alternifolius, asparagus sprengerii, asparagus plumosus, grevillea robusta, acacia, nicotiana affinis, impatiens sultana, cineraria hybrida, geraniums Asa Gray, single new life, and pennyroyal scented, with leaves of softest emerald velvet; oxalis, bowei and buttercup, and a palm, balmoriana or filifera. If any one, having tried these plants for winter, can give a better list, we would like to have it. More than half of them can be grown successfully in a north window, with no direct sunlight-a great advantage, surelygiven ordinary garden soil, good drainage, warm water in abundance, but only when they get dry. They will yield a continuous supply of flowers and fine foliage for many months in the winter season.

Of course, a good showering-a whisk broom will answer for the purpose-twice or thrice a week, to keep clean and free from insects; a drink of Bowker's Plant Food twice a month after growth starts in earnest; and protection from draughts of cold air, are among the little essentials of success. If any one has room for two dozen, add begonias rubra and sanguinea; lopesea rosea; libonia penrhosiensis; senecio petasites; abutilon Enfanta Eulalia, lobster cactus and a basket of othouna. The writer often feels like going into the nice, steam-heated homes here in a big city and pulling down the heavy draperies from the big south windows and filling them with baskets, brackets and pots of these God-given beauties.

Illinois.

I. A. AULd. 


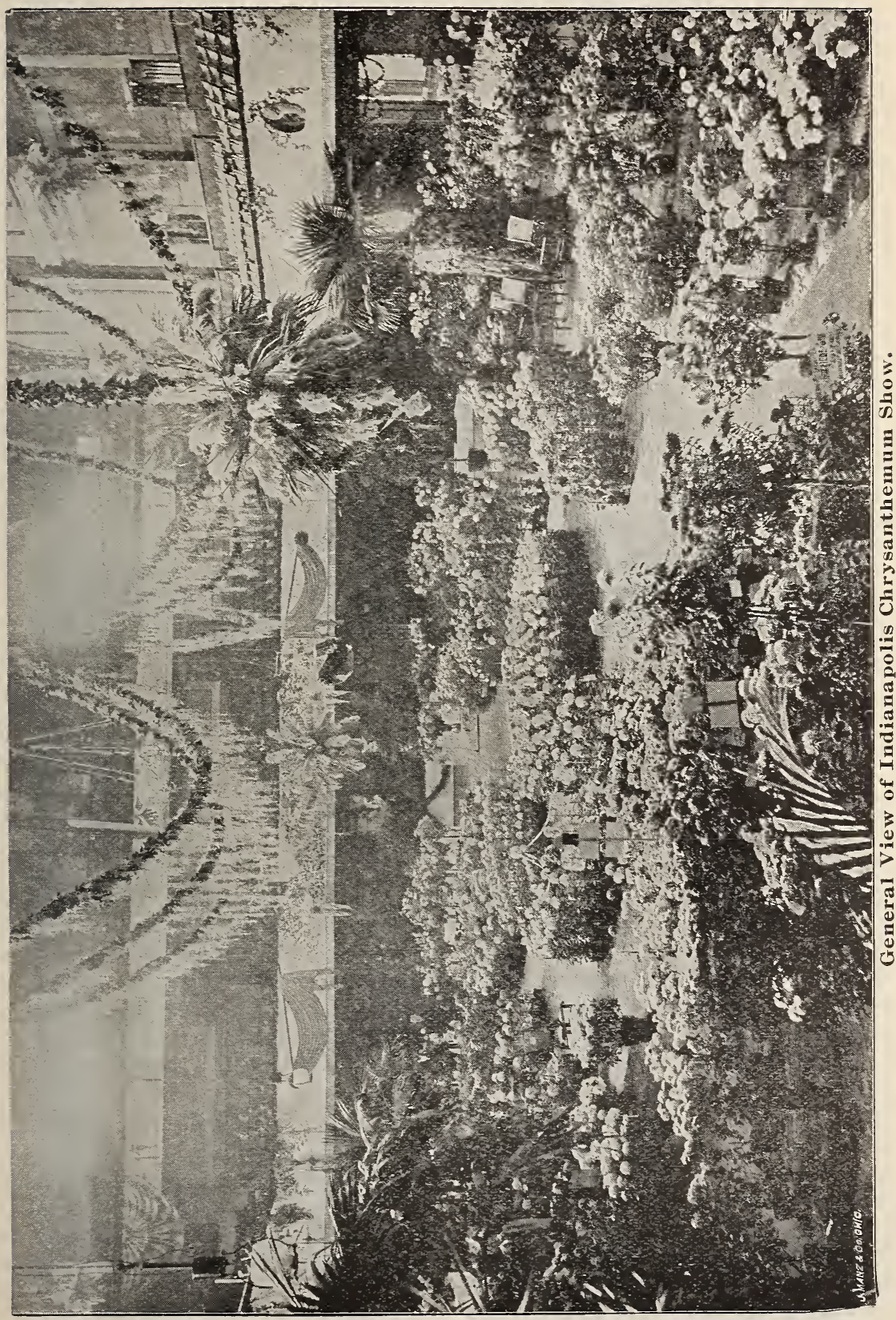




\section{WREATHS FOR CHRISTMAS TABLE}

For years I have grown the hallianna honeysuckle and bitter-sweet (Celastus Scandens) vines for Christmas decorations. The former, if well grown, is a beautiful evergreen here, and will stand hard freezing, the foliage remaining green and glossy.

Make wreaths about twelve inches in diameter of the green vine and the bitter-sweet, now in its prime, with its scarlet berries. I use two bunches together, tied in four equal places, on the wreaths. Then tie with bows of silk flag ribbon one and one-half inches wide. Place one or two wreaths on the table and set the cake (on cake stand) in a wreath. Make a small wreath of the green single vine and tie bows with one-inch "red, white and blue" ribbon - one-piece ribbon, I mean.

I dump bushels of barn-yard sweepings around my vines semi-annually. The vines I have named are pretty for yard decoration all winter.
Illinois.
Annie J. Paddick.

\section{CARNATION PINKS}

In May I secure my plants from a first-class florist, which I think is cheaper than sowing the seed. Then I can select the colors I like best. I plant them with a little leaf mold or woods' earth mixed with the common soil. When the plants begin to grow I pinch them back, taking out the whole of the heart so they will make a bushy growth for winter. As the buds appear I pinch them off. This makes the strength go to the plants. I keep the soil well stirred and free from weeds, using a common table fork. I wet them a couple of times a week with manure water (using cow manure). About the middle of August I lift the plants and pot them for winter, shading a few days to keep from wilting. As soon as they are back to their natural state again, I remove them to the place from which I lifted them. There they are set on a board to protect them from worms. I let all buds grow as they appear, and when ready to move in the house I have carnations full of blossoms and buds.

New York. Mrs. G. E. Passage.

\section{A WINDOW GARDEN}

By this time all flower lovers should have their plants in winter quarters. Our sunny windows are a source of great pleasure. Each morning our plants are looked over for new buds, and it is with keen satisfaction a tiny bud is spied. Flowers need much attention, but a real flower lover does not consider it a trouble to care for her choice plants. Each day we look to see if a single plant is afflicted with insects. If one is found, immediately the unfortunate plant is taken to the sink and given a thorough bath in luke warm water and soap suds.

A choice abutilon of mine has been dying, and I could find no cause. Today I emptied the pot, and there I found four angle worms. The roots were nearly destroyed. I removed the worms, baked the soil, cooled it, and then repotted it. If you have a drooping plant, look for worms. They are a terrible enemy to pot plants.

Try to let your plants have a breath of fresh air each day. It does house plants much good to shower the foliage once in a while. We use a common tin clothes sprinkler. Pick off dying leaves and soften top soil when it becomes packed. Once a week a little plant food will encourage them to do well.

I believe plants do better for not continually turning the pots. Let them face the sun one side. Remember, Jack Frost is around, and unless you watch will put his icy fingers on your plants. Beware of him. "An ounce of prevention is worth a pound of cure."

Mrs. Charles F. Tuthill.

New York. 

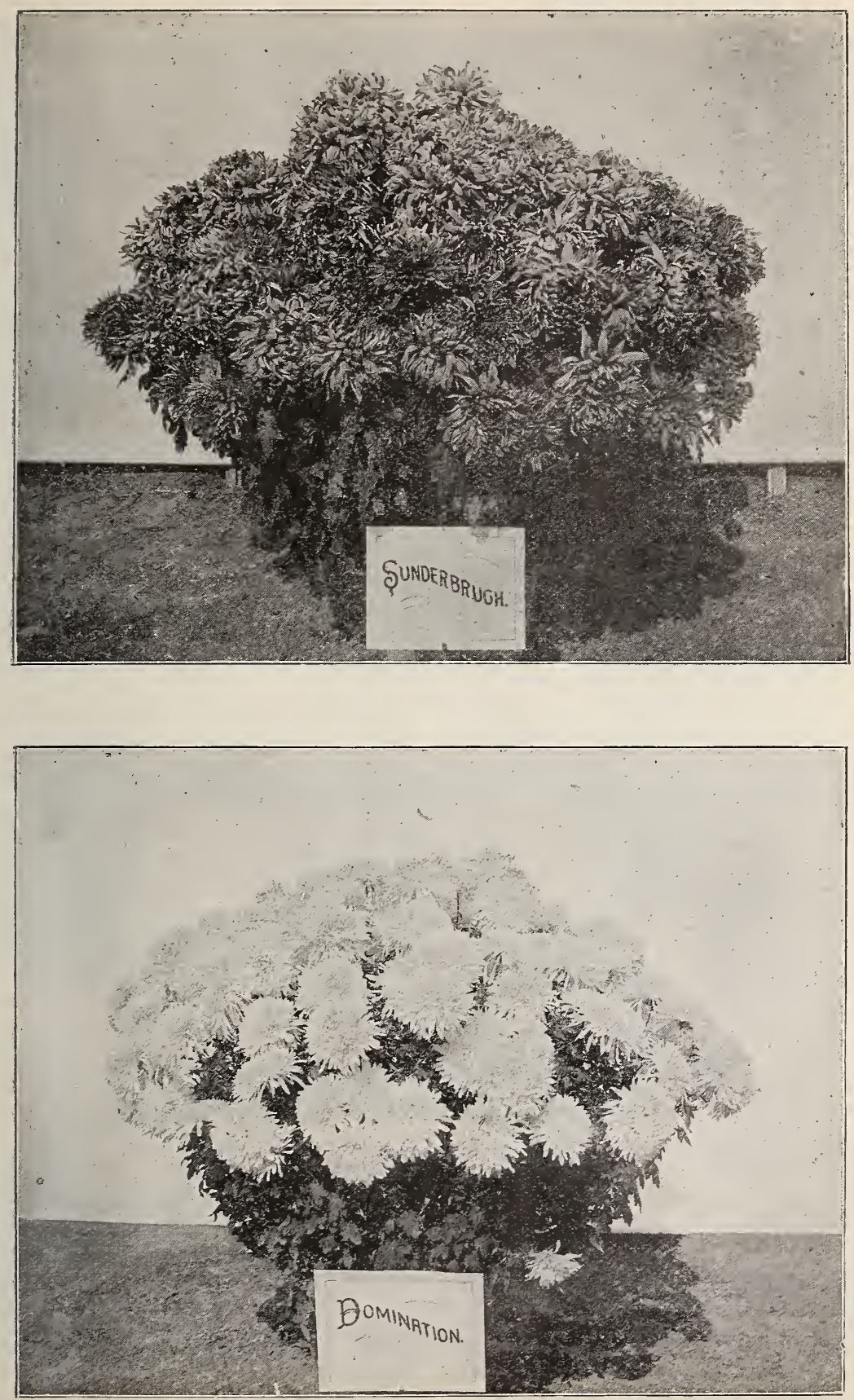


\section{A WORD FROM ARIZONA}

I have received the first number of "Floral World," and I am much pleased with its size and make-up. Lovers of flowers need this little newcomer. I live away down in Arizona, near the line of Old Mexico. There are not many flowers here-too dry and sandy. The cactus grows wild here, and we have another plant that is quite pretty to look at-they grow ten and twelve feet high. These are called sotos. They are stately, like sentinels. standing out over the country, and have white, waxy flowers. These plants are evergreen, and the trunk is used for fuel in some places.

I have some cannas I brought here. They have done well, and are still in bloom. I want to ask the readers of our paper if it will do to leave them in the ground over winter, with a little mulching. Our winters are not very cold. We nave a little ice and frost. Will they do better to take them up, as you do in colder places, and plant out in the spring? The cosmos is very pretty for fall blooming, and does well here-very hardy in this climate.

Arizona. Mrs. M. I. Hopps.

\section{A HANDSOME BASKET PLANT}

For the amateur's window there are few basket plants that will give more satisfaction than the oxalis. It will endure the extremes of temperature better than most other plants, and if given sun will bloom profusely all winter. A season of rest can be given it in summer and it will be ready for the next winter. There is the Bermuda buttercup, rich yellow; the grand duchesse, white, pink, lavender; the deep-rose bowaii lulla fl. pl. rich lemon; arborea alba and pink, vessi color, white and pink; every one good. Give light, rich soil and keep moist. I have had them to bloom continuously for six months in the year. The blooms, bright and distinct, borne in large clus- ters, are produced so freely that the plants appear as a mass of bright color, and if well treated they are good for many years. Oxalis ortgiesi differs from the others in being of shrubby growth, branching freely and being loaded at all times with clusters of bright golden, star-shaped flowers. The leaves are rich olive green, shining purple underneath. It is a beautiful plant for side brackets; a good, every day plant, not at all fussy, which is the kind most amateurs want. About the only thing the oxalis demands and will not do without, is sun. They will grow all right, but to bloom as they ought they must have the sun.

Missouri. A. Elizabeth Badger.

\section{MY CULTURE OF CHRYSANTHEMUMS}

About the middle of June my bed for chrysanthemums was spaded and well prepared with mixed fertilizers, thoroughly rotted. After a good rain, my small plants were taken from the three-pound tomato cans, finely rooted and placed in holes two feet apart each way. After the dirt was pressed firmly about them, I gave them a good drenching of soap suds, until they were well started. About two months later my plants-as I thought at the timewere ruined by having old plastering scattered over and around them (by a careless workman); the drouth came on and I was almost in despair over my poor plants. I had as much of the trash removed as possible, then the long-looked-for rain came, and my plants once more put forth new growth. I took all the fertilizer I could get, piled it close about them, and kept them wet with suds from washings. The pinching of limbs and buds kept me busy the rest of the time, and not an insect about. They have repaid me in lovely blooms. I have a lean-to of old sashes placed over them, against the southeast end of the house. Alabama. Mrs. W. D. BRown. 


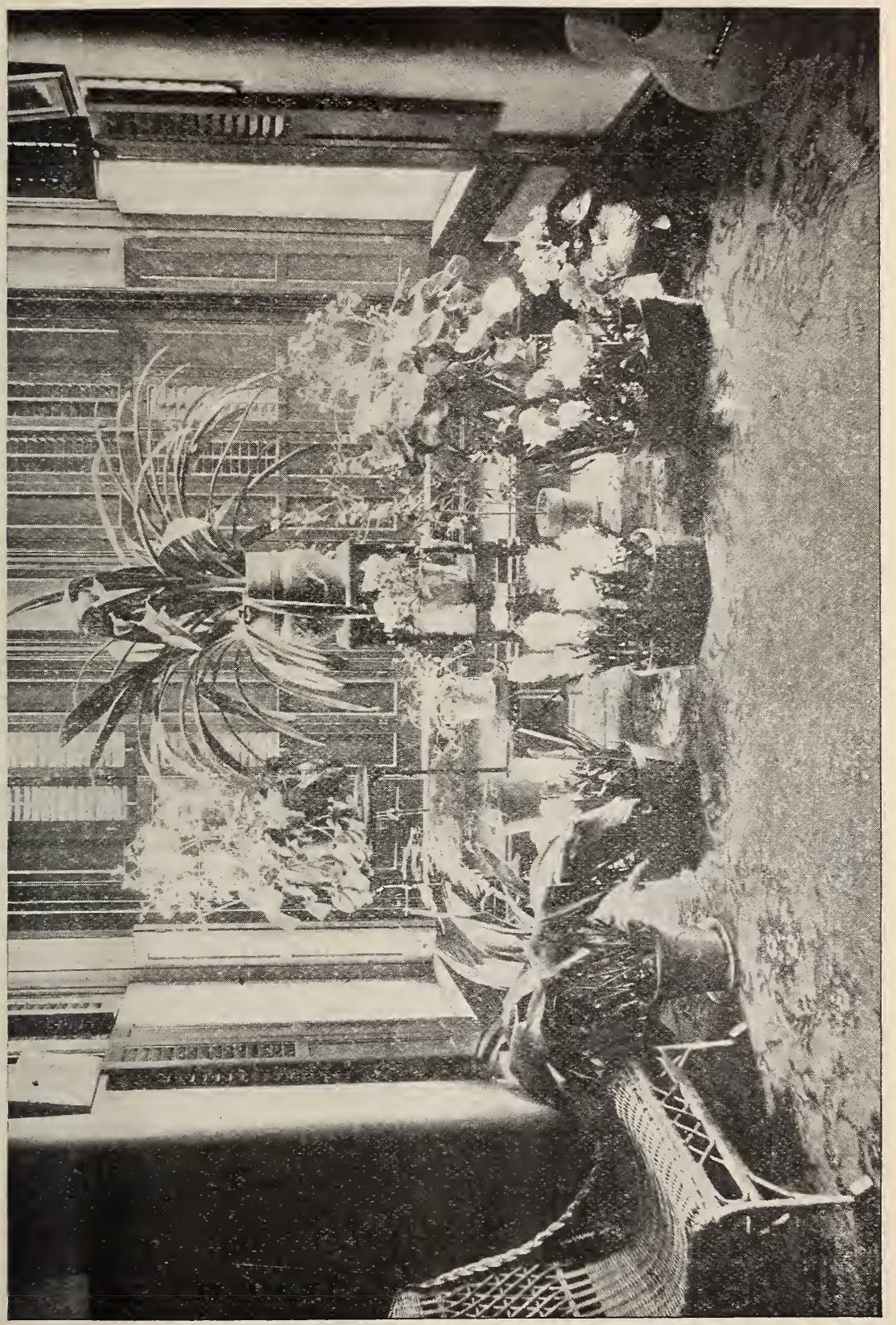




\section{The Floral World}

PUBLISHED MONTHLY BY THE

FLORALWORLD COMPANY,

12 to 14 South Limestone Street, SPRINGFIELD, OHIO.

Subscription Price, 25 Cents a Year.

Correspondence invited from all persons interested in flowers, Write us your experience with plants.

\section{OUR EDITORIAL PLAN}

Each month we give $\$ 50.00$ in cash prizes for the best contributions that reach us. The first prize will be $\$ 20.00$; second, $\$ 15.00$; third, $\$ 10.00$; fourth, $\$ 3.00$ and fifth $\$ 2.00$.

Our subscribers will award the prizes. Each one can vote-blank coupons or ballots will appear in every issue. The amounts offered will be paid to the persons whose articles receive the greatest number of votes.

We now request articles for publication February. These must not exceed three hundred words in length, and must be in our hands by January 1. If we receive more articles than can be published in January issue, the most seasonable ones will be run in that number and the remainder held for subsequent months.

Ballot for vote on January article will appear in that issue, the awards to be made public in April number. It is now time for a vote on the articles in this issue. Every subscriber for THE FLORAL WORLD is urged to at once fill out and send us this coupon.

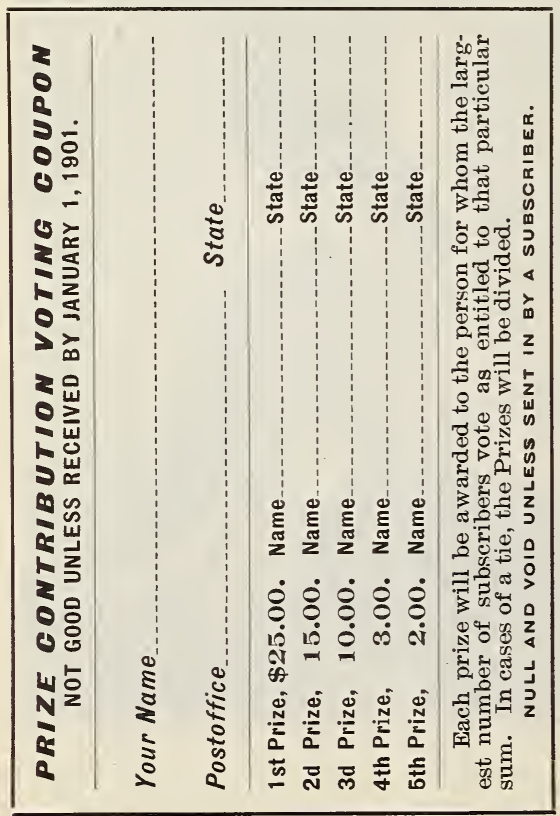

WE SHOULD STUDY THE "WHY"

Hundreas of flower lovers read floral magazines and waste on bulbs that fail enough money for a bountiful supply of perfect blossoms from the greenhouses, yet seldom produce a flower. One reason is aptly expressed in the language of the king to Paul, "Much learning hath made thee mad."

For, one paragraph in "The Only True Guide to Successful Flower Growing" states that bulbs must be covered in a dark place, and in the same pamphlet a subscriber's experience advises light. Again, the amateur reads, "use rich soil," and another "experienced grower" writes that it is immaterial. But, as the former method seems most in favor, the puzzled beginner stuffs the earth with fertilizer, and the rich soil process is settleu-so is the fate of the bulb. The poor unfortunate reads on, "Tiss plant requires plenty of water." He pours on the liquid, and the next step is accomplished. If the bulb survives the first step, this drenching performance is all needed for a finishing process.

The truth is, amateurs do not realize that successful flower culture requires study. In this "off month" of December is a good time to do a lot of thinking about the nature of a plant-how it generates and breathes like ourselves. Yes, and it will sulk, too, if not properly cared for and given attention whenever needed.

Thoughtfully note how one loves the sun while another prefers a cool, retired spot, and all will pıne and droop away if we forget that all they ask is good food, pure air and water. And they love a bath. Wrap a cloth around the earth and immerse the tops in plenty of clean water-see how they strengthen up and thank you with their fresh glow. Quarantine unhealthy plants, freely using the bath, and you will not need insecticides.

New Jersey. I. M. Stacy McLeod. 


\section{CARE OF HOUSE PLANTS}

Our window garden is unique, and I believe the most beautiful and satisfactory arrangement on record for wintering plants, being wide and deep, with brick walls and cementea bottom, sloping back and drained to carry off surplus water. Plants are profusely sprayed without injury to walls or carpet. Three bushels of charcoal is overlaid with woods earth, which is formed into little hillocks in the background, with a ravine between, and the surface carpeted with moss, wherein vines and trees are planted. A basin of water furnishes a bath for the canary, whose open cage allows him the freedom of the window, and a family of little tree toads who were enchanted, and voluntarily appropriated it for their permanent quarters. A moss-covered stump with little ferns on its sides and top was procured and carefully located where most effective, and large ferns planted between its spur roots, with still larger kinds grouped elsewhere. Large shells and showy minerals are tastefully disposed among the plants and along the margin as a hint to "please keep off the grass." Swainsonia or jessamine blooms continuously on one side with English ivy scrambling over the opposite and festooning the archway. Hanging baskets and brackets of primroses and begonias adorn all windows with ficus repens creeping up between, with a large jardiniere of flowering plants before each window. Stars of hoya cornita shine down from their glossy depths overhead, from which a scarlet fountain plant is suspended in the act of crowning a venerable sago palm queen of this fairyland. A stately rubber tree at its extreme right, with an oleander opposite, are rival companions. Excepting the palm, the kinds and arrangement are changed each season for variety, and given a carpet of fresh moss, converting it into "a thing of beauty and a joy forever."

Indiana.

Sarah A. Pleas.

\section{SOME SUGGESTIONS}

I think we should make our homes as happy and beautiful as possible, for such homes exert a powerful influence on the minds and hearts of the children to start them and keep them in the pathway that leads to happiness and to heaven.

So I am glad for all the publications and all that is being said and done for the happifying and beautifying of the home. I am especially glad for the birth of this new influence, "The Floral World," and I hope it will grow to be a power for good. To help in the good work, I give a few hints from my experience.

Neatness is of first importance. Rake up all leaves and trash, trim off or tie up all straggling vines and branches. It is not too late to plant bulbs yet, so by all means plant some, tulips especially, for if a bed of tulips in bloom will not convert the worst old reprobate into a flower lover, nothing will.

Bulbs can be bought very cheaply now, as our seedsmen usually have a lot of left-over stock and will sell at about cost-a cent a piece for tulips, crocus, fifty cents per one hundred. Stick them in any where and they will be up and in bloom before the snow is gone. The narcissus is a large and varied family, many of them wonderfully sweet and beautiful-one dollar per one hundred and once planted, always there. Hyacinths are more expensive, but are so sweet and beautiful they are worth all they cost-fifty to seventy-five cents a dozen. Oh, there are so many kinds of bulbs that can be planted yet, both outdoors and for the house. But my space is full. Get seedismen's catalogues and study them this winter and get acquainted with nature's beauties.

Ohio.

S. J. GallowaY. 


\section{ROSE CUTTINGS}

For best results in growing rose cuttings, I would advise growing under glass jars. In this way success is assured. In November, when the weather begins to get cold, take cuttings eight or nine inches long; with trowel dig holes about four inches deep; fill two-thirds with sand; set cutting in straight; fill with good garden soil; water well; then cover with two-quart fruit jar. Do not remove until spring, when all danger of frost is past, then you will find your cuttings full of new growth and doing nicely. By next fall they will be from twelve to fifteen inches high. They will bloom before they are a year old, and I think we appreciate and enjoy them a great deal more than if ordered from a florist. Then, too, they always prove true, which is not the case when we buy them. When planted in this way I have few failures. I have fourteen beauties grown the past year, and all have bloomed.

North Carolina.

B. G. WARD.

\section{A WATER BOUQUET}

At this season, when bouquet materials are scarce and precious, the idea of the water bouquet presents itself as a pleasing and attractive substitute to our winter flower lovers. OnIv a very few flowers and tiny sprigs of green are required in its manufacture. The delicate, airy leaves of asparagus sprengeri and plumosus lending themselves to graceful arrangements, will be found among the prettiest and daintiest green material for the purpose. These, with one or two geranium blossoms, a cluster of stevia, sweet alyssum, or any other fine flower, will be all that is needed. Arrange and tie together with thread, cutting the stems quite short to permit the long ends of thread to extend below, which should be fastened to a small pebble, piece of coral, or anything suitable for a weight. Next place a plate in the bot- tom of a pail of water, take a hyacinth glass in one hand, bouquet in the other, lower the latter in the water, and cover it with the inverted glass. Then lift the plate with the glass, and you will see suspended midway something novel and unique in the form of a bouquet, the water giving to the flowers a rich, silvery look, because of which mine have often been mistaken for wax work. Pansies are especially beautiful used in this way.

Louisiana. Florence M. WALKer.

\section{CACTUS POINTERS}

Upon receipt of cactus, put in lukewarm water one-half hour. Examine closely for any soft, bruised spots. Cut all such out down to the firm, undiseased portion, even if it takes half the plant. Cut the roots close to plant, and pot in very sandy soil, water well and set in sunsuine. It is well to look over your cacti occasionally; if any does not seem thifty, remove from pots at once, clean well in lukewarm water; cut out any soft spots, and repot in sand. These cut cacti will send out new offshoots, and form a very pretty plant. Of course this must be done before the cactus is too far gone, though often one-third of a cactus will live and send out several offshoots, making an odd and unique plant. All cactus received from collectors direct from their native haunts, should have their old roots cut off closely, and potted in sandy loam, with sharp sand under roots and base of plant. Even if the old roots are left on, they are useless, as the cactus forms new ones anyhow.

The spineless types of cactus are more widely known and cultivated than those with spines, yet the latter are more easily grown and are more effective for window or conservatory culture. Varieties should be chosen in regard to contrast of spines, and blossom, to have the best result.

New Mexico. Sudie L. Pattison. 


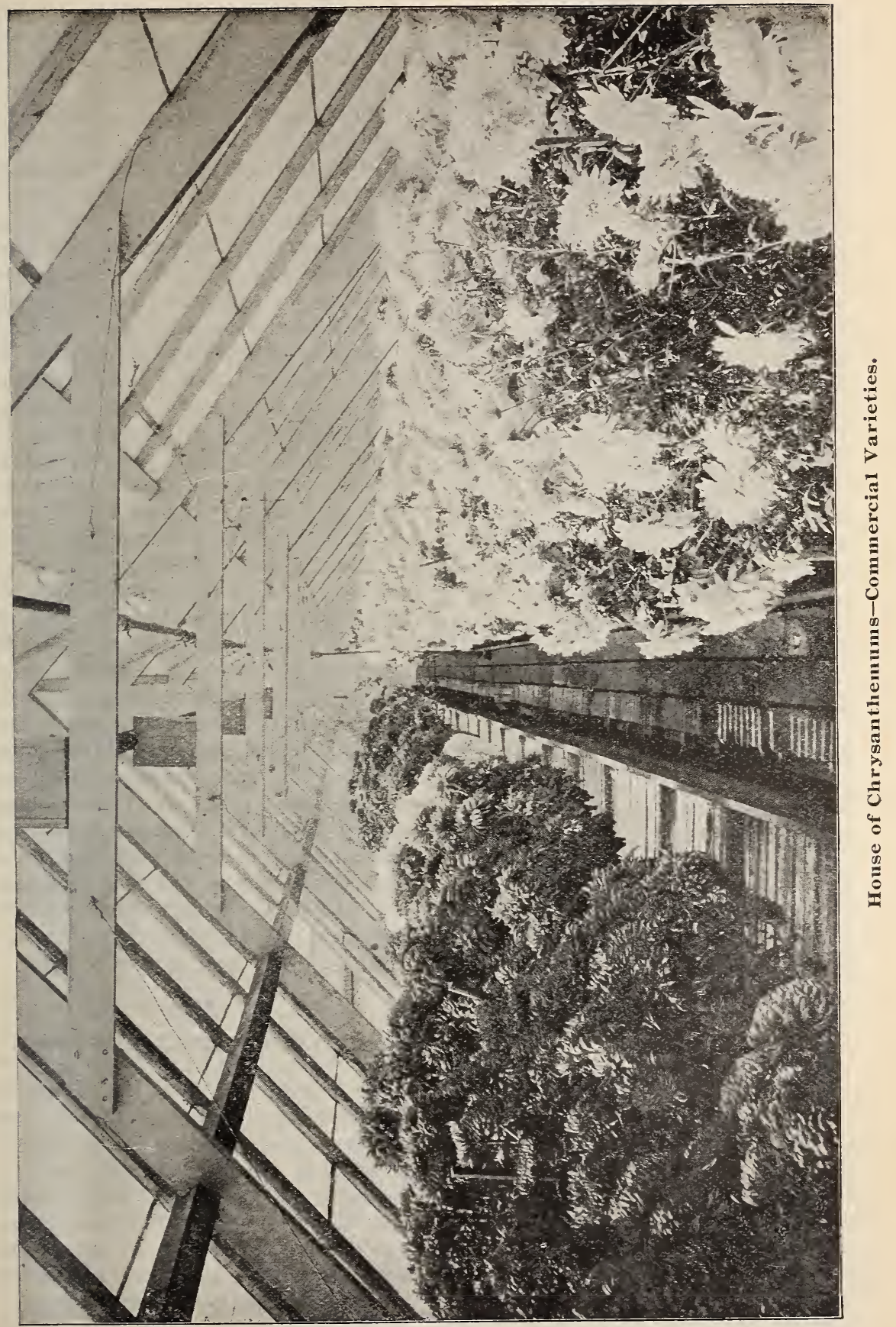




\section{CHINESE SACRED LILIES}

Even in December it is not too late to plant these charming bulbs. Get your bulbs from some reliable florist that can be depended upon to send sound heavy bulbs. It pays to get the best, in all kinds of bulbs. I put three or four in a large, deep glass dish. I first remove the brown skin from the bulbs. Then make, with a penknife, three or four incisions half an inch deep from the top to near the base of each bulb. Be careful not to cut off any sprouts that may have started. Also be sure that your hands are free from grease while handling the bulbs. I put about a teacupful of sand in the bottom of the dish, then about an inch of gravel; set the bulbs in the middle, and press them in firmly. Now fill the dish half full of pebbles mixed with a small amount of charcoal. Then pour in water until it reacnes half way to the top of the bulbs. I change the water once a week by pouring in water from which the chill has been taken until it runs over enough to have completely changed. Now set dish in a cool, light place away from the sun. In a week or more bring them into a sunny room. By the time they have been planted from three to four weeks they will be a mass of fragrant blooms. A dish of these lilies in bloom makes a lovely Christmas or New Year's gift that will be a delight to each member of the household fortunate enough to receive it.

Iowa. Mrs. C. L. Whitaker.

\section{DAHLIAS FROM SEED}

It is not generally known among those who grow flowers from seed, that the very finest dahlias may be grown in one season from seed to the perfection of flowers. Nevertheless, I have done it for three seasons, and each time bought seed from a different seedsman. Last March I took a soap box, sawed it through half way down, making two boxes each about four inches deep, then I filled them with garden soil, and planted two packets of dahlia seed, one of double mixed "pompone" and one of double mixed show dahlias. I watered with warm water, set boxes on a table and put them in the front room, where there seldom was any fire. When it was very cold I set a lighted lamp on the floor under the center of the table, which warmed the soil from the bottom up. This is the best plan to keep house plants from freezing. In about ten days the plants came up, and they grew stalky and strong. In April, when the buds started, I set the boxes outdoors and covered them frosty nights, and in June I set out the plants, then bushes six to ten inches high, in beds, prepared by digging manure into them. In late August they were bushes two to four feet tall, and began to bloom. There were many blossoms three and four inches across, and double to the center. By the last of September about every plant was in blossom, and there were some a pure frosty white, some pink, yellow, chocolate brown, crimson, scarlet and lavender, and many shaded and variegated ones. A few were single, and for bouquet purposes they excel the double ones. The last of October I dug the bulbs and there were just about four and one-half bushels or them by measure, all large healthy tubors, one or two inches in diameter.

Michigan. Mrs. Jennie E. Lipe.

\section{FALL PLANTING AND CARE OF ROSES}

For the South, fall is the best time for planting or rooting roses. The plants ordered from the florist are less affected in trasmission then, and in better condition every way. Roses may be planted or rooted any time when the ground is not frozen, or too wet to dig. The first secret of success is good drainage. Drain with anything handy, except wood, that makes "wood lice," which will destroy your 
plants. After roses are well started they will do in any kind of ground, with a little care, but they do vastly better in good ground with moderate care. My garden spot is good to begin with. The old, settled roses I dig about and mulch with good stable manure twice a year, fall and spring, and prune either in fall or early spring, and they certainly pay well. My mosses and other spring roses are solid masses of bloom. After cutting each day all I wish for the house, and giving to all who come, I snip off all the full blown ones, leaving them on the ground. Keeping the open roses cut off is a three-fold good. It prolongs the blooming season, preserves the vitality of the plant, and serves as a fertilizer. Of course, these older bushes don't need watering. The younger roses, not fully settled in their new quarters, receive the same attention, with the additional care of stirring the soil and mulching throughout the hot summer, and watering whenever needed with suds fyom the weekly wash, which also enriches the ground. The cuttings receive the same treatment as the young roses, except that the soil must be kept moist, and they must be protected by evergreen boughs or glass jars, summer or winter.

Georgia. Miss M. E. Greene.

\section{SUCCESS WITH HOUSE PLANTS}

When some one writes to banish the roses, heliotropes and lantanas to the cellar in winter, I wish they could see mine. Of course, I must have bulbs, too, but can not dispense with the others, even if they do require daily care. I always think those who would replace them with bulbs must have a tinge of "that tired feeling." My heliotropes and lantanas are green from the roots up, and there is no day during winter that I could not cut a bouquet of roses.

I obtain small rose plants or root cuttings in early spring, pot in small pots to suit their size, in a compost of good garden loam, well enriched, shifting to larger pots when their growth requires it, and keeping the buds picked off during summer. The buds in winter come on new branches. When the blossoms fade cut the branch back severely. This will promote more new growth and more buds. A south window suits them best. As to the heliotropes, I use either young or old plants and pot in pure leaf mold, well enriched, and provide extra good drainage, for they are hearty eaters and always tnirsty. They should never be allowed to cry out enough to wilt, though the soil should appear rather dry before watering; then water copiously. If an old plant is used, I take it up in Septemuer and cut it back severely and keep it in a cool, dark place for several days, then bring gradually to the sunshine. Heliotropes want all the sun to be had, but the pots should be so placed that tne sun can not strike them.

In other ways I care for these plants just as I do my other house plants, of which I have told before.

Ohio. Annice Bodey Calland

\section{GERANIUMS}

Probably the geranium is more commonly grown in American dwellings than any other plant, and, in all its varieties, is one of the most satisfactory among house plants, being aãmirably adapted for either window, parlor, green house or garden culture. But very frequently we see poor and ugly specimens of worthless varieties. If some taste be given to the selection of pretty varieties and some care to the growing, the satisfaction derived from geraniums will be greatly increased. They are among the easiest plants to grow from slips. They must have at least two joints, and three would be better, the cutting being just at the third. They are less $a^{+}$to damp or 
rot off if laid aside for two or three days in the shade before planting, as by that time the broken end heals over or forms a scar, which prevents the sap from escaping. They are then ready for planting. Plant in shallow boxes, in wet sand, the slips being potted as soon as the roots are assured. Geraniums require a rich, loamy soil. To have them bloom well in winter, they must not be allowed to bloom during summer, and should be kept with a scanty supply of water. The first of September repot and trim back well, give more water and occasionally liquid fertilizer. The geranium is a gross feeder, and no plant will show better returns for liberal fertilizing. With a well-drained soil and moderate waterings, success with geraniums is sure. Most geraniums have sweet-scented foliage, and are quite free from insects, hence they are great favorites of mine for window culture. At this time my bay window is all aglow with their bright blooms. I prefer the double and semi-double sorts, as tney do not drop their petals as readily as single ones.
Indiana.
Mrs. R. A. Houk. QATS Choice Angoras. Thoroughbred. Prices and par-

Ferrets trained to hunt rats, rabbits, etc., cheap. The J.F.NELSO N Poultry Farm. London, Pa.

TRIGKS 387 TrICKS BY MAIL, 10e, with ness. John G. Scheidler, Cleveland, Ohio

ORIENTAL STAMPS 15 Choice Japanese, Chidifferent, 10 cents. Warranted nese \& Corean stamps. all catalogue $\quad$ o. T. JoIINSON, Laurel, Md.

FOX TERRIER rUPS, nicely marked and eligible to registration. For wale at reasonable prices. GXFORD KENNELS, 1218 North 9th street, East St. Louis, Illinols.

POILTRY PAPER, illust'd, 20 pages;
trial 10 cents. Sample Free. 64-page practical
poultry book freo to yearly subscribers.
Book alone 10 cents. Catalogue of poultry
pooks fres. Poultry Advocate, Syracuse, N.Y.

\section{FOR HOLIDAY GIFTS!}

BEAUTIFUL SPARKLING GOLDFISH

Handsome gallon HANGING FiSH GloBE with chains, 3 BEAUTIFUL GOLDFISH. Green Moss and box of FisH FOOD sent BY EXPRESS for \$1. GOLDFISH 10 CTS. EACH. Add $10 \mathrm{c}$ per lot for shipping can. All aquaria supplies. Beautifu Parlor collections $\$ 2,50-\$ 3.50$. Send for list. Arthur V. Kempton, 515 Vinewood Ave., Detroit, Mich.

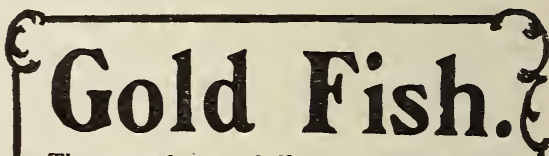

The most elegant of all parlor ornaments, as well as the most attractive and easily cared for of all pets. They are hardy, can be kept in any ordinary room, require little care and are always beautiful and interesting. We have many fancy new shapes and colors from Japan and China, as well as fish of our own breeding, and we ship everywhere.

Free Book. A sk large catalogue, telling how to care for and breed fancy fish. Also describing cage birds. Very complete; 200 illustrations, some in colors. Mailed free if you mention this paper.

Iowa

Seed Company, Des Moines, Iowa.

Address FUN AND FROLIC,
1 South Sunset.
DAYTON, OHIO.

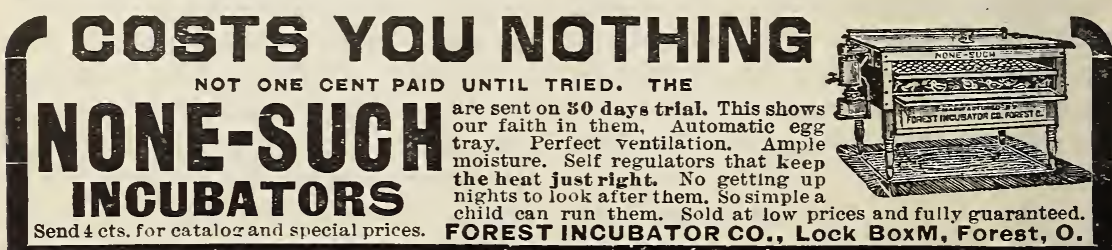




\section{PREMIUMS

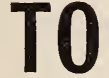

\section{THE MOST LIBERAL OFFERS EVER MADE BY A PUBLICATION}

We want THE FLORAL WORLD to attain a larger circulation than has any other floral paper. To secure it quickly we will give liberal premiums to club raisers.

YOU CAN MAKE MONEY BY GETTING SUBSCRIBERS FOR THE FLORAL WORLD "MONEY SAVED IS MONEY EARNED"

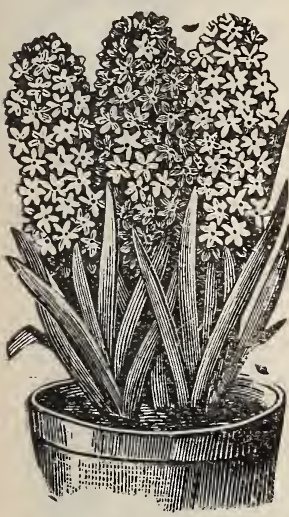

HYACINTHS.

\section{FOURTEEN SELECTED BULBS}

Given as a premium for a club of two yearly subscriptions for THE FLORAL WORLD at 25 cents each. This collection is composed of two Hyacinths, six Tulips and six Narcissus. All are blooming bulbs, though small, and an assortment will give a succession of charming flowers. The fourteen bulbs are enough to make a pretty window garden. This is premium No. 2.

\section{FOUR ROSES FOR FALL PLANTING}

Given as a premium for two vearly subscriptions for THE FroRAL WORLD at 25 cents each. This collection contains four varieties, plants of which usually sell for at least ten cents each, as follows: Isabella Sprunt, rich yellow, flowers freely in Winter; Papa Gontier, deep red, free bloomer; Devoniensis, creamy-white color, magnolia fragrance; Bridesmaid, deep pink, very popular. This is Premium No. 3.

\section{FOUR ASSORTED GERANIUMS (OUR SELECTION)}

Given as a premium for a club of two yearly subscriptions for THE Froral WorLd at 25 cents each. The kinds will be those best adapted for Winter blooming in the club raiser's locality, chosen from a stock which includes more than two hundred varieties. There is no more charming house plant than a good Geranium. This is premium No. 4.

\section{TWENTY-FIVE CHOICE HOLLAND BULBS}

'Given as a premium for a club of four yearly subscriptions for THE FIORAL WORLD at 25 cents each. This collection is composed of five assorted Hyacinths, ten Choice Tulips and ten selected Narcissus. All are good, vigorous bulbs, grown in Holland, and sure to give satisfaction. This is Premium No. 5.

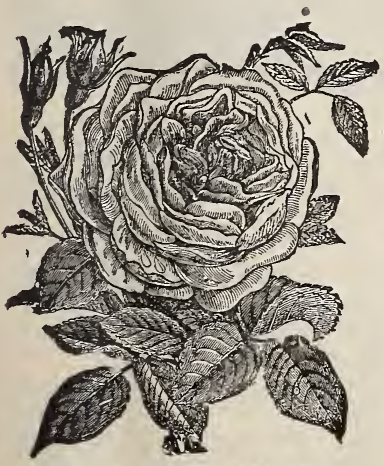

EIGHT NEW ROSES

Given as a premium for a club of four yearly subscriptions for THE FLORA L WORLD at 25 cents each. These eight Roses are the cream of the new introductions. Liberty, rich crimson; Mrs. Robert Garrett, dainty pink; Bouquet of Gold, rich, deep yellow; Helen Gambier, white and orange-yellow; Priscilla, snow-white, of immense size; Sanguinea, (Otaheite $\mathrm{R}$ os e), crimson, fine for house culture; Francis Willard, new pure white; Perle Des Jardins, clear golden-yellow. ROSE, HELEN GAMBIER. This is Premium No. 6.

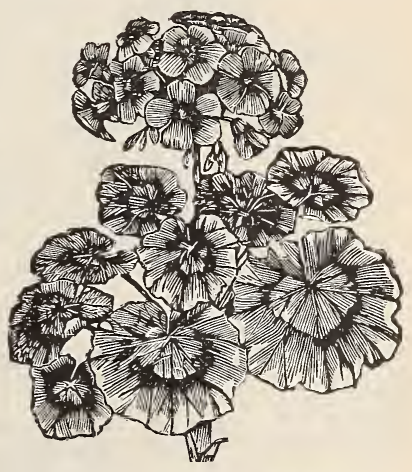

WINTER BLOOMING GERANIUM.

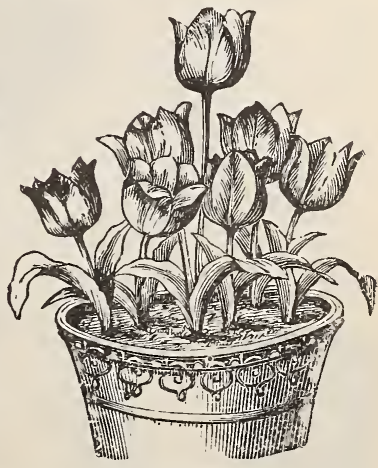

TULIPS.

ADDRESS, THE FLORAL WORLD, SPRINGFIELD, OHIO. 


\section{HIGH GRADE NICKEL-PLATED SCISSORS}

\section{SEVEN-INCH SCISSORS}

Given as a premium for a club of SIX yearly subscriptions to THE FLORAL WORLD, at 25 cents each.

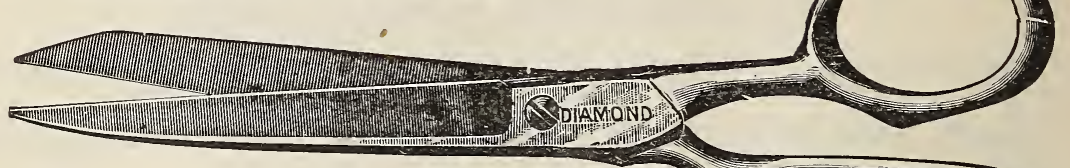

Thousands of these scissors have been used without a single complaint. They are seven inches long, heavily nickel-plated and
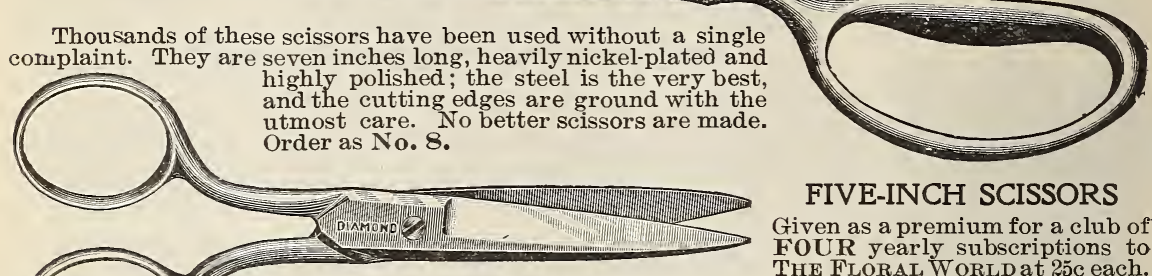

FIVE-INCH SCISSORS

Given as a premium for a club of FOUR yearly subscriptions to THE FLORAL WORLD at $25 \mathrm{c}$ each.

These scissors are of exactly the same high quality as the seven-inch scissors, and are offered to meet a big demand for smaller scissors than those above. They are just five inches long.

This is Premium No. 9.

\section{HIGH GRADE POCKET KNIVES}

Either Ladies' or Gentlemen's Knife given as a premium for a club of SIX yearly subscriptions to THE FLORAL WORLD at 25 cents each.

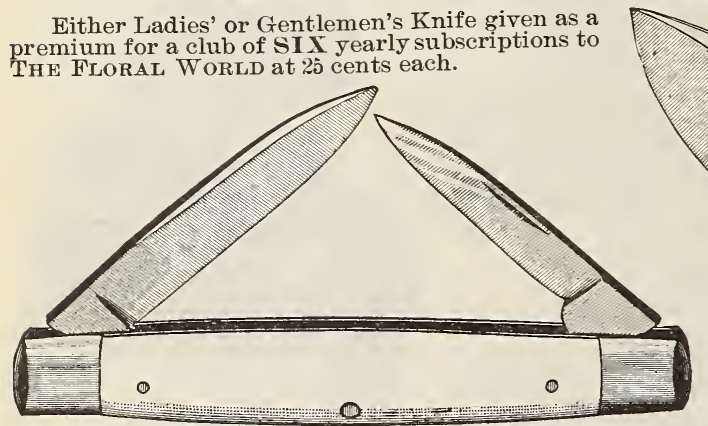

Both of these knives are the finest grade of cutlery. Bot h have blades of the very best razor steel, tempered by experts, ground to a keen edge and then highly polished. Both knives are brass-lined. The illustration shows them in actual size.

THE LADIES' KNIFE' has beautiful pearl handle of the newest design, the pearl running clear to the end of the knife.

THE GEN'TLEMEN'S KNIFE is the new curved shape anc has handsome real stag handle and German silver bolster.

The knives are sent post-paid. Order as No, 12 for the gentlemen's knife, or as No. 13 for the ladies' knife.

\section{SOLID SILVER THIMBLE WITH GOLD BAND}

Given as a premium for a club of FOUR yearly subscribers for THE FLORAL. WORLD at 25 cents each.

This is a most attractive and pretty thimble. It is made of solid sterling silver, is carefully finished and is of good, heavy weight. The embossed band around the base is heavily gold-plated, giving the thimble an unusually rich appearance. It can be furnished in any size; state which size you want. The thimble is sent by mail, charges prepaid by us. This is Premium No. 14. 


\section{STEEL REPEATING AIR RIFLE}

Given for a Club of Sixteen Yearly Subscribers for THE FLORAL WORLD at 25 cents each.

\section{SHOOTS 300 TIMES. IS UNBREAKABLE. CHEAP AMMUNITION.}

We offer the best and most reliable repeating air-rifle that any manufacturer has ever made. Every working part of this rifle is of pressed sheet-steel and can be Guaranteed Absolutely Not to Break.

The rifle shoots three hundred times with one loading of the ammunition-chamber. It shoots hard and accurately, and will carry a long distance. The ammunition is B. B. shot, which can be obtained in the stores everywhere. Ten cents will buy about one thousand bullets. The total length of the rifle is thirty-two inches. The barrel is nickelplated and the stock is walnut. Every rifle is fitted with good sights. Sent by express, charges to be paid by receiver. The express charges will be from 25 to 50 cents; generally 25 to 35 cents, according to the distance. Order as No.17.

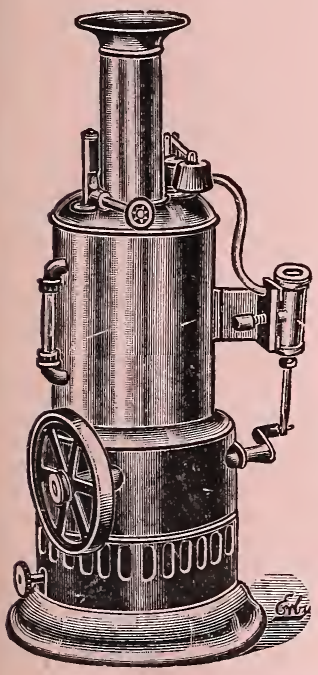

\section{GIANT BRASS-BOILER STEAM-ENGINE.*.*.**}

\section{Given for a Club of Twenty Yearly Subscribers for \\ THE FLORAL WORLD at 25 cents each.}

The most complete and satisfactory engine on the market. It has a heavy brass boiler, well made and strong in every particular, and fitted with a

\section{PRACTICAL WATER GUAGE}

showing exact amount of water in the boiler. The guage is fitted with adjustable nuts, so that it can be kept always both water and steam tight. It is a unique and valuable feature. It has steam whistle and automatic safety valve, thus doing away with any danger of explosion. Best of all, this engine can be run

\section{ALL DAY FOR ONE CENT}

for it is fitted to burn ordinary kerosene instead of alcohol, if desired. The draft is specially arranged for this purpose. This feature makes the cost of running almost nothing. The engine is eleven inches high. Delivery charges are paid by us. Order as No. 18.

\section{Our New Twentieth Century Watch}

Given as a Premium for Sixteen Yearly Subscribers for THE FLORAL WORLD, at 25c each.

Sterling quality at a popular price-that is our aim and our claim in this great watch offer. Ten years ago a reliable watch for any reasonable sum of money was impossible. Today we have closed a contract with one of the most famous watch manufacturers in the world by which we obtain

\section{AN ABSOLUTELY RELIABLE WATCH}

at a price that places it within the reach of all. Not only that, but this watch has a handsome appearance as well. It can be furnished with Roman or Arabic figures, as you desire. The cut shows the Roman figures. Best of all, the watch is of

\section{MEDIUM SIZE}

being of the dimensions that jewelers call the "Sixteen Size." It is in nickel finish, open face, and has deep milled edge and hinged back. Finally, we are going to guarantee every one of these watches.

\section{OUR GUARANTY}

In the back of every watch will be found a printed guarantee by which the manufacturers agree that if without misuse this watch fails to keep good time for one year they will, upon its return, and five cents for postage, repair it free of charge. Order as No. 15.

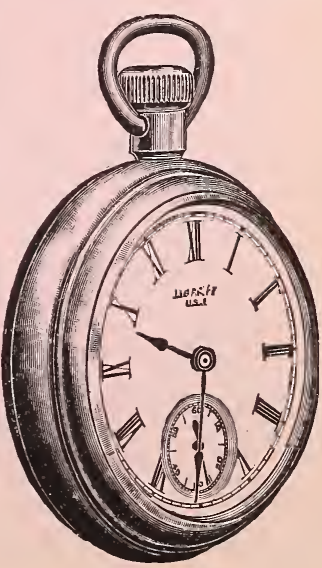




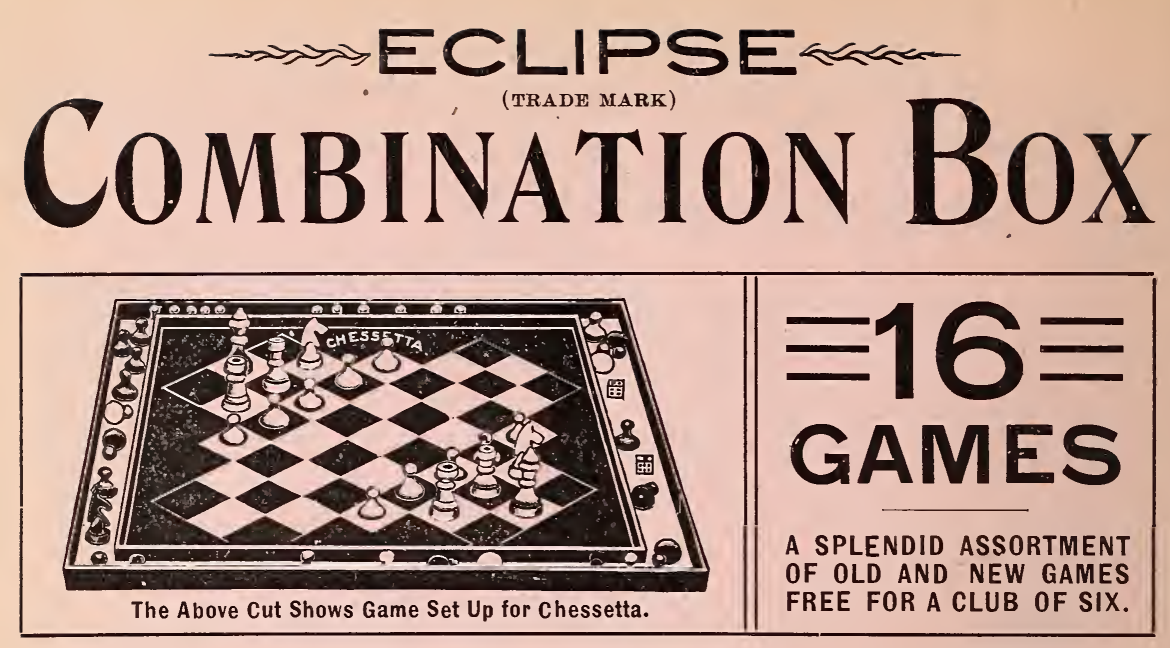

\section{Diagrams are Furnished with this Matchless Combination.}

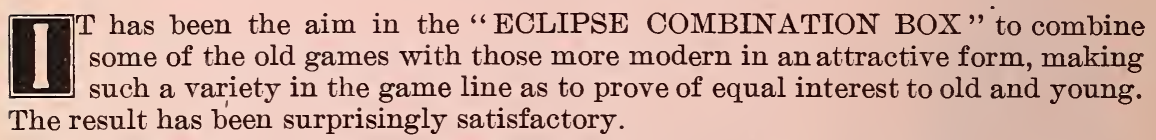

1. CHESSETTA.-A variation of chess, retaining same moves as the original game, but not so difficult, as less men are used.

2. SPIDER AND FLIES.-A new and fascinating game for two persons, scientific and interesting.

3. CRADO-A splendid new game for two or four persons.

4. CHECKERETTE.-A new and interesting variation of checkers.

5. FOX AND GEESE. - One of the best of the old games.

6. CATS AND MICE.-A splendid game played on the Fox and Geese diagram.

\%. WEDA.-A fine puzzle.

8. GO-BANG.-A well known and interesting game for two to four persons.
9. TWELVE MEN MORRIS.-A fine old game which has proved its merits.

10. CYCLE RACE.-A new game played with dice which cannot fail to interest the players.

11. TIT TAT TOE.-An old friend in a new dress.

12. STAR PUZZLE. - A new puzzle which will bother you.

13. CHESS.-A full set of chessmen furnished in this remarkable combination.

14. CHECKERS.-With a fine diagram and men.

15. BACK-GAMMON. - With complete outfit.

16. EGYPTIAN MAZE PUZZLE.-Something new and bewildering.

THE EQUIPMENT WHICH GOES WITH THIS REMARKABLE COMBINATION IS AS FOLLOWS:

60 Go-Bang Men (four colors), 1 Complete Set of Chessmen, 2 Patent Collapsable Dice Boxes, 2 Dice, 1 Book of Rules and Directions.

The "Eclipse" Combination Game outfit will be given free for a club of only six yearly subscriptions for THE FLORAL WORLD, at 25 cents each. Express charges are to be paid by the receiver. In no case will these exceed 25 cents.

Adress, THE FLORAL WORLD, Springfield, $O$. 


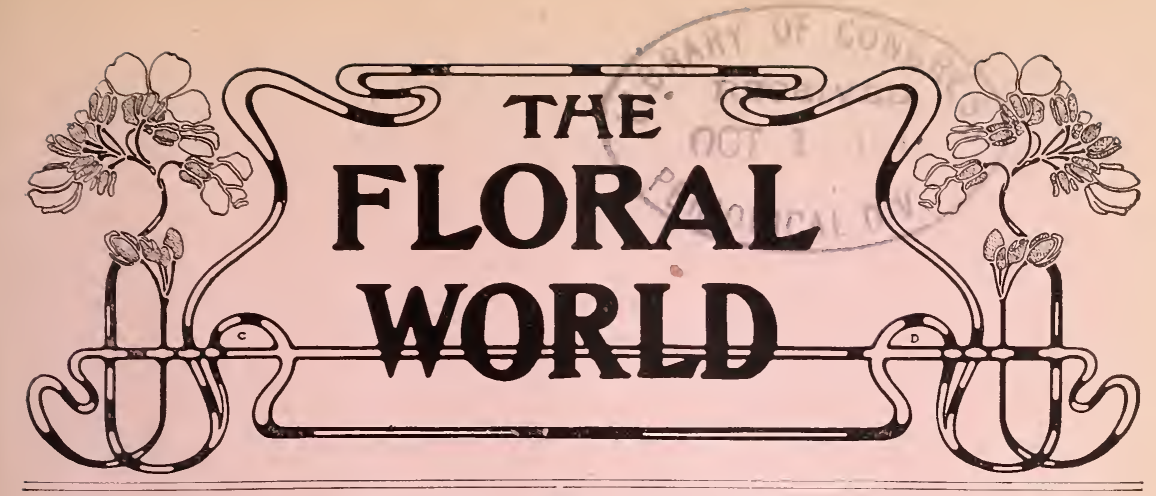

Vol. I, No. 4 Springfield, Ohio, January, 1902

25 Cents a Year

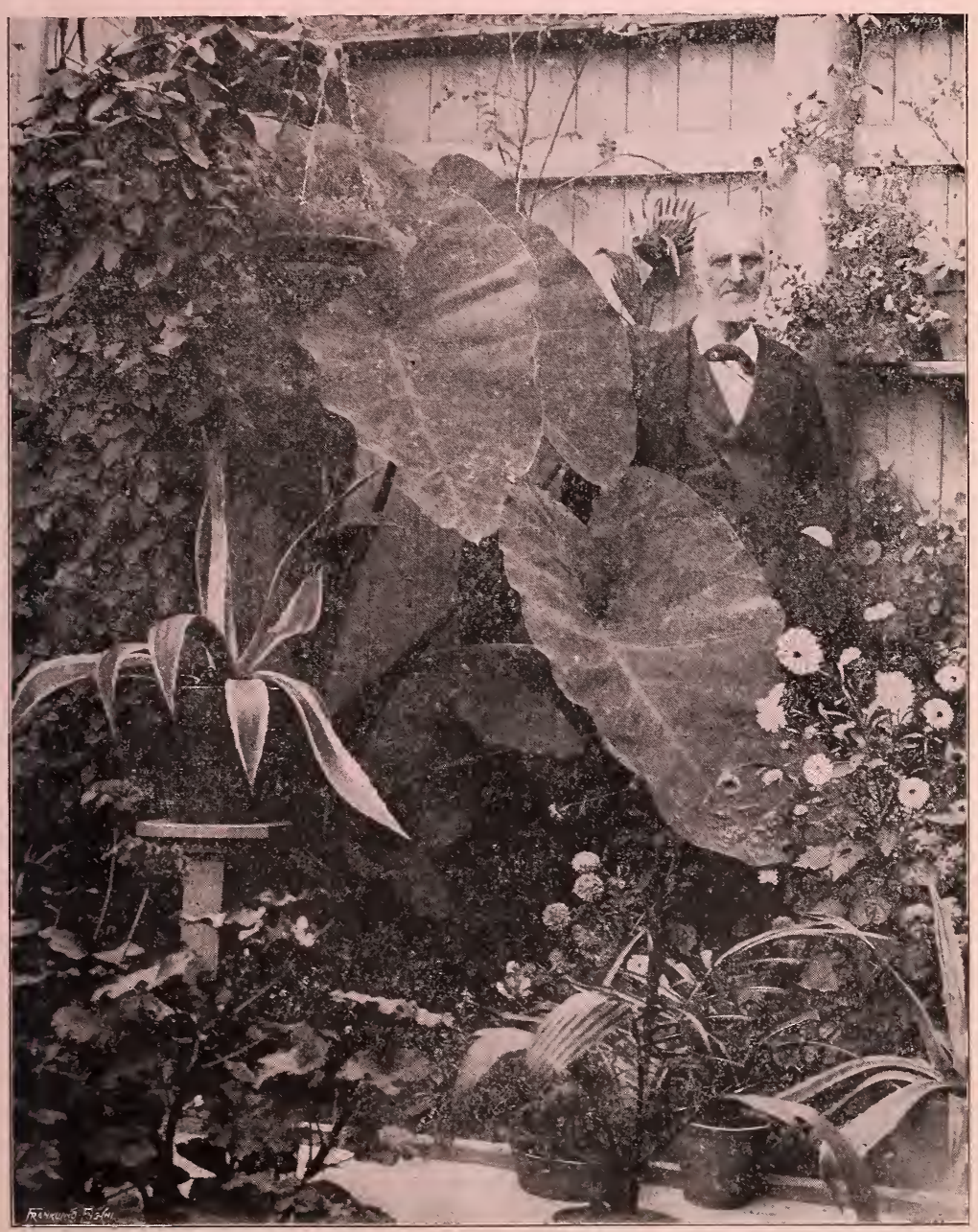




\section{A MATTFR OF IMPORTANCE}

The post-office department of the United States govern. ment refuses to allow the same rates and privileges to The Floral WorLd as are accorded to other magazines and news. papers.

Instead, the demand is made that its publishers pay a postage rate on The Floral World more than twenty times as great as that charged other journals. If this demand is enforced, it means that we shall be obliged to discontinue the publication of our little paper.

As a reason for their action in this matter, the post-office department officials state that they believe the people who have subscribed for The Floral World did not do so because the journal was desired by them, but for some other purpose.

If we can prove that you have subscribed for The FloraL WoRLD because you wish the paper, it will be possible for us to secure mailing rights equal to those given other periodicals. If we can not furnish this proof the chances are that the publi. cation of our journal can not be carried on.

Please sign the following statement with your full name and address, therefore, and send it to us by return mail. In a matter of so much importance to all of us, we feel sure you will respond promptly, and shall expect to hear from you at once. Address your letter to The Floral World, SpringFIELD, OHIO.

\section{Date} 190

This is to certify that I have subscribed for THE FLORAL WORLD, published at Springfield, Ohio, because I wish the publication and desire to have it come to me regularly.

(Name)

(Post-office)

(State) 


\section{The Floral World}

\section{A Fournal of Home Floriculture}

Vol. 1, No. 4

Springfield, Ohio, January, 1902

25 Cents a Year

\section{THEY LIKE "THE FLORAL WORLD."}

Permit me to thank you for the first two numbers of "The Floral World." It is just what we want, and we hope it won't get spoiled as it grows older, as some other floral magazines that I could name. I am taking three others, but I must say in truth the little "Floral World" is my ideal. You shall have my subscription immediately, and $I$ will show it and try to interest my friends.

Iowa

Mrs. P. W. Hopkins.

I like our new paper so much. I like it because the articles are all short and timely. If your paper improves as fast as it has done so far, it will do. The second number was better than the first. I will try to send one or two new subscribers as soon as possible. I am glad you offered flowers as club premiums.

Oregon.

Mrs. Ina KellogG.

I think your journal a success. I am especially pleased with its hints and suggestions as to makeshifts and utilizing common, every-day objects and environments. People able to afford greenhouses can usually afford exhaustive works on any subject. Your magazine will suit the masses by meeting the conditions that surround the masses.

Yours for more and more flowers,

Iowa. Mrs. Eva I. GRIFFith.

If the numbers of your magazine which are to follow are as good as those I have received, I think they are worthy of a place in every home and equal to any magazine of the kind I have seen.

Connecticut. Mrs. R. J. Bradley.

I am a great lover of flowers, and I think "The Floral World" is just the guide we need. I like it very much.

Kansas. MRS. B. R. HARRIS.

\section{WORK FOR JANUARY.}

Now is the time to thin out the window garden. Put away the plants that are through blooming, making more room for the ones that are trying to do their best. Watch carefully for insects. Frequent spraying, or sprinkling, will keep down the red spider. If you see any sign of scale put the plant by itself and treat it to a bath in soapsuds, scrubbing with a brush until the scale is removed.

In mild climates, now is the time to plant sweet peas and poppies. I have planted narcissus and tulip bulbs in January, and they bloomed well. Rose slips will root well if put in the ground now in places where the winter is mostly rain. In the window, the bulbs that are through blooming can be set in a place where they don't take so much room that other plants need.

If you have any dwarf abutilons, which are blooming well, sprinkle them frequently to keep the red spider away. Infanta Eulalie is the loveliest pink, and, after getting well started, shows new buds always coming. Grandiflora is a bright, pretty yellow; Africain is a deep, dark red, and Snowstorm pure white. These are all large 
size blooms. Then Savitzii is a variegated or silver-leaved variety, Iuuch the rame as Souvenir de Bonn, only more white.

Oregon. Mrs. Ina M. KellogG.

\section{A NOVEL CONSERVATORY.}

One of the cosiest homes in one of the most charming suburbs of Chicago contains a miniature conservatory that is original with its mistress.

Her whole house is heated by a hotair furnace in the basement. A portion of the large parlors is partitioned off with large plate glass doors, and the outer front is a double swell one, and all of glass, also. This dainty room is heated from below by the furnace pipes, which keep it at the proper temperature.

The floor of this room is the "cutest" contrivance of the whole idea. A high zinc pan to fit the floor is set in the room. This is filled with rich dirt, and all the heavy plants, such as palms, etc., are planted right in this pan, and the whole covered with moss.

When this "baby park," as she calls it, is sprayed from its dainty fountain in the center, it gives a delicious odor through the house, and in winter reminds one of summer greenness.

Of course, the pan is drained by pipes that carry off the surplus moisture.

The windows are full of wire shelves and brackets that hold the smaller plants.

On the evening of "At Home" parties the conservatory doors are left open and the fountain plays its soft music all the evening, reminding one of fairyland.

\section{Wyoming.}

Mrs. Florence Parkinson.

\section{CARNATIONS.}

I get good seed, to begin wirn, irom a reliable florist. I plant the seed in boxes in April, in good, rich soil.
When an inch or more high I transplant to a good, rich bed, where they can have the full sunshine, work well, can have the full sunshine. Work well; and water, if a drouth occurs. Be careful in transplanting not to break the roots.

Keep all buds pinched off, if any come during the summer. In September lift the plants and pot in good soil, mixed with sand; keep in the shade for a week or more, and place in a sunny window or pit. I prefer tin vessels to earthen pots for nearly all kinds of plants.

Do not water carnations too much, as they resent having wet feet, and will not thrive.

Arkansas. Mrs. Jennie Field.

\section{AGERATUM AND OXALIS ORTGIESI.}

Have any of the floral band tried Ageratum for winter flowers? Sow the seed the last of May, so the plants will be nice ones by fall. Set the plants in a sunny window and give them plenty of water, never letting them get dry, and you will have flowers all winter. The colors are blue and white.

Oxalis Ortgiesi is a plant for every day in the year. I do not think mine has been without blossoms a day since it was large enough to blossom. I think it must be a rare plant, as I never saw one, except the plant my slip came from, more than seven years ago. I have received more than twenty catalogues this year, and but six mention it. I prefer good garden soil and chip dirt, equal parts, for all my plants and bulbs.

Connecticut. R. J. BRADLEY.

\section{A BULB.}

Misshapen, black, unlovely to the sight, O mute companion of the murky mole,

You must feel overjoyed to have a white, Imperious, dainty lily for a soul. $-R . K$. Irunkittrick. 


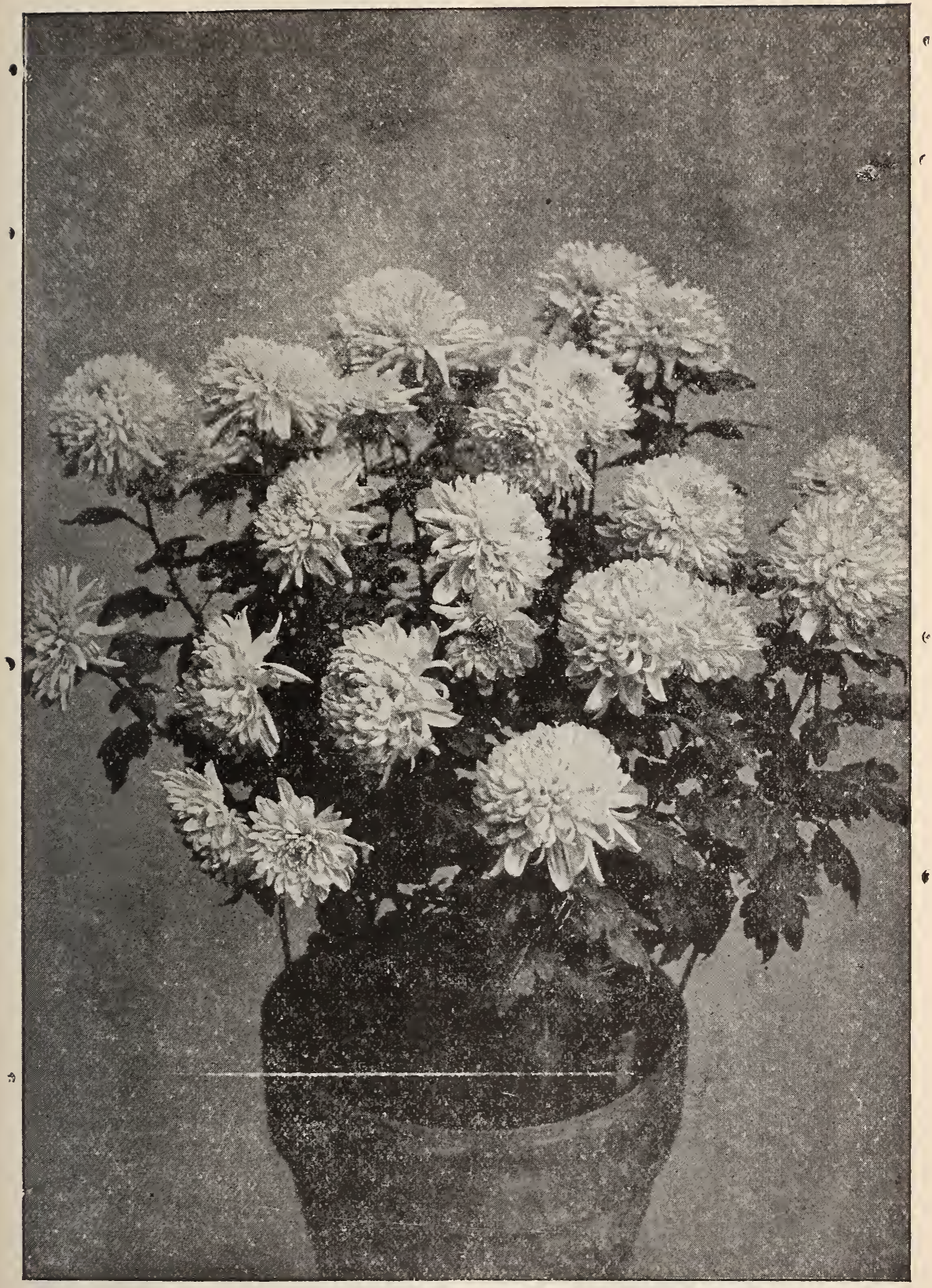

Vase of Exhibition Chrysanthemums. 


\section{CHRYSANTHEMUM CULTURE.}

Take the slips in spring or early winter when they are through blooming, and set in small pots or cans. Keep in a frost-proof room until spring. Then change to a larger pot, as they become root-bound. Change about three times, letting the last change be about the last oi August; into, say, about ten-inch pots, in good, rich garden soil and rotten stable manure, equal parts; give good drainage. Keep the tops pinched out, to make nice-shaped plants, and water once or twice a day, as needed. Chrysanthemums are great drinkers, and will stand lots of water. Feed liquia manure once a week till buds appear.

If you want large, perfect blooms, pinch out all but one bud to the stem; that is, of the large sort; of the small sort, I think they look better in clusters. I let my slips get four or five inches high, and then pinch out the top, leaving three or four eyes to make branches. When the branches get three or four inches long, I nip the tips again, and so on, till I have them in shape.

Kansas.

Mrs. B. R. HARRIS.

\section{AN OLD FASHIONED GARDEN.}

We children loved to visit grandma's homestead, partly because of the lovable old woman herself, but more particularly, I think, to enjoy the beauty and inhale the fragrance of her oldfashioned garden. No novelties flourished there; grandma had neither the time to devote in their cultivation nor the money to expend on them. Flowers of the simplest culture only could be scen and these were principally perenials or self-sown annuals.

$\mathrm{Up}$ against the clapboards was a row of brilliant hollyhocks. Their great satiny, cup-like flowers attracted the eye of the passer-by at once. The second row from the house was formed of hybrid perpetual roses, which in the month of June were a daily delight and furnished armfuls of luxuriant bloom. The rest of the garden consisted of moonflowers and evening primroses, showy zinnias, aristocratic marigolds, lowly forget-me-nots, human-faced pansies, a tangle of sweet williams, and nasturtiums-all varie. ties crowded together regardless of color harmonies. Here and there a pepper plant lifted its rich green leaves and bright-hued fruit, ripening in the sun; the golden blossom of the mustard grew side by side with the brilliant asters, and the onion mingled its hollow stalk with the sword-like leaves of its aristocratic relative, the gladiolus.

Connecticut. Lawrence D. FogG.

\section{FINE FOLIAGE PLANTS FROM SEED.}

There is a large class of beautiful plants that can be easily raised from seed. Sow in February, using good porous soil, not over rich. Cover with glass and keep in a warm place, with a dark paper over the glass until the seeds are up. Keep the soil moist.

The plants named below are all fine, and $I$ can recommend them as sure to give satisfaction.

Acacia lophanitha: This will hold its own in point of effect with many more costly ones.

Acanthus Latifolia and A. Mollis are indispensable for the lawn. Their deep green, elegantly formed leaves having a fine effect.

Melianthus Major is another having handsome leaves of silvery hue.

Ferdinanda Eminens, with beautiful, fine cut foliage.

Jacaranda Mimosaefolia is an elegant foliage plant.

Grevillea Robusta, trained standard high, is one of the most graceful plants for room decoration. and will stand a good deal of hardship.

Ferula Comminius prodouce deep green foliage and make handsome plants for the lawn. 
Centaureas, with their beautiful, silvery foliage sets off the others well. Another fine foliage plant with curled and crested leaves, glistening like silver, is Glaucium Corniculatum.

Asparagus Penmosana and A. Sprengeri are easy to raise from seed. A. Verticillatus is a graceful, hardy climber-a perennial.

Eryngium Amethysturium is a noble and handosme plant, with spiny, laciniated foliags and heads of flowers of a lovely amethystine blue, the bracts as well as the upper portion of the stem being of the same color.

Nebraska. MRs. O. H. HEREFORD.

\section{CYCLAMEN A GOOD PLANT FOR AMATEURS.}

the most satisfactory plants that an amateur can have are three or four Cyclamens-red, white, rose, and the white with pink eye. They will bloom for several months in succession during the most gloomy days of winter.

The corymbs increase year by year until they lack the vitality to produce the largest flowers. Those about two inches in diameter are the best. Pot them in five-inch pots. Use porous soil; leaf mold, old manure, with a little wood soot is good. Do not cover the corymbs; but press into the soil until half covered. Good drainage is important. They dislike stagnant soil. When they are started, give a free supply of water until after the blooming period. A sunny window will make thrifty plants and fine bloorns.

The roots of the cyclamen live from year to year. Therefore the corymb should never be dried off. Always keep the soil moist, not wet. Even after blooming, when summer comes, place the pots in al sunny spot in the garden and cover with a mulch of old manure. At the end of August the pots can be taken up, the corymb shaken out and put in larger pots, if needed. Cyclamens are not often troubled with insects, but you should sponge the leaves once a week to remove dust.

The propagation of Cyclamen is always by seed. Seeds are easy to grow, but the seedlings do not bloom till they are about three years old.

Missouri. Mrs. John P. ERnst.

\section{ODDS AND ENDS ABOUT FLOWERS,}

Select the seed from your zinnias from the first and second flowers. A good way to mark them is to tie a piece of yarn as near the color of the flower as possible, and the same with other flowers. Amateur growers should not attempt to save seed from sweet peas, cosmos, petunias, etc. I would say, save all the good seed you can, buy all you can, and give away all you can. The tiny brown seed may convey a divine message.

An important thing is to have your house plants healthy and free from insects. A good sousing in kerosene emulsion will rid them of soft-bodied insects.

Arrange your plants to suit their wants. Great care should be taken in watering the rose geranium. Nothing but clean water should be used, as dirty water will kill the foliage. Fish geraniums thrive well with dirty water. With geraniums that are for wintet blooming, the buds should be pincned off all summer. Most living rooms are too dry for plants, so a basin of boiling water should be set near the plants daily. Maderias, dahlias and gladiolas should be lifted the last week of October, the dirt shook off and put to dry. Before they are lifted a thick layer of horse manure should be put on the ground.

Pennsylvania. E. JANE GRAY.

\section{THORN VINES.}

Last April I secured a few thorn vine seed, soaked them over night, cut a slit in each seed to hasten growth, 
then planted in cans of garden soil. This I kept moist and in the shade till the seed came up, never allowing the earth to become dry. When the vines had begun to run, I used a string for each can, tying it to a stick pushed down in the soil. I allowed them to grow until they were over a yard long, when I changed them to a well-prepared trench beneath the gutter. The roots had partly filled the cans. so I carefully slipped them out, dirt and all.

I put them out a dark, rainy morning, the first of June, and the change didn't disturb the growth, nor did they even wilt. They were left on the same strings, and when they had reached the top of the porch I had a strip of poultry netting fastened around the porch for them to cover.

By August 1 they had covered the netting, forming a dense awning around a gallery twenty-four feet long. Three vines have done this, and they had nothing but plenty of water and a little training. They bloom after sundown and last until about 8 o'clock in the morning. Some evenings I have counted twenty blooms, and were the vines less dense there would be more.

Mississippi. Mrs. W. B. BYRD.

\section{FERTILIZING PLANTS.}

A lover of the beautiful can take delight in cultivating the most tiny flower. Geraniums are hardy and give good satisfaction. Hen manure is the best fertilizer for them I've had any experience with. In the summer, when your plants are in the open air, it is the time to apply it, as then you will not get the odor. I work among them with a stick, or IJrk, stirring the soil, which makes it light and loose. Turn them towards the light, thus prevent-

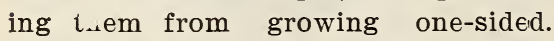
Ammonia water is a good fertilizer. Apply it once a week, not too strong. I generally use one tablespoonful to a two-quart pail of water. Equal parts of sand, leaf mold and garden soil is what I use when obtainable. I get the best results for miles around, because I always base my work on actual, practical experience, which, after all, is the only thing that tells in the end.

New York. Mrs. L. RyaN.

\section{FLOWER DECORATION.}

A big bowl of Bohemian amber, filled with superb yellow plumes of full grown golden rod, artistically arranged with clusters of flaming maple leaves, can not be surpassed as a center piece in fall. Cut a large branch of rose geranium, then arrange pansies among it and see what a pretty bouquet you will have.

Scarlet cannas and spikes of tuberoses go well with the leaves of mahonia or barberry.

Take a large vase of the wild maiden hair fern as a basis, and put among them large clusters of pink oleanuer -nothing else is so fine.

A large plant of the white-leavea centuria, cut entire, and put in a vase, with white and lavender asters of the simple type filled in, makes a beautiful center piece.

White foxgloves and blue delphium look fine among a mass of asparagus plumosa, with several sprays of asparagus sprengeri.

A large standing wicker basket is in my room filled with the large wnite day lily, "Funkia," stems cut entire, with buds, as well as open lilies, with the large leaves ol the oak fern for foliage. These are put in cans of water held steady by spagnum moss packed tightly around them.

A lovely center piece is composed of the branches of acacia daltreata, a silvery green, and the tall spikes of the old hardy lupin, a delicate, shell-like porcelain blue.

Missouri. A. Elizabeth BadGer. 


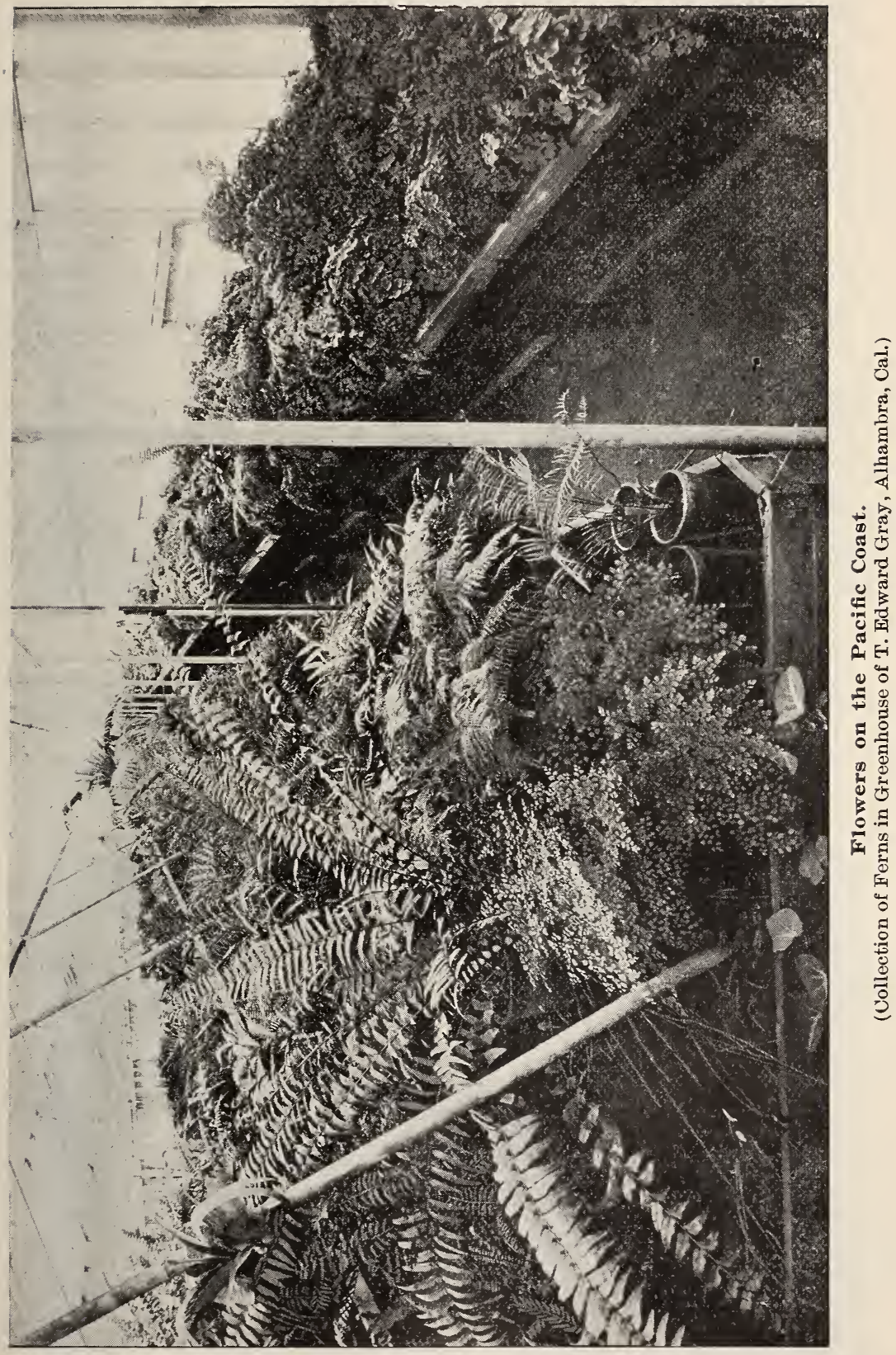




\section{The Floral World}

PUBLISHED MONTHLY AT SPRINGFIELD, OHIO.

Subscription Price, 25 Cents a Year.

Correspondence invited from all persons interested in Flowers. Write us your experience with plants.

THE three numbers of THE FLORAL WORLD which have already appeared have by the growth of its subscription list. The number of approving letters which the editor has received has been so large that the publishers feel greatly encouraged, and have no doubt that the publication has now secured for itself a permanent place in the world of periodicals.

The American people eridently want a practical and inexpensire magazine devoted to home flower-growing. THE FLORAL WORLD will continue to be what its first numbers have indicated-a practical magazine for the people. It will publish only articles written by persons who succeed with flowers, and whose experience and advice will help amateurs. It will be published for home flower-growers, and no professional florist or gardener will be permitted to write for it.

The editor has received many letters from readers, suggesting improvements. He is always glad to receive such friendly letters, giving advice as to how the magazine may be made more helpful and valuable to its readers. Some one suggests a floral puzzle department, another a department for children. What do the readers in general think about these ideas? Write and give your views, so that the publishers may know how you look upon the matter.

Upon the suggestion of many other friends, the editor has decided to limit contributions to 200 words. In that space, if you write crisply and to the point, you can tell all about the culture of any plant. Hereafter, then, 200 words will be the limit of contributions. That will improve the magazine, because the shorter the articles the more of them $\pi$ e can publish.

THE Floral WORLD will be published for the benefit of its subscribers, and they can help the management to help them by increasing the subscription list. Send us your own subscription, get others also to subscribe, and do not fail to send us your experience in flower-growing for the help of other readers. Thus you can all become assistant editors.

The publishers thank the readers of THE FLORAL WORLD for their assistance and good will in the past, and promise to do their very best to deserve it in the future. 


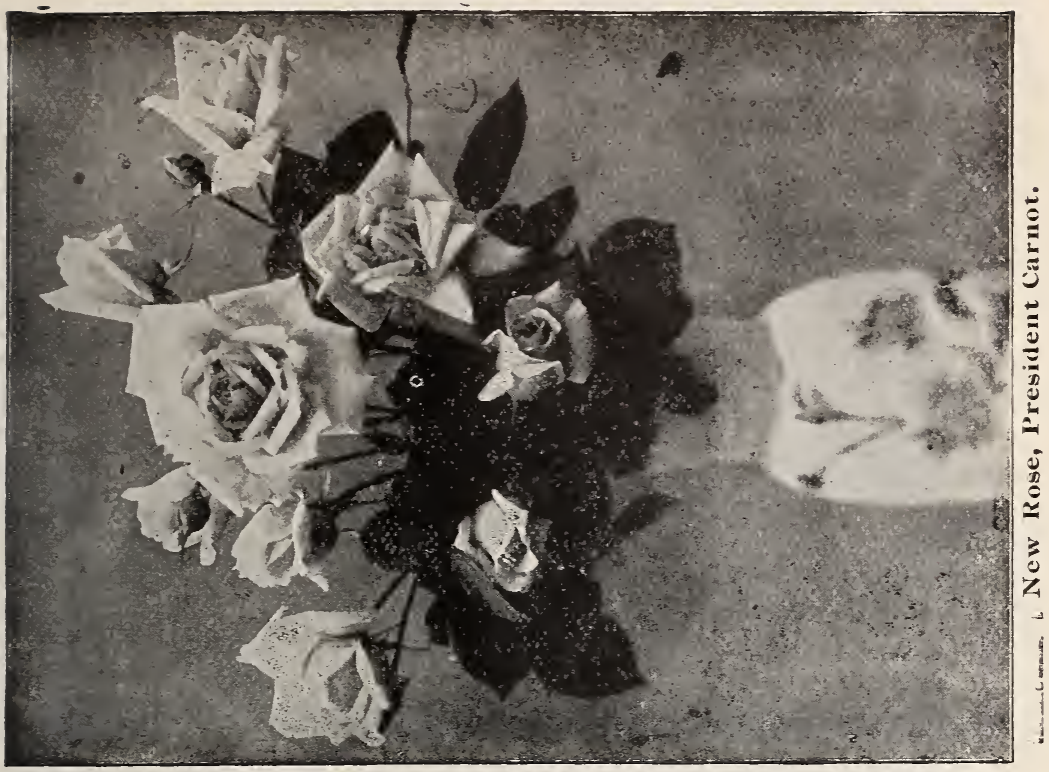

:.8:-

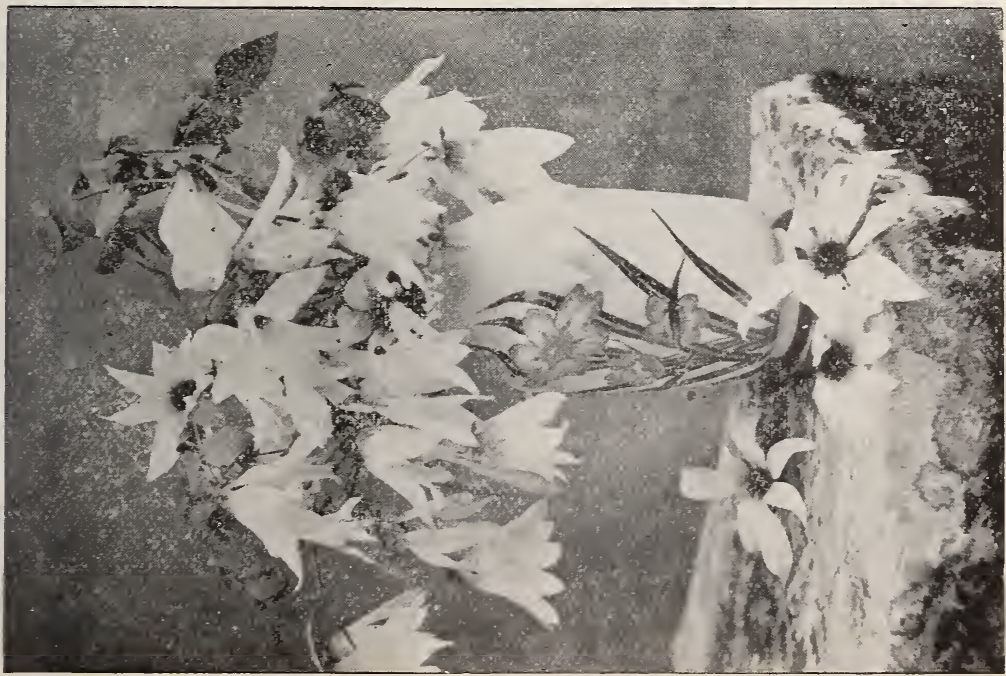




\section{CALLA AND FREESIA IN JANUARY.}

The Calla, if given proper soil at repotting time, is now at its best, and, as the blooming period is short, will pay us well for all extra trouple. First give them sunshine, all that is poss1ble. They are aquatic plants and, although we grow them in pots of soil, they must be kept constantly moist. The first of this month I begin giving them a cup of hot water on the soil each morning. This greatly helps to force the flowers.

I use liquid fertilizer twice a week, half a teaspoonful of ammonia to half a gallon of water. I find also, that a cupful of boiling water set on the flow. er shelf-among the plants-is very beneficial. Even on the coldest days a cupful of boiling water will steam for some time, and when it cools off, a few minutes on the stove will bring it to the boiling point again. This steaming process is very beneficial to all plants at this time, and especially so to the Calla.

The swectest of all our winterblooming plants, the Freesia, is blooming now, and this same hot water treatment is very beneficial to it. I move my plants to or three times a day to give all the sunshine possible. I allow neither lof them a temperature lower than fifty-five degrees.

Kentucky. Miss Laura Jones.

\section{CINERARIAS FROM SEED.}

In my first trial with Cinerarias, I hit upon the right treatment quite by accident, as I knew aımost nothing of their requirements. I succeeded in raising a number of plants, which grew and bloomed very satisfactorily. But, at my next trial, every plant died off. This, I think, was the cause of the failure: The soil I selected was too close and heavy, and I sifted it, making it yet more compact; while the cinerarias loves a porous soil, with perfect drainage, though fond of plenty of water.

Give them good ventilation and the coolest place you can find (without freezing). I tried some seed again last spring and now have some very

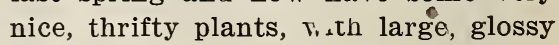
leaves.

The greatest enemy of the cinerarias is the aphis, or green fly. He will surely ruin your plants unless you take measures to prevent him. I used to wash my pıants with soapsuds and tobacco tea, after they became infested with the insects. But this year I have tried to prevent their appearance, thus far with success. I keep a light mulch of tobacco on the soil. Any kind of tobacco will do; powdered cigar stubs are good.

After the plants are done blooming, the tops can be cut down and new shoots will spring up from the ruots, which will bloom quite well another season.

New York. MRS. J. M. PERKINS.

\section{THE DEATH OF THE FLOWERS.}

Oh, woe is me today!

King Jack, what hast thou done?

Where are my beautiful treasures, I say,

Thou cruel, mocking one!

But yester-night old Cardinal Sage

Stood strong, erect, and all aglow,

Breathing cheer on youth and age

And now, of a truth, it is fallen low.

And my lovely nasturtiums, cadmium-reds,

Like butterflies hovering gorgeously massed,

Brave to the last, held up their golden heads.

But they, too, went down as the king of terrors passed.

I sighed, oh, for one more precious flower,

But not even a daisy was left in the lot.

I stooped, lo, a little blue face close to mine from 'neath the bower

Faintly breathed, "Forget-me-not."

Ah, what punishment is meet for him of the icy heart.

Who has wrought all this havoc in a few short hours?

Old Sol shall come forth and wither him with a dart,

As tolls the knell of the passing flowers. 


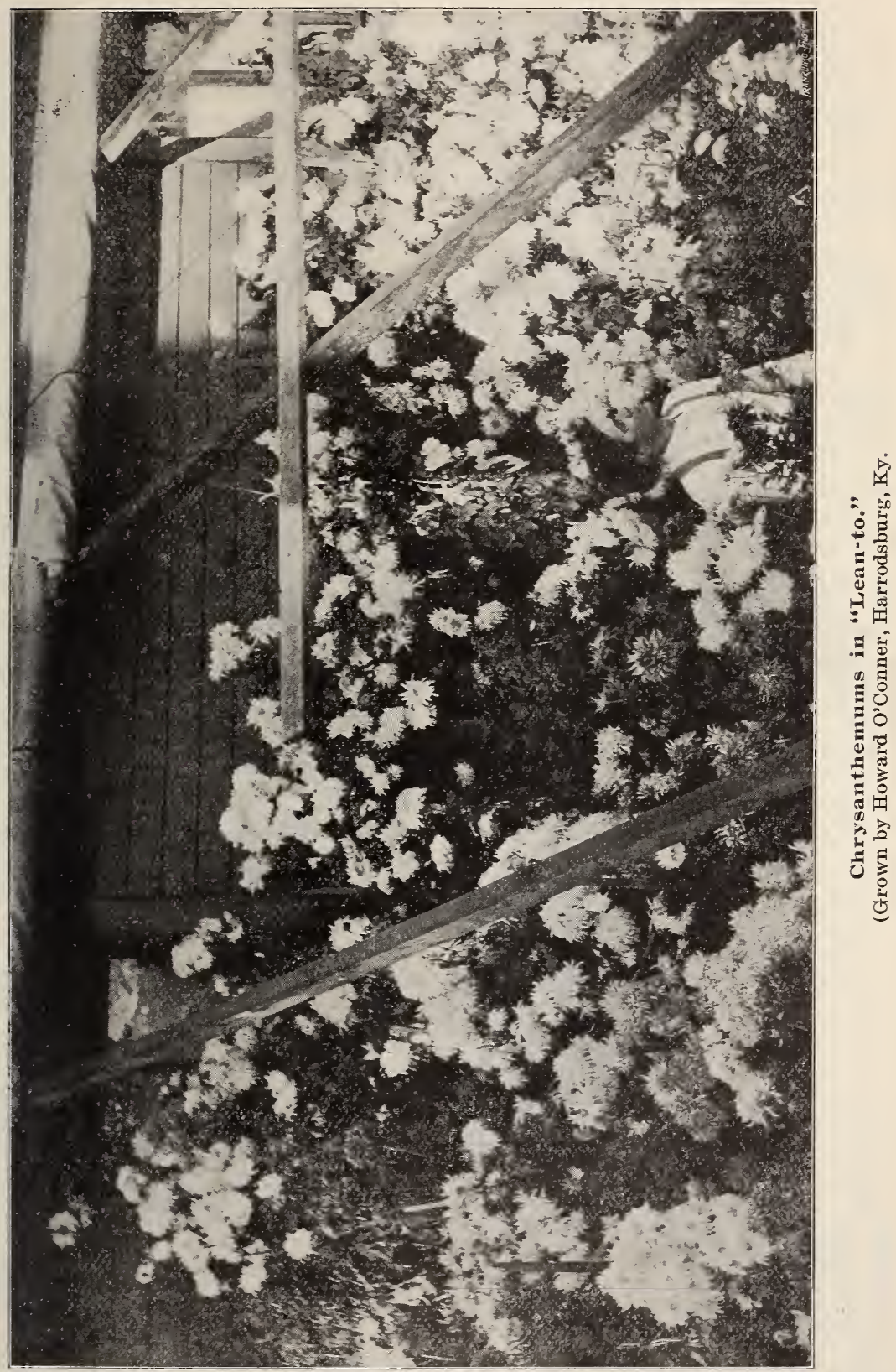


NORTH WINDOWS.

What will you have at that double north window? Let me tell you. Have a long box made that will reach across, one foot deep and wide enough to admit of a row of six-inch pots with a row of five-inch ones in front. Have the top of the box even with the window sill, for the plants-not the potsneed the sun.

Half way up the window casing, in the center, have a four-foot bracket. Below this have two one-foot brackets, one turning each way. Up each side casing put two two-foot brackets. Hang a basket in each window so they come half way down. Select baskets that are deep. Shallow ones are a snare and a delusion. They dry out too quick and do not afford room for the roots.

Now for our plants. I have grown them all, and what I have done, you can do. Put asparagus sprengeri in one basket, asparagus plumosa in the other. You do not need anything else with them. They may look lonesome at first but they need the room and will soon fill the space and you will have something that will last, for, if given rich soil and water, they will not require repotting for more than a year. For the brackets, have cyclamens, Chinese primroses, bezonias, cyrtomium falcatum, called "holly fern," adicintum cuneatum, panicum variegatum, talinum fratens, white and green. For the box, have a palm or a large sword fern in the center, then select to suit yourself, acacia fainesiana, arabia filicifolla, aucuba japonica, grevillea robusta, phynumi variegatum, eurnymus, silver and gold varieties, begonia rubra, farfugum grana, anihericum variegatum. When your pots of bulbs are in bloom, set tnem in among these plants, and you will be delighted at the brightening of that double north window. Try it and tell us your success.

Missouri.

Annie E. Croft.

\section{ONE SMALL YARD.}

Last spring we moved to a town. We had only a small yard front, four feet from porch to pailings, while a side yard four feet wide led to the back yard, which was eighteen feet wide and forty long. Yellow clay, from the digging of the well, formed the top soil of the back yard.

I had brought my flowers, including quite a number of fine rose bushes, with me. These I felt anxious to set out, but what a prospect! We hired a man, who spaded the entire back yard, then hauled good dirt and old manure, and in less than a week the place was much improved. We had a path made on either side of the yard, three fect from the fence, leaving a plat nine feet wide in the center of the yard. This we had sodded to within twelve feet of the bacis fence, leaving a circle four feet in diameter a short distance from the front end, in which I planted my Magna Cnarta, La France and Gen. Jacqueminot roses. Then six feet from that I left a space four by three feet for my gladiolas. Between the two I had a clump of carnas. Against the fence at the west side I put my sweet peas, and in front of them planted my Harmosa, Magnolia and Ulrich Bruner. Between the roses were several clumps of tuberoses. Against the back fence we put morning glories. We put an arbor at a back buiıding and planted two moon flowers. Between the back fence and plat, I found room for my Chrysanthemums. On the other side of the yard, to the front, I placed my dahlias; at the back porch the Baltimore Belle and Clematis. The whole idea and its execution was "home made" and modest. But I thoroughly enjoyed the work. So did my husband. And my back yard was lovely.

Delaware. Mrs. G. W. Bowman. 


\section{A RELIABLE FLOWER.}

The petunia has been greatly improved during the last few years, and the large flowers and bright colors attest to the hybridizer's skill. It is a most reliable annual, never failing to give an abundance of bloom all summer and late into the fall. The petunia is the flower for everybody. The humblest yard and the finest public park is incomplete without this grand flower, which minds neither heat, drought, nor rain.

Seed sown early in spring will produce flowering plants in June. It is best started in boxes in the house or in cold. frame or hot-bed, and the young plants transplanted.

The seeds of the double petunia do not possess as much vitality as the single varieties, and care must be taken to get them to germinate. All will not come double, as the petunia is inclined to sport. The better plan, when the best varieties are desired, is to get plants just beginning to flower from the florist.

Seeds of the commoner kinds may be sown thinly after the trees have started out in leaf in the spring. When well up they should be thinned or transplanted to one foot apart, or, if desired, may be left five or six inches apart and thinned when the flowers show, retaining the largest flowers and the brightest colors. The petunia grows quickly and is useful for sowing here and there where the flower bed becomes bare, at anytime during the season.

Connecticut. Lawrence D. FogG.

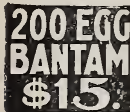

SELF-REGULATIHG INCUBATORS IN ONE. 2 Hatch every good egg. $R$ tgut $S \in$ nu 2 .

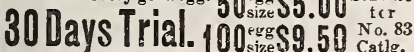
BUCKEYE INCUBATOR CO., SPRINGFIELD, OHIO.
A.T Choice Angoras. Tboroughbred. Prices and particulars free. Champion Kennels. Spring field, 0 .

Ferrets trained to hunt rats, rabbits, etc., cheap. The J.F.NELSON Poultry Farm. London, Pa.

TRPYS 38 TRIOKS BY MAIL, 10c, with $1 \mathrm{H} S$ particulars how to start in the show dusiness. John G. Scheidler, Cleveland, Ohio.

ORIENTAL STAMPS 15 Choice Japanese, ChiURIEN AL STAMPS nese \& Corean stamps, all different, 10 cents. Warranted genuine. Send stamp for catalogue O. T. TOINSON, Laurel, Md.

FOX TERRIER PUPS, nicely marked and FOL ICR ER with best of pedigrees eligible to registration. For sale at reasonable prices. GXFORI KENNELS, 1218 North 9th Street, East St. Louis, Illinols.

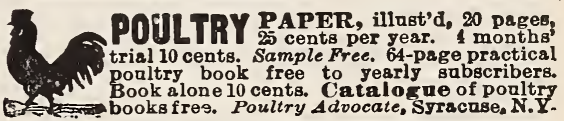

FOR HOLIDAY GIFTSI BEAUTIFUL SPARKLING GOLDFISH

Handsome gallon HANGING FisH GLOBE with chains, 3 BEAUTIFUL GOLDFISH. Green Moss and box of FIS FOOD sent BY EXPRESS for \$1. GOLDFISH 10 CTS. EACH. Add 100 per lot for shipping can. All aquaria supplies. Beautiful Parlor collections $\$ 2,50-\$ 3.50$. Send for list. Arthur V. Kempton, 515 Vinewood Ave.. Detroit, Mich.

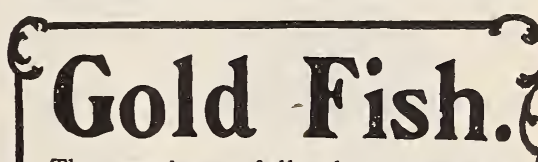

The most elegant of all parlor ornaments, as well as the most attractive and easily cared for of all pets. They are hardy, can be kept in any ordinary room, require little care and are always beautiful and interesting. We have many fancy new

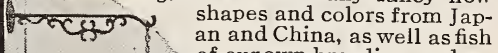
of our own breeding, and we ship everywhere.

Free Book• Ask large catalogue, telling how to care for and breed fancy fish. Also describing cage birds. Very complete; 200 illustrations, some in colors. Mailed free if you mention this paper.

Iowa

Seed

Company, Des Moines, Iowa.

\section{COSTS YOU NOTHING NOT ONE CENT PAID UNTIL TRIED. THE \\ are sent on $\mathbf{5 0}$ days trial. This shows our faith in them, Automatic eg tray. Perfect ventilation. moisture. Self regulators that keep the heat just right. No gettlng up nights to look af ter them. So simple a child can run them. Sold at low prices and fully guaranteed. Send 4 cts. for catalog and special prices. FOREST INCUBATOR CO., Lock BoxM, FOrest, O.}




\section{OUR PRIZE AWARDS.}

Each month we give $\$ 50.00$ in cash prizes for the best contributions that reach us. The first prize will be $\$ 20.00$; second, $\$ 15.00$; third, $\$ 10.00$; fourth, $\$ 3.00$ and fifth $\$ 2.00$.

Our subscribers will award the prizes. Each one can vote-blank coupons or ballots will appear in every issue. The amounts offered will be paid to the persons whose articles receive the greatest number of votes.

We now request articles for publication in March. These must not exceed three hundred words in length, and must be in our hands by February 1. If we receive more articles than can be published in March issue, the most seasonable ones will be run in that number and the remainder held for subsequent months.

Ballot for vote on March article will appear in that issue, the awards to be made public in May number. It is now time for a vote on the articles in this issue. Every subscriber for THE FLORAL WORLD is urged to at once fill out and send us this coupon.

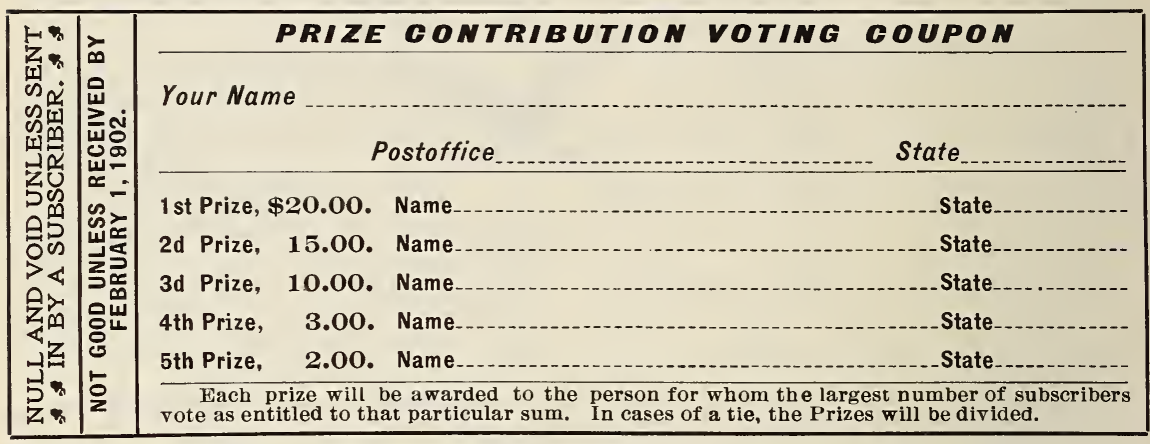

\section{OCTOBER AND NOVEMBER LETTERS.}

Some time ago the publishers of THE FLORAL WORLD offered a set of prizes, aggregating $\$ 100.00$, for contributions from subscribers. All the articles submitted in this contest, except some which were too lengthy, appeared in our October and November numbers. The prizes offered were as follows:

For the best article submitted ......... \$25.00

For the second best article .............. 15.00

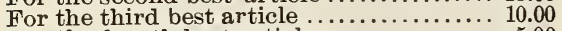

For the fourth best article ............... 5.00

For each of the ten next best articles....... 2.50

For the best article which does not exceed 200 words

For the second best article which does not exceed 200 words ................ 5.00

For each of the five next best articles which do not exceed 200 words ........ 1.00

The selection of the prize winners in this competition was by vote of subscribers for THE FLORAL WorLd. After a careful tabulation of the returns in the voting contest, it has been found that the prizes are to be awarded as follows:

First prize, $\$ 25.00$, Mrs. O. H. Hereford, Nebraska; second prize, $\$ 15.00$, A. Elizabeth Badger, Missouri ; third prize, $\$ 10.00$, Mrs. E. R. B. Barber, Michigan; fourth prize; $\$ 5.00$, S. J. Galloway, Ohio; fifth prize, $\$ 2.50$ each, as follows: Eva I. Griffith, Iowa; Benj. B. Keech, New York; Mrs. A. P. Adams, Maine; Mrs. A. B, Mitchell, Arizona: Mrs. M. S. Stoddard, Kansas; Mrs R. A. Houk, Indiana; Candace C. Powell, Missouri ; Louise Varnell, Texas; Mrs. Henry Wight, Georgia, and Mrs. D. B. Hill, Texas.

Special prize, $\$ 10.00$, Annie E. Craft, Missouri ; special prize, $\$ 5.00$, Mrs. S. A. Pleas, Indiana; special prize, $\$ 1.00$ each: Mrs. J. M. Fowle, Massachusetts; J. A. Eves, South Dakota; Mrs. A. Sigler, Indiana; Mrs. L. E. Jones, Missouri, and Mrs. W. N. White, Louisiana.

\section{THE "FLORAL BALL."}

1. In popular language what was the ball called? Hop.

2. What name was applied to the bashful ones sitting around the room? Wall-flowers.

3. What did a bad boy throw through the window? Snowball.

4. What old-fashioned article of dress worn by the host was struck by the missile? Stock.

5. What did he threaten to do to the young rascal if he could catch him? Cane.

6. What were the given names of his three charming daughters who were laughing at him behind his back? Lily, Violet, Myrtle.

7. By what pet name did they call him when about to ask a favor of him? Poppy.

8. With what salutation did he bid goodnight to his parting guests? Speedwell.

No absolutely correct list of answers was received.

The nearest correct list was sent in by Mrs. L. H. Jennings, Granville, N. Y.

Prize of $\$ 3.00$ is divided between Mrs. E. R. B. Barber, Michigan; Grace A. Flory, Nebraska ; Mrs. P. A. Sanders, Tennessee; Mrs. A. L. Clark, Massachusetts; Mary E. Sheldon, New York, and Sarah A.' Pleas, Indiana, each of whom sent the same number of correct answers.

The prize of $\$ 2.00$ is divided between Mattie L. Furber, Kentucky ; Mrs.G.H.Birnie, Maryland Mattie B. Poe, Ohio; Mrs. B. G. Ward, North Carolina: Mrs. J. M.'Perkins. New York; Mrs. Candace Powell, Missouri; Mrs. T. S. Calhoun, Pennsylvania; Mrs. Nelson Puff, Jr., New York; A. Crain, Texas, and Mrs. Mary Hooper, Michigan, all of whom sent an equal number of correct answers. 


\title{
PREMIUMS \\ TO \\ CLUB \\ RAISERS
}

\author{
THE MOST LIBERAL OFFERS \\ EVER MADE BY A PUBLICATION
}

We want THE FLORAL WORLD to attain a larger circulation than has any other floral paper. To secure it quickly we will give liberal premiums to club raisers.

YOU CAN MAKE MONEY BY GETTING SUBSCRIBERS FOR THE FLORAL WORLD "MONEY SAVED IS MONEY EARNED"

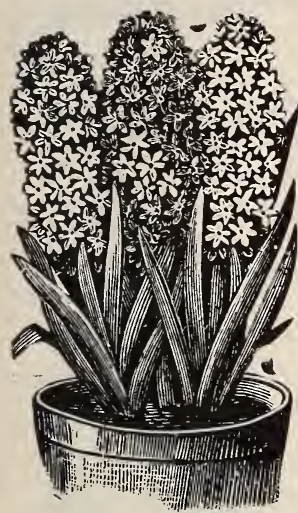

HYACINTHS.

\section{FOURTEEN SELECTED BULBS}

Given as a premium for a club of two yearly subscriptions for THE FLORAL WORLD at 25 cents each. This collection is composed of two Hyacinths, six Tulips and six Narcissus. All are blooming bulbs, though small, and an assortment will give a succession of charming flowers. The fourteen bulbs are enough to make a pretty window garden. This is premium No. 2 .

\section{FOUR ROSES FOR FALL PLANTING}

Given as a premium for two yearly subscriptions for THE FLORAL WORLD at 25 cents each. This collection contains four varieties, plants of which usually sell for at least ten cents each, as follows: Isabe11a Sprunt, rich yellow, flowers freely in Winter; Papa Gontier, deep red, free bloomer; Devoniensis, creamy-white color, magnolia fragrance; Bridesmaid, deep pink, very popular. This is Premium No. 3.

\section{FOUR ASSORTED GERANIUMS \\ (OUR SELECTION)}

Given as a premium for a club of two yearly subscriptions for THE FLorar Wormo at 25 cents each. The kinds will be those best adapted for Winter blooming in the club raiser's locality, chosen from a stock which includes more than two hundred varieties. There is no more charming house plant than a good Geranium. This is premium No. 4.

\section{TWENTY-FIVE CHOICE HOLLAND BULBS}

Given as a premium for a club of four yearly subscriptions for THE FLORAL WORLD at 25 cents each. This collection is composed of five assorted Hyacinths, ten Choice Tulips and ten selected Narcissus. All are good, vigorous bulbs, grown in Holland, and sure to give satisfaction. This is Premium No. 5.

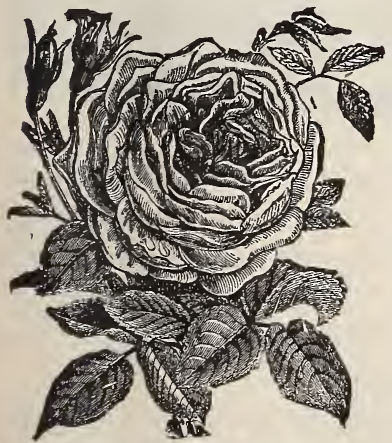

EIGHT NEW ROSES

Given as a premium for a club of four yearly subscriptions for THE FLORAL WORLD at 25 cents each. These eight Roses are the cream of the new introductions. Liberty, rich crimson; Mrs. Robert Garrett, dainty pink; Bouquet of Gold, rich, deep yellow; Helen Gambier, white and orange - yellow; Priscilla, snow - white, of immense size ; Sanguinea, (Otaheite Rose), crimson, fine for house culture; Francis Willard, new pure white; Perle Des Jardins, clear golden - yellow. This is Premium No. 6.

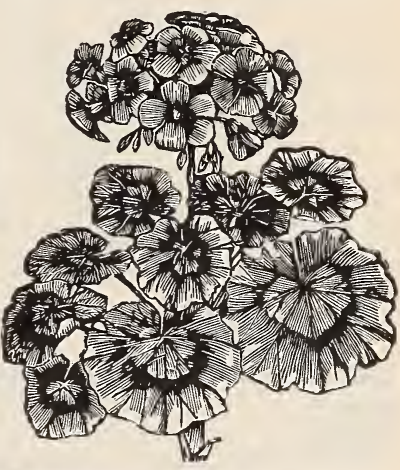

WINTER BLOOMING GERANIUM.

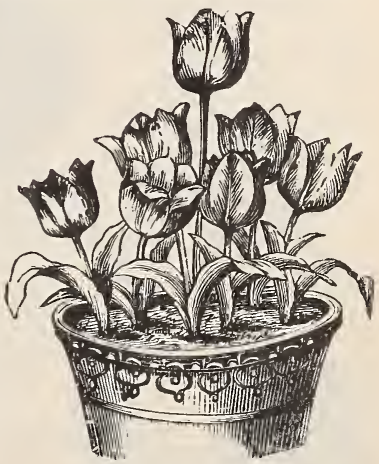

TULTPS.

ADDRESS, THE FLORAL WORLD, SPRINGFIELD, OHIO. 


\section{HIGH GRADE NICKEL-PLATED SCISSORS SEVEN-INCH SCISSORS}

Giren as a premium for a club of SIX yearly subscriptions to'THE Floral World, at 25 cents each.

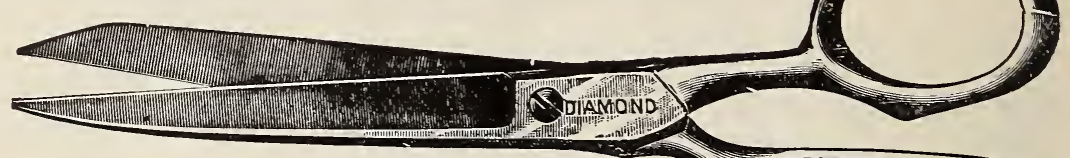

Thousands of these scissors have been used without a single onplaint. They are seven inches long, heavily nickel-plated and
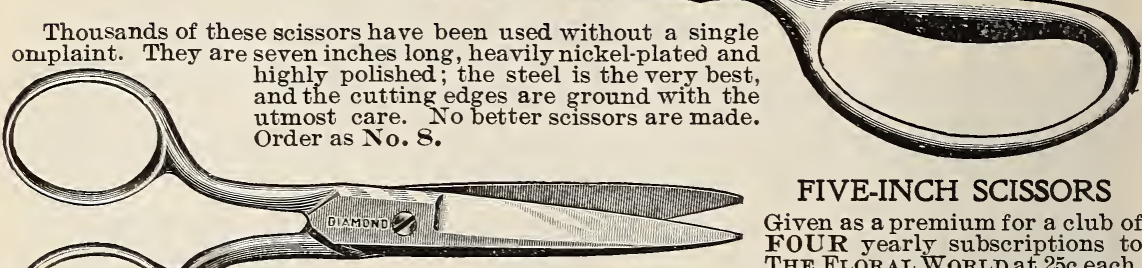

FIVE-INCH SCISSORS

Given as a premium for a club of FOUR yearly subscriptions to THE FLORAL WORLD at $25 \mathrm{c}$ each.

These scissors are of exactly the same high quality as the seven-inch scissors, and are offered to meet a big demand for smaller scissors than those above. They are just fire inches long.

This is Preminm No. 9.

\section{HIGH GRADE POCKET KNIVES}

Either Ladies' or Gentlemen's Knife giren as a premium for a club of SIX yearly subscriptions to THE FLORAL WORLD at 25 cents each.

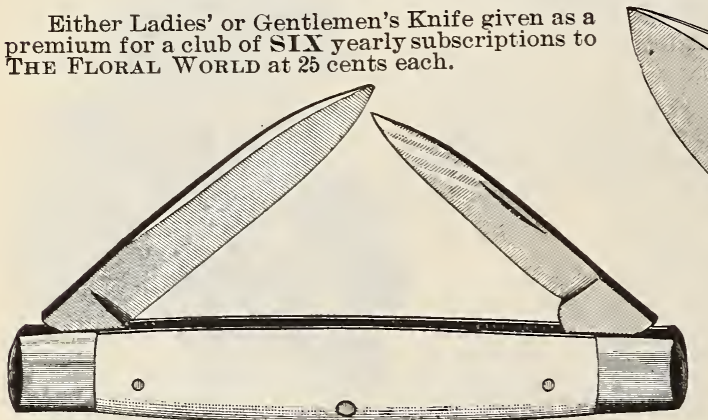

Both of these knives are the finest grade of cutlery. Both have blades of the very best razor steel, tempered by experts, ground to a keen edge and then highly polished. Both knives are

brass-lined. The illustration shows them in actual size.

THE LADIES' KNIFE has beautiful pearl handle of the newest design, the pearl running clear to the end of the knife.

THE GENTLEMEN'S KNIFE is the new curved shape and has handsome real stag handle and German silver bolster.

The knives are sent post-paid. Order as No. 12 for the gentlemen's knife, or as No. 13 for the ladies' knife.

\section{SOLID SILVER THIMBLE WITH GOLD BAND}

Given as a premium for a club of FOUR yearly subscribers for THE FLORA WORLD at 25 cents each.

This is a most attractive and pretty thimble. It is made of solid sterling silver, is carefully finished and is of good, heavy weight. The embossed band around the base is heavily gold-plated, giving the thimble an unusually rich appearance. It can be furnished in any size; state which size you want. The thimble is sent by mail, charges prepaid by us. This is Premium No. 14. 


\section{STEEL REPEATING AIR RIFLE}

Given for a Club of Sixteen Yearly Subscribers for THE FLORAL. WORLD at 25 cents each.

SHOOTS 300 TIMES. IS UNBREAKABLE. CHEAP AMMUNITION.

We offer the best and most reliable repeating air-rifle that any manufacturer has ever made. Every working part of this rifle is of pressed sheet-steel and can be Guaranteed Absolutely Not to Break.

The rifle shoots three hundred times with one loading of the ammunition-chamber. It shoots hard and accurately, and will carry a long distance. The ammunition is B. B. shot, which can be obtained in the stores everywhere. Ten cents will buy about one thousand bullets. The total length of the rifle is thirty-two inches. The barrel is nickelplated and the stock is walnut. Every rifle is fitted with good sights. Sent by express, charges to be paid by receiver. The express charges will be from 25 to 50 cents; generally 25 to 35 cents, according to the distance. $\quad$ Order as No. 17.

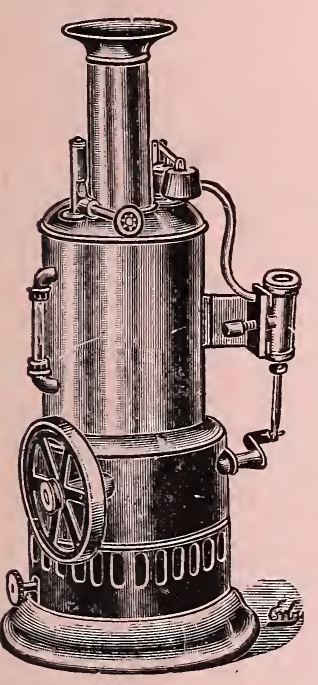

\section{GIANT BRASS-BOILER STEAM-ENGINE ***}

Given for a Club of Twenty Yearly Subscribers for

THE FLORAL WORLD at 25 cents each.

The most complete and satisfactory engine on the market. It has a heavy brass boiler, well made and strong in every particular, and fitted with a

\section{PRACTICAL WATER GUAGE}

showing exact amount of water in the boiler. The guage is fitted with adjustable nuts, so that it can be kept always both water and steam tight. It is a unique and valuable feature. It has steam whistle and automatic safety valve, thus doing away with any danger of explosion. Best of all, this engine can be run

\section{ALL DAY FOR ONE CENT}

for 1 is is fitted to burn ordinary kerosene instead of alcohol, if desired. The draft is specially arranged for this purpose. This feature makes the cost of running almost nothing. The engine is eleven inches high. Delivery charges are paid by us. Order as No.18.

\section{Our New Twentieth Century Watch}

Given as a Premium for Sixteen Yearly Subscribers for THE FLORAL: WORLD, at 25̆c each.

Sterling quality at a popular price-that is our aim and our claim in this great watch offer. Ten years ago a reliable watch for any reasonable sum of money was impossible. Today we have closed a contract with one of the most famous watch manufacturers in the world by which we obtain

\section{AN ABSOLUTELY RELIABLE WATCH}

at a price that places it within the reach of all. Not only that, but this watch has a handsome appearance as well. It can be furnished with Roman or Arabic figures, as you desire. The cut shows the Roman figures. Best of all, the watch is of

\section{MEDIUM SIZE}

being of the dimensions that jewelers call the "Sixteen Size." It is in nickel finish, open face, and has deep milled edge and hinged back. Finally, we are going to guarantee every one of these watches.

\section{OUR GUARANTY}

In the back of every watch will be found a printed guarantee by which the manufacturers agree that if without misuse this watch fails to keep good time for one year they will, upon its return, and five cents for postage, repair it free of charge. Order as No. 15.

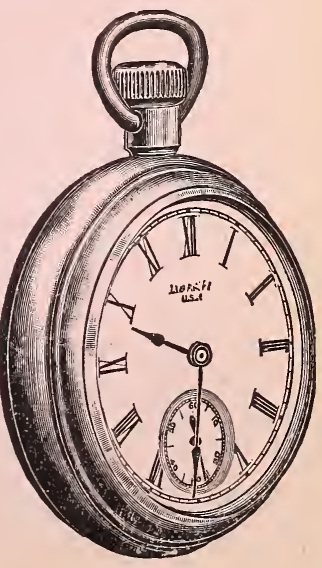




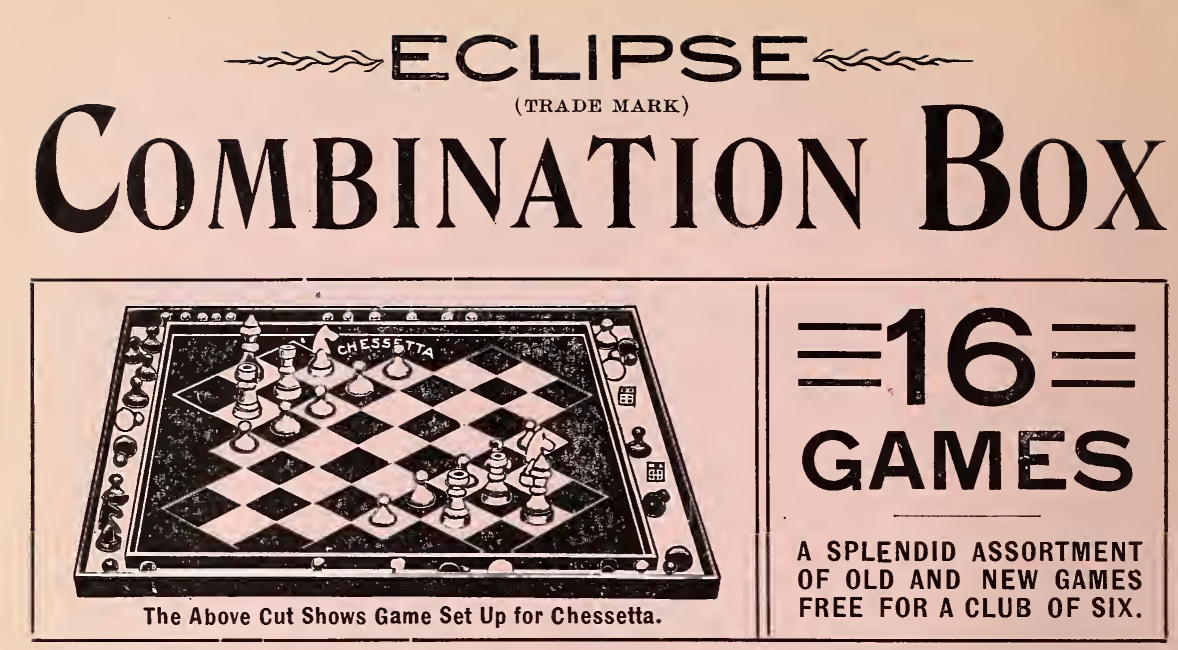

\section{Diagrams are Furnished with this Matchless Combination.}

I $T$ has been the aim in the "ECLIPSE COMBINATION BOX" to combine some of the old games with those more modern in an attractive form, making such a variety in the game line as to prove of equal interest to old and young. The result has been surprisingly satisfactory.

1. CHESSETTA.-A variation of chess, retaining same moves as the original game, but not so difficult, aş less men are used.

2. SPIDER AND FLIES.-A new and fascinating game for two persons, scientific and interesting.

3. CRADO--A splendid new game for two or four persons.

4. CHECKERETTE.-A new and interesting variation of checkers.

5. FOX AND GEESE.-One of the best of the old games.

6. CATS AND MICE.-A splendid game played on the Fox and Geese diagram.

7. WEDA.-A fine puzzle.

8. GO-BANG.-A well known and interesting game for two to four persons.
9. TWELVE MEN MORRIS.-A fine old game which has proved its merits.

10. CYCLE RACE.-A new game played with dice which cannot fail to interest the players.

11. TIT TAT TOE.-An old friend in a new dress.

12. STAR PUZZLE. - A new puzzle which will bother you.

13. CHESS.-A full set of chessmen furnished in this remarkable combination.

14. CHECKERS. - With a fine diagram and men.

15. BACK-GAMMON. - With complete outfit.

16. EGYPTIAN MAZE PUZZLÉ. - Something new and bewildering.

THE EQUIPMENT WHICH GOES WITH THIS REMARKABLE COMBINATION IS AS FOLLOWS:

60 Go-Bang Men (four colors), 1 Complete Set of Chessmen, 2 Patent Collapsable Dice Boxes, 2 Dice, 1 Book of Rules and Directions.

The "Eclipse" Combination Game outfit will be given free for a club of only six yearly subscriptions for THE FLORAL WORLD, at 25 cents each. Express charges are to be paid by the receiver. In no case will these exceed 25 cents.

Addres, THE FLORAL WORLD, Springfield, $O$. 


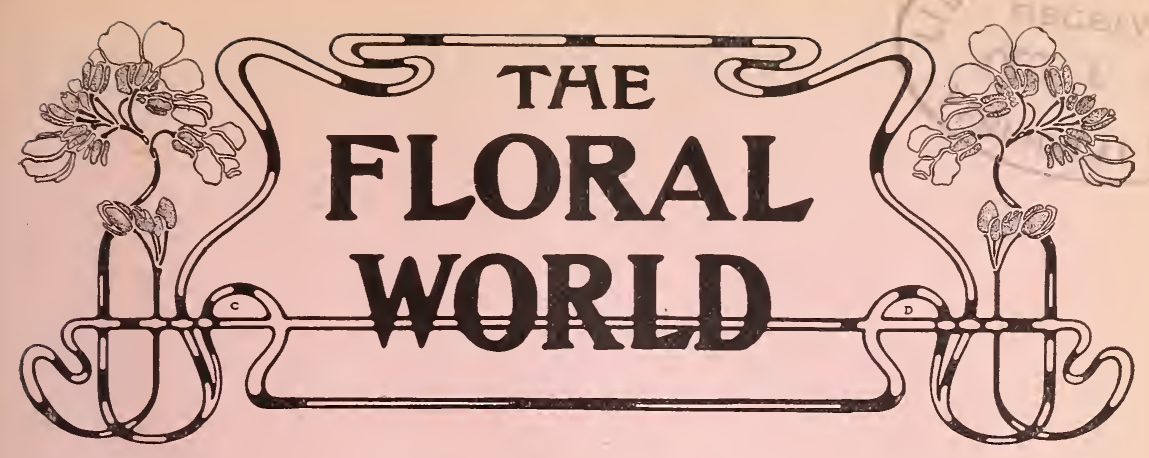

Vol. I, No. $5 \quad$ Springfield, Ohio, February, $1902 \quad 25$ Cents a Year

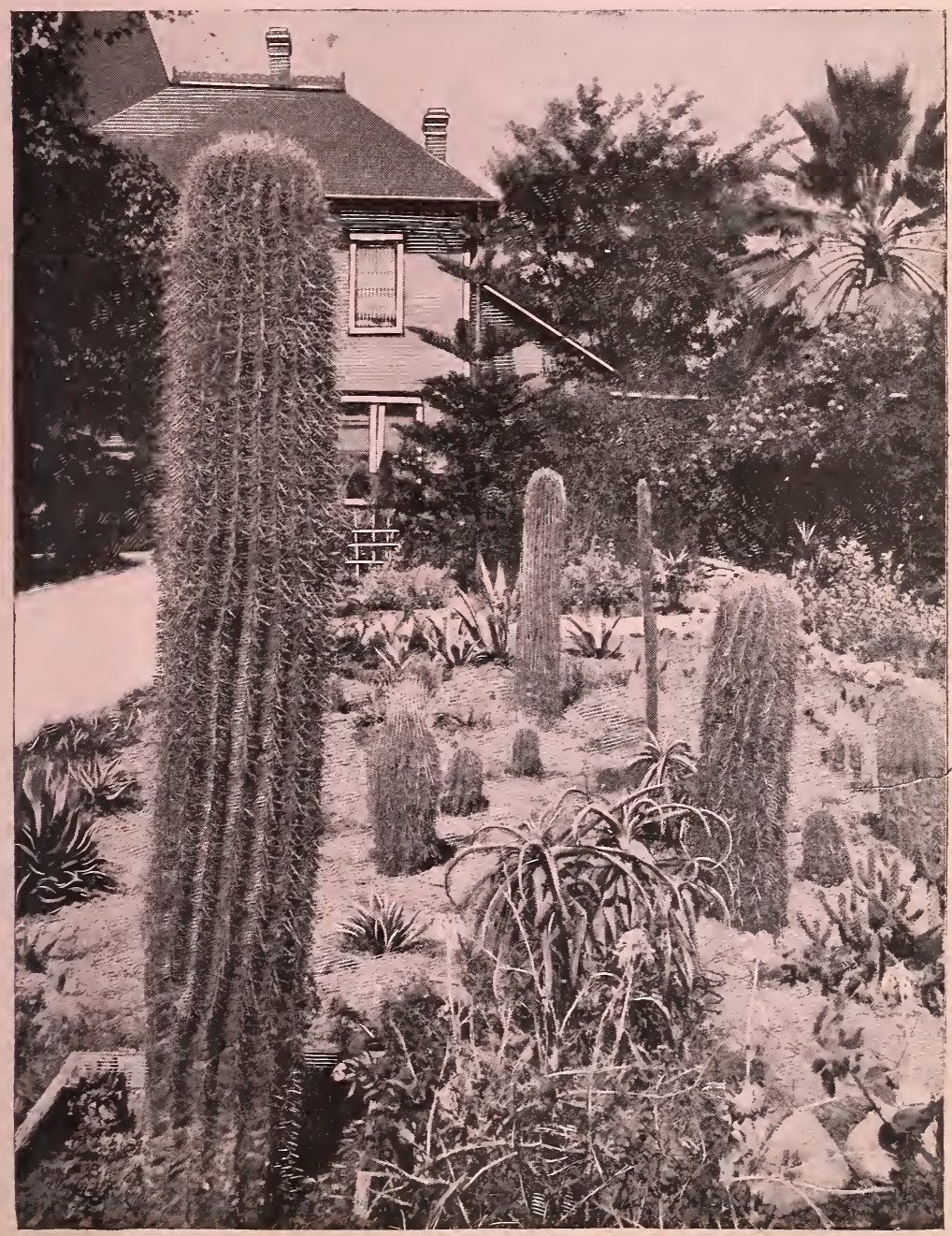




\section{0,000 Subscribers Wanted!}

How We Propose to Get Them.-Your Help Needed.

No publication was ever more warmly welcomed than has been The Floral World. This month's issue will go to fully five thousand paid subscribers.

It is evident that flower-loving people desire a publication which is exclusively devoted to the home culture of plants, bulbs, etc., and the contents of which are practical and to the point.

The Floral World ought to have fifty thousand sub. scribers by March 1st. These can be easily obtained if our present friends will give us their assistance. To start the ball rolling in a manner that will insure success, we have decided to make two or three special offers of the most liberal character.

Our first offer is to send The Floral World one year absolutely free of charge to any one who will secure and forward us two other yearly subscriptions at twenty-five cents each. In other words, three yearly subscriptions for the price of two. Any person may take advantage of this offer-present subscribers as well as others.

Our second offer is to accept yearly subscriptions, in clubs of ten or more, at ten cents each. In order to secure these astonishingly liberal terms, a club of ten or more must be sent in at one time, accompanied by remittance in full, at ten cents for each subscription. The person who sends in the club will receive a choice Rose plant, of our own selection, for each five subscriptions it contains. For ten subscriptions, the clubraiser will be forwarded two Roses; for a club of twenty, four Roses, and so on.

Now let us have your help and the fifty thousand subscribers will be secured in thirty days. Always address,

\section{THE FLORAL WORLD, Springfield, 0.}




\section{The Floral World}

\section{A Fournal of Home Floriculture}

Vol. 1, No. 5

Springfield, Ohio, February, 1902

25 Cents a Year

\section{THEY LIKE THE FLORAL WORLD.}

I love our little magazine, The Floral World. It is like a missionary away down here in our home. What a nice little present it is to send to a friend or relative! In this way we can help our editor and also our friends. Surely it will be like leaven in many a home. The flower pictures in our last (December) number are very nice. I hope we can have a little coupon and not have to cut our magazine-also that our highest prize will be $\$ 5$, so that more of our contributors will get a prize. It is hard to decide the best. All are good and deserving.

Arizona.

Mrs. M. J. Hopps.

I like the magazine very much. One of its best points is that one can feel at home when reading it, knowing that it is written by amateurs and not by regular florists who stand off and tell us we can not do so and so, and must put up with such and such plants. By our own experience, and by that of other amateurs, we learn that by the right treatment we can grow almost any plant.

Ohio.

Annie B. Calland.

Not long ago I received a number of your magazine as a sample copy. I was so delighted with it that I immediately sent in my subscription for one year. The articles are short and interesting, and just what busy flower workers need.

Pennsylvania. Mrs. T. S. CaLHoon.
I have seen only two issues of The Floral World, but I want to say right here that never in my life have I received so much for such a small expenditure. It is an invaluable fund of condensed information.

\section{California.}

Mrs. Thomas B. Dorsey.

To say I am pleased with the magazine does not express it. I see a steady improvement. I especially congratulate you on your unique method of offering prizes.

Louisiana. Mrs. W. N. White.

The Floral World is first class, brimful of flower lore, interesting and practical. Its visits are always eagerly looked for. Let us speak a good word for it to all our friends.

Nebraska. HARRIET W. Leighton.

The Floral World is fine. With its low price and being exclusively devoted to flowers, it will no doubt have a large circulation.

New York. Mrs. O. A. Adans.

I am more delighted with The Floral World than I can say.

New York.

Mrs. JohN R. WoODHULL.

\section{WINTER BEAUTY.}

Roman hyacinths will soon have spent their strength in blooms, and the Dutch hyacinths will fill their places. Some of these will be brought to the light early in January, yet others 
will wait to keep up the succession of flowers in February and March.

If one has but little space, a stand of Chinese primroses with a few hyacinths will be all-sufficient to make a cheerful window all through the winter. One of my large double windows is filled with begonias, which are now doing their best. A tall abutilon, Souvenir de Bonn, with its variegated leaves, stands at one side, while not far from it is a begonia, Manicata Aurea. This latter plant is about three feet high and has large, handsomely spotted leaves, making a fitting mate for the abutilon. These two plants and the begonias are about six or eight years old. Each season they are broken and new plants started from them.

The most desirable and excellent of the begonias for winter blooming are Nonpareil, Semper-florens Rosea, Argentea Gutata, and President Carnot. Sanguinea is handsome both summer and winter, and occupies a stand by itself.

I want to speak a good word for the Chinese hibiscus, which every one should add to his next order. The hibiscus make a grand show in the late summer and far into the winter. I do not find them quite able to stand being placed in the cellar during their first winter, but need to become well established and have plenty of good root room before being placed there.

Pennsylvania.

\section{Mrs. T. S. CALHOON.}

\section{CACTUS COLLECTING.}

There is something so fascinating about the thorny things, that, once a cactus lover, always a cactus lover. If you live where they grow, there is nothing like a day spent clambering up precipitous cliffs, and down steep canyons; peering here and there for strange specimens; feeling amply rewarded if only one new variety is added to your collection, and how much more prized than one ordered from a dealer?

Often in the radius of two miles: only, thirty or forty varieties are found. Besides, you always have the chance of finding a new, or unknown variety, and mayhap a prized monstrosity. In my collecting tours, I found that the most hardy sorts grew more abundantly on the west and northwestern exposures; and the more sensitive sorts, sheltered by huge crags and tufts of bushes, on the eastern sides of mountains entirely; with the tall and handsome agaves bordering the canyon walls like sentinels.

\section{New Mexico.}

Sudie Lavinia Pattison.

\section{WHAT TO DO IN FEBRUARY.}

This is a good time to make arrangements for correcting the mistakes and failures of last season's plant growing. It would be well, just at this season of the year, to examine all bulbs and tuberous rooted plants, stored in the cellar and elsewhere, and see that they are quite dry and cool, as this is the season they are apt to attract moisture and begin to rot. An ounce of prevention, just at this season, means a great deal of pleasure a little later on, when we bring from their winter quarters strong, sound tubers of dahlias, cannas, caladiums, calocasias, gladioli, tigridias, tuberoses, zephyranthes, etc.

This is the best season of the year for using the knife on your hardwood trees and shrubs. If you want shapely shrubs and trees, do not be afraid to prune.

This is the time to move shrubs and perennials that have worn out the soil and need a change of location, or that have not "done well."

This is the very best time to plan the shape, size, and number of the flower beds you intend to have, and just where you will plant each kind and variety.

Ohio.

LUCY JOHN. 


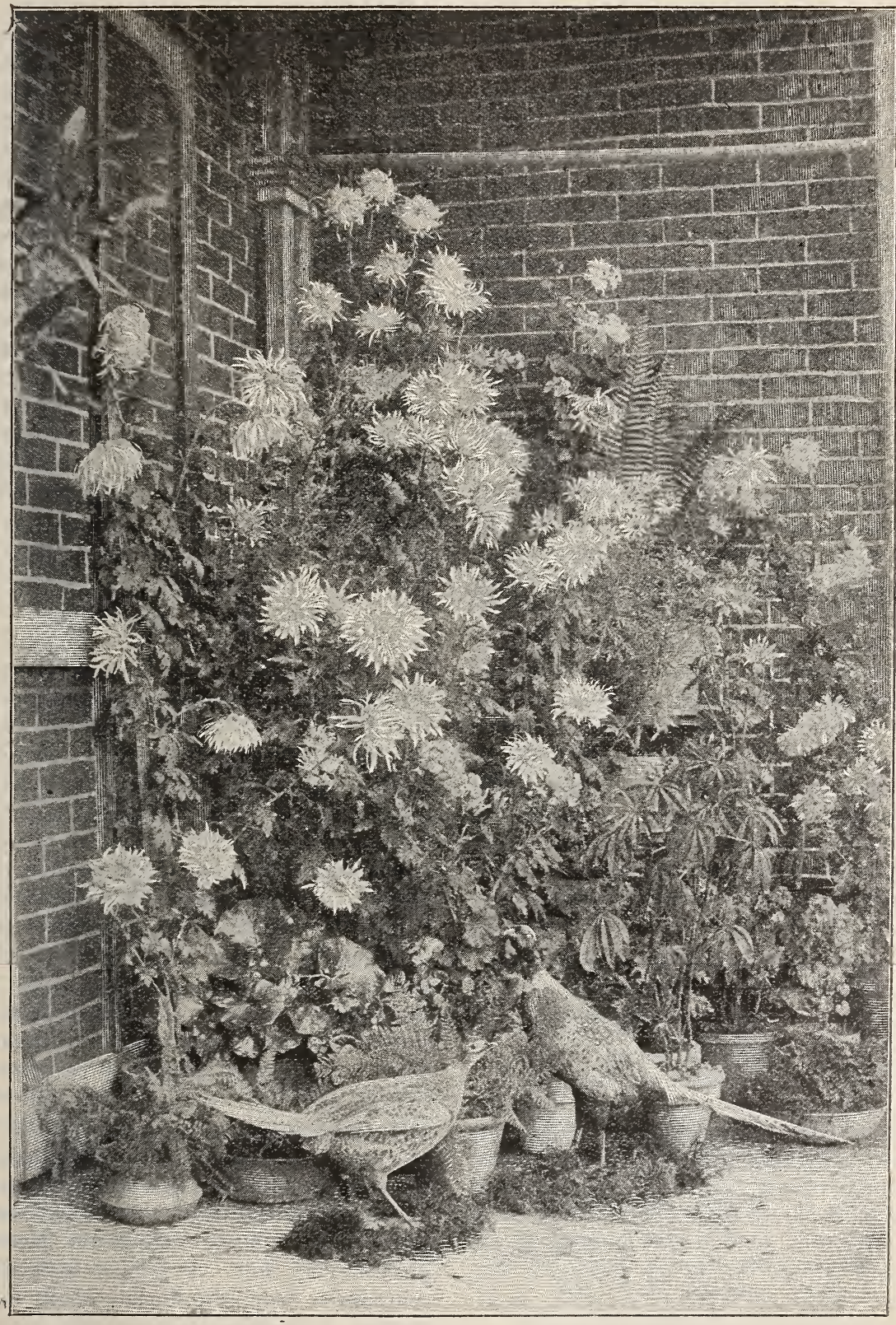

"Chrysanthemums"for'a Prize." 


\section{SUCCESS WITH HARDY ROSES AT THE NORTH.}

Plant in spring and mulch heavily in a rich, heavy soil well drained, which protects their roots from extreme heat and cold. Of many kinds tested, Madam Plantier is the best white; General Jack, the prettiest crimson. Achille Gounod has long-tufted buds, deep rose and very fragrant. Marquis de Bocella has rosettes of brownish, glossy leaves, crowned with clusters of very double pink roses, sweet as the old Damask, with a more delicate color, blooming almost continuously. These and Hermosa have stood for over thirty years without protection, except a mulch from the stable, most winters. Glory of Mosses has no superior among annual bloomers, having buds heavily mossed, fragrant foliage, delicate rosecolored petals, broadly tipped pearl white. From a small plant, the second year there were thirty-seven branches over four feet high. These produced clusters of from five to nine buds at the apex of each leaf, an average branch bearing thirty-six clusters aggregating eight thousand buds. The weight of the flowers bending the plants gracefully, forming a large hemisphere of most enchanting beauty and fragrance, recalling a sweet flower myth as aescribed by a German poet:

\footnotetext{
"The Angel of the flowers one day

Beneath a Rose tree sleeping lay;

That spirit to $w$ hose charge is given.

To bathe young buds in dews from Heaven:

Awaking from his light repose,

The Angel whispered to the Rose:

'O, fondest object of my care,

Still fairest found where all are fair,

For the sweet shade thou'st given to me;

Ask what thou will, 'tis grarited thee.'

'Then,' said the Rose, with deepened glow,

'On me another grace bestow.'

The Spirit paused in silent thought;

What grace was there that flower had not?

'Twas but a moment; o'er the Rose

A veil of moss the Angel throws,

And, robed in nature's simplest weed,

Could there a flower that Rose exceed?"
}

Indiana.

Sarah A. Pleas.
CARE OF FROSTED PLANTS.

Perhaps some of your plants are frozen. As soon as discovered, move to a cool, very dark room, and let remain there for several days. Don't let the sunshine or even strong light strike them, if it can possibly be avoided, for sunlight is nearly sure death to tender frozen plants. I have sometimes restored slightly frosted geraniums, by inverting the plants in a pail of cold water. Soon the leaves will be covered with ice. Don't water the roots until the plant shows signs of health. If frozen solid to the heart, and soft when thawed, trim off top, for the soft frozen stalks are poison to the plant. Never water the soil of frosted plants, but wait until growth starts. Then give water.

Iowa. Axxie Paddick.

\section{A SEED-SOWING EXPERIENCE.}

It is a genuine joy to the flower lover to grow fine plants from seed, and to watch the tiny baby plants grow. By the last of February one may begin sowing seeds of annuals for early bloom. I use wooden boxes three or four inches in depth, burn holes in the bottom, and fill in about an inch with charcoal for drainage. Then I put in two inches of fine soil, composed of equal parts of leaf mold, garden soil and sand sifted together very fine. I then set the boxes in a basin of water to soak up, but do not submerge them. Then cover with a glass and set away till the next day, when the soil will be just right to sow the seeds. If they are very fine, I mix a little white sand with them, and they will scatter more evenly over the soil. Then I cover with a very little sphagnum moss, ground very fine. I always save all that comes from the florists about my plants. It does much better than soil for the smallest seeds. I then cover again with the glass and set the boxes 
where they will receive bottom heat till the seeds germinate, always keeping the soil moist, but not wet. Then I move them to a sunny window and tilt the glasses to allow free access of fresıl air. On very warm, sunny days I cover the glass with a cloth.

When the seedlings have three or four leaves, I transplant, using the same kind of boxes and soil, and keep them covered with the glass for a few days. Have them tilted during the day. A poor ventilation and a wet soil are the causes of many failures with seeds. une should always allow sufficient time for germination, as some seeds require even months to germinate. When one has once mastered the art, many fine plants of cyclamen, cinerarias, primroses, tuberous begonias, fuchsias, heliotrope, and many others, can be successfully grown from seed that would cost a pretty sum of a florist.
Ohio.
Anvie B. Calland.

\section{AN EXPERIENCE WITH CANNAS.}

I have learned what cannas will do. I had some that did not bloom. They were from small bulbs, so, when it was late, I took some of them up, put tilem in pots and set them in my window. They have grown and are now in bloom (December), with beautiful leaves and flowers. How much they yield to good treatment?

Arizona. MRs. J. Hopper.

\section{MEMORIAL ROSES.}

When my sister was married, more than a year ago, it occurred to me to preserve her bridal roses in all their loveliness for her golden wedding day. From twenty-six cuttings we secured twenty-two plants. These bride roses are such a constant source of pleasure to us, that we want to pass the idea on. They bloomed for my sister's anniversary, and for her baby's christening.
By the following method, roses may be propagated any month of the year: With a sharp knife remove the bloom just above the nearest leaf. Form a cutting about six inches long by severing the stem again just below a bud. Place a dozen cuttings in a glass fruit jar of water, adding charcoal to keep the water fresh. Expose to sun and air, but protect from wind. Change water and wash cuttings once a week until tiny rootlets start. Then plant in sand, and keep moist. When vigorous leaf growth sets in, the plants are ready for potting.

I have propagated hundreds of roses in this way. In summer, rootlets often develop within two weeks; the process is much slower in winter, but just as sure.

Tennessce. Lizzie D. Abernethy.

\section{WILL "FLORAL WORLD" READERS HELP?}

I want to build a rockery in the spring, and if I could get some suggestions through The Floral World, I would be very much pleased. I want to grow ferns on the rockery and can get a great many different kinds of nice rock, but cannot quite get an idea through my head how to make it. Will The Floral World or its subscribers give me an idea? I should be very grateful.

Kansas. Mrs. M. F. Powell.

\section{SWEET PEAS.}

It may seem early to talk about planting seed in the garden. But if you want some fine blossoms and thrifty vines that will stand the hot days of summer, you will have to begin early with peas. In March, as soon as the ground is dug, I make a trench a foot deep and about six inches wide, put in some old manure from the varn or henhouse, and cover to depth of about an inch with dirt. Then plant the peas and cover them two inches. 
This leaves quite a deep place. As fast as they grow, hoe the dirt up to them. I stick mine with brush, and plant them very thick, so there will be enough after the cutworms have gone.

When the sun gets very hot, mulch them with any old litter; it keeps them moist, and the flowers last longer. Keep off all the old blossoms and do not let them form pods, for it stops them from blooming.

Massachusetts.

$$
\text { Mrs. J. M. FowLER. }
$$

\section{SPADING FLOWER BEDS IN FEBRUARY.}

$\mathrm{My}$ beds are now deeply spaded and exposed to hard freezing. This not only purifies the soil, but makes it mellow, and, from experience, I know they will retain the moisture through the entire season. When late spaded they dry out, and much flower seed is lost for want of moisture. Then perhaps the seed man bears the blame of sending out poor seed.

In early-worked beds the cutworms are frozen to death and many insect eggs gathered by the snow bird.

Later I cover my beds with old pulverized cow manure that has not been exposed to rain, and by planting time the manure is incorporated in the soil. It makes the beds warmer, too. And the beds are in fine condition for any kind of seed.

Illinois.

AnNie J. PADDICK.

\section{GROWING OF COMMON WOOD FERNS IN THE HOUSE.}

I have a very pretty window garden of begonias and foliage plants, with pretty vines. But my delight the whole year is my common wood ferns, which always do so beautifully for me. I take much pains in selecting pretty small and medium sized ones, and get plenty of pretty moss at the same time. I take small, round pie tins, or long bread tins, according to where I want to place them, and put in any ordinary dirt (of course, the woods dirt is the best), and put them in thick, so chey will look nice and bushy, and put moss all about the roots, covering the dish completely with it. Then water them often. If they get dry they will die. I have them always. I have a pretty large bowl of them on my dining table the year around, and in summer have them in cosy corners and many places. The only secret is, keep them moist.

\section{New York.}

Mrs. Josie A. Woodhull.

\section{FERNS AND LILIES IN THE WINTER.}

Every flower lover should grow a few ferns in his winter collection. These lovely children of the grovis and dells are fine for household decoration, easily grown, and furnish an interesting study in plant growth. Although ignorant of their names, the details of their growth and structure, the busy housewife shows her fondness for them, stealing away from her weary labors to tend these beautiful plants. Our woodlands abound in many beaut1ful varieties. With care they may be removed, never withering in the least. Use soil from the woods, rich, black earth and leaf mould. They can be srown successfully outside of a fernery, in a shaded or north window. When the room is to be swept, remove the ferns, so that the dust will not settle on the foliage. Give them plenty of water, but not too much, also plenty of fresh air, avoiding a draught.

Every collection should also have the Easter Lily, to have lilies at Easter. 'Tis the fairest flower that blooms on earth, teaches lessons of trust, reminding us of the Christ who, when $\mathrm{He}$ dwelt here below, said: "Behold how they grow. 'They toil not, neither do they spin; the Father's love arrayeth them so."

\section{HARRIET W. LEIGHTON.}




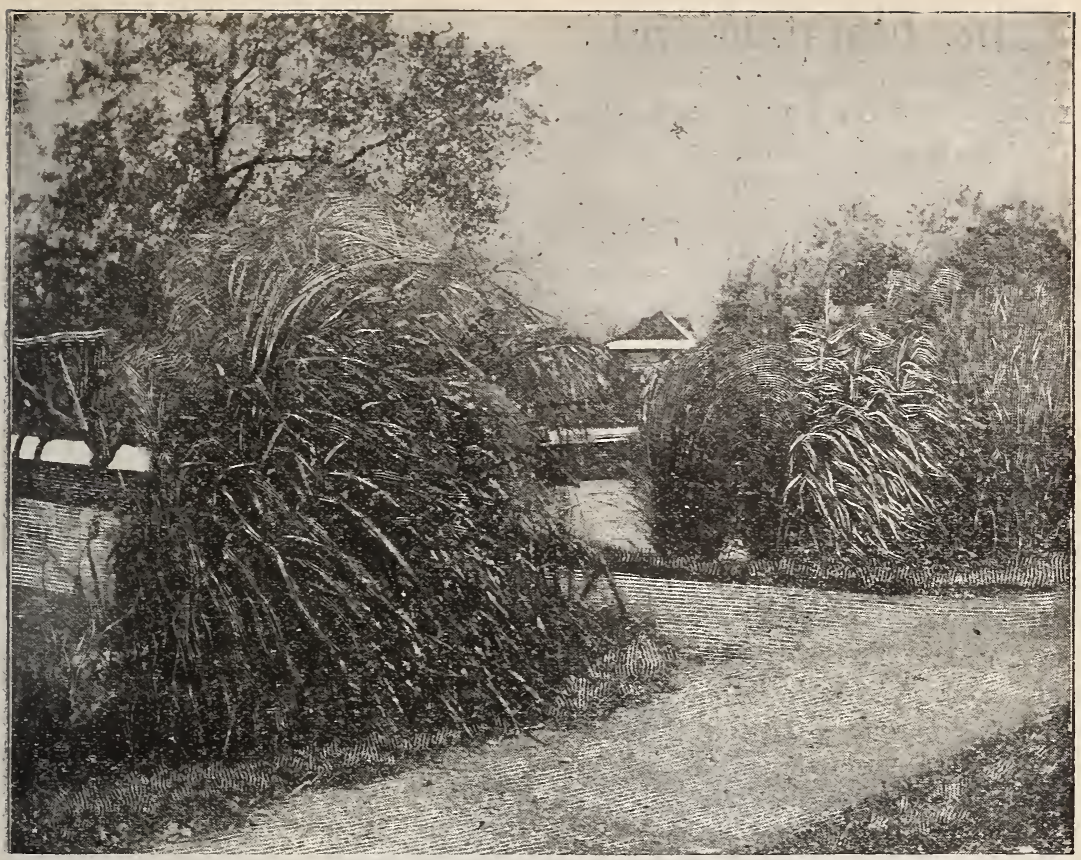

Eulalia Japonica Gracilliana.

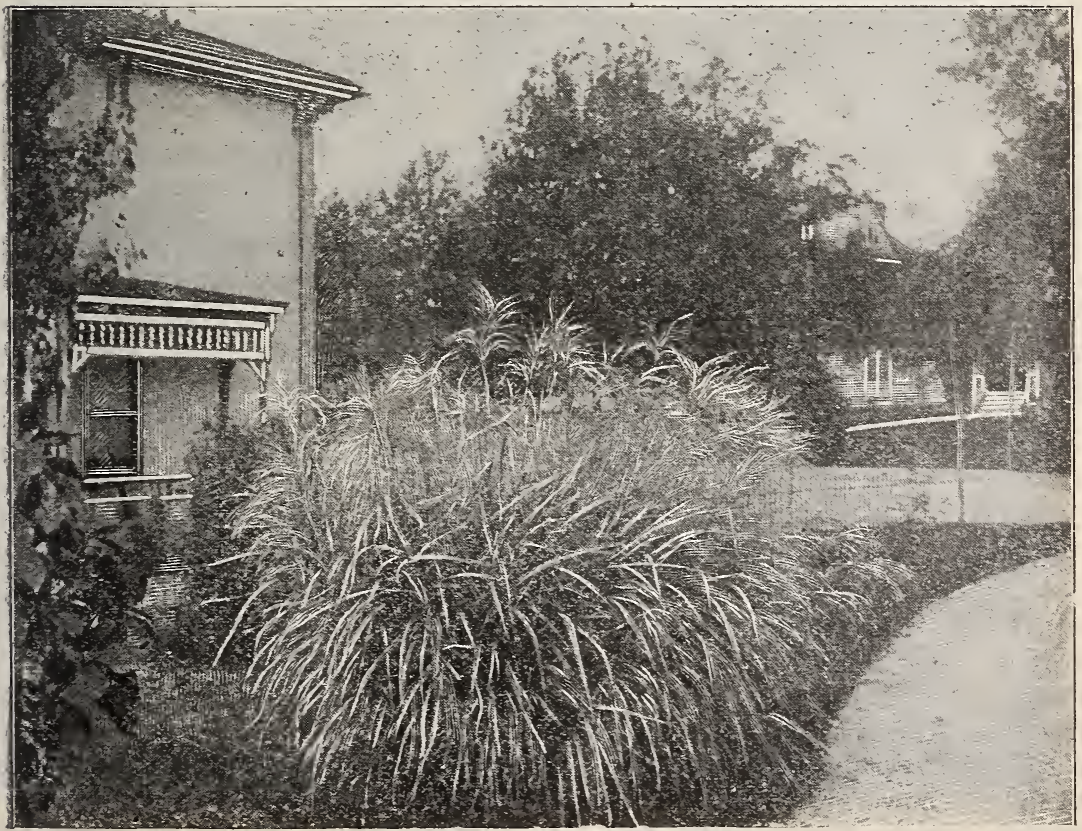

Eulalia Japonica Variegata. 


\section{The Floral World}

PUBLISHED MONTHLY BY THE

FLORAL WORLD COMPANY,

12 to 14 South Limestone Street, SPRINGFIELD, OHIO.

Subscription Price, 25 Cents a Year.

Correspondence invited from all persons interested in flowers. Write us your experience with plants.

\section{TIMELY PREPARATION FOR THE SUMMER} GARDEN.

I start my bulbs from the 15th of February to the 1st of March in my pit. In starting seed, we must decide just what we want them for, plan for the summer beds, and allow for accidents and failure to grow.

For small seed I use shallow tin pans, cans and boxes, good drainage, and light, porous soil. For the finest seed-double petunias, coleus and such -I press soil into the box, sift seed lightly over, then sift a thin Iayer of soil over the seed. I cover all the seed in proportion to its size. Take care in watering seedlings of all kinds. Much moisture causes them to "damp off."

In starting bulbs of canna, dahlia. and caladium, I use long narrow boxes, eight inches deep, and when ready to transplant, the boxes can be pulled apart without injuring the roots.

The bright flowers of the verbena are indispensable for tubs, rockeries, and, in fact, can be used almost everywhere. They grow readily from seed and are usually healthy from the start.

Kentucky. LAURA JONES.

\section{CANNAS FROM SEED AGAIN.}

If any of the readers of The Floral World desire a bed of choice cannas with very little expense, let them try growing them from seed. Start seed in February or March. Any good soil, free from worms, will answer the purpose. I bought one paper of seed of the large, flowering kind, and it contained twenty-four seeds-half of which are enough to furnish one large bed. I soaked the seeds one night in water, and in the mornilig filed through the hard outside covering with the sharp edge of a file. I used twoinch clay pots, as I had a supply, setting six in a large plant saucer for convenience in handling and watering. I put only one seed in each pot and every one grew and was shifted into a larger pot as required. By placing a flat piece of broken crockery over the hole in the bottom of the pots, and pressing against it, the ball of earth may be raised without disturbing the roots.

Two plants proved to be the dark red leaved variety and were placed in the center, with others around them. I had a variety of colors and was surprised that they bloomed so early. Give them plenty of water and fertilizer during the summer, and when the tops have been frozen, lift the bulbs and place them in a dry cellar. Cover over with sand. Care must be taken, for, if too cold and damp, they rot; if too warm and dry, they will fail to come up in the spring.

New York. Mrs. J. A. AdAMs.

\section{ABOUT WINTER-BLOOMING BULBS.}

Last winter I had lilies, hyacinths, narcissus of different kinds-oh, such fire ones-crocus of many colors. They all just bloomed and bloomed. People would say: "How lovely your flowers are," and many a one found its way to a sick friend or neighbor. I planted them in pots and cans, any time in the winter, set in cellar for a few weeks and then brought to the sitting room. My Chinese lily I planted in a dish, with sand, pebbles and shells and plenty of water, on the 9 th of January, and what a delight to watch it grow. In three weeks from that day it had open flowers, and soon there were twenty-seven open, sweet-scented double flowers on it.

Ohio.

E. Stewart. 


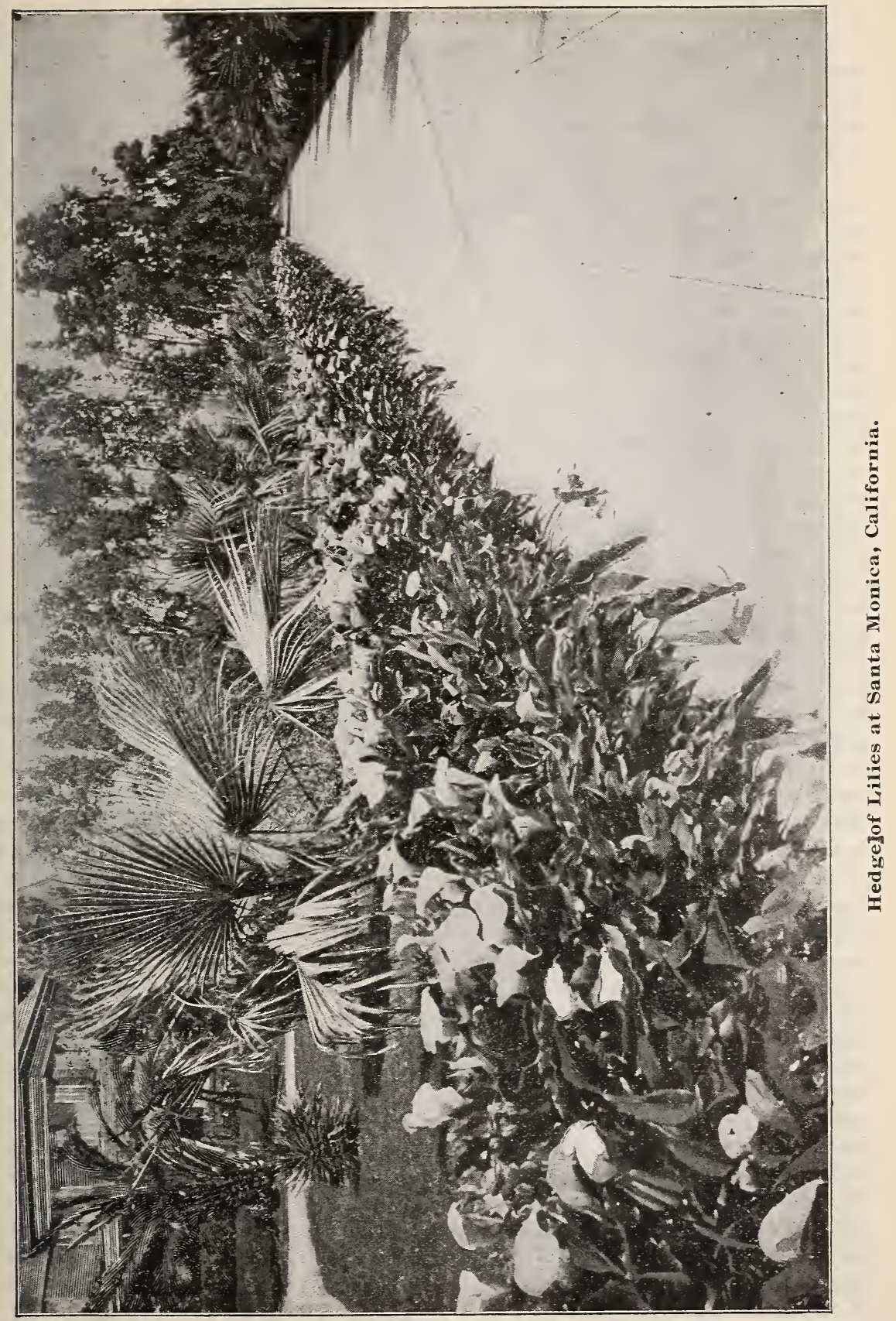




\section{A NEW LIST OF WINTER BLOOMERS.}

In the December number, Mrs. Auld says, if any one can improve upon her list for winter bloomers, she wants to know it. I am vain enough to think I can.

I should leave out Cyperus Ali and have Farfugiain Grand or Aspidistra Variegata, and Cinerarias, although beautiful in bloom, are so much trouble to keep free from aphis, too much so for a busy housewife. Why not fill their place with cyclamens, that are always in bloom and that have no insect pests-at least mine have not. Why not have a plant of Linum Trygnum, with its cheerful, golden blooms, instead of that Loperia? The Liboina is not a sure bloomer for every one, and a Habrothamnus, with its bright rose flowers, would give much more satisfaction. I can see no beauty in Othouna. Why not have the so-called German ivy or Kenilworth ivy? Russilias are beautiful basket plants, especially the new sorts. Senescio Petasites is such a big grower for a common window. It is all right for a bow window or a cunservatory, but there are so many more that in my estimation would give far more satisfaction-say either a heliotrope, Justicia Velutina, Chinese primrose, lantana, and I would keep the geraniums for blooming in the yard in summer and fill their place with an azalea or a crinum or amaryllis. A plant of Allumanda Williamsii bloomed all winter last year in $\mathrm{my}$ bow window and was something new and grand. Allendendron Fragrans was very sweet, and Meyenia Erecta called forth much praise with its b1g, rich blue flowers. Jas Gracillium and Grandiflora are good, while Browallia Major, with its brilliant blue, could not be surpassed as a good winter bloomer. Now, don't you think my list is an improvement on yours?

Missouri.

Annie E. Crafer.

\section{A COMPLIMENT IN VERSE.}

I am in receipt of my first copy of The Floral World. When I first beheld its minute form before examination, I must confess I felt somewhat disappointed, but after reading it I think the old adage very applicable, that the most precious jewels are put up in small packages.

This little floral guide

Holds many a pleasing thought,

Each lady will confide.

Fair, true, the experience bought,

Let each one do her part,

Our journal will succeed,

Receive and then impart.

Assistance we must need,

Let's help to make it bright.

With love and friendship too,

Our hearts will then delight,

Rewards will come to you.

Long live The Floral World,

Delight the homes of all the world.

Tennessee. Mrs. W. H. LADD.

\section{A BEAUT.FUL BINDER FOR "THE FLORAL} WORLD."

Cut pasteboard one inch larger each way than the magazine. Cover these all over with cotton batting, smoothly laid over cheesecioth. Tack each corner securely to hold it in place. Use for outside covering either nice quality of black sateen or taffeta silk. Paste dainty flowers cut from discarded catalogues, artistically arranged, on the outside cover. Cut twelve pieces of cardboard the length of back only one inch wide. Cover these with colored tissue paper for neatness. Bore four eyelet holes through the entire construction. Also through the magazine and near the edge of each slip.

Secure each copy, as it comes, to its place, by running narrow ribbon through and finish with a neat bow. Run a cord through the corresponding hoıes of cover and tweıve slips. Tie firmly at one corner and hang in a convenient place to show your friends and use for reference.

Louisiana. Mrs. W. N. White. 
6

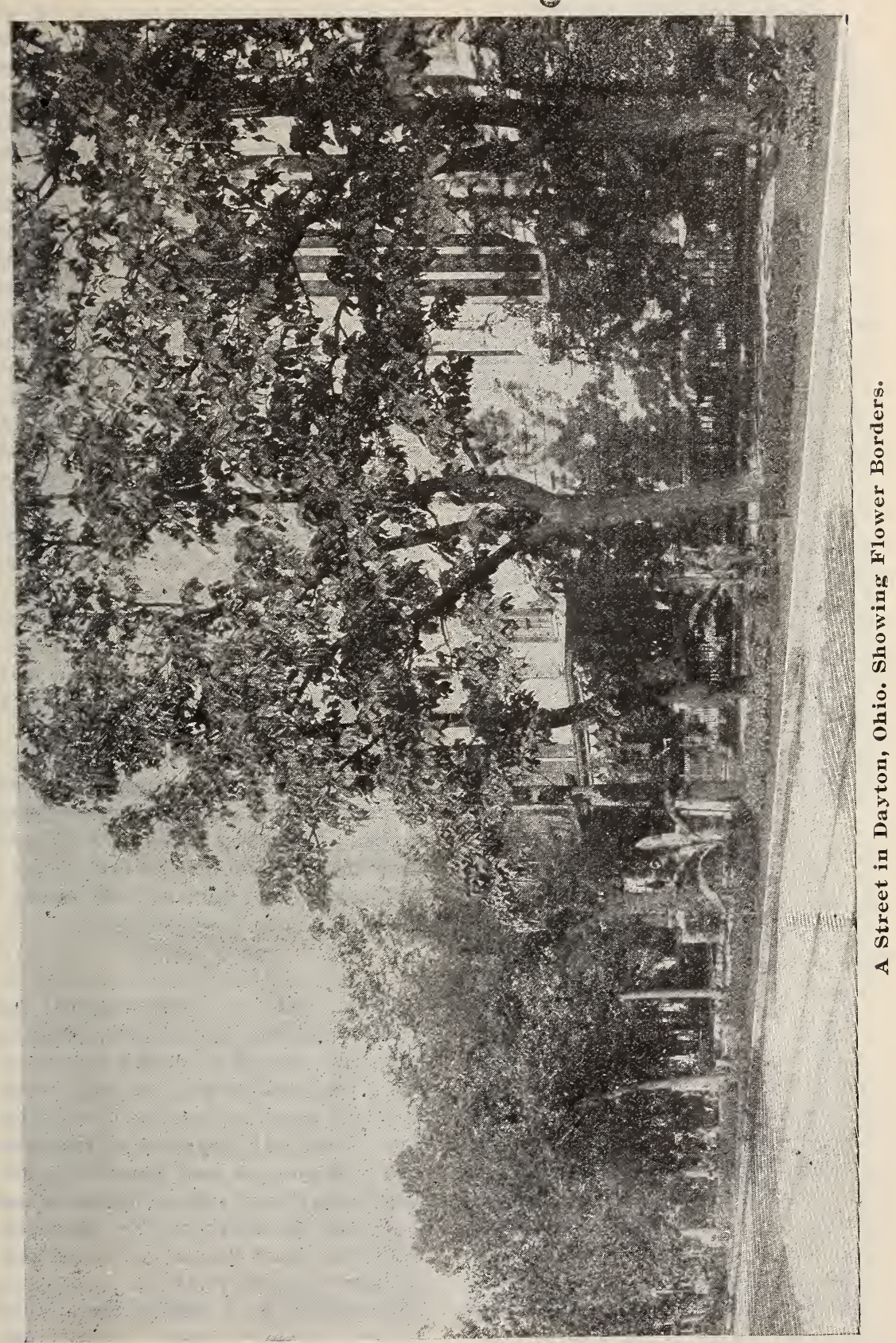




\section{PALMS AND THEIR CULTURE.}

These pre-erninently useful decorative plants are much misunderstood. They are much easier to grow than is usually supposed, though the treatment commonly given accounts very well for the failures. Contrary to the usual belief, palms do not want a hot room, but one hardly warm, and they are quickly injured by a dry, hot atmosphere. Palms will thrive in the coolest living rooms and with comparatively little water. Water does them by far the most good when evaporated into the atmosphere, or when showered on them. Palms delight in showering, but they should be kept out of the sunshine till dry. They should have a very heavy, clayey soil, firmed well down about the roots. The best surts for house culture are Kentias, Latania Borbonica and Cocos Weddelliana. And where room is not limited, add a Cycas Revoluta and a Fillaferia. Unhealthy, yellow leaves are most frequently caused by imperfect drainage. The scale is almost the only insect which attacks palms. If it appears, it may be easily removed by scrubbing the stalks and leaves with a tooth brush dipped in soap suds. A new bath for palms is said to be milk and water, and has a wonderful effect of preserving them and preventing the brown spots, which are so disfiguring.
Indiana.
Mrs. R. A. Houk.

Seaforthia Elegans is a very handsome palm, well adapted to the amateur's window on account of its being so easy to grow. It becomes ornamental when only ten or twelve inches high, is easily propagated from seeds. and increases in beauty as the plant develops.

The culture with me is very simpıe. I use rich fibrous loam with a little bone meal, as all palms dislike being disturbed by repotting often. Sponge off the leaves every week with soap- suds, being careful to syringe off all the suds with clear cold water, as the particles of soap drying on the foliage will injure it. Keep the pots clean, the drainage open, and constantly moistened, and you will find this palm one of the best for the window garden.

Another fine plant you will find in a well-grown one of Farfugiain Grand, and this is a very valuable addition to your window. I have one that has grown to an immense size. What caused this ine growth was rich sandy soil, good drainage, an abundance of water, partial rest in winter, fine particles of charcoal mixed in the soil caused the foliage to grow very glossy and to keep the foliage fresh looking; it was grown where it would only get the early morning sun. Be very careful about disturbing the roots of this plant.

A beautiful centerpiece for the dinner table was a pot of Acorus Gramineus Variegatus, surrounded with four pots of Asparagus Plumosa. The Acorus looked like a miniature New Zealand flag, and the contrast between its variegated foliage and the mist-like green of the Asparagus was lovely. The pots were covered with wood moss of different shades.

Missouri. A. Elizabeth Badger.

\section{EASTER LILIES.}

Easter lilies for blooming in the window should be strong, healthy bulbs and should be potted before the roots begin to grow. Use good drainage and have the soil a rich, turfy loam, some leaf mold and a little bone meal. I find six and eight-inch pots large enough and the bulb must be put half-way the depth oi the pot, as it wants at least three inches of soil over it.

Set away in a warm place until growth begins. Water moderately, and never allow them to suffer from excesses. Give a light, cool place and 
keep the atmosphere moist. Neglect of these points will make success doubtful.

Easter lilies like the cool, moist atmosphere of spring, and this we must try to produce in an artificial way, and as the strong perennial roots which support the bulbs are destroyed, much of the substance is taken in reproducing them after the bulbs are first potted, so they require a little more care at first.

After blooming, keep them growing until they turn yellow, or it is safe to set the plants out, then plunge the pots in some corner of the garden, where the bulbs will ripen and remain dormant.

Before growth begins, take the pots up, remove all the soil you can without disturbing the roots, repot in same pot with rich soil as in the beginning, and the bulbs are ready for service again.

Nebraska. Mrs. O. H. HEREFORD.

\section{A FLORAL GOOD SAMARITAN.}

Here, as we stand almost at the door of another year, let us one and all agree to raise more flowers than we did last year, for the benefit of those who have not the time, or, worse yet, the ones-if there be any such in your town-that always greet us with the remark: "If I could only afford it, I would raise flowers." Any woman, for the price of a calico wrapper, can get enough wire netting to enclose a small space even in the midst of chickens, where she can for a small sum raise a splendid collection of ever-blooming fragrant beauties.

Also, let each one of us make some one a present of this dear little Floral World for a year, that we may help at least one poor soul along a flowery path. Let us select those whom we know cannot afford such things as they desire. Then let us find out secretly their favorite flower, and if they are not able to buy it, let us rnake them a present of a plant or some seeds, whichever the case may be. I have made it a rule for many years to give away at least a dollar's worth of seeds to little children to plant for themselves.

Iowa. Mrs. L. C. Whitaker.

\section{A PLEA FOR THE OLD-FASHIONED GAR- DEN.}

In our modern haste and eagerness for something new, have we not almost forgotten the dear old flower gardens of our grandmothers' time?

What showy beds now on the handsome lawns, filled with beautiful and rare plants, can compare with some of the quaint, charming, old-time gardens? Most of us remember, somewhere, such a pleasing old garden. with the walks straight and clean; the beds neatly bordered with clove pinks, candytuft, and cowslips, and odorous with rows of herbs and sweet, oldfashioned flowers that seemed to share their gardener's pride that not one weed flourished inside the enclosing picket fence-a spot where love and labor blossomed into beauty.

There is one sucl garden where I delight to walk. The dear gardener no longer toils there, but its neglected tangle is still beautiful to me; the sweet odors are not all of the flowers that grow there now-some of the fragrance has lingered, through all these long years, of the biossoms my grandmother made grow and bloom with her own loving hands.

Let us plant more of these gardens and cultivate in them stately rows of hollyhocks, lilies and larkspurs; beds of foxglove, asters, sturdy marigolds, gay poppies, blue chickory, goldẹn daffodils, roses, verbenas, nasturtiums, scented pinks, lavender, mint, peonies and sweet peas of every color, these precious blossoms know how to paint themselves.

Ohio. Margaret Truesdale. 


\section{"A WE BIT ABOUT MY FLOWERING."}

My conservatory has an east, west and two south windows, a shelf on three sides one foot high, reaching the windows, also a shelf on two sides halfway up the windows. Brackets, hanging baskets, and boxes made like paper holders to hang on wall between the doors made that a bank of green. I had two light doors to stand up, buttoned on outside, so as to steam my plants by putting in a large kettle of boiling water. Heating stones and irons red hot, dropping in the water, made a mist that covered every leaf and flower. Sometimes with my brass syringe I would give them a real summer shower, drenching them from top to toe; thus everything grew rank and thrifty. Vines add much beauty. My Hoya, trained overhead, loaded with blossoms, made a fine show. The English ivy running out into the sitting room spread across two sides. Maurandia, white and purple, had to be watched closely to cut off seed pods. A variegated passion vine was one of my prettiest vines. Hanging boxes and baskets were filled with oxalis, sweet alyssum, kenilworth ivy, peristrophe and 10belia. Asparagus tenuissimus up to top of window was lovely. Senecio scandens and Cobea, with its purple bells, with the yellow asters, made a good contrast. One year I got some cow manure over a year old and potted̃ all my plants. A friend coming in, said: "Throw that away; your pots will have worms in." I didn't believe him, had I not read one ought to get manule a year old? One day I found six biz white grubs in one pot. I soon got fresh earth, baked it and potted them again - the hardest day's work I ever did. But I didn't tell my friend-I had heard "I told you so" before, and did not care to hear it again.

Wisconsin.

Aunt Kate.
TO PREPARE_PRIMROSES FFOR WINTER BLOOMING.

The primroses are very attractive flowers in all their varieties, but those best adapted for the amateur culturist are of the species distinguished as the Chinese. These bloom most freely during the latter part of winter and through spring and often into the summer. The leaves are soft and downy, the flowers are like delicate porcelain and appear in clusters, with a plain or fringed margin. The colors are white, rose, and varying shades through to crimson. They can be grown from side sioots (used as cuttings), which, when low down on the plant, start the rudiments of roots even before removed. The great trouble is that they are apt to "damp off" or decay at the base before rooting. The following method we rave always found successful in our garden.

We take the cutting as soon as sevcied and dust the end with powdered chircoal; then press it against the soil, taking care not to emhed it too deeply, and then cover with a glass, tilted slightly so as to admit fresh air. These primrose cuttings require a moist, still atmosphere when taking root, but they do not thrive if too damp, as a rot attacks the stalk, sometimes looking quite healthy at the top when it is gone past redemption just above the root. Keep tlie plants in a low temperature and a shady situation. Do, not over-water. When in bloom they can be placed in north windows. With a little care and good judgment, these ri]ants can be made general favorites in our winter window garden. Baby Fimrose is already in bloom at this time (December 17). Obonicia is a variety that ought to be in every collection. These little beauties were rightly named when they were given the name primrose, for they are always looking prim.

Incliana.

Mrs. R. A. HouK. 


\section{CAN FLORAL WORLD READERS SUGGEST ANYTHING IN ANSWER?}

In the December number of The Floral World, Mrs. Sarah A. Pleas, under the heading "Care of House Plants," mentions "Hoya Cornita." The catalogues advertise "Hoya Carnosa." Are there two kinds of the hoya, or wax plant? I know of only one-the Hoya Carnosa.

California. Mrs. J. E. Cobenour.

I want to know about the cultivation of chrysanthemums and carnations in this climate. I had some very pretty and large sized chrysanthemums two years ago. They were transplanted, and since then have not done well. My carnations I bought in pots from a nursery and care for them as directed, but they have all died. Do they need to be transplanted every year? Some one told me the reason mine died was that I had not transplanted them.

California.

Mary A. George.

I have a dwarf Calla Lily; had it two years; got it in a sunny window; have rested it in summer and given it all kinds of treatments already-fertilizer good soil, constantly kept moist, etc.but it won't bloom. Could you give me advice? Do you know of a sweetscented cyclamen? Which lettuce is best for forcing in a hot bed?

Wisconsin. Rev. F. A. Franke.

Can any one tell me whether a Chinese water lily is good after having once bloomed?

Idaho. $\quad$ F. M. CoNGer.

\section{OUR PRIZE AWARDS.}

Each month we give $\$ 50.00$ in cash prizes for the best contributions that reach; us. The first prize is $\$ 20.00$; second, $\$ 15.00$; third, $\$ 10.00$; fourth, $\$ 3.00$ and fifth $\$ 2.00$.

Our subscribers will award the prizes. Each one can vote-blank coupous or vallots will appear in every issue. The amounts offered will be paid to the persons whose articles receive the greatest number of votes.

We now request articles for publication in April. These must not exceed two hundred words in length, and must be in our hands by March 1. If we receive more articles than can be published in the April issue, the most seasonable ones will be run in that number and the remainder held for subsequent months.

Ballot for vote on April article will appear in that issue, the awards to be made public in June number. It is now time for a vote on the articles in this issue. Every subscriber for THE Floral WorLD is urged to at once fill out and send us this coupon.

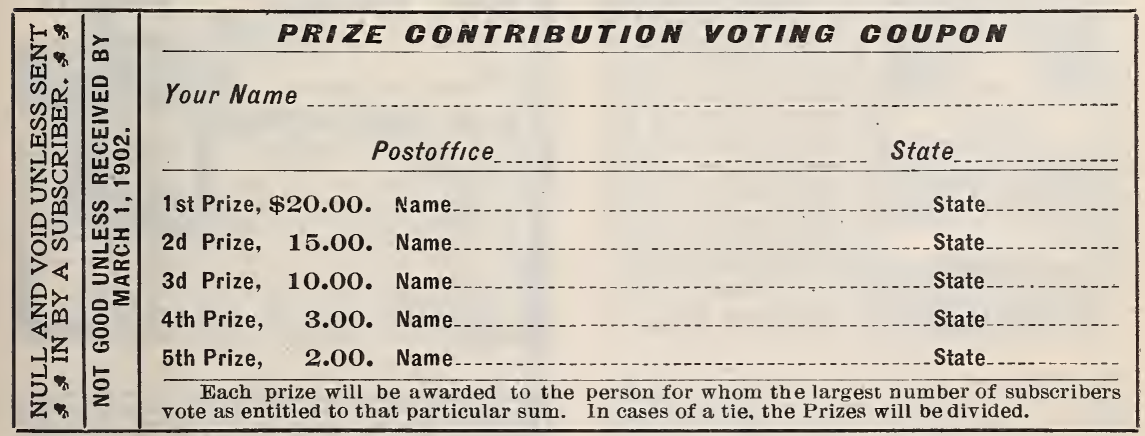

The selection of prize winners in this competition for February was by vote of subscribers of The Floral World. After a careful tabulation of the returns in the voting contest, it has been found that the prizes are to be awarded as follows: First prize, \$20.00. I. M. Stacy McLeod, New Jersey; second prize, $\$ 7.50$ each, as follows: Mrs. R. A. Houk, Indiana, and Miss Sarah A. Pleas, Indiana; third prize, $\$ 10.00$, Mrs. Chas. F. Tuthill, New York; fourth prize, $\$ 1.50$ each, Mrs. C. Powell, Missouri, and F. M. Walker, Louisianna ; fifth prize, $\$ 1.00$ each, Mrs. G E. Passage, New York, and I. A. Auld, Illinois. 


\section{THE "I9OO" FAMILY WASHER FREE.}

Greatest Invention of the Age. TIME, LABOR AND EXPENSE Of Washing Clothes Cut in Two.

No More Stooping, Rubbing or Boiling of Clothes.

Every Household Needs One.

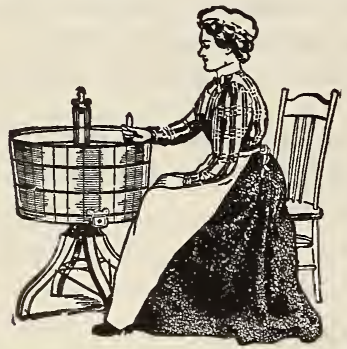

\section{THE "I900" BALL-BEARIMG FAMILY WASHER SENT FREE,}

without deposit or advance payment of any kind, freight paid, on 30 days' trial. T'be 1900 Ball-Bearing Washer is unquestionably the greatest labor-saving machine ever invented for family use. Entirely new principle. It is simplicity itself. There are no wheels, paddles, rockers, cranks or complicated machinery. It revolves on bicycle ball-bearings,
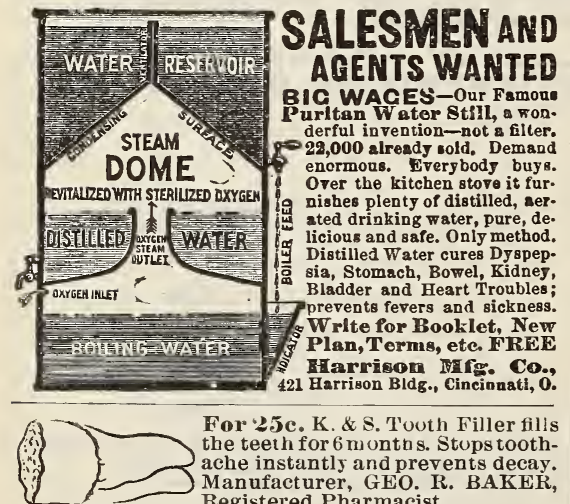

For '25c. K. \& S. Tooth Filler fills the teeth for 6 month s. Stups toothache instantly and prevents decay. Manufacturer, GEO. R. BAKER, Registered Pharmacist.

65 ('U.A IR I'I'., - CHICAGO.

FOX TERRIER rUPS, nicely marked and eligible to registration. For sale at reasonable prices. GXFORD KENNEL, 1218 North 9th street, East st. Louls, Illinois.

ANGORA CATS PURE BRED Woodlawn Kennels, LouisANGORH GATS ville, Ky., N. L. D. Barnes, Manager. making it by far the easiest running washer on the market. No strength r quired, a child can nperate it. No more stuoping, rubbing, boiling of clothes. Hot water and soap all that is needed. It will wash la r.ge quantities of clothes (no matter how soiled) verfectly clean in 6 minutes. Impossible to injure the most delicate fabrics. As the Sup't. of the Savannah Yacht Club says:

"It is a wonder. Our washing is very large and we "have always had two wom $\neq n$ on Monday and one on "Tuesday. Our cook and the yard boy now do the "washing in $\mathbf{4}$ hours much better than before."

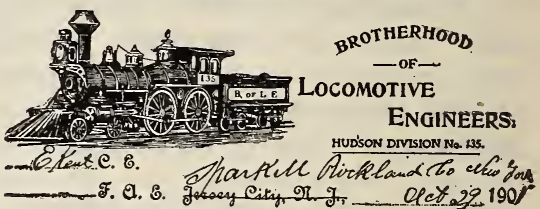

SPARKILL, Rockland Co., N. Y., Oct. 29, 1901

"I900" Washer Company :

1 have given your washer a fair trial and found it all right as recommended. It is one of the best washers I ever saw. It washed three pairs of my dirty and greasy civeralls and overshirts in ten minutes and washed them clean. My housekeeper says it would have taken her two hours to have washed them the old way. It will wash ten shirts, with colliırs and cuffs, in seven minutes. It will wash three washes without changing the water, only adding soap suds and about two quarts of hot water after the first wash.

Enclosed you will find check in full payment of the washer. Please acknowledge receipt of the same and oblige. Respectfully yours.

EDWARD KENT.

P. S.-I have been a delegate and attended twentysix conventions held in different parts of the country, and my name is known on nearly every railroad in the United States and Canada. I am an engineer of the New York Division of the Erie road and have run an engine for forty years.

Write at once for CATALOGUE and FULL, PARTICULAR's to

\section{"1900" WASHER CO.,}

216 S. STATE ST., - - BINGHAMTON, N. Y.

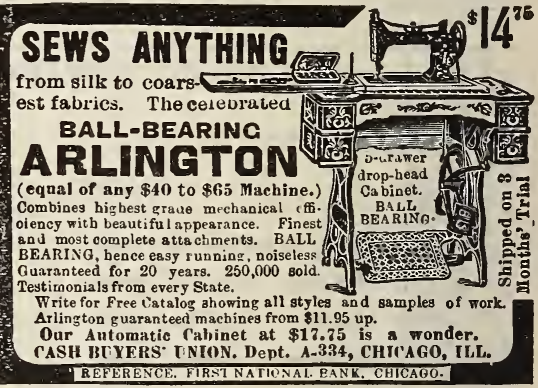

\section{NO SPAVINS}

The worst possible spavin can be cured in 45 minutes. Ringbones, Curbs and Splints just as quick. Not painful and nover has failed. Detailed information about this new method sent free to horse owners.

Write today. Ask for pamphlet Nn. 110 Fleming Bros., Chemists, Union Stock Yds., Chicago. 


\section{A Burglar Is a Coward}

He fears a sudden noise next to death. It means his capture. To scream or attack him in your house induces him to murder you. But the explosion of a blank cartridge at door or 'window terrifies the boldest thief and awakens

\section{CANNON-LOCK} lation and bolts the door securely. It holdslike a giant and fires a blank cartridge when moa giant and There is neither trouble or danger in lested. There is neituely harmless even for using it. It to play with when loaded, yet a thousand times more protection than a revolver. doubly safe at home, and travelers use them in hotels. Made of steel -resembles a fountainpen-shoots a blank cartridge ( 22 caliber) will last a lifetime.

Price 50 cents. But if you order two from this ad we will send one extra, making three Cannon-Locks for \$1, and refund y our dollar if you don't say it is the only true burglar alarm

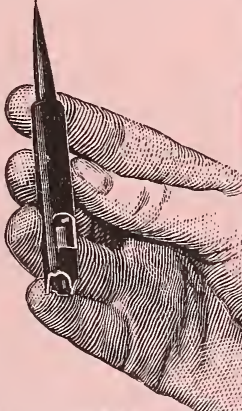

THE EAGLE STEEL COMPAN 98 TRUST BLDG.. CINCINNATI. base of door or upper sash of window
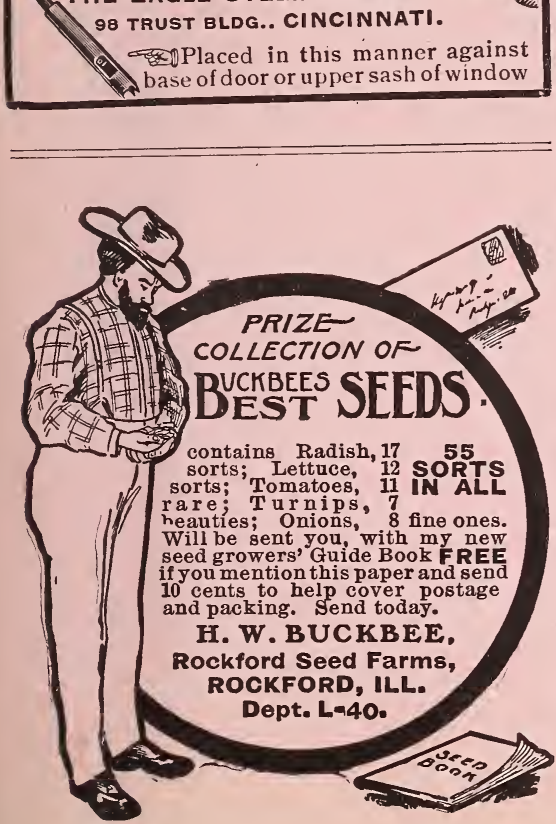
help. The Eagle

Locks a window open any distance for ventiTimid women feel

Placed in this manner against

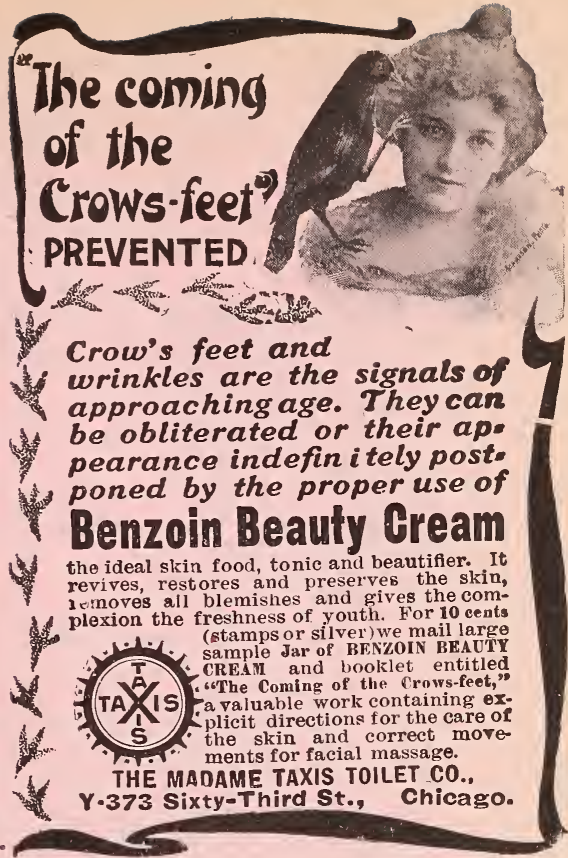

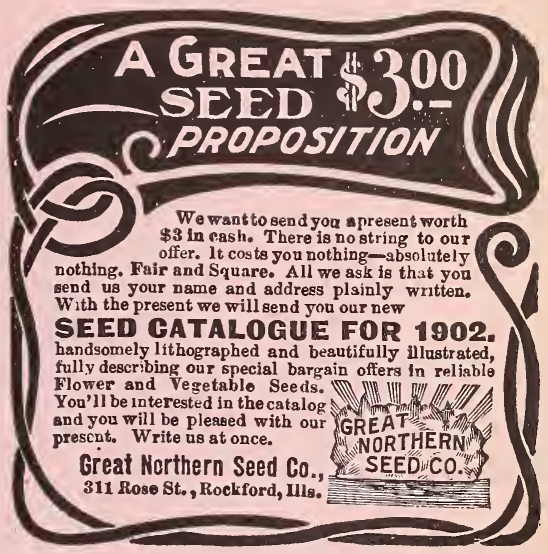

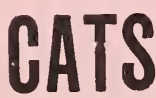

Two very fine pictures, one head, one full view, of Persian long-haired cat Crystal. Size $9 \times 12$, suitable for framing. Mailed for 10c. Just the thing to send to cat lovers for ChristDo you own a cat? If so, you should mas Souvenir. Do you the finest publication of have The Cat Journal, the finest publication of its kind in the world. Profusely illustrated. Printed on heary enameled book pable to cat owners. Special mation of interesto breeding and care of long-haired attention given to breeding and care The abuve piccats. Price $\$ 1$ per year in advance. The abuve picJournal, Box D, Palmyra, N. Y. 


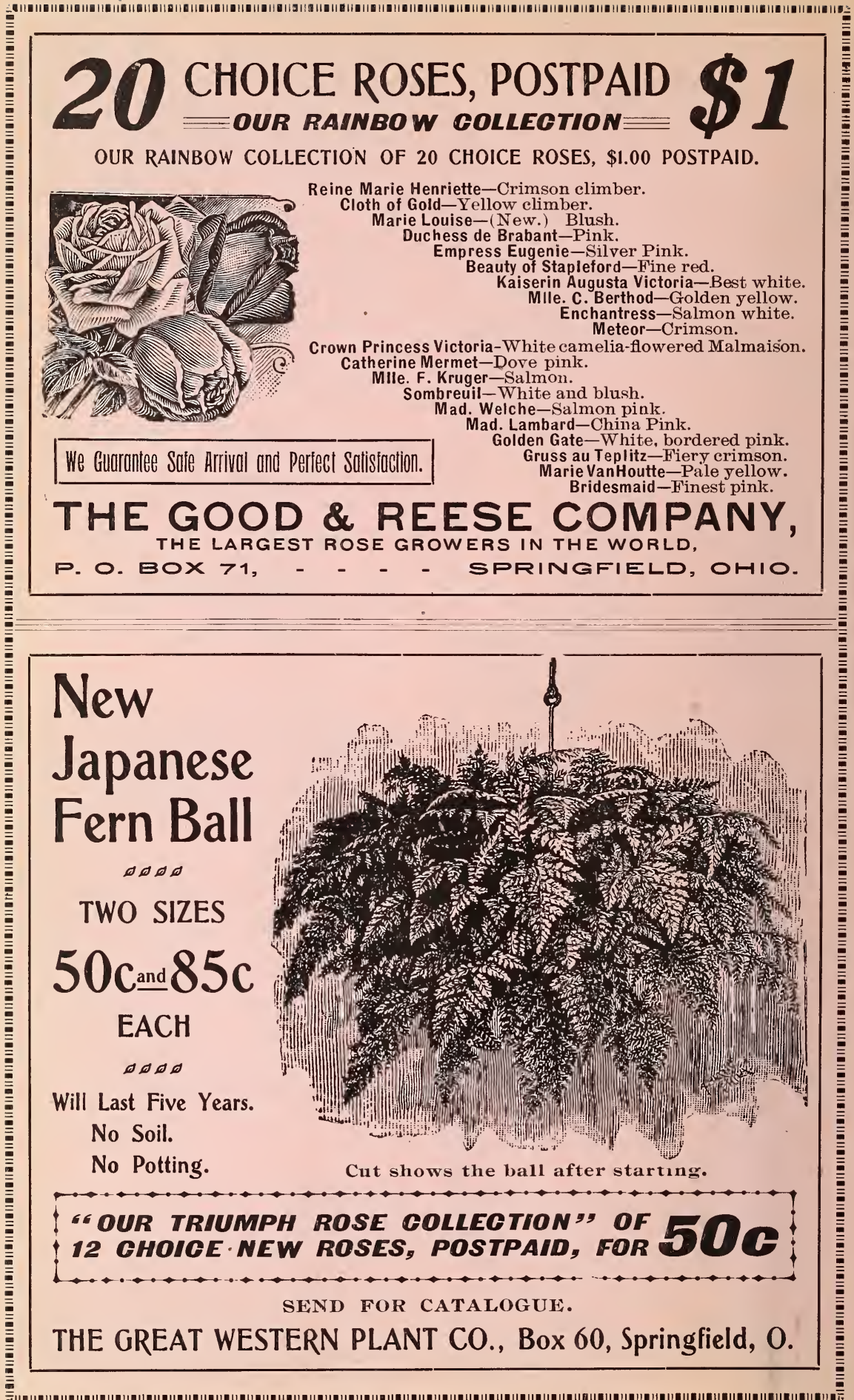



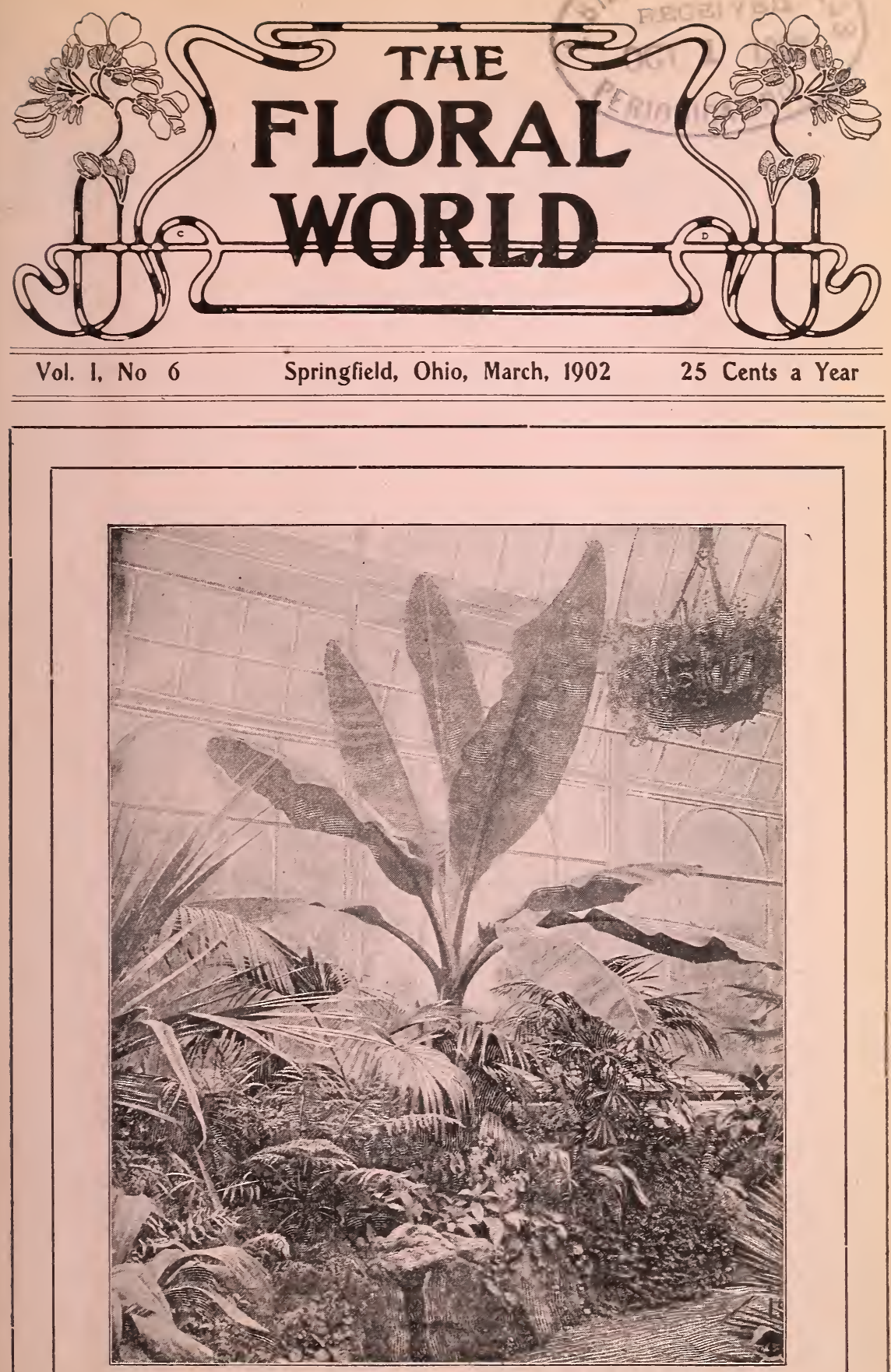


\section{A WORDTO OUR FRIENDS}

We have erery reason to believe, from interviews with the Third Assistant Postmaster General of the United States, that upon presentation to him of the present issue of The FloraL WorLd it will be accorded mailing privileges as second-class matter.

If this is done, The Floral World will have the same rights as other legitimate publications, and will be in position to assure its future by meeting the demand which has called it into existence - the need for a practical journal wholly devoted to flower growing in the home.

We need your help, of course, in bringing The FloraL WORLD to the attention of those who are interested in its mission. Our aim will always be to give you a journal so practical and so helpful that you will be glad to recominend it. Kindly say a good word for our little magazine on erery possible occasion.

The postoffice department having refused to recognize $T_{H E}$ Floral World as a legitimate publication while the prizes offered by us for the best contributions were awarded by vote of our subscribers, that feature has been eliminated. The editor will be glad to have your assistance in selecting the prize. winners, howerer, and you are invited to write us freely each month as to the articles which you regard as the most helpful. 


\section{The Floral Wor orld}

\section{A Fournal of Home Floriculture}

Vol. 1, No. 6

Springfield, Ohio, March, 1902

25 Cents a Year

THEY LIKE THE FLORAL WORLD.

The Floral World is just what amateurs need-a paper for them alone.

Ohio.

Annice B. Calland.

I wish you every success with this bright little magazine. I take other floral works, but think we can not receive too much information on floral culture.

Mich.

Mrs. A. Z. Hoyt.

I certainly want the magazine, and am crazy to read about flowers. I will take it as long as it is printed, if it is as good as now.

Maine.

Caroline P. Adams.

I am very much pleased with the magazine and I look for its coming each month with much interest. I have already profited by it in a material way, for I have followed the directions in the October number, in regard to hyacinths, which I tried for the first time, and my success is beyond my expectation.

Massachusetts.

TEACHER.

Let The Floral World be just what it started out to be-strictly amateur experience. Do not think of such a thing as discontinuing our magazine. We need the plain, every-day experience of home flower-growers, much more than the elaborate descriptions of fine greenhouses and park decorations. It is our "private homes" that we strive to beautify, and no one is better able to help us than the successful amateur.

IowA.

Mrs. P. W. Hopkins.

This is the first journal I have ever seen that meets the demands of all. A good many women are perhaps situated much as I am. On a large farm, with lots of work to do and a family of children to care for, I find very little time to spend with flowers, and I am so glad : have at last found a journal that will instruct me in selecting flowers and bulbs that are easily grown, and the kind of soil and care they need to make them grow and bloom. I earnestly hope the publication of The Floral World will be carried on, for it is just the journal I want.

Mich.

Mrs. F. L. Perrine.

Long live The Floral World! We are not going to give it up. It is meeting the demand of a long-felt need. A journal of home floriculture is what we amateurs want, and that is the kind of stuff we find in The Floral World. It is just the journal for the thousands of beginners (and those who are not beginners), who do not care to subscribe to an expensive floral journal. Practical experience is what we want to read about, instead of tourists' travels and hot-house management. I hope success will crown your efforts. We want something short and easy to digest. The Floral World is my ideal.

Indiana.

R. A. Houck. 


\section{PROTECTING THE LILY BED.}

Many of our most beautiful lilies that are considered hardy often make their advent in the world before their time, and for their rashness require extra care to prevent their being frozen or frosted.

When first up, before any leaves show, they can be easily protected by a few evergreen boughs. When once above ground they grow very rapidly, and it is very hard to protect them without breaking the tops. I have a skeleton frame made to fit the lily bed, and about three feet high. I place this around the bed, lay a few slats over the top, put on old covers and carpets, and tuck in tightly at the bottem. This frame is easily put on and off and can be placed out of sight when not in use. Longiflorum seems very tender at the start, and if not protected from frost, we see nothing of the chaste purity of the long trumpet flowers.

Kentucky. Laura Jones.

\section{DAHLIAS FROM SEED.}

I should advise all who have never tried raising dahlias from seed to try some this season. Last year I procured a packet of seed, paying fifteen cents, and received twenty-eight fine dahlias of almost every color. They are so hardy. I started my seed in March, the very last part, as they grow very fast. I found a box, put a good layer of charcoal in the bottom and mixed a little common garden soil, tolerably rich, and just enough sand to keep the soil moist and not hard or packed, making small rows with my finger. I dropped the seed about two inches apart, and then covered them. They came up quickly. When they were three or four inches high I prepared my bed, dug out the soil about fifteen inches and put in about six or eight inches of well-rotted manure, and then filled in the remaining space with good, rich soil and transplanted the seedlings.

Missouri.

$$
\text { Miss InZA GuTHRIE. }
$$

\section{CULTURE OF SWEET PEAS.}

Last summer I had a row of sweet peas that were the admiration of all who saw them. They grew six feet high, and every day I picked great bunches of lovely blossoms. I will give you my method of culture. As early in the spring as the ground can be worked, erect a neat wire trellis the length you wish your sweet pea row. Dig a trench eighteen inches deep and six inches wide both sides of the wire trellis. Carry the earth away. You will not need it to refill the trench. Cover the bottom of the trench about two inches deep with ashes (coal) to retain moisture, and cover with six inches of good fresh stable manure. Saturate all with several pails of water. Then cover with three or four inches of good rich soil, leaving the trench still six inches deep. Plant your peas as near the wire as possible. Plant thickly, but see that there is some space between the peas. Cover with one inch of soil and press firmly. Sprinkle the soil sufficiently to swell the peas, but be careful not to rot them with too much water, especially if the weather is still cold.

As the peas grow, keep filling in the trench until it is almost level; leaving a slight depression to retain water. Watch every day for green lice and use tobacco dust if you discover any. Never allow the vines to become dry after they begin to blossom. Use your soapy wash water, but not greasy dish water. Pick the blossoms every day, avoiding the buds that will furnish blossoms for the next day. Never allow a seed pod or a faded blossom to stay on the vines, as it will sap the vitality of the vines.

Conn. Mrs. W. A. Hinckley. 


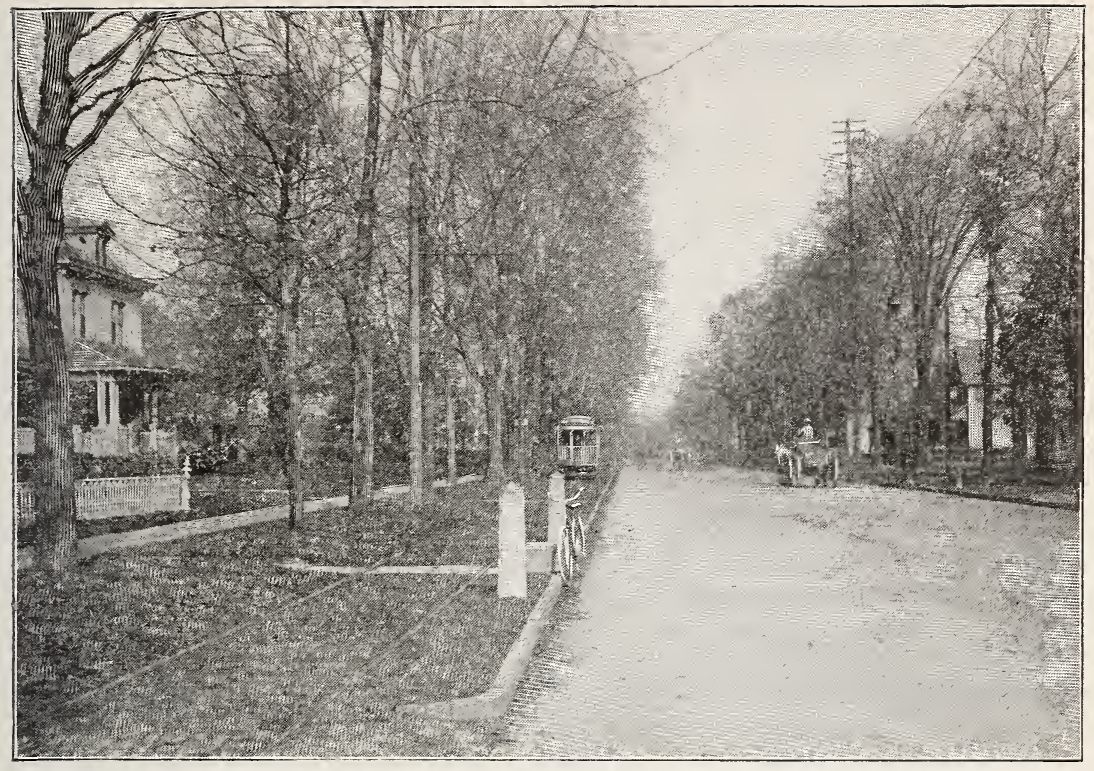

Lake Avenue, Rochester, New York.

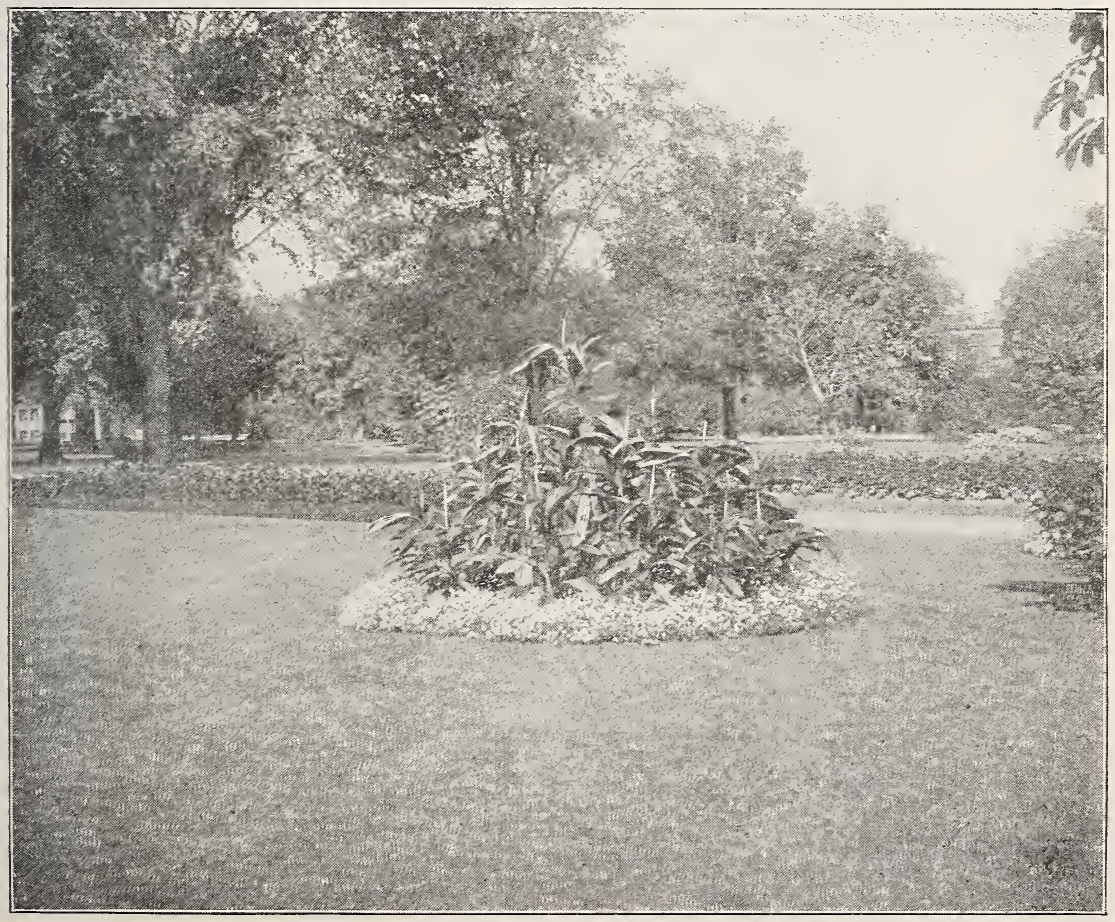




\section{SUGGESTIONS FOR ODD CORNERS:}

About our dwellings there are often sheltered nooks where it is difficult to grow even a good sod. These are ideal spots for ferneries or little wild woodsy nooks that are always surprises and delights to lovers of the beautiful. Perhaps my own experience may be suggestive along this line.

On the north side of the house, between two projecting portions of the building, there was a spot where grass did not thrive, and we had to sod it over every year. It occurred to me to try ferns and moss, and I sent to the woods for as picturesque and shapely hollow stump of a tree as could be found. Then I carpeted the space with moss and ferns, which we could find on the banks of a creek in a spot called the fernery, and where we could roll it up like matting. In the hollow of the stump I placed a silver fern, also a sword fern, and a mamanda vine. At the base of the stump, among the projecting roots, I put the wild fern in clumps, then spread the mossy carpet, and every morning gave it a light sprinkling. In a few days it looked as though it had always been there; indeed, a friend made the remark that "when we built our house we had built around that stump, and what a beautiful thing to do." This shows how well we had imitated nature in our arrangement. To my surprise, in taking up the moss carpet, we had taken seeds and roots of flowers as well, and during the season thirteen varieties blossomed. In all our grounds nothing was more admired than our bit of the wildwood.

\section{New York. Mrs. D. K. Town. \\ BEGONIAS FROM SEED.}

March is a good month to plant begonia seed for winter blooming. My Vernons were planted late in June, but if room had been given them, fifty would have bloomed before Christmas. I planted less than a packet of mixed seed in two little tins from the grocery. They were four inches in diameter and less than two in height. Holes were punctured in the bottom, and then covered with a piece of old cloth. The tins were then filled with rich, well-sifted garden soil. The seed, which is very fine, was placed in a teaspoon, which was gently rapped to scatter the seed as evenly as possible. The tins were placed in warm water until the soil was damp, then covered, and kept damp until the plants appeared, which was in about ten days. They were then set in an east window and covered with glass. They came up so thickly that they had to be transplanted when very small, some not having formed their third leaf. They were always watered from the bottom, always transplanted into sifted soil, have grown rapidly, and are beautiful. There were over two hundred of them and but few have died.

New York. Mrs. Helen T. JAYne.

\section{FLOWERS FOR THE FARMER'S WIFE.}

"Yes, I love flowers, but I can not spare the time to cultivate them." And then come thoughts of the housework, care of the children, the poultry, the dairy, and possibly the vegetable garden, too, and we realize that the statement is true. But let me offer a few suggestions.

Get some hardy bulbs and plants that will root themselves year after year with but little attention-for early spring such bulbs as snowdrops, hyacinths and narcissus. Later come the roses and the lily family. For fall blooming get the hardier varieties of chrysanthemum. Lift a few plants when the buds are beginning to burst, bring them into the house, and the blooms will last until Christmas.

One of the best all-summer bloom- 
ers I have found is the perennial sweet pea. It is perfectly hardy and gives an abundance of bloom all summer. The blossoms must be picked daily, or seeds will take the place of flowers.

Among the annuals the common petunia is certainly one of the best for the busy woman. Given a good soil, with the weeds kept down, they will seed themselves every year and keep the yard bright all summer.

But do not attempt too much at once. Get one or two varieties at a time, and succeed with them before trying others. Study the catalogues and select the hardy sorts and such as will give a succession of bloom.

Ohio. Mrs. Amy Garman.

\section{EXPERIENCES WITH PANSIES.}

Last summer I had pansies that were much larger than a silver dollar. About the middle of March I sowed seed of the mammoth varieties in well pulverized soil, taking equal parts of leaf mold and common garden soil that had been well baked to free it from insects. Then I moistened with water to the right consistency for seed sowing (not making it soggy). When the plants are large enough, transplant to make them stocky. As soon as the weather will permit, set the pansies where they are to remain, giving them a sunny location, and where not shaded. As soon as the first buds appear, and preferably after a hard rain, cover the bed to the depth of about four inches with well-rotted cow manure. Hold the plants straight with one hand while covering the bed. The manure will hold the moisture and they will seldom need spraying through a dry season. In a few weeks you will be surprised to see your bed covered with mammoth pansies.

New York. Mrs. G. E.PAssaGe.

If you want a good pansy bed, make your seed bed as early in
March as possible. Set the frame on the ground in a sunny, sheltered place. Fill with two parts loam and one part well rotted manure. Make rings an inch in diameter and two inches deep of cardboard or heavy paper, and place these in the frame, filling with soil. Plant your seed in these, one or two in a place. Sprinkle well and cover well. When plants are two inches high, make a bed on east side uf a wall, as pansies require a cool place with very little sun.

Fill the bed with soil like that used in the seed bed. Prepare quart tin cans by making holes in the bottom and sides and fill with droppings from your henhouse, and sink them in bed two feet apart. Cover slightly to hide cans. Now lift your miniature pots, setting your plants five inches apart. Sprinkle well and shade for a few days. When necessary to water, pour through the cans and that will be all the fertilizer you will need. The results will repay all your trouble.

Missouri. Mrs. Candace Powell.

A fine, sandy loam, or any good, rich garden soil will give good results in raising pansies. The place to be selected should, if possible, be one to the east, with plenty of shade from the afternoon sun. Start the seed in February, and, as soon as large enough, transplant about two inches apart. As soon as danger from frost is past, set out in the ground one foot apart both ways. To succeed with pansies, one must observe the following rules: Cultivate often, sprinkle liberally every evening, when the ground is dry; pick the withered flowers every day. Pick liberally of the fresh pansies for the house. I picked between four and five hundred off my bed one day. In two days' tims you would hardly know I had ever picked any off, and you should have seen my bed when it was in bloom:

New York. Mrs. W. F. GARLock. 
THE PANSY GERANIUM.

The pansy geranium is one of the most profuse blooming plants suitable for window culture. It is in many respects superior to the ordinary geranium, being of more compact growth, and is most beautiful.

I like to start my cuttings early. They will blossom sooner, and frequently, when the plants are through blooming, cuttings will fail to root. When the plants begin to blossom, a branch about three inches long is broken from the main stalk and placed in water in the window to root. When it is well rooted it is potted in one of the smallest-sized thumb pots. For a potting soil a mixture of two parts good garden earth, one part sand, and one part leaf mold, is used, and a layer of charcoal or bits of crockery put in the bottom of the pot for drainage. The little plant is set in the shade till growth begins, then brought to a sunny window, and its top pinched out unless it branches naturally. When the pot is filled with roots, the plant is transferred to the next sized pot. When the branches are about three inches long, they are pinched back. The plant is watered only when the soil becomes dry. The repotting and pinching back is kept up until November or December, or possibly even later. When the plant shows buds, a prepared fertilizer is given each fortnight.

Treated in this way, my plants blossom in February or March, and for nearly three months are almost covered with the beautiful pansy-like blossoms. If the old plants have no branches suitable for cuttings, they are cut back severely after flowering, repotted and treated the same as cuttings. Young plants are usually better shaped, however, and, I think, more desirable.

New York.

MARy E. SheldoN.
A SPRING SONG.

Sing, sing, sweet birds, oh, sing,

The springtime comes this way,

With lilies and roses and other sweet posies

That with soft zephyrs play.

Sing, sing, sweet birds, oh, sing,

Out in the warm spring rain,

That calls up mignonette, daisy and violet,

And lilacs in the lane.

Sing, sing, sweet birds, oh, sing,

Both are part of heaven's care-

The birds and flowers of summer bowers

That make the world so fair.

-Annice B. Calland.

\section{EASTER DECORATION.}

Let me tell you of an Easter decoration I shall use. You may like the idea. It is for a small church, and is to be placed behind the communion rail and in front of the pulpit. A few palms with several tall plants of Grevillea Robusta form a background, with several pots of Easter lilies at the ends. Between and in front of the tall plants will be ferns and any ornamental leaved plant that I have. In front of this I will put an easel five feet high, on which a picture generally stands, and on this a long, narrow box five inches deep. At each end Asparagus Plumosa grows thickly to the top of the easel; several plants of Asparagus Sprengeri fall over the front of the box, with Panicum Variegata in between. The box is filled with Pteris Arygea, justicias and pink and white zephranthus, two plants of Anthericum Variegatum, a plant of Lygodium Scandens which thrives among the plants. The plants will be in full bloom for Easter, and I know from experience how lovely the pink plumes of the justicia will look among the mass of feathery green.

Missouri.
Miss A. E. Craft. 


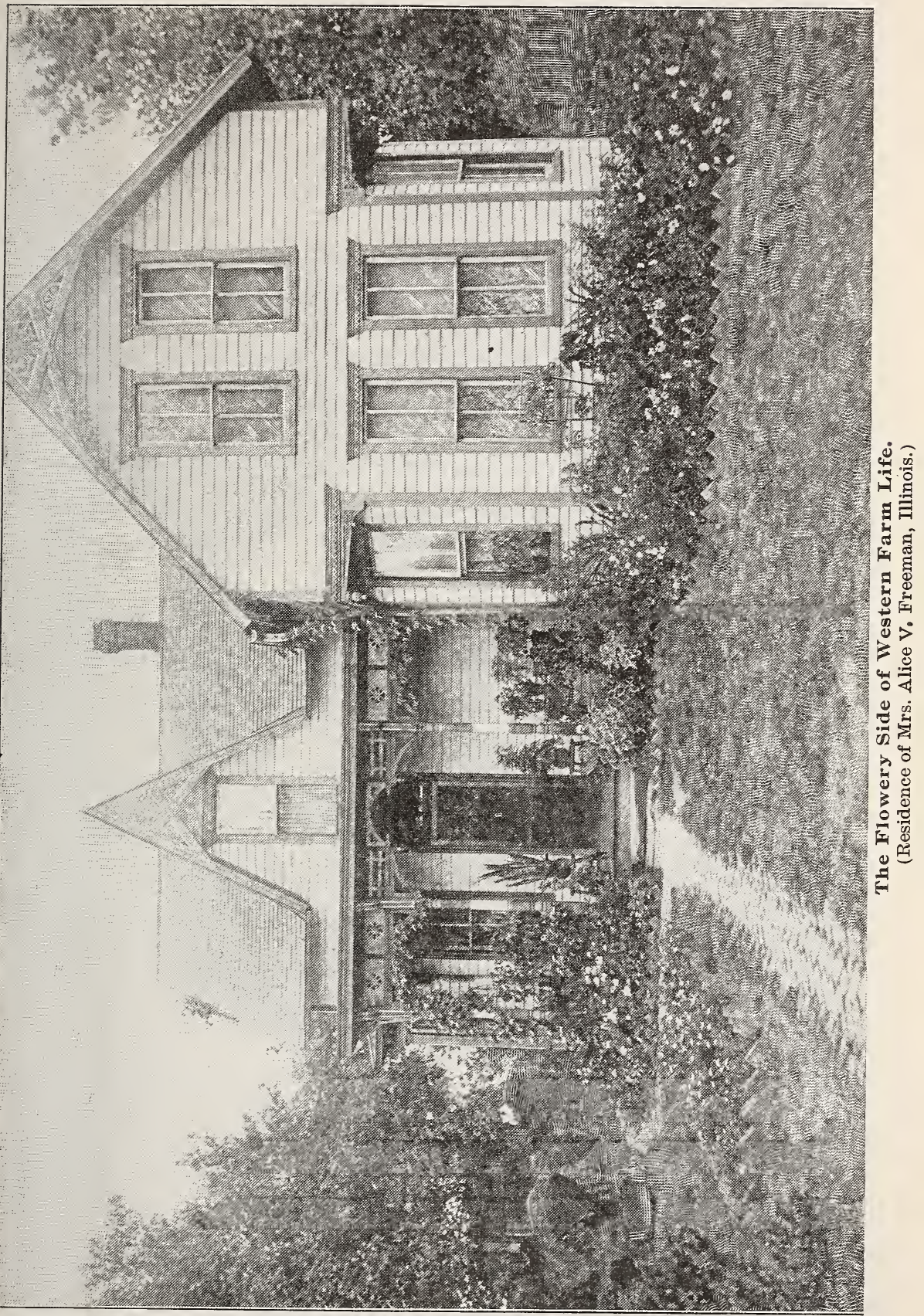




\section{The Floral World}

PUBLISHED MONTHLY BY THE

FLORAL WORLD COMPANY,

12 to 14 South Limestone Streèt, SPRINGFIELD, OHIO.

Subscription Price, 25 Cents a Year.

Correspondence invited from all persons interested in flowers. Write us your experience with plants.

We will give $\$ 26.00$ in prizes for the five best articles for publication in the May number of ThE Floral WORLD which may be submitted by subscribers.

The first prize will be $\$ 10.00$; the second, $\$ 7.50$; the third, $\$ 5.00$; the fourth, $\$ 2.50$; and the fifth, $\$ 1.00$. The awards will be announced in our July issue.

No article which contains more than two hundred words will be considered. All contributions entered in this prize contest must reach us not later than April 1.

The purpose of these prizes is to secure for publication in The Floral WORLD matter which gives the actual experiences in flower growing of those who have subscribed for the journal. Prizes offered for articles published in the February number have been awarded as follows:

Mrs. John P. Ernst, Misssouri, first prize.

Annie E. Croft, Missouri, second prize.

Miss Laura Jones, Kentucky, third prize.

A. Elizabeth Badger, Missouri, fourth prize.

Mrs. G. W. Bowman, Delaware, fifth prize.

\section{SOME SEASONABLE HINTS.}

Now is a good time, with the holidays and their pleasures in the past, to while away some of the long winter evenings by holding consultations with the floral catalogues. By selecting seeds and plants now, an early order can be sent in, you will get better plants by avoiding the later rush, and will not have a belated garden. You will also derive much pleasure from anticipating the flowers you expect to have during the coming summer.

It will not be very long before the seeds of cineraria and Chinese primrose can be sown in boxes in a sunny window. The last of February or first of March will insure good plants for the winter. Do not forget to order plenty of seed for the long rows of sweet peas. Without them no garden is complete. Plan for your geranium beds, order young plants as soon as danger from frost is over. They will have time to get gradually accustomed to the change from the greenhouse before planting out, and one can derive much pleasure from them in the meantime.

Watch the cannas and caladiums stored in the cellar to see that they are keeping well. They can be potted in March, and, when the time arrives for putting outdoors, fine, growing plants will be ready for you. Chrysanthemums may be brought up in February to make growth for cuttings in March. Hydrangeas may be brought to the upper regions in February, pruned, repotted, watered and placed in a shady warm corner until they show growth. Then place them in a sunny window. A little forethought now will bring a rich harvest later on.

\section{WORK FOR MARCH.}

March is the month in which to root your slips and plant your seeds, if you want a good start. I have two boxes, miniature hot beds, you would call them, three feet long, one and a half wide. I can not afford glass, so the top is covered with canvas. I put three inches of drainage in the bottom and use leaf mold for soil. I find this soil does not pack or dry out so quickly, and the seeds come up nicely and 
quickly. The slips of the different plants root nicely and do not damp off. I keep these boxes in a cellar bowwindow on the south, where they get plenty of sun.

If March is very cold or turns cold at times, I set the boxes over a little coal oil stove, having a pan of water between hot bed and stove. When rooted the slips are put in small pots or several of a kind in a large one. The seedliıgs are transplanted in other boxes and the hot beds filled again. When May comes, I have thrifty plants to fill my beds.

\section{Missouri. A. Elizabeth Badger.}

I prepare my earth in the fall, before the ground freezes, and then fill a large pail with the earth and set it where I can get it in the spring. When the ground is frozen I can bring this earth in and set it in the warm room, where the ice will thaw out. Then I prepare my pots for the seeds. I prefer small old tin cans. Those I can set among my other flowers or in front of them.

Mrs. B. A. Hineline.

\section{Indiana.}

March is often trying to plants. It is now time to turn on the searchlight and prune, snip, spray and cleanse, and give all the fertilizer they will stand.

It is a good idea to have a hot bed for flower seed and tubers. The frame should be at least four by ten feet. Here seed of annualsl that will bear transplanting can be started. Cosmos started here will bloom before frost. Dahlia seed sown here will bloom the first year. Cannas, dahlias, gladiolas and tuberous begonias started in it will bloom much earlier. Summer flowering bulbs that are kept in pots should be potted in March.

Ohio. Annice Bodey Calland.

Do not think that a few bright days mean springtime, and uncover your beds only to have them injured by heavy freezes later on. Remove the litter gradually from around your plants, a little at a time, and keep it piled in heaps near by, so that you can return it to the beds easily at the first approach of wintry weather. Sometimes, instead of the litter, especially if the plants are high and show bloom, we cover with large papers weighted down with bricks or pinned with stakes so that the wind can not blow them off. For indoor blooming plants and bulbs this is the most trying season, as they need careful attention to have the bloom last any length of time. They should be kept away from the direct rays of the sun and just as cool as possible without injury to the plant. Give them plenty of fresh air and keep them as moist as is possible in our dry, heated rooms. Under this treatment, callas, hyacinths, tulips, crocus, alliums, triteleras and nearly all early spring blooming plants, will thrive in our living rooms.

Ohio. LUCY JOHN.

\section{TUBEROUS BEGONIAS AND GLOXINIAS.}

I wonder why so few people cultivate the gloxinia and the tuberousrooted begonia. They require so little care, and are so free flowering, especially the begonia.

In the fall, after the foliage dies, we put several bulbs in a pot, cover them with dry earth, and keep them where they won't freeze. Then, early in the spring, we pot them in good soil and water them. We have found by experimenting that equal parts of sand, loam and good, rich garden soil make an excellent soil for begonias. After potting, they soon grow, and in early summer begin to blossom, continuing until cold weather. I have one begonia bulb which I have had several years, and every year it has produced an abundance of dark red flowers all summer. We also had light red, yellow, white, and white edged with 
pink; some of the blossoms measured more than four inches across.

The gloxinia, too, is a very desirable plant, with its large, velvety leaves, and beautiful, bell-shaped blossoms. It requires about the same treatment as the begonia, although I keep mine in the house and the begonias on the east porch.

Ohio.

M. C. Eyman.

March is none too soon to plant the bulbs of begonias and gloxinias for the best results. I have found the best soil to be leaf mold. If you can't get that, use light, rich, porous soil. Both these plants require plenty of water while growing and blooming, but resent stagnant soil. Use five-inch pots and press the bulb gently into the soil, leaving the crown of the gloxinia above the soil, while the begonia may have an inch on top of the bulb.

Water well and set in a sunny window. Sprouts will show in a week or ten days, if they are not already sprouted when you pot them. When danger of frost is over, you can set the begonias in the yard facing the morning sun and sheltered from the afternoon rays. Nip off the tops if inclined to grow tall and spindling.

Set the gloxinias on the north side, where they can be cool and moist. Mine bloom all summer in such a place. Do not delay in getting and starting these tubers. The sooner they are started in spring, the better will they succeed.

Missouri.

Mrs. J. P. ERnst.

The tuberous-rooted begonias are our most beautiful bedding plants for partially shaded situations. I have been growing them in pots and tubs under shade trees, but last year I planted them on the north side of the house, where they only received the very early morning and late evening sun. They were much taller than usual, with the brightest, prettiest foliage I have ever seen. The bright, wavy flowers were exceedingly large, some of the stems measuring over a foot in length, and borne in the greatest profusion. The beds had been spaded at least two feet deep, and made very rich, with leaf mold, sand and well rotted cow manure. I start the tubers early in March, pull off all the old, matted roots, plant in light. porous soil, and place in the sun until well started.

Kentucky. LAURA JONES.

\section{A NOVEL AND BEAUTIFUL WAY TO GROW VINES.}

Plant a pole rather deep in the ground, so the wind can not blow it over. Then spade a circle two or three feet from it, and of about the same width. Set the vine plants, about six or eight inches apart, on the inner margin of the circle. From a nail in top of the pole tie the end of heavy twine, or light wire (making the thing more taut), extending to the plant and fastening securely in the ground back of it, returning to nail and back to plant, until every vine has a support.

Morning glories make a fine vine to grow in this manner. Most lovely indeed are the bells of all colors, flung out so early each morning. Japan Hop (Humulus Japonicus) is another fine vine, making a very dense shade and a most rapid grower. The madeira. vine will make you a bower of exceeding loveliness.

Low-growing plants can be grown. on the outer margin. Giant pansies, forget-me-nots, sweet alyssum and dwarf poppies are all beautiful and desirable. They should be sown in the fall, or a better way is to raise in house in early spring and transplant, all except the poppies, which should be sown thinly in tne bed, as they are very difficult to transplant.

Pennsylvania. Mrs. S. R. Welsh. 


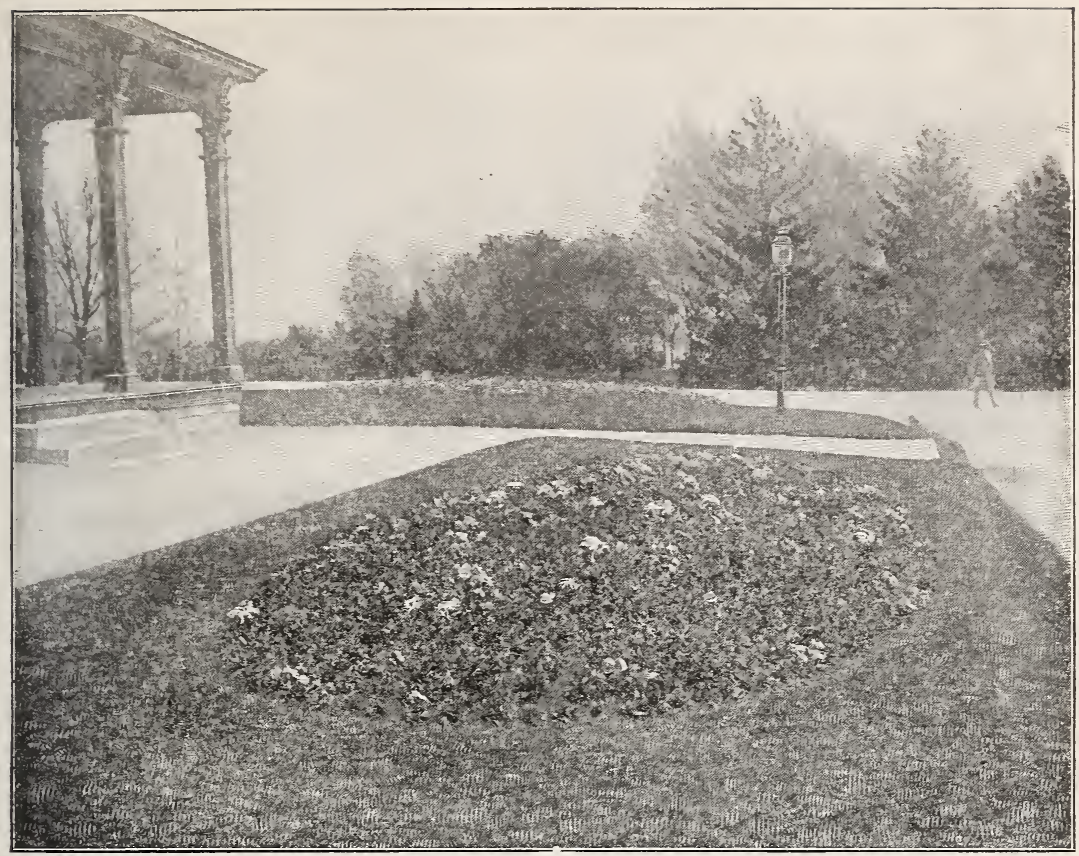

An Exhibition Bed of Pansies.

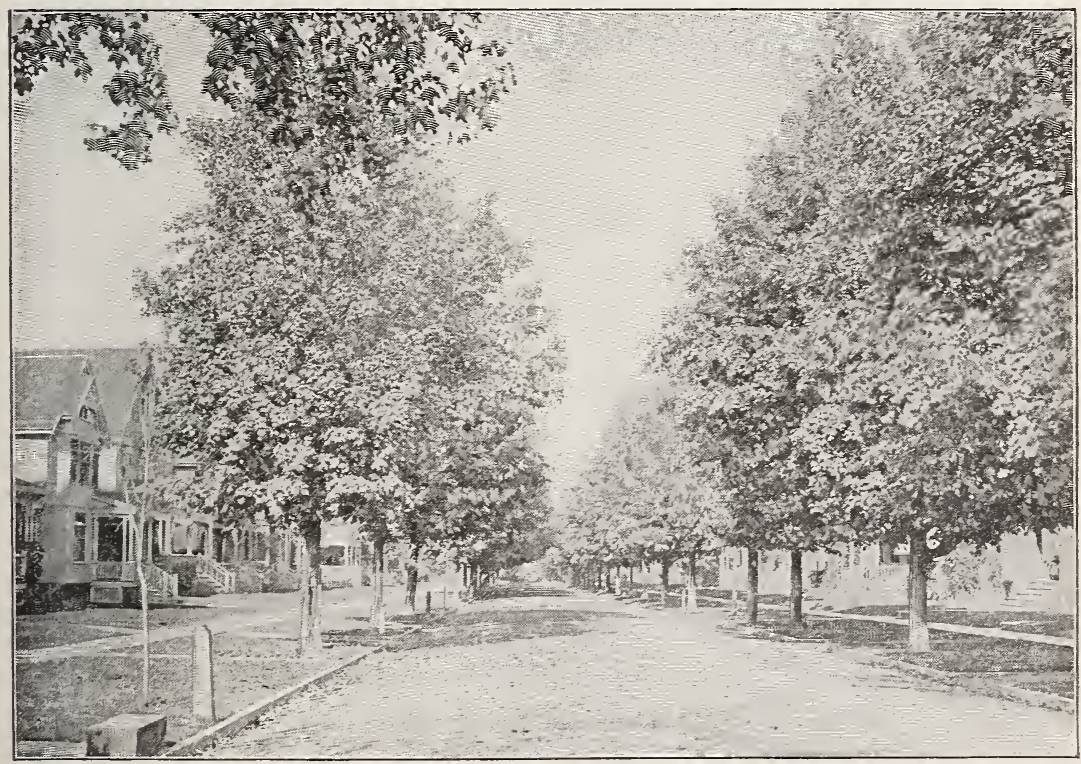

Avenue of White Birches, Rochester, New York. 


\section{HARDY PERENNIALS FROM SEED.}

Many of the finest perennials can be raised from seed. The seed should be sown in June or the early part of July. I make a frame of boards, eight or ten inches high and as large as I wish my bed. Have the soil soft and mellow and moderately rich. I plant in rows five or six inches apart, usually a row of each variety. Pack the soil well, then cover with boards to keep out sun and dashing rain. When the plants begin to appear, remove the boards and tack muslin on the frame, leaving it there till the plants are one or two inches high. Never let the plants suffer for want of water. When the cloth is taken off, tack slats or wire over the frame, to keep out chickens, cats, etc. Do not disturb the plants until spring. In December fill the frame loosely with evergreen boughs or witn leaves and brush. In the spring, as soon as the frost is all out of the ground, transplant to their permanent position. Most of them will bloom that season. New York. Mrs. J. PERKINs.

\section{WATERING FROM THE SAUCER.}

I am a crank on capillary attraction. Great success has attended my method of watering plants by setting the pots in pans of warm water, or of filling the saucers with water. My garden plants, watered by means of ditches, are vastly superior to those by which the water is applied to the top of the soil. So I carry the treatment to my window plants.

In this manner I have successfully treated all the plants I have-the geranium, cactus, heliotrope, cyclamen, hyacinth, narcissus, asparagus, petunia and oxalis. These are thoroughly soaked from the bottom whenever the soil seems to need water. Pots of calla, umbrella plant and amaryllis (when growing) are set in pans of hot water every morning. No plant has water applied to the top soil except some large bucket plants that I can not lift.

Water poured on top soil runs through to the saucer, carrying with it fine liquid manure. Many throw this away and then buy fertilizers to apply. By the absorption method more food is retained. With us soft water, so beneficial to flowers, is scarce. When I have any, I save it in old buckets and reheat it for several mornings for callas and the like. I add liquid manure to the water when a plant seems to require it.

\section{New Mexico.}

$$
\text { Mrs. LeON W. Martin. }
$$

\section{THAT BOX OF BEGONIAS.}

It was my first trial of such tiny seeds. I read they needed a temperature of 75 , so I sowed them in July. I took woods earth, sandy garden soil and sand, sifted through an old flour sieve, wet it till thoroughly moist and when I squeezed a handful and it fell apart on opening my hand, I knew the tiny roots could penetrate it. I made drainage holes in a four-inch deep box put a layer of small bits of charcoal for drainage, then the soil, pressed it slightly with a piece of glass, mixed a little of the moist soil with the seed and scattered it over the soil, after which I slightly pressed again with the glass to make the seeds adhere. Next I watered by taking a hair brush, dipping in warm water and holding it where by rubbing with a comb or my finger a fine mist would fall on the box, but not a drop, for that would bury the seed or break the seedling. I gave good light, but no sun. They came up-every one, I guess.

I had enough to pot fifteen, gave a lot away and have a box full, too. How they are growing! They have the green and bronze leaves-the flowers are to come later. Try some begonia seeds.

Maine.

ABoline. 


\section{ASTERS FOR CUT FLOWERS.}

Aster's which rival in beauty the best chrysanthemums may be raised on any good garden soil.

Send to the most reliable seedsman; don't select the cheaper packets, but the best. For some early asters, plant a few seeds in boxes in the house in April, or March. Transplant them into other boxes when two inches high, and into the garden in May. But for the main crop and best results, sow seed outdoors about June 15. When about four leaves have formed, transplant to another bed and a week later again transplant to a permanent bed, setting at least sixteen inches apart, and then the tops will be a tangle when in bloom. Keep well watered-about twice a week in time of drouth-and the ground well hoed between them as often.

'The best kind, I think, are the Sempels, the shell pink and the pure white. They have stems twelve to eighteen inches long on each flower, the blossoms three to five inches across and showing no yellow center. Last September I had forty-five fine flowers on one plant. Keep them cut as fast as well open. The main points are, good seed; transplant at least three times; plenty of water; cold, loamy soil; good cultivation.

Michigan. Mrs. Jennie LiPE.

\section{GREENERY FOR EASTER.}

Decorating churches with sprays of evergreen shrubs is carrying out God's injunction by Isaiah: "I will plant in the wilderness the cedar and the myrtle and the olive tree together," and in another place, "The glory of Lebanon shall come unto thee. The fir tree, the pine tree and the box tree together, to beautify the place of my sanctuary." We take small sprays of cedar and make a complete stand cover, and festoon the edges with daphne or myrtle. Use ropes of myrtle to hold festooning in place. Remove the leaves from one side of the myrtle, wind this around inch bunches of light green silk floss, for roses, and double the silk to represent the pistils and stamen. Fasten to the top of the other drapery with these roses. Use the cedar Mahonia between the windows. Place the Bermuda lily on this trimmed stand.

Early spring is the best time to plant Mahonia, daphne, rhododendrons. Strip off the leaves and trim back some. We think best to add leaf mold and some sand. This soil suits their fine roots. If a dry spring, keep a pail of water with a small leak near the shrub, and cover around the base with yard mowings.

Illinois. AnNie J. PADDOCK.

\section{WATERING HOUSE PLANTS.}

House plants need a great deal more water as the days grow longer and warmer than in midwinter. There is not much danger in overwatering if you have good loose soil and proper drainage and the plants are growing fast or blooming, but if the soil is hard and the plants are dormant or not in full growth, care should be taken not to apply too much water. Over-watering does untold harm. It causes sour soil and finally yellow and falling leaves. A safe rule for the amateur florist to follow is to water when the surface looks dry. Water about the temperature of the room should be used in winter and spring.

Umbrella plants, callas, oxalis, vinca. oleanders and others require plenty of water. The best way to water them is to set the pots in shallow pans of tepid water and let stand until the top of the soil looks quite moist. Cacti, begonias and ivy geraniums require but little water. If too much water is given the begonia it will wilt as though it needed water; when in this condition, if more water is applied, it is liable to kill the plant.

Iowa.
MARY B. KeECH. 


\section{LILIES IN POTS.}

The best are the Japan Lilies Auratum, and the pink and white Speciosums. The Auratum does really better when planted in the spring, either in the ground or in pots. Use eight-inch pots and see that the drainage is good, a fibrous loam and well-rotted manure. Set the bulbs near the center, so you can put at least three inches of soil on top to support the fibrous roots that grow on the stem above the bulbs. Do not let the soil dry out, nor keep it too wet. Lilies like a cool soil for their roots and a sunny place to bloom in, but when in full bloom do not expose them to the direct hot sun, as that will shorten their blooming period.

If they are in pots, you can set them in places to suit their needs. After blooming keep them growing well. With good care they will make fine, new bulbs and be ready for the next year. Do not disturb their roots-simply take away the top soil and replace with rich soil. Keep in the cellar through winter, dry. In March bring out and water and they will soon start.

Nebaska. Mrs. O. H. Hereford.

\section{THE PASSION VINE.}

Passiflora, or the passion vine, is one of our prettiest summer climbers. I remove mine to the cellar for winter, planting out in the spring, cutting back to the ground. Decasine, alata, arcenciel, are fine varieties. The flower is beautiful and curiously constructed.

The name was given by the Jesuits of South America, who saw in it an emblem of Christ's crucifixion-the column representing the pillar to which he was bound, fringes of the flower the crown of thorns; the tendrils, the cord with which $\mathrm{He}$ was bound; the styles, with their capitate stigmas, the nails which held Him to the cross, and the stamens the hammers to drive them.
The legend says that the flower grew among thorns a thousand years, then its significance unfolded. Early one morning, soldiers came and plucked the thorns, and with them, unwittingly, the flower, wove them together into a crown, placing it upon the head of our Lord. The sharp thorns pierced his temple, and the flower was bathed in purple which flowed from His wounds. All through the darkness of that day this fragrant flower bloomed in the bloody garland.

Nebraska.

\section{Miss HARRIET LeIGHTON.}

\section{CAN SOME READER HELP?}

I have a monthly rose which blooms regularly, bearing a sweet, double, pink flower nearly the size of a silver dollar. I never found it advertised in any catalogue, nor ever mentioned in any floral magazine. Has any one of the readers anything like it? I have seen many pretty cyclamen in bloom, but only once a sweet-scented one. Now I should like to know if any of the flower lovers have ever come across anything like it.

Michigan.

F. P. Franke.

R. J. Bradley speaks of the Oxalis Ortgiesti. Where can I get the bulbs or slips? In regard to the Ageratum as a house plant for winter bloooming, I would like to ask him if he saves his foliage. When I cut mine back, I put the clippings in a thin sack and hang it in my clothes closet. It has a very delicate, sweet perfume and lasts for years.

Michigan.

Mrs. A. Z. HoYT.

I have a large Cameal, or Patient plant, which measured nearly two feet six inches across this last fall, but all at once I discovered it was completely covered with tiny black lice. Can any one tell me the cause or the cure?

Michigan. 


\section{A STATIONARY BASKET OF FLOWERS.}

The bulb bed being nicely rounded in the center is just the thing to convert into a perennial basket of flowers. If it is of large proportion, use two gas pipes for the handle. Thrust them down firmly eight inches apart on opposite sides of the bed, wiring together in the center to add firmness, and suspend a pretty hanging basket from this point. Train tall-growing nasturtiums to cover and gracefully festoon this handle, and plant dwarf mixed kinds between the bulbs, bordering with sweet alyssum. Mixed petunias or other annuals may be substituted, using whatever vine is preferred over the handle, Convolvulus, Maurandies, Maderia or some neat growing perennial kind, as Akebia Quinati or Ampelopsis Veitchii and English ivy where these are hardy, but perennials must not be planted among the bulbs, nor plants requiring to be lifted in the fall. We like to vary the planting each year, but the alyssum seems always our prettiest border.

Indiana. Mrs. SARAH A. Pleas.

PREPARE FOR DROUTH.

Did your canned fruit freeze during that cold weather? Let me tell you how serviceable those bottomless glass jars can be made among your flowers. I have a number that I have been using for years.

When I set any choice plant in the open ground, I fit one of these broken jars into the hole on the upper side. When the earth is filled in around the plant, only the top of the jar shows above ground. I never remove the top of the jar except when the plant needs water. Then I fill the jar and carefully replace the top. This is the best plan I have ever tried for watering roses planted in the spring. In the autumn, when they have become established, the jars may be pulled up after a rain, and the holes filled with earth.

Tennessee. Lizzie D. ABERNathy.

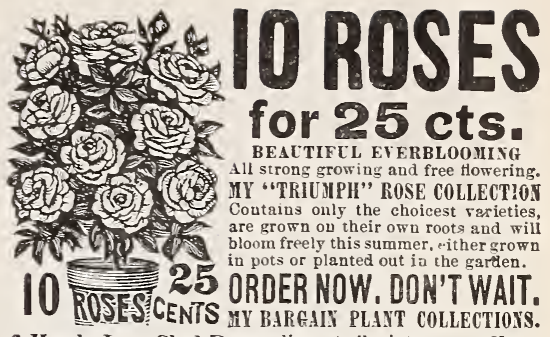

6 Hardy Iron Clad Roses, live out all winter, - 25 cts. 8 Splendid Flowerinu Geraniums. double $\&$ single 25 " 8 Carnation Pinks. the Diviue Flower, assorted - 25 10 Chrssanthemums, Prize-winuing varieties,

8 Assorted Planta, for garden or pot culture,

8 Gorceous Coleus, charming bedders.

6 Gorceous Coleus, charmine bedders,

4 Grand Urehid Flowering tiannas.

4 Grand Orehid Flowerine Ciannas.

8 sweet-scented Dwarf Peari Tuberose

10 Giadiolus, the loveliest and prettiest of all,
12 Kainbow Pansies, giant flowered kinds,

3 Magniticent Palms, worth Sl each next year

8 Beautiful Flowering Fuchsias, Ear Drops,

6 Splendid Flowering Beronias, assorted,

10 Mammoth Flowering Verbenas, all colors, - 25 “

CDFCIAL OFECR Any 6 Sets for $\$ 1.25$ or the eistire SPECIAL OFFER 16 sets for $\$ 8.00$ postpaid. The

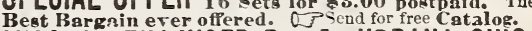
MISS MARTHA HISER, BOX A, URBANA, OHIOO.
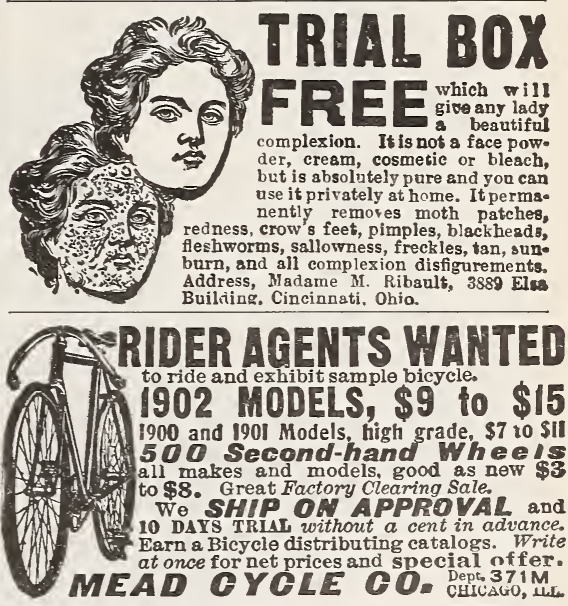

UAT PIIITIREN 3 C 6 beautiful

size $6 \times 8$ for

framing, sent by mail 50c. The Cat Journa1, very fine, devoted entirely to CATS, $\$ 1$ per year; sample 10c., free with picture orders. Address Cat Journal, No. 5 Avenue A, Palmyra, N. Y.

\section{Magic Age Thermometer.}

You can tell the age of any person, number of dollars in their pocket and the number of lovers they have; barrels of fun for young or old. Sample and catalogue of useful novelties 10 cents. Agents Supply House, 639 Elm street, Dept. E, New Haven, Ct.

WHITE SILK FRENCH POODLES. Woodlawn Pet Stock Kennels, Louisville, Ky. 


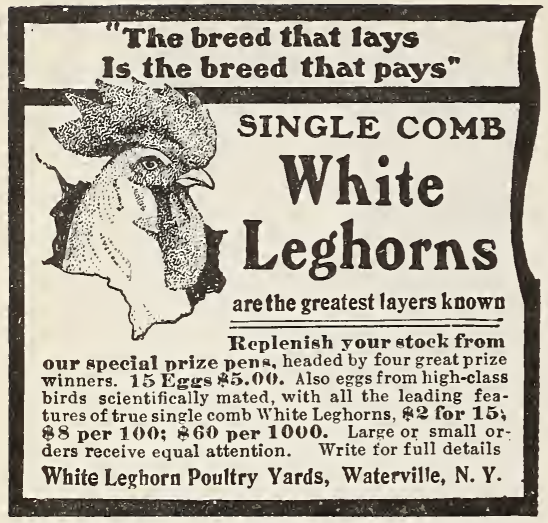

FOX TERRIER PUPS, nicely marked and FOX TERRIER with best of pedigrees XXF OXFORD KENNELs, 1218 North 9th Street, East st. Louls, Illinols.
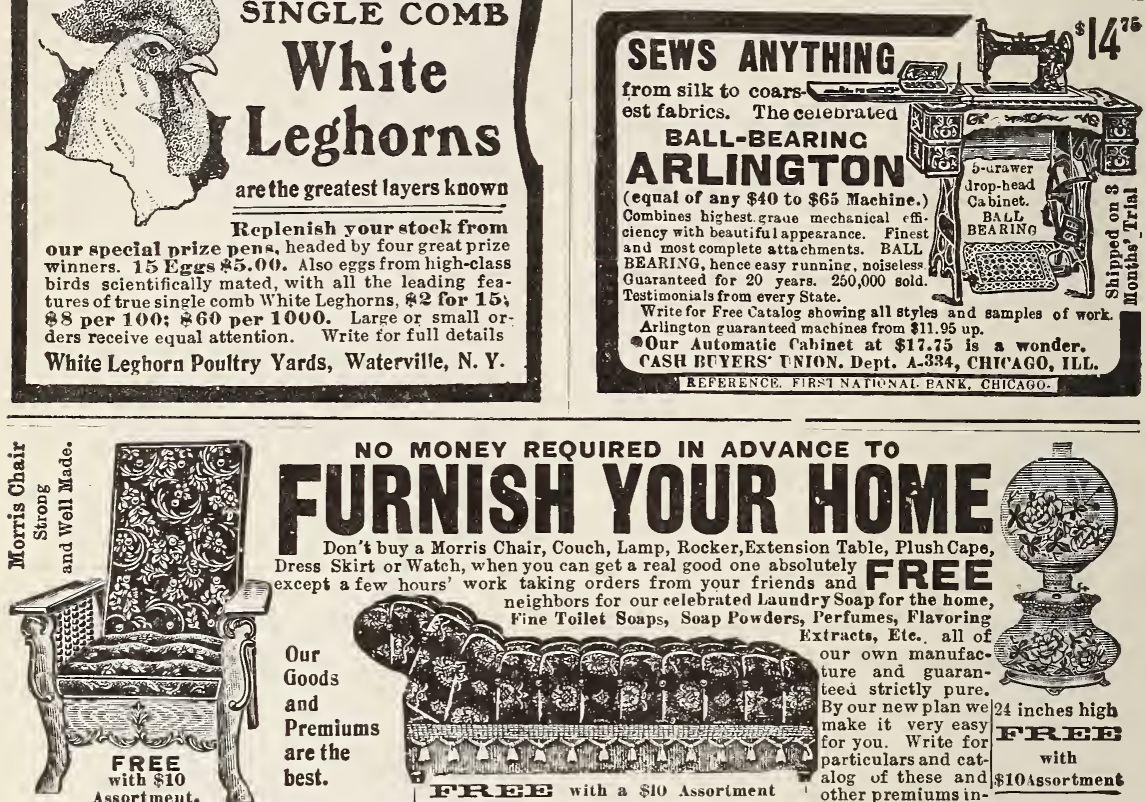

Dress Skirt except a few hours' work taking orders from your friends and 1
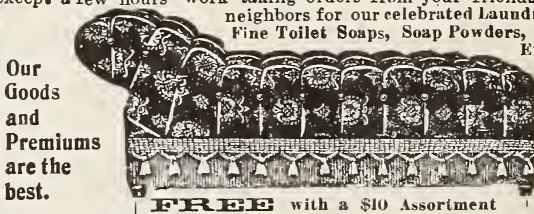

Perfumes, Flavoring

our own manufac.

teed strictly pure.

By our new plan we 24 inches high make it very easy for you. Write for

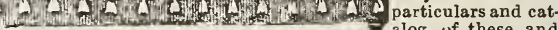
with eluding Ladies Desk, Clock, Sideboard, Dinner Set, Camera, Mackintosh, Go-Cart, Washing Machine, Iron Bed, Rug, Mandolin, Guitar,Bicycle, Etc. Premium and goods shipped on 30 DAYS' FREE TRIAL in your own home. If desired we will send a

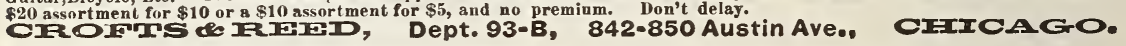
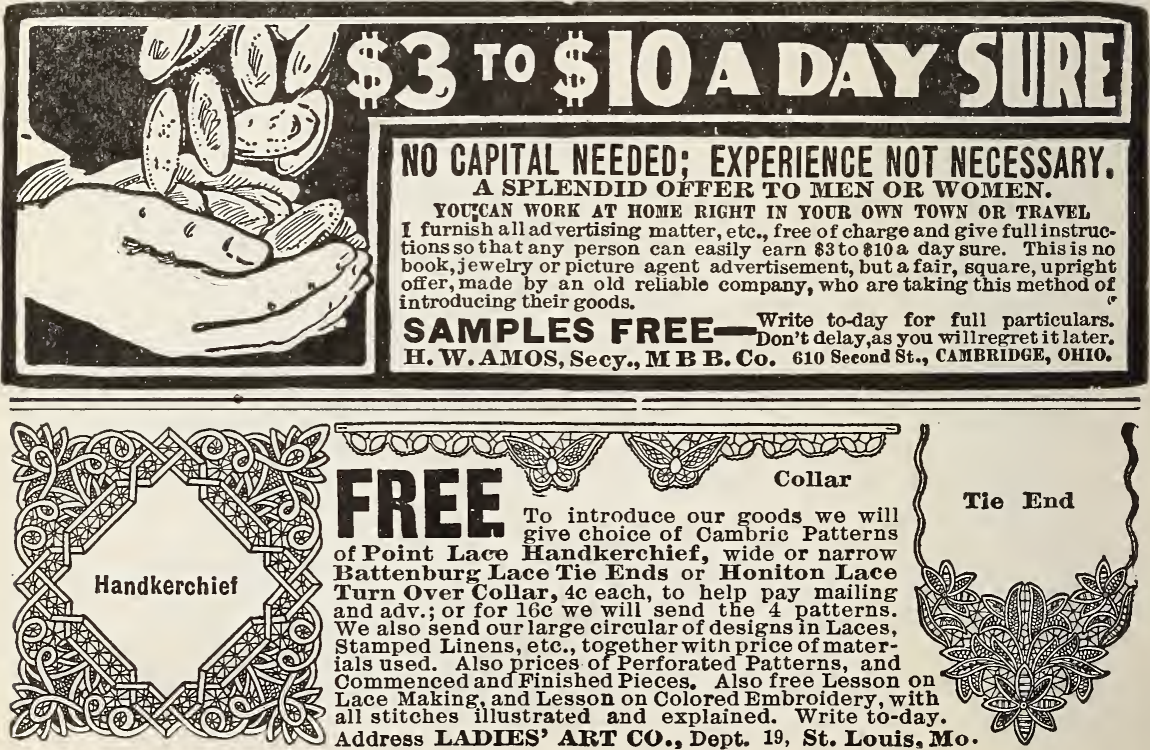

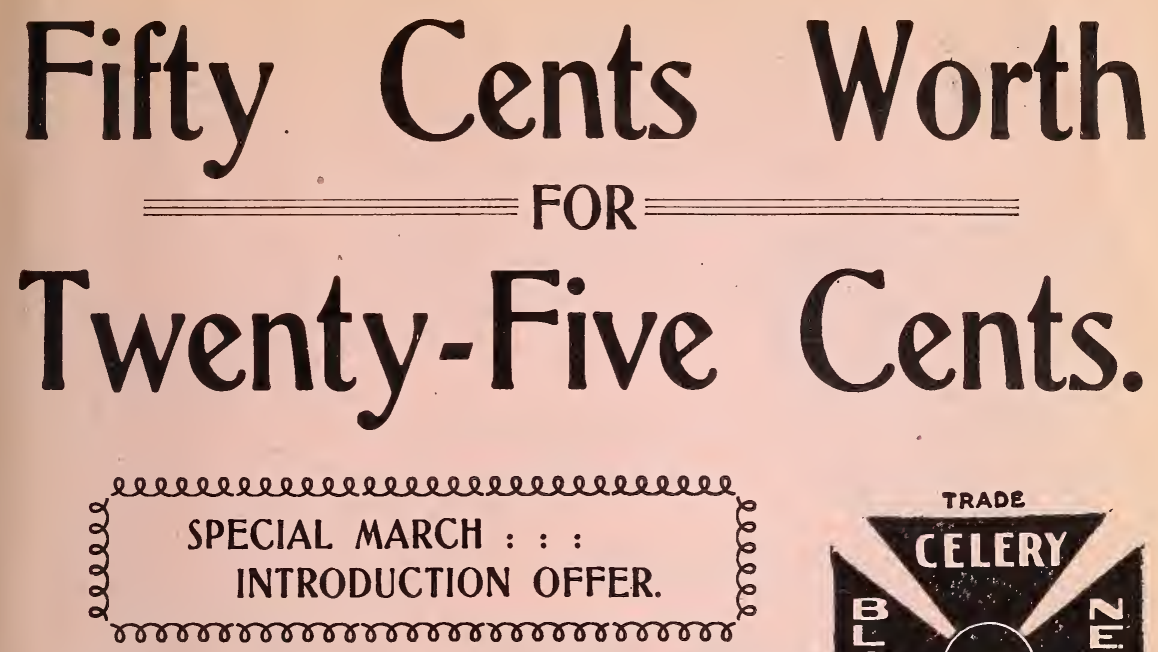

As this is our first appearance in the Floral World, during March we will send a full package of Celery Blood and Nerve Tablets, regular price fifty cents, on receipt of only twenty-five cents to pay postage and packing. We make this special offer one month in order to more thoroughly introduce our wonderful remedy. This splendid proposition will be open until April 1st. Remember, only twentyfive cents for a full sized fifty-cent package of Celery Blood and Nerve Tablets, an unfailing blood purifier and nerve tonic for men, women and children.

\section{MAKES SOLID MUSCLE \\ AND GIVES STRENGTH}

In Celery Nerve and Blood Tablets are contained the highly concentrated extracts of some most wonderful curative Herbs and Vegetables, and in such a form as to give all the strength of large doses in a small tablet.

Celery Blood and Nerve Tablets are guaranteed to purify the blood and CURE all forms of diseases arising from a poor and unhealthy condition of the blood, such as Pale and Sallow Complexion, Loss of Appetite, Lack of Ambition, Depression of Spirits, Anæmia, Shortness of Breath on slight exertion, Palpitation of the Heart, Green Sickness, Dark Rings under the Eyes, Muscular Weakness, Coldness of Feet or Hands, Swelling of the Limbs, Rheumatism, Neuralgia, Partial Paralysis, Locomotor Ataxia and Nervous affections of every description.

Celery Blood and Nerve Tablets also invigorate the Blood and System when broken down by over work, worry, disease, excesses and indiscretions of living. These Tablets are not a purgative medicine. They are not a cure-a11. They effect their wonderful cures by acting through the blood.

By their cleansing action on the blood they help the Liver, Kidneys and Stomach to regain their even balance and to accomplish the work required by nature to keep that wonderful piece of mechanism, the human system, in perfect health and condition.

Sleeplessness, we all know, puts a most terrible strain upon our constitution, and allows us no time for rest and recuperation. The cause is a diseased nervous system and a quiet and refreshing sleep can be had by a treatment of Celery Blood and Nerve Tablets.

\section{DurIng March On/y,}

\section{A Fifty Gent Box for Twenty.Five Gents,}

Postage Prepaid.

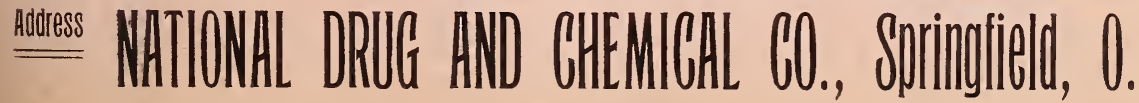




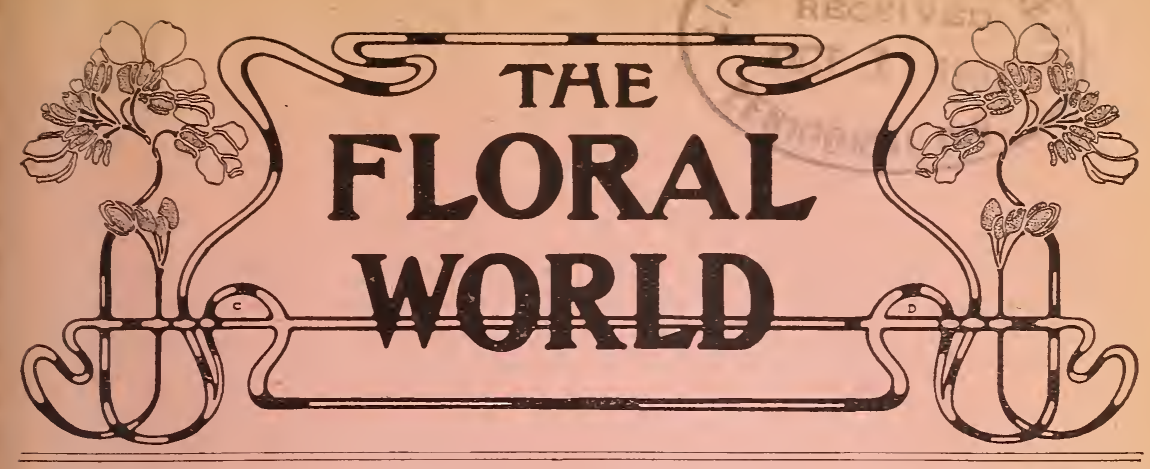

Vol. I, No. 7

Springfield, Ohio, April, 1902

25 Cents a Year
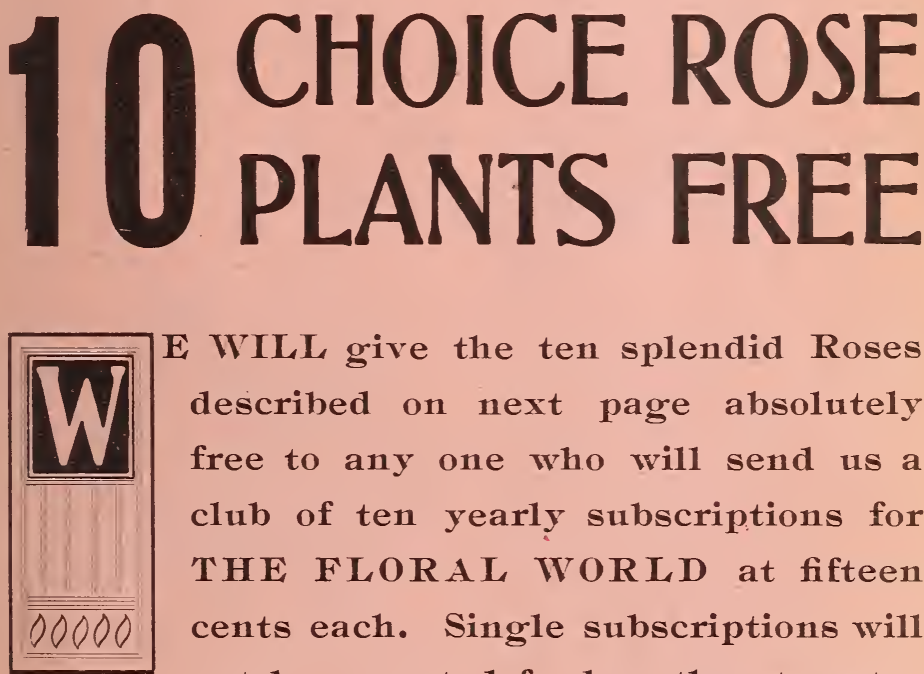

E WILL give the ten splendid Roses described on next page absolutely free to any one who will send us a club of ten yearly subscriptions for THE FLORAL WORLD at fifteen cents each. Single subscriptions will not be accepted for less than twentyfive cents, but in clubs of ten or more a special price of fifteen cents a year will be made for

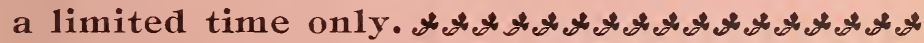

Ten Roses, fully described on following page, will be given for every club of ten, which is accompanied by a remittance of $\$ 1.50$. We make these liberal offers in order to quickly secure a circulation of one hundred thousand for The Floral World. The journal deserves your good will, we think, and the Rose plants will amply reward you for the little trouble required to raise a club of ten at fifteen cents each. 


\section{TEN BEST ROSES GIVEN AWAY!}

\section{THESE ROSES FREE FOR A CLUB OF TEN YEARLY SUB. SCRIPTIONS FOR, THE FLORAL WORLD AT 15 CENTS EACH}

Psyche, the New Pink Rambler Rose.

A cross between Crimson Rambler and the Polyantha Rose, Golden Fairy. The flowers are produced in clusters of eight to thirty-five and are two to two and a half inches across when fully expanded. Color, white, suffused with salmon-rose and pink, with yellow base.

\section{Mrs. Mawley.}

This grand variety embodies so many good qualities that it is difficult to describe it. ${ }^{\circ e}$ could say no more in its praise than to say it is like Maman Cochet, only several shades lighter in color.

New Rose, Gold Nugget.

This magnificent Tea Rose is a rich, goldenyellow, a strong, healthy and vig: orous g row e r, immense bloomer, bearing flowers a n d buds early and late. The flowers are very deep, rich and full, excellent substance, very sweet. Remarkably hardy both as to heat and cold, frequently stand. ing the Winters here uninjured in open ground

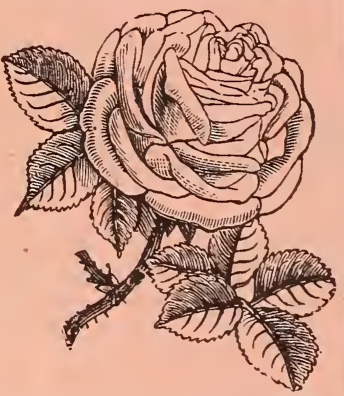
without protection, and blooming nicely all through the hottest part of the Summer.

Mrs. Robt. Peary, or Climbing Kaiserin.

The flowers are extra large, full, deep and double. They are of excellent substance, and produced on long, stiff stems, like a forcing Rose. The buds are long and pointed, a remarkable feature not found in any other climbing Rose. The color and shape of the bud and flowers identical with Kaiserin Augusta Victoria. Pure ivory white. The fragrance is delicious. The most remarkable feature of this variety. however, is that it blooms contin. uously the first year. It grows to perfection outdoors, throwing up numerous shoots, ten to fifteen feet high in a single season.

\section{Bridesmaid, Deep Pink Mermet.}

Here we have a new Rose, a sport from that old standby, Catherine Mermet. This new variety retains all the good qualities of the parent, besides adding charms not possessed by the sweet Catherine. It is about two shades deeper in color-just enough to make it bright, and it is the same color all the time under every condition of weather and surroundings.
Rheingold, a Wonderful Color.

The flowers last well, and the name, Rhein. gold, convers but little of the true worth and beauty of this flower. The buds are long and oval, and the color is a Naples-yellow, shaded with orange. The petals pass in the center to a deep citron.

F Gruss an Teplitz. (Greeting of Teplitz.)

As a bedding Rose this is one of the finest and most useful varieties ever sent out. The color is brightest scarlet, shading to deep, rich, velvety crimson. It is very fragrant. The freest grower and most profuse bloomer of any ever. bloomer. The mass of color produced is wonderful, and the foliage is extremely beautiful, all the younger growth being a bronzy. plum color. A queen among scarlet bedders.

Priscilla, or White Maman Cochet.

The flowers are of enormous size, remarkably round and full, pure clear snowy-white throughout, and are delightfully Tea scented. It is by far the finest and most reliable white bedding Rose yet produced, and should be planted by everybody. By planting a few plants of it any one can have the very finest Roses for cutting and for use in vases, upon altar, dining table, parlor, etc., all Summer and Autumn.

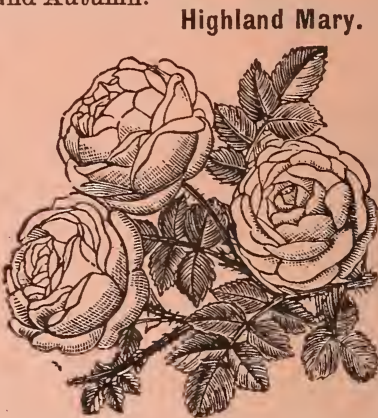

This lovely Rose originated in Cana d a, a n d claimsAgrip. pina for its parent. It is a persistent bloomer both Summer and Winter.

Flowers large and sweet; blos. soms beautifully cupped. each petal being white, with a delicate lemon tint, and broadly bordered with a delicate band of pink.

\section{New Pure White Royal Tea Rose,} Kaiserin Augusta Victoria.

This beautiful Rose has not only a royal name, but is a royal Kose as well. It is a continuous bloomer, producing successive crops of buds and flowers in the greatest profusion. Buds are very beautifully formed, with large petals of best substance. It shows no center when fully open; color pure, snowy-white.

\section{ALL THE ABOVE FOR CLUB OF TEN}

yearly subscriptions for THE FLORAL WORLD at the special clubbing price of fifteen cents a year. No single subscription accepted for less than twenty-five cents, and no premiums given for less than ten. The above collection of the latest and best Roses absolutely free to any one who sends us a club of ten at fifteen cents each $-\$ 1.50$ in a11. Use blank enclosed, and address, 


\section{The Floral World}

\section{A Fournal of Home Floriculture}

Vol. I, No. 7

Springfield, Ohio, April, 1902

25 Cents a Year

\section{THEY ARE PLEASED WITH "THE FLORAL WORLD."}

Long live The Floral World. Kentucky.

LAURA JoNes.

I find The Floral World a pure gem.

Oklahoma. Mrs. C. A. Garrett.

I am very much pleased with The Floral World.

\section{Indiana. Mrs. B. A. Hineline.}

I am interested in the magazine and wish it success.

Illinois.

Mrs. S. E. BRowne.

I like your magazine and will do what I can to gain subscribers for it.

Delaware. Mrs. G. W. Bowman.

I enjoy your little magazine very much. I find it bright, interesting and helpful.

La. Mrs. Florence M. Walker.

I think The Floral World is a very nice little magazine. It is just the thing for flower lovers.

Illinois. MRs. MARIAH Jenkins.

I have been a reader of every number of The Floral World, and it is growing more interesting all the time.

Indiana.

Mrs. R. A. Houk.

I look forward every month for the coming of The Floral World, and I think it a great help to amateurs.

Ohio. Mrs. Clark SMith.

To me your readable little magazine will supply a long-felt want, and I re- gret that a copy has not reached me before.

New York. Mrs. E. M. KeAN.

I think The Floral World a very interesting little paper. As I am interested in flowers, it is a great benefit to me, and I wish you every success.

Canada.

Mrs. C. Hodgens.

My flowers are doing finely this winter with the aid of the little Floral World. I hope you will continue to publish it, as I could not do without it.

Pennsylvania. Edna Janet Gray.

The little magazine is improving each month. It has a "homey," friendly air that I like to see, and you have my best wishes for its greater success.

Ohio.

Annice B. Calland.

To give pleasure to others is among the highest of human virtues. This is what The Floral World is doing. My pleasure is only equaled by my surprise that you are able to give so charming a magazine at so reasonable a price. I wish you abundant success.

Ohio.

Mrs. L. D. Bowers.

\section{AS TO CALLAS AND CHINESE LILIES.}

If no one has made suggestions to Rev. F. A. Franke, tell him to put his calla in the garden this summer, and if that does not bring out the bloom, to throw it away. And the same will answer for F. M. Conger. Chinese lilies bloom only once, or, if they do happen to bloom a second time, the blossoms are not worth their trouble.

New Jersey. Mrs. G. M. Stacy. 


\section{CANNAS FROM SEED.}

Procure a packet of good French canna seed, chip a tiny bit off the germ end of each one and soak for about three days in warm water. Then stick each seed down in the soil in a box and place in a sunny window. When the plants are three inches high, pinc's out with a good ball of earth at the root and set out if the weather is warm and settled. Set them in clumps where they can be kept moist, and you will be well repaid for your trouble.

How wonderfully the canna has been improved! It is no longer raised for the tropical appearance of its foliage alone, but for the great, gorgeous, lilylike blossoms. It is as easily raised, when once set out, as the zinnia or balsam. The great yellow, or vivid scarlet, or the blotched yellow and red, make a grand bed of color. In the fall the roots can be taken up and stored in the cellar.

Nebraska.

G A. Flory.

\section{PRACTICAL EXPERIENCE IN GROWING FERNS.}

I read quite a good bit about growing ferns, most writers claiming they must be grown in the shade, if grown successfully. I must differ with them. Two years ago I received from a florist two small Boston ferns. I planted them in a shallow fern pan, set it in a shady place, and gave it water as needed, but they did not grow, and I was disappointed. Lasi spring I took a cracked jardiniere, seven inches across, and ten inches deep. In this I put good garden soil mixed with sand and then planted my poor, sick-looking ferns. After watering them well, I put them in the sitting room until June, when I moved them to the front porch, where they were put partially shaded from the sun the entire day. Every night and morning we gave them a good shower bath and they awakened and began growing. In the fall I put them in the sitting-room window, where they have the full. benefit of the afternoon sun. My pot of ferns is now a thing of beauty, some fronds measuring twenty-seven inches, drooping gracefully over the sides of the table. They alone occupy one window and are admired by all who see them. I give them a shower bath in tepid water twice a week. I have some runners turned down and will be able to start other plants from them in a few months.

Delaware. Mrs. G. W. Bowman.

\section{SOME GOOD COMBINATIONS IN BEDDING.}

On each side of the row of tall-growing sweet peas plant bush sweet peas and border with Cupid sweet peas. Around a cone of moon flowers try planting daturas, sweet nightingale, and encircle these with nicotiana affinis and border with miothola bicornis or with evening primroses.

A gladiolus bed is nice carpeted with myosutis or mignonette and bordered with sweet alyssum. Phrynium variegatum is fine to border the canna beds.

For a moist, shady corner nothing equals wild ferns transplanted from the woods when new growth first. starts in April. Use soil from where they grow wild, and border the bed with wild violets. This bed will improve year after year.

To cover a blank wall on the south nothing equals cyclanthera explodens, a very desirable annual climber, which, when planted in very rich soil, will grow twenty-five feet in one season. Dwarf nasturtiums planted at the foot of these vines will prove a lovely combination. A clump of purple heliotrope bordered with a dense row of sweet alyssum is fine. For tropic effect try a clump of richinus zanzibarensis surrounded with tall-growing cannas; encircle these with dwarf cannas and border the whole with phrynium variegatum.

Ohio.

Annice B. Calland. 


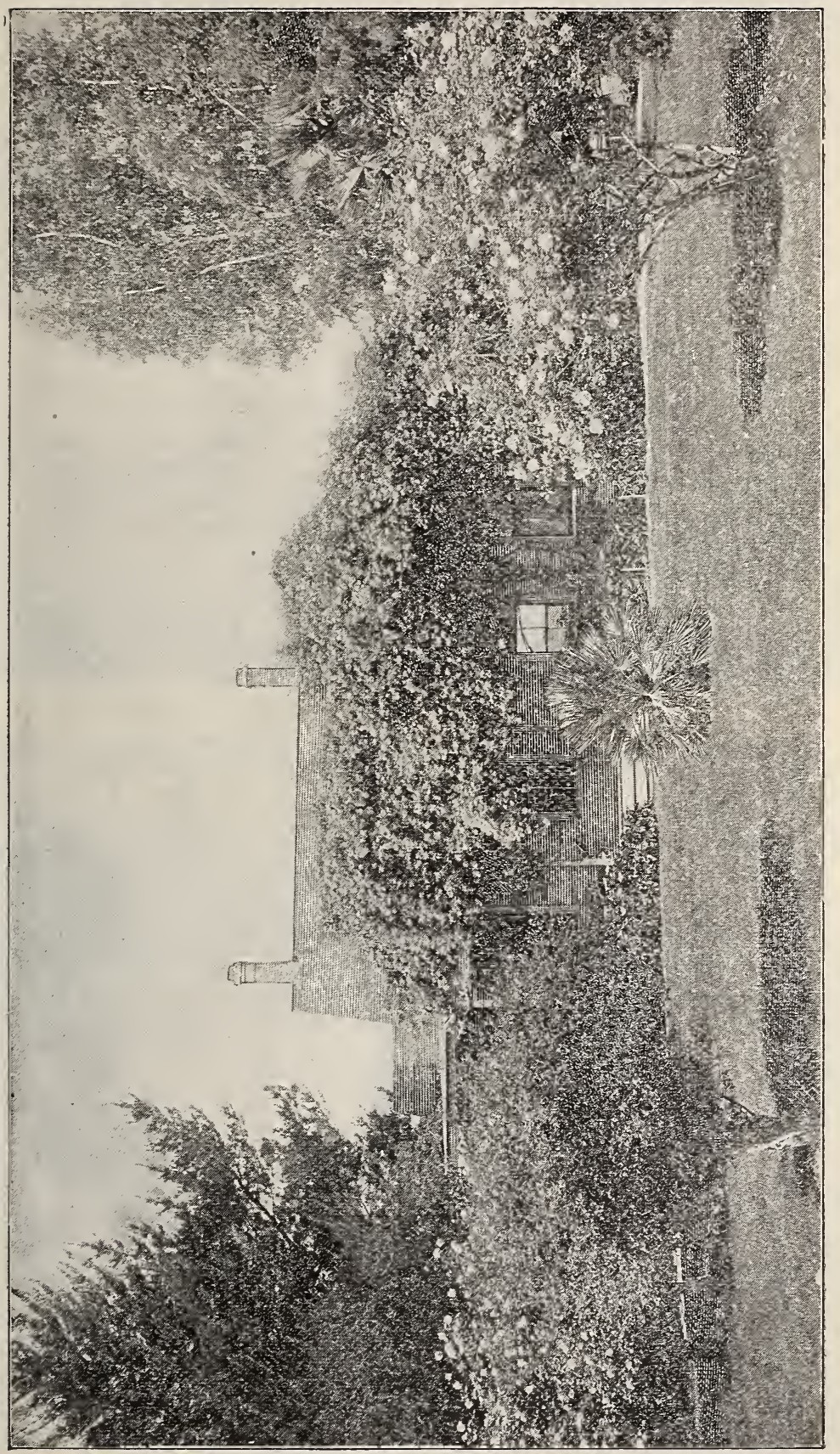




\section{HOW TO BUILD AND CARE FOR A ROCKERY.}

In the February number of The Floral World Mrs. M. F. Powell asked for some ideas on building a rockery. Let me give some of $\mathrm{my}$ experience. I drew a circle three feet across, put a layer of rocks, each about the size of a brick, all around, filling the center with good garden soil, covered the rock well with earth from the woods and planted a row of ferns with the roots well in earth and tops hanging off. Then put another layer of rock and earth and ferns, drawing each layer in just enough to give a pretty shape, until about six inches across at the top, always filling the center with rich earth. I then planted ferns in the top. The center, being well filled with good earth, carries the water from the top through the whole rockery.

Mississippi.

Mrs. N. L. LoRd.

I will answer Mrs. Powell's question with regard to rockeries. I had several in my yard when I lived in Kansas. First have good rich soil ready to use. Build the rocks around as large as desired, at least three feet across, and fill inside with this good soil. Place nice rocks around, leaving places to plant ferns or ivy, moss or any little flower desired, with an everblooming rose on top. Build the rockery with the prettiest, most attractive looking rocks you have, closing in gradually to the top about three feet high. This will charm all who see it. But it will need care. Every evening it should be sprinkled with water. Ivy moss, myrtle and little vines are very pretty creeping over the rocks.

The Floral World has been a great benefit to me, as well as much company.

Arizona.

M. J. HopPs.

Given a favorable location, and half the battle is won. When grounds and material are unsuitable, more skill is required. It amounts to creating a picture. Having no shady ravine or declivity on the grounds, select a lowbranching shade tree. Place at its roots several large, thin slabs of rock, planted on edge to show well without occupying much ground space. These will do much to protect the plants from wind and sun. Fill in with rich soil, placing the smaller stones and fern roots, lady slippers, trilliums, etc., working for future effect.

Do not surmount tle rockery with large-leafed ferns. Plant them low down. The entire picture should have a suitable background, which, with quick shade, may be provided by planting cane, bamboo, or any tall waving grass, and a few seeds of Ricinus or a Paulonia Imperialis near by.

Porous limestone and puddingstone are very effective but where few rocks are availaple a large jagged stump will help out wonderfully. A few creeping vines of not very vigorous growth will add much grace.

Florida.

Mrs. Lilie Pleas.

To dispose of your tin cans and other reîuse make a rockery. Select a niche around the buildings or in the garden, build a wall of stone as large as a cart wheel: place inside, standing upright, tin cans filled with bones, small bottles, etc. Put coal ashes upon the pile and then a layer of boots, shoes and broken dishes. Build a second wall of stone a little inside the first, to make it mound shape. Fill tin cans with manure, standing them upright, Over this put all the leaves and litter from the mulching in the garden last fall. Continue building the outside wall until the structure is three feet high. Then fill in all the garden soil it will hold and cover with stones of various size. Plant seeds between the rocks. Arbonia portulacca, morning glory, any low-running vine, will cover the stones in a short time.

N. H.

SARAH M. BaILEy. 


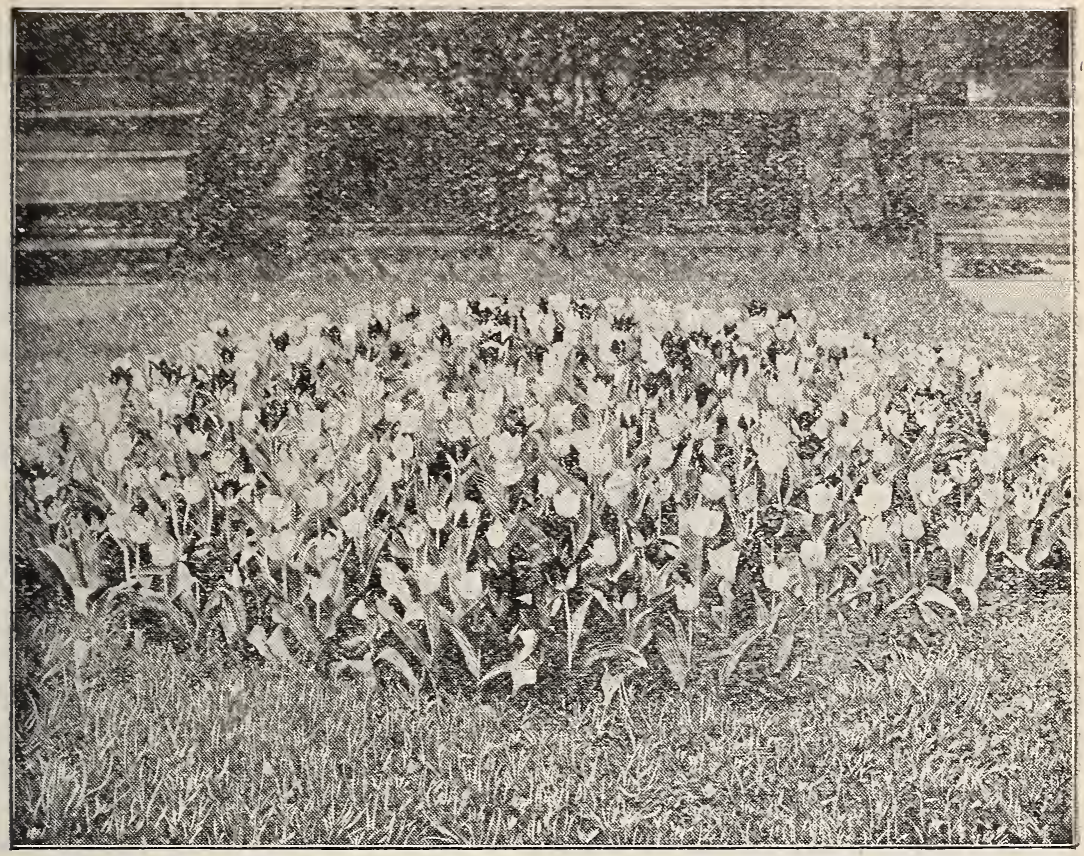

An Attractive Tulip Bed.

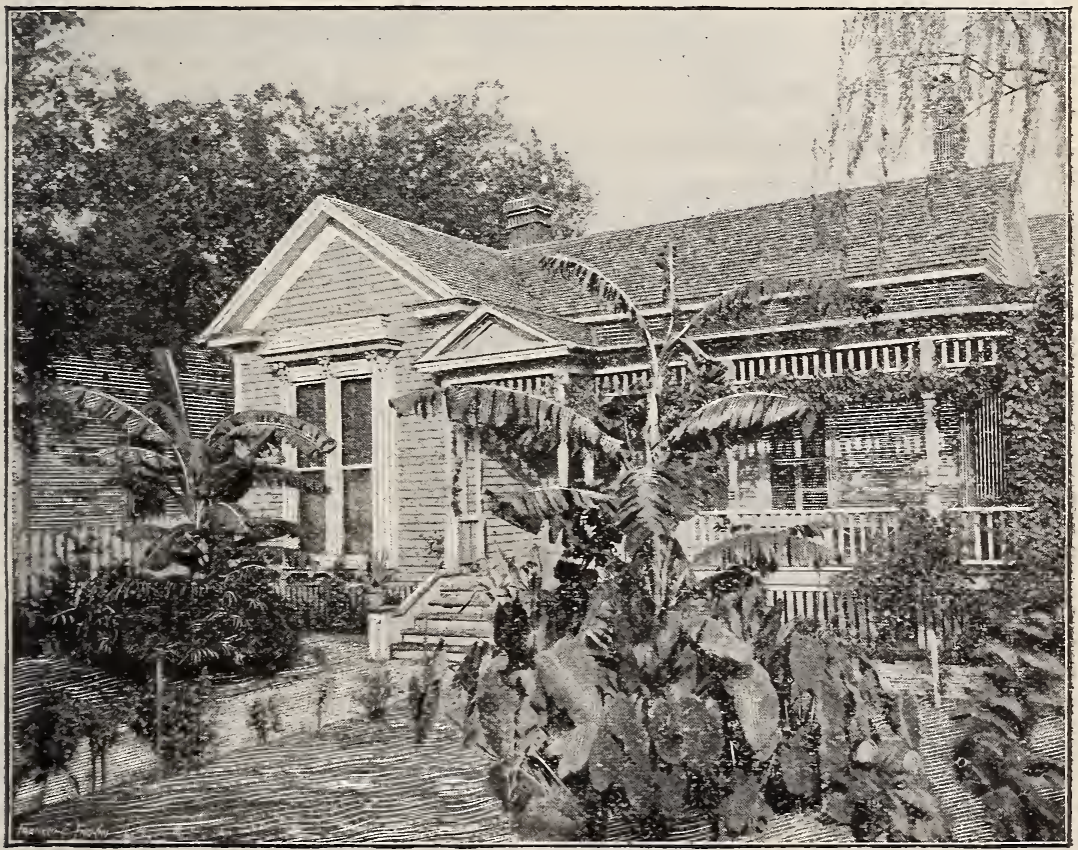




\section{ROOTING CUTTINGS.}

We should now be busy starting slips as well as seeds for planting outdoors. I had a number of geranium and begonia cuttings given me in January. I was doubtful of starting them, but set each little slip in a tiny pot of sandy loam, pressed the soil firmly around it, then set the pots in a zinc pan, filled around them sand, watered all well, and set on a warm shelf in my plant window, which is like a tiny room facing the south. Every slip is growing and two are already budded. Later, when the weather is warmer, I prefer to root slips in a glass of water in a sunny window. I enjoy watching the roots form and fill the glass; one does not feel tempted to pull the cutting up to see if it has rooted. I take each rooted slip from the glass of water in May when the weather is warm and the ground in good condition, and plant it out of doors, then Ikeep the buds pinched off all summer and enjoy blooms in the winter.

Nebraska.

G. A. FLORY.

\section{PERENNIAL PHLOXES.}

Among the many valuable and beautiful flowering plants that come to our notice in the list of perennials, these ought to hold a prominent place, and April is the time to send for and secure these plants.

There are several shades or colors, also a pure white. The dwarf varieties grow very bushy and compact, and are loaded with bloom all summer long. The giant varieties make a lovely background for those of lower growth.

Plant in very rich soil, watering ireely. The filst year the panicles of bloom will not be so large as they will be in the years to come, as they take a year or two to get a good start. If an ancrease of plants is desired, divide the roots. This can be done every few years.

Every year they must be fed with new rich soil. The first winter they will need some protection. Cover them with leaves or strawy manure.

Iowa.

MRS. L. C. WHITAKER.

\section{ANSWERS TO SOME QUERIES.}

Yes, Mrs. Cobenour, "there are several different Hoyas," but Mrs. Pleas” "hoya cornita" is hoya carnosa. The printers made a mistake as they sometimes will. Besides the well-known "carnosa" there is hoya belle, a smaller grower, but most beautiful; hoya paxtonice, hoya cunninghamii, hoya cuniamomifolia with chocolate flowers; hoya campanulata, the bellflowered hoya, pale greenish yellow flowers; hoya globulosa, straw-colored blooms; hoya lasiantha, orange and white; hoya lineris, white, pink center; hoya palidifolia, white; hoya Ehepherdii, white and rose; hoya imperialis, the largest grower of all, a fine stone climber with very large blooms of yellow and brown; hoya ovalifolia, bright yellow, red center; hoya curpurerfusea, blooms purplish brown; hoya pallida, straw color, pink center; hoya coriacea, yellow and brown. But the old carnosa, belle and paxtonice, are really the prettiest of all. The last two are of shrubby growth and can be grown in bush form with ease, in case you do not want a climber.

All cyclamens that I have ever had were fragrant, not strong, but of a faint, sweet; elusive fragrance.

No; I can truly say that a Chinese lily, after blooming, is only fit to throw away.

Missouri. AnNie E. CRafts.

\section{CAN ANY READER HELP?}

The Floral World, my first, came to me after spending days studying gardening books trying to avoid too many mistakes in my spring list. I was seized with depression when reflecting upon the probable difference between my idea and its realization, my work 
being to renovate old grounds around a new residence, the driveway only remaining in its former state. I have not only trees, shrubs and flowers to select, but, wishing natural effects, no bare spaces of earth must be seen, so vines and mosses must come to my assistance. The trees of the driveway are silver birch and mountain ash, with evergreens as a background. Hol1yhocks and sunflowers peep out from lower branches, underneath a carpet of myrtle with crocuses, daffodils, narcissus, hyacinth and tulips. A bed of Madonna lilies will be carpeted with blue forget-me-nots, also a bed of yellow tulips. My fall bulbs will have a carpet of creeping nasturtiums, a bed of mixed roses, a carpet of ramblers. All other rose beds are carpeted with pansies sown in July and transplanted in October, each bed a separate color. as white with laurette massing, yellow with safrano, purple with others. Will Eloral World readers please suggest other combinations?

New York. Mrs. E. M. KEAN.

\section{AS TO ORDINARY MOSS.}

In early spring I gather ordinary soft green moss from our country roadside, wash, dry, and pack it away to use in all kinds of floral work. It is just as useful as sphagum moss and more decorative, as it retains its rich color for months. As a top dressing it adds to the appearance of potted plants, while forming a good mulch for the soil.

Many plants thrive best in tin cans. When in flower, such plants may be set in a jardiniere, with paper stuffed around the can, and then both the pa'per and the mouth of the can concealed by a layer of damp moss.

For cut flowers this green moss is indispensable. Try filling dishes with damp moss heaped high in the center, when arranging violets, pansies, ferns, etc.

I have a dainty hanging basket made of a pink sea shell. This I fill with vines, using moss to keep them in place. The vines develop roots in the damp moss and stay fresh for weeks. When they decline, I wash my shell and fill it with other vines and moss.

Large hanging baskets of great beauty may be made in this way to decorate rooms for special occasions.

Tennessee. Lizzie D. Abernathy.

\section{THE ZAMIA INTEGRIFOLIA.}

I have wondered more than once why it is that, while other less attractive plants are lauded to the skies, so little mention is ever made of the zamia integrifolia. It is a strikingly beautifil decorative plant, closely resembling the cycas revoluta, or sago palm. It resembles both the palm and the fern, but is neither. The leaves are pinnate, quite thick, and retain their beauty indefinitely. The blossom is somewhat remarkable-in shape resembling a pine cone, and of a rich, velvety maroon color. It bursts open when ripe and shows large seeds of glossy yellow, changing later to a deep red. It is as easily grown as a geranium, is not particular as to location, doing equally well in sunshine or shade, and is not expensive.

My experience with it was rather unique. I bought a large plant in the fall, and though it kept its beauty all winter, in the spring the leaves turned yellow, and, thinking it past resurrection, it was put out on the back lawn for future removal. Some time after one of the family chanced to look at it, and found five shoots about four inches long pushing up from the cen ter. It was brought in and grew into a handsome plant, with leaves thirty and thirty-one inches long. For piazza or window it is invaluable, and well repays the slight care it requires. It is mentioned in but one of the catalogues I have seen this year, but it can probably be gotten at the greenhouses.

New Jersey.
"MARCh Tenth." 


\section{The Floral World}

PUBLISHED MONTHIY BY THE

\section{FLORAL WORLD COMPANY,}

12 to 14 South Limestone Street, SPRINGFIELD, OHIO.

Subscription Price, 25 Cents a Year.

Correspondence invited from all persons interested in flowers. Write us your experience with plants.

We will give $\$ 26.00$ in prizes for the five best articles for publication in the June number of THE FLORAL WORLD which may be submitted by subscribers.

The first prize will be $\$ 10.00$; the second, $\$ 7.50$; the third, $\$ 5.00$; the fourth, $\$ 2.50$; and the fifth, $\$ 1.00$. The awards will be announced in our July issue.

No article which contains more than two hundred words will be considered. All contributions entered in this prize contest must reach us not later than May 1.

The purpose of these prizes is to secure for publication in THE FLORAL WORLD matter which gives the actual experiences in flower growing of those who have subscribed for the journal. Prizes offered for articles published in the March number have been awarded as follows :

First prize-Annie E. Crafts, Missouri.

Second prize-Elizabeth Badger, Missouri.

Third prize-Mrs. O. H. Hereford, Nebraska.

Fourth prize-Mrs. R. A. Houk, indiana.

Fifth prize-Mrs. J. A. Adams, New York.

\section{SUCCESS WITH THE UMBRELLA PLANT.}

I would like to tell the readers of The Floral World my experience with the umbrella plant. To my mind there is no more satisfactory decorative plant for the window or veranda than this. After trying various methods of culture with very unsatisfactory results, I filled a large size flower pot first with broken pottery and charcoal, then leaf mold mixed with sand. Into this I put my plant and then placed the pot in a large jardiniere, which I keep filled with water. It is simply wonderful the amount of water this plant will "drink." The result is as handsome a plant as one would wish to see, with stalks standing three feet high and measuring from 12 to 15 inches across the top of the leaves, each top surrounded with a beautiful crown of flowers. Whenever I see a slender shoot starting, I cut it out, and thus give the large stalks more room and also secure a more symmetrical plant. Ohio. Mrs. L. D. Bowers.

\section{CENTRANTHUS FOR BORDERS.}

The Centranthus is a very pretty flower for rock worlk, or borders. The flowers are small, but borne in clusters on light green, almost transparent stems, very showy and attractive. They grow freely in any good garden soil. I had a border of them last summer; they flowered all summer and until late in the fall.

The seed can be sown as soon as the frost is out of the ground. Keep the ground moist.

Canada.

Mrs. C. Hodgeds.

\section{WHAT SHOULD BE DONE WITH POT PLANTS IN SUMMER?}

This is a subject on which I would like to hear some or several give their experience. My trouble in summer is the medium-sized black ants. They work into my pots until they almost destroy some of my plants before I am aware of what the trouble is. Last summer I tried an experiment. I stuck matches in the earth. I put from four to six matches in each pot, and it stopped the ants from working, but I could notice the plants did not thrive so well from the effect of that kind of medicine.

Ohio.

Mrs. Clark Smith. 


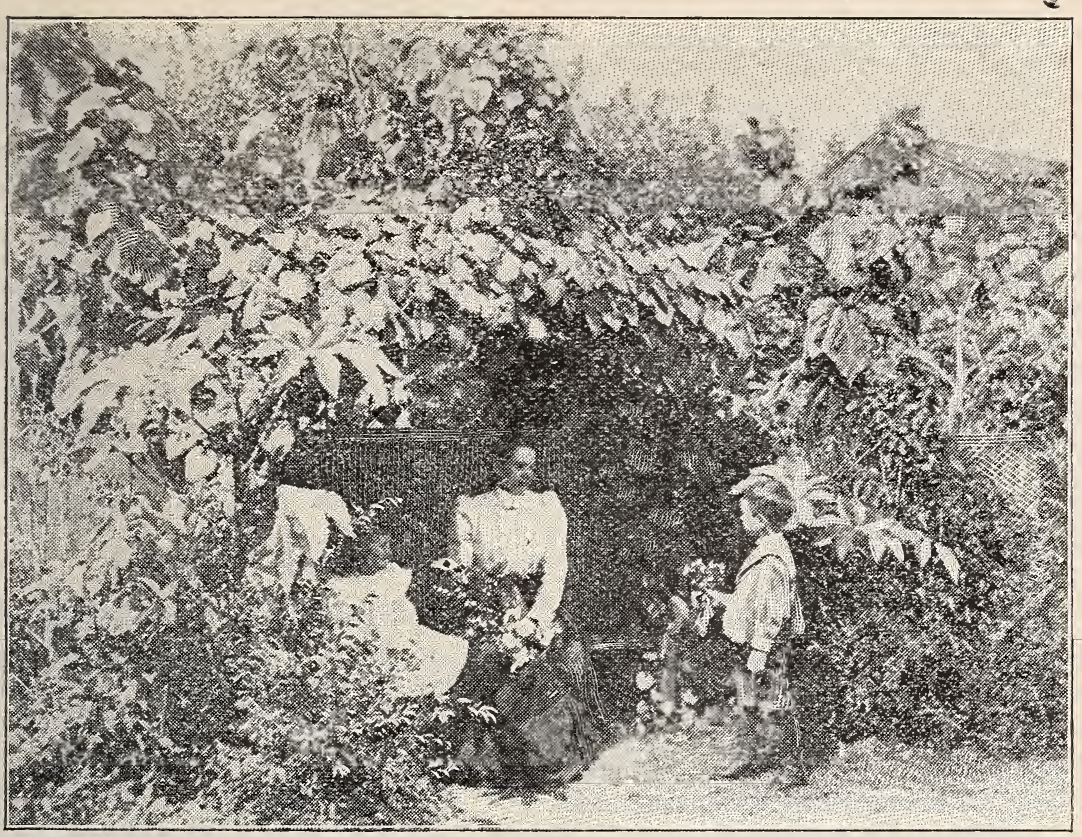

"A Flower Bench" in Kentucky.

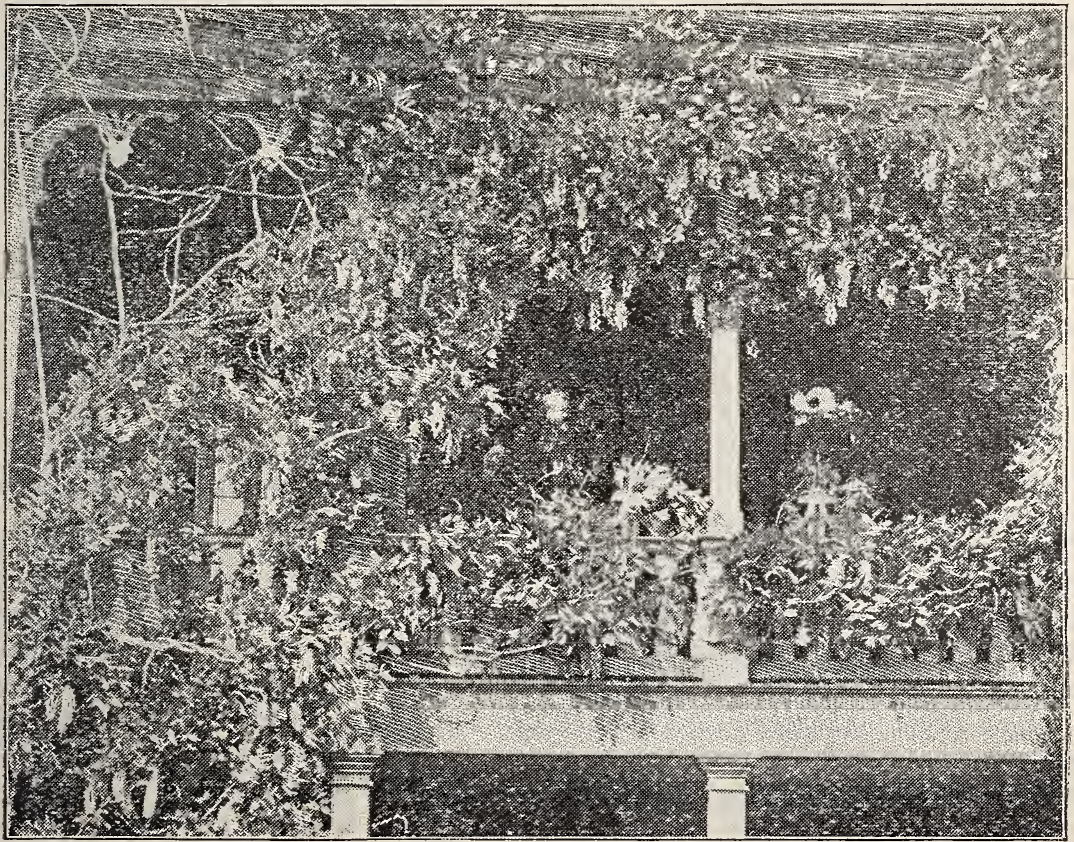

Wisteria Siuensis. 


\section{A PREACHER'S FLORAL SERMON.}

I know a tidy home in our midst and although I have never been inside, I am right in saying people of refinement live there, as the evidence of their taste is apparent in its outward adornment. Early in the spring you might see its master, a Methodist preacher, in its trim little garden, making preparations for its coming glory. Beds are dug and raked. Rows are made for the garden seeds and bulbs, for all are in one garden, as the space is limited. Later on I have passed there, when the place was all a bloom, and a beautiful sight it was. I thought the morning glory a common thing, but over the low white fence it trailed and held up its brilliant bells to catch the sparkling dew and-

"Close to the window the woodbine clung,

And down at its feet the sweet pea swung,

While over it all the blue dome hung, And finished a picture fair."

The preacher was a busy man, but he taught us that we could never be too busy to adorn our homes with some at least, of nature's graces.

Minn. Mrs. W. J. Dougherty.

\section{VIOLETS FOR EASTER SEASON.}

No doubt every feminine flower lover enjoys wearing a bunch of sweet scented violets, but how few ever think of cultivating them. From my own experience I can recommend them as flowers most easily grown.

They can be readily cultivated in the summer garden, but for Eastertime bloom in early spring make a bed of fine, rich soil, six feet long by three feet wide, facing east or south, in which plant one dozen good violet roots at equal distances apart. In dry weather water and cultivate the soil. In October place around the bed an oblong frame made of boards six feet long, three feet wide and one foot deep. Set the frame deeply in the ground on a slant, that rain may run off the glass. When November winds blow chill, put on the sash and the winter garden is complete, and soon the reward will come.

From a cold frame the above size in my own garden I gathered over one hundred dozen blossoms last Eastertide, enough for our own enjoyment and gifts to many iriends. The wise woman might add profit to pleasure in thus raising violets.

Penusylvania. Mrs. M. D. Brown.

\section{LILIES OF THE VALLEY.}

Procure bulbs (or pips) early in the spring. Select a partially shaded location for your bed. Remove the soil to the depth of a foot. Add one-third of its bulk well rotted manure, mix well and return to the bed, which must be three inches above the ground to be sure that no water stands on it. These flowers like moisture, but must not be water-soaked.

Put your bulbs four inches apart each way and cover an inch and a halt deep. You may not have many flowers the first year, but you are preparing for years of sweetness and bloom. Late in the fall, after the foliage is dead, give a top-dressing of manure, wnich will protect your bulbs and enrich the soil. Do this each fall and in a few years you will have a bed of which you will be proud.

Mo. Mrs. Candace Powell.

\section{AN EXPERIENCE WITH GLADIOLUS.}

Why not have a bed of these choice summer bulbs? Nothing could be easier to raise. They need good soil, well drained, rather sandy. Plant bulbs three inches deep and four or six inches apart. When a foot or so high, stake and tie with strips of soft cloth. Keep down the weeds and stir the soil in the bed, being careful not to disturb the bulbs. A bed of red and pink bulbs in the center, with white ones all 
around the edge, makes a very striking appearance. The first time I planted gladiolus bulbs I did not plant them deep enough, so that after a few hard summer showers, the ground being rather elevated, I found several of $\mathrm{my}$ choice bulbs washed out.

The bulbs increase very rapidly, I always find, on digging mine in the fall, at least thrice as many as I planted. I plant about the first of May. In warmer latitudes they can be planted in April. They are also easy to keep over; they never rot. Pack in sand, free from frost.

Iowa. Mrs. L. C. Whitaker.

\section{SUCCESS WITH CHRYSANTHEMUMS.}

Many amateurs having failed at first with Chrysanthemums, think these flowers can be raised only by the man with a greenhouse. This is a mistake. For several years I have had no trouble in raising fine blooms six to eight inches in diameter. Get well-rooted plants the last of April or first of May. Put into four-inch pots. The first of June transfer to pots where they are to bloom. For bush plants use eightinch pots. When plants are four or five inches high, pinch out the tops to make them branch. When branches are three or four inches long, pinch again, and so on till the first of August, after which allow branches to grow, pinching off buds until there is but one bud left to develop on each branch. When single stems are desired, transfer to six-inch pots, take off side shoots and allow one bud to develop on a plant. A good potting soil is made of one-half black muck, onefourth sandy loam and one-fourth well rotted manure thoroughly mixed. A good place to grow them is on a platform on the east side of a building.

Michigan.

TIMMERMan.

\section{THINGS TO DO IN APRIL.}

There will be plenty of work for the amateur gardener this month. We must get ready fur active operations which May will usher in, and should bear in mind that a thorough preparation for important work is quite essential to success. As soon as frost is out of the ground, sow sweet peas, the sooner the better. See that the hotbed is ready for the sowing of annuals, such as verbena, vinca, salvia, pansy, petunia, coxcomb, etc.-any hard seed that requires steady heat.

Young gardeners are anxious to uncover the bulb bed as soon as the snow is gone. But make haste slowly, and do not remove the covering until danger of severe frost is over. Roses and all other tender shrubs should not be uncovered until we are reasonably sure of settled weather. If hardy border plants were not divided and reset in fall, this work can be done now. Clean up about the yard and have everything that is connected with the garden in apple-pie order.

Indiana. - Mrs. R. A. Houk.

A great deal of planting can be done in April. The gladiolus, the queen of the summer bulbs, can be planted by the 15th of April. In preparing the beds I prefer the low ones on the level with the surrounding surface, as the raised beds dry out so quickly. This will grow in any good soil, but the flowers will be so much larger and more brilliantly colored that it will pay to give a very rich soil and plenty of water. The dahlia can also be planted by the 15th of this month. In preparing the bed, have a hole dug to the depth of tiree feet, the old soil taken out and then filled up with alternate layers of old, well-rotted manure, very rich earth and common garden soil. Last year I gave mine a partially shaded place under a tree, and they stood the drought and bloomed so much better during the hot summer months. Divide tubers when planting, 
but see that both ends are sound, or they will not sprout.

Kentucky.

LAURA JoNES.

April is the best time to sow seeds of Chinese primroses and cinerarias, and to root cuttings of geraniums, heliotropes and other winter flowering plants. It is time, too, to start the hanging baskets, trailing abutilons, new weeping lantana and Mexican primrose for sunny windows, while for shaded windows asparagus sprengeri and Kenilworth ivy are fine. When the soil is in condtion suitable to be worked, flower beds may be spaded up.
Then they may be worked over before setting the plants out. When the soil is dry enough, seeds of hardier annuals may be sown outside, while some plants may be set out permanently this month, such as pansies. daisies and others of a rugged nature. If the weather is mild, roses may be uncovered and mulched, some of the old rotted mulch being worked into the soil about the plant. Hardy lilies may be planted yet this month, and the division of hardy herbaceous plants should not be delayed.

$$
\text { Ohio. Annice B. Calland. }
$$

(Continued on page 13.)

\section{Marvelous Growth of Hair.}

\section{A Famous Doctor-Chemist Has Dis- covered a Compound That Grows Hair on a Bald Head in a Single Night.}

Starting Announcement Causes Doctors to Marvel and Stand Dumfounded at the Wonderful Cures.

The Discoverer Sends Free Trial Packages to All Who Write.

After half a century spent in the laboratory, crowned with high honors for his many worldfamous discoveries the celebrated physicianchemist at the head of the great Altenheim Medical Dispensary, has just made the startling announcement that he has produced a compound that grows hair on any bald head. The doctor makes the claim that after experiments, taking years to complete, he has at last reached the goal of his ambition. To the doctor all heads are alike. There are none which cannot be cured by this remarkable remedy. The record of the cures already made is truly marvelous and were it not for the high standing of the great physician and the convincing testimony of thousands of citizens all over the country it would seem too miraculous to be true.

There can be no doubt of the doctor's earnestness in making his claim nor can his cures be disputed. He does not ask any man, woman or child to take his or anyone else's word for it but

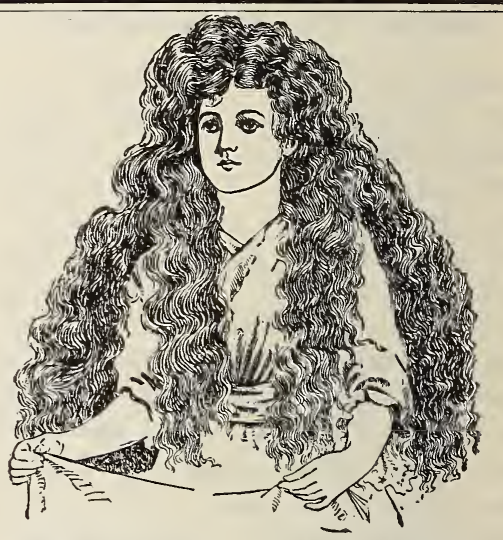

MISS HISI,OP, of New Zealand and Her Marvelous Growth of Hair.

he stands ready and willing to send a free trial package of this great hair restorative to any one who writes to him for it, enclosing a 2-cent. stamp to prepay postage. In a single night it has started hair to grow on heads bald for years. It has stopped falling hair in one hour. It never fails no matter what the condition, age or sex. old men and young men, women and children all have profited by the free use of this great new discover 3 . If you are bald, if your hair is falling out or if your hair, eyebrows or eyelashes are thin or short write the Altenheim. Medical Dispensary, 6446 Butterfield Building, Cincinnati, Ohio, enclosing a 2-cent stamp to prepay postage for a free package and in a short time you will be entirely restored.

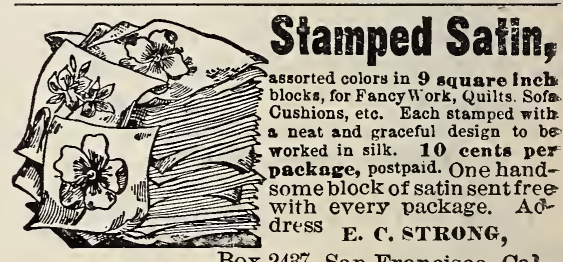




\section{THINGS TO DO IN APRIL.}

(Continued from page 12.)

Wake up, floral lovers! Spring is truly cycling near. Tuberous roots and seeds of lazy-flowering plants should be growing in the house now. Dress the garden beds now, that spring rains may rot it in. Soon as the soil can be forked attend to that sweet pea bed, for early blossoms are finest, and alternate a few climbing caprice nasturtiums, in front of which have a row of low caprice. Soon as frost is over put a row, twenty feet long, if possible, of your giant cosmos seedlings along that high rear fence. In front of that plant a row of salvia splendens, then a row of brilliant poppies and a fcurth row of prize verbenas, and don't trim the salvia. Try this.

New Jersey.

MCLEOD.

The loveliest season of the year is here. Our house plants are doing their best, but our interest is in the awakening life outdoors. If frost has hindered so far, now spade your gar. den and plant your sweet peas first. Gradually uncover your pansies and choice roses. Already my forget-menots, hardy pinks, polyanthus and bulbs are green and in a few days will unfold their early blooms. Our grandmothers' gardens were beautiful, but many of her favorites require too much room. I have tried nearly all the annuals and this year I shall plant seeds as follows: Sweet pea, pansies, asiers, Marguerite, carnation, dwarf pe(Concluded on page 14.)
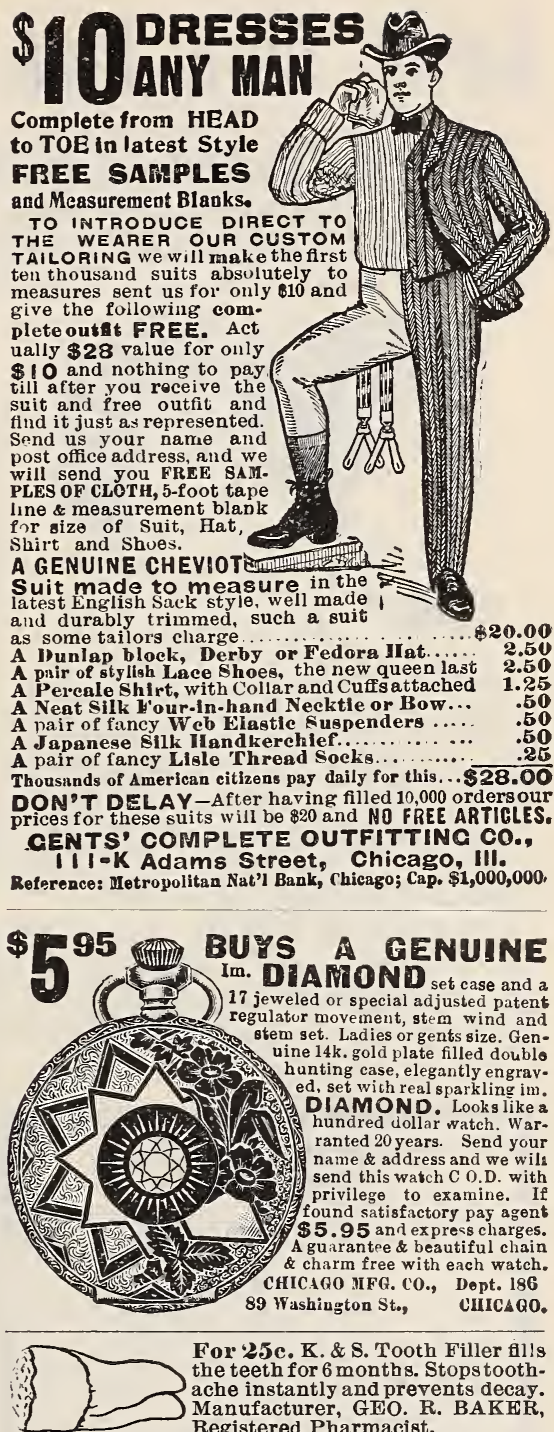

For '25c. K. \& S. Tooth Filler fills the teeth for 6 months. Stops toothache instantly and prevents decay. Manufacturer, GEO. R. BAKER, Registered Pharmacist.

65 CLARK ST'. - CHICAGO.
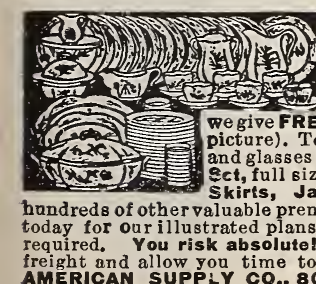

(ख) 2010
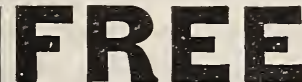
CHINA DIN INER SET

For a Fow Hours' Work Selling Queen Baking Powder ous. To every purchaser of a pound can Queen Baking Powder pire a beautiful Pischer and 6 Glasses to match, latest cut glass pattern (like and glasses to each purchaser, we will make a present of a handsome 50-Piece Dinner and glasses to each purchaser, we will make a present of a handsome 50-Piece Dinner
Qct, full size tableware, handsomely decorated and gold traced. We also give Waists,
Skirts, Jackets, Furniture, Sewing. Machines, Musical Instruments, and

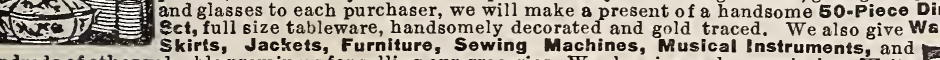
andreds of other valuable premiums for selling our groceries. We also give cash commission. Write today for ourillustrated plans offering many premiums to customers; it will pay you. No money
required. You risk absolutely nothing, as we send you the goods and premiums you select, pay freight and allow you time to deliver the goods and collect for them before paying us. 


\section{Goitre Cure Free.}

Any Lady Can Quickly Cure Herself of this Ugly and Dangerous Disfiguration in the Privacy of HerOwn Home.

This charming and beautiful English woman after trying great surgeons and doctors, cured herself in her own home. She says: "I noticed a slight swelling on my neck. A noted London

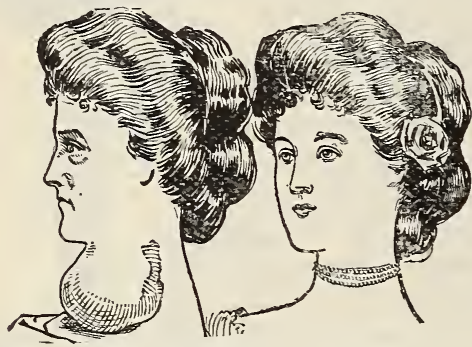

MRS. LUCILLE LYTTON,

Duchess of Newha11, London, Eng.

surgeon pronounced it goitre and felt sure he could remove.it quickly. Instead, it grew rapidly. My appearance was dreadful, my ejes nearly popping from my head. Surgeons refused to operate for fear of rupture of the jugular vein. My husband heard of Dr. Haig's home cure for goitre and we tried it - the effect was marvelous. In a few weeks all traces of it was gone, the pain ceasing the first time we used the remedy. Lucille Ly tton."

Your goitre can be cured at home without pain, danger or any inconvenience. Write today to Dr. John P. Haig, 3361 Glenn Bldg, Cincinnati, Ohio, tell him your age, the size and location of your goitre and how long you have had it and he will be glad to send you free a large trial package of his home cure, posta re paid.

\section{THE BEST SPECULATIVE} INVESTMENT

today is Oil and Mining Stock. Before rou invest it will pay sou to write for our free booklet, "How to Judge Oil and Mining Stocks.

\section{FORTUNES.}

have been and are being made in Oil and Mining. A little money invested now in stocks that we recommend will start you right. We never off $t r$ or recommend a stock until we have made a careful and searching investigation.

Development Oil Strcks, 2c to 10c per share. Dividend Paying Stocks, $20 \mathrm{c}$ to $50 \mathrm{c}$ per share Development Mining Stocks, 3c to I5c per share.

Write us today stating the kind you prefer whether low-priced development or dividend paying stncks, and we will send you our special offer, which if taken advantage of will start you on the high road to iortune UNION SECURITY C0..391 Gaff BIdg.,Chicago

JAPANESE STAMPS 15 Japanese Stamps, all JAPANESE STAMPS different, 10c. 25 Oriental Stamps, all different, 10c. 7 Oriental Coins, all difierent, 10c. All three lots, 25c. All genuine. No reprints.

c. T. JOHNSON, LAUREL, MD.

\section{THINGS TO DO IN APRIL.}

(Concluded from page 13.)

tunias, eschscholtzia, gaillardia, mignonette, nasturtiums, portulaca single, verbena, candyiuft, phlox, sweet alyssum, zinnia.

For the amateur these are easily grown and will give a wealth of blossoms until late frost comes. With the exception of the pansies I know from experience that seeds do best when planied in the open border. The house seedlings are apt to be weak and sickly and will not bloom much earlier than seeds sown in the open ground. From May 20 to June 1 your house plants, such as geraniums, double petunias, heliotrope and daisy may be planted in the ground.

\section{N. Y. Mrs. Chas. L. TuthilL. \\ BEDDING OUT HELIOTROPES.}

Those who have grown the helio trope only as a pot plant have no idea of the wonderful beauty of this plant when bedded out in a sunny situation and given a rich soil and necessary moisture. I have had a single plant to grow three feet in height and branch out until it was almost five feet in circumference, and have cut any amount of the fragrant purple flowers from this little tree.

The bed should be very rich. It is best to.dig out all the old soil and fill up with new, the richest that can be had. Give all the sunshine possible. Moisture and frequent stirrings about the roots will keep a continuous growth, and it is on this new growth that the flowers are formed.

In bedding out do not crowd, but leave plenty of room for the expanding. of each plant. This is quite frequently bedded out in the cemetery, but as they receive little care, we seldom see fine specimen plants here. In watering the heliotrope, care must be taken to water thoroughly, as this has soft fibrous roots.

Kentucky.

LAURA JONES. 


\section{Free to Ladies}

One Full-Sized $\$ 5.00$ Package of Dr. Mary Lock's Wonderful Home Treatment Given Free to Every Lady.

Cures Every Form of Female Weakness, Displacements, Leucorrhea, Suppressed or Painful Menses, Falling of the Womb, Change of Life, Etc.

The celebrated lady specialists have decided for a short time to give free, one full-sized $\$ 5.00$ package to every suffering woman in order to quickly introduce their most wonderful remedy

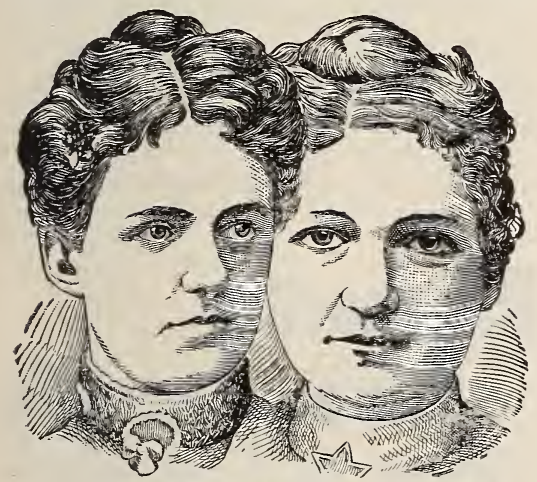

Two of America's Greatest Lady Specialists.

in every city, town and hamlet in the U.S They could not afford to do this only that they expect after you are cured and they know you will be and that you will recommend the remedy to suffering friends who will gladls order the treatment and in this way they will be amply rewarded for making this most liberal free offer Send your name and address to Dr. Mary Lock Co., 4346 Englewood Station, Chicago, Ill, , for a free $\$ 5.00$ package and be quickly cured in the privacy of your own home.

Remember this is not a patent medicine but a full three-course treatment sent complete, in a plain package so that no person will know what it contains.

The above offer is genuine. We ask no questions or references of any kind. Every lady who writes will be given a full $\$ 5.00$ package free. Write today.

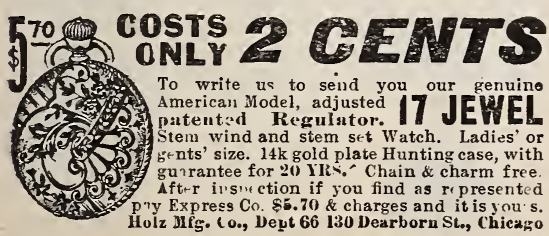

AN OPEN SECRET.

Have you had trouble protecting your rose bushes from their many enemies? Have you watched precious buds that promised rich returns for all labor and love, blast or half develop? Let me whisper a secret known to but few. Whale oil soap is a panacea for all these ills. Take a tablespoon full, dissolve this in two gallons of water. With a whisk brocm or sprayer put it on the bushes once in two weeks or so. This treatment should begin with the first green leaves, for it is then the eggs are laid that later hatch and work such havoc. This remedy has been to me one of the greatest revelations I've ever experienced in plant culture. Now, instead of that dreading, heartaching, helpless feeling before rose season I look forward with joy to rich rewards-for I'm master now, and each effort is amply rewarded.

Ohio. Mrs. Mary T. Milliamson.

\section{HOW SHOULD A CENTURY PLANT BE TREATED IN WINTER?}

Some tell me my century plants require very little water. The place we keep them is not very warm, but frostproof. Our old plant has been kept in the same place during the past winters, but now we find nearly all the leaves rotten. We did not give it much water, but about two weeks ago I sprayed the leaves quite freely. Of course the leaves retain the water, and I should attribute its present condition to an over-supply, if the centre from which the leaves gradually unfold themselves were sound. The water could not remain on it, nor get inside of it, yet it is in the same condition as the leaves A few of the bottom leaves which were more liable to retain the water are sound.

The plant appears to be frozen, but î can scarcely conceive how that could be possible. We learn, moreover, from experience, that it is a very hardy 
plant, and some of the young plants which were more liable to be frozen owing to their situatioll, are still sound. Do you think the plant would live if all the leaves were cut off? It's a magnificent plant, consequently we would like to save it.

Ohio.

J. M. ECKERT.

\section{PLANTS MUST NOT BE NEGLECTED.}

People often say to me, "How is it you have such nice plants? What do you do to make them grow? They won't grow like that for me." My answer is simply, that I never neglect the plants. I love them and think of them as living, breathing things. I compare them sometimes to little children. The neglected ones, like the children of the slums we often read about, are sometimes gorged, more often starved. Let plants breathe gas and foul air, give them a drink once a week and food once in six months, or, on the other hand, gorge them, and then when the leaves turn yellow and plants wither and droop like children with diphtheria or scarlet fever, do you wonder why it is?

Even if the themometer stands at zero, I open doors and windows every day long enough to purify the air. I give all plants that need it a warm drink every day, food once a month, a bath once a week, and many of them a sprinkle or a sponge bath every day, using a small, soft sponge and a dish of water. Watch the leaves closely for verm:n and the earth for worms. If found, eradicate thoroughly. Punish, when needful, by taking scissors and clipping ofi leaves, buds and flowers, to make them good plants. Shelter the weak ones and give strong sunlight to the hardy. Tenderly care for them at all times and the leaves will have a glossy, eye-resting green, the flowers will lift their little, fragrant faces to you in thankfulness, and will repay their care.

Illinois.

Mrs. S. E. Browne.

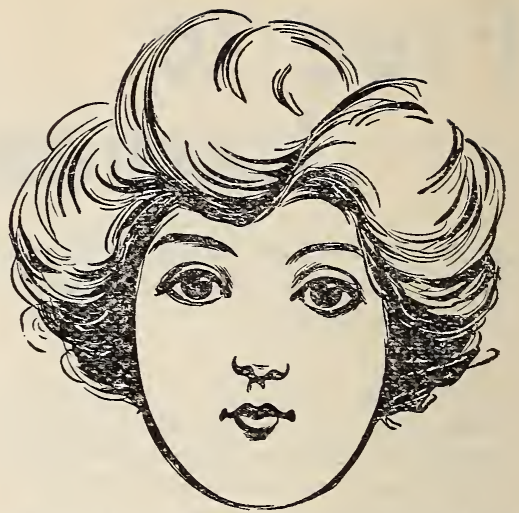

No lady should despair if her complexion is imperfect. Merely send your name and address to Mme. M. Ribault, 4346 Elsa Bldg., Cincinnati, Ohio, and she will send you free, prepaid, in plain wrapper a trial package of her wonderful remedies that absolutely guarantee a perfect clear skin. It is not a face powder, cream, cosmetic or bleach, but is absolutely pure and you can use it privately at home. It permanently removes moth patches, redness, crow's feet, pimples, blackheads, flesh worms, sallowness, frer.kles, tan, sunburn and all other complexion disfigurements. Write today and learn for sourself how easy it is to attain beauty when sou know the simple truth and the right remedic's.

\section{Drunkards}

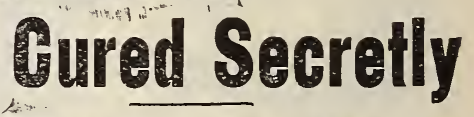

Free Package of the Only Euccessful Gure Known for Drunkenness Sent to All Who Send Elame and Address.

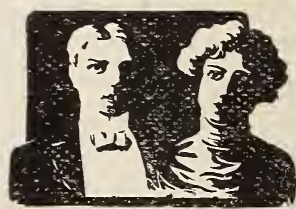

A new discovery, odorless and tasteless, which any lady can give in tea, coffee or food. It does its work so silently and surely that while the devoted wite, sister or daughter looks on, the drunkard is reclaimed even against his will and without his knowledge or co-ol,eration. Send liame and adIIR. \& MRS. IIARIRY BLRNSIUE. dress to Dr. J. IV. Haines, 3071 Glenn Bldg., Cincinnati, O., and he will mail enough of the remedy free to show how it is used in tea, coffee or food.

coffee or food. Brs. Harry Burnside says "With Golden Specific 1 cured my husband of drinking. I put it into his coffee and after that he couldn't drink liquor or bear to be around where it was."

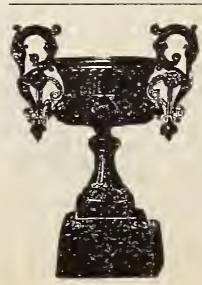

IRON VASES

For Lawns and Cemeteries.

These Vases have reservoir holding water, and flowers do not need watering but once in 10 to 15 days We guarantee them in every way. Vases from $\$ 4$ to $\$ 90$. We save jou money on Vases. If you want a Vase, write

F. A. FLOOM \& CO., Tiffin, Ohio. 

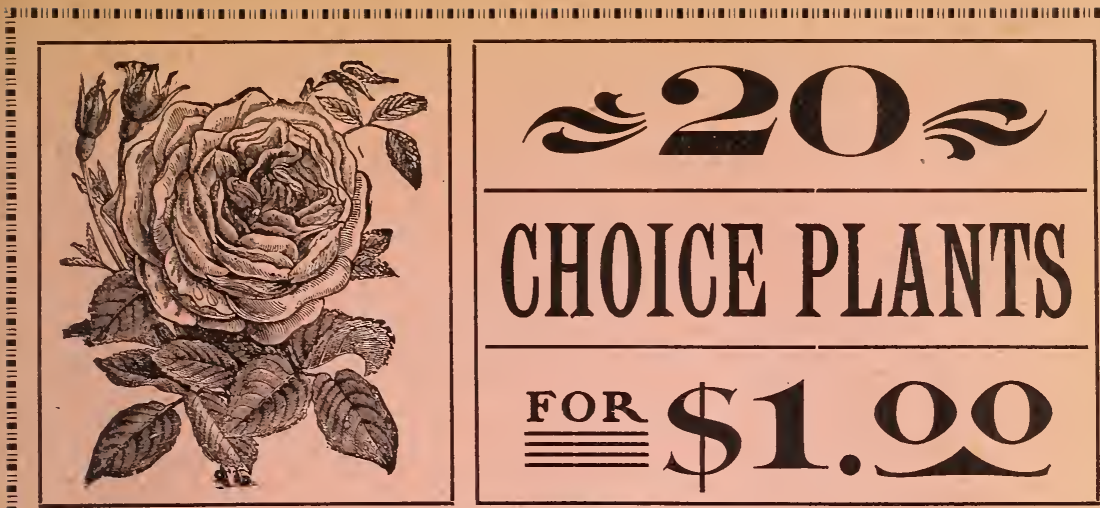

\section{OUR "HOUSEHOLD" COLLECTION}

CYPERUS GRACILIS. - The beautiful Umbrella plant.

PALM, KENTIA.- One of the most beautiful and valuable of all.

FERN, MAIDEN HAIR.-Elegant, graceful and easily grown.

FERN, THE BOSTON FOUNTAIN FERN. -Nothing more useful for the house.

ASPARAGUS SPRENGERII.-The emerald feather plant; very. hardy and easily grown.

FUCHSIA, MRS. HILL. - Big double white. No collection of house plants complete without a fine Fuchsia.

BEGONIA, LE VESEUVE.-A new everblooming variety; bright, coral red.

BEGONIA, MRS. TOWNSEND.-Another new variety, highly ornamentál, grand in bloom.

HIBISCUS, PEACHBLOW. - The new, double pink; a grand plant for house or garden.

SANSEVERA ZEYLANICA. - An elegant decorative plant that lives anywhere.
JASMINE, REVOLUTUM.-A highly fragrant, yellow-flowered sort.

JASMINE, MAID OF ORLEANS.-A delightful double white with a penetrating perfume.

OTAHEITE ORANGE - With its lovely orange blossoms and beautiful ornamental fruit.

NEW GERANIUM, JEAN VIAUD, the Pink Beaute Poitevine.-One of the finest of the new Geraniums.

NEW GERANIUM, RICHELIEU. - Fine, large trusses; fiery scarlet, shaded with maroōn.

NEW GERANIUM, MRS. LAUDRY. Enormous trusses of double salmon flowers.

ROSE, MAMAN COCHET.-A beautiful pink that everybody can grow.

ROSE, CLOTHILDE SOUPERT.-A household Rose for everyone.

ROSE, WHITE LA FRANCE.-A grand favorite with all.

NEW CHRYSANTHEMUM, CHRYSTALINA. -A big, double white; grand flower in every respect.
0 UR imagnificent " HOUSEHOLD COLLECTION" consists of such plants as have sterling worth for flowering or for ornamental vurposes. Each and every one is a gem, and worth double what we are asking for them. Any one inclined to sell flowers, could grow this collection for a few weeks and then retail them for a handsome profit to themselves.

Send us \$1.00 and we will send you this fine lot of plants postpaid. SAFEARRIVAL GUARANTEED.

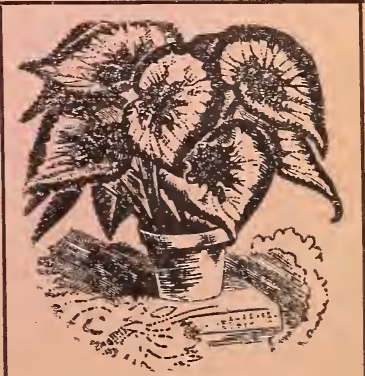

Address, THE C. A. REESER CO., URBANA, OHIO. IIIII) 


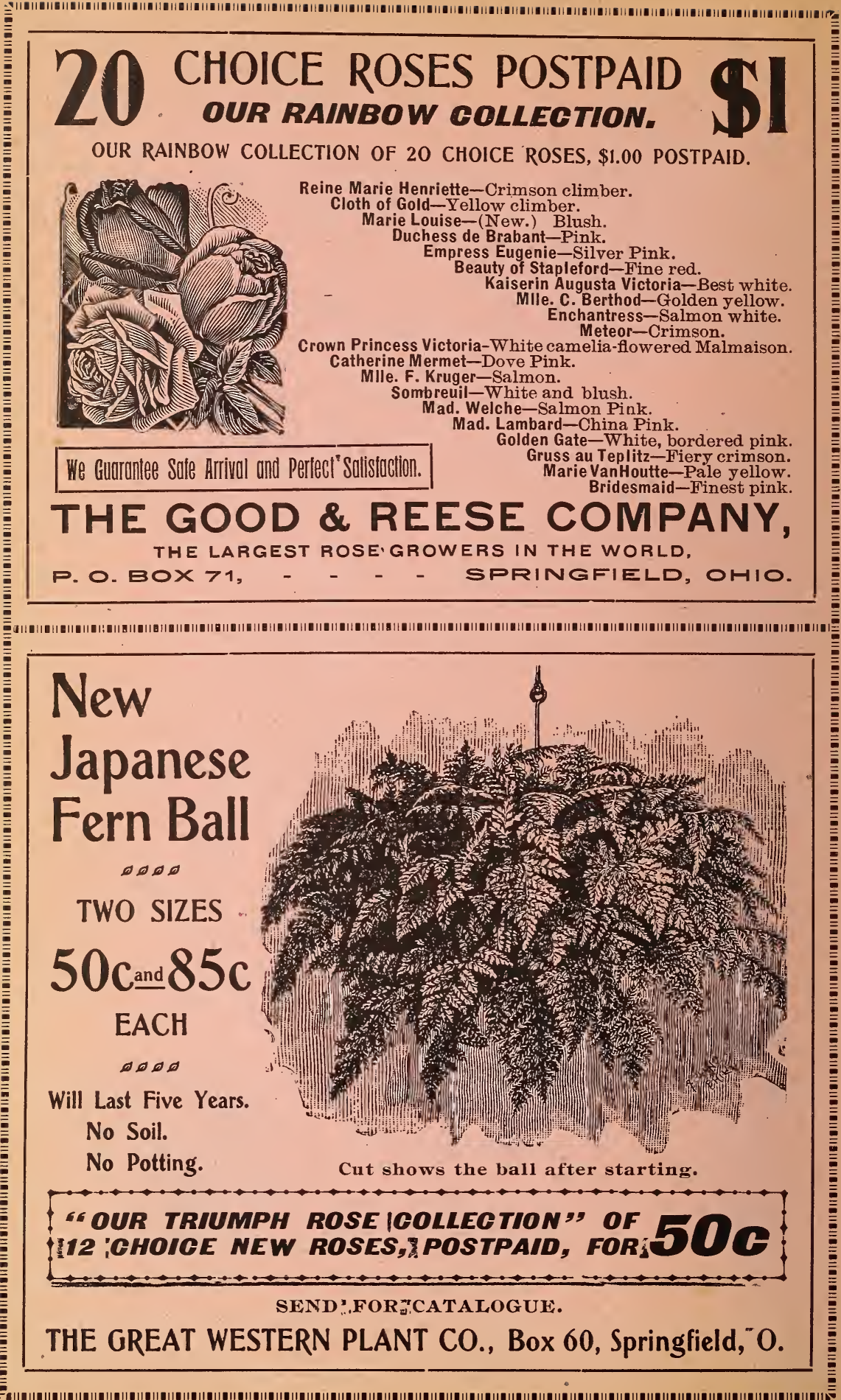




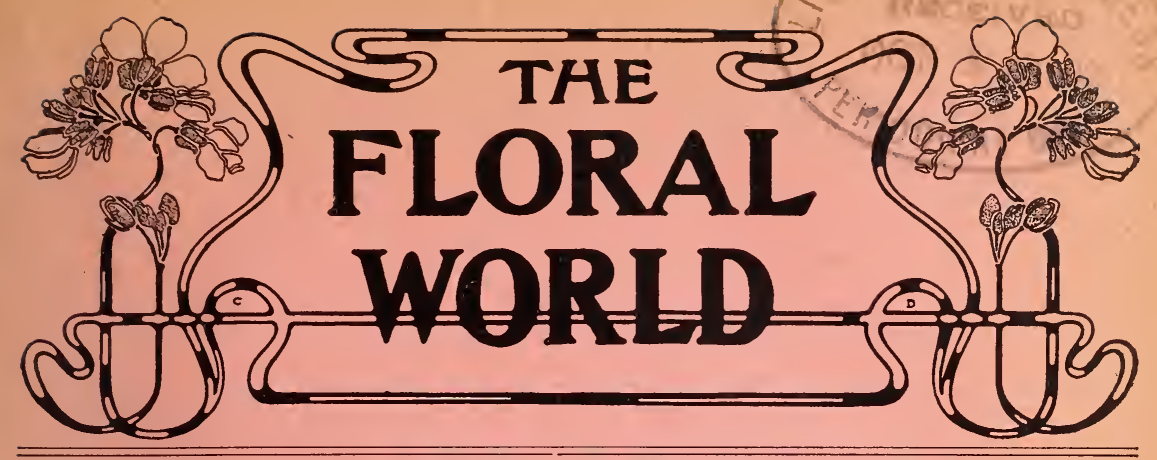

Vol. I, No. 8 Springfield, Ohio, May 1902

25 Cents a Year

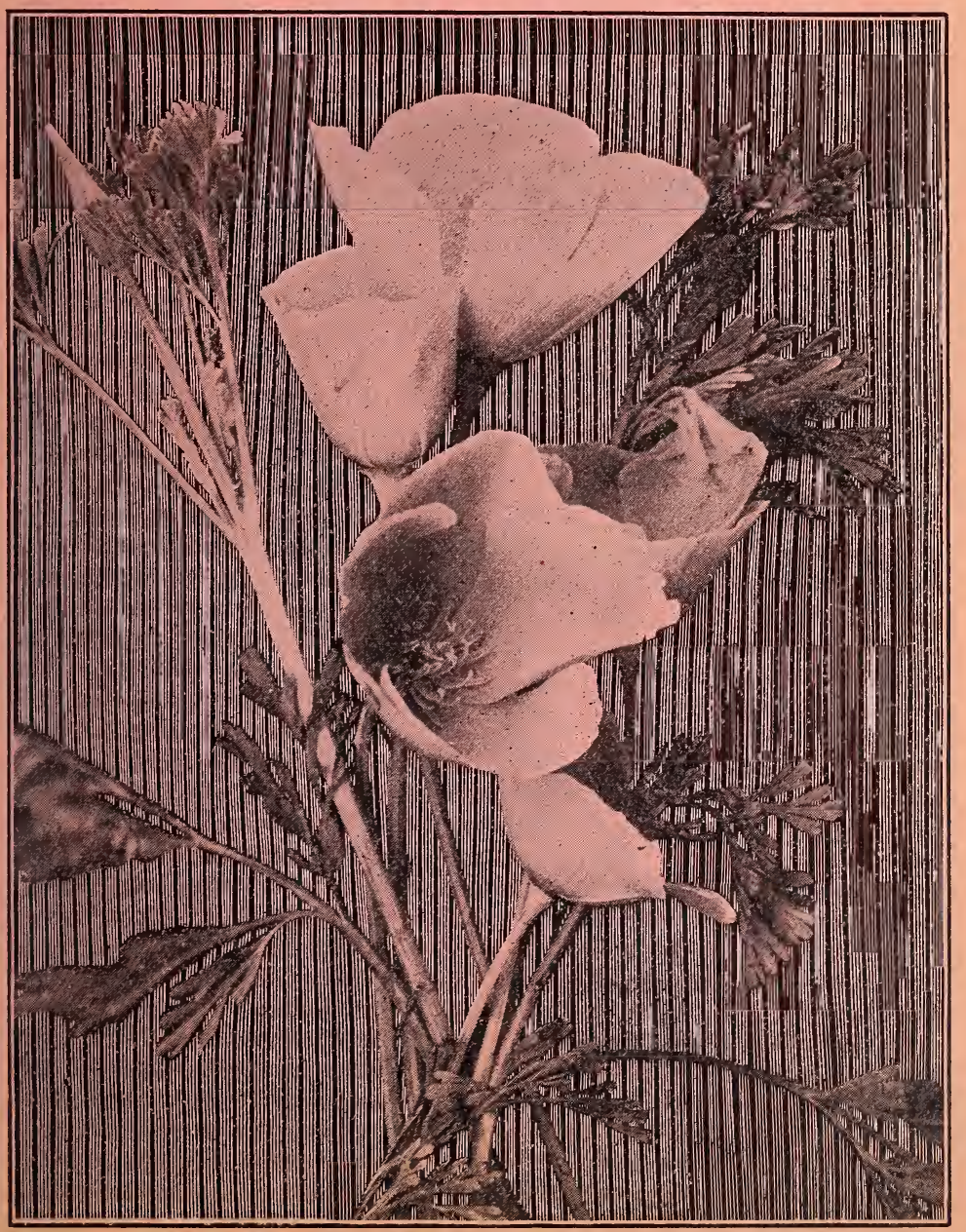




\section{FREE PREMMUM COUPON}

Name

St. No. or P. O. Box
If this Coupon is sent to THE FLORAL WORLD, Springfield, Ohio, with 25 cents, and your name and address, you will receive that journal a year and one plant each of Asparagus Sprengeriand Boston Fern. Write here.

\section{Two Splendid Plants Free!}

\section{WITH THE FLORAL WORLD, ONE YEAR FOR 25 CENTS.}

DETURN us the Coupon above, with 25 cents, and we will send you The Floral I WORLD a year and the following plants :

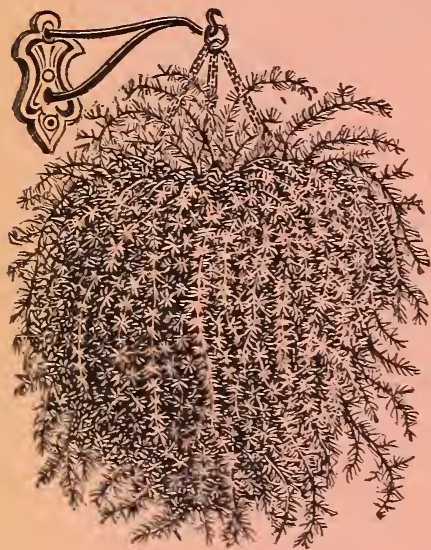

ASPARAGUS SPRENGERI.

\section{BOSTON FERN.}

The popularity of Ferns has increased wonderfully in the past few years, and they are now indispensable in all choice floral decorations, and are especially valuable for fern. eries, for room and table decorations. No collection of plants is complete without ferns.

In the vicinity of Boston no other plant is used so extensively as this graceful Nephrolepis, which differs from the ordinary Sword Fern in having much longer fronds, which frequently attain a length of six feet. These arch and drop over very gracefully, on account of which it is frequently called the Fountain Fern. This drooping habit makes it an excellent plant to grow as a single specimen on a table or pedestal. Always address,

THE FLORAL WORLD, SPRINGFIELD, OHIO.

\section{ASPARAGUS SPRENGERI.} THE EMERALD FEATHER.

A most desirable new species, especially useful to grow as a pot plant for decorative purposes, or for planting in suspended baskets. The fronds are frequently four feet long, of a rich shade of green, and most useful for cutting, retaining their freshness for weeks after being cut. It will make an excellent house plant, as it withstands dry atmosphere, and will succeed in almost any situation.

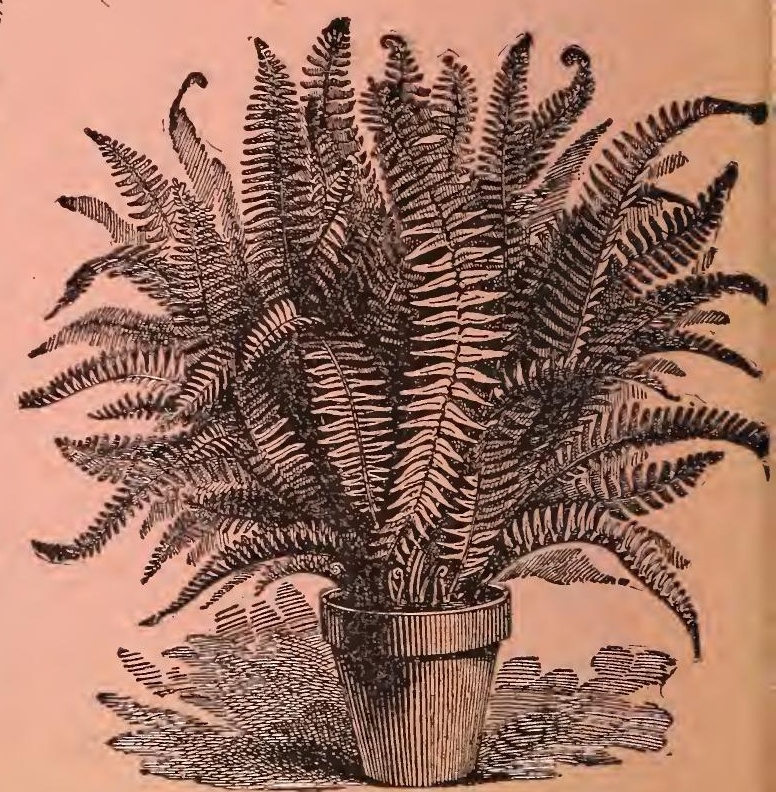

If you send a club of ten, all subscribers who pay 25 cents a year instead of 15 cents, will receive free these two plants. 


\section{The Floral World}

A Fournal of Home Floriculture

Vol. 1, No. 8

Springfield, Ohio, May, 1902

25 Cents a Year

WORDS OF APPRECIATION.

I enjoy The Floral World, and I wish it came oftener.

Minnesota.

Mrs. W. A. H.

I hope the dear Floral World will continue on its mission.

Maine.

Mrs. A. P. A.

I am a subscriber for The Floral World, and like it very much.

Kentucky.

M. L. J.

Every article in The Floral World seems up-to-date, and every one contains something one wants to know.

Missouri.

A. C.

The Floral World is always on hand in good season, full of practical information.

Connecticut.

Mrs. R. J. P.

I think The Floral World is one of the best floral magazines for amateurs ever published, and I hope it will always continue to be just what it is now.

Nebraska.

Mrs. O. H. H.

I am pleased with the little Floral World. I shall bind my numbers. I hope you will continue publishing the unique floral educator.

California.

Mrs. J. E. C.

The Floral World is the best and cheapest floral guide I have ever taken. Every flower raiser should have it to get the best results.

Virginia.
I am much pleased with T'he Floral World, and think it will be a success. Missouri. Mrs. N. P. B.

The monthly advent of The Floral World has become a red-letter day at our house. We consider it a little jewel. "May it live long and prosper."

Texas.

Mrs. J. M. BALliNGer.

\section{FLORAL CLUBS-AN EXCELLENT IDEA.}

I have just been looking over the subjects for discussion at the next meeting of our Floral Club, and it occurred to me that the readers of The Floral World might care to hear how we Texans are trying to promote the love for and increase the cultivation of flowers in our town.

Our club grew out of the desire of five or six ladies to meet and "talk flowers." From that it has grown to a membership of twenty-eight or thirty. We meet every other Tuesday at the homes of the members and spend an hour most delightfully in discussing flowers and their needs, eacn giving the rest the benefit of her experience, and, in fact, enjoying an (unpublished) Floral World. Last fall we held a most successful flower show, chrysanthemums constituting the principal feature. This May we will have another, with flowers and plants of all descriptions. We offer simple prizes to induce outsiders to exhibit, and charge a small door fee to defray expenses. Why not have more floral clubs? They are educational and refining.

'Texas. Mrs. J. M. BALlinger. 


\section{MY CHIPYARD GARDEN.}

We have our chipyard in front of the woodshed, which joins the kitchen, consequently it has been an eyesore during summer, but it is so no longer. I went on my knees, figuratively, for possession of that chipyard, the trouble being to get the wood out of it early enough. The chips were raked and put in barrels, the sawdust and rubbish thrown into the closet and henhouse.

A strip on the east was well spaded and planted with string beans, tomatoes and lettuce. These grew finely. A path through the middle and on the west, nearest the house, was bordered with flowers.

Next the road was a round bed of dwarf nasturtiums, with three castor beans for the center, next a bed of cannas, with castor beans for center of that, with sweet alyssum border. Nearest the house was a three-cornered bed of asters, and such giants 1 never saw.

A strip where the yard was uneven was planted to morning glories, which were given support. I used phosphate, but no barn dressing. The only drawback was weeds, but ten minutes with a hoe on hot days kept it clean. I did all the work myself after it was spaded, and did some of that.

Maine.

Sister BeE.

ONE WINDOW BOX.

A small boy and a puppy will preclude the possibility of vines at the windows this year in the ordinary way, so I will procure a box of the proper size and length and suspend it by means of stout hooks and a small rope, and in the rich soil it contains will plant my window garden, including a generous supply of smilax, secure from the mischievous youngsters. The hooks will first be wound with cloth, so as not to cut the rope, and there will be two pieces of boards a little longer than the width of the nailed across the bottom of it, and the rope fastened around the ends of these so the box will not tip and spill the contents.

Then, when the frosty nights come, we will unhook the ropes and transfer the box, with all its beauty, to the inside of the window as the strings for supporting the vines will be tied to a stick fastened across the top of the window frame, and can be removed and placed on the brackets inside the window.

Minnesota. Eleanor R. Bartlett.

\section{BEDDING OUT VIOLETS.}

Last June I took my violets out of the boxes in which they were planted for the winter. I separated them and made a bed of good, mellow soil along the fence, where they would only get the morning sun. I planted each violet separately and pinched off all the tops and the runners. I liept them watered and did not let them dry out during the hot summer months. The first day of September I took them up, planted them in clumps in shallow boxes. They soon filled the boxes and bloomed continually all winter, and 1 had violets till the following summer.

$$
\text { W. Va. Miss. Carrie La Rue. }
$$

\section{A BIT ABOUT DAHLIA CULTURE.}

I plant my dahlias on the east side of a shed, about three feet from it, so the water from the eaves falls back of them. This provides them with. water most of the time. If the soil is good, it will do without a fertilizer; if not, give a good supply of well-rotted manure. Let your border be two feet wide and spade it well; then you are ready to plant. About the first of May get good dahlia roots, plant two feet apart in the row, cover the top 
of the roots at least two inches. When they are well up, hoe as you would regetables. When two feet high put good, strong bean poles well in the ground just back of the plants, to tie them up, to keep the wind from breaking them. Mine grow from four to nine feet high.

Kentucky. Maria L. JoHnson.

\section{HOW TO GROW FERNS.}

I have been very successful with Boston and Sword ferns. I never allow them to become root-bound, but shift to larger pots and fill around with well-rotted manure. I keep pots In pans of water during summer. I put a few drops of household ammonia or aqua ammonia in water twice a week, and sprinkle with cold water occasionally. Keep the runners cut off and give liquid manure once a week. Keep pots sitting in one position, as the fronds will turn to the light. Keep in a cool, well-lighted location-not sunshine, but with bright light.

By August I had mine in two and four-gallon kegs. The fronds measure from 36 to 58 inches long, perfectly symmetrical. The secret of growing ferns is, Give plenty of pot room, water, nourishment, cool, bright location, and never neglect to attend to them.

Georgia.

Mrs. I. O. CrabB.

\section{AMATEURS' SUCCESS WITH ROSES.}

I ordered twenty roses from a reliable florist at five cents each, to be nnsent when he thought best. Before they came I had borders in a sunny location spaded fourteen inches deep. The soil was sandy and loamy, so all that was needed was plenty of wellrotted cow and horse manure, worked in smoothly. The roses came on May $\mathbf{1}$, and were placed in lukewarm water for an hour. Then I set out two feet apart, care being taken to place rootlets in a natural position with the earth pressed firmly to them. I watered them then and constantly all summer. The first week I protected them from the sun with newspaper funnels, removing them late in the afternoon and replacing them next morning. I raised eighteen out of twenty, and several were in bloom by August. In the spaces between the roses I put beds of phlox and sweet alyssum, nasturtiums and geraniums.

Virginia.

BRIDGET.

I know of no flower that requires so little care and gives flowers almost the year round as roses-tea and hybrid roses, in particular. 1 get oneyear plants from the florist, and can usually find what I wish in the tencent list, so the cost is but little. Clay soil is best, and good drainage.

Pack the soil firmly about the roots, leaving it loose at the surface of the ground. When manure is scarce, use it in making a weak tea for the plants.

Soot from the stove and soapy wash water are good for roses. Frequent stirring of the soil gives good results, and I don't neglect going over your garden once a week with shears, clipping off all faded blooms. For green aphis spray with kerosene. Give all large bushes a stout stake for support. My roses, which I heartily recommend, are as follows: Champion of the World, Highland Mary, Papa Gontier, Perle des Jardins, Queen, Sunset, Winter Gem, Pink Polyanthus, Kaiserin A. Victoria, Crimson Rambler and Mary Washington.

Oregon. Mrs. Olive Chamberlain.

\section{OLD-FASHIONED FLOWERS ON THE EAST SIDE OF THE HOUSE.}

In a strip of garden six by forty feet I planted in the foreground (or front bed), five feet square, choice pansies; in the next, Phlox Drum- 
mundii Grandiflora; then a bed of Dianthus pinks, one of Marguerite carnations, one of gaillardias, one of choice antirrhinums, one of asters, with choice red cannas in the background. Close up to the house was a row of smilax, trained on strings fastened to small stakes in the ground and nails in the eave trough. The border to the whole was red, white and blue; first acaranthus (red); second, sweet alyssum (white), with the front border of blue lobelia.

On the opposite side of the walk, where the plants got more sunshine, I planted in the front bed, verbenas, bed two, colossal ten weeks stocks, next, mixed stocks, a bed of double and large single petunias, one of French marigolds, one of coreopsis, one of zinnias, one of African marigolds, with a bed of cosmos in the background. On the east side a row of choice chrysanthemums the full length, sixty feet, with a hedge of La France rose bushes. Each bed got the proper care and culture, watering, mulching and liquid manure when needed. The border next the walk was first sweet alyssum, second mignonette, third white Rocket candytuft. As a whole, it as greatly admired. We had an abundance of flowers at little cost, with plenty of choice seeds and plants to start our garden the next year.

California.

\section{J. HoOPE}

\section{MAY NOTES.}

Chinese primroses that have bloomed all winter should be placed out in a shady place in the garden and only watered enough to keep them alive. In autumn repot them in light, rich, porous soil, setting them a little deeper than they were before, being careful not to cover the crown. Have your drainage good.

Plunge your pots of cyclamens out in a sunny spot in the garden until the end of August. Then repot in rich, porous soil, disturbing the roots as little as possible. These plants bloom all winter with little care.

Feverfew is hardy if not allowed to exhaust itself blooming. When the first crop of flowers fade, cut the stems close to the ground. This will make both roots and foliage grow well and strong, so as to enable the plant to withstand severe weather of winter.

Abutilons do best in part shade and in rich, well-drained soil. Water only when the soil becomes dry; then give plenty. A good place for abutilons in summer is in a rich bed on the east side of the house. Golden Fleece is the best yellow, Enfanta Eclipse, the new white, Driven Snow.

Nebraska. Mrs. O. H. Hereford.

\section{PLUMBAGO LAPENSIS.}

This is one of the finest shrubby plants for the amateur. It grows rapidly and blooms in large clusters at the ends of the branches, a superb light blue bloom. It may be grown as a pot plant, and will make a fine specimen if given a large pot and rich soil. It will also bloom in a small pot, among the window plants. The flowers are produced in the new wood soil, so it is desirable to encourage good growth. This can be done by pruning. I prune as the flowers fade, cutting them away with a good portion of the branch, thus stimulating the growth of new shoots with their terminal clusters of flowers. The plant likes strong fibrous loam, with frequent top dressing of rotted manure, plenty of water and always full sun.

Missouri.

Axnie E. Crafts. 


\section{ABUTILONS AND CINNAMON VINES.}

The abutilon, or flowering maple is as easily cared for as a geranium, but requires a liberal supply of water. It blooms in the winter, and brightens the room with its bell-shaped flowers of pure white, different shades of yellow, ranging from pink to dark shades of red. The leaves of the plant are beautiful in shape and color, without the blossoms, but I have tound them free bloomers.

For a vine for all places $I$ find the cinnamon vine fills every requisite. It has handsome leaves, glossy green and pointed, blossoms small and fragrant, nothing to admire, but the vine is beautiful, attaining a height of fifteen to twenty feet in a season. In the fall the vines die down to the ground, are hardy, have seeds that look like miniature potatoes.

Connecticut. Mrs. R. J. Bradley.

\section{ROOTING ROSE SLIPS.}

Rose cuttings may be rooted without the aid of a hothouse. Prepare the bed as for rooted roses, by throwing out two feet of soil, filling in six inches for drainage and the remainder rich, fertile soil. Two by four feet will hold sixty slips. Just after a blossom has matured the wood is usually in prime condition.

Cut slip with four buds; firm soil over two; cover with glass jar till leaves start, then lift slightly for air. Shelter from hot sun; keep soil moist. Slips may be rooted in this way from early spring till freezing weather. Those placed under jars in fall will be ready for spring growth.

My cuttings, kept in wet sand under flower benches in pit without artificial heat, by March are healed and ready to set out.

Missouri.

EMnIA VANDIVERT.

\section{SWEET PEAS.}

Sing a song of Sweet Peas,

Growing in a row,

In the flower garden,

Where warm breezes blow.

Sing a song of Sweet Peas,

Red and white and blue,

Colors of our flag here,

Wave the summer through.

Sing a song of Sweet Peas,

Blithe they wave and gay,

Optimists of flowers,

Care cannot stay.

Sing a song of Sweet Peas,

Full of gladness, so

None can but love them

Everywhere they blow.

Ohio.

Arлice Bndey Calland.

\section{CALIFORNIA POPPIES.}

(See illustration on corer of this issue.)

Poppies are the brightest flowers in bloom now. They rival the roses of June. Impressed with their beauty, as all beholders are, the amateurs apply three rules to heart, and succeed in cultivating these dazzling red, white and yellow beacon lights of the garden. First, gather the seeds ripening in June, and either sow them at once, broadcast, or reserve them till fall and sow them over the beds prepared for bulbs. They will not interfere with the bulbs. The seeds lie dormant through all changes and severities of weather, springing to life early in the spring. The pretty little seedlings in whitish-green, scalloped leaves, look tender, but are iron-clad. Never sow poppy seeds in spring.

Do not transplant. Let the top roots anchor the plants to their birth spot. Let them bloom and seed where they are born. Then sow the seeds in sunny places. Poppies flourish only in the hot sunshine. Oriental poppies are the brightest red, California poppies the finest yellow sorts.

Louisiana. Mrs. G. T: Drennax. 


\section{OUTDOOR BEAUTY SPOTS.}

The articles on rockeries in the April Floral World are good, if rockeries are desired. But do we want trem, if not in harmony with our surroundings? Think over the situation before one is made. Ferns and wild flowers in an out-of-the-way nook, with a few moss-grown stones irregularly placed, as though by nature, are restful and pleasing, but a symmetrical arrangement of stones in a mound, where nature gives no evidence of their existence, does not carry out the eternal fitness of things. I have even seen the stones whitewashed. Think of the incongruity?

When planning beauty-spots let us wisely consider whether the arrangement admired in neighporing gardens is appropriate to our own. Better adopt plans that harmonize perfectly with our own surroundings. For a porch with sunny eastern exposure, place a long box outside the porch railing, filled with luxuriant plants and vines. Beneath plant a row of scarlet salvia, then one of caladiums, next one of scarlet geranicms, edged with sweet alyssum. Most of the plants can be raised from seeds or cuttings.

Michigan. Mrs. E. R. B. BARber.

\section{A FEW HINTS ON TRANSPLANTING.}

Having lost but two out of over 1,000 seedlings set out in sunshine, I will tell my secret. It is strawberry baskets. Turn a little water in each hole, carefully put in the seedling, fill in and press the soil about it, then give a good watering; next a mulch of dry soil. Now cover each plant with a strawberry basket, which will protect from the sun, but not keep out the air. A heavy shower ruined some that were not covered, while the others were unharmed. Remove the baskets in a few days, when it is cloudy, or at night. Don't crowd the plants. Asters, stocks, etc., look lonesome at first, twelve to eighteen inches apart; so do verbenas, two to three feet. but soon the branches will be so intertwined that you cannot see the ground.

Cutworms work at night. If you carefully search in the earth near the eaten plant you usually find them. A bran mash, with a little molasses and Paris green to flavor, spread about the plants at night, will finish $\mathbf{M r}$. Worm.

Maine.

Aroline.

\section{TWO PRETTY GARDEN NOVELTIES.}

Try a Gypsy camp-fire this summer and see how quaint and pretty it is. Make a strong tripod, drive it into the ground far enough to make it firm. Then suspend an iron pot from it, filled with rich, loamy earth. In this plant sweet alyssum and candytuft. Under and around the pot set scarlet geraniums or freesias. When in bloom and seen from a little distance there is a wonderful resemblance to a steaming pot with a bright fire beneath. The tripod and pot is very pretty with weeping lantana to hang over the sides and pansy geraniums in the center.

This floral basket we never tried, but it is said to be lovely. You make it thus: In the spring set willow twigs in the ground in the shape of a basket, weaving them together; then put two long willows on opposite sides and twist together to form a handle. Fill with soil and plant dwarf nasturtiums or phlox inside. Water the base of the basket copiously to insure the willows living, and keep them well trimmed in shape. When your nasturtiums bloom, your friends will think you have gathered a basket of flowers and forgotten to bring them in.

Virginia.

BRIDGET. 


\section{SPRING ITEMS.}

Don't forget that June is the best month for planting tuberoses and sladiolas and for sowing perennials.

The best time to start rose cutting is in June and July. Put them in a shady, moist place, protected from the wind. Leave only a leaf and an eye above the surface. Do not use sand for outdoor propagation; it dries out too quickly.

Many persons fail with tuberoses because the bulbs have not been kept warm and dry through the winter, or because they have been planted too early. The soil should not be wet or cold after planting to have the best results. None of the tender bulbs should be watered freely immediateiy after planting in the soil.

Lon't forget to include the Moutbretias in your spring order. It is a fine flower, graceful in growth, drooping slightly, fine for bouquets, the color a glowing orange red, and just what we need in early fall. You can grow it in boxes and then you can take it indoors. Put a dozen bulbs in one and see what a very pretty pot full you will have for your window.

Try Canna, Martha Washington, Rosemawe, Shenandoah and Duke Marlborough.

Missouri.

Mrs. John ERNst.

\section{THE USEFULNESS OF HOT WATER.}

No one thing, I believe, is so necessary in the care of house plants in winter as plenty of hot water. First, I place among my pots each morning several granite pans filled with boiling water, before even I raise the window shades. Next, I pour water from the same teakettle into the saucers underneath pots of calla, sword fern, Asparagus Plumosa and Asparagus Sprengeri. I fina no fertilizer to compare with it. I spray or sprinkle all plants but rough-leaved begonias and primroses, plentifully, at least twice a week, to freshen foliage and keep off red spider. For aphis, I dip the plant into hot water (since coolking one plant I do not use it more than 100 degrees Fahrenheit), and for white worms I pour hot water on the soil in the pot. When amaryllis start, I use hot water in the saucer to strengthen and hasten growth. And my Olea Fragrans, when budded, I give a hot foot bath, with the result that it bursts into bloom.

Minnesota. Mrs. E. A. TAYLOR.

\section{GETIING BEGONIAS READY FOR SUMMER.}

My collection of begonias has outgrown their summer quarters, and I am planning to get a new home ready for them. I shall have a strip a foot wide dug all along the north side of the house, next the foundation, and plenty of well-rotted manure dug in it. Then I shall dig holes in it at equal distances, in which to sink my pots of begonias, and set them in empty pots of the same size. Next I will go up to the woods and get clumps of wild maidenhair, bringing lots of wood earth along with the roots, and plant them between the pots, back against the foundation, while to the front of the pots and between them I shall put bunches of striped grass, and make a border of myrtle vines-both the grass and myrtle being plentiful. Then when it gets warm enough, I shall lift out my empty pots and set in the pots of begonias, and that bed will be a thing of beauty all summer-and many summers.

New York. Mrs. Nelson Puff, JR.

MAY TO APRIL.

Without your showers

I breed no flowers,

Each field a barren waste appears,

If you dor't weep

My blossoms sleep, Indiana.

They take such pleasure in your tears. Mrs. R. A. Houk. 


\section{The Floral World} PUBLISHED MONTHLY BY THE

FLORAL WORLD COMPANY, 12 to 14 South Limestone Street, SPRINGFIELD, OHIO.

Subscription Price, 25 Cents a Year.

Entered as second-class matter at the Postoffice in Springfield, Ohio.

We will give $\$ 26.00$ in prizes for the five best articles for publication in the July number of THE FLORAL WORLD which may be submitted by subscribers.

The first prize will be $\$ 10.00$; the second, $\$ 7.50$; the third, $\$ 5.00$; the fourth, $\$ 2.50$; and the fifth, $\$ 1.00$. The awards will be announced in our August issue.

No article which contains more than two hundred words will be cousidered. All contributions entered in this prize contest must reach us not later than June 1.

The purpose of these prizes is to secure for publication in THE FLORAL WORLD matter which gives the actual experiences in flower growing of those who have subscribed for the journal. Prizes offered for articles published in the April number have been awarded as follows:

First prize-Annice B. Calland, Ohio.

Second prize-Lizzie D. Abernethy, Tennessee.

Third prize-Laura Jones, Kentucky.

Fourth prize-L. C. Whitaker, Iowa. Fifth prize-G. A. Flory, Nebraska.

\section{CALLA BULBS.}

After the usual season of rest and drying. my calla bulbs (not unusually large) were potted in good earth, with which was mixed about two cents' worth of powdered glue to each pot. Nothing further in the way of care or fertilizing was used, and at the present writing one pot containing one bulb has thirty leaves; some of them, aside from the stems, being fourteen inches long; three blossoms, two buds, and I have picked five blossoms from it already this year. The blossoms and stems are thirty-eight inches long. It stands in a large, forty-eignt-inch wide window, and fills it entire.

I attribute all of this to the glue, which is the fertilizer best adapted to the calla.

New York.

Mrs. D. H. T.

\section{THE RIGHT TIME TO PREPARE FOR WINTER}

If you want a nice window garden next winter, begin now. Don't wait till summer to start slips. Don't wait till fall to buy young plants. Get them now, repot as they need it, and have them in good blooming condition when taken in.

Most varieties will need to have buds pinched off, to make them store up their energies for winter. I never find it necessary with begonias or abutilons. They may bloom when they please, and, if well treated, will not fail to bloom well in the house. Begonias have very fine, delicate roots, and need an open, porous soil. The arbutilons need rich dirt and plenty of water after becoming well established.

When you bed out your geraniums save a few for winter blooming. Such varieties as Souvenir de Mirande and Mme. Bruant are lovely, and will bloom all winter if kept in pots durfng summer.

Give them just enough water to keep them from wilting, and pick off the buds till early in September. Then give more water and some fertilizer, and don't let them stay out on frosty nights.

Missouri. Mrs. M. P. BurCH.

I wish The Floral World the best of success.

Kentucky.

Miss. L. J. 


\section{OLD ROSE BUSHES.}

It is not necessary to reset the hedge of hardy roses if properly planted at first. I think commercial fertilizers less liable to breed insects than barnyard manures. Work lightly into the top of the soil in the fall and fill in and around the bushes with dead leaves. Do not remove the leaves in the spring, but, when leaf buds begin to swell, cut away all the dead and small weak canes of last year. Go over it again, removing most of the scraggy three-year-old canes and more of the weak ones. Once more go over it, cutting off the tops of the remaining canes. Leave them about two feet long at the outside, increasing to five or six at the back. A rope tied around them to a stake at the back before the leaves start will soon be hidden, and will be needed when blooms appear.

I have followed this plan on roses set out ten years ago, and every year the roses seem larger and richer. The secret lies in severe pruning. My neighbors think I must be crazy when I prune my bushes, and that I am "lucky with roses" when they bloom.

Iowa. EVA I. GRIFFITH.

\section{FOUR FLORAL BEAUTIES.}

Asparagus sprengeri, Bostonian fern, asparagus tennissimus and arancaria excelsa, form a beautiful quartette that has just been awarded the first premium at our third annual fair. These plants combine in a remarkable degree the two requisites of easy culture and floral beauty. The chief danger lies in the decaying of roots by watering too copiously when in growth, or by not withholding water when in a state of rest, which is from January to March. Understanding the philosophy of how to water, success is assured. Asparagus sprengeri, when a mere featherless sprig, was received through the mail in midwinter and planted in a four- inch pot filled with well mixed leaf mould, sand and rotted manure, the latter put in the bottom over charcoal for drainage. Keep in the summer on a cool shady gallery, and in the winter in a frost-proof room, but always in fresh air and good light.

There is no plant which makes a grander show and yields so large a return of beauty with so little trouble as the Boston fern. Light, air and cleanliness are three primary rules to follow. Being a strong, rapid grower, frequent feeding with fresh loam conduces to its vigor. Be careful not to crowd this plant, a free circulation of air is essential. With the same method advised, the asparagus tennissimus will reach the summit of a five-foot trellis symmetrical in shape, healthy in color and gemmed with a profusion of lace-like foliage. The arancaria excelsa will do well for an amateur florist under good treatment. It is a moisture-loving plant, though it resents stagnant water. Use sand liberally to make the soil porous to allow the water to percolate freely.

Louisiana. Mrs. W. N. White.

\section{BEGONIAS EASILY GROWN.}

Begonias are beautiful and easily grown plants. Take cuttings and place them in water until well rooted, then put in small pots, providing good drainage, using a soil composed of leaf mold, sand and a little loam. Water only when the soil looks very dry. In winter give them a rather warm place, but not in strong sun. Shower them once a week, also fertilize them once or twice a month. In June cut them back half, keep rather dry and in the shade until September. Then repot, using pots a size larger.

The best varieties I have grown are first, Manicata Aurea, beautiful green leaves with cream spots, grows very fast. I have a young plant of this va- 
riety with leaves four inches across. Second, Metallica; I have a plant three years old, nearly two feet high, and it fills the upper part of a window. It never gets a ray of sunshine all winter. Third, Argentea Guttata, leaves bronze, covered with small white spozs, grows very fast in sun or shade, and soon makes a fine plant. Fourth, Rubra; this variety needs to be pinched back when small to make it branch, is beautiful when well grown. Begonia Vernon is fine also, and always in bloom, even when greatly neglected.

Another thing begonias like is moisture in the air, and to secure this I keep a can of water on the coal stove. Admit fresh air to the room daily, if possible. A temperature of 65 or 70 degrees through the day suits the begonia, and it should not go lower than 50 degrees at night.

New York. Jennie M. Reynolds.

\section{SOME GOOD VARIETIES OF BEGONIAS.}

I think one of the very best plants Tor amateurs is the begonia. One could have a window garden of begonians and two plants alike. They are so easy to grow. I use very rich soil, light and porous, with little. humps of charcoal mixed through it, and old bones, for drainage. Sometimes I use a little bone-meal in the soil. Pot well and then let them alone. Disturbing the roots by frequent repotting is all wrong. They do better let alone.

Let me give you a list of some that have done remarkably well for me. It is so much more satisfactory to get a plant that has been a success with some one else, for I hold that what one person has done another can do.

First must come some of Mrs. Shepherd's new begonias from "Ventura by the Sea." They are extremely beautiful-enchantress, brilliant, autumn leaf, heart's delight, ernani, fair Rosamond, striking beauty. Of the older sorts, there is ricini folia diadema, rubena, gilsoni, weltoniensis, pink and white varieties, gebrina, odovrata, pink and white varieties, Otto Hacker, rubra and the pink rubra, Carolinafolia, Pres. Ganbri, Pres. Carnot, Paus Bruant, Mme. de Lesseps, haageana, duchartreii, compta, robusta, the semper florines class, both single and double, aggrostignia picta, verschoffeltii, olbia, vitida, feastii, manica la aurea. With all these I want more. Nothing seems to answer every purpose and situation like the different varieties of the begonia.

For summer we have the tuberous begonias, but we will speak of them near spring. If one can have only one sort of plant, I say invest in the different sorts of begonias, and such a pretty window garden you will have. Mrs. O. H. HerEFord.

Nebraska.

THE VERNON BEGONIA.

The most satisfactory plant for all the year round bloom, that I know of, is the Vernon begonia. I use common garden soil, with one-third rotten sods, and, when in full bloom, give liquid manure once a week. After mine had bloomed in the window all winter, I divided my plant and placed it in a bed in my back yard. I then filled in all around the begonias with sweet alyssum-"little gem." I just had blooms to give away from that bed all summer. When frost came I carefully lifted my plants, shaded them for a few days and placed them in the south window of the kitchen, where their crimson blooms cheered us all the winter. A few plants of curly parsley look fine among the begonias.

Iowa. Mrs. G. L. Flowers.

\section{BULBS AND CACTI.}

My hobby is bulbs and cacti. I have some fine specimens of grafted cacti. 
The friesia I grow from seed, and they bloom for me the first year, as does also my smilax and passiflora. I srow from seed and can get a greater variety for far less money.

Iowa. MRs. P. W. Hopkins.

\section{GERANIUMS IN THE WINDOW.}

Geraniums are unsurpassed window bloomers. They have no eccentricities to be humored; varied enough to fill a window themselves, they yet harmonize with the rank and file of winter bloomers, including Holland bulbs. Many disappointments occur from want of congeniality among plants in the same collection. Geraniums have greater adaptability and bloom under like conditions with greater variety of plants than any other ever-blooming plants. They bloom freely in any but the northern window, in a temperature not above seventy nor below fifty degrees.

Three or four hours of sunshine per day keeps them flowering from fall to spring. Unglazed earthenware pots are decidely the best. Fill them with cured or dried cow chips, broken into pieces. Fill the interstices and an inch or two over the surface with leaf loam, decayed to the consistency of sawdust and silver sand. Open enough for the free passage of water, this soil is yet spongy in retaining a due amount of moisture. The roots van ramify and feed without obstruction, and the sun-warmed air can penetrate unglazed earthenware pots with this porous soil. Every particle of this home-made potting soil is nourishing. It is half the battle.

Watering geraniums (and all other potted plants) is the fine art of floriculture. Few, almost no amateurs, understand watering window plants. Geraniums ought to be thoroughly watered and then let alone until the soil is barely moint, almost dry. Too copious and too frequent waterings are disastrous. If the opening in the bottom of the pot kept free for egress, and all surplus water escaping, overwatering will be counteracted in a measure.

The foliage of geraniums must be sprayed or showered oftener than water is given the roots. The under as well as the upper surfaces of the leaves must be sprayed. Bushy plants, dense with foliage from their moisture, help to keep the air humid, which is highly important. Hot, dry air is injurious to geraniums.

Tobacco snuff scattered over the plants before spraying will wash off, settle at the apex of the leaves and on the soil, proving itself a preventive of insects, worth a pound of cure.

Liquid fertilizer is necessary for blooming plants, and for geraniums in the window of the sitting room I unhesitatingly recommend one gill of ammonia to a gallon of rain water. It is vitalizing to the plants and purifying to all emanations.

Transoms over the doors, if opened, and sashes drawn down from the upper part of windows, are better means of ventilation than direct currents of air. The pots must be set several inches apart to permit circulation of air.

Geraniums under this mode of treatment bloom grandly. Trinity church, New Orleans, on Easter morning, 1900, was profusely ciecorated with White Swan, Favcrite and Mrs. Gladstone, all pure white geraniums. They even surpassed the lilies in loveliness. Bruant, General Grant, Profusion, Mars, Souvenir de Mirande and Beaute Poitevine are heroic bloomers. Their average never ialls below ten or a dozen fine blooms to a plant, if given suitable culture.

Louisiana. Mrs. G. T. Drennan.

The Floral World is an ideal magazine for flower lovers. Long life to it. Kansas.
JoHN P. HAYNES. 


\section{SWEET VIOLETS.}

The violet is one of the most satisfactory plants that an amateur can have for winter blooming. Here in Western Nebraska violets do not thrive as well in the yard as in a climate where there is more moisture in the ground in the early spring and fall. If given a slight protection, they will do fairly well. About the first of September I take up my plants, and put them in pots. They need four inches in depth for the roots to thrive well, and good, rich garden soil. I put them in a north window. In a few days new leaves and buds appear. I then give them a place with my other plants in the south window in the dining-room. I do not give them the direct heat from the sun; but they must have sunshine. They will bloom all winter and fill the room with their sweet fragrance. If I could have but one house plant, I should choose the violet. Swanley white, Imperial, Alaska are a desirable collection for house blooming. Get your plants so as to put them in open ground in April.

Nebraska.

M. W. H. Pedley.

\section{BEAUTIFUL FLOWER BEDS.}

In Southern California this is the time to arrange your nower beds. Spade and mix the soil thoroughly with well-rotted manure from the barn yard, or, if your ground is very hard, dig down six inches or more and fill with leaf mold and sand to a depth of one-third. Water this well before planting or sowing seed. Pansy seed sown now and kept damp will bloom nicely by spring. I have a charming design, which always looks well. The shape is a large crescent flower bed with a star-shaped bed a little distance from curve crescent far enough for a nice walk between the two. At present these beds are full of various bulbs, and later on, (Concluded on page 13.)
DR. CHARLES' FLESH FOOD.

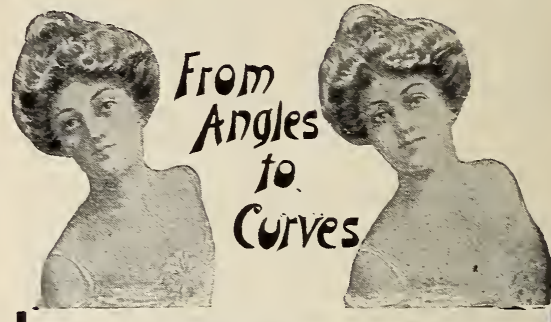

\section{Dr. Charles' Flesh Food}

has been used by leading actresses, singers and women of fashion for more than twenty-five years.

It has the highest endorsement of the medical profession who acknowledge it to be the only preparation that will increase flesh in the face, neck and shoulders.

For remoring erery blemish of the complexion and DEVELOPING THE FORM it is without equal.

The regular price is one dollar a box. but to all who mention this paper and send us $\mathbf{8 1 . 0 0}$, we will send two (2) boxes by return mail, also our book "Art of IIassage," which is illustrated and contains much valuable information.

FR EE-A sample box of Dr. Charles' Flesh Food; also one of the abore books will be sent free to any lady sending us 10 cents to cover cost of mailing. Address :

19 Park Place. D. CHARLES CO., New York.

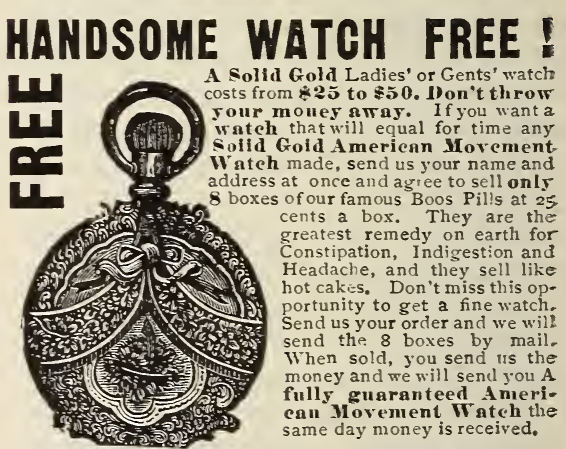

BOOS MANUFACTURING CO., POXEEPSIE, N. Y.

\section{Magic Age Thermometer.}

You can tell the age of any person, number of dollars in their pocket and the number of lovers they have; barrels of fun for young or old. Sample and catalogue of useful novelties 10 cents. Agents Supply House, $639 \mathrm{Elm}$ street, Dept. E, New Haven, Ct.

\section{GOLDFISH : GOLDFISH! GOLDFISH:}

Handsome gallon HANGING FiSH GLOBE with chaing, 3 BEAUTIFUL GOLDFISH, Green Moss and box of FisH FOOD sent BY EXPRESS FOR \$1.10. GOLDFISH 10 CTS. EACH. Arthur V. Kempton, 515 Vinewood Ave., Detroit, Mich.

ARENTS MAKE $\$ 5$ a day selling Toco-Lo. Gum AGENTS of the wash-day. No rubbing. Samples 10c. Toco-Lo IIfg. Co., Portland, Oregon. 
(Concluded from page 12.)

when they are through blooming, my pansies and other low-growing plants which are up now from seed, start blooming all through spring and summer. While verbenas and petunias bloom way into the fall when witner bulbs start viooming again. These flower beds are a constant delight the year round. Avoid planting anything that will grow too high, which would spoil the artistic effect, except in the center, where I put plants growing a little taller.

California. Mrs. H. C. SNYDER.

\section{PLANTS IN THE SCHOOLROOM.}

In September I beg from my friends good, healthy slips of geraniums, foliage plants and ferns. I choose these because I have good results from them. This year I have also a pink oxalis whose cheery blossoms are a constant delight to us all. My schoolroom is well arranged for the growth of plants, being well heated and having seven large windows, four with the morning and three with the afternoon sun. The sills are fitted with raised boards, each holding eight five-inch pots. I pot my slips before the children and often with their help. I use leaf mold and rich black swamp earth mixed, for the geraniums, and the black soil alone for the ferns and foliage, without manure of any kind for eitner. I have never rooted a slip first. I plant them at once and rarely lose one. I keep on hand a tin pail of horse manure well filled with water, and this I use twice a week instead of the daily supply of water. I attribute my lovely plants and blossoms to the regularity of their care. They are watered, aired and sprayed daily with a whisk broom for an atomizer. I pick oif and save the dead leaves and old blossoms. Once a week I dig up the soil and give each plant and pot a thorough bath and (Concluded on page 14.)

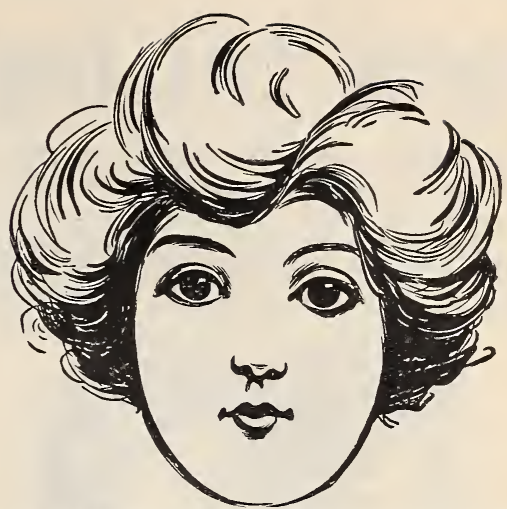

No lady should despair if her complexion is imperfect. Merely send your name and address to Mme. M. Ribault, 4346 Elsa Bldg., Cincinnati, Ohio, and she will send you free, prepaid, in plain wrapper a trial package of her wonderful remedies that absolutely guarantee a perfect clear skin. It is not a face powder, cream, cosmetic or bleach, but is absolutely pure and you can use it privately at home. It permanently removes moth patches, redness, crow's feet, pimples, blackheads, flesh worms, sallowness, freckles, tan, sunburn and all other complexion disfigurements. Write today and learn for yourself how easy it is to attain beauty when you know the simple truth and the right remedies.

\section{Drunkards Cured Secretly}

Free Package of the Only Successful Cure Known for Drunkenness Sent to All Who Send Rame and Address.

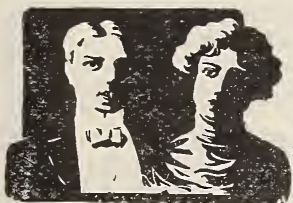

A new discovery, odor. less and tasteless, which any lady can give in tea, coffee or food. It does its work so silently and sure. work so silently and surewife, sister or daughter looks on, the drunkard is reclaimed even against his will and without his knowledge or co-ojeraMR. \& MRS. HARRY BURNSIDE. dress to Dr. J. W. Haines, 3071Glenn Bldg., Cincinnati, $O$., and he will mail enough of the remedy free to show how it is used in tea, coffee or food.

Mrs. Harry Burnside says "With Golden Specific l cured my husband of drinking. I put it into his coffee and after that he couldn't drink liquor or bear to be around where it was."

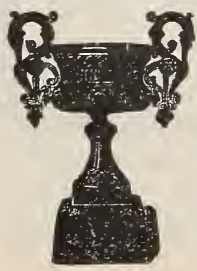

IRON VASES

For Lawns and Cemeteries.

These Vases have reservoir holding water, and flowers do not need watering but once in 10 to 15 days. We guarantee them in every way. Vases from $\$ 4$ to $\$ 90$. We save you money on Vases. If you want a Vase, write

F. A. FLOOM \& CO., Tiffin, Ohio. 


\section{Goitre Cure Free.}

Any Lady Can Quickly Cure Herself of this Ugly and Dangerous Disfiguration in the Privacy of Her Own Home. This charming and beautiful English woman fter trying great surgeons and doctors, cured herself in her own home. She says: "I noticed a slight swelling on my neck. A noted London

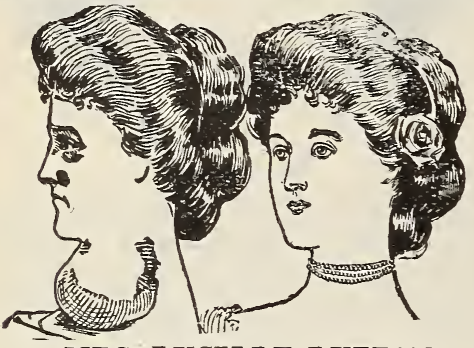

MRS. LUCILLE LYTTON,

Duchess of Newha11, London, Eng.

surgeon pronounced it goitre and felt sure he oould remove it quickly. Instead, it grew rapIdly. My appearance was dreadful, my ejes nearly popping from my head. Surgeons refused to operate for fear of rupture of the juguLar vein. My husband heard of Dr. Haig's home cure for goitre and we tried it - the effect was marvelous. In a few weeks all traces of it was gone, the pain ceasing the first time we used the remedy. Lucille Ly tton."

Your goitre can be cured at home without pain, danger or any inconvenience. Write today to Dr. John P. Haig, 3361 Glenn Bldg, Cincinnati, Ohio, tell him your age, the size and location of your goitre and how long you have had it and he will be glad to send you free a large trial package of his home cure, postare paid.

\section{THE BEST SPECULATIVE}

\section{INVESTMENT}

today is Oil and Mining Stock. Before you invest it will pay you to write for our free booklet, "How to Judge Oil and Mining Stocks."

\section{FORTUNES.}

have been and are being made in Oil and Mining. A little money invested now in stocks that we recommend will start you right. We never offer or recommend a stock until we have made a careful and searching investigation.

Development Oil Stccks, 2c to 10c per share. Dividend Paying Stocks, 20c to 50c per share. Development Mining Stocks, 3c to I5c per share.

Write us today stating the kind you prefer, whether low-priced development or dividend paying stocks, and we will send you our special offer, which. if taken advantage of will start you on the high road to fortune, UNION SECURITY C0.,391 Gaff BIdg.,Chicago

JAPANESE STAMPS 15 Japanese Stamps, all APANGSE STAinP different, 10c. 25 Oriental Stamps, all different, 10c. 7 Oriental Coins, all different, 10c. All three lots, 25c. All genuine. No reprints.

c. T. JOHNSON, LAUREL, MD.
(Concluded from page 13.)

change of window. On Saturdays and Sundays a boy waters my plants. When school closes for the summer I give a plant to each child to take home and keep. Aside from our pleasure in the winter, I think my plants are doing much for the children.

Massachusetts.

A TEACHER.

TINELY SUGGESTIONS.

In May you can set out almost all plants grown in the house. Keep young and tender ones shaded for a few days. It sometimes happens that we have a few very hot days in May. Care should then be taken to protect. young plants from the sun's rays. When setting plants out or transplanting, always serect a cloudy day to do it in. If it is raining mildly, all the better; it won't hurt you and will do the plants a whole lot of good.

If there is a spot in the garder. where it is possible to plant one or two more hardy shrubs without crowding, then let them be Stophy lea lochica, pure white bells; Spiraea Sorbifolia, white plumes; S. Anincus Kneiffi and S Palmata, Dentzia Lamoine, D Venista, Weigelia Coquette, Styrae Japonnica.

Don't plant any seed until the ground is in proper working order. If worked too wet, the soil will bake over the seeds, and few plants can push up through a hard soil.

Impatiens Sultana will do well outdoors, sheltered from wind and the midday sun. Do not let other plants crowd. It likes porous soil, well drained.

\section{Missouri. A. Elizabeth Badger.}

Through the kindness of a friend, I receive this year your magazine, The Floral World. I am pleased with my first number and would like to help the magazine.

Massachusetts. N. F. JoHnson. 


\section{Free to Ladies}

One Full-Sized $\$ 5.00$ Package of Dr. Mary Lock's Wonderful Home Treatment Given Free to Every Lady.

Cures Every Form of Female Weakness, Displacements, Leucorrhea, Suppressed or Painful Menses, Falling of the Womb, Change of Life, Litc.

The celebrated lady specialists have decided for a short time to give free, one full-sized $\$ 5.00$ package to every suffering woman in order to quickly introduce their most wonderful remedy

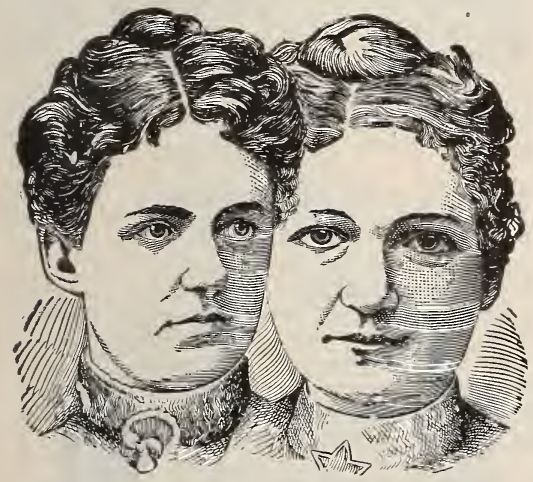

Two of America's Greatest Lady Specialists.

in every city, town and hamlet in the U. S They could not afford to do this only that they expect after you are cured and they know you will be and that you will recommend the remedy to suffering friends who will gladly order the treatment and in this way they will be amply rewarded for making this most liberal free offer Send your name and address to Dr. Mary Lock Co., 4346 Englewood Station, Chicago, Ill., for a free $\$ 5.00$ package and be quickly cured in the privacy of your own home.

Remember this is not a patent medicine but a full three-course treatment sent complete, in a plain package so that no person will know what it contains.

The above offer is genuine. We ask no questions or references of any kind. Every lady who writes will be given a full $\$ 5.00$ package free. Write today.

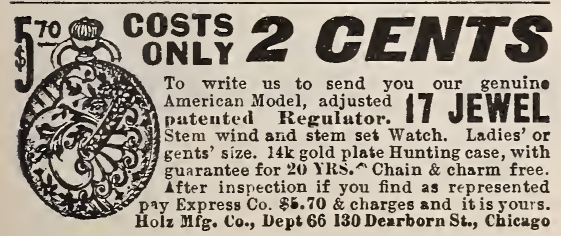

\section{THEY WANT TO KNOW.}

Where can une purchase Hoya belle and Hoya paxtonice? And how can one tell whether the right kind is obtained? I have never seen descriptions of them. Are the blossoms pretty and fragrant? Will they flourish in the house?

California. Mrs. J. E. Cohenour.

I have three carnations, from two to three feet high. In February they got tipped over and one was broken. 1 replaced them in the soil, but they seem to be dying. Should I water them and keep them in the sun, or out of the light?

Vermont.

A SUbSCRIBER.

Will some one kindly enlighten me how to treat my Perles des Jardins and Soupert roses? The bushes have fine foliage and grow nicely, but the buds blight by turning brown and sometimes the stems seem to die three or four inches below the buds. 1 pull them off and find a small yellow insect on the inside, which sucks the substance from the bud. If some one will give me a remedy to rthis trouble I will feel that I've received the worth of my subscription for The Floral World.

Texas.

Mrs. J. P. Patterson.

Will you please tell me what treatment an Azalea Indico requires? When shall I trim it, and in what way?

New York. X. Y. Z.

\section{BRIEF BITS OF FLORAL WISDOM.}

For Black Plant Lice-If Mrs. F. $\mathbb{L}$. Perrin will make a tea by steeping tobacco in boiling water and, whers cool, wash her plants with it, the black lice she complains of will entirely disappear.

: Texas. Mrs. J. M.'BALlinger.

(Concluded on page 16.) 
(Concluded from page 15.)

The Baby Primrose-This is among the loveliest of the constant blooming plants, bearing many dainty colored flowers. All it needs is planting, and it will grow.

Michigan.

Amelia Hyne.

As to the Oxalis Ortgiesi-I would say to Mrs. A. Z. Hoyt that the plants of Oxalis Ortgiesi can be purchased from the George H. Mellen Company, the Great Western Plant Company or the Good \& Reese Company, all of Springfield, O., good reliable firms I know, as I have had dealings with all of them.

Connecticut. Mrs. R. J. Bradley.

PRAIRIE DOGS The finest pets. Shipped anybooklet telling a full history of this curious little animal for Ten cients. Address, H.P. SIMONDS, 299 Main Street, Dallas, Texas.

WHITE SILK FRENCH POODLES. Woodlawn Pet Stock Kennels, Louisville, Ky.

C.TS Choice Angoras. Tboroughbred. Prices and particulars free. Champion Kennels. Springfield, 0

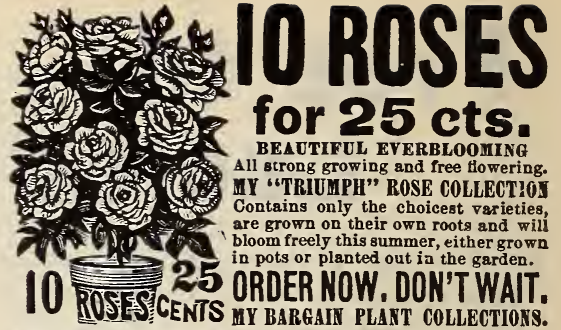

6 Hardy Iron Clad Roses, live out all winter, - 25 cts. 8 Splendid Flowering Geranlums, double \& single 25 " 8 Carnation Pinks, the Divine Flower, assorted - 25 “" 10 Chrysanthemums, Prize-winning rarieties, - 25 "6 8 Assorted Plants, for garden or pot culture, - - 25 " 8 Gorgeous Coleus, charming bedders, - - 25 ". 6 Decorative \& Follage Plants, assorted, for house 25 " 4 Grand Orehld Flowering Cannas, - - 25 “ 10 Glad iolus, the loveliest and prettiest of all, - 25 " 12 Rainbow Pangies, giant flowered kinds, - - 25 " 8 Magnificent Palms, worth $\$ 1$ each next year - 25 " 8 Beautiful Flow ering Fuchsias, Ear Drops, - 25 " 6 Splendid Flowering Bezonias, assorted, - 25 " 10 Mammoth Flowering Verbenas, all colore, - 25 “ SPFCIAL NFFFR Any 6 Sets for 1.25 or the eitirs SPEGIAL OFFER 16 sets for 8.00 postpaid. The Best Barcain ever offered. of Send for free Catalog. IISS MARTHA HISER, BOX 5, URBANA, OHIO.

ORIENTAL STAMPS 15 Choice Japanese, Chidifferent, 10 cents. Warranted genuine. Send stamp for catalogue.

O. T. JOHNSON, Laurel, Md.

TRIAKS 38 T TRIOKS $13 \mathrm{Y}$ MAIL, 10c, with ThNS particulars how to start in the show ousiness John $G$. Scheidler, Cleveland, Ohio.

Ferrets trained to hunt rats, rabbits, etc., cheap.' The J.F.NELSON Poultry Farm. London, Pa.

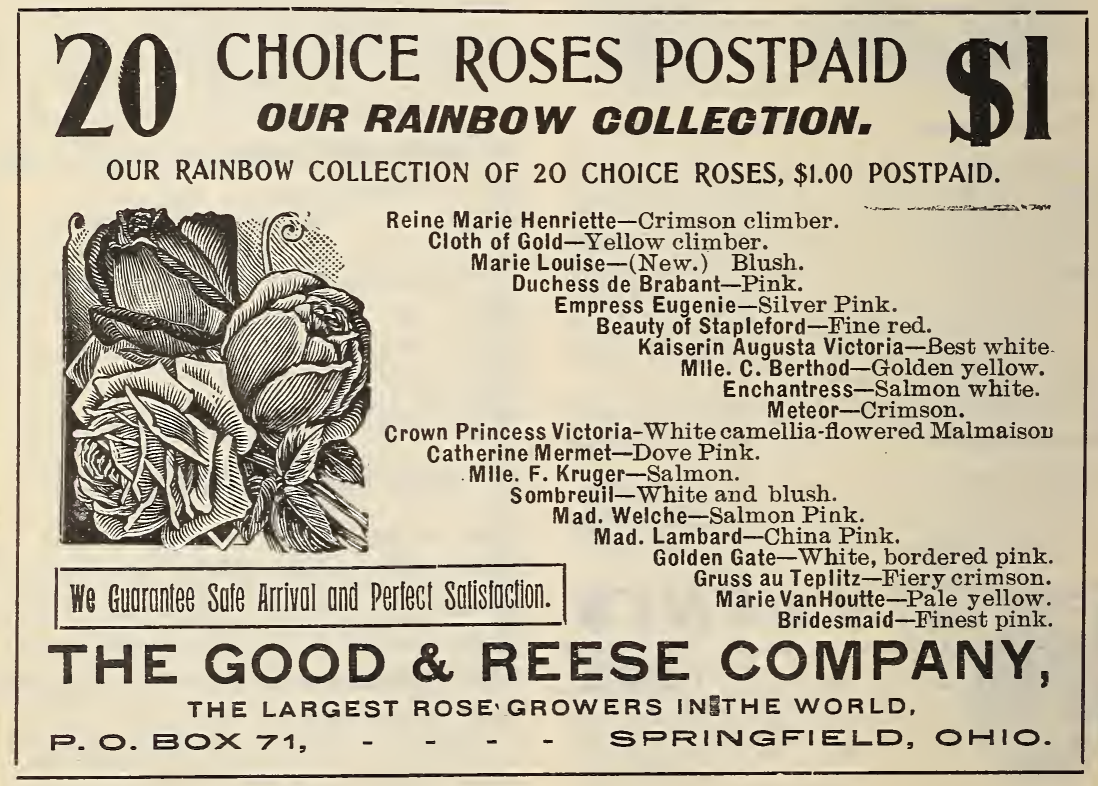


Marvelous Growth of Hair.

A Famous Doctor-Chemist Has Discovered a Compound That Grows Hair on a Bald Head in a Single Night.

Startling Announcement Causes Doctors to Marvel and Stand Dumfounded at the Wonderful Cures.

The Discoverer Sends Free Trial Packages to All Who Write.

After half a century spent in the laboratory, crowned with high honors for his many world: famous discoveries the celebrated physicianchemist at the head of the great Altenheim Medical Dispensary, has just made the startling announcement that he has produced a compound that grows hair on any bald head. The doctor makes the claim that after experiments, taking years to complete, he has at last reached the goal of his ambition. To the doctor all heads are alike. There are none which cannot becured by this remarkable remedy. The record of the cures already made is truly marvelous and were it not for the high standing of the

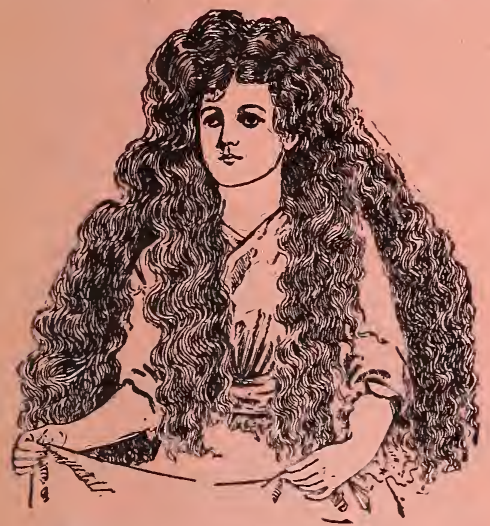

MISS HISLOP, of New Zealand

and Her Marvelous Growth of Hair. great physician and the convincing testimony of thousands of citizens all over the country it would seem too miraculous to be true.

There can be no doubt of the doctor's earnestness in making his claim nor can his cures be disputed. He does not ask any man, woman or child to take his or anyone else's word for it but he stands ready and willing to send a free trial package of this great hair restorative to any one who writes to him for it, enclosing a 2-cent stamp to prepay postage. In a single night it has started hair to grow on heads bald for years. It has stopped falling hair in one hour. It never fails no matter what the condition, age or sex. old men and young men, women and children all have profited by the free use of this great new discovery. If you are bald, if your hair is falling out or if your hair, eyebrows or eye lashs are thin or short write the Altenheim Medical Dispensary, 6446 Butterfield Building, Cincinnati, Ohio, enclosing a 2-cent stamp to prepay postage for a free package and in a short time you will be entirely restored.
\$10 DARY MAN

Complote from HEAD to TOE in latest Style FREE SAMPLES and Measurement Blanks.

TO INTRODUCE DIRECT TO THE WEARER OUR CUSTOM TAILORING We will make the first ten thousand suits absolutely to measures sent us for only $\mathbf{8 1 0}$ and give the following com. plete outht FREE. Act ually $\$ 28$ value for only $\$ 10$ and nothing to pay till after you receive the suit and free outfit and find it just as represented. Send us your name and
post office address, and we will send you FREE SAM. PLES OF CLOTH, 5-foot tape line \& measurement blank for gize of Suit, Hat, Shirt and shues.

A GENUINE CHEVIOT' Suit made to measure in the latest English Sack style, well made | and durably trimmed, such a suit as some tailors charge as some tailors charge........................ A Dunlap block, Derby or Fedora Hat..... A pair of stylish Lace Shoes, the new queen last $\mathbf{2 . 5 0}$ A Neat Sllk Hour.in-hand Necktle or Bow... A pair of fancy Web Elastic Suspenders ..... .50 A Japanese Silk Handkerchief............. .50 A pair of fancy Lisle Thread Socks........... .25 Thousands of Ameriean citizens pay daily for this...\$28.00 DON'T DELAY-After having filled 10,000 orders our prices for these suits will be $\$ 20$ and NO FREE ARTICLES. GENTS' COMPLETE OUTFITTING CO,, I I I-K Adams Street, Chicago, III. Beference: Metropolitan Nat'l Bank, Chicago; Cap. $\$ 1,000,000$
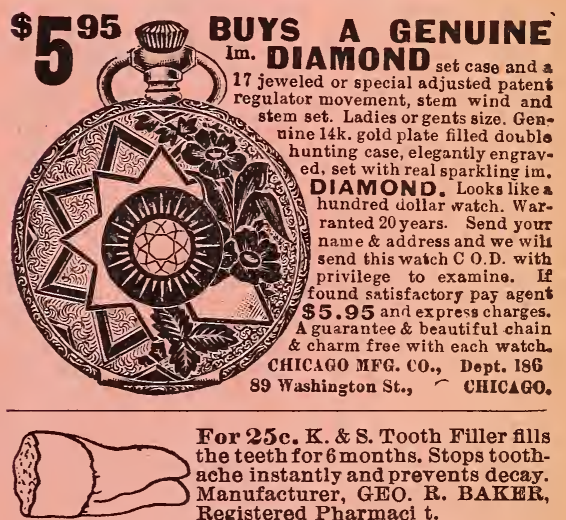

For 25c. K. \& S. Tooth Filler fills the teeth for 6 months. Stops toothache instantly and prevents decay. Manufacturer, GEO. R. BAK HR, Registered Pharmaci t.

65 CLARK ST., - CHICAGO.

CAT PICTURES ing, sent by mail, $50 \mathrm{c}$ The Cat Journal, very fine, devoted entirely to OATS, $\$ 1$ per year; sample $10 \mathrm{c}$, free with picture orders. Address Cat Journal. No.5 Avenue A. Palmyra. N. Y. FOX TERRTER PUPS, nieely marked and eligible to registration. For sale at reasonable, priees. OXFORD KENNELS, 1818 North 9th Street, East St. Louls, Illinole.

GA 13 Lovely new styles for 1802 ; also Xmas, $\mathrm{N}$. $\mathrm{Y}$. Boyce \& Co.. Lynn Mass.

FOR SUIC Angora cats and kittens. 1 pair Angora kitFOR SHLE tens \$10. Mrs.A.T. Rice, Box 814, Paris, Ky, 


\section{TEN BEST ROSES GIVEN AWAY!}

THESE ROSES FREE FOR A CLUB OF TEN YEARLY SUB. SCRIPTIONS FOR THE FLORAL WORLD AT 15 CENTS EACH, WITHOUT PREMIUM; 25 CENTS A YEAR WITH 2 PREMIUM PLANTS DESCRIBED ON SECOND COVER.

Psyche, the New Pink Rambler Rose.

A cross between Crimson Rambler and the Polyantha Rose, Golden Fairy. The flowers are produced in clusters of eight to thirty-five and are two to two and a half inches across when fully expanded. Color, white, suffused with salmon-rose and pink, with yellow base.

Mrs. Mawley.

This grand variety embodies so many good qualities that it is difficult to describe it. $\mathrm{We}$ could say no more in its praise than to say it is like Maman Cochet, only several shades lighter in color.

\section{New Rose; Gold Nugget.}

This magnificent Tea Rose is a rich, goldenyellow, a strong, healthy and vigorous $\mathrm{g} \mathrm{r}$ ow er, immense bloom er, bearing flowers a n d buds early and late. The flowers are very deep, rich and full, excellent substance, very sweet. $\mathrm{Re}$ markably hardy both as to heat and cold, frequently standing the Winters here uninjured in open ground

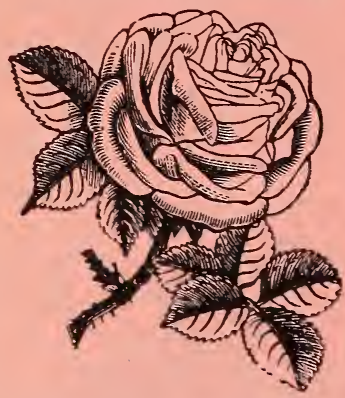

without protection, and blooming nicely all through the hottest part of the Summer.

Mrs. Robt. Peary, or Climbing Kaiserin.

The flowers are extra large, full, deep and double. They are of excellent substance, and produced on long, stiff stems, like a forcing Rose. The buds are long and pointed, a remarkable feature not found in any other climbing Rose. The color and shape of the bud and flowers identical with Kaiserin Augusta Victoria. Pure ivory white. The fragrance is delicious. The most remarkable feature of this variety. however, is that it blooms contin. uously the first year. It grows to perfection outdoors, throwing up numerous shoots, ten to fifteen feet high in a single season.

\section{Bridesmaid, Deep Pink Mermet.}

Here we have a new Rose, a sport from that old standby, Catherine Mermet. This new variety retains all the good qualities of the parent, besides adding charms not possessed by the sweet Catherine. It is about two shades deeper in color-just enough to make it bright, and it is the same color all the time under every condition of weather and surroundings.
Rheingold, a Wonderful Color.

The flowers last well, and the name, Rhein. gold, conveys but little of the true worth and beauty of this flower. The buds are long and oval, and the color is a Naples-yellow, shaded with orange. The petals pass in the center to a deep citron.

\section{Gruss an Teplitz. (Greeting of Teplitz.)}

As a bedding Rose this is one of the finest and most useful varieties ever sent out. The color is brightest scarlet, shading to deep, rich, velvety crimson. It is very fragrant. The freest grower and most profuse bloomer of any everbloomer. The mass of color produced is wonderful, and the foliage is extremely beauti. ful, all the younger growth being a bronzy. plum color. A queen among scarlet bedders.

Priscilla, or White Maman Cochet.

The flowers are of enormous size, remarkably round and full, pure clear snowy-white throughout, and are delightfully Tea scented. It is by far the finest and most reliable white bedding Rose yet produced, and should be planted by everybody. By planting a fow plants of it any one can have the very finest Roses for cutting and for use in vases, upon altar, dining table, parlor, etc., all Summer and Autumn.

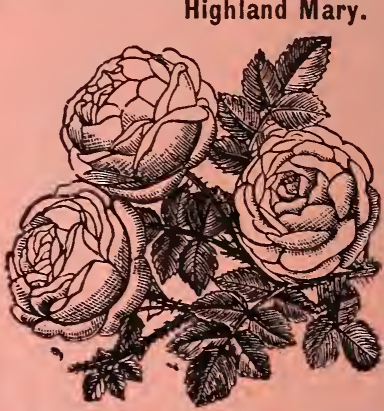

This lovely Rose origin. ated in Cana d a, and claims Agrippina for its parent. It is a persistent bloomer botb Summer and Winter.

Fl ow ers large and sweet; blossoms beautifully cupped. each petal being white, with a delicate lemon tint, and broadly bordered with a delicate band of pink.

New Pure White Royal Tea Rose, Kaiserin Augusta Victoria.

This beautiful Rose has not only a royal name, but is a royal kose as well. It is a con. tinuous bloomer, producing successive crops of buds and flowers in the greatest profusion. Buds are very beautifully formed, with large petals of best substance. It shows no center when fully open; color pure, snowy-white.

\section{ALL THE ABOVE FOR CLUB OF TEN}

yearly subscriptions for THE FLORAL WORLD at the special clubbing price of fifteen cents a year, without premiums. Each subscriber who wishes the premium plants named on second cover page must pay 25 cents a year. No single subscription accepted for less than twenty-five cents, and no club premium given for less than ten. The above collection of the latest and best Roses absolutely free to any one who sends us a club of ten. 


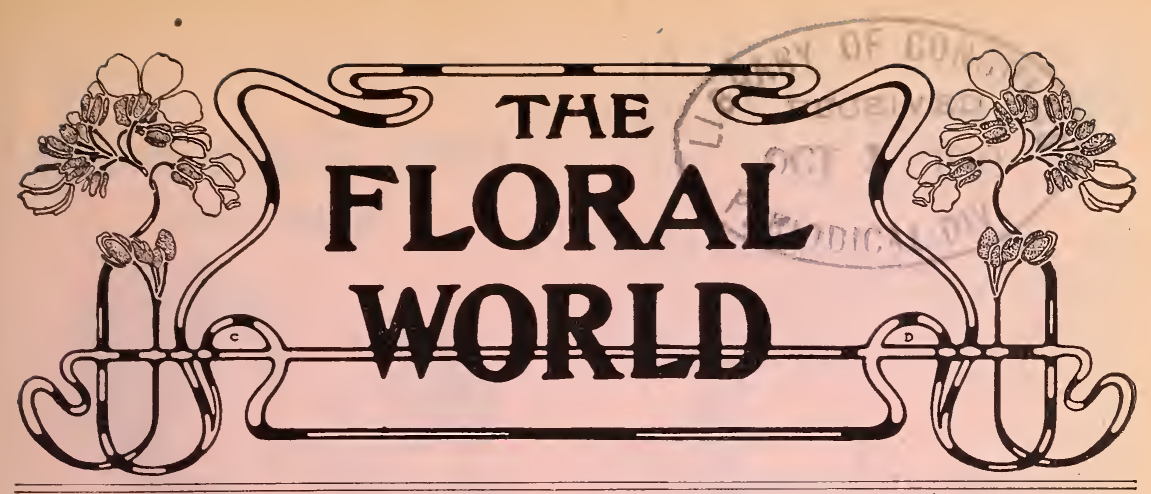

Vol. I, No. $9 \quad$ Springfield, Ohio, June 1902

25 Cents a Year

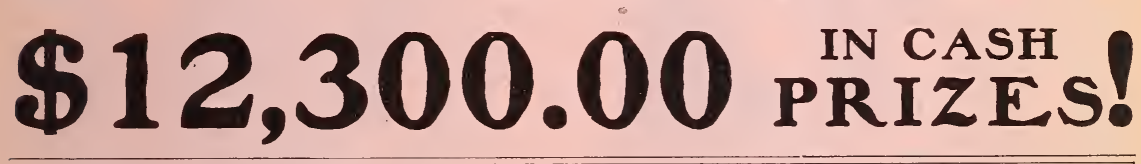

Subscribe for THE FLORAL WORLD During June and You May Share in the Distribution.

\section{THE PRESS PUBLISHING ASSOCIATION}

Of Detroit, Michigan, offers $\$ 12,300$ in Cash Prizes, to those making the nearest correct estimates of the Total Revenue of the Post-Office Department for the fiscal year ending June 30th, 1902.

To the nearest correct estimator..................................

To the 2nd

To the 3rd

To the 4 th.

To the 5th.

To the 6th.

To the 7th.

To the 8 th.

To the 9 th.

$\$ 5.000$
2.000
1.000
500
300
200
100
75
50

To the 10 th.

To the next 10 nearest $\$ 15$ each To the next 35 nearest $\$ 10$ each To the next 142 nearest $\$ 5$ each To the next 160 nearest $\$ 4$ each To the next 180 nearest $\$ 3$ each To the next 200 nearest $\$ 2$ each To the next 260 nearest $\$ 1$ each. 997 Prizes amounting to...
$\$ 25$ 150 350 710 640 540 400 260

$\$ 12,300$

In case of a tie, or that two or more estimators are equally correct, prizes will be divided equally among them.

\section{VALUABLE INFORMATION}

To aid in forming your estimates, we furnish the following figures which we obtained direct from the Post-office at Washington, D. C., giving the gross or total revenue of the Department for each and every year from 1892 to 1901 inclusive. The fractional part of a dollar is not considered. The total revenue of the Post-office Department for the year

$$
\begin{aligned}
& 1892 \text { was } \$ 70,930,475 \\
& 1893 \text { was } 75,896,933 \text {, increase } 7 \% \\
& 1894 \text { was } 75,080,479 \text {, decrease } 1.07 \% \\
& 1895 \text { was } 76,983,128 \text {, increase } 2.53 \% \\
& 1896 \text { was } 82,499,208 \text {, increase } 7.17 \%
\end{aligned}
$$

$$
\begin{aligned}
& 1897 \text { was } 82,665,462 \text {, increase } 0.20 \% \\
& 1898 \text { was } 89,012,618 \text {, increase } 7.68 \% \\
& 1899 \text { was } 95,021,384 \text {, increase } 6.75 \% \\
& 1900 \text { was } 102,354,579 \text {, increase } 7.72 \% \\
& 1901 \text { was } 111,631,193 \text {, increase } 9.06 \%
\end{aligned}
$$

As above stated, these figures were obtained of the Department at Washington, and are therefore absolutely correct. It will, therefore, be unnecessary for you to annoy the Department, or to cause yourself any trouble or expense by writing to Washington for information.

The certificate of the Postmaster General showing the Total Revenue of the Post-office Department for the fiscal year ending June $30 \mathrm{th}, 1902$, will determine who are entitled to the prizes, and the awards will be made by a DISINTERESTED Committee within 10 days after the result has been announced.

Every person holding a certificate in this Contest will receive a printed list of the successful estimators, giving their names and addresses, the certificate number and the estimate contained therein, and the amount of the prize to which each successful estimator is entitled.

All successful estimators will receive payment by presenting their certificates to the PRESS PUBLISHING ASSOCIATION, Detroit, Mich,, or by draft on said Association through ANY BANK IN THE UNTED STATES OR CANADA.

The publishers of THE FLORAL WORLD have completed arrangements whereby they are enabled to offer every person who subscribes for their magazine during June an opportunity to, participate in the distribution of the prizes offered by the Press Publishing Association.

A certificate good for one estimate on the revenue of the Post-office Department will be given: FREE to every person who remits 25 cents in payment of a year's subscription for THE FLORAL WORLD, during June, provided no other premium is taken. For the certificate alone, without. subscription, 12 cents will be charged. Always address, 


\section{CREATEST HOUSEHOLD U NECESSITY FREE!}

Wash Day No Longer a Drudgery. No More Stooping, Rubbing, Boiling or Wearing Out of Clothes.

\section{THE "1900" BALL-BEARING FAMILY} WASHER SENT FREE without deposit or of any kind, freight paid, on 30 days' trial. It is unquestionably the greatest labor-saving machine ever invented for family use. Entirely new principle. It is simplicity itself. There are no wheels, padd les, rockers, cranks or complic ated machinery. It revolves on bicycle ballbearings, makin: it by far the easiesi running washer on the $\mathrm{m}$ arket. No strength required, a child can operate it. No more stooping, rubbing, boiling of clothes. Hot water and soap all that are needed. It will wash

large quantities of clothes (no mauter now soiled) perfectly clean in 6 minutes. Impossible to injure the most delicate fabrics.

\section{A Convincing Testimonial.}

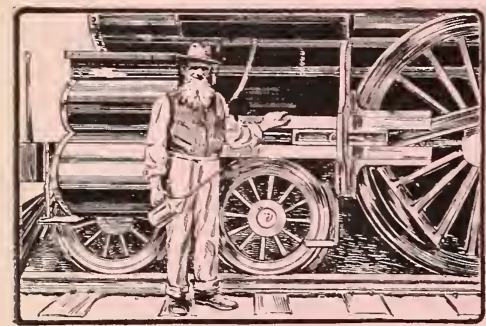

Brotherhood of Locomotive Engineers, Hudson Division, No. 135.

SPARkILL, Rockland Co., N. Y., Oct. 29, 1901.

"1900" Washer Company:

I have given your washer a fair trial. It is one of the best washers $I$ ever saw. It washed three pairs of my dirty and greasy overalls and overshirts in ten minutes and washed them clean. My housekeeper says it would have taken her two hours to have washed them the old way. It will wash ten shirts, with collars and cuffs, in seven minutes.

My name is known on nearly every railroad in the United States and Canada. $1 \mathrm{am}$ an engineer of the New York Division of the Erie road and have rum an engine for forty years.

EDWARD KENT.

REMEMBER, you take absolutely no risk, incur no expense or obligation whatever. The washer is sent by us on 30 days' trial, freight paid going and coming, and positively without any advance or deposit of any kind. Write at once for catalogue and full particulars to "1900" WASHER CO.,

216Y State St., Binghamton, $N$, $Y$.

\section{SHOT GUN FREE!}

Also Watches, Bicycles, Guitars, Banjos, Fountain Pens, Silver Set, Rings, Bracelets, Air Rifle, Stevens Rifle, Revolver, Camera, Typewriter, Reclining Chair, Couch, Rattan Rocker, Morris Chair, Parlor Suit, Dining Table, Kitcben Cabinet, Writing Desks, Go-Cart, Pocket Knives, Silver Tea Set, Sewing.Machine, Printing Press, Dinner Set. Boys and Girls can earn any of them by a few hours of pleasant work. An Al opportunity for Agents. Premium catalog free. Address,

CAMPBELL \& COMPANY, 1125 Plum St., Elgin, III.
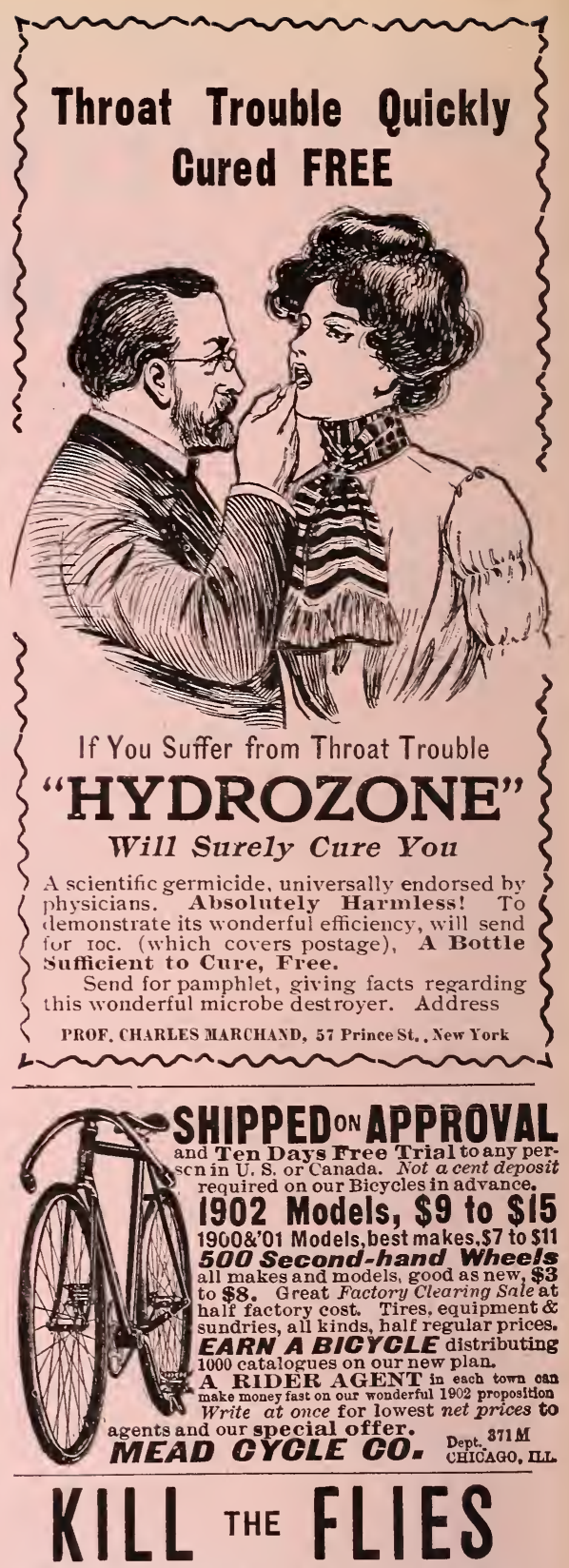

Flies breed in filth and assimilate it, then get into your house and travel over you and your food. Order KING FLY KILLER and do away with them at once. SURE KILL. Sample, postpaid, 15 cents. AGENTS WANTED.

A. W. KAUFMAN \& CO., Dept. D., CANTON, OHIO.

Dead-Shot Squirt pistol.

"Didn't know 'twas loaded," but its a great trick. Postpaid 8c. F. Colines \& Co., Arlington Hts., Mass. 


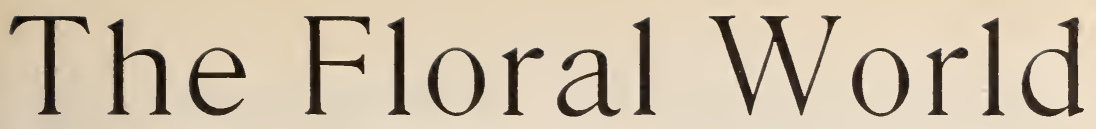

A Fournal of Home Floriculture

Vol. 1, No. 9

Springfield, Ohio, June, 1902

25 Cents a Year

WORDS OF APPRECIATION.

I am much pleased with The Floral World.

Pennsylvania. Mrs. IdA E. CozIns.

I wish The .Floral World the best of success.

Kentucky.

Miss LaURa Jones.

I am interested in the Floral World and wish it all success.

Illinois.

Mrs. S. E. Brown.

I enjoy the little paper, The Floral World, and wish it came oftener.

Minnesota.

S. C. Millie.

The Floral World is a periodical in due season. I appreciate it very much.

North Carolina.

J. O. HINes.

I hope to be a lifelong subscriber to The Floral World. Long may it live to bring happiness into many homes.

Indiana.

MrS. M. E. TUCKER.

I have found many things to help me in growing flowers, in your little gem of a magazine, The Floral World.

Ohio. ANNice Body Calland.

I am a reader of several floral publications, but can truthfully say that The Floral World is the most practical of all.

Pennsylvania.

Frank Walter.

I have had The Floral World since its first number and find it a great help. Almost every number has contained at least one article which told me just what I wanted to know. I wish the little magazine all success.

D. C.

Mrs. E. C. Reynolds.
The Floral World is a bright little necessity in my home. I spend many happy moments persuing its contents and hope it will prosper and be as much help to everyone else.

New York. Mrs. Charles ERMis.

Have received two copies of The Floral World. I find many interesting and helpful articles in its pages. It surely will take well with the busy housewives who are flower lovers. I shall certainly continue taking it so long as it is instructive as at present.

Oregon. Mrs. Olive Chamberlain.

I am very much pleased with The Floral World. When I am expecting: it to come I can hardly wait until I have read it through. It contains. helpful, plain and to-the-point facts. I only hope the publishers continue to publish it, for it is so helpful to those who love and grow flowers.

Pennsylvania. Edxa Janet Gray.

\section{THINGS LEARNED FROM THE FLORAL} WORLD.

When I first subscribed for The Floral World my "worser half" wondered what I expected to learn, not in the half-dozen other floral magazines that came. But in the very first number the article on "Tub Plants" was worth more to me than the whole year's subscription, as we move from one town to another so much. Then in the November number the article on wintering cannas in the ground was new to me. I shall try it, first taking up some of the new shoots for fear of failure the first time. In the 
January number "Suggestions for Odd Corners" and "Protecting the Lily Bed" was of much interest to me. "An Open Secret" in the April number was another article worth a year's subscription. I have already tried it on my tea roses successfully. Then in the May number the use of glue in calla culture was new to me. I shall try it this fall. These are not all, but just a few of the good things I found, so you see with half a dozen others there was still room for a new inagazine.

Ohio.

Annice Bodey Calland.

\section{DAHLIAS FROM SEED.}

It is not generally known among those who grow flowers from seed that the very finest dahlias may be grown in one season from seed to the perfection of flowers. Nevertheless, I have done it for three seasons, and each time bought seed from a different seedsman. Last March I took a soap box, sawed it through half-way down, making two boxes, each about four inches deep. Then I filled them with garden soil and planted two packets of dahlia seed, one of double mixed "pompone" and one of double mixed show dahlias. I watered with warm water, set boxes on a table and put them in the front room, where there seldom was any fire. When it was very cold I set a lighted lamp on the floor under the center of the table, which warmed the soil from the bottom up. This is the best plan to keep house plants from freezing. In about ten days the plants came up, and they grew stalky and strong. In April, when the buds started, I set the boxes outdoors and covered them on frosty nights, and in June I set out the plants, then bushes six to ten inches high, in beds prepared by digging manure into them. In late August they were bushes two to four feet tall and began to bloom. There were many blossoms three and four inches across and double to the center. By the last of September about every plant was in blossom and there were some a pure frosty white, some pink, yellow, chocolate brown, crimson, scarlet and lavender, and many shaded and variegated ones. ' A few were single, and for bouquet purposes they excel the double ones.

The last of October I dug the bulbs and there were just about four and one-half bushels of them by measure, all large, healthy tubers one to two inches in diameter.

Michigan. Mrs. Jennie E. Lipe.

\section{PROCURE YOUR CHRYSANTHEMUMS}

EARLY.

If you wish large show flowers during October, November and December, order your chrysanthemums early. Too many neglect this until it is too late to prepare them for fine flowers. Remember it takes one season's growth to make fine flowers. I order mine in June, shade for a few days and bring into the sunlight. In potting them I use the very richest soil procurable-cow manure, well rotted-liberally. Change this from time to time, as they fill these pots with roots. Twice a week I place the pots in tubs of water, allowing them to soak for half an hour. Those I grow in ground until September, are lifted, potted in very rich earth and shaded for a few days. This lifting must be done with care, roots must not be crowded into small pots. This lifting always gives them a backseteven if done with the greatest of care. I prefer growing in pots from start, then they can not only be protected from early frosts, but from drouths.

Kentucky. 
AS TO GERANIUM CULTURE.

In order to produce rapid and healthy growth in geraniums I take them up in early spring and refill my boxes with a sufficient quantity of loose, pulverized soil of ordinary strength. Then I set and put.on top a coat of pulverized cow manure, one inch thick. This greatly invigorates the runners, retains moisture, and is a sufficient guard against destructive vermin. Box flowers neither have strength nor beauty so long as the roots have to "gimlet" through a tight, hard soil. Whatever obstructs the runners tends to destroy capillary attraction, a very important factor in the distribution of plant food. These flowers should never be subjected to heavy rains, nor watered so as to cause drainage from the vessels that contain them; either is injurious and may be destructive. Away with your wet, hard and dry soil. But give me a balance of moisture. I water once or twice a month with liquid manure. North Carolina.

I. O. Hines.

Geraniums are not often troubled with insects, and if you cultivate them intelligently for winter bloom, they will not disappoint you: Do not expect plants that have blossomed outdoors or in pots all summer to continue doing so all winter. For winter bloom do not pot small plants in large pots. They will grow well and be thrifty plants with an abundance of blossoms next spring and summer.

To have geraniums bloom during the winter, root your slips in the spring or early summer, and set in small pots, having good drainage. If an old plant, cut it back nearly to the root. Keep all the buds nipped off during the summer and they will be sure to blossom in the winter. Always water when the soil is dry. There are so many varieties one can have a beautiful window with nothing but geraniums. The single and semidouble are the best for winter bloom. Mrs. E. G. Hill heads the list with its enormous clusters that come continuously, of salmon-colored flowers, closely followed by John Lewis Childs, color pale pink heavily mottled and spotted with crimson. Madam Bruant, Freedom, Sov. de Miranda, three Aureoles, Marde Layres, the finest of all single whites. Flowering Rose geranium combines free flowering qualities with fragrant foliage. Its bloom is very fine and the foliage makes it a truly novel plant. The tri-color and silver-leaved varieties are so beautiful we hardly realize their lack of flowers. The ivy geraniums are equally good for basket or pot plants. They must have good sunlight, small pots, water and good drainage.

Michigan.

Jessie L. Austin.

I would suggest, in selecting plants for the window garden, to select those that like the same temperature, not to mix up those that like a cool room with those that must have summer heat, or you will have "spor luck," and no wonder. I think the geranium the best all-round window plant for the amateur, provided you can keep the room at a high temperature. Six to a dozen assorted geranium plants with one or two decorative plants or vines makes a lovely window garden. And they won't sulk and require so much coaxing and petting as some others, if you will give decent soil and attention. Some one speaks of ugly, straggly geraniums. I have seen that kind, but I see no excuse for having such, as it can easily be avoided by keeping all faded leaves picked off and cutting back those limbs inclined to grow too fast, or pinching out the "terminal bud" end of shoot, and pruning away the weakly, sickly looking branches, and you will have a prettier bush and 
a lot more flowers, which is what we all want. If not prepared to have these, select bulbs and plants that like a cooler room, such as hyacinths, narcissus, .etc., and always include a pot or two of sweet violets (or pansies). They bloom here all winter -outdoors-if given a protected situation, like under a low-spreading evergreen tree or the corner of a paling or hedge where the sun can reach and yet are protected from cold winds and let the leaves drift over them (not pack) and you can find $a^{\circ}$ bouquet at Christmas or any other time of the winter.

Georgia.

(Miss) M. E. Greene.

In North Carolina the rose geranium withstands the winter with the tops cut off and sawdust spread over the stump, and in spring it sprouts up beautifully.

Both fish and rose geraniums do well in a shaded situation.

They should be pinched into goodshaped plants, and this also adds to their appearance and is a great help to them. When let grow to their own will they are broken and twisted by the wind.

The fragrant-leaf apple geranium should be raised from seed; they germinate very easily.

For dining-room decoration scarlet and white geraniums slipped late in autumn and potted in smallest size pots will give remarkable clusters of bloom. Several pots may be set in a rustic basket, making a unique and cheerful centerpiece.

Geraniums are very pretty planted along a walk in rows, each color in separate rows.

For house culture they should get a good ducking every week in clean water to keep the soil from getting sour.

$\mathrm{Pa}$.

Miss Edna Janet Gray.
MAKE HOME BEAUTIFUL.

The flower garden should not be neglected, in the rush of other work. Plant flowers to bud and bloom. The flower garden, of all spots on earth, should be pre-eminently woman's own. It is important, in beginning a garden, to stock it with good shrubs. and herbaceous perennials. With ordinary cultivation these will give bloom and beauty year after year.

April showers are favorable for transplanting annuals. Gardening without seed planting would seem anamolous. Never buy poor, cheap seed. Do not start seed in too soft, boggy earth. I mix sand with garden soil. If you have never gardened, buy a good manual and study it. There is considerable art in seed planting.

Every garden should have a bed of pansies. I buy plants which the florist started in February, and so have early flowers. By all means plant sweet peas. Poultry-wire netting. makes the best support for these plants. Cut the blooms every morning, to prevent seed pods. For a showy bed, plant nasturtiums, having. a soil of only moderate richness. Have also a bed of cannas. Give them good, rich soil, and they will grow to perfection.

Neb. Mrs. Harriet W. Leighton.

\section{THE WINDOW AND THE CONSERVATORY.}

You will find five out of every six bay windows or conservatories that. are too much crowded with common plants to excite admiration as they should. It should be our study to have only the finest flowers and to grow them with the attention they re quire to develop them satisfactorily. A few well-grown plants of popular sorts and some of the rarer kinds will afford more pleasure than a jumble of sorts good, bad, or indifferent. Easily grown plants that respond to the am- 
ateur's treatment should be given preference. When these are obtained do not crowd them together promiscuously.

Hanging baskets are always decorative, and a large vase for a center piece adds not a little to either window or conservatory. Brackets on the sides of the window are much prettier than shelves. They display the different plants so much better. A pedestal or two set around in center of conservatory with a fine grown specimen of a plant on it will call forth much praise.

Mrs. O. H. HeREFORd.

\section{A PRETTY BED ARRANGEMENT.}

Last summer I reserved eighteen inches of ground around three sides of the house and had a great flat oval bed on the northeast slope of the yard. Around the veranda we planted white and purple beans and madeira vines, and under the windows sowed mixed morning glories. On one side of the bay window were scarlet geraniums and nicotinias; on the other pink oxalis and white geraniums with golden coreopsis scattered around them. On the south side of the house grew the chrysanthemums and cosmos. In the center of the large bed a lantana was set and around it in rows according to height were touch-me-nots, petunias, candytuft, dianthus and verbenas. The border was a mass of sweet alyssum. The beds were beautiful with the contrasting colors, and the profusion of flowers furnished great handfuls for the vases, the cemetery, and for our friends who were less successful. When the first snow came it found chrysanthemums and cosmos waving their snowy plumes in the very face of winter.

Missouri. Mrs. F. D. GARdNER.

Broken or burnt bones are the very best drainage for flower pots.
PREPARATION FOR THE WINDOW GARDEN.

It will not do to wait until fall to begin preparations for the window garden. Slips will not be a success. One must begin in the early spring to procure plants and to root slips, and grow them through the summer.

In most window gardens the heliotrope is a complete failure; so is also the hibiscus and oftentimes the geranium. There are some plants that will grow with very little artificial heat and others that require very little sunlight, so, if you cannot give your greenhouse plants greenhouse privileges, it is best to leave them alone, and procure plants that will not only live, but grow and bloom in the ordinary window garden.

One usually wants trailing plants for baskets and side brackets, and for this purpose the Boston fern, Russellia Grandiflora and Asparagus Sprengeri are all excellent if procured early and grown through the summer; then they are large enough to make some display during the winter. Carnations procured now will make blooming plants by February or March of another year. Sweet violets should be procured now, bedded out until September and then potted for the window.

In making your plans include some bit of greenery for cut flowers.

Kentucky.

LAURA JONES.

\section{A PRETTY COMBINATION BED.}

A thing of beauty is a joy forever. Make a diamond shaped bed. Any or. dinary soil will do. Place in the center Marguerite daisies, which grow three and four feet high. Surround these with the white and pink perennial phlox alternately; for the border sow seed of the white and pink annual phlox, and you have a bed, which will grow in beauty each year.

Mich.

(Miss) Amiael Hyne. 


\section{PLANTS FOR ROOM DECORATIONS.}

Palms are among the most desirable for room decoration. They thrive well in small pots, considering the size of the foliage, which is tropical in appearance, graceful, and will stand considerable ill usage. I think the most graceful and beautiful are the Kentias, Cocus Weddeliana, Seaforthea Elegans, Phoenix Reclinata, Zamias.

Pandanus and Aspidistia are stately and effective, while Phomium Colensoi Vasi is a grand plant for a stand. The long sword-shaped leaves are striped green and creamy white, radiating from a common axis, giving the extended fan shape. It will en. dure heat, cold, drouth and moisture better than most of the plants grown in rooms. The India rubber tree is also a good room plant. All these plants are easily kept. Keep them free from dust. Water when needed and keep from frost and where they can have a strong light and a modicum of heat.

Missouri.

Annie E. Crafts.

\section{AN EFFECTIVE BAY WINDOW.}

I have a bay window on the south side of my house which is greatly admired. It is very wide and deep. Between the window and the sitting room there is an arch twelve feet wide. Inside this arch another is formed six feet wide and six and onehalf feet high, made up of posts, panels and grill work. Below the window sills a shelf nine inches wide is put up. All is wood work and the floors are of polished oak. There are no carpets; just a rug in the sittingroom, free from the furniture that can be taken out to dust. I use a broom bag on broom when sweeping, as it gathers dust without raising it. There are brackets on each window and hooks at the tops for baskets. A bird cage, some stands and tabour- ettes for jardinieres and the large number of plants on shelves with a few trees make enough for one busy woman to care for them.

But I have a plant I am proud ofthat is an English ivy l have had nine years. It had only one stalk at first, but as branches formed I bent them down till rooted. I had seven. Some of them must be over forty feet in length with innumerable branches. It is planted in a tub, sits at one end of a large arch behind a panel out of sight. The vines are put in coils and loops up one side of the arch across the top on grill and down the other side; it is tied up with green silk the color of the leaves. In summer it is taken to an east porch where it gets the morning sun. The stalks are tough and hardy, and will bear quite rough handling.

Illinois.

Mrs. S. E. Browne.

\section{THE VARIEGATED JAPANESE HOP.}

In 1900 I sowed a few seeds of variegated Japanese hop, and they were lovely. In 1901 they came up thickly from self-sown seed. I set a row across the south side of our piazza and gave them stout twine to climb on to the top of the upper balcony railing. How they grew! In a short time they reached the end of the twine; they would have gone to the roof if the twine had, I guess. The leaves were immense with lovely creamy shadings, and from each leaf a branch shot straight across to the next twine, making a complete network and lovely screen. Then it was covered with its pretty blossoms, and now in 1902 the seedlings are up again, enough for the whole village. I know nothing prettier, so quickly and easily grown.

Main.

Aroline P. Adams.

Avoid sowing seeds of annuals outdoors too early. Unless bed is well sheltered, about the time the apple blooms is soon enough. 
START YOUR SEEDING OUT OF DOORS.

I would like to say to the many amateur flower growers who, like myself, have tried to start seed in the house and who have only ordinary windows, "don't do it." I have tried so many times with such poor results that now I wait until about April 15 and sow my seed out of doors in boxes or in a small bed. I scatter the seed thinly on finely pulverized soil, cover very lightly, and sprinkle several times a day to keep the earth from getting dry. The seedlings are all sturdy and ready from the very first to stand the sun and wind which the frailer house-grown plants must be very gradually accustomed to.

Always transplant when they have four or six leaves. It is better to transplant at first to a larger box and again to the beds where they are to grow, but they will do very well if put at once in the beds. If possible, shade a little during the hottest part of the day at first. Water only in the evening, and after watering draw a little dry soil over the damp to keep the sun from baking it.

\section{Mrs. E. C. Reynolds}

Washington, D. C.

\section{RAISING BULBS FROM SEED.}

As most bulb seeds ripen in May or June, and grow best if planted immediately, I take small boxes filled with good garden soil and sharp sand, half of each, to sow the seeds in. Set the boxes in a partly shaded place, keep damp but not wet. When it gets cold put boxes in cellar. In January bring up, water well, cover with glass and put in sunny window. Keep growing as long as possible.

In August transplant into a bed of rich, sandy soil. Put a frame over the bed for shade and protection. Mulch with a little well-rotted manure the first hard freeze in December.
Dutch bulbs, day lilies, lilies, also hardy roses, can be raised in the same way.

I have had some success with crocus, late tulips, crown imperials, planted outdoors during a thaw in February. An immense amount of valuable seeds annually go to waste that would give much pleasure if planted.

$\mathrm{Pa}$. Mrs. IDA E. Cozins.

\section{PLUMBAGO COCCINEAISA.}

This is a very beautiful plant for the winter window garden. Procure a. young plant in the spring and pot it in good fibrous loam in a five-inch pot, with sufficient drainage material to assure good drainage. Place it. where it will get the morning's sun, and encourage growth by judicious watering and pinching in the shoots to promote branching. By September the plant will have obtained a systematic and good-sized growth. If the vessel is filled with roots, give a size larger, but do not overpot it or it will not do so well. By November it will commence to bloom, sending out its. very pretty rose-colored flower sprays. It will continue in bloom until late in. spring, when it can be cut back and treated like the previous spring, and the following winter it will indeed prove a plant of great beauty, as many of the branches will have two and three sprays of bloom of different lengths, which, mingling together, give the appearance of one continuous spray, fully one-quarter of a yard: long. The plant must have the conditions just right to do well, a temperature from sixty-eight to seventy degrees, and either an eastern or southern exposure, but do not overwater it.

Pennsylvania. Mrs. S. R. Welsh.

Be patient, and do not hurry your plants too much by applying a fertilizer before it is needea. 


\section{The Floral World}

PUBLISHED MONTHLY BY THE

FLORALWORLD COMPANY, 12 to 14 South Limestone Street, SPRINGFIELD, OHIO.

Subscription Price, 25 Cents a Year.

Entered as second-class matter at the Postoffice in Springfield. Ohio.

We will give $\$ 26.00$ in prizes for the five best articles for publication in the August number of THE FLORAL WORLD which may be submitted by subscribers.

The first prize will be $\$ 10.00$; the second, $\$ 7.50$; the third, $\$ 5.00$; the fourth, $\$ 2.50$; and the fifth, $\$ 1.00$. The awards will be announced in our September issue.

No article which contains more than two hundred words will be considered. All contributions entered in this prize contest must reach us not later than June 1.

The purpose of these prizes is to secure for publication in THE FLORAL WORLD matter which gives the actual experiences in flower growing of those who have subscribed for the journal. Prizes offered for articles published in the May number have been awarded as follows:

First prize-Bridget, Virginia.

Second prize-Mrs. E. A. Taylor, Minnesota.

Third prize-Mrs. J. M. Ballinger, Texas.

Fourth prize-"'Sister Bee," Maine.

Fifth prize-Mrs. G. T. Drennan, Louisiana.

\section{ONE WAY OF DOING IT.}

Sixty-six years ago this spring I began flower gardening. With an old "nigger hoe" I hacked up a little loose dirt in a rail fence corner and planted a few seeds of a tall coarse-looking single marigold. They grew and thrived wonderfully, and to me-a flower-loving child-they were beautiful, and the fragrance just simply ex- quisite. I still love the marigold perfume, but to my father it was nauseating and he would not allow me to bring the flowers into the house, or even come in myself, from my flower garden, until I had shaken the scent from my clothes and washed my hands. From that time until the present there has been but very few seasons that I have not cultivated at least a few plants either in garden, yard or house.

I have just recently received, in fine condition, thirty-five fine plants from "The Woman Florist" of your townto whom I am indebted for a sample copy of Floral World: When the plants were unpacked they were laid in a pan of warm water while the cans-I cannot command pots-to grow them in are made ready by placing a few bits of charcoal and burnt bone over the drainage holes in bottom of cans, then a little very rotten wood to hold moisture; about a couple or three inches of moist (not wet) top soil from the garden was gently pressed in, the wet roots carefully spread out, loose mellow soil sprinkled in among them and firmly pressed down, and the can filled nearly full of loose soil, slightly watered and set away in a dark corner for thirty-six hours. Then they were brought out into the light of an east window, the leaves washed, the cans filled up with mellow earth, and a half of an egg shell filled with water set on top of the soil of each can to supply, by evaporation, the needed moisture for the leaves. Every morning I wet the leaves with tepid water. I think that every plant will grow, as most of them show new buds or leaves. One rose has already bloomed, but I clipped off the blossom as soon as open.

Nebraska. Mrs. E. C. Lewis.

For the hottest, driest place in your garden, get a plumbago, either the blue or the white. 


\section{AS TO THE SOIL FOR POTTING.}

It seems to me while so much is being said in The Floral World about the methods of cultivating plants, it would not come amiss to speak of the paramount importance of the foundation work which to insure success means clean pots and well prepared soil. It is evident The Floral World is the medium through which we are all bound to awaken to a practical knowledge of caring for our plants. The articles contributed by such flower-loving pens are on such a common sense and practical plan that even under the most unfavorable conditions some success is achieved.

Clean pots I deem very necessary; also the adaptation of the size of pot and plant. After removing a plant never replace until the pot has been well washed, soaked, aired and dried. Keep at least four compost beds in operation, for it is so important the matter should undergo a thorough decomposition. Fill one compost with leaves liberally supplied with sand. One with fowl house refuse. Another, pile the grass after each mowing. Utilize all available material considered reproductive. After one year mix equal parts of each pile for filling pots.

\section{Louisiana. Mrs. W. N. WhIte.}

This is the time of year that many of our plants will need repotting. To have fine foliage and flowers, plants must have with all other requisites a soil that is light, loose and fibrous, and rich in plant food-not a hard clay soil with all the nutritious elements washed out or used up. Such might be dug up in the back yard, but could not be called potting soil.

A good formula for composting potting soil is three parts of fibrous loam or rotted sod, one part well-rotted manure and one part silver sand. There is nothing better unless it is to replace one part of the fibrous loam with leaf loam. Plants potted in fibrous loam alone do well, but of course the sand and manure is an im. provement. Fibrous loam is easily obtained by those who live in the country or who visit there occasionally. Go to some old meadow, cut a square of sod and lift it free from the ground. Just beneath this sod is found the fibrous loam, a layer of fine, loose, soft earth, full of little threadlike fibres.

Leaf loam is composed of decayed leaves. Bog soil of decayed water weeds, mosses and grasses. Both are very rich in plant food, and when used alone, if plants thrive at all, they usually grow luxuriantly, and the 1oliage is noticeably dark and rich in color.

Indiana.

Lecta Plackard.

\section{CHINESE SACRED LILIES.}

Even in December it is not too late to plant these charming bulbs. Get your bulbs from some reliable florist who can be depended upon to send sound, healthy bulbs. It pays to get the best, in all kinds of bulbs. I put three or four in a large, deep glass dish.

I first remove the brown skin from the bulbs. Then make with a pen. knife, three or four incisions half an inch deep from the top to near the base of each bulb. Be careful not to cut off any sprouts that may have started. Also be sure your hands are free from grease while handling the bulbs.

I put about a teacup full of sand in the bottom of the dish; then about an inch of gravel, set the bulbs in the middle, press them in firmly. Now fill the dish half full of pebbles mixed with a small amount of charcoal. Then pour in water until it reaches half-way to the top of the bulbs. I change the water once a week by 
pouring in water from which the chill has been taken until it runs over enough to have completely changed it. Now set the dish in a cool, light place away from the sun. In a week or more bring them into a sunny room. By the time they have been planted from three to four weeks they will be a mass of fragrant blooms. A dish of these lilies in bloom makes a lovely Christmas or New Year's gift that will be a delight to each member of the household fortunate enough to receive it.

Iowa.

Mrs. L. C. Whitaker.

\section{MY CULTURE OF CHRYSANTHEMUMS.}

About the middle of June my bed for chrysanthemums was spaded and well prepared with mixed fertilizers, thoroughly rotted. After a good rain my small plants were taken from the three-pound tomato cans, finely rooted, and placed in holes two feet apart each way. After the dirt was pressed firmly about them, I gave tnem a good drenching of soap suds until they were started. About two months later my plants, as I thought at the time, were ruined by having old plastering scattered over and around them (by a car'eless workman), the drouth came on, and I was almost in despair over my poor plants. I had as much of the trash removed as possible, then the long-looked-for rain came and my plants once more put forth new growth. I took all the fertilizer I could get, piled it close about them and kept them wet with suds from washings. The pinching of limbs and buds kept me busy the rest of the time, and not an insect about. They have repaid me in lovely blooms. I have a lean-to of old sashes placed over them against the southeast end of the house. I will have my pretty blooms until Christmas holidays, I think.

Alabama.

Mrs. W. D. Brown.

\section{WHY NOT A ROSE DAY?}

Where all roses are so lovely, it is. hard to make a choice, but their adaptation to our special need must be considered. If we desire roses that will bloom from year to year without the probable task of replanting, the hybrid perpetuals is the class best suited. There are the "June roses," and, contrary to expectation, seldom. bloom again during the summer, though if the dried blossoms are prevented from maturing into seed after the first flowering is over, they will. continue to bud and blossom until. fall. I have gathered a small nosegay of perpetuals grown in a private garden as late as October, but the plants must be well nourished and cared for to produce so well.

In the perpetual class we have the royal Jacquiminot, Giant of Battles and Madame Charles Wood, all crimson; the exquisite Madame Plantier, Coquette des Blanches and Madame Joseph Desbois, all white; Countess. Serenye, flesh color, Baroness Rothschild, Paul Myron, Mrs. John Laing, varying shades of pink.

These few named varieties with a hardy Persian yellow rose, and two moss roses, red and white, would form a good collection for a small garden.

Included in the list of hardy roses we also find the beautiful climbers, which are unsurpassed as vines for verandas.

Lastly we come to the hybrid teas, noisettes, bourbons and fairy roses, which include so many charming members that it seems an almost endless task to enumerate.

Where pleasure grounds are extensive, the roses should have a plot to themselves, quite removed from the other garden flowers. Then, surrounded by a privet or lilac hedge. which will afford protection from the rude winds, yet not exclude light and heat, climbers, dwarfs and standards 
will grow and bloom to perfection. Throughout the garden no more delightful retreat will be found for a summer evening's stroll than the fragrant blooming rosary. When the garden plot is too small to allow separate space for roses, the bushes look well planted by dividing fences, thus screening the stiff outlines, making a thing of beauty out of that which, in its best estate, is an object of ugliness, and our neighbors, as well as ourselves, will be the gainers.

In this country during the last few years Arbor Day has grown very popular, hundreds of trees being planted annually. Would it not be worth while for flower lovers to have a Rose Day, not publicly observed by schools and colleges-though a rose fete would be charming-but by individual families? If each member of the family, especially the children, would, on a special day, plant a hardy rose, quoting some verse or line descriptive of its charms to the sisters, brothers and parents gathered about, it would become a pleasant festival for all.
PA.
Margaret D. Brown.

\section{A DESIRABLE CACTUS.}

Some six months ago, while reading some descriptions of cacti, I was tempted to send for about a dozen different kinds. I had not the slightest notion of how to care for them, yet I was agreeably surprised to find. that with one exception all lived and throve.

Early in April little red dots about the size of a pinhead appeared upon one of them, and I watched it with great interest. All became discouraged, howerer, with the exception of one, which grew and at last expanded into a most beautiful red blossom just half the size of the plant, which is six inches.

I had a general idea that cacti needed no water in winter, but this little one looked so dry and thirsty that I gave it a drink with the rest of the plants, and when the blossom was coming, stood the pot in hot water every few days.

The name of this one I find is "Epiphyllum Russellianum Gaertner." It is a comparatively new variety and not as well known as some. Large specimens, it is sald, will bear three or four flowers on every leaf. The blossoms resemble those of the Cereus or Phyllocactus, and are a dazzling scarlet. I find that the plants should be kept in a cool place during the winter until three or four weeks before they are wanted to bloom, then give warmer quarters. They need abundance of sun, good ventilation to prevent weak growth, and an occasional dose of liquid manure. Given these, the best results may be confidently expected.

New Jersey J. T. TAYlor.

\section{ORCHID FLOWERED CANNAS.}

On April 15 of last year we procured five orchid flowered cannas, as an experiment. We had a trench dug. fifteen inches wide by twenty deepr and this was half-filled with manure from the cow pen, well rotted. On this a little soil. We then set the cannas (which had been started in pots) a little below the surface, so that water would lie around them. Every second day we flooded them. They grew and blossomed beyond our expectations till frost cut them down. In the fall we stored away more than a bushel of roots in dry sand, had many to give away this spring and have started in pots a much larger number, with the satisfaction of feeling no doubt about results.

Kansas.

Mrs. I. H. GRAY.

Grow a few tobacco plants; the leaves crushed and laid on the tops of plants liable to the attacks of green lice will keep them away. 


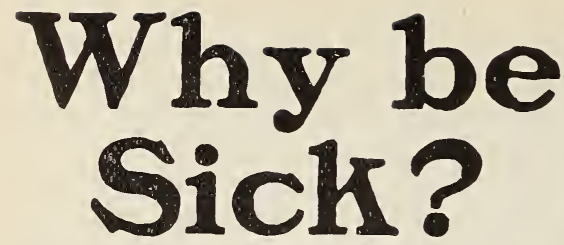

After Fifty Years of Constant Study Dr. J. M. Peebles, of Battle Creek, Mich.. Has Perfected a Treatment That Gives Hope to Every Sufferer.

Write for His Valuable Book which Explains Fully this Wonderful Treatment.

\section{Test the Treatment Free!}

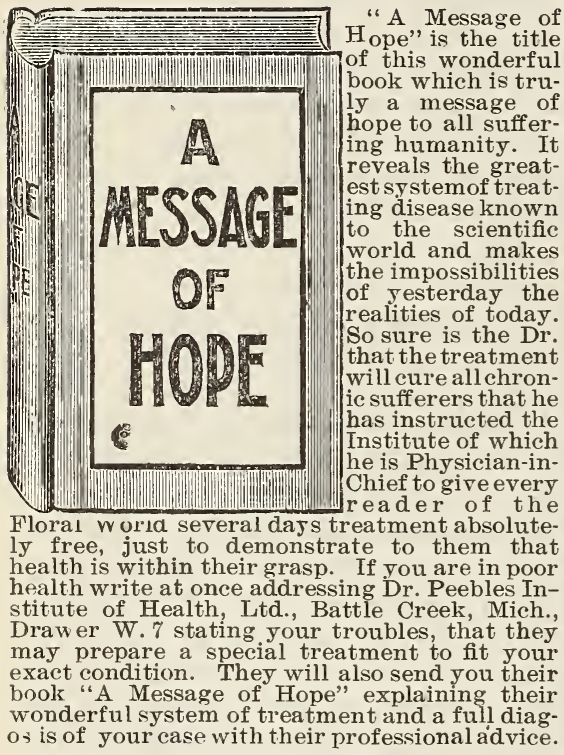

Last summer my bed of several kinds of Tea Roses yielded great fat buds and fragrant blossoms, after I had safely tucked their roots into the rich bed prepared for them. Roses are benefited by all the old manure you use. When preparing the bed I always think of the old lady who gives this receipt for rhubarb pie. "Put in all the sugar your conscience will let you, and then shut your eyes and put in a double handful more." I have found this applies excellently to the manure for roses.

Ohio.

J. W. M.
JULY AND AUGUST ROSES.

My roses are not called "July and August roses," but "ever-blooming roses." That they bloom during these months is beyond doubt proof of ever-blooming qualities. With few exceptions no other roses are worth cultivating. There are classes that bloom in July and August, and there are individual roses in each class that excel in continuous blooming. These are now in full view. They face me as I write. I could cut a bushel of blooms from spring to fall, any day, from these rose vines and bushes. I plant ever-bloomers, and always have roses. No mode of culture, no art nor science can accomplish the purpose like the constitutional peculiarity that makes a rose ever-blooming. Plant these, and there will be roses all summer, as sure as the dew falls and the sun rises. Suitable culture must be given; but the same culture would not attain the same end with any but true ever-blooming roses. The names are easily found in catalogues. They are celebrated.

Louisiana. Mrs. G. T. Drennan.

Summer flowers being arranged for, in June one can plan for winter. Cacti are always interesting and odd, equally pretty the year around; they require very little care, and many varieties bloom young. Cuttings are easily rooted if left a day to form a callous before being placed in moist sand. They can also be easily raised from seed. Some people enjoy grafting different varieties of cacti onto others, forming unique combinations. In summer, cacti may be grouped in their pots, on lawn or porch. They need small pots, good drainage, rich soil with one-third sharp sand, and plenty of water and sunshine in summer. Hardy varieties are nice in a rockery. An indoor rockery may be made, using an old sewing machine frame or other stand, one having cas- 
tors being more convenient. Have a galvanized iron tray six inches deep to fit the top, with an outlet and two inches of broken crockery for drainage. Fill nearly full of rich soil with one-third sand, and set cacti in it. leaving some room to grow, and it will last several years without requiring more room, as most cacti are slow growers. They need no sun in winter.

Illinois.

M. S. ANDREWS.

\section{CLEAN FLOWER POTS AND POTTING.}

To insure success, plants must have clean pots, free from germs, especially clean on the inside. We have inverted pots and sometimes injured the fibers, by not first scouring the pot before setting the plant. Clean them clean and sterilize to kill all germs by heating in the oven. Bring the temperature up to 350 degrees, then cool gradually. Then the ball of roots will hold perfect and the plant change safely.

Don't paint the flower pots. Why? Because it fills up the pores of the pot and stops that circulation of air so beneficial to the little fibres, and that is why clay pots are far superior to other receptacles.

In potting roses, oranges, figs, azalea, camellia and palms and other woody plancs, after planting I take an old potato masher and press the soil around them, being careful not to injure the roots. Water well. This packing of the soil is almost a necessity with this kind of plant, but not so with watery, pulpy ones.

While plants are growing, stir the surface lightly and give sulphate of potash. It hardens the growth; it is in most all the box fertilizers in the right proportion.

Illinois.

Annie J. PADdick.

$\mathrm{He}$-You appear to be alarmingly ignorant in horticulture. You hardly know one flower from another.

She-I guess you're about right. Not even graham from white.

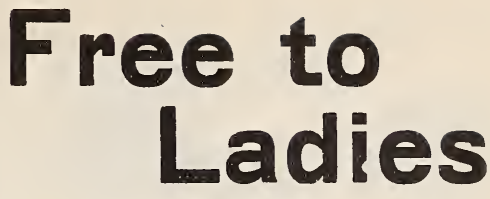

One Full-Sized $\$ 5.00$ Package of Dr. Mary Lock's Wonderful Home Treatment Given Free to Every Lady.

Cures Every Form of Female Weakness, Displacements, Leucorrhea, Sup pressed or Painful Menses, Falling of the Womb, Change of Life, Etc.

The celebrated lady specialists have decided for a short time to give free, one full-sized $\$ 5.00$ package to every suffering woman in order to quickly in troduce their most wonderful remedy

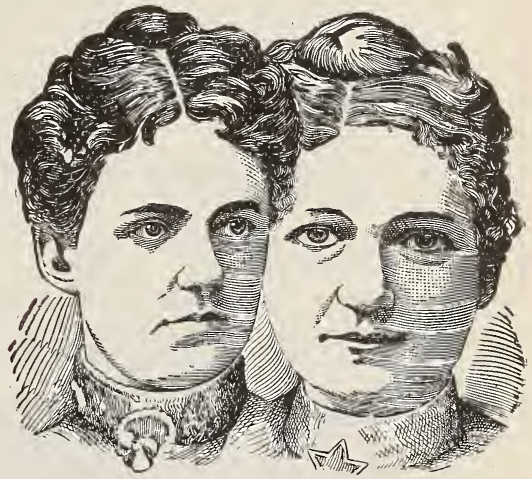

Two of America's Greatest Lady Specialists.

in every city, town and hamlet in the U. S They could not afford to do this only that they expect after you are cured and they know you will be and that you will recommend the remedy to suffering friends who will gladly order the treatment and in this way they will be amply rewarded for making this most liberal free offer Send your name and address to Dr. Mary Lock Co., 1020 Englewood Station, Chicago, Ill., for a free $\$ 5.00$ package and be quickly cured in the privacy of your own home.

Remember this is not a patent medicine but a full three-course treatment sent complete, in a plain package so that no person will know what it contains.

The above offer is genuine. We ask no questions or references of any kind. Every lady who writes will be given a full $\$ 5.00$ package free. Write today.

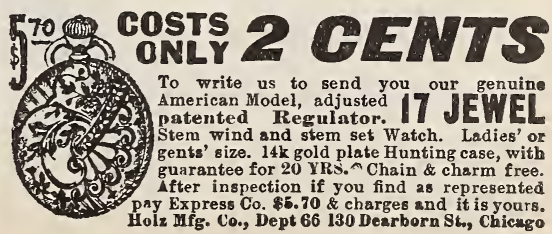




\section{DR. CHARLES' FLESH FOOD.}

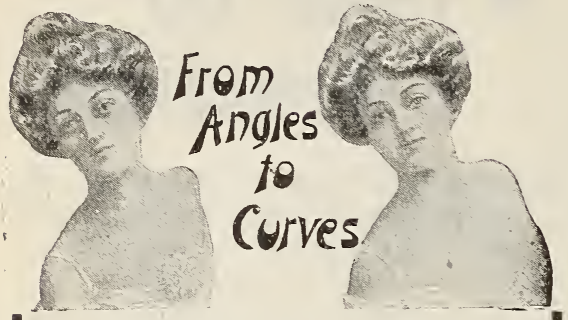

\section{Dr. Charles' Flesh Food}

has been used by leading actresses, singers and women of fashion for more than twenty-five years.

It has the highest endorsement of the medical profession who acknowledge it to be the only preparation that will increase flesh in the face, neck and shonlders.

For removing every blemish of the complexion and DEVELOPING THE FORN it is without equal.

The regular price is one dollar a box. but to all who mention this paper and send us $\$ 1.00$, we will send two (2) boxes by return mail, also our book "Art of llassage," which is illustrated and contains much valuable information.

FR E E-A sample box of Dr. Charles' Flesh Food; also one of the above books will be sent fiee to any lady sending us 10 cents to cover cost of mailing. Address :

19 Park Place.

DR. CHARLES CO.

New York.

\section{KIMSEY'S Improved Waist}

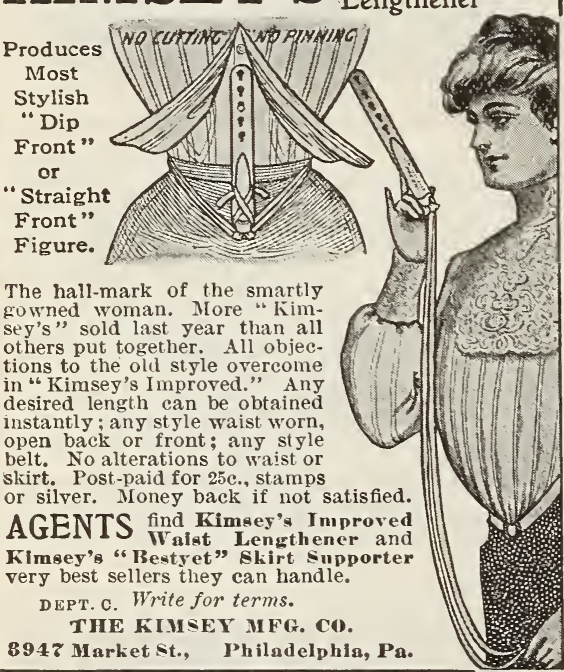

HOUSE WIFE

The Dandy Scraper fits and cleans every pot, pan or dish. By mail 10c. Agents wanted. Dandy Mfg. Co., Dept. B., Newark, N. J.

CDS Lorely new styles for 1902 ; also Xmas, N. Y ARDS and Novelty Cards; samples sc. F. G. Boyco \& Co.s Lynn Mass.
FREESIAS.

To have each of your freesias a miniature gladiolus in appearance, plant deep, the top at least an inch below the surface, keep in a cold atmosphere and give strong sunshine and moisture. This will induce sturdy growth. The best time to plant is in July and August; five bulbs in a five-inch pot, using a compost of equal parts of turfy loam and leaf mold. They do not require a dark place to root, but should be sheltered till the tiny blades appear, then place in the strong sunshine. Water carefully until the pots are filled with roots, then if the drainage is perfect there is little danger of over-watering. I use no fertilizer until the buds appear, then water once a week with weak liquid manure.

Ohio. Annice Bodey Calland.

THIS, THAT AND THE OTHER.

As June is the month of roses, we should be vigilant. By beginning early in May with kerosene emulsion or whale oil soap dissolved in water and applied with a sprayer, we can succeed in keeping our roses free from insect pests. For the leaf hopper, white hellebore is the best remedy I ever tried. Wet the foliage with soap suds and dust the hellebore on with a dusting box or bellows.

A pretty combination can be made with a scarlet geranium for center, followed with blue ageratum, with a border of sweet alyssum. In these we have three shades of green in foliage, with red, blue and white bloom.

Z. M. Eckert, Ohio, asks how a century plant should be treated in winter. The agave should be kept dormant in winter, without any water, for they will absorb sufficient moisture by evaporation. The cause of your plant rotting was low temperature and over-watering. If decayed as you say, it is perhaps dead already. 
Mrs. Clark Smith asks what to do with pot plants in summer. Sink your potted plants in the ground in a partially shaded situation, water when necessary, and you will have no further need of "doctoring" with matches for black ants.

I can endorse Mrs. L. D. Bowers' method of treating the umbrella plant, for they are great "drinkers" and must be kept full all the time if we would have them look their best.

Indiana.

Mrs. R. A. Houk.

\section{FERTILIZING.}

It is very interesting to study how Flora's children consent to care and proper treatment. An important factor in having success, especially with window plants, is fertilizing. You may try any prepared artificial plant food, or aqua ammonia, or anything else in this line, nothing can be compared to liquid manure when properly. handled. Take an old nail keg or something similar, have some small openings in the bottom part, and fill this with manure, then place over some slightly larger receptacle and pour water into the keg, which, if properly diluted, gives an excellent plant food. Thus given twice a week will soon show its beneficial effect on your plants.

Wisconsin. Rev. F. T. Franke.

\section{A QUERY AS TO CALLAS.}

I have a Calla two years old that has grown well, but has not bloomed. I have kept it in a warm place and in full sunshine, have watered it with warm water and rested it for three months in the summer, by turning the pot on its side in the shade. Is my treatment defective? How old should it be to bloom?

Kansas. Mrs. Gray.

"Vines are nature's drapery". Have an abundance of them over your fences.
Drunkards

\section{Gured Secretly}

Free Package of the Only Successful Cure Known for Drunkenness Sent to All Who Send Name and Address.

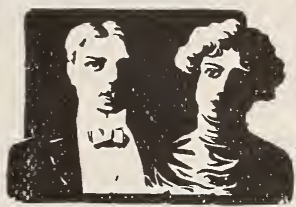

A new discovery, odor. less and tasteless, which any lady can give in tea. coffee or food. It does its work so silently and sure. ly that while the devoted wife, sister or daughter looks on, the drunkard is reclaimed even against his will and without his innowledge or co-ojeraMR. \& MRS, IARRY BURNSIDE. dress to Dr. J. W Haines 3071 Glenn Bldg., Cincinnati, $O$., and he will mail enough of the remedy free to show how it is used in tea. coffee or food.

Mrs. Harry Burnside says "With Golden Specific I cured my husband of drinking. I put it into his coffee and after that he couldn't drink liquor or bear to be around where it was."

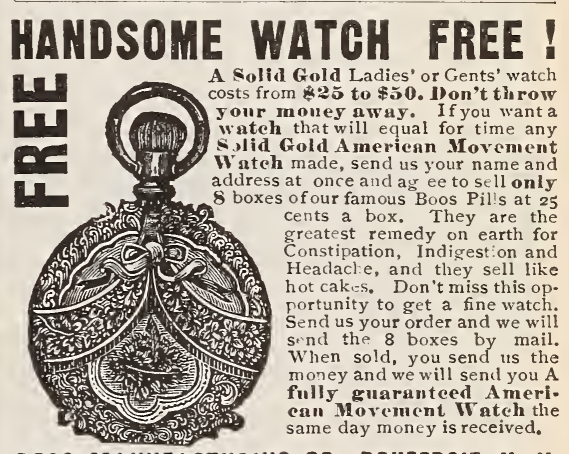

BOOS MANUFACTURING CO., POKEEPSIE, N. Y.

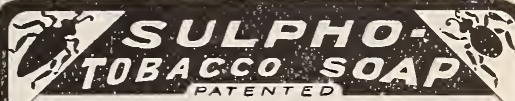 \\ KILLS BUGS AND INSECTS}

In the Flower and Vegetable Garden.

Insurpassed for rose bushes and small fruit trees. powerful fertilizer, giving new life to plants; noninjurious and absolutely safe to handle.

A SUPERIOR INSECTICIDE.

I'sed by thousands with most satisfactory results. Buy it now of your seedsman. If not for sale by him, send us his name and TEN CENTS, mentioning this paper: we will mail you a trial 3-oz. eake, sufficient for 1 1-2 gallons prepared solution.

\section{Larkin Soap 6.}

Chemists, BUFFALO, N.Y.

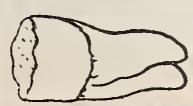

For 25c. K. \& S. Tooth Filler fills the teeth for 6 months. Stops toothache instantly and prevents decay. Manufacturer, GEO. R. BAK ER Registered Pharmacist.

65 CLARK ST., - CHICAGO. 


\section{SUMMER CARE OF HOUSE PLANTS.}

About the first of June put your plants outside, where they can be protected from high winds and hard rains. Old plants that are to be kept over for another winter should be cut back half, repotted and kept rather dry, and shaded from the sun. This treatment forces them to rest. The last of August give more water and full sun and encourage them to grow again. Young plants should have plenty of water, full sun, and should be pinched back to make them bushy. Stir the soil in all the pots with a fork once a week and shower them as often. Do not apply any fertilizer until September, then apply according to directions. What we must aim at is a strong, healthy growth. A good soil for most plants adapted to house culture is equal parts of good garden soil and leaf mold with a little sand added.

New York. Jennie M. Reynolds.

\section{AS TO POT PLANTS IN SUMMER.}

Mrs. Clark Smith wants to know what to do with pot plants in summer. I make a large round bed in my yard where it is sunny, and, the last of May, set all my geraniums and roses in it. My Boston fern I keep in my parlor, also my two begonias in my dining room. In July I take a small slip from each geranium and set it under each one alike, and they are ready to pot in September. For the house in winter I have very handsome geraniums in bloom. But I take good care of them.

New York. Mrs. Charles Ennis.

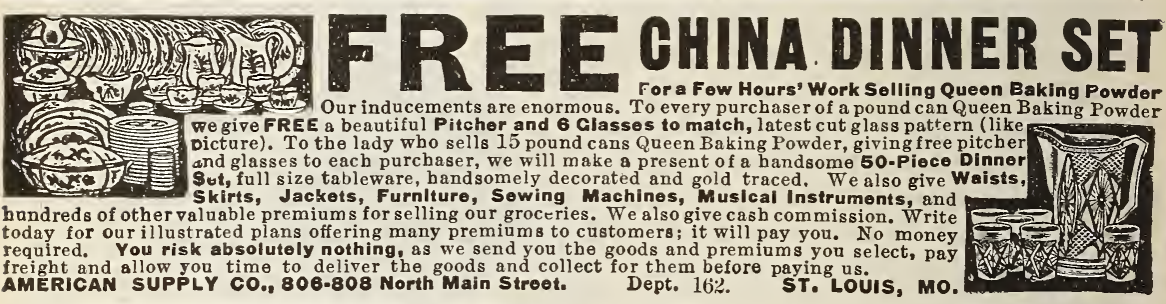

freight and allow you time to deliver the goods and collect for them before paying us.

\section{THE
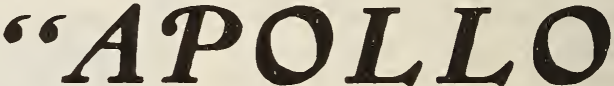

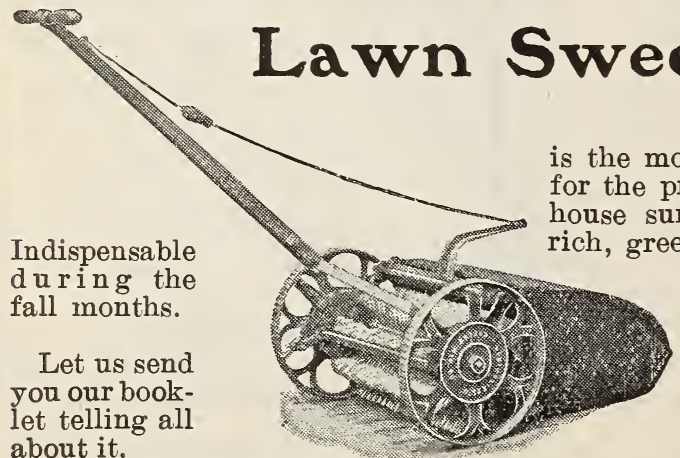

is the modern time and labor saver for the proper care of the lawn and house surroundings. Produces the

Indispensable during the all months.

Let us send about it. lightful to the eye, removes CUT and DEAD GRASS, LEAVES, Twigs, Stones, etc., from the lawn, sw e e s SIDE - WALKS, PAVEMENTS and BARN FLOORS.

\section{THE GREEN MFG. CO., Springfield, O., U.S.A.}




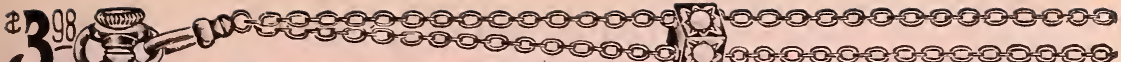

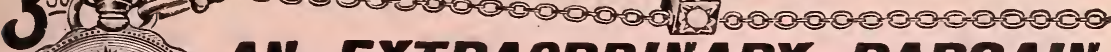

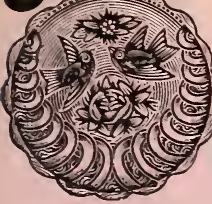

AN EXTRAORDINARY BARGAIN

Jewelers charge $\$ 15.00$ to $\$ 35.00$ for gold filled watches that look no better and keep no better time than this. Double hunting, richly engraved gold plate case with diamond cut ruby jeweled works, stem
wind and stem set, an accurate-to-the-second timekeeper. BEAUTIFUL CHAIN FREE. wind and sten set, an accurate-to-the-second timekeeper. BEA TIF UL CHAIN FREE. handsome 12 inch vest chain. SEND NO MONEY. Cut this out and send it to us with your name and address and we will send the WATCH AND CHAIN to you by express. You examine them atyour expressoffice and if as represented pay express a charges and they are yours. Mention size wanted LADYS or CENTS. A guarantee for 20 Y with every watch. Address K. E. CIIALMEIS \& CO., 352.356 Dearborn St., Chicago, III.

OUR MAGNANIMOUS OFFER WE WILL POSITIVELY GIVE THIS ELEGANT

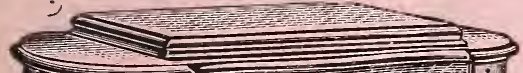
$\$ 65.00$ Style Sewing Machine FREE to any person who will accept onr offer and sell only 10 packages of our Laxo-Tonic Pillets. This machine is sold nnder a full guarantee. IT ACTOMATIO BOBBIN WINDER, DOUBLE FEET SELF-TIIREATING SIIUTTLE, NOISELESS SHUT. TLE CARIIER. IEAI IS IANDSOMEAND PLEAS. ING IN APPEARANCE. All parts highly finished and carefully fitted. WOODWORK is quartered oak, highly polished and fitted dust proof. In short, it is just the same style as machines selling for $\$ 65.00$ with attachments, To introduce cur Laxo-Tonic Pillets in every town and hamlet, we will give our special liberal offer of this high grade sewing machine to anyone who will sell only 10 boxes of our Laxo-Tonic Pillets at 25 cents a box and send us our money. DO NOT SEND A CENT OF YOUR MONEY. Simply send your name and address, we send the Pillets postnaid. When sold, send us our mone and we will at once send our special offer of THE SEWING MACHINE described above, ABSOLUTELY FREE, together with A HAND SOME and accucurate SWISS CLOCK, Our plan is to get people to help us popularize our Laxo-Tonic Pillets by giving liberal premiums instead of spending thousands of dollars in newspapers. Laxo-Tonic Pillets cure Constipation, Headaches, Liver Troubles, Impure Blood, etc. We are a responsible house and rant our tablets, gewing machines and clocks to be just as represented Send your name at once, also P. O. address and nearest express office. We pay all express and packing charges. You have no other expense.

Q. WEST INDIA IMPORTIKG CO.. Dept, S, 442 Washington St., New York.

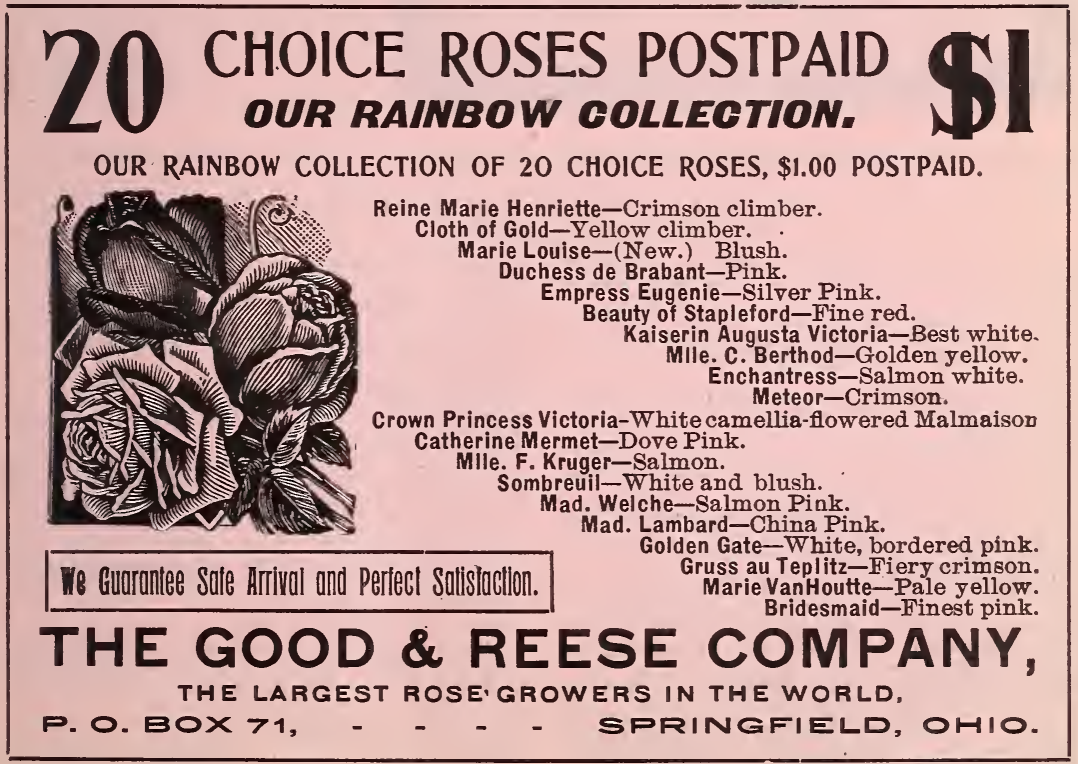



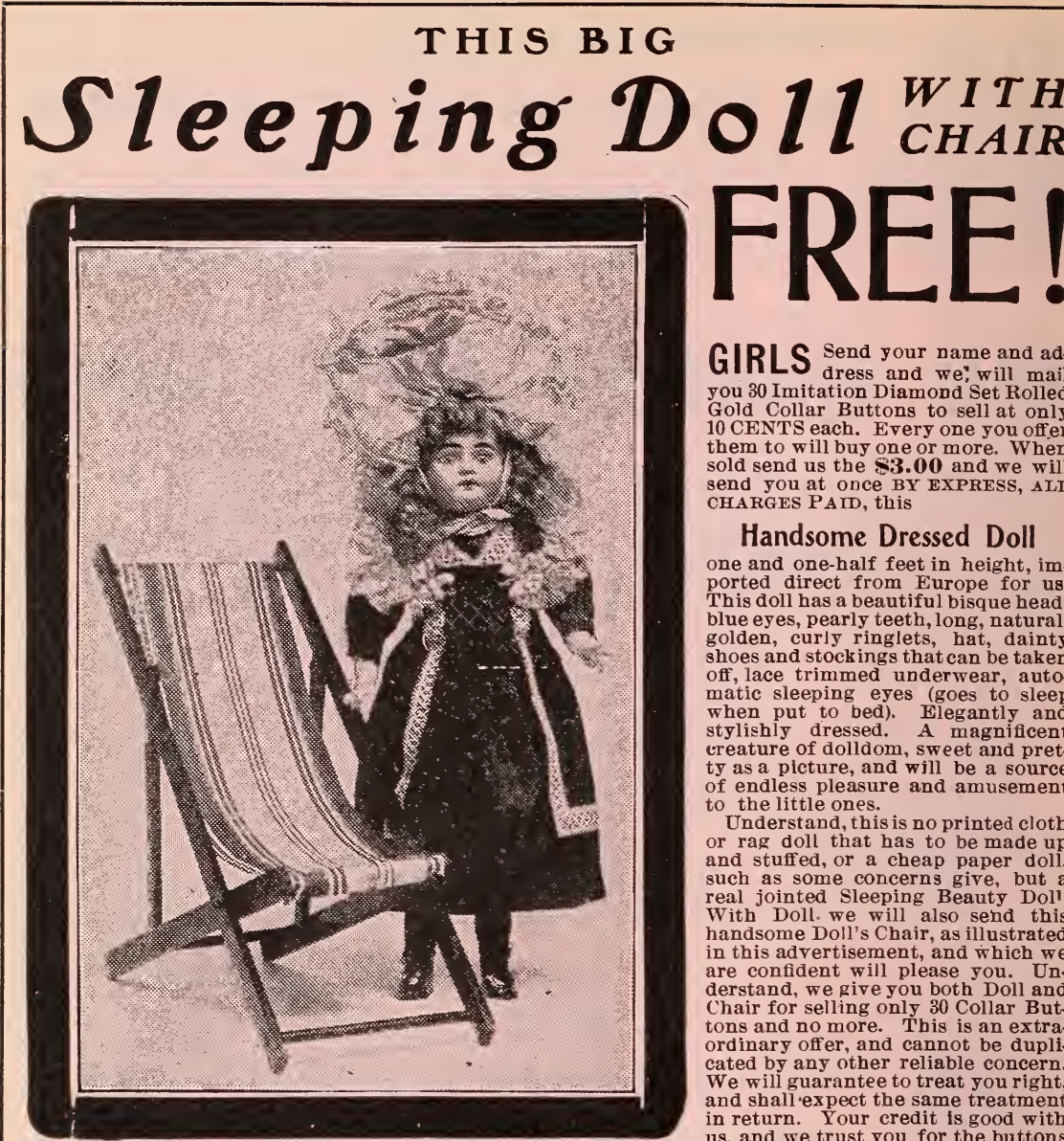

GIRLS Send your name and adGIRLS dress and we; will mail you 30 Imitation Diamond Set Rolled Gold Collar Buttons to sell at only 10 CENTS each. Every one you offer them to will buy one or more. When sold send us the $\$ 3.00$ and we will send you at once BY EXPRESS, ALL CHARGES PAID, this

Handsome Dressed Doll

one and one-half feet in height, im. ported direct from Europe for us. This doll has a beautiful bisque head, blue eyes, pearly teeth, long, natural, golden, curly ringlets, hat, dainty shoes and stockings that can be taken off, lace trimmed underwear, automatic sleeping eyes (goes to sleep when put to bed). Elegantly and stylishly dressed. A magnificent creature of dolldom, sweet and pretty as a picture, and will be a source of endless pleasure and amusement to the little ones.

Understand, this is no printed cloth or rag doll that has to be made up and stuffed, or a cheap paper doll, such as some concerns give, but a real jointed Sleeping Beauty Doll. With Doll. we will also send this handsome Doll's Chair, as illustrated in this advertisement, and which we are confident will please you. Understand, we give you both Doll and Chair for selling only 30 Collar Buttons and no more. This is an extraordinary offer, and cannot be duplicated by any other reliable concern. We will guarantee to treat you right, and shall expect the same treatment in return. Your credit is good with us, and we trust you for the buttons until you sell them.

\$100 REWARD is hereby offered any person who can prove that we have not given Free a beautifu Doll for selling 30 Collar Buttons, or that our testimonial letters are not genuine.

\section{JOIN OUR ARMIY OF LOVING FRIENDS.}

Our patrons are exceedingly well pleased with the Doll, as the following letters will show :

Iola B. Mills, Rochester, N. Y., writes: "Doll received this p. m. all right. I think it is lovely. Well paid me for my work."

Mrs. F. Cousen, Jacoby, La., writes: "Doll received and we are more than delighted with it. It surely surprised my little girl, and she is delighted."

Mrs. Charles Gray, Paines' Point, Ill., writes: "Received doll all right yesterday. It was all right. Many thanks."

Bosa Fehrenbach, East Bottoms, Mo, writes: "Received my doll from you and was very much pleased with it. I thank you.'

Mrs. J. W. Hallard, Easton, Pa., writes: "Received doll for selling goods and was very much pleased with it. Will answer any question anyone may ask concerning it."

Mabel Bircher, W.Lebanon, N. H., writes; "I received the doll and am very much pleased with it, and a cousin of mine said that if you would send her goods she would try hard to sell them to get a doll like mine."

Mrs. C. Marshall, Upper Nyack, N. Y., writes: "Received the doll all right yesterday, and we are

We have hundreds of similar letters on all very much pleased with it. I am glad to see it is what you claimed it to be, as in some places things are not what they advertise."

Lulie Richmond, Harrisburgh, Pa., writes: "I received my doll and was very much pleased with it. Many thanks."

Katie Livingstone, Yulan, N. Y., writes: "I received the doll Friday all right, and it was just as nice as I expected. Thank you kindly for sending it so promptly.

Miss G. E. Folger, No. Foxboro, Mass., writes: "The doll received $O$. K. and was very much pleased with it. It was perfectly satisfactory, and I must thank you for your kindness.'

Mary Welch, Millis, Mass., writes: "I am very much pleased with my doll. My mother would like to know how much you would sell a doll for without selling any goods."

Mrs. Lilly Eales, Des Moines, Ia., writes: "My husband found the doll all $O$. $K$. at the express office, for which accept my thanks. My daughter is delighted with it, and has taken it to school today to show her friends and teacher."

file. WRITE US TODAY. Address

\section{STANDARD JEWELRY COMPANY, 269 Pearl Street, BOSTON, MASS.}




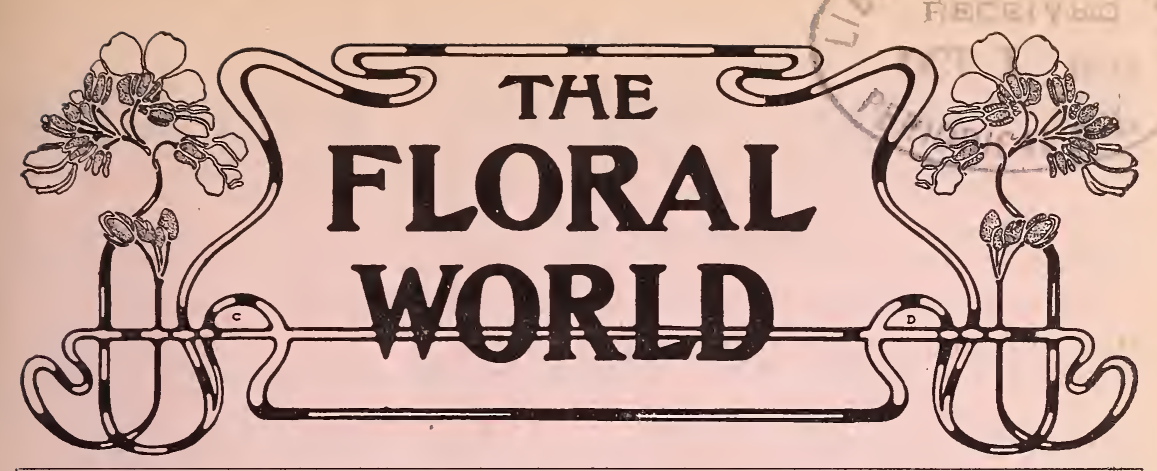

Vol. 1. No. 10 Springfield, Ohio, July, 1902

25 Cents a Year

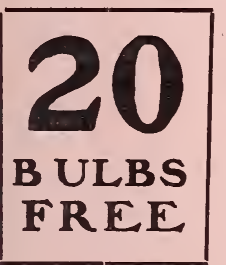

\section{During July}

TO ANY ONE sending 25 cents for

FLORAL WORLD one year, we will give, postage prepaid, Twenty Choice American Grown, Winter-and-SpringBlooming Bulbs.

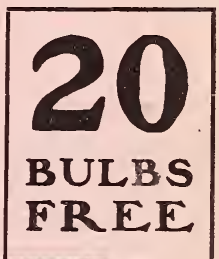

\section{Cॄelve Freesias.}

Freesias are the most popular and charming bulbs for pot culture, flowerin in winter or spring in the conservatory or window garden. Six or eight bulbs should be planted in a four-inch pot. They force readily and c an be had in bloom by Christmas if desired. The flowers produce six to eight on stems about nine inches high, and are particularly useful for cutting. The blooms remain in good condition, if kept in water, for two weeks. The flowers are pure white, with a yellow blotched throat, and are exquisitely fragrant.

\section{Eight Oxalis.}

An unrivaled winter-flowering pot plant of easy culture. It is a strong and luxuriant grower with handsome foliage. The profusion of bloom produced in uninterrupted abundance for weeks is astonishing and delightful. The flowers are of the purest bright buttercup yellow. Properly treated the plants will flower in six weeks from the time the bulbs are set out. Well grown plants have produced as high as seventy flower stems at one time.

There are no finer flowers for woindow cuiture.

THESE BULBS will give best results if planted in the summer or early fall. This makes our offer most seasonable and one which every one of our present subscribers should accept at once and have his time extended for one year.

\section{TWO MORE SUBSCRIBERS.}

We would like very much to have two more subscribers for The Floral World from every one of our present subscribers, and there are thousands of them who could secure $\boldsymbol{a}$ club of t $\mathbf{t} \boldsymbol{0} 0$ for us if they would only speak about it to their friends. If you will get two of your friends to accept this offer of $\boldsymbol{C}$ he Floral World and TEenty Bulbs for 25c., we will send you the collection of bulbs free, postage prepaid. 


\section{THE PRESS PUBLISHING OFFERS $\$ 25,000$ CASH PRIZES}

To be distributed among successful estimators of the total vote for Governor in the States of New York, Pennsylvania and Michigan on the 4th day of November, 1902.

The money, $\$ 25,000$, has already been deposited in the Central Savings Bank, Detroit.

\section{CONDITIONS OF THIS GREAT CONTEST.}

Any one sending us only 25 cents for THE FLORAL WORLD one year and an est imate of the total vote of Governor in New York, Pennsylvania and Michigan on November 4, 1902, will receive a certificate which will secure for him any prizes his estimates entitle him to claim, provided no other premium is taken.

You may estimate as many times as you desire by sending us only 12 cents with each additional estimate. An investment of a few cents and careful study may bring you $\$ 10,000$.

The contest will close at midnight, November 3,1902, and no estimate received after that hour will be allowed. The official certificates of the Secretaries of the three States, showing the total vote for Governor, will determine who are entitled to the prizes, and the awards will be made by a disinterested Committee of prominent judges, just as soon as the official figures can be obtained.

\section{HERE IS THE LIST OF PRIZES.}

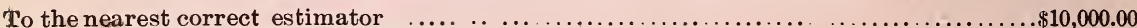

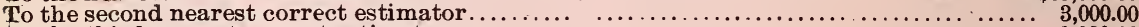

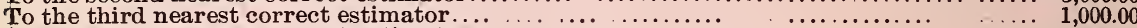

To the fourth nearest correct estimator $\ldots \ldots \ldots \ldots \ldots \ldots \ldots \ldots \ldots \ldots \ldots \ldots \ldots \ldots \ldots \ldots \ldots \ldots \ldots$

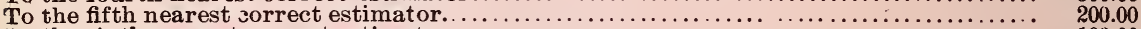

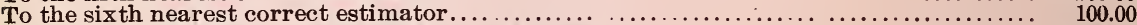

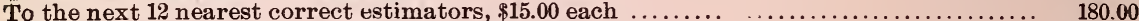

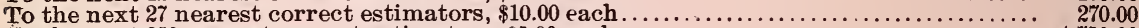

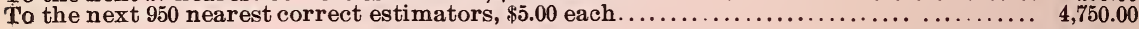

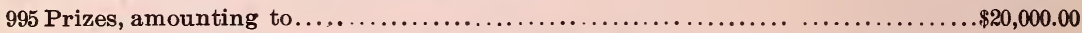

\section{The following Special Prizes will Also be Paid:}

For the nearest correct estimate received before August $1,1902 \ldots \ldots \ldots \ldots \ldots \ldots \ldots \ldots \ldots 1,000.00$ For the nearest correct estimate received on or after August 1, and before August 15.... $1,000.00$ For the nearest correct estimate received on or after August 15, and before Sept. 1..... 1,000.00 For the nearest correct estimate received on or after Sept. 1, and before Sept. 15 . . . . 1,000.00 For the nearest correct estimate received on or after Sept. 15, and before Oct. 1........ 1,000.00

Total 1,000 Prizes, amounting to. $\$ 25,000.00$ in case of a tie or that two or more estimators are equally correct, prizes will be divided equally between them.

\section{VALUABLE INFORMATION.}

To aid in forming your estimates we furnish the following data:

Pennsylvania elects a Governor only once in four years. Michigan elects a Governor every two years, and since 1894 New York has elected a Governor every two years.

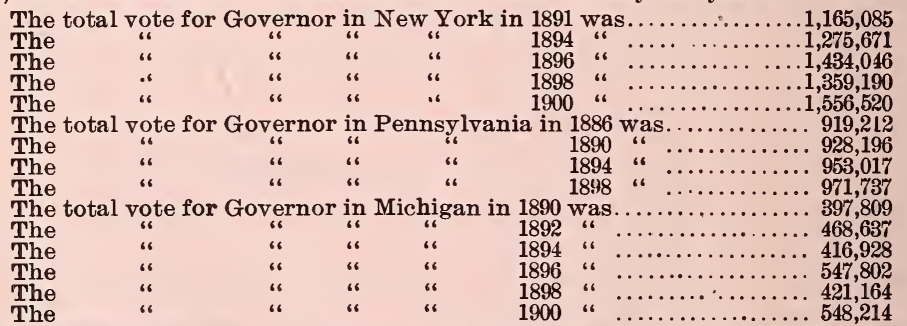

The total aggregate vote for Governor in these three states in 1894 and 1898, the years in which all three states elected Governors at the same time, was as follows:

In 1894 the aggregate vote for Governor in these three States was 2,645,616.

In 1898 the total aggregate vote for Governor in these three States was 2,752,091.

What will the total aggregate vote for Governor in these three States be on November 4 , 1902? Figure it out or guess at it, and send in your estimates. It may mean $\$ 10,000$ in cash to you. The official certificates of the Secretaries of the States of New York, Pennsylvania and Michigan, showing the combined total vote for Governor in these three States, will determine who are entitled to the prizes, and the awards will be made by a Committee of prominent judges within twenty days after the official vote is known.

Be sure to include your estimate in plain flgures when remitting. 


\section{The Floral World}

A Fournal of Home Floriculture

Vol. 1, No. 10

Springfield, Ohio, July, 1902

25 Cents a Year

THEY LIKE THE FLORAL WORLD.

The Floral World is increasing in interest all the time.

Indiana.

Mrs. R. A. Houk.

Have received my first number of the Floral World, and appreciate it very much.

Texas.

Miss Ellie Steele.

The Floral World meets the need better than any magazine I have seen. It is foundational and concise.

Colorado. Mrs. B. H. Fowler.

The Floral World is certainly favorable to create the love of flowers, as well as giving instructions in caring for them.

Miss.

Mrs. E. E. Dix.

I am interested in the prosperity of the Floral World, and am determined to enjoy its monthly visits as long as I live. Many young gardeners will eagerly accept such adequate instructions as are ever at hand in the Floral World.

M. S. H.

\section{REPOTTING PALMS.}

Palms should be repotted in early spring before growth begins, in soil which is rather rich and contains some sand. The stem should rest on the soil, but should not be covered. After potting, sponge the leaves daily for a week, and once a week afterward. The roots should never dry out, nor we kept too wet. They need frequent watering and a little sun in summer, and less water and no sun in winter. The leaves will be a richer green if grown without much sun. Examine leaves and stems for scale and mealy bug, sponging occasionally with soapsuds to keep off the insects. In purchasing, small sizes are less injured in the mail. Nearly all varieties are desirable, particularly the Kentias, Latania, Areca and Washingtonia. Good-sized palms can be grown from seed in four or five years.

Illinois.

M. S. ANDREWS.

\section{SUCCESS WITH THE LANTANIA PALM.}

My palm is about five years old, has eleven leaves and measures from base of stem to tip of leaf fifty-two inches, and the leaves are twenty-four inches from stem to tip, and thirtyfive inches broad. Visitors from Nashville and I.ouisville say there is nothing in their greenhouses so handsome. I have it in a tin can made just large enough around for the roots to slip in comfortably-thirtytwo inches, and eighteen inches deep; you know the roots grow down. I put an inch or two of small pebbles and charcoal in this and fill with good garden soil mixed with leaf mold; water only when dry, then thoroughly. It lived in my room last winter when other plants froze, and is now a wonder to my neighbors who lost theirs. Here is the secret: In very cold weather give no water, no matter how dry. Sponge the leaves about once a week with water mixed with sweet milk. Let it get a little morning sun and it will well repay for so little care.

Kentucky. Mrs. E. B. Weatheas. 


\section{GROWING PALMS FROM SEED.}

Most amateurs admire a choice palm, but many are debarred from the pleasure to be derived from one by the price asked for fair specimens, and some time is required to grow them from seed. But if you have some patience they are well worth waiting for.

For your first attempt select the Filicera palm. It is not the handsomest, but is the most easily grown. The seeds will require from six to eight weeks to germinate and should be sown during the hot summer months. Select a moderately rich soil for the seeds. When they have germinated, transplant into fair-sized pots as often as needed. At eighteen months the plants will begin to develop character leaves, at two years they will be two and one-half feet high with several fully developed leaves, and will then be very pretty and valued much more than one of the same size purchased.

Always supply good drainage and do not plant too deep. They should always be given a warm temperature and a moist soil.

After you have grown a Filifera, try a Lantania Borbonica, then a Seaforthia, Kentia, Phoenix, Chamerops Excelsa, in the order named.

Pennsylvania. Fraxk Walter.

\section{THE RUBBER PLANT.}

Some little time ago I read a good article by one of Washington's most prominent florists, on the way to treat a rubber plant. He said that every spring the plant should be shifted to a larger pot, filled with fresh soil, and during the summer be kept on a piazza, or in the shade of a tree. In winter it should have light, but not much direct sun. Once a week the pot should be placed in a tub of water and allowed to remain over night, or until thoroughly soaked, then drained, and not watered again until the surface looked somewhat dry. At the expiration of a week repeat the soaking. The leaves must be kept clean by frequent wiping with a damp cloth.

To make the plant sprout at any desired point, put a small sponge kept wet where a leaf joins the main stem. To make two plants from one, make a cut partly through on each side of the stem near the top, bind with florists' moss kept wet. Detach the slip when rooted and bind a little moss on the stem of the old plant until the wound is healed.

New Jersey. Mrs. J. T. TAYLOR.

\section{THE CAMELLIA JAPONICA.}

Perhaps the readers of The Floral World (the most interesting little magazine in the country) would like to hear of the great success I had with camellias last winter. A year ago last February I purchased two thrifty plants, patting them firmly in a soil of one part sandy peat, three parts loam and another part leaf mould, first filling the crock one-third full of "potsherd." After a good bath they were kept shaded until growth began. The camellia thrives in a cool, moist atmosphere with frequent syringing and leaf-washing. Never allow a drop of water on a leaf in the sunshine. In spring the pots were plunged in a bed where there was shade in the middle of the day. They were never allowed to become dry. By September buds had formed, but I only allowed one bud to a shoot, wishing the flowers to be as large as possible. The first one bloomed in December. It was white and perfectly double, the size of an American Beauty rose. The second, a red, reached its perfection in February. The plant had nine flowers, but not as large as the first.

Pa. Mrs. John Bernard Raser. 
HOW TO PRODUCE CHOICE BULBS.

Experience is very costly. Choice bulbs are also costly. But they are worth the cost, when we consider the rich blooms and greait amount of pleasure they give. The question with many is: "How can we prevent that degeneracy which they so soon fall into?"

First, prepare the soil in the best possible manner. Plant the bulbs in rows, putting a layer of well-rotted cow manure in the bottom of each trench. Cover this with good garden loam. Mulch with leaf mold or wellrotted manure. Bulbs should be taken up every year, for if allowed to remain longer they will foul and break into small increase. Experience as well as science teaches us that almost all flowers confined too long to the same earth and same spot (I was going to say the same air) degenerate and dwindle away. A change in all three respects is often requisite to renovate, as it were, their crescive faculties and to insure their return to their prestine health and condition.

Just think of the millions of dollars that we ship each year to Holland, Bermuda and the Sicilly Islands for bulbis! I am sure that there are gardens and farms in this bright, beautiful, productive land that will produce bulbs equal to those of any land, if we give them the same care and culture. Let us then plant and care for our plants in the best possible manner. And care for the bulbs first by cutting off the flower stalk as soon as through blooming, never allowing the leaves to be removed until dry. The health, strength and size of the bulb for the succeeding year depends upon its storing up a proper amount of sap. which you will in a great degree prevent by cutting off the leaves when in a green state. Care is also requisite in drying the bulbs thoroughly with- out sun-scalding. Iay them away in shallow boxes one bulb deep, covered with one nch diry sand. This means a great deal of work, but you will be richly paid in magnificent blooms and coin for bulbs, beside the pleasure afforded your friends and neighbors.

California. JoHN HOOPER.

\section{CARE OF VARIOUS PLANTS.}

Geraniums for winter should be prepared in spring and roots not disturbed in fall. They need small pots. I had one bloom last winter in a twoinch pot. I have three and four-inch pots for geraniums and begonias for next winter. House plants need good drainage and frequent showering of foliage. Begonias, palms and ferns. do not want a south window. They need a cool, moist atmosphere. Set them on a tray of tin or galvanized iron, filling with wet sand, or keep a dish of water evaporating in the rooms, preferably on the stove.

Calla and amaryllis should rest in summer, and have plenty of sunshine and water in winter. Water should be warmed before being applied to plants in winter.

Cactus rests in winter and makes its growth in summer, when it should be plentifully supplied with water and sunshine-the lobster-claw varieties excepted.

Palms and begonias require but little water in winter.

Umbrella plant thrives with its pot kept in a pan of water, or planted out in an aquarium.

Hyacinths, after blooming, can be ripened off and set out in the garden, and will bloom there each spring.

Never wet nor crown Chinese primrose leaves.

Illinois. MARY ANDREWs.

Keep seeds in wooden, not metal boxes. It will help prevent moisture. 


\section{THE OLEANDER.}

How many readers of this little paper, I wonder, are admirers of the double pink oleander! We have our large bush in a good-sized box and always winter it in the cellar, bringing it out in the spring as soon as all danger of frost is over, and set it not far from the kitchen door, where it gets considerable of the waste water, the east or morning sun and is shielded from the hot afternoon sun. They do not need changing of soil very often, but should have a good top-dressing of well-rotted manure or other rich soil, occasionally, at least once a year. This with sun and plenty of water never fails to bring a mass of bloom that is much admired.

Cuttings of the oleander are readily rooted in the spring. Take a bottle with a goodsized mouth, put some fine sand in it to the depth of an inch or two, fill with rain water, in which place a cutting or two, having their ends embedded in the sand. Set the bottle away where it will not be disturbed, and in four or five weeks the cuttings will very likely be nicely rooted. Let them stay in the bottle till the roots get strong, then take them out and pot in good soil containing considerable sand, and they will never stop growing.

I once read how the oleander received its name. A maiden lost her lover, whose name was Leander, and this misfortune caused the girl to become demented. Some passers-by saw her sitting under a beautiful tree in bloom and, not knowing, inquired of her its name, but she, not thinking of the tree, but bewailing the loss of her lover exclaimed: "O, Leander! O, Leander!" Believing this to be an answer to their question, they gave the bush the name of oleander, and so it was ever afterward called.

Indiana.

\section{MY BEGONIA EXPERIENCE.}

The tuberous begonia is a plant I can conscientiously recommend. My first experience with it was not very flattering, but the last season I seem to have had perfect success. I had six varieties potted in six pots, in soil composed of leaf mold and a little sand.

I think they require considerable water, and to be kept out of strong wind, as I find the branches are easily broken. They were given soapsuds once a week, occasionally weak ammonia water. They were on the north porch, in front of the sittingroom window, where they got the morning sun for a short time. They began blooming early in the season and bloomed constantly till late fall. $\mathrm{Oh}$, but they were beauties, all of them.

When cold weather approached I set them inside of the same window. It made no difference on which side they were, they were always there to greet me with their pretty blossoms whenever I went into the room. I never had plants that attracted the attention they did. I am going to try an experiment this season-that is to start some of the tubers later in the season, so as to know how late they will bloom.

Indiana. Mrs. M. C. TUCher.

\section{HOUSE BEGONIAS.}

Rex begonias are not well adapted to sitting-room culture. The atmosphere here is too dry for them. They also should be transplanted just before they make their new growth. It can easily be known when to transplant them, if they are watched carefully. The flowering begonias are much more satisfactory under the conditions which prevail there. If begonia leaves drop it is in most cases 
due to diseased roots coming from poor or no drainage. It is a very important thing to have good drainage for all plants. Begonia cuttings should be rooted in clean sand, which should be kept warm and moist. Also give them a light, spongy soil, keep them moderately moist and not in too strong sunlight. They should be turned about often, so the light can get at all sides of them.

The tuberous begonias do better in the pots in which they grew during the summer. Let them get quite dry and keep them so until in March repot and start into new growth. They should have a rich soil composed of sand and leaf mold, and should be repotted as often as the roots become crowded.

$\mathrm{Pa}$.

Mrs. Edna Janet Gray.

\section{SOME FINE PLANTS.}

Oh, those beauties! What are they, and how do you make them so lovely? First, they are the grand bangainnilliea sanderiana, begonias, coral gem, ferns and palms, draceanea " $\mathrm{S}$," and the splendid hybrid geraniums. Second, I take pots just a size larger than the plants to be potted, provide plenty of drainage, to two-thirds coarse sand add one-third soil and a tablespoon of fertilizer, mix well, set plants a little deeper than at first, water well and keep from sun and wind until plants rebound, then give morning sun. This is right for all but palms. They require a heavy soil, pack with a stick, and do not cover bulb. And those lovely asparagus! When two inches high they were transplanted to fourinch pots and now you see such great beautiful plants covered with bloom. Palms and ferns grow better under a shelter that the sun and rain can filter through.

Georgia. Mrs. Allan Mamble.

"There is rest and sweet enchantment in the shadow of a fern."

\section{A SPECIMEN BEGONIA.}

I like to grow a plant that I can feel proud of-one that is handsomer than everybody's else, and I must write you about my pet, a begonia Weltoniensis Rubra. It is now five or six years old, but was no larger than my finger when I got it. I potted it in good garden soil, into which I had worked some sand and well-rotted manure, keeping it well watered and sitting in a shady place during summer, and repotting whenever the roots began to fill the soil. It now fills a wooden tub holding about a bushel of earth.

When winter comes on I set it in a well-lighted frost-proof cellar, watering sparingly, and the leaves and part of the stem fall off, showing a great clump of knotted tubers on top of the soil. Early in spring I cut off the rest of the stems and bring up to the light and heat, when it starts rapidly into growth, sending the shoots out so thickly that by early summer it is a solid half sphere of silky green leaves and waxy pink flowers, extending way out over the sides of the tub.

N. Y. Mrs. Nelson PiefF, JR.

\section{FERNS.}

Yes, ferns; you can have in your windows if you wish. I have always srown them, so why not you? I use almost all pure leaf mold with charcoal for drainage. You can also use nearly all manure if it is old and well rotted. They like a little sun also. I keep a very large sword fern at the south window in my bedroom, where it gets full sun in winter, and it is simply grand. Let me tell you what varieties I have which are all good and are easy to grow. Nephrolepsis Bostoniensis, Forcans Compacta, Asplenium with wedge-shaped leaves, Adiantum Cuneatum, Gracillimum, 
Cyrtomeum Falcata, Lastrea Aristata, Pteris Argyrea, Polypodium, Phyllitides; this has undivided lance-like fronds, forms a clump and is very unique. Lygodium Scandens, a beautiful vine and a tree fern, name not known. But the pride of my heart and the ornament of my collection is a fine, healthy plant of Asplencum Vidus Avis. This is rather new. I do not try to grow these in shade. They set at the double east window, some in the south bowwindow partly shaded by the other plants, so all of them get some sun each day-this in winter. In the summer they are all put out in the yard, mostly on the north side of the house. They get a weelily sprinkle in winter, every day in summer. At no time is the sun allowed to strike the foliage while wet, and the soil in the pot is not allowed to become dry. If the drainage is good, so the water can run off freely, there is not much danger of giving too much. Mo. Avrie E. Crafts.

\section{GRAFTING CACTI.}

To graft cacti is a simple thing, and to one who loves the curious cacti as I do, it is ever a source of enjoyment to watch them develop into something entirely different from what anyone else owns. I find it so easy to graft on Cereus Grandiflorus, and have a Philacactus and Albus Superbus grafted on one now three years old, and a grand specimen; also Epiphylum on Cereus Columbrinus, and also Flageliformis, and Crab cactus grafted on the Cereus. To graft, take a cutting when the plant is in good growing order, with a sharp knife make it wedge-shaped, make an incision in stock and insert, take a stitch or two with needle and thread. leaving thread there, as it will do no harm.

Try growing fresias, smilax, chrysanthemums and geraniums from seed.
Fresias bloom first year from seed, and bulbs increase rapidly. Oh, how they love to drink water, and more water, but be sure to have good drainage. I use the liquid manure twice a week and gather the guano from the chicken house. Do not put it on begonias, as it always causes mine to shed their leaves, and by its use I lost several valuable begonias before I knew what was the trouble. My callas, full of bud, enjoy sitting for an hour in the morning on the shelf of my range, where they get the benefit of bottom heat and the steam from the kettle.

Iowa. MRs. P. W. Hopkiss.

\section{CARE OF PLANTS FOR WINTER BLOOMING.}

By this time one has out all the bedding plants-shrubs, vines, pot plants, etc. By having the beds well worked and mulched, first with stable manure, ashes and' salt dug lightly in the soil, and, after a good season, a top mulch of fine straw, you will be delighted with the results. They will grow and bloom well and stand the hot weather. Sow seed of perennials now for next year's bloom. Sow pansies for fall and winter blooming. When the little seeds come up, mulch and see how they grow. Put out cuttings for geraniums and other things for winter blooming. Keep carnations pinched back and buds off. Give your plants a tablespoonful of cotton seed meal once a week, stirring on the top of pots-it makes fine bloom and rich foliage. Do not let any of your plants bloom before winter. Give begonias a moderate supply of water and a light, rich soil, and they will repay you. When watering never put it on top of soil of yard plants, but dig a small trench around each plant, water well, and draw the dry soil over this.

Georgia.

Mart Meclants.

Flowers are words which even a babe may understand.-Bishop Cox. 


\section{A MOST SATISFACTORY PLANT.}

Begonias sown in July (as told in former letter) have grown immense leaves and many branches loaded with bloom from white to pink and crimson -doing better in sun.

Browallia Speciosa Major, seed sown in spring, budded in garden, potted, have been loaded with lovely blue flowers all winter.

Acacia Lophantha seed sown in spring, lovely fern-like foliage, needs frequent repotting. If it becomes rootbound or very dry, the leaves fall.

Begonia Speculata is a beauty, also the new tuberous Rex, Helen Gould.

Boston fern is fine, but Australian is grand.

A jar of Madeira bulbs is on one end of mantel and twines about the pictures and completely covers the wall on that side of mirror, as would the other if given string to climb.

A large Argentea Guttata begonia covers the other side and a statuette sets under the branches.

Coleus seed sown in spring for garden, slips taken in fall. In a warm, sunny window they are gorgeous.

Roses have bloomed most of the winter.

Geraniums will not bloom, although tended by rule, and will not take my time another winter.

Bulbs were a success to be told of later.

Maine.

Aroline.

\section{A WINDOW BEAUTY.}

One of my handsomest window plants is a balsam, which is a street wonder to those who pass-a gentleman actually coming to my door and asking if it was a real, live plant. I wonder it is not grown by more flower lovers, as it is easily grown in almost any kind of soil, and has from one to a dozen blossoms on each stock blooming continually. Give plenty of water and fresh air, and a south window if possible. My balsam is a deep pink and has been in bloom ever since last fall-at no time has it been without from ten to twenty-five shoots in blossom. The more it is slipped the bushier it gets until it is a perfect beauty, filling a large window four and one-half feet wide. Slips will root and blossom in two or three weeks, and it is the most satisfactory of any of my plants.

Ohio. Mrs. Mattie Woodson.

\section{LITTLE GRASS PINKS.}

Within the garden fair, we walked, My baby son and I;

And, culling here and there a flower, The sunny hours drift by.

"Come choose, said I, the fairest flower, The one you love the best."

Then down the garden walk he ran In eager, earnest quest.

On past the stately Roses there, Ladies of high degree;

and past the snowy Lily fair A saintly nun is she.

He slights the winsome Pansy flowers, The witching, bright Sweet Peas-

The gay Nasturtiums charmless areA sweet Grass Pink he sees.

Down by the garden gate alone They bloom through summer hours.

"Oh dese I loves the velly best Tause they's the feetest fowers."

Dear little child, with thoughts as pure As these sweet flowers you love.

Dear little one, with eyes as blue As summer skies above.

You may not climb Parnassus height, A crown of laurel bear;

You may not be a Croesus, Nor yet a coronet wear.

But yet I hold greater than these Is he of virtuous heart,

Who loves the good, the beautiful Of evil has no part.

And so for you, my little one, No greater boon I crave

Than that you keep through all your life Your true, pure thoughts that save

From sin, and sorrow born of sin, And stinging, sharp remorse;

Oh may you love the pure, the good, Of happiness the source.

And like these little Grass Pinks here, That give their fragrance sweet,

Although they are not Queen of Flowers, Their own life is complete.

So will your influence live always, You will not live in vain-

Love all, and unto you shall come, That pure love back again.

Ohio. Annice Bodey Calland. 


\section{The Floral World}

PUBLISHED MONTHLY BY THE

\section{FLORALWORLD COMPANY,}

12 to 14 South Limestone Street, SPRINGFIELD, OHIO.

Subscription Price, 25 Cents a Year.

Entered as second-class matter at the Postoffice in Springfield. Ohio.

We will give $\$ 26.00$ in prizes for the five best articles for publication in the September number of The Floral World which may be submitted by subscribers.

The first prize will be $\$ 10.00$; the second, $\$ 7.50$; the third, $\$ 5.00$; the fourth, $\$ 2.50$; and the fifth, $\$ 1.00$. The awards will be announced in our October issue.

No article which contains more than two hundred words will be considered. All contributions entered in this prize contest must reach us not later than August 1.

The purpose of these prizes is to secure for publication in The Floral World matter which gives the actual experiences in flower growing of those who have subscribed for the journal. Prizes offered for articles published in the June number have been awarded as follows:

First Prize-Margaret D. Brown, Pennsylvania.

Second Prize-Mrs. Jennie E. Lipe, Michigan.

Third Prize-Mrs. S. R. Welsh, Pennsylvania.

Fourth Prize-I. O. Hines, North Carolina.

Fifth Prize-Annie J. Paddick, Illirois.

\section{TEN YEARS' EXPERIENCE.}

For ten years I have experimented with flowers and plants, and now I look back to my first attempt with wonder that I tried to work with them at all. The failures I have had would have discouraged an older person long ere this, but I kept on and finally was rewarded with success. The greatest mistake I made was trying to raise flowers under shade trees. Of course, it was a failure. The tree roots absorbed all the nourishment out of the soil and starved the plants. After a second trial I seeded the bed with blue grass and now it looks like the rest of the yard. 'I'hen I had a bed dug near the house and enriched with manure. After pulverizing it and waiting until the weather was settled somewhat, I planted gladiolus bulbs in it. They soon came up and grew rapidly until blooming time. Then they put all their strength in the beautiful blossoms they gave me, and I was amply rewarded for my labor.

Among the house plants I have a large hibiscus. It is a love $e_{\perp}$ red, and some of the blooms will be as double as a rose and some quite single. It was a very small slip when I got it, but now it is a good-sized shrub. In the summer I set it in the ground or leave it in the pot. Last year I left it in the pot and dug out the top dirt, replacing it with new, and it bloomed all the time. Once it had eight large flowers on it and was the wonder of all. I keep it in my window all winter.

\section{HARDY LILIES FOR MID.SUMMER.}

There is no other flower grown that can compare with the lily for midsummer flowers. The brush cannot paint or pen portray the exquisite purity and delicacy of the stately lily. As a rule lilies are of the easiest cultivation. For outdoor culture these bulbs require a good, sandy loam which should be dug to a depth of sixteen inches and well worked. The Japanese and Chinese lilies do best in a clay soil. Bulbs ought to be set five to eight inches deep and left undisturbed for several years, as they thrive much better and give more 
bloom. I can recommend the following varieties: Wallacer is one of the best, blooming in May; then Candidum, which is soon followed by Auratum, Elegans, bi-color Elegans, Robusta and Longiflorum Pardalium (leopard lily), Tenuifolium, the lovely coral lily of Siberia; then comes Tigrinum (tiger lily) and Umbellatum, one 01 the very best, blooming in July, with large, perfect flowers. Then follow with the grand Speciosum lilies, continuing to bloom all through August, which are the hardiest of all lilies, most robust, and free flowering, while in beauty they are second to none. Best varieties of these are Rubrum, Melpomene, Opal, Punctatum. There is another that is worthy our attention. Funkia (or day lily) is one of our August bloomers, which we have in white and blue, and should be in every collection. The lily seems to vie with the daisy for its share of musical honors, for many is the lyre that has been tuned to its praises.

\section{Indiana. Mrs. R. A. Houk. \\ SIMPLICITY OF ARRANGEMENT.}

Among flower lovers and cultivators there are still many who have yet to learn that the most beautiful bouquet or garden is not necessarily that which contains the greatest variety. Who has not seen marigolds crowding petunias, verbenas overrunning asters, coreopsis mingling with phlox in vase or garden, when each sort would look infinitely better by itself? I remember when my own ambition was not satisfied till my plot held every lauded plant in the catalogue which my purse could afford, from abronia to zinnia. The result was a jumble of colors discordant enough to make an educated eye weep. Now I know that a bed solely of nasturtiums (excluding: the "rose-colored" kinds) is far preferable to any number of warring colors.
Last year a collection of large-flowered snapdragons-white, yellow, scarlets, with the darkest variety, known as "Black Prince"-was sufficient to fill a large bed, and was very handsome and interesting. If something more novel is desired, the newer Nemesias will be sure to please. Nemesia Strumosa Suttoni gave me a variety of brilliant colors-orange, yellow and rich red. The compact sorts form charming masses of small flowers in blue and white.

\section{Mass. \\ Mrs. E. A. Josselyn. \\ PRETTY ARRANGEMENTS OF FLOWERS.}

Place a goblet in a tall glass dish. then fill them with sweet peas, letting some trail over the side with their own green leaves. A few sprays of gypsophila (baby's breath) will be pretty with this or any of the following:

A shallow glass dish or soup plate filled with asparagus, alleghany vine, or any fine green sprays, then as many great velvety pansies as will look well; but not crowded or cut with too short stems.

An oblong dish with two egg glasses in it, rose geranium leaves around the ed'ge, with sprays in glasses. Now fill with scarlet and white verbenas. Another time pink and purple verbenas with white sweet alyssum. Or Drummond phlox or dianthus, but always choosing colors that harmonize.

A clear glass bowl filled with nasturtiums and a few sprays trailing over the table.

I could tell many more, but what could equal a great bowl full of roses?

Maine. Aroline P. Adams.

If Mrs. E. M. Kean would plant Clematis cocinia among her rose bushes she would find it very ornamental. as the red flowers resemble hips on the rose trees toward late summer.

New York. Mrs. M. E. Blatsdell. 


\section{FLORAL EXCURSION.}

The steamer left the early in the morning with a party of excursionists composed of four distinguished gentlemen,

- Also four ladies of high distinction, - - - - - - - One of the ladies was noted to be - but considered a - and was given the - After reaching the _- forest, a basket was opened and contents proved to be a tempting lunch. A meat, a berry, a vegetable, a fruit, a nut, a condiment, a candy. - - $\longrightarrow,-,-,-$ - - After dinner one of the ladies accidentally spied - on a - Quicker than a flash one of the gentlemen and fired — which missed its aim and struck one of the ladies. There being no physician present, the wound would - until there was a Fearing death might result, her affianced was called. Being much grieved to see his - $\longrightarrow$, he administered - and tied the wound with and started homeward. La. Mrs. W. N. Whire.

\section{A BACK YARD IN TEXAS.}

Our back yard was small, bare, rocky, and a perfect eyesore. The fence enclosing it is unpainted up-anddown boards, somewhat dilapidated. Early this spring I measured off a flower bed about three feet wide, all along the fence, and with pick and hoe dug out all the rocks in this space, and bordered the beds with the rocks to prevent washing. Then with shovel, hoe and coal scuttle I scraped off rich surface dirt from every nook and corner of the premises, and filled in my beds. It was slow work, but in a week I was ready, and went out on the prairie and took up tiny plants of wild yellow and red gaillardia, dainty blue flax, pink primrose, purple ver- bena, coreopsis and phlox, setting them carefully in the beds, and planted with wild buckwheat vines along the side of the bed, next to the fence. Then dug out the rocks and made a little round plot about the middle of the yard, planting a sunflower in the center and phlox around the border.

In a few weeks the unsightly yard was a creation of perfect loveliness. The beds a continual glory of bloom, and the unsightly fence a wall of beautiful green vines.

Texas.

Miss Ellie Stelle.

\section{HINTS ABOUT GLADIOLUS.}

Be sure to include yellow bulbs in your list of gladiolus. Among the reds have some dark velvety ones.

I advise setting the bulbs five inches deep, as they can be cultivated better.

A liberal top-dressing of manure does them good.

The bulbs always come true in color, but the seed, if planted (caring for the tiny bulblets as for the large ones), will in three years produce flowers in new combinations of color and markings.

Gladiolus bloom longer if not allowed to produce seed. I like mine best when planted in clumps or long rows; if the latter way, put a stake at each end and then a slat across and tie the plants to this. Here we protect them in winter, only taking them up every other year. They bloom much earlier if left in the ground.

For the busy woman they are certainly a boon. If only fragrant, one could not ask for a better general purpose flower.

Oregon. Mrs. Olive Ch.imberlain.

In Japan, arrangement of flowers is considered a fine art, and taught to girls as one of the valued accomplishments. 
JULY NOTES.

There is hardly a month in the year when there is not plenty of work for the flower grower. This is the month in which to start seed of pansies for fall flowers. Sow your pansy seed thinly in shallow boxes, and keep well watered; do not allow to dry out at any time. The seed will germinate in two weeks' time if given sufficient moisture. When large enough to transplant give a cool, shady situation, rich, loamy soil, and moisture, and keep well worked about the roots, and in September, October and late into November they will give an abundance of their bright, velvety blossoms. If grown in pots or boxes, they can be kept in pit and will give you flowers most of the winter.

I sow my poppy and petunia seed the last of this month, and they are up and ready to bloom early in the spring. In saving seed, if pods burst before seed ripens, I tie a thin muslin rag around pods and thus secure seed that would be lost.

Keutucky. Miss LaUra Jones.

\section{PUTS.}

Put charcoal in the bottom of your flower crocks. Keeps the soil pure and sweet.

Put rusty nails about your begonias, petunias and asters. The color will be much brighter.

Put cow manure in a crock, half-full, fill with garden soil; plant your moonvine seeds on the top, cover lightly, and every seed will give you a vine.

Put an onion (sliced) at the root of your English ivy. You'll never be sorry.

Put one teacup strong tobacco tea in a gallon of water. Sprinkle cucumbers or chrysanthemums and kill the black lice.

Mass.

Mrs. E. E. DIx.
Dead-Shot Squirt Pistol.

"Didn't know 'twas loaded," but its a great trick. Postpaid 8c. F. Collns \& Co., Arlington Hts., Mass.

FOR THE KITCHEN

The Dandy Scraper fits and eleans every put, pan or dish. By mail,

10 cents. Agents wanted. Liberal Terms. Address Dandy Mfg.Co,.Dept.B,Newark,N.J
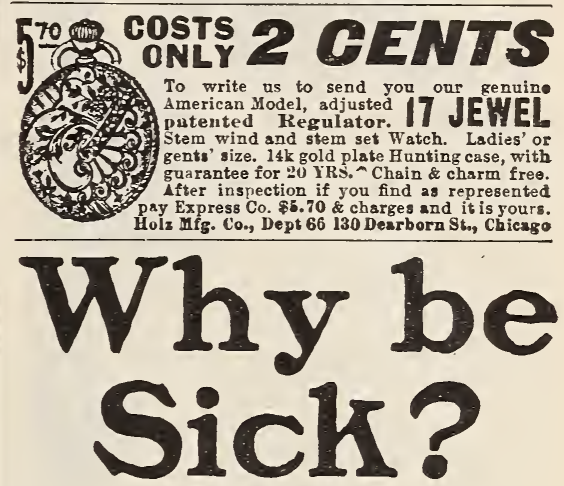

After Fifty Years of Constant Study Dr. J. M. Peebles, of Battle Creek, Mich., Has Perfected a Treatment That Gives Hope to Every Sufferer.

Write for His Valuable Book which Explains Fully this Wonderful Treatment.

\section{Test the Treatment Free!}

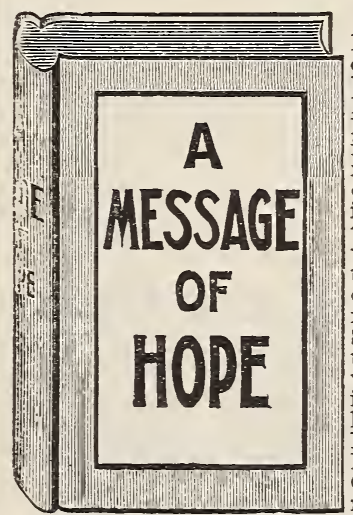

"A Message of Hope", is the title of this wonderful book which is truly a message of hope to all suffering humanity. It reveals the greatest system of treating disease known to the soientific world and makes the impossibilities of yesterday the realities of today. So sure is the Dr. that the treatment will cure all chronic sufferers that he has instructed the Institute of which he is Physician-inChief to give every reader of the ly free, just to demonstrate to them that health is within their grasp. If you are in poor health write at once addressing Dr. Peebles Institute of Health, Ltd., Battle Creek, Mich., Drawer W. 7 stating your troubles, that they may prepare a special treatment to fit your exact condition. They will also send you their book "A Message of Hope" explaining their wonderful system of treatment and a full diagnosis of your case with their professional advice. 

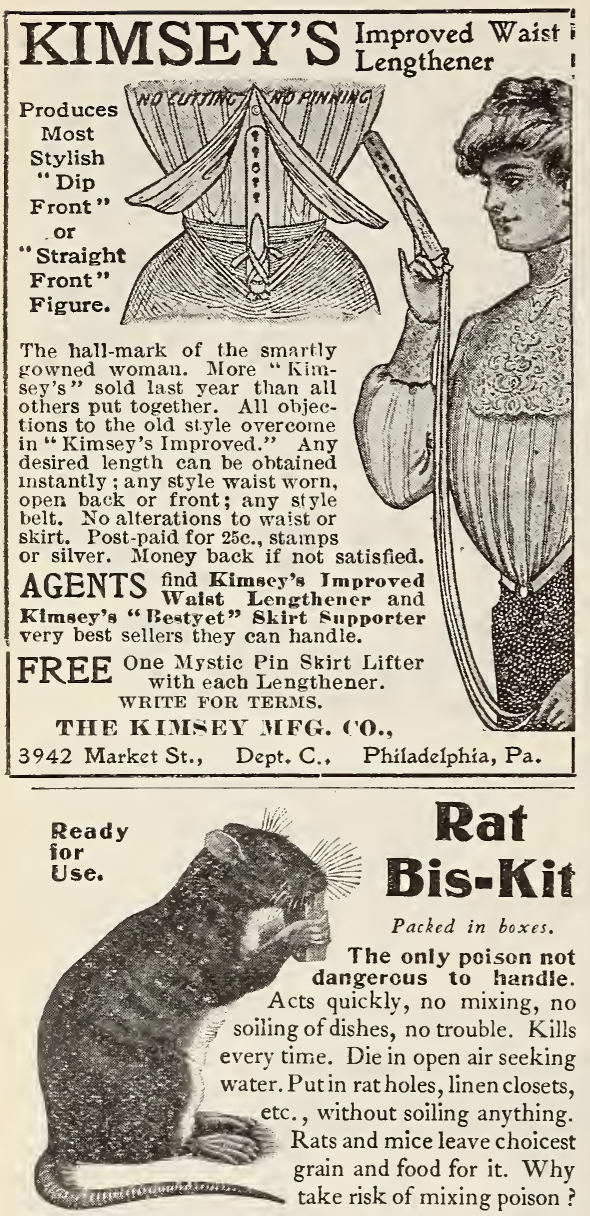

Ask your druggist. If he hasn't it, send us 20 cents for one full size box, or 50 cents for three boxes, postpaid.

The Rat Biscuit Co., Dept. D, Springfield, Ohio.

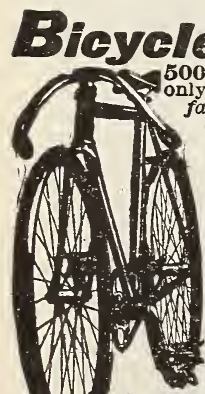

Below Cost

000 Bicyces, overstock. For 30 days factory will sacriflee at less than actual cost HeW 1902 mo 0 dels.

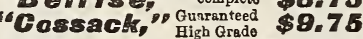
"Siberiang," a Beauty $\$ 10.75$

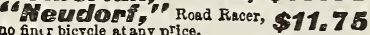
no fint $\mathrm{r}$ bicjcle at any price.

Choice of M. \& W. or Record tires and best equipment on all our bicycles. Strongest guarantee.

We SHIP ON APRRGVAI C.O.D. to anyone without a cent deposit \& allow 10 DAYS FREE TRIAL before purchase is binding.

500 good 2nd-hand wheels $\$ 3$ to $\$ 8$. Do not buy a bicycle until you have written for our free catalogues with large photographio engravings and full descriptions.

WEAD BYCLE CO DEpt 375 s Chicago.
WHAT I SAW.

My Asparagus Plumosus was turning yellow. An examination through a reading glass revealed nothing. Then I got the magnifying glass, which showed tiny black spiders with white nests.

Some leaves were dying on Solanum Grandiflorum. I examined one through the glass. Wonderful! There were great spiders running and fighting. They were bright green with black spots and many legs. Eggs were all over the leaf.

A salvia was troubled with that little white fly, and the under side of the leaves looked as though tiny drops of grease had cooled on them, the glass showing they were transparent green eggs not easily gotten off. But careful and frequent washing and constant care in killing every little white fly will finally finish them.

So use a magnifying glass even if you think, as I did, you can see everything, and perhaps there won't be so many asking what makes the leaves turn yellow on their plants.

Maine.

Aroline.

\section{SOMETHING DIFFERENT.}

One of the most beautiful window plants I know, and one rarely seen, is the double nasturtium. It is a rapid grower and perpetual bloomer, and seems to be entirely exempt from the numerous pests that must be guarded against with so many plants. Slips root quickly in water, and indeed blossom well if kept in a bottle in a sunny window. Then, too, the old plant can be set in the flower bed in summer, where it is a host, and slips easily started ready to bring in the house in the fall.

One of these young plants last winter was the wonder and admiration of passers-by, for it covered a fan-shaped 
frame that reached to the top of a large east front window. The prevailing colors in house-plant blossoms are red, white and pink, so the novelty of a mass of delicate yellow only. splotched with carmine is to be desired. Our beautiful bowl of nasturtiums for table or sick ones can thus be had in winter as well as summer.

Colorado. Mrs. B. H. Fowler.

\section{GOOD TREATMENT FOR ROSES.}

It is nine years since I started my rose bed. I have nearly a hundred hybrid, and a hundred ever-bloomers. Make your bed rich with cow and hen manure. Use a teaspoon of paris green to an even pail of water. With one hand turn over the bush, and with a brush broom throw the water over and under the bush. Do this twice a week from the time they leaf out until the last of June. In July cut the hybrids back so they cannot grow, and they will bloom more. The last of November cut them back within a foot and a half of the ground, bank them well with dirt-ever-bloomers and all -and cover three feet deep with leaves. They will settle down as soon as it thaws in April. Remove the leaves, but do not disturb the dirt until May. Never put cold water on them at night; better water in the morning, or else use warm water. Sprinkle often if it does not rain, but do not give them a thorough wetting more than twice a week.

Mich. Mrs. Nathaniel Lane.

\section{FOLLOWING DIRECTIONS.}

This spring I followed the directions for sowing seed in boxes, even to the least detail, and had such success I want to tell about it. Procuring some leaf-mold, sand and garden loam, I mixed all together and filled shallow boxes within an inch or so of

(Concluded on page 14 )
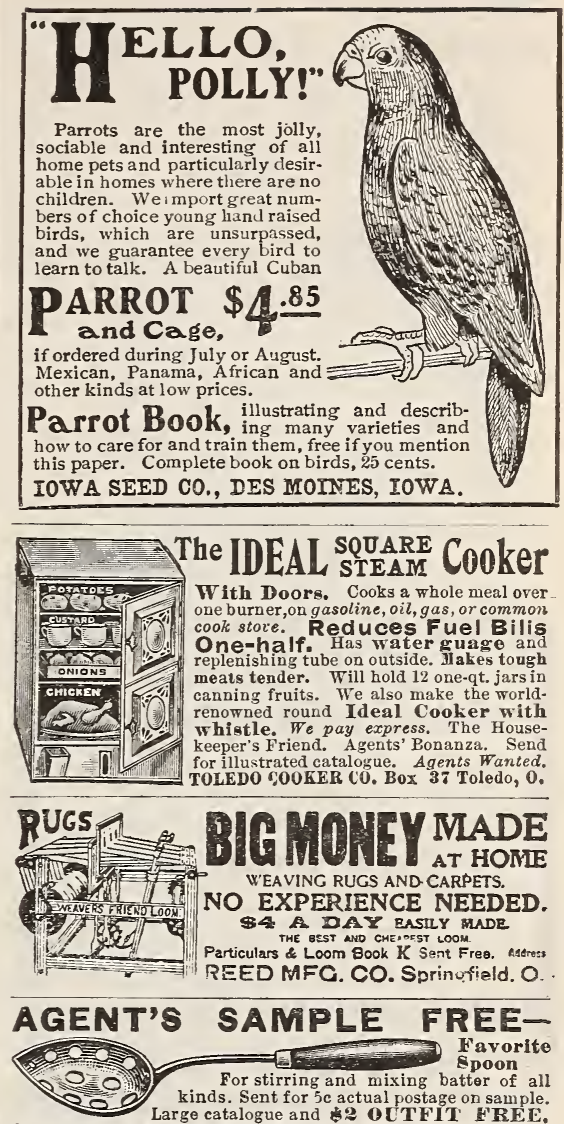
Comprising 5 Articles, Express prepaid. Dept. HOC'SEHOLD NOVELTY WORK\$, 25 Randolph St., Chicago, I11. or New York, Buffalo, St. Louis, Kansas City, Denver, Seattle. This Co. is worth a Million Dollars and is reliable.

\section{LEARN PROOFREADING}

If you possess a fair education, why not utilize it at a genteel and uncrowded profession paying $\$ 15$ to $\$ 35$ weekly? Situations always obtainable. We are the original instructors by mail.

Home Correspondence School, Pluiladelphia

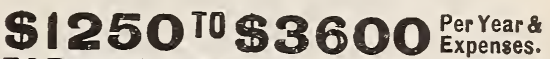
FOR HUSTLERS-BOTH MEN \& WOMEN

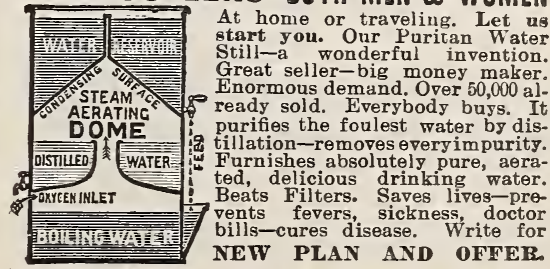

HARRISON M'F'G CO., 12 Harrison BIdg., Cincinnati, 0. 


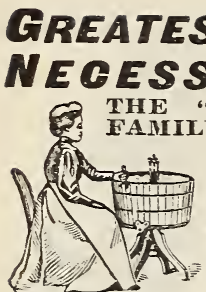
and is therefore easiest running washer ever made. Will do two hours washing in 11 minutes. Washes blankets as well as laces, absolutely clean, and without the slightest injury. The Supt. of the Savannah Vacht Club says:

"It is a ronder. Our rrrsting is very large and re have "ilways had two zommen on Monday and one on Tuesifay. "Our cook and the yard boy mov do the wasting in 4 "hours much lietter than before"

It costs nothing to try. Sent absolutely free, freight paid both ways for a trial of 30 days. No money requiren in advance.

Write at once for bonk and narticulars to

THF, 1900 WASHER CO.

$15 \mathrm{Z}$. State St., Binghamton, N. Y.

\section{N S E C T S}

\section{SULPHO-TOBACCO SOAP.} (PATENTED.)

QTICKLY EXTERMIXATES INSECTS

In the Flower, Window or Vegetable Garden. Non-injurious to tenderest plants : perfectly safe to liandle. Satisfactory lesults guaranteed. Neglect of Flants Results Disast rously.

Sold by Seedsmen. or a 3-oz. trial cake, making 11-2 gallons prepared solution, mailed for 10c. LARKIN SOAP CO., Buffalo, N. Y.

\section{K I L L E D}

\section{Save Your Plants,} Fruit Trees and Crops

by using VITA PLANT FOOD. Non-poisonous, Insecticide fungicide, seed germ cide. One application will kill parasites that destroy flora, and restore and nourish unhealthy foliage and flowering plants. Destroy disease by supplying oxygen to the respiratory organs, causing luxuriant growth of palms, roses, etc. Will prevent rust and smut by treating seed.

\section{WILL SAVE YOUR TREES}

Package containing enough for 1,000 applications for plants, 100 bushels of cereals, or 50 trees sent prepaid on receipt of $\$ 1.00$. Money refunded if not satisfac tory. Special prices to Florists. Agents Wanted.

Vita Plant Food Co., 871 Drexel Bldg., Philadelphia, Pa

\section{STEM-WIND WATCH,CHAIN AND CHARM}

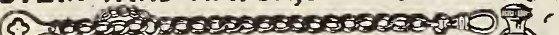

You can geta Stem-Wind, Nickel-Plated Watch, warranted, also a (chain and Charm for selling 19 packages of Blnine at 10 ceach Send nameand addressat once and we will forward you the Bluine and our large Premium List, postpaid. No money required. mium Iist, postpain. No money required.

\section{FOLLOWING DIRECTIONS.}

(Concluded from page 13.)

the top. Over this I sifted fine soil and pressed it smooth. After wetting it I sowed the seed and covered according to size of seed. In a few days the stocks were up, and soon after, the pinlis. In two weeks nearly all the rest were up-primroses, petunias, salpiglossis, pansies and dahlias. When the nights were cold I heated the bottoms of the flats on the top of the high closet on the range. It was March and the weather was cold, but the little seedlings grew, and now the dahlias are large and thrifty plants. I transplanted them when they had their second leaf. Now I have them all in a cold frame in the southwest corner of a south bay window. where they get plenty of sunshine and air. Minn. Mrs. W. J. Daugherty.

\section{UTILIZE YOUR SPACE.}

Persons of even limited yard space should utilize every available spot for raising flowers for the "flower mission." For instance along my grape trellises I have planted columbine, two between the vines and one on top of each vine. As their roots do not penetrate to any great distance, they do no injury whatever. The space in front can be filled in with marigolds, sweet allyssum, forget-me-nots or any other plants to suit the individual taste, and for a margin plant parsley or dusty miller. An angle formed by a fence, I spaded and raked fine and sowed with cosmos, which will look pretty in the flower basket, as will also the rahlias from the tall and stately plants along the fence. Bury a bottomless can under each plant, into which pour all the suds, and you will be surprised at the myriad and magnificence of the blooms.

Pa. Mrs. Samuel B. Welsh. 


\section{ROOTING SLIPS.}

I am very successful in rooting slips of all kinds. Roses I find best to root where they are to grow, and they root best in this month. I break off slips with a heel, with half-ripened wood, place in rich soil, turn a glass tumbler or jar lightly over them and leave them this way for three weeks, keeping them well watered. At end of three weeks they are usually well rooted. I then put a prop under one side of jar and allow them to have air in this way. for a week; then I remove the glass and allow them to grow undisturbed the rest of the summer.

The hibiscus and most other hardwooded plants I root in this way. I prefer rich soil to sand, as the sand dries out so quickly and the young roots are injured. This is for most plants. Cactus slips will root much better in sand. Oleander and lemon verbena slips I root in water. I hang a bottle of water on the sunny side of house and after placing slips in, I fill in around the neck of bottle with cotton, so as to exclude all air.

Kentucky. Miss Laura Jones.

\section{FOUR $0^{\circ}$ CLOCKS.}

On the east side of the house extending from the step at my back door to the end of the porch, was a narrow strip of ground against the wall where grass never grew. One spring I had a happy thought. I planted this little plot with four o'clocks. They were such a joy to me that summer that I have never failed to have them since. They are exactly suited for just this kind of place. In the early morning their red and white and mottled flowers are open wide to greet me, and seldom close until my morning work is done. When the afternoon grows late and I must take up kitchen work

(Concluded on page 16.)

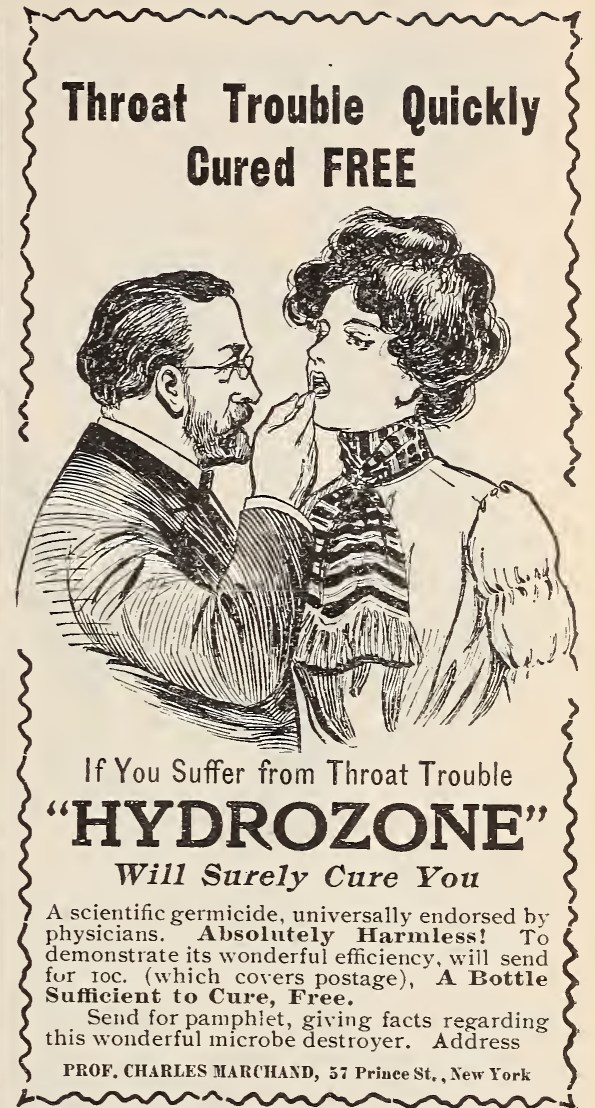

Drunkards

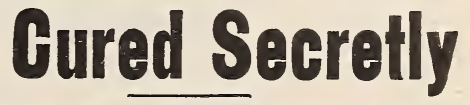

Free Package of the Only Successful Cure Known for Drunkenness Sent to AlI Who Send Name and Address.

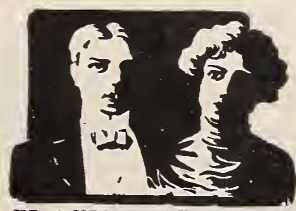

A new discovery, odor. less and tasteless, which any lady can give in tea, coffee or food. It does its work so silently and sure. ly that while the devoted wife, sister or daughter looks on, the drunkard is reclaimed even against his will and without his knowledge or co-olera. MR. \& MRS. HARRY BURNSIDE. tion. Send liame and ad3071Glenn Bldg., Cincinnati, $O$, and he will . Haines, of the remedy free to show how it is used in tea,

coffee or food.
Mrs. Harry Burnside says "With Golden SpeMrs. Harry Burnside says "With Golden Spe-
cific l cured my husband of drinking. I put it into his coffee and after that he couldn't dink liquor or bear to be around where it was." 


\section{Fine Freesia Bulbs} ONLY 25 CENTS.

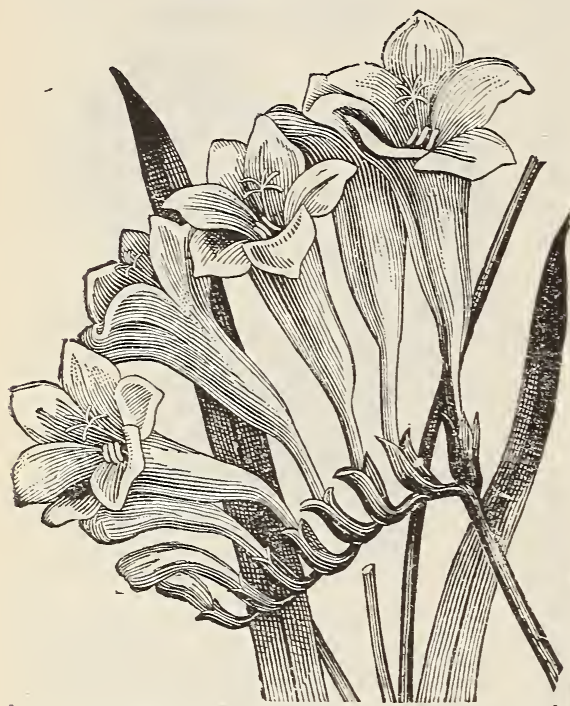

NO description cau do adequate justice to the beauty of the Freesia. The flowers are two inches long, and about the same in width, shaped like miniature Gladioli, and borne in clusters of six to ten on depressed horizontal scapes. The body of the flower is pure white, large segments, spotted with yellow. The perfume is most delicious. The cultivation of the Freesia is of the simplest, as the bulbs require only to be potted, watered sparingly at first, placed in a sunny window, and watered more freely as growth progresses. To have the best results, the bulbs should be planted during July or August. Late planting is he cause of nearly every failure with t reesias. We have an enormous $F_{\text {ock }}$ of the finest Freesia bulbs. st rder at once, and insure success by Olanting early. Our prices are the powest consistent with good quality.

We will send you a splendid collection of wenty bulbs for only twenty-five cents. Three ollections, sixty bulbs, only fifty cents. Single ulbs, or collections of less than twenty, iw' entseach. Address

THE GOOD \& REESE CO., P. O. Box 71 .
Springfield, Ohin.

\section{FOUR O'CLOCKS.}

(Concluded from page 15.)

again, there are the four o'clocks just waking up, it always seems to me with added beauty. Their perfume takes me back to my youthful days, when I made chains of their blossoms by putting one within another. I hope some Floral World sister who does her own work and whose feet go out and in her back door as often as do mine will try my four o'clocks.

Mich.

Mrs. MARY HoOPER.

\section{INQUIRIES.}

While my roses are strong and vigorous, and apparently free from insects, the rose buds seem to be injured while quite small, and when opened out the outside leaves are dried and curled up, spoiling the beauty of the rose when in full bloom. Will some one give the cause and cure for this trouble? Also, cause and cure for small ants on roses?

Kentucky.

C. BREMAKER.

Will some reader of Floral World please give directions for making a small pit? Keeping flowers through the winter is my greatest trouble. Should like to hear from other readers concerning the care of flowers during the winter season.

Kentucky.

Mrs. M. W.

Will some one tell me in the Floral World what will keep snails from eating off young plants that have just been set out? I lost one dozen fine asters last night. This morning there were a number of snails on the ground.

New York. Catherine M. Look.

Will some one write about the care of fuchsias in the Floral World, as I do not know anything about them except that they are a delicate plant?
Conn. 

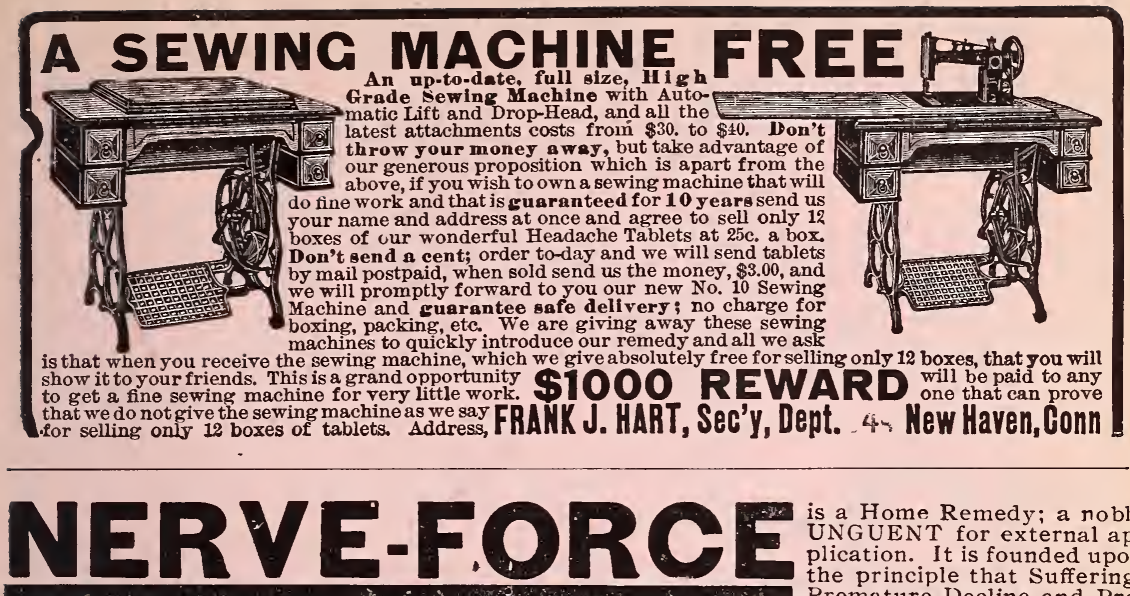

is a Home Remedy; a noble UNGUENT for external ap. plication. It is founded upon the principle that Suffering, Premature Decline and Pre

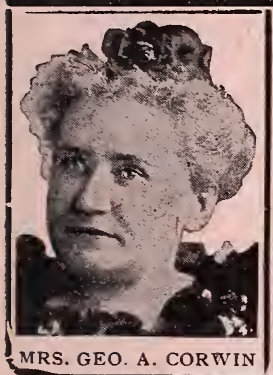

mature Death are the direct, and indirect, results of

\section{DORMANT CIRCULATION;}

that rescue can only be assured by its re-establishment by directly charging the controlling battery-cells with an element imitating the nerve force prepared for that purpose by Nature. This imitative element is our faithful NERVE-FORCE, and it will positively re-establish the most sluggish CIRCULATION to normal. It has wnn for us many Gold Medals for life-saving in the past twenty years. We do not, however, advertise it - but our NERVE-FORCE Journal which explains its every detail. We send this Publication free, in plain envelope, to as many addresses as you may send us.

We appeal especially to the "chronically ill" who are wearied and discouraged with "st. mach dosing" as a means of warfare against Disease; to sufferers threatened with cruel "operations;" to men and women who, in spite of heroic efforts for cure, feel themselves steadily declining; to men and women who are victims of sedentary employment or excessive "brain exhaustion," and to those who have been cast aside as "incurable."

MR. and MRS, GEO. A. CORWIN, 1586 Mt. Morris Bank Building, NEW YORK CITY.
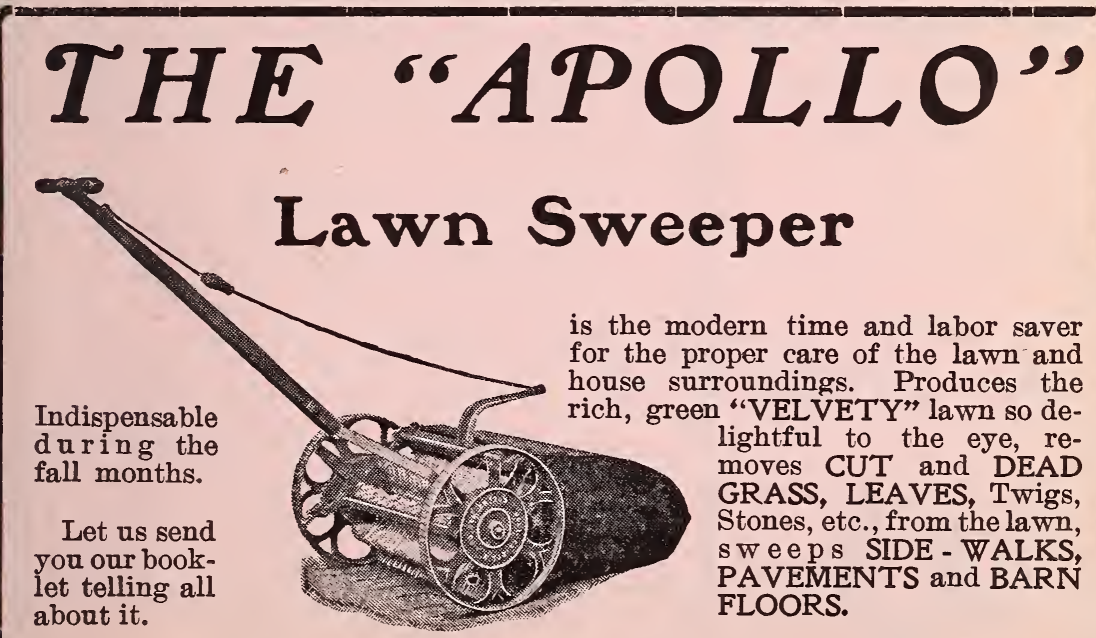

THE GREEN MFG. CO., Springfield, O., U.S.A. 

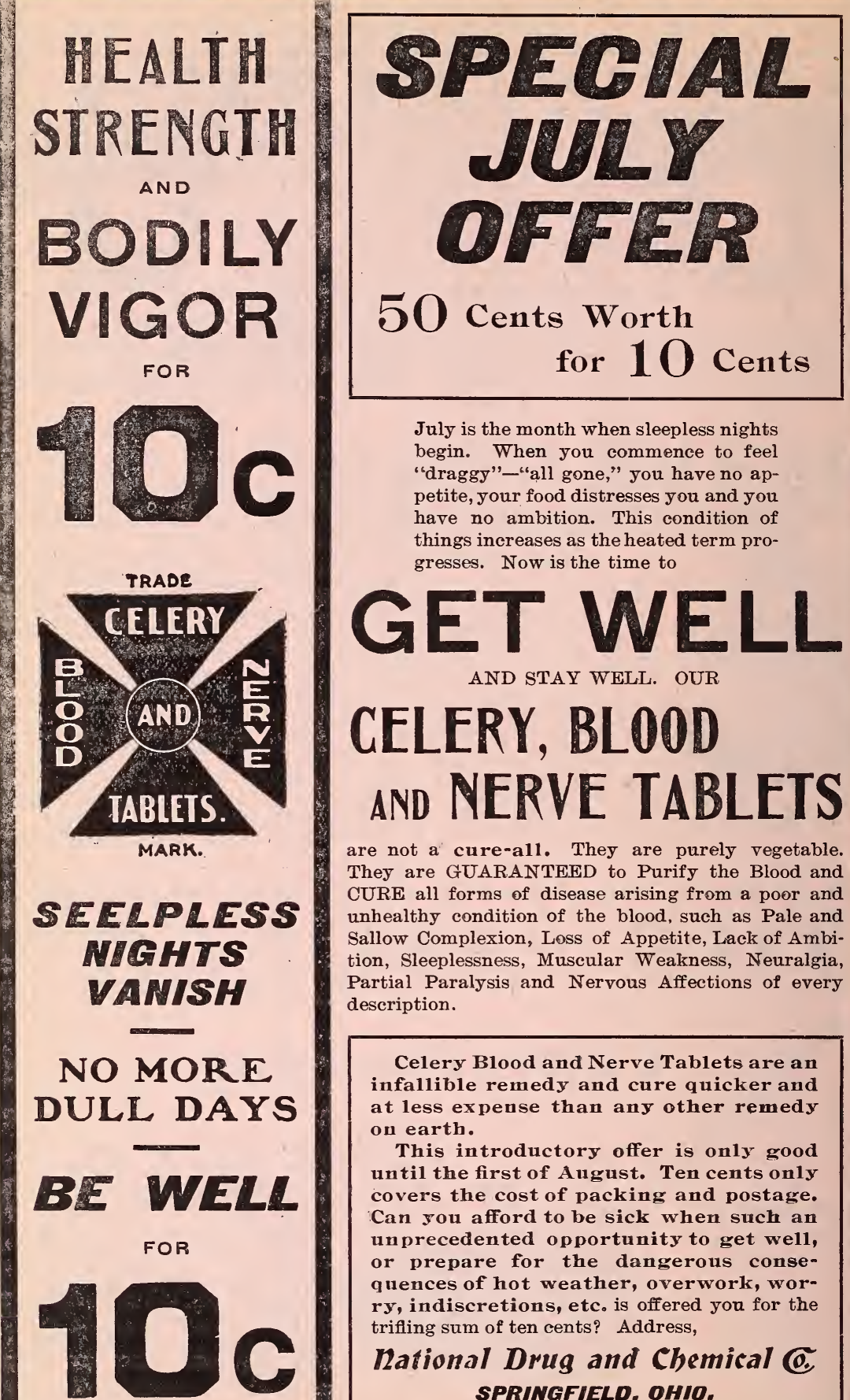

July is the month when sleepless nights begin. When you commence to feel "draggy"-_all gone," you have no appetite, your food distresses you and you have no ambition. This condition of things increases as the heated term progresses. Now is the time to

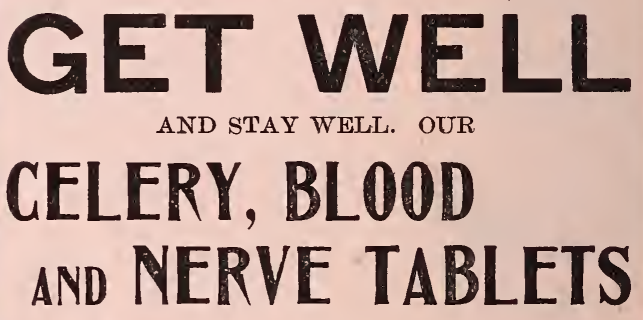

are not a cure-a11. They are purely vegetable. They are GUARANTEED to Purify the Blood and CURE all forms of disease arising from a poor and unhealthy condition of the blood, such as Pale and Sallow Complexion, Loss of Appetite, Lack of Ambition, Sleeplessness, Muscular Weakness, Neuralgia, Partial Paralysis and Nervous Affections of every description.

Celery Blood and Nerve Tablets are an infallible remedy and cure quicker and at less expense than any other remedy on earth.

This introductory offer is only good until the first of Angust. Ten cents only covers the cost of packing and postage. Can you afford to be sick when such an unprecedented opportunity to get well, or prepare for the dangerous consequences of hot weather, overwork, worry, indiscretions, etc. is offered you for the trifling sum of ten cents? Address,

\section{Dational Drug and Chemical @} SPRINGFIELO, OHIO. 


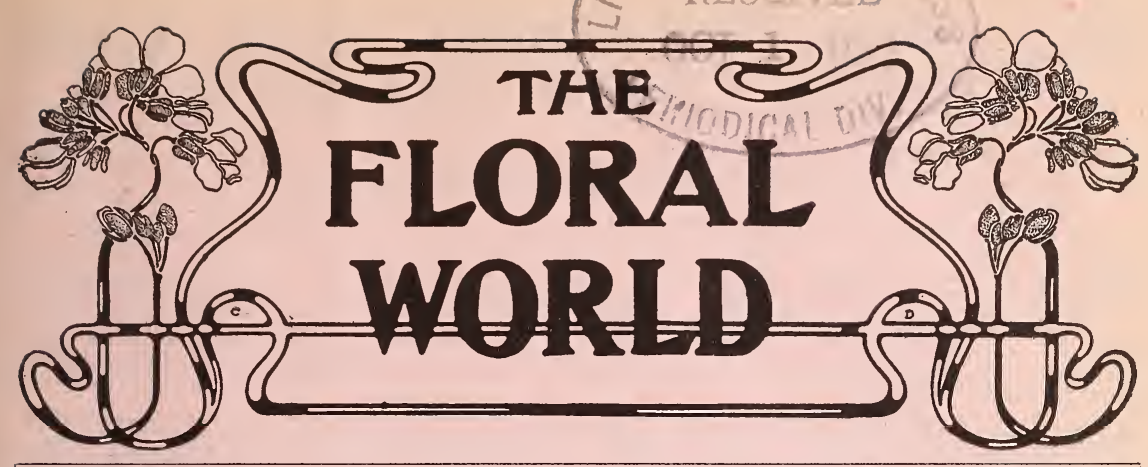

Vol. 1. No. II

Springfield, Ohio, August, 1902

25 Cents a Year

\section{Our Splendid Summer Offer}

THE FLORAL WORLD ONE YEAR
20 WINTER BLOOMING BULBS only 25 兵

SUBSCRIBE NOW AND GET CHOICE BULBS

\section{Twelve Assorted Freesias}

Freesias are the most popular and charming bulbs for pot culture, flowering in winter or spring in the conservatory or window garden. Six or eight bulbs should be planted in a four-inch pot. They force readily and $c$ an be had in bloom by Christmas if desired. The flowers produce six to eight on stems about nine inches high, and are particularly useful for cutting. The blooms remain in good condition, if kept in water, for two weeks. The flowers are pure white, with a yellow blotched throat, and are exquisitely fragrant.

\section{Eight Bermuda Buttercup 0xalis}

An unrivaled winter-flowering pot plant of easy culture. It is a strong and luxuriant grower with handsome foliage. The profusion of bloom produced in uninterrupted abundance for weeks is astonishing and delightful. The flowers are of the purest bright buttercup yellow. Properly treated the plants will flower in six weeks from the time the bulbs are set out. Well grown plants have produced as high as seventy flower stems at one time.

There are no finer flomers for moindow culture.

T $H E S E$ BULBS will give best results if planted in the summer or early fall. This makes our offer most seasonable and one which every one of our present subscribers should accept at once and have his time extended for one year.

\section{TWO MORE SUBSCRIBERS.}

We would like very much to have two more subscribers for The Floral World from every one of our present subscribers, and there are thousands of them who could secure $a$ club of two for us if they would only speak about it to their friends. If you will get two of your friends to accept this offer of $\mathcal{C}$ he Floral World and TEenty Bulbs for 25c., we will send you the collection of bulbs free, postage prepaid. 


\section{THE PRESS PUBLISHING ASSOCIATION OFFERS $\$ 25,000$ CASH PRIZES}

To be distributed among successful estimators of the total vote for Governor in the States of New York, Pennsylvania and Michigan on the 4th day of November, 1902.

The money, $\$ 25,000$, has already been deposited in the Central Savings Bank, Detroit.

\section{CONDITIONS OF THIS GREAT CONTEST.}

Any one sending us only 25 cents for THE FLORAL WORLD one year and an estimate of the total vote of Governor in New York, Pennsylvania and Michigan on November 4, 1902, will receive a certificate which will secure for him any prizes his estimates entitle him to claim, provided no other premium is taken.

You may estimate as many times as you desire by sending us only 12 cents with each additional estimate. An investment of a few cents and careful study may bring you $\$ 10,000$.

The contest will close at midnight, November 3,1902 , and no estimate received ufter that hour will be allowed. The official certificates of the Secretaries of the three States, showing the total vote for Governor, will determine who are entitled to the prizes, and the awards will be made by a disinterested Committee of prominent judges, just as soon as the official figures can be obtained.

\section{HERE IS THE LIST OF PRIZES.}

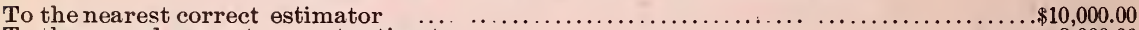

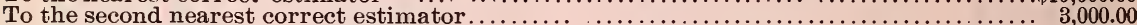

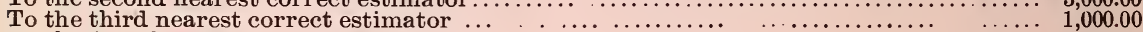

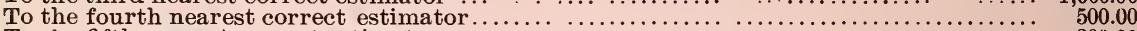

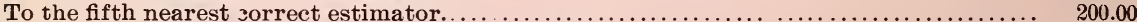

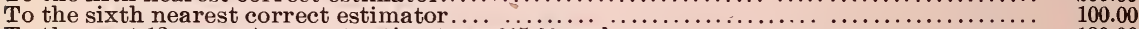

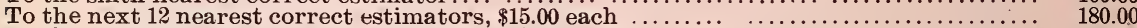

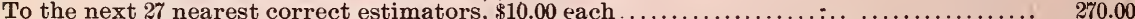

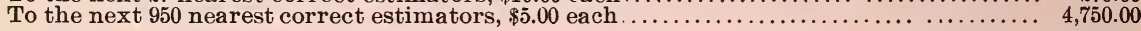

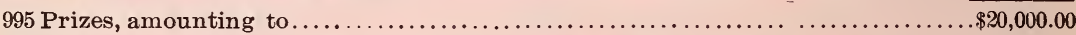

The following Special Prizes will Also be Paid:

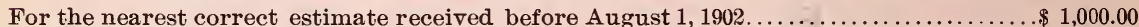

For the nearest correct estimate received on or after August 1 , and before August $15 \ldots \ldots 1,000.00$ For the nearest correct estimate received on or after August 15, and before Sept.1..... 1,000.00 For the nearest correct estimate received on or after Sept. 1, and before Sept. 15 . . . 1,000.00 For the nearest correct estimate received on or after Sept. 15, and before Oct. $1 . \ldots \ldots \ldots \ldots 1,000.00$

Total 1,000 Prizes, amounting to.

$\$ 25,000.00$

In case of a tie or that two or more estimators are equally correct, prizes will be divided equally between them

\section{VALUABLE INFORMATION.}

To aid in forming your estimates we furnish the following data :

Pennsylvania elects a Governor only once in four years. Michigan elects a Governor every two years, and since $1894 \mathrm{New}$ York has elected a Governor every two years.

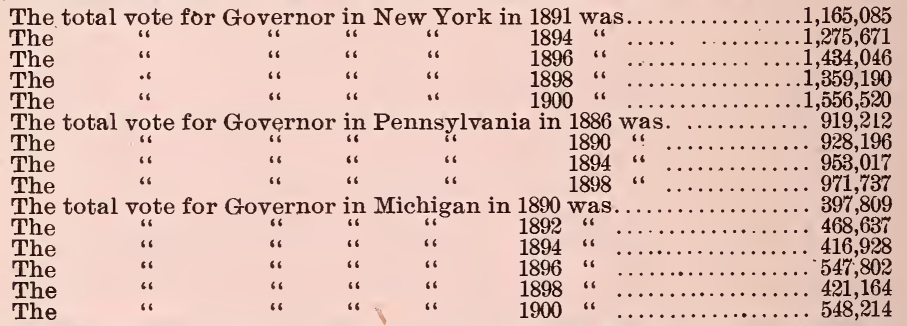

The total aggregate vote for Governor in these three states in 1894 and 1898, the years in which all three states elected Governors at the same time, was as follows:

In 1894 the aggregate vote for Governor in these three States was 2,645,616.

In 1898 the total aggregate vote for Governor in these three States was 2,752,091.

What will the total aggregate vote for Governor in these three States be on November 4, 1902 ? Figure it out or guess at it, and send in your estimates. It may mean $\$ 10,000$ in cash to you. The official certificates of the Secretaries of the States of New York, Pennsylvania and Michigan, showing the combined total vote for Governor in these three States, will determine who are entitled to the prizes, and the awards will be made by a Committee of prominent judges within twenty days after the official vote is known.

Be sure to include your estimate in plain figures when remitting.

Address, THE FLORAL WORLD, Springfield, Ohio. 


\section{The Floral World}

A Fournal of Home Floriculture

Vol. 1, No. 11

Springfield, Ohio, August, 1902

25 Cents a Year

APPRECIATIVE WORDS.

I am delighted with The Floral World. It is just the thing.

Tennessee. Mrs. Thos. Ledinger.

To me The Floral World is the best magazine for amateurs I have seen.

Texas.

Mrs. J. P. Patterson.

Each number of The Floral World is an improvement over the preceding ore.

Kentucky. Miss LAURA JoNes.

I find The Floral World a great help in directing me how to care for house plants.

Minn.

Eleaxor R. Bartlett.

I wish The Floral World came once a week instead of once a month. It has taught me many things about flowers that I longed to know.

Ohio.

Mrs. H. A. Woodson.

My premium plants came in excellent condition, although they were shipped during our hottest weather. The Floral World is a perfect gem. Its articles on pretty and simple arrangements of flowers are alone worth the subscription price.

Texas. Mrs. V. H. Montgomery.

\section{PONDEROSA LEMON.}

My lemon tree bloomed on the first of May, and its white blossoms are as pretty as a tuberose. Its lemons are a dark green, now about the size of a thimble. It is so pretty and easy to grow, I believe I could plant one any month in the year. I told the neighbors I sould plant Good \& Reese's roses in hot weather with success. I slip grew, and the temperature at 98 lived. I cut one back a little and the slip grew, and the temperature at 98 degrees-just ordinary soil. I set in the shade a few days, but with good light, now in full sun. I gave the lemon the same treatment.

Illinois.

AxNie J. PADDich.

\section{A STRAWBERRY BARREL.}

This is not original with me, though two or three improvements have been evolved from my own experiences.

Take a barrel of convenient size and bore good-sized auger holes six inches apart all over it, removing the top and boring holes in the bottom. Put stones in the botom for drainage. Fill with prepared earth, putting strawberry plants in holes as you come to them, the root inside and slanting up. This is important, as the settling of the earth pushes the roots down. When about a foot from the top, set in a piece of old stove pipe about fifteen inches long. It will settle about three inches soon, making the top level with the barrel top. Plant around it as before. I find the pipe useful for watering the lower half of the barrel and also put old manure in it for the water to soak through. An umbrella plant looks pretty growing in the pipe. This strawberry bed can be moved to any desired location, takes little room, is easily protected, and is a decided ornament to any garden. Oxalis and many other plants could be grown the same way.

Ariz. Mrs. Thos. D. Satterwhite. 


\section{THE NOVEL EXPERIMENT OF A NOVICE.}

A college student, and then a college teacher, from six to twenty-one, I had no leisure to tend, or even to study, flcwers. But when I found my self possessed of a professor and a home, I turned eagerly to The Floral World. My flower-growing neighbors speedily gave me seeds, slips and suggestions. All the slips I carefully planted in their respective soils! But, alas! I found only "slips"-and "a harvest of barren regrets." Thrice I tried, and thrice I failed. Love and random hints could not work the wonders of study and patient experience. Thrice I "rested from all my labors!" Last spring I chanced to subseribe for The Floral World, and what a new world of possibility opened before me! I tried again; and, lo! there came "the seventh year'-of prosperity!

Succeeding out-of-doors determined me to try indoor again this winter, and two hundred carefully prepared (and painted) tin cans early held two hundred fine bulbs. The cool and dark oloset (made by an old quilt in front of rude shelves in an unfrequented and well-aired room) brought up elegant fat "noses" in six and eight 'weeks' time. These grew well in a west window, with only an hour's sunshine, until the unprecedented "cold snap" of December. Twenty or more of the forty out were then seriously injured. Lack of sunshine, over-watering, and extremes of temperature from day to night were the cause. I chased away despair with desperate study. Light came at last! -glorious sunlight-from our kitchen transom (the only "southern exposure" in our large house). My husband finally yielded to "the unheard-of notion" and changed the shelf from the sitting-room double (but almost sunless) window to the sunlit kitchen transom. In addition to six hours of steady sunshine, my plants now receive a continual steam bath from the constantly boiling water on the kitchen stove-and much fresh air from the frequently opened door. And life, new and abundant, has come to all-and fragrant bloom. "Where there is a will there is a way," which is "a word to the wise."

Tennessee. Mrs. F. A. Peake.

\section{SUCCESS WITH GERANIUMS.}

I want to tell you my success with a small flower bed last season. I had a great deal of work to do which kept me busy all the time. I almost gave up the idea of having a flower garden, but I had a few pretty geraniums which needed repotting, so I had a bed three feet by eight feet spaded and enriched and made ready for them. There were six of the geraniums, so I planted them in a row the length of the bed and between and back of them I set aster and poppy plants, and in front, some ageratum plants. The graniums began to blossom, and there wasn't a day from that. time on that there were not several nice bunches of flowers. They required so little care, and did us so much good, I kept them picked quite. olose, as there were so many places I wanted to send them.

Michigan. Mrs. T. L. Perrinf.

\section{THE BERMUDA BUTTERCUP OXALIS.}

No plant produces a greater profusion of uninterrupted bloom during: the winter months than does the Bermuda buttercup oxalis. Plant the bulbs in Augut or early in September, placing six bulbs in a six-inch pot. Set the bulbs one inch deep and put $a$. layer of fine sand under them. Water thoroughly and set the pot in a dark. place for a few weeks for the bulbs to root. Do not water again unless the 
soil becomes dry. When the bulbs are all growing finely, accustom them gradually to the light. Then give them a sunny window and plenty of water, and in a few weeks they will begin to bloom. Give liquid manure or some prepared fertilizez after the buds show. In the spring, when the plants cease blooming and the foliage begins to turn yellow, gradually reduce the supply of water until the soil becomes dry and the tops are dead. Then set the pot away until August, when the bulbs may be taken up and repotted. They increase so rapidly that there should now be enough bulbs for two or three pots, and the largest bulbs will be found on the bottom of the pot.

New York. Mary E. Sheldon.

\section{CHRYSANTHEMUMS.}

I have found chrysanthemums remarkably satisfactory flowers for any one who has but little time for gardening. I got small roots of hardy sorts after they were done blooming in the fall and planted them in pots. I watered them for about two weeks, until they seemed established, then cut the tops off close to the ground, covered the earth with about onefourth of an inch of sand and put them in the cellar. Nothing more was done for them until toward spring, when they each sent up a number of strong shoots. Then I watered occasionally and put them in the best light in the cellar, where they remained until about April 1, when they were set out close to the house on the southeast side in ordinary garden soil. I never watered them except during a drouth, gave them no fertilizer and no further attention whatever, but in the fall I had just as fine plants as one could wish, covered with blossoms from October first until the last of November.

D. C. Mrs. E. C. Reynolds.
THE DAHLIA.

A hedge of well-grown dahlias is a thing of beauty. Give them rich, deep soil, and they bloom freely. The flowers always carry me back in memory to my mother's old-fashioned garden growing near the well, with the old oaken bucket mossed over.

A great improvement has been made in the gladiolus, double hollyhack, zinnia, and the dahlia since that period. The flowers of the latter, when first introduced, were single, with a yellow disk, and dull scarlet rays, unlike the beautiful double varieties now in cultivation. The dwarf pompon varieties, with small flowers, are very pretty and ornamental, if planted in beds and pegged down as they grow.

The dahlia takes its name from Dr. Dahl, a pupil of Linnaeus. It is a native of Mexico, where it grows in sandy meadows, at an elevation of five thousand feet above the sea, from whence the first were introduced into England by the Marchioness of Bute, in 1789 .

Dahlia imperialis is a tall-growing species, which sometimes attains the height of ten feet. There are two varieties, one with white flowers, the other with a red spot at the base of each ray.

Neb. Mrs. Harriet W. Leighton.

\section{HYDRANGEA OF UNUSUAL SIZE.}

I feel that as I am so much benefited by reading the little magazine each month, it would be selfish for me not to give a few of my successes and then ask for help. I planted an "Otos" ka monstrosa" hydrangea last fall in well-rotted cow manure. After cutting away one-half of the roots, I put it in the pit and only watered it when it needed it until February, then I gave it water every other day, as the buds had begun to appear. I didn't have time 
to give it any more fertilizer, but when it did bloom I was astonished at the blossoms. Two of them measured twenty-three inches each in circumference. There were several other large clusters of blossoms which I didn't measure. Next year I shall clip all superfluous shoots. I should have added that the foliage has been admired almost as much as the blossoms-it is so luxurious. It has had nearly a bucketful of water every day since its flowers have commenced to show.

My other success has been with the umbrella plant. After taking it out of the pit this spring I gave its roots a good washing by holding it under the hydrant, then put fresh soil into the same pot in which it was wintered, set it on the north porch, where it gets only a little of the afternoon sun. It is simply grand now, two of the largest umbrellas measuring fortyeight inches in circumference. It must have plenty of water. I often give it a good drenching of the toilet water.

Texas. Mrs. J. P. Patterson.

\section{THE CANDIDUM LILY.}

One of the purest, sweetest and hardiest lilies grown is the Candidum. The bulbs are dormant only in August and early September. August is the month for planting the Candidum bulbs. Other lilies can be planted in September, October and November, but the Candidum starts new growth with the first fall rains, and must be planted in August while dormant. Have the bed spaded to the depth of about three feet, select a well-drained situation, and if a naturally well drained one cannot be found, then place drainage in bottom of bed before filling up with soil. Use well-rotted cow manure, common garden soil and sand. The Candidum is probably the most popular of all flowers for commencement cut flowers. This makes an excellent pot plant. Secure good drainage, set away in dark for six weeks; water sparingly at all times. After roots have formed, gradually bring to light, warmth and sunshine.

Kentucky. Miss Laura Jones.

Several years ago I bought five white candidum lilies just for Children's Day. They bloom about the first of June. I made a mistake by not planting them deep enough. Iater, I reset and planted eight $ı$ ches deep, dug out a cavity ten inches deep, filled in a good layer of sandy soil, placed in the lilies, sifted in a covering of sand, then filled in with rich garden loam.

August is the best time to plant, so they will not disappoint you for next evergreen before winter comes, then they will not disappoint you for next Children's day. They are so easy tc grow. Don't place manure near the bulbs-it will eat holes in them. The best time to move any plant is when it is at a standstill as these lilies are now.

Illinois.

Annie J. PADdick.

\section{“AUTUMN KING"-COSMOS.}

The cosmos does not get the attention and praise that it deserves. It is the king of fall flower's and a true rival of the fall queen, chrysanthemum. Seed sown early in the spring will produce a bountiful harvest of bloom from Sepember until frost ends their glory. Give light, rich soil, three plants to a support, and they will reach a height of from four to seven feet. The dark green feathery foliage furnishes a mossy setting for the daisy-like blossoms that bend and sway on their long graceful stems. The pure white, dainty pink and soft rose shades are exquisite and' sweet, attracting the hungry bugs, bees and 
butterflies. The klondike grows as vigorous and rank as a weed. With rich soil and a generous supply of water, its reward is a profusion of large, rich, orange-colored flowers. Last June I put two "suckers" or sprouts in a small box of rich soil. They grew three feet high and bloomed as early as the original plant. I brought them in before frost and used as a background for my chrysanthemums, thus white, pink, yellow and "cloth of gold," with klondike towering above them all Sisters, "go thou and do likewise."

$$
\text { Kentucky. MARY JEMison. }
$$

\section{THE HOYA CARNOSA.}

A beautiful summer blooming vine is the hoya carnosa. It was a favorite of my mother's, and in the summer she trained it against the wall, under the south porch, where it grew and blossomed to perfection in a six-inch pot of sandy soil. Every evening the vessel was filled to overflowing with water. The blossoms are star-shaped with scarlet centers; the texture is like wax.

As fall weather set in the plant was transferred to the bay window, with southwestern exposure, where it would be allowed to rest. It needs very little attention until spring, unıs growth commences again, when you must once more become kind and give your hoya a top-dressing of good soil or a good drink of some fertilizer every week or so and lieep the heavy leaves wiped free from dust. If the vine is treated thus it will not fail to blossom, but it is of very slow growth. The plant can be propagated from a leaf. Insert the stem in the soil under its parent and after some weeks you will be rewarded with a growing plant; or, rather, I should say months, as this plant is very, very tardy in starting.

$\mathrm{Pa}$. Mrs. Samuel R. Welsh.

\section{THE UMBRELLA PLANT.}

First, you want to know how to get one. If you can't aiford to buy one, just beg a leaf, that has begun to fade, from some one who has a plant, take it home and place it top down in a glass or bottle of water and set in the south or east window. In a couple of weeks there will be roots and leaves growing out just at the center, and after another week you can pot it in almost any good, rich soil containing a little sand, and provide good drainage. Water often, but don't let it stand in a dish of water, as some say, for if the soil and water becomes sour, as it sometimes will, it will spoil the plant. They are prettier grown out of the direct sunlight, possessing a more dainty coloring. They grow very rapidly, and one will soon fill an ordinary window.

\section{Minn. Eleanor R. Bartlett.}

\section{A GOOD WINTER-BLOOMING PLANT.}

There is nothing I enjoy so much as to write my experience to The Floral World.

At this season of the year we begin to look ahead for winter flowers. It is none too early to give this matter attention, as a good plant cannot be grown in a month or two. If we wait until winter is upon us before making a selection we will be likely to get but few flowers. One of the most satisfactory winter flowering plants of recent introduction is browallia gigantea. This is a form of the browallia elata, which was at one time very popular among florists. A few years ago a florist took it in hand, and by careful management has secured a variety which gives flowers several times as large as the old sort, and of a very rich shade of dark blue. It is a very free-flowering plant, blooming in midwinter season when so few others are to be depended upon. Specimens pro- 
cured in early fall and put in six-inch pot will grow well the remainder of season, and make a plant three or four feet high and one foot across, with numerous branches, and every branch flower bearing. Very little attention is needed in the way of pruning. When flowers have developed it should be gone over and shortened at all points, so as to speedily start new growth. It will then bloom as at first. Give plant light, spongy soil, consisting of equal parts of leaf-mold, loam and sand, water moderately. Few plants are freer from insects of all kinds, but occasionally the aphis will try to establish itself on it. If it does, an infusion of Ivory soap to spray plants will quickly exterminate them. Or give a dip bath. Because of the peculiar shape of the browallia's blossoms it has been given the name of giant violet, but it is, however, entirely different from the violet family. Ohio.

Mrs. H. A. Woodson.

\section{A BEAUTY SPOT IN THE GARDEN.}

We sometimes secure a happy combination of plants by accident. Where we fail, we try again. It is to give others the benefit of my successful planting of a large far-shaped bed in the angle between two walks that I describe it. Its straight edges were bordered with dwarf iris, the rounded edge with mixed tulips, hyacinths, narcissus and Spanish iris. Spirea sodifolia occupies the center, filled around with hardy plants. Its prettily ribbed, brownish green, pinnate leaves come very early. Every branch terminates in a spike of dense creamy white, fluffy flowers, ten to fifteen inches long. As it attained large size, the border of irises presented a strip of deep blue two feet wide. The bulbs have increased in number and beauty correspondingly. Valley lilies have penetlated every part and ring tri- umphantly their thousands of fragrant bells, flinging sweetness over variegated myrtle, which carpets the bed fringing its very edge, unfolding its myriads of innocent blue eyes as unblushingly as though not practically crowding out all else, except Crown Imperial, whose sturdy stems refuse to be denied their crowning glory of a few days, when they die and are forgotten, leaving the myrtle undisputed victor. This, like a true friend, remains unchanged through all the vicissitudes of life.

The spirea affords protection to the valleys, its stems inviting the myrtle to scramble up through them, slightly rounding the surface underneath, adding to the general pleasing effect, which is pretty as a picture, even when none are in bloom.

Indiana. Mrs. Sarah A. Pleas.

\section{FALL. PLANTING AND CARE OF ROSES.}

For the South, fall is the best time for planting or rooting roses. The plants ordered from the florist are less affected in transmission then, and in better condition every way. Roses may be planted or rooted any time when the ground is not frozen or too wet to dig. The first secret of success is good drainage. Drain with anything handy except wood; that makes "wood lice," which will destroy your plants. After roses are well started they will do in any kind of ground, with a little care, but they do vastly better in good ground with moderate care. My garden spot is good to begin with. The old settred roses I dig about, and mulch with good stable manure twice a year, fall and spring, and prune either in fall or early spring, and they certainly pay well. $\mathrm{My}_{0} \cdot \operatorname{mosses}$ and other spring roses are solid masses of bloom. After cutting each day all I wish for the house, and giving to all 
who come, I snip off all the full-blown ones, leaving them on the ground. Keeping the open roses cut off is a threefold good. It prolongs the blooming season, preserves the vitality of the plant, and serves as a fertilizer. Of course, these older bushes don't need watering. The younger roses, not fully settled in their new quarters, receive the same attention with the additional care of stirring the soil and mulching throughout the hot summer, and watering whenewer needed with suds from the weekly wash, which also enriches the ground. The cuttings receive the same treatment as the young roses except the soil must be kept moist and they must be protected by evergreen boughs or glass jars, summer or winter.

Georgia. (MIss) M. E. Greene.

\section{A FLORAL EXCURSION.}

[In answer to the "puzzler" in The Floral World for July.]

The steamer 1 ft the dock early in the morning with a party of excursionists composed of four distinguished gentlemen-Cardinal, Supple Jack, Marsh Eder, Men-of-the-Earth; also four ladies of high distinctionVictoria Lily, Lady Fern, Rosemary, Queen-of-the-Prairie. One of the ladies was noted to be Sloe, but consid. ered a Rutland Beauty, and was given the Rush.

After reaching the Willow forest, a basket was opened and the contents proved to be a tempting lunch, a meat, a berry, a vegetable, a fruit, a nut, a condiment, a caudy-Duckmeat, Dewberry, Radish, Peach, Chestnut, Cayenne Pepper, Marsh Mallow. After dinner one of the ladies accidentally spied three buds on a cotton tree. Quicker than a flash one of the gentlemen Rose and fired Indian Shot, which missed its aim and struck one of the ladies. There being no physi- cian present, the wound would Leek until there was a Gill-over-the-ground. Fearing death might result, her affianced was called. Being much grieved to see his Love-lies bleeding, he administered Indian Physic and tied the wound with soft grass and started homeward.
Louisiana.
Mrs. W. N. White.

[In a letter accompanying these answers Mrs. White writes as follows:]

"The July issue of The Floral World has just been received and perused with increased interest. I find each number more instructive. I was very much pleased to see my little floral story entitled "A Floral Excursion" included in its make-up. The answers can be found in Woods' Class Book of Botany, pages 838, 839, $840,841,842,848$.

"I must tell you of the numerous congratulatory letters I have received from contributors and subscribers of The Floral World on one or two of my contributions to your worthy magazine, each thanking me for valuable information contained therein. I wish the dear little Floral World unbounded success and happiness in its flowery mission."

\section{GIVE YOUR CHILD A GARDEN.}

It is an exceptional child who would not value flowers and a garden of its own. Boys and girls alike are delighted with the very idea of possessing a bit of ground where they can "plant things" and watch them grow. People living in villages or small cities usually have some ground around their homes in which they can set apart a place for the children's garden. The love of nature fostered by this gardenmaking will prove a constant source of pleasure through the child's life.Woman's Home Companion. 


\section{The Floral World}

PUBLISHED MONTRLY BY THE

FLORAL WORLD COMPANY,

12 to 14 South Limestone Street, SPRINGFIELD, OHIO.

Subscription Price, 25 Cents a Year.

Eutered as second-class matter at the Postoffice in Springfield. Ohio.

We will give $\$ 26.00$ in prizes for the five best articles for publication in the October number of The Floral World which may be submitted by subscribers.

The first prize will be $\$ 10.00$; the second, $\$ 7.50$; the third, $\$ 500$; the fourth, $\$ 2.50$; and the fifth, $\$ 1.00$. The awards will be announced in our November issue.

No article which contains more than two hundred words will be considered. All contributions entered in this prize contest must reach us not later than September 1.

The purpose of these prizes is to secure for publication in The Floral World matter which gives the actual experiences in flower growing of those who have subscribed for the journal. Prizes offered for articles published in the July number have been awarded as follows:

First Prize-Mary Jemison, Kentucky.

Second Prize-Miss Laura Jones, Kentucky.

Third Prize-Mrs. Mattie Woodson, Ohio.

Fourth Prize-Mrs. Samuel R. Welsh, Pennsylvania.

Fifth Prize-Eleanor R. Bartlett, Minnesota.

\section{VERBENAS AS WINTER BLOOMERS.}

Have any of the readers of The Floral World tried verbenas as winter bloomers? I did last winter and was more than satisfied. As early winter bloomers they surpassed any other plant I had. I took slips from the most desirable of the garden plants as they bloomed; some in August and some as late as October. I placed them in water until rooted, tnen potted them in quart cans, using soil composed of one-half good garden soil, one-fourth leaf mold, one-fourth sand, allowing one teaspoon Bradley's fertilizer to each plant. They bloomed in a few weelis, and were covered with flowers until the last of February. Then they showed signs of exhaustion. I think if I had given them more fresh soil or some good plant food they would have bloomed all winter; but my geraniums and other plants were in bloom, and as the window was somewhat crowded, I moved them into another room just above freezing point, and watered only when very dry. This spring I set them in the garden, and they are now full of blossoms.

Maine.

Mrs. Albert F. Bean.

\section{PLUMBAGO-CAPENSIS.}

A small plant received in the spring was bedied out beneath the parlor window, in full sun, where it has been a mass of bloom all the while. This plant was given fairly good soil, but other than that has received almost no care at all. And the weather has been very hot and dry.

Texas. Mrs. V. H. Montgomery.

\section{GROW FLOWERS, BUT WISELY.}

I never had the pleasure of seeing that charming little magazine, The Floral World, until yesterday, yet aIready feel interested in its prosperity and am determined to enjoy its monthly visits so long as I live.

The first earnest word I feel impelled to speak is to the married man, especially the young husband. If you would have your wife domestic and an ardent home-lover, be generous to her in the matter of seeds, bulbs and 
growing plants. The care of such beautifiers to her home is one of the strongest ties to bind her to that home. The next word let me say to the woman herself, be she matron or maid, elderly or young. In these days of over-strained nerves and diversified activities, cultivate fiowers as the surest of all healers as well as the sweetest of all recreations. There is no occupation that yields so rich a return in benefit to both body and mind. Try it for one year and be convinced that this is true. But work, in any field, to be successful, must be intelligent, hence the wise young gardener will eagerly accept such adequate instructions as are ever at hand in The Floral World. MARY STUART SuIth.

New York.

\section{GJOD LITTLE BULBS FOR WINTER BLOOM.}

I have two varieties of freesias, the plain white and the white with yellow throat. The white is much the larger in blossom, but is not one bit sweeter. To bloom well, they should be potted early in the season. I pot some as early as the middle of July, and I find that the ones that are set away in the dark, cool cellar come into blooming first. For potting soil I scrape the roots and dirt from off of sods and mix with it wood earth until it is of a dark, rich color. Then plant the bulbs one inch deep, five in a five-inch pot, or more in a larger one. When potting I provide each bulb with a support in the form of a wooden skewer, tied well around the sides of the pot. When all of the plants are up I furnish string, winding in and out and around about both plarts and supports to hold up well, then place in a sunny window and keep well watered. Another fine winter bloomer is the Bermuda oxalis, often called the buttercup oxalis on account of its color. It should be treated the same as the freesias.

$\mathrm{Pa}$.

Mrs. Sayelel R. Welsh.

\section{A BEAUTIFUL WINDOW BOX.}

Dear Readers of The Floral World: I have a box that I wish you would all try for a window garden this winter, and you will have something of which everybody will envy you. Take a box about ten by thirty-six inches and ten inches deep. First make a few holes in bottom of box. Add broken flower pot or bone for drainage, then put good black loam and a layer of hen or cow manure, topped with more good soil. Then put a border of pansies which have been sown in a small shallow box, in good, rich, loamy soil, and watered well and not allowed to dry out. When they have five or six leaves trarsplant in this box for winter, the pansies being the front row, and of a blue or purple color, then a row of white double petunias, or white tea roses, and lastly a row of double red geraniums, having the geraniums the tallest of the three rows. Keep buds pincheci off till September or October ard you will have a flower window that will pay you tenfold for all your trouble and making the nation's pet colors, with a fine fragrance. Try this and report.

Ohio. Mrs. Matte Woodson.

\section{A BIT ABOUT THE FREESIA.}

In August I procure bulbs of freesias-I prefer the giant Bermuda, as they produce larger flowers-and pot half a dozen in a six-inch pot. I usually use a long, narrow box to fit the window sill, and plant about three rows of the bulbs. I use pienty of broken crockery or charcoal for drainage, and then use the richest of leaf mold, sand and common garden soil. I pot ana set away in a dark cool place for five or six weeks for roots to form, and then gradually bring to light and air. In December I commence to water with water as warm 
as I can bear the hand in-pour this on the roots-keep the foliage bright and green by spraying daily with a fine spray, and twice a week give a stimulus of liquid fertilizer. After the foliage gets a good start I make a kind of trellis or fence around it, to hold it up.

I move plants from east to west windows daily, to give all the sunshine possible, and then I have an abundance of these sweetly fragrant, trumpet-shaped flowers during the dreariest months of the year. Your success depends upon securing the largest sized bulbs and starting them early.

Kentucky. Miss Laura Jones.

\section{FLOWERS FOR THE DINING.TABLE.}

The dining table for every day is not complete without flowers. Durirg summer this is not difficult, for there are many suitable flowers. I prefer vases of clear glass, suggestive of cool, sparkling water-how beautiful the stems appear in them. For the breakfast table these hot mornings nothing equals the bright spicy nasturtiums arranged with their own leaves. For "green" for sweet peas I use the foliage of the garden peas. Pansies are fine with their own foliage. Phlox and pinks appear very nice on the din. ing table. Roses are sweetest and best of all, but one likes the more common plants for a change. In the fall cosmos, asters and chrysanthemums can be used.

In winter, when flowers are not so plentiful, and "green" still more rare, I place a modest jardiniere on the table and set a pot of some plant in flower in it. Primroses are fine. Freesias, narcissus, Chinese sacred lilies, hyacinths, roses and heliotrope are each used this way. Sometimes a pot of asparagus plumosus nanus, or some choice fern, is used in place of a flowering plant.

Ohio.

Annice Bodey Calland.

\section{A PLEA FOR OLD AGE.}

Just a word to our flower-loving readers who have homes of their own. How delightful it will be as old age creeps along and we are not able to care for flowers, to go out in our garden and gather flowers for the table or sick friend or neighbor.

Begin now to plant hardy bulbs and shrubs. For bulbs there are the snowdrops, scilla, crocus, hyacinth, tulip, lily of the valley, iris, and many others. In the spring I often go and see the beautiful blossoms of the snowdrop and scilla peeping up through the snow which has fallen the night before, looking as bright as ever.

For shrubs there are the spirea, deutzia, snowball, althea, lilac, philadelphus or mock orange, forsythia, weigela, hydrangea, cydonia japonica, syringa, yucca, and the roses to plant where you can find room.

If your pocketbook is very light, just plant two or three every year, then in a short time you will have a nice collection to gather from all summer when you are not able to care for annuals.

Conn.

R. J. BRAdLEy.

\section{EARLY FALL PREPARATIONS.}

I want to tell the readers of The Floral World how I raise plants from the seed to fill my beds for summer blooming. I begin in the fall by filling boxes with rich, mellow garden soil and storing in the cellar. In January I fill shallow boxes by putting in charcoal as drainage and filling with garden soil and sowing the seed and carefully pressing down the soil. Then I take brown wrapping paper, cut the size of the box and dampen it and place over the box, placing it in my sunny bow window, and in a surprisingly short time tiny green shoots will appear. At the present writing I 
have callas, heliotrope, fuchsia, ageratum, asters. They are now ready to transplant in small pots. The middle of April I will again transplant in a bed made on the sunny side of a high board fence, and covered with canvas. I will leave them there to harden, until the middle of May. Then they will be nice bushy plants, ready to put in beds ready for them. In this way I raise a great variety of plants. Idaho. Mrs. SEnNIE HaRMan.

\section{ROOTING OLEANDER CUTTINGS.}

I have rooted four oleander slips this summer. Two of them I placed in fruit jars filled with water. I placed a few pieces of charcoal in the jar to keep the water sweet. They had plump white roots in a few days. The other two I bedded in moderately rich soil on the east side of the house, turning a fruit jar over each one. I think they rooted as quickly as those in the jars. Perhaps I should say that I chose well-ripened slips, as I had previously failed with young, sappy ones.

Texas. Mrs. V. H. Montgomery.

\section{SOME THINGS TO DO THIS MONTH.}

Chrysanthemums should not suffer for water this month. They will need staking and top dressing. When the flower buds appear, begin using weak manure water twice a week.

Callas should be repotted this month in well-enriched soil. Place in a shaded place until the roots become established in the fresh soil.

Some old plants of fuchsias will flower during winter if they are cut back to within a few inches of the ground and the soil washed from the roots. Then pot in new rich loam, water sparingly at first and keep shaded until new growth starts, then the morning sunshine will be beneficial.

(Concluded on page 12.)

\section{Send the Floral World to a Friend}

We desire the names and addresses of all persons who are interested in home flower growing. Send us the names of twenty-five of your friends whom you think would like to see a copy of THE FLORAL WORLD, and promise us that you will write or speak to all of them about our little magazine, asking them to become subscribers, and we will give you absolutely free one year's subscription for any friend whom you may designate.

Address,

THE FLORAL WORLD, Springfield, Ohio.

\section{Make Your Money EARN MONEY}

Persons who have money to invest are invited to write us. We offer no extravagant profits, nor do we make improbable promises. Engaged in an established business, for the assuredly profitable extension of which additional capital is needed, we have for sale stock which bears a guaranteed dividend of

\section{SIX PER CENT}

\section{PAYABLE SEMI=ANNUALLY}

No higher dividends can be secured from any other investment of equal safety and character. Let us send you full particulars. Address

"INVESTMENT",

P. O. Drawer 755. Springfield, 0 . 


\section{SKIN DISEASES}

If you suffer from Eczema, Salt Rheum, Ringworm, Itch, Ivy Poison, Acne, or otherskin troubles,

\section{HYDROZONE}

will cure you.

Cures sunburn in 24 hours.

In cases of Prickly Heat and Hives it will stopitching at once, and surely cure, also will relieve mosquito bites.

Hydrozone is a scientific Germicide. Used and endorsed by leading pbysicians. It is absolutely harmless, yet a most powerful bealing agent.

As these diseases are caused by parasites, killing them without causing injury to the sufferer, naturally cures the trouble.

FR FE to any one sending me 10c. to F RE cover actual postage,will send a bottle containing sufficient to prove to your satisfaction the claims here made. Pamphlet sent free. Address

Prof. Chas. Marchand, 59 Prince St., N. Y.

\section{$\$ 4.00$ A DAY \\ Easily Made at Home Weaving Rugs.}

NO EXPERIENCE NEEDED. If jou making $\$ 15.00$ a week or less, write for particulars at once

REED MFG. CO., Box 12, Springfield, Ohio.

1D when fur a 2 cent stamp 40 N 5 me for a ${ }^{2}$ cent stamp TO $D E$ E F T Times Building. New York TO BEFAT will tell you how her \$1 prescription took 20 to $120 \mathrm{lbs}$. off each of over 6.000 men and women. Most effective \& least expensive treatment ever offered. Endorsed by United States IIealth Reporta.

\section{FREE TO BOYS AND GIRLS FREE} Send postol today for large premium list, 200,000 premiums given away last year. Dept. 10 .

\section{SUPERIOR C()., North Adams, Mass.}

FOR THE KITCHEN

The Dandy Scraper fits and cleans every pot, pan or dish. By mail,

10 cents. Agents wanted. Liberal Terms.

Address Dandy Mfg.Co.,Dept.B,Newark, N.J

LADIES, SUPERFLLOUS HAIR removed from the face, neck and arms. Harmless preparation, positively guaranteed. Receipt and full instructions sent secureIy sealed.One dime.Empire Nov.Co.,G.,Garrison, Tex
(Concluded from page 11.)

Freesias shoud be potted for early winter flowers.

Pansy seed should be sown for early spring flowers. The bed or border should be well drained.

Old plants of pelargoniums should be well cut back, then when new growth begins remove some of the old soil and repot, using pots in propoltion to the size of twe plants. Use a compost of three parts turfy loam, one of rotted manure and coarse sand. Keep the plants shaded until they become established in the fresh soil, then give plenty of strong sunshine.

Ohio. Annice Bodey Calland.

\section{INQUIRIES.}

Is liquid manure made by using fresh or rotted manure?

Texas.

Mrs. J. P. Patterson.

Please tell me how to successfully grow the aloe maculata.

Iowa. Mrs. W. R. LANCASTER.

Can you tell me what to do with my peonies? I have had them for years and they never bloom.

Ohio.

Mrs. F. Wuenker.

I have twenty small cinerarias plants which I have grown from seed. Now that I have them growing I don't know how to care for them. What kind of soil do they require? Are they liable to be attacked with lice?

Michigan. Mrs. T. L. Perrine.

I have four heliotropes. Three of them I rooted from the parent plant, and they won't bloom for me. They are potted in moderately rich soil. Some of them only get a part of the morning sun, while one of them gets all sun until noon. They show a ten(Concluded on page 13.) 
(Concluded from page 12.)

dency to make rapid growth, but I keep them pruned back. They are watered every day during the dry weather. Any advice given me will be appreciated and acted upon.

Texas. Mrs. J. P. Patterson.

\section{REMEMBER THIS NEXT SPRING.}

One spring I got the best chrysanthemum seed catalogued, planted them in rich garden soil in a box four inches in depth. I marked the soil in rows each way, an inch apart, putting one seed at each cross. When the tiny seedlings were showing the third leaf I transplanted to cans and boxes. When nearly four inches high I pinched out the top and put in the ground in a well-prepared bed. I pinched them back all summer and lifted in August. I had fourteen blooming plants, and some of them were as beautiful as any I ever bought. They were admired by all.

Ind.

LIDA O. B每NETT.

\section{VIOLETS FOR SHUT.INS ALL THE YEAR.}

How do I care for these sweetscented beauties that God has given me, though confined in the walls of my room, solitary and alone? As I look around I see on my center table my bouquet of these little beauties. I gathered sand and soil for them last fall and placed them in a little wooden box with lumps of coal for drainage. They are peeping out with their sweet blue heads above the box, seeming to say: "I spy you lying there on your bed of affliction. I came to cheer you up, so stop repining and rejoice." They should be kept cool and damp. They will surely repay you with their sweet fragrance. In your room they are sweeter than all the roses. I prefer California violets.

Tenn. Mrs. Thos. Ledinger.

\section{BEAUTIFUL PLANTS}

Cacti, Succulents, Palms, Pot-Grown Fruits, Bulbs and Seed. Rare greenhouse plants of every description from the tropics; odd and curious plants for the lover of flowers. Beautiful catalogue free. Address

J. EDGAR TODD, Morris Park, L. I., N. Y.

\section{Save Your Plants, Fruit Trees and Crops}

by using VITA PLANT FOOD. Non-poisonous. Insecticide, fungicide, seed germicide. One application will kill parasites that destroy flora, and restore and nourish unhealthy foliage and flowering plants. Destroys disease by supplying oxygen to the respiratory organs, causing luxuriant growth of palms, roses, etc. Will prevent rust and smut by treating seed.

\section{WILL SAVE YOUR TREES}

Package containing enough for 1,000 applications for plants, 100 bushels of cereals, or 50 trees sent prepaid on receipt of $\$ 1.00$. Money refunded if not satisfac tory. Special prices to Florists. Agents Wanted.

Vita Plant Food Co., 871 Drexel Bldg., Philadelphia, Pa

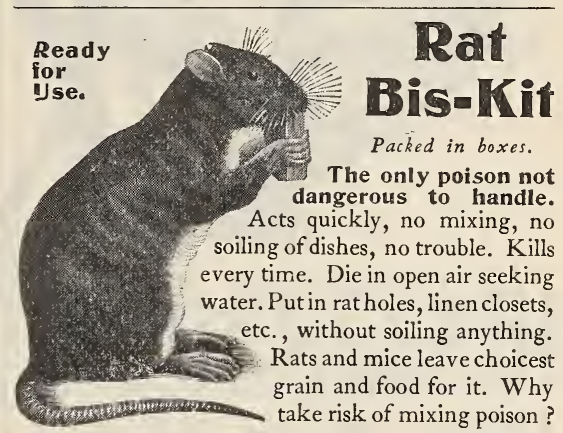

Ask your druggist. If he hasn't it, send us 20 cents for one full size box, or 50 cents for three boxes, postpaid.

The Rat Biscuit Co., Dept. D, Springfield, Ohio.

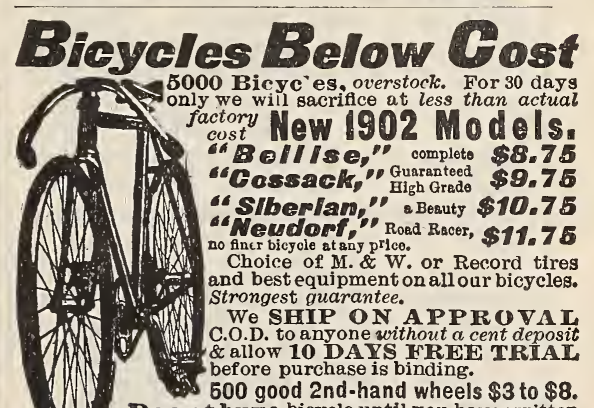

Do not buy a bicycle until you have written for our free catalogues with large photographio

GEAD GYOLE BO. Dept.375 S Chicago.

SOAP and WASH for Cats and Dogs; kills fleas; keeps coat silky soft, cures ecze$\overline{\text { Angora Cats, White silk FRENCH Podples. }}$ 


\section{Fine Freesia Bulbs ONLY 25 CENTS.}

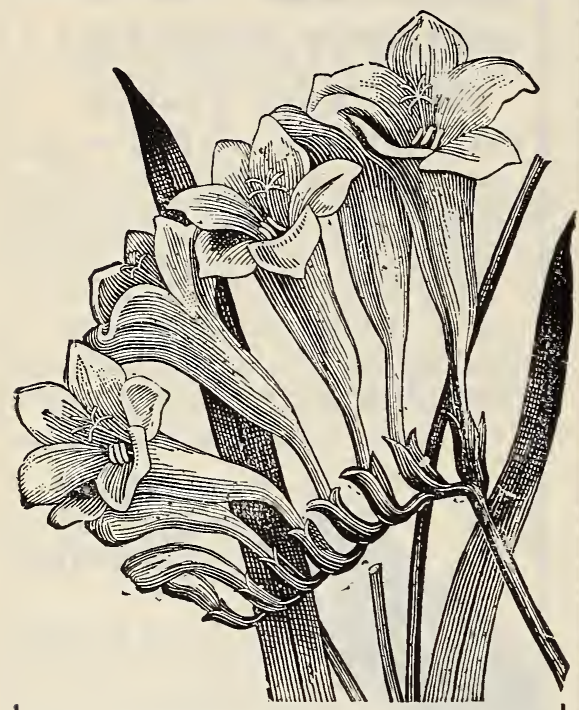

NO description can do adequate justice to the beauty of the Freesia. The flowers are two inches long, and about the same in width, shaped like miniature Gladioli, and borne in clusters of six to ten on depressed horizontal scapes. The body of the flower is pure white, large segments, spotted with yellow. The perfume is most delicious. The cultivation of the Freesia is of the simplest, as the bulbs require only to be potted, watered sparingly at first, placed in a sunny window, and watered more freely as growth progresses. To have the best results, the bulbs should be planted during July or August. Late planting is the cause of nearly every failure with Freesias. We have an enormous stock of the finest Freesia bulbs. Order at once, and insure success by planting early. Our prices are the lowest consistent with good quality.

We will send you a splendid collection of twenty bulbs for only twenty-five cents. Three collections, sixty bulbs, only fifty cents. Single bulbs, or collections of less than twenty, two cents each. Address

THE GOOD \& REESE CO., P. O. Box 71 . Springfield, Ohio.

\section{AN EXPERIENCE IN GRAFTING CACTI.}

I would like to give my method. The best time? Begin preparations, if possible, in February, by changing to a larger pot, if necesisary, and gradually dampening the soil. Give a little fertilizer from sheep stable if available. As soon as the plants start the new growth they are in condition to graft. Take the graft and cut to wedge shape, also make a wedgeshaped incision on the stalk and insert graft and pin fast with cactus spine. Then bind gently to keep from spreading apart. Set in the cellar or other cool place for four or five days. Let no water touch where cut until healed over. Bring the plant from the cellar and set it in the shade for a short time before giving it the full sun.

Grafting has a tendency to increase bloom. It has another advantage. You can' graft tender varieties on plants of hardy varieties and the graft. will become as hardy as the plant on which it is grafted. I have been quite successful in grafting by this method and hope some Floral World subscribers will try it and report success. I had a candle cactus for ten years and never got a bloom until I grafted on it a cactus commonly named rat-tail, and it bloomed the first season, and by the second season was just full of bloom.

Ohio.

Mrs. Thomas Moore.

\section{ANSWER TO QUERY.}

Tell Rev. F. A. Frank, who inquires about callas, to try putting two ounces of castor oil on the soil around his lilies. With a stick work it down around the roots. I knew a Wisconsin man to try it with very good success.

Neb.
Mrs. W. H. P. 

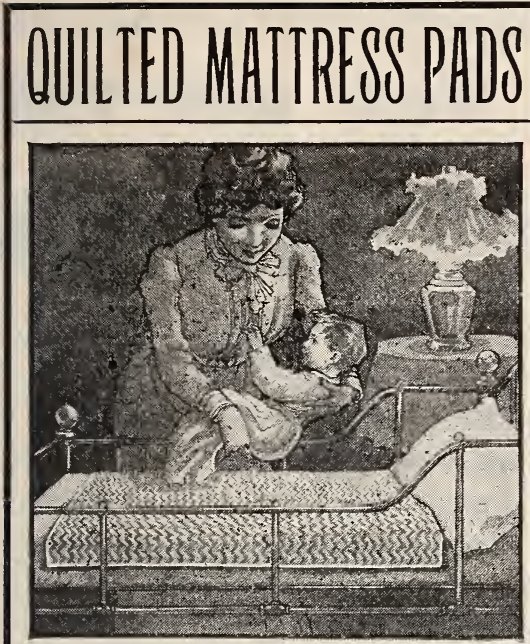

Fit your bed with a Quilted Mattress Pad and keep it in a cool and sanitary condition. A sound, refreshing sleep on hot nights will be made possible.

These pads are made of bleached muslin, both sides quilted, with pure white wadding of the best grade between. They wash perfectly.

Good as new after laundering, and the low cost places them within the reach of all.

$$
\text { SEND FOR SAMPLE }
$$

\section{The Excelsior Quilting Co.}

15 Laight St.

NEW YORK.

"Let the GOLD DUST twins do your work."

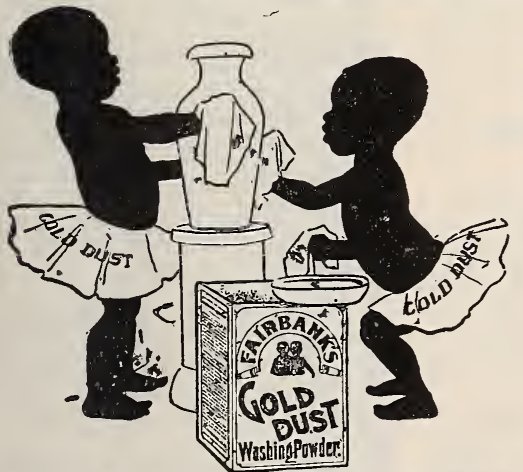

As a cleaner soap doesn't begin to compare with

\section{GOLD DUST.}

GOLD DUST does more work, better work and does it cheaper. It saves backs as well as pocketbooks. Made only by THE N. K. FAIRBANK COMPANY Chicago, New York, Boston, St. Louis. Makers of OVAL FAIRY SOAP.
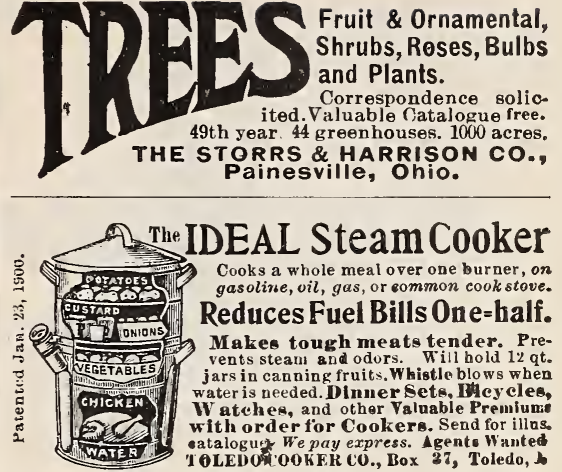

DARKENYOUR GRAY HAIR DUBY's OZARK HERBS restoregray, of streaked or faded hair to its natural color, Q.

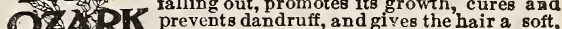
O2 GNI prevents dandruff, and gives the hair a soft, His. 35 NOT STAIN THE SCALP, is not sticky or dirty, contains no sugar of lead, nitrate silver, rom copperas, or poisons oi any kind, but is com: posed of roots, herbs, barks and flowers. It ONLY 25 CENTS TO MAKE ONE PINT. It will produce the most luxuriant tresses from dry codrse and wiry hair, and most luxuriant tresses from dry, coarse and wiry hair, and Tring back the color it originally was before it turned gray. OZARK HERBS than in all the hair stains and dyes made. Full size package sent by mail, postpaid, for 25 cents. Address OZARK HERB COMPANT, St. Louis,

\section{BOOKKEEPING}

\section{TAUGHT PREE}

Pay your tuition from your earnings a fer we place you in a position. Our methods excel all others. You can learn at your own lome without loss of time or money. We guarantce it. We teach you free and get you a position. "How To Become A Successfui I usiness"Man" is the title of an extensive treatise on bookkeeping and business. It ex lains how you can make more money and better your position in life. The book and full information sent absolutely free. Write to day.

Commercial Correspondence Schools, Drawer 30 Rochester, N. Y

\section{$\$ 1250$ TO \$3600 Per Year \&} FOR HUSTLERS-BOTH MEN \& WOMEN

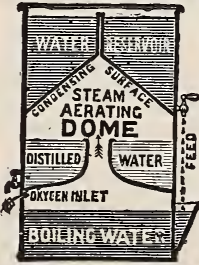

At home or traveling. Let us start you. Our Puritan Water Still-a wonderful invelation Great seller-big money Enormous demand. Orer maker. ready ready sold. It: purifies the foulest water by distillation-removes every impurity. Furnishes absolutely pure, aerated, delicious drinking water. Beats Filters. Saves livesvents fevers, bills-cures disease. White NEW PLAN AND OFFER. HARRISON M'F'G CO., 12 Harrison BIdg., Cineinnatl, 0. 


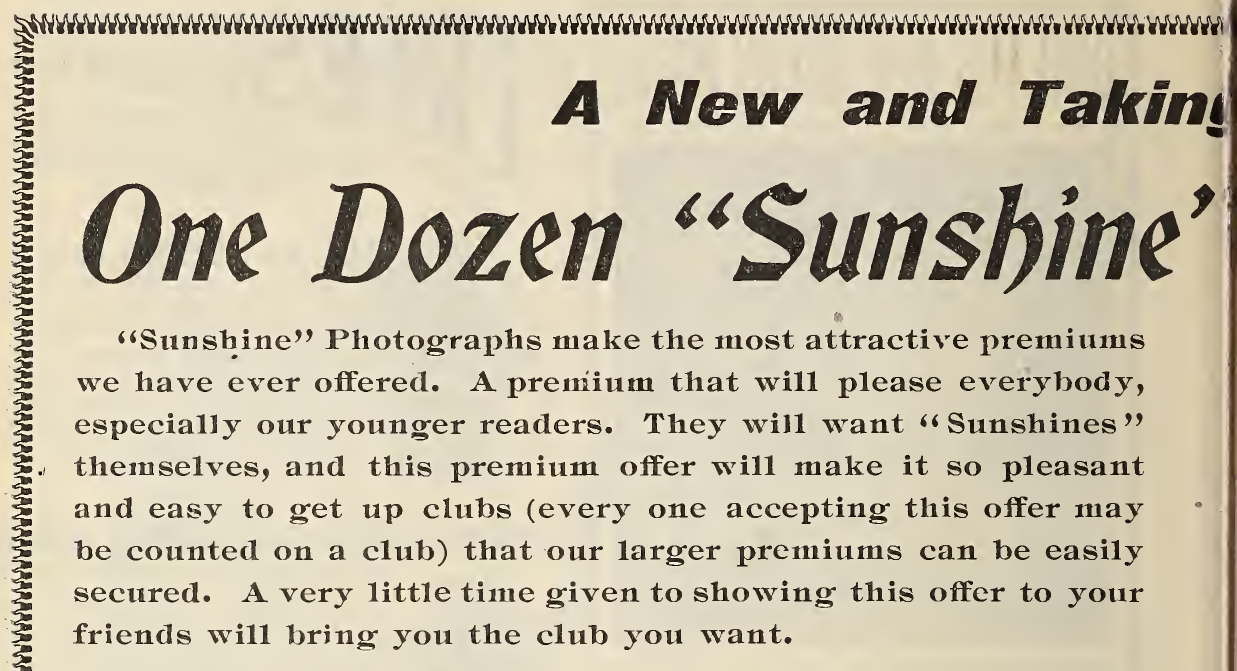

\section{Sunshine Photographs $\frac{\text { What they are and how to ge them. }}{\text { Send us an photogegaph you have }}$} (cabinet size if possible) and we will have made from it one dozen beautiful reproductions, showing perfectly every effect of pose, lighting and expression of the original. The work will be done by an expert professional photographer, and "Sunshines" will be perfectly finished, burnished photos, equal in workmanship to such as cost $\$ 3.00$ to $\$ 4.00$ per dozen in cabinet size, the only difference being that "Sunshine" photos are reduced in the reproducing to the size of the cut on this page. There will be no advertisement printed on them except as these cuts show.

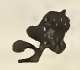

\section{Read these Instructions with Care}

1. Send us as good a picture as you have, for "Sunshines" will be just like the original.

2. Write your name and address on the back of each picture and on the corner of the envelope so they cannot be lost.

3. Be sure you send your photo so it will not get broken in the mail. We will return it unharmed with the "Sunshines."

4. Wait at least two weeks before making a complaint if you don't receive photos. It takes time and sunshine to make them.

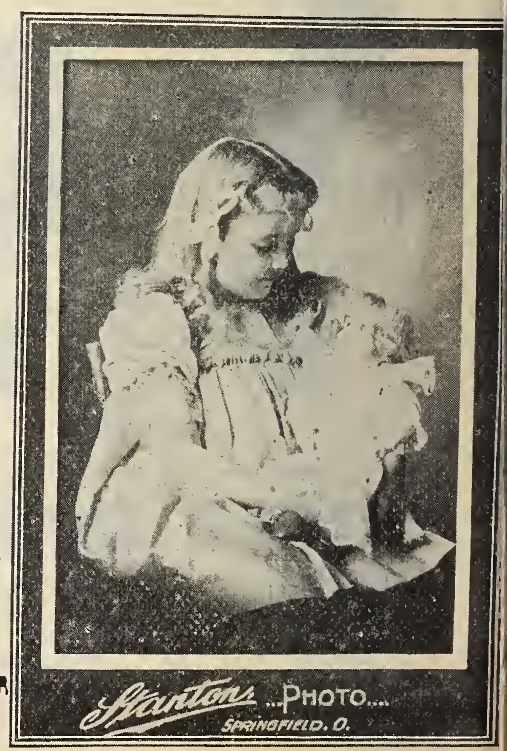




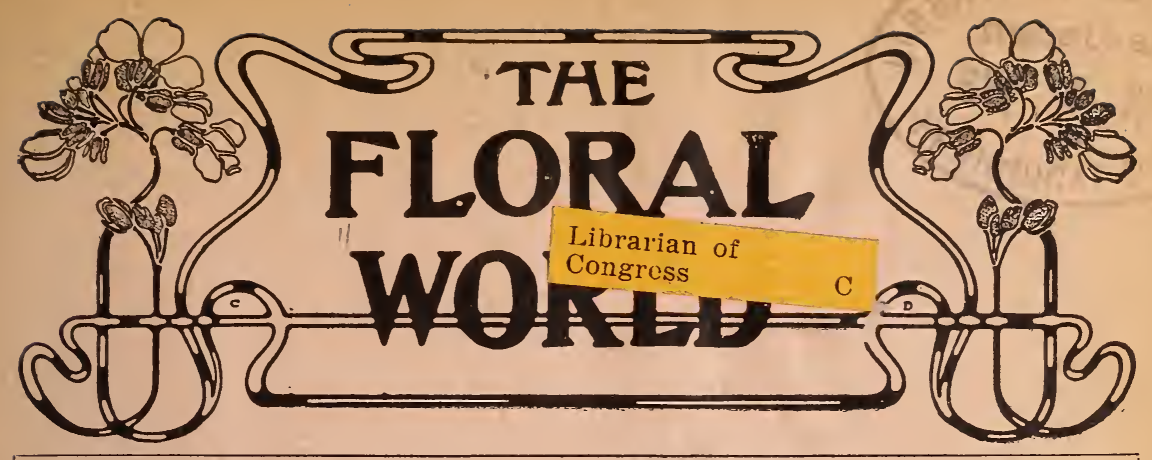

Vol. 1. No. 12 Springfield, Ohio, September, 1902 25 Cents a Year

\section{Our Splendid Fall Offer}

\section{THE FLORAL WORLD ONE YEAR 20 WINTER BLOOMING BULBS $\}$ only $25 \cong$}

SUBSCRIBE NOW AND GET CHOICE BULBS

\section{Twelve Assorted Freesias}

Freesias are the most popular and charm. ing bulbs for pot culture, flowering in winter or spring in the conservatory or window garden. Six or eight bulbs should be planted in a four-inch pot. They force readily and ran be had in bloom by Christmas if desired. The flowers produce six to eight on stems about nine inches high, and are particularly useful for cutting. The blooms remain in good condition, if kept in water, for two weeks. The flowers are pure white, with a yellow blotched throat, and are exquisitely fragrant.

\section{Eight Bermuda Buttercup Oxalis}

An unrivaled winter-flowering pot plant of easy culture. It is a strong and luxuriant grower with handsome foliage. The profusion of bloom produced in uninterrupted abundance for weeks is astonishing and delightful. The flowers are of the purest bright buttercup yellow. Properly treated the plants will flower in six weeks from the time the bulbs are set out. Well grown plants have produced as high as seventy flower stems at one time.

There are no finer flowers for window culture.

THESE BULBS will give best results if planted in the summer or early fall. This makes our offer most seasonable and one which every one of our present subscribers should accept at once and have his time extended for one year.

\section{TWO MORE SUBSCRIBERS.}

We would like very much to have two more subscribers for The Floral World from every one of our present subscribers, and there are thousands of them who could secure $a$ club of t $\boldsymbol{w O}_{0}$ for us if they would only speak about it to their friends. If you will get two of your friends to accept this offer of $\mathscr{C}$ he $F$ loral World and Twenty Bulbs for 25c., we will send you the collection of bulbs free, postage prepaid. 


\section{THE PRESS PUBLISHING ASSOCIATION OFFERS \$25,000 CASH PRIZES}

To be distributed among successful estimators of the total vote for Governor in the States of New York, Pennsylvania and Michigan on the 4th day of November, 1902.

The money, $\$ 25,000$, has already been deposited in the Central Savings Bank, Detroit.

\section{CONDITIONS OF THIS GREAT CONTEST.}

Any one sending us only 25 cents for THE FLORAL WORLD one year and an estimate of the total vote of Governor in New York, Pennsylvania and Michigan on November 4, 1902, will receive a certificate which will secure for him any prizes his estimates entitle him to claim, provided no other premium is taken.

You may estimate as many times as jou desire by sending us only 12 cents with each additional estimate. An investment of a few cents and careful study may bring you $\$ 10,000$.

The contest will close at midnight, November 3,1902, and no estimate received after that hour will be allowed. The official certificates of the Secretaries of the three States, showing the total vote for Governor, will determine who are entitled to the prizes, and the awards will be made by a disinterested Committee of prominent judges, just as soon as the official figures can be obtained.

\section{HERE IS THE LIST OF PRIZES.}

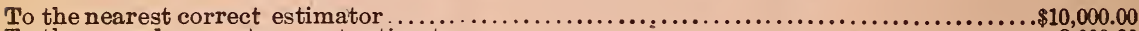

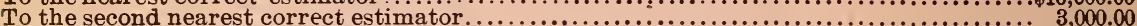

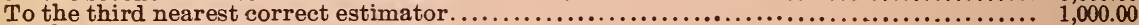

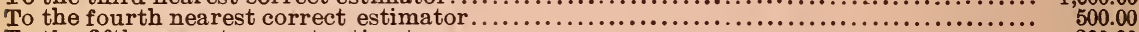

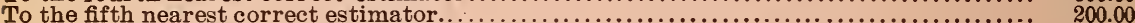

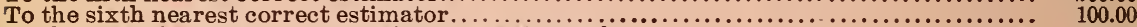

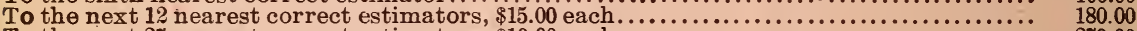

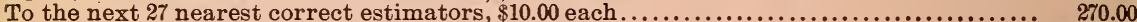

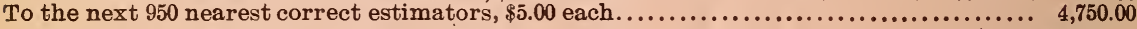

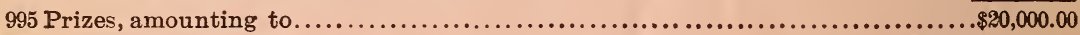

\section{The following Special Prizes will Also be Paid:}

For the nearest correct estimate received before August $1,1902 \ldots \ldots \ldots \ldots \ldots \ldots \ldots \ldots \ldots$ For the nearest correct estimate received on or after August 1 , and before August $15 \ldots \ldots .1,000.00$ For the nearest correct estimate received on or after August 15, and before Sept. 1...... 1,000.00 For the nearest correct estimate received on or after Sept. 1, and before Sept. 15...... 1,000.00 For the nearest correct estimate received on or after Sept. 15, and before Oct. 1....... 1,000.00

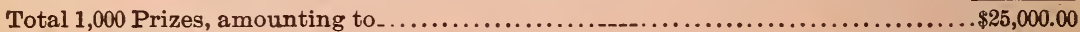
In case of a tie or that two or more estimators are equally correct, prizes will be divided equally between them

\section{VALUABLE INFORMATION.}

To aid in forming your estimates we furnish the following data :

Pennsylvania elects a Governor only once in four years. Michigan elects a Governor every two years, and since 1894 New York has elected a Governor every two years.

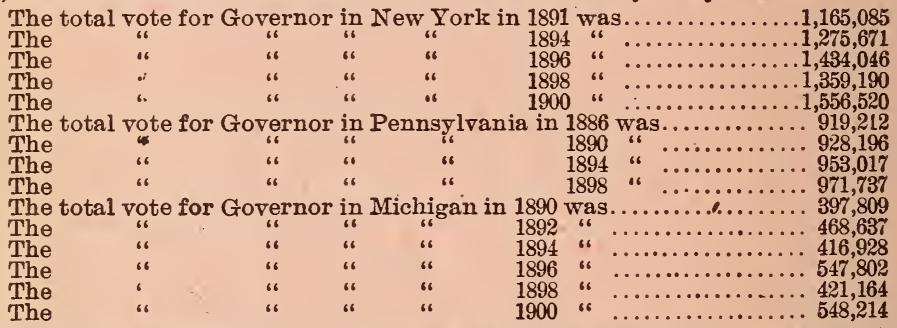

The total aggregate vote for Governor in these three states in 1894 and 1898, the years in which all three states elected Governors at the same time, was as follows:

In 1894 the aggregate vote for Governor in these three States was 2,645,616.

In 1898 the total aggregate vote for Governor in these three States was. 2,752,091.

What will the total aggregate vote for Governor in these three States be on November 4, 1902 ? Figure it out or guess at it, and send in your estimates. It may mean $\$ 10,000$ in cash to you. The official certificates of the Secretaries of the States of New York, Pennsylvania and Michigan, showing the combined total vote for Governor in these three States, will determine who are entitled to the prizes, and the awards will be made by a Committee of prominent judges within twenty days after the official vote is known.

Be sure to include your estimate in plain figures when remitting. 


\section{The Floral World}

\section{A Fournal of Home Floriculture}

Vol. 1, No. 12

Springfield, Ohio, September, 1902

25 Cents a Year

WORDS OF APPRECIATION.

I like The Floral World very much. It is very interesting.

Mich.

Mrs. S. J. Patterson.

I am a lover of The Floral World as well as of flowers.

Ohio.

Mrs. Mattie Woodson.

I find quite a lot $o_{\star}$ valuable information in each issue of The Floral World.

Illinois. Mrs. W. G. Delashiutt.

The Floral World is just what is needed in every household, for it gives actual experiences in the culture of plants.

Connecticut

E. C. Beebe.

I find The Floral World very instructive and entertaining, and consider it valuable to all interested in plant culture.

Mass.

Mrs. L. A. Coolidge.

I do not see how I got along without The Floral Worid, for it is such a help and should be in every household that raises flowers.

Pa. M. Perle Heitzenrater.

I must say that, of the differen floral magazines which come to me, your little Floral Worıd is always most heartily welcomed.

Wis.

Rev. F. P. FraNke.

I think The Floral World gets at the practical ideas, every-day actual facts and experiences of flower lovers, better than any other journal I have seen. I hope it may continue to send out its. concise instructions, divested of theory and big terms, for years in come.

Iowa.

Eva I. Griffith.

\section{CASTLE ROCKERY.}

The readers of The Floral World may be interested in a description of my rockery and water garden. The rockery represents a portion of a ruined castle, including a corner, a broken window, an arched doorway and a tower. The stones which have fallen from the wall give breadth to the rockery and afford crevices for nearly a hundred plants and vines. The water garden at the base represents the mcat, around which grow many ferns. In the background are dahlias, cannas and golden glow. Through the arch is seen a vista of flowers, brilliant poppies and geraniums. In the water garden, conrposed of several hogsheads and barrels sunken level with the ground, are lilies of various colors, water poppies, parrot's feather, papyrus, rushes and sagittaria.

Numerous frogs have appropriated the water garden for a home. Their green heads, as they peep out from among the lily pads, made a novel addition to the scene. The garden is not only greatly enjoyed by my own family, but affords much pleasure to friends and attracts universal attention from passers-by.

Mass.

Mrs. L. A. CoOlidge. 


\section{COBAEA FROM SEEDS, AND OTHER SUG.} GESTIONS.

Everyone knows how hard it is to raise cobaea seedlings. Suppose you try my plan, which proved very successful last year. Put some sphagnium in the bottom of a seven-inch pot; on this put a four-inch one, so as to bring the rims even, and fill the space between with sand. Fill the inside pot one-third full with drainage, cover with rough soil, and fill to the top with sand.

Sow the seeds not very deep, and on edge, moisten and cover with a piece of glass.

If you can give bottom heat, do so. If not, keep in warm place. Water only the sand between the pots.

Amaryllis reticulata, when kept starved in a smail pot, will bloom much better than if kept well fed in a large one. A potted hydrangea makes a beautiful veranda ornament. Browallia S. Major can be grown as a pot or border plant, blooms either summer or winter, can be raised from seed, and its beautiful, ultra-marine blue color is rare and beautiful.

To encourage the formation of buds on your hoya carnosa let the plant become root bound and avoid enriching the soil.

Missouri. Mrs. J. P. ERnst.

\section{PREPARING FOR THE WINTER GARDEN.}

The first thing to be considered in planning for a successful winter garden is to secure plants suitable for winter. While some plants now very desirable (such as palms and ferns) we must keep all the year, our most successful flowering plants for winter are not desirable for summer. The queen of winter bloomers is the primlose, Chinese primula, abconica and baby primrose are all desirable. Writers tell us they will do well in north windows, but my best success with all house plants has been to have them, if possible, in a room with a south window. Then place the plants requiring the least sunshine farther from the glass, or at one side, where they will have the sun only part of the day. In our short days the light is not sufficient to give the best results with blooming plants in a room where the sun shines only id small part of the day.

Indiana. MRS. N. J. GARD.

\section{PANACEA FOR SHRUBBERY.}

I have a wee bit of information for the readers of The Floral World, regarding shrubbery, such as orange and lemon trees, hydrangeas, hibiscus or any wooded plants. Sometimes they are sick, lose their leaves and refuse every treatment. I have discovered a panacea. Make a paste of sulphur and water; use a tooth brush and paint the plant, from bottom. In a few weeks you will notice such a vigorous change you would not believe it to be the same plant. The sulphur acts on the shrub, like on the blood of the human system.

How to know a double from a single flower, compare the buds. Those of the double are more globular. Cut the bud through the middle; the double flower will have no stamens.

Illinois.

Mrs. W. G. D.

\section{TO TAKE UP PLANTS WITHOUT DROPPING LEAVES.}

Cut around each plant with a sharp spade or large knife, leaving as much earth in cutting as will fill flower pot you intend for it. Then insert spade the depth of the blade, making a lever of handile and bearing down on it, lift it out. The earth should not be broken around roots. Slip it off the spade into the pot. If the soil is very sandy it should be watered heavily, 
making the earth solid. Have soil an inch from top of pot, so water won't run off when watered and will penetrate through the soll to the roots. This, too, is important, good drainage, to insure against over-watering. After potting plants, water well to settle soil in all parts of the pot, then put in a shady place to establish itself in the new soil. Leave them in a cool place for several weeks, to get as much fresh air as possible, and light is very essential to fine foliage. Do not take them indoors right away after potting, and avoid fire heat as long as you can, as they will do weli without it until long in November; then have them in an adjoining room to where stove is located. They will be far superior to plants kept by fire and will bloom throughout the entire winter. Too warm rooms and too little fresh air greatly debilitate tender plants. Last winter I kept over fiity plants and never lost but two by freezing. Those were too close to the window pane and I forgot to put newspaper between them.

\section{Ohio. Mrs. Mattie Woodson.}

\section{THE FALL BEAUTY-THE DAHLIA.}

There is no question but what the dahlia is the most beautiful fall flower we have. There are so many colors and so many shades of the same color that with all the different mixtures it is difficult to find another flower to equal it. Did you ever raise them from seed? If not, don't fail to try it next season. It is easy, and you may get some very choice colors. It is interesting to watch their growth and wonder what the colors will be. Sow seeds about April 1, in the house, in good soil; water freely. As soon as fcur leaves are formed transplant incu six-1nch pots. Do not set out in the ground until the weather becomes settled. Then, as they grow, pinch off the lower branches from the main stock, so there will be eight or more inches space from the lowest branches to the ground. In doing this you will get fine flowers and long stems. I sowed seeds April 21, and at this writing (July 21) have plants in bud. So you see, you can get dahlias from seed as soon as you can from bulbs, and no more trouble.

Massachusetts.

E. C. B.

I have never seen in The Floral World my way of taking care of dahlia bulbs. In October I take my boxes, cover the bottom four or five inches deep with dry garden earth, then I place my dahlia roots close together and cover with dry earth, ready to start in the spring. I put them in the cellar, and in March bring them up and put in the windows, where they will start in a few days. As soon as warm enough I set them out in the garden, and I always have them blossom by the fifth of June, and they blossom all summer. I have never lost. one bulb yet.

Mich.

Mrs. S. J. Patterson.

\section{AS TO FLORAL SPECIALTIES.}

What I mean by cultivating floral specialties is making a wise selection of foliage plants and bringing them to a state of perfection. Without the least intention of discouraging the amateur florist from growing this, that and the other, in The Floral World I would emphasize specimen plants-stand out with such distinct individuality, and are suitable to adorn the humblest cot or the queen's palace.

Exercise judgment in watering, as growing plants extract moisture from the soil in proportion to the rapidity of growth. Consequently they require very little early in the season. Give no fertilizer to plants begun in January, until about March or April. 
Palms, without exception, make the grandest show, and are about the easiest to succeed with. I consider Lantania Borbonica, Areca Lutescens, Kentia Fosteriana, the finest for general cultivation. The Zamia does well under amateur treatment, and is a plant of great beauty and adaptability. Palms grow deep roots. I find painit keg's, well cleaned, admirable receptacles. Bore a hole the size of a silver dollar in the bottom, fill with leaf loam, sand and well-rotted stable manure. Have the bottom covered two inches with charcoal for drainage. The soil will gradually wash through, making it necessary to feed with fresh soil frequently. By this simple method repotting is avoided.

A well-developed Ficus Elastica is lovely. Like the sturdy Sanseveria, it has a nature to resist abuse and all inimical conditions of a living room. My method of arranging the umbrella plant is simple yet attractive. In lifting it from the yard where it has luxuriated all summer, it is put in a bucket with a Farfaguin and Asparagus Sprengeri planted around the edge. It is impossible to conceive of the beautiful combination.

N. Y.

Mrs. W. N. White.

\section{A GARDEN IN A DOUBLE BED}

For greater effect and to reduce labor, all our yard was sodded, except a level space on which was raised a circular flower bed, thirty-six feet in diameter. A walk was cut through the center and all around the circle, and extended to meet the walks around the house. These walks were all laid with cinders and overlaid with gravel. The edges of the two semi-circular beds were banked with sod. The bedis were planted in circles, not taking the center walk into account. In the center were planted two great bunches of rudbekia golden glow, which crowded the next circle, cannas, so much that next year the cannas alone shall fill the whole center. Next, a circle of fifty spotted callas. After this a space walk sufficient for weeding. The nexi circle was iris, and then one of Marguerite carnations, followed by aque. legias, lovely in bloom and foliage. For border the funkias or day lilies were ideal. I do not think anything can be more effective than such a simple scheme, and it has made a miniature park of our grounds.

Nebraska.

Mrs. J. L. NebLe.

\section{SUCCESS WITH THE AZALEA.}

When the Azalea is through blooming in the spring, trim out all weak branches and shorten up the long ones. The latter part of May dig a deep hole in the flower bed, partly fill with ashes, to keep the worms from crawling "into the pot, and set the plant in its pot down in the hole and fill in all around the pot with ashes. Water thoroughly every night through the summer, as the buds form in $\mathrm{Au}$ gust. In the fall take up the pot and dig out an inch or two of the earth and fill with fresh soil. When brought into the house, set in the sun if you wish it to bloom by Christmas. Keep water in the saucer while in bloom, or the buids will blast. The branches cut from the plant can be rooted by putting down in the ground in a shady place, and by fall can be potted, and will bloom the first winter, if they are good-sized slips.
Connecticut.
E. C. BeEbe

\section{SOME EASILY GROWN ANNUALS.}

Sweet peas, pansies, petunias and nasturtiums.

Sweet peas are perhaps the easiest of culture. They should be planted in March, or as soon as the ground can be worked. If in February, dig a trench eight inches deep, put one inch wood ashes, then one of good, rich, well-rotted stable manure. Plant peas 
one inch apart and cover four inches. As they come up draw the dirt to them. I plant my sweet peas by the wire netting fence running north and south. They need plenty of sunshinc.

For pansies, use at least half wood earth. One can hardly make the pansy bed too rich. I find they do best in shade the hottest part of the day. Mine do best on the north side of the house. They get morning and evening sun. Keep well watered.

In growing nasturtiums use very little manure and a rather heavy soil. Give them all the sunshine possible. Petunias, like pansies, enjoy a light, rich soil, but plenty of sunshine.

Pansies are best planted in a box in the house. I plant early in January, then I have bloom by May.

Kansas.

S. J. HARRIS.

\section{AN INDOOR GARDEN.}

I have in mind some contrivances that we may make in order that our plants may be more attractive.

First-A jardiniere stand that the owner is not ashamed of made out of an-old lawnmower wheel and a chain pump wheel, with an upright piece made of eighteen inches of a broom handle, and all painted black. You can make a pretty hanging basket of a bird cage. Make a light box three inches high, fill with soil, plant with vines or oxalis bulbs and they will soon cover it.

One more suggestion, and then I have firished. To malie a frame for smilax or other delicate vine, take strong wire and make a frame of any size or shape (I prefer round). Ravel a piece of wire screen. Put the fine wire across the frame, fastening each end and crossing in the middle. Now commence in the middle and weave around in imitation of a spider's web, fastening at each cross-piece as you go around.

Mo.

\section{FERNS-A BIT OF EXPERIENCE.}

My success with ferns this season is phenomenal. I venture to give my method after so many repeated failures, trusting it may help some fern crank like myself. Yes, I am an ardent lover of ferns, and since my wonderful triumph am more enthusiastic than ever. Conditions for growing ferns in my house and on the gallery are so unfavorable I decided to try a new and rustic situation under a large tree, arranged on some old steps and stumps. Pots of adapted sizes were filled with light, fibrous leaf loam and sand, an inch of charcoal for drainage. The one great secret is regularity of treatment. I resolved to give my ferns the first and last attention of my numerous duties of each day, and the result is wonderful. Work with them systematically. Don't alternate between a drouth and deluge; water and sprinkle every day; keep the surroundings moist and cóol; add fresh fibrous loam occasionally. Ferns love companionship. There is something invigorating in affinity. Besides, it is less trouble to have plants classified.

La. MrS. W. N. White.

\section{A GOOD OLD ROSE.}

Among the many varieties of climbing roses which have lately come into notice I have not found one which, for all-around good qualities, outrivals the old La Marque. There is scarcely a Southern garden in which it is not found, either cut back into bush form, or running high over frame or trellis at its own sweet will. It would be hard to find a time in the blooming season of roses when the La Marque would be without some stray clusters, and in the early spring it is a revelation in the prodigality of its blossoms. They are usually large, full, and fragrant, and the color is a pure untinled white in the open rose, and bud, with 
only a suggestion of cream color, in the half-opened flower.

It makes an immense vine. One in my own garden has climbed on a breadth of woven wire almost to the top of the second story of my house in less than two years.

It is hardier than any other climbing rose. In our climate, all roses are comparatively hardy, but sometimes the severe cold snaps which come late in winter, after the sap has started up in the plants, will kill almost to the ground the Marechal Niels and Marie Henriettes which we love to plant together. After this they are inclined to be very slow to recuperate, but La Marque only waits for the first warm days to send up great, strong young sprouts from the roots, each one tipped with a thick cluster of bloom buds.

Georgia.

Mrs. Henry Wight.

\section{THE CREAM OF HARDY PLANTS.}

Flower lovers are rejoiced that our fickle mistress, fashion, again favors the dear old hardy plants. Those who have had indifferent success with bedding plants may indulge in these, confldently expecting unbounded pleasure with minimum expense. Where strictly hardy plants are used in good soil they increase in size and beauty indefinitely. Having tested most that are listed by florists, the following are found to give a satisfactory display of the best bloom from earliest to latest, with no disappointment: Herbaceous, pearl achillea, anemones, antirrhinums, boecomia, coreopsis lanceolate, columbines, crown imperials, dianthus barbtus dwarf pinks dicentras, delphinums, eulalias, funkias, hemerocallis, irises, martensia, marguerites, lathyrus, phloxes, peonies, rudbeckia, spireas, thalictrum, valley lilies, white lilies, tiger lilies, yucca, shrubs, doube flowering almonds, altheas, weige- lia, Japanese quince and snowball, lilacs, philadelphus, flowering currants, and exochordia; vines, cinnamon, akebia quinati, clematis, bignonia, ampelopsis variegata and quinquefolia, honeysuckle and wisteria. Much disappointment is avoided where each variety is congenially located. Florists will furnish this information if recuested.

A half-dozen plants, well chosen and properly located, are better than four times as many huddled together indis criminately. An annual dressing of manure, and pruning to keep shapely, is all that is required until they need thinning.

Indiana.

Saraft A. Pleas.

\section{SWEET VIOLETS FOR HOUSE CULTURE.}

Early in September I divide and repot my sweet violets for house culture. I use the double varieties Lady Hume Campbell, Marie Louise and Swanley White, and the single varieties California and Hardy Russian. I use long boxes about eight inches in depth, which fit in the window sill. Have perfect drainage of broken charcoal or crockery. I procure the richest of leaf mold from the woods and mix in a little sand and well-rotted chip manure, making a light, porous soil that the violet delights in, and this, unlike a heavy soil, can be kept sweet by frequent stirrings. After potting I water them well and set them away in a cool shady place until the first or middle of October. All buds I keep pinched off until November; then I give them a cool, frostproof room and all the sunlight possible. Liquid fertilizer I give twice a week, and this of course is never allowed to touch the foliage. Foliage is sprayed with a fine spray often, and I have thrifty plants and flowers in profusion.

Kentucky.

Miss Laura Jones. 
ANTIGONUM LEPTOPHUS AND ITS CULTURE.

Among the many vines which grow luxuriantly in Southern gardens I know of none more beautiful than the one we know as the Pinh Vine-the Antigonum Leptophus. The roots are hardy, and although the vine dies to the ground each winter, it starts into growth so vigorously with the first warm days, that in a very little while it will completely cover yorch or trellis. The leaves are cordate, large, and so exquisitely veined as to remind one of the begonia family, while they will retain their rich green color when everything else is turning yellow with. the heat and drouth of midsummer. It will climb anywhere, and is like the Virginia Creeper, in the gentle insistence with which it will force its tendrils into firm anchorage in the smallest crevice of the most unpromising surfaces. It shows at its best, however, when given a support of woven wire, long, strong and broad; it will soon form a thick screen of verdure, daintily throwing into relief the long, swaying racemes of bloom.

The cut blossoms make an ideal table decoration, when arranged in a clear glass vase, with sprays of dusty miller, or fronds of maidenhair fern.

\section{Georgia. Mrs. Henry Wrght.}

\section{TRAINING A VINING ROSE.}

Plant the rose in an open space on the lawn, allowing only one stalk to grow. Tie this loosely to a stout stake three or four feet high. When the vine has grown a few inches above the support, pinch off the end, which will cause it to throw out many side vines. Allow only those near the top to remain. As they become six or eight inches long, nip off the points, and the former process will be repeated. Continue training, and after a year or two there will be formed the most beautiful object imaginable. A dense, swaying mass of lovely green, reaching almost to the ground, crowned, in "rose time," with buds and blossoms in profusion. The training is a most important point, making of a neglected, straggling vine an object of perennial beauty. The idea of nipping off the ends is to secure as many vines or branches as possible, and thus produce a symmetrical form and many blossoms.

Pa. Mrs. Margaret D. Brown.

\section{HELIOTROPE FROM SEED.}

Heliotrope seeds germinate slowly, but, given proper care, are sure to grow and make stronger plants with larger clusters of blossoms than cutting plants. Fill a cigar box with light, porous soil, scatter the seeds thinly, sift over a light covering of soil, water carefully but thoroughly, and set in a warm place, a pane of glass over to retain the moisture. Keep moist, not soggy, and when the plants appear slightly raise the glass for ventilation. Give good light. When plants have two or three pair of leaves, transplant-carefully, or the leaves will drop-to small pots and to larger ones as needed, providing good drainage. They require asundant root room-never let them get pot-bound or dry out-are rank feeders, enjoying liquid manure, soap. suds and bone meal in reasonable quantities; but don't kill with kindness. When old, prune severely in spring. Their fine roots will form a dense mat, occasionally run a sharp stick through them before watering. Shower daily for red spider-an ounce of prevention is worth a pound of cure. Wood ashes or powdered charcoal given occasion. ally lightens the soil and brightens the color of the flowers. Gas is injurious to them.

California. Mary Kent Flint. 


\section{The Floral World}

PUBLTSHED MONTHLY BY THE

FLORAL WORLDCOMPANY, 12 to 14 South Limestone Street, SPRINGFIELD, ОhIo.

Subscription Price, 25 Cents a Year.

Entered as second-class matter at the Postoffice in Springfield, Ohio.

With the beginning of the fall months The Floral World greets its readers and wishes them all success in growing flowers and in all their other affairs as well. There are now more readers of our little magazine than ever before, and, while the publishers talie this as a sign of appreciation, they will not rest satisfied wits present attainments, but intend to malie the magazine so attractive and helpful that it will be indispensable to every lover of flowers. We all-the editor and every reader who sends in his or her experience in flower culture -are joint editors of the magazine. And this, we are persuaded, is what makes The Floral World so helpful. It is a practical periodical for amateurs. Its mission is to extend the cultivation of flowers by publishing only articles written by persons who succeed with flowers, and whose experience and advice will help amateur's. Every phase of floriculture that can possibly interest growers of flowers-indoors and out-is "up" for consideration in these pages. Every one is invited to contribute his or hei experience.

The monthly prize offer continues to hold good. We will give $\$ 26.00$ in prizes for the five best articles for publication in the November number of The Floral World which may be submitted by subscribers, and which comply with the few simple conditions stated further on.

The first prize will be $\$ 10.00$; the second, $\$ 7.50$; the third, $\$ 5.00$; the fourth, $\$ 2.50$; and the fifth, $\$ 1.00$. The

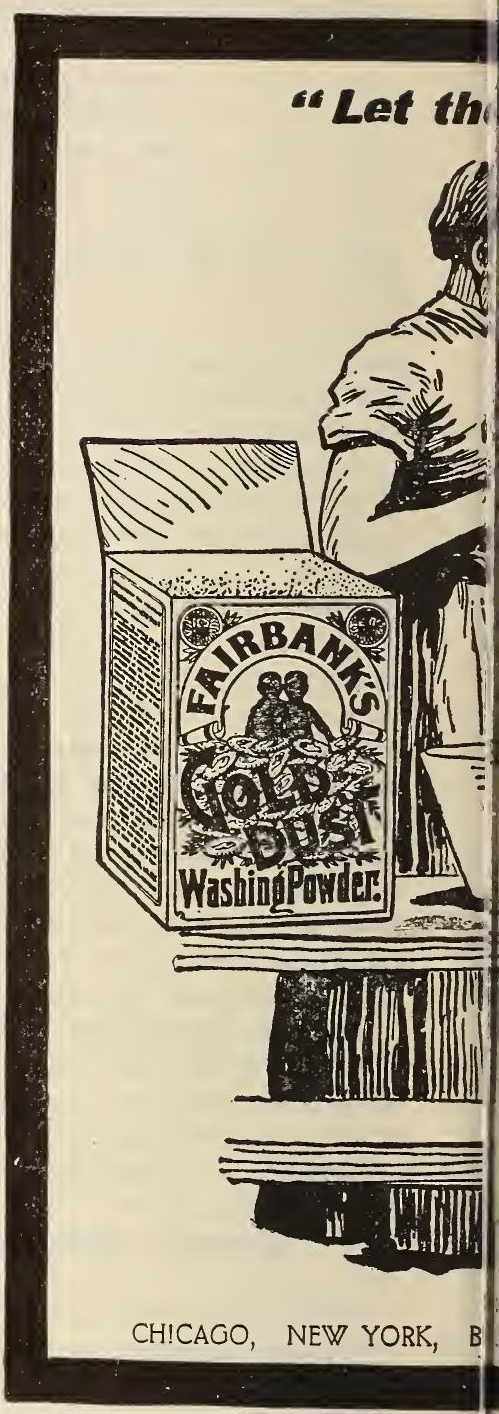

awards will be announced in our December issue.

No article which contains more than two hundred words will be considered. All contributions entered in this prize contest must reach us not later than October 1.

The purpose of these prizes is to secure for publication in The Floral 


\section{DARKEN YOUR GRAY HAIR}

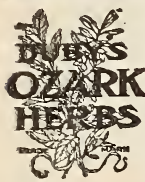

DUBY'S OZARK HELRS restore gray, streaked or faded hair to its natural color beauty and softness. Prevents the hair from falling out, promotes its growth, cures and prevents dandruff, and gives the hair a soft. prevents dandruff, and gives the hair a soft, glossy and healthy appearance. IT WILL NOT STAIN THE SCALP, is not sticky or copperas, or poisons oi any kind, but is com posed of roots, herbs, barks and flowers. It posed of roots, herbs, barks and flowers. It OMLY 25 CENTS TO MAKE ONE PINT. It will produce the most luxuriant tresses from dry, coarse and wiry hair, and bring back the color it originally was before it turned gray. Thene is more health to the hair in a single pack age of DUBY's DIARr HERBS than in all the hair stains and dyes made. Fvil size package sent by mail, postpaid, for 25 cents. Address DZARK HERB COMPANY, St, Louis, Ho.

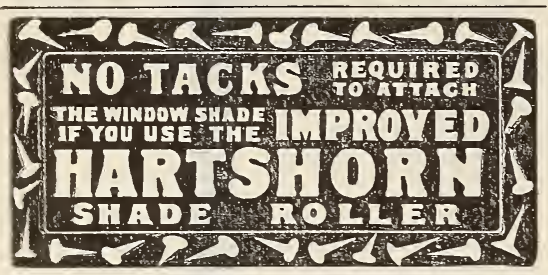

\section{BEAUTIFUL PLANTS}

Cacti, Succulents, Palms, Pot-Grown Prraits, Bulbs and Seed. Rare greenhouse plants of every description from the tropies; odd and curious plants for the lover of flowers. Beautiful catalogue free. Address

J. EDGAR TODD, Morris Park, L. I., N. Y.

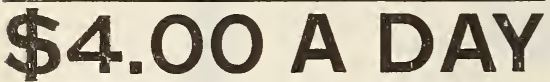

Easily Made at Home Weaving Rugs.

NO EXPERIENCE NEEDED.

If you are making $\$ 15.00$ a week or less, write for particulars at once.

REED MFG. Co., Box 12, Springfield, ohio.

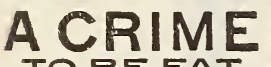

when for a 2 rent stamp, Mre. Louisa Lafierge, Times Building. New York, TO BEFAT will tell you how her \$1 prescription took 20 to 120 lbs. off each of over 6.000 men and Bcription took 20 to 120 lbs. off each of over 6.000 men and
romen. Most effective \& least expensive treatment ever offered. Lindorsid by United States Iealth Reporta.

\section{V Can Easily Make} 1. 5 weekly by representing us in her locality azd as the position is pleasant and profitable the year round we will gladly send particulars free to all. Even your spare time is valuable. This is no deception, and if you really want to make money sdaress WOMAN'S MUTUAL BENEFITCU., Box 21, JOLIL'T, 1 LL.

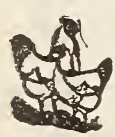

CDT RATES on all varieties EGGS and POULTRY. All varieties Fancy Pigeons and Belgium Hares Send for Rates and for 60-Page Book, which one and all, each and everybody Bargains are included. All for $10 \mathrm{c}$.

Add ess, J. A. BERgEY, Telford, Pa.

and Iiquor Habit Cured with. out inconvenience or detention from business. Write THE DR. J. I. STEPHENS Co., Dept. A-9, Lebanon, ohio.

98 PAll Per 100 for Distributing Samples of Washing

\section{SEPTEMBER NOTES.}

Prepare potting soil and drainage material and store up for winter use.

Scald old pots, soak new ones.

Spade around plants to be lifted from border, making ball of roots to fill pot. Pot after two or three weeks and growth will not be checked.

Give amaryllis new, rich top soil, plenty of water and sun.

Cut back pelargoniums; give smaller pots and shade until started.

Repot callas in rich soil.

Fertilize chrysanthemums weekly after bud's form.

Repot roses, cut back, watch for insects.

Order bulbs early; pot or plant immediately upon arrival.

Pot oxalis; supply water constantly.

Give freesias light, rich soil and cool, shady place outdoors till started, then give sun.

Pot and plant candidum lilies.

Pot balsams, petunias and other an. nuals in large pots for winter.

Transplant peonies into very rich, deep soil.

Cover bulb beds with straw, etc., to prevent thawing in winter.

Plant lilacs and weigelas.

Cut off seed pods from annuals to prolong blooming season.

Sow pansy seed for spring blooming; cover lightly through winter with leaves. Early flowers are largest.

Illinois.

MARY ANdRews.

The dahlias, chrysanthemums, roses and tuberoses are doing their best now. Prepare covers by first putting up stakes and drawing sacks over your plants when the nights get frosty and they will bloom till Christmas. Take up tuberoses, pot them and they will bloom till January. By plantins the Roman hyacinth, both in pots and bedis, the calla lily and other early flowering bulbs will come into bloom by the time the above gives out. Pot 
last of August for early flowers, and then every three weelis, with the large Dutch hyacinth, the tulips, the narcissi, and a host of other bulbs, the last to be planted in the beds, Christmas week, will give lovely blooms after all other bulbs are gone. The potted bulbs can be kept in a dark, cool place and brought up as needed. For a succession of flowers, give the calla a small pot or two large bulbs for a ten-inch pot, get muck, fill twothirds full, set the bulbs in and put in good garden soil. This will bring great, fine blooms. This muck is the best soil for all lilies, and if one rants blooms and not leaves, give a medium-size pot for all. These will give flowers from now till late spring. Georgia. Mrs. Mary MoCants.

All palms, ferns, dracaenas, geraniums and all plants that are intended for winter decoration and ulooming should have the top soil to the roots taken off, and rich soil of half coarse sand and garden soil with old manure put on. Water well and set in half shade till September, then bring in for a quantity of lovely flowers all winter. Pot the linum trigynum and fountain of gold this month. Take up the brugmansia and pot now, giving root room and plenty of water and sunshine; this will give you quantities of its great, fragrant belis all winter long. Try the schizanthus, sowing the seed any time from now on, for the lovely orchid-like clusters of flowers all winter. Cherianthus, sown now, will give one lovely sprays of wallflower-like blooms. If you wish the sweet old lilac and the showy hydrangea, take up now, with clump of soil, and put in cellar, where they will not get too cold, keeping damp and taking off all the leaves. If wanted' for Easter blooming, bring up a few weeks before wanted to warmti
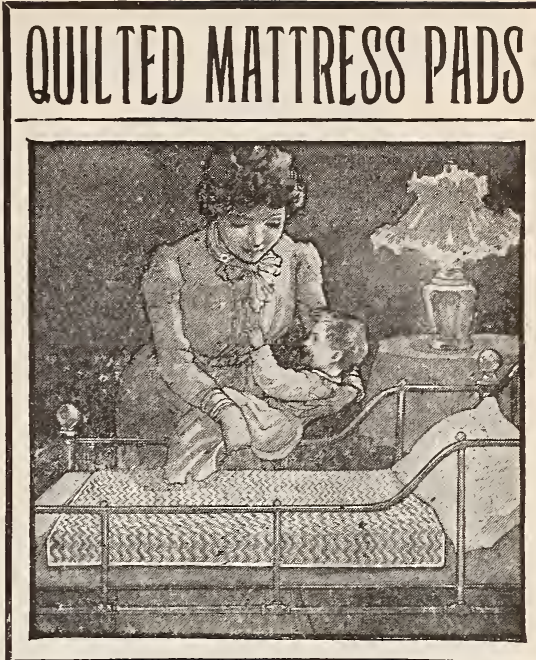

Fit your bed with a Quilted Mattress Pad and keep it in a cool and sanitary condition. A sound, refreshing sleep on hot nights will be made possible.

These pads are made of bleached muslin, both sides quilted, with pure white wadding of the best grade between. They wash perfectly.

Good as new after laundering, and the low cost places them within the reach of all.

SEND FOR SAMPLE

The Excelsior Quilting Co.

15 Laight St. NEW YORK.

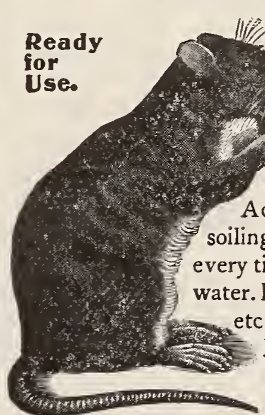

\section{Rat Bis-Kit}

Packed in boxes.

The only poison not dangerous to handle. Acts quickly, no mixing, no soiling of dishes, no trouble. Kills every time. Die in open air seeking water. Put in rat holes, linen closets, etc., without soiling anything. Rats and mice leave choicest grain and food for it. Why take risk of mixing poison?

Ask your druggist. If he hasn't it, send us 20 cents for one full size box, or 50 cents for three boxes, postpaid.

The Rat Biscuit Co., Dept. D, Springfieid, Ohio.

FOR THE KITCHEN

The Dandy Scraper fits and cleans

every pot, pan or dish. By mail,

10 cents. Agents wanted. Liberal Terms.

Address Dandy Mfg.Co.,Dept.B,Newark, N.J

LADIES, SCPERFLUOUS HAIR removed from the face, neck and arms. Harmless preparation, positively guaranteed. Receipt and full instructions sent securely sealed.One dime.Empire Nov.Co.,G.,Garrison, Tex 


\section{BULBS AND PLANTS} FOR WINTER

\section{GIANT ROSE COLLECTION}

\section{Our Selection, All Fine Sorts, For} Your Locality, Named

TEN CHOICE KINDS ONLY $50 \mathrm{c}$.

Three choice Hyacinths, different colors, 25 cents.

Twelve elegant Tulips, all colors, price 25 cents.

Thirty Crocus, assorted colors, price 25 cents.

Three large field-grown Carnations, price 25 cents

Five elegant Geraniums for house culture, price 25 cents.

Five finest Chrysanthemums, best for winter blooming, price 25 cents.

Five Fuchsias, splendid for the winter window-garden, price 25 cents.

Five flowering Begonias, the best, price 25 cents.

Three Rex Begonias, choiceselection, price 25 cents.

I hree Decorative Palms, price 25 cents.

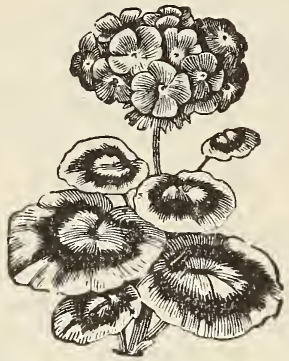

Send in your order to-day. Handsomely illustrated catalogue senc tree. Address,

GREAT WESTERN PLANT CO.

Box 60 . SPRINGFIELD, OHIO. and light, and they will soon be in bloom. This collection any amateur can grow, giving the culture of the geraniums and grown well, any one will be proud of it.

Georgia. Mrs. Allan Wamble.

\section{FLOWER CULTURE AS A MEDICINE.}

A young wife, almost an invalia through overtaxing her strength, was crdered by her physician to "live out of doors." In giving up her beloved occupations of reading and sewing, she fortunately turned to gardening, with much ardor and a little aptitude, and now, at an age when many find the pleasures of life palling upon them, she would earnestly recommend other delicate women to have recourse to the same source of health and good spirits.

One cannot bring against the cultivation of flowers the objection that it is a selfish enjoyment. Ah, no! The good angel of the household is she whose table and sitting-room are perennially graced with flowers. What token of sympathy with the mourner or invalid so speaking as blossoms, made tenfold more beautiful by the tender nurture of loving hands! Cultivate flowers, and you will reap a harvest richer and sweeter than idlers àream of.

M. S. H.

\section{CARE OF THE FUCHSIA.}

Some consider the fuchsia a delicate plant to grow and make bloom, but $I$ have never found it such. I have seven plants or trees, some are five years old, some two years old. started them from slips rooted in tin cans in a soil of sandy loam. The were left in these small cans until the soil was filled with roots, then shifted to four-inch pots filled with the same kind of soil, with charcoal in the bottom of the pots to insure good drainage. I give them plenty of light and

Dr. Bidaman's Safe Arsenic Complexion Wafers remove pimples, freckles, blackheads, and all blemishes of the skin. Make the complexion clear, transparent, rosy, smooth and soft. Used by noted beauties and actresses. Sample box sent on receipt of $\mathbf{2 5}$ cents in stamps. Corre-pondence absoluteiy confidential. DR. ISRA EL BIDAMAN, Established over Thirty Years. NEWTORK. 
the morning sun, water enough to keep the soil moist, but not real wet. When the pots get filled with roots the plants are again shifted to still larger quarters. They begin to bloom while in the four-inch pots. In the winter I put them in the cellar to rest, from which I take them in March and give water and light. As soon as they show signs of growth I cut them back to within two inches of the main stalk, repot them in fresh soil, after which they make rapid, healthy growth, and bloom until late in the fall.

Michigan.

M. В. Воотн.

SWEET PEAS.

I have made it a habit to have a bed of sweet peas every summer, putting them out as early as possible and planting where the morning sun will find them. Planting in latter part of March or first of April generally gives the largest and best results. My vines are over six feet in height. Prepare the soil by digging up five or six inches deep and mix thoroughly with wellrotted cow manure. Plant seeds about an inch deep and keep ground loose around the stalks until they are grown cuite high. I always fill ground around the stalks to keep them deeply rooted. This keeps them from dying off in August and September, when they should still be in their beauty.
Never allow them to suffer for water. Water in the evening. A liquid of manure poured close to the roots gives good results in having large flowers. Spraying with soap water after sundown is refreshing to the foliage and strengthens the bloom. The flowers must be cut nearly every two days; if allowed to go to seed the strength all goes to the seed pods. Have also had good results planting the seed in fall. Most of my flowers this year are double.

$\mathrm{Pa}$.

Perle Heitzenrater.

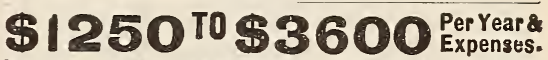
FOR HUSTLERS-BOTH MEN \& WOMEN

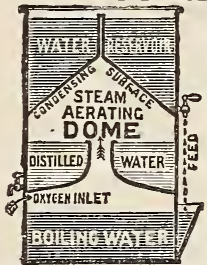

At home or traveling. Let us start you. Our Puritan Water Still-a wonderful invention. Great seller-big money maker. Enormous demand. Over 50,000 already sold. Everybody buys. It purifies the foulest water by distillation-removes everyimpurity. Furnishes absolutely pure, aerarer ed, delicious drinking water. vents fevers, sickness, doctor bills-cures disease. Write for NEW PLAN AND OFFER. HARRISON H'F'G CO., 12 Harrison Bldg.,Cincinnatt, 0.

FOR WOMEN Silver Moon Tablets are absoformula. Give quick, usually instant relief in all cases of disordered or delayed periods trum whatever cause. Thousands of women relieved by this wonderful harmless vegetable compound. At druggist's, or we will send postpaid a bottle of Silver Moon Tablets in plain

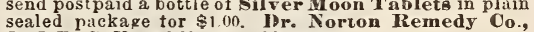
2.58 13. C. Franklin st., Chicago.

\section{LEARN PROOFREADING}

If you possess a fair education, why not utilize it at a genteel and uncrowded profession paying $\$ 15$ to $\$ 35$ weekly? Situations always obtainable. We are the original instructors by mail.

Home Correspondence School, Philadelphia

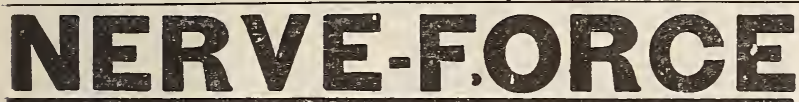

is a Home Remedy; a roble UNGUENT for external ap. plication. It is founded upon the principle that Suffering, Premature Decline and Pre:

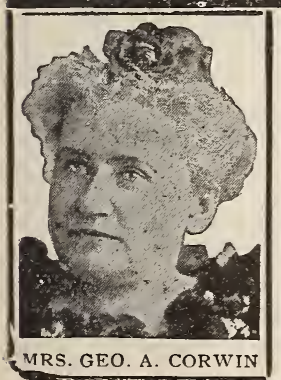

mature Death are the direct, and indirect, results of

\section{DORMANT CIRCULATION;}

that rescue can only be assured by its re-establishment by directly charging the controlling battery-cells with an element imitating the nerve force prepared for that purpose by Nature. This imitative element is our faithful NERVE-FORCE, and it will positively re-establish the most sluggish CIRCULATION to normal. It has won for us many Gold Medals for life-saving in the past twenty years. We do not, however, advertise it-but our NERVE-FORCE Journal which explains its every detail. We send this Publication free, in plain envelope, to as many addresses as you may send us.

We a ppeal especially to the "chronically ill" who are wearied and discouraged with "stomach dosing" as a means of warfare against Disease; to sufferers threatened with cruel "operations;" to men and women who, in spite of heroic efforts for cure, feel themselves steadily declining; to men and women who are victims of sedentary employment or excessive "brain exhaustion," and to those who have been cast aside as "incurable."

MR. and MRS. GEO. A. CORWIN, 1486 Mt. Morris Bank Building, NEW YORK CITY. 


\section{INQUIRIES.}

Will some reader tell me how to make tuberoses bloom? Iine have bloomed only once in six years.

Penn. M. Perle Heitzenrater.

Will the readers of The Floral World tell me how to care for the New Century Caladium during the winter?

Ohio.

D. P. O.

I have twenty-two roses which I expect to care for in the house during the winter. Can some one tell me what treatment they should have? Some of the varieties are Burbank, Ohio, The Queen, Admiral Schley, Bessie Brown, Helen Gould, Winter Gem and others. I would be glad also to know what to do with Australian Iille Oak.

Missouri.

i. O. P.
I have a hybrid tea rose seven years old, which has stood our winters fifteen degrees below zero, and has never failed to bloom until last year and this. It gets killed every winter almost to the ground, but comes out fresh in the spring with its loads of bloom. It has been growing in a dark, rather heavy mesquite soil until last year, when I took it up, in May, with a good lot of soil around the roots, and put it in a bed of vary dark marl and a little more sandy soil than it had been growing in. It has grown luxuriantly, throwing up new canes over two feet high, and the foliage looks rich and healthy, but never a bloom. Can some one give me a probable cause and cure? I have a violet bed cn rorth side of house, just common wood violets brought from the woods (Concluded on page 15.)

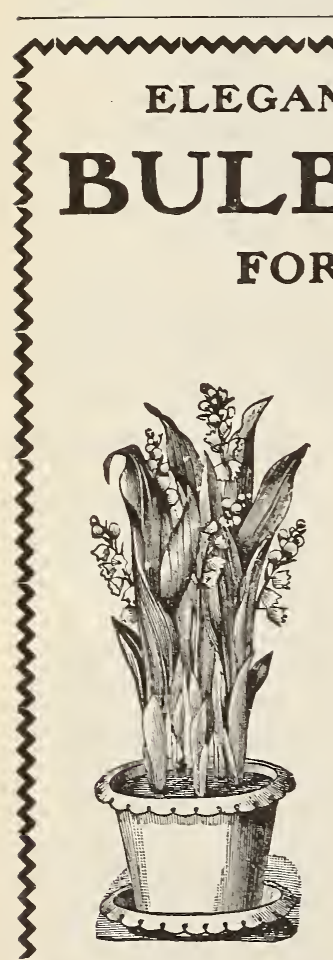

Set 1-12 Everblooming Roses, twelve colors - * 50c

Set 2-12 Prize-winning Chrysanthemums, all different 50c

Set 3-10 Lovely Fuchsias, all different - - $50 \mathrm{c}$

Set 4-10 Assorted Geraniums, single, double, scented 50c

Set 6-8 Lovely Eegonias, choicest kinds - - - 50c

Set 7-15 Choicest kinds of Narcissus - . . . 50c

Set 8-25 Lilies of the Valley, exquisite - • $\quad$ - 50c

Set 9-4 Chinese Sacred Lilies, or Joss Flowers - - 50c

Set 10-60 Crocus, in four kinds . - . . . $50 \mathrm{c}$

Set 1-:5 Parrot Tulips, all kinds - . - . . $50 \mathrm{c}$

Set 12-25 Double Tulips, all kinds - - - - $50 \mathrm{c}$

Set 13-25 Single Tulips, all kinds . - . - $\quad 50 \mathrm{c}$

Set 14-12 Vines and Plants for vases and baskets - 50c

Set 15- 4 Choice Decorative Palms, elegant - - 50c

Set 16-6 Carnation Pinks, ready to bloom - - $\quad 50 \mathrm{c}$

Set 17-5 Begonia Rex, all different - • • • 50c

Any three Sets for $\$ 1.25$; half of any one Set for $25 \mathrm{c}$; any five Sets for $\$ 2.00$

By mail postpaid, safe arrival and satisfaction guaranteed. Order by number. Catalogue now ready-write for it today. Address,

MISS ELLA V. BAINES, The Woman Florist Box 240. SPRINGFIELD, OHIO. 
INQUIRIES.

(Concluded from page 14.)

two years ago. The foliage is luxuriant and ciark, and is continually covered with seed pods, but they have never blossomed. If some one can help me in my trouble I shall appreciate it.

New York.

J. P. T.

I have a jasmine affinis, three years old, planted against a west wall. It grows abundantly from roots, but does not grow tall, and winter kills almost, or quite, to the roots. Does it need protection? Should most of the growth be pruned to make main shoots stronger? What treatment should it have this season? Can any Floral World reader help?

A rose, low-growing, pale-green, thrifty foliage, with blossoms peculiarly bright rose-colored, semi-double, or rather usually having two, perhaps three, rows of petals, opens wide showing great numbers of bright stamens, buds very beautiful, flowering season June, July, unusually long; flowers last long for those of that character. A friend tells me it is "An Old English Cottage Rose." Can any one name it from description?

An herbaceous perennial, three feet or more tall, the stems come directly from the roots and are set closely with rounded leaves, and at the top with yellow bells. Some one told me it was a "loose strife." If moneywort could stand upright, put its leaves all around its stems instead of flat, and make its whole coloring soft, it would look like my plant. Can any reader tell me what it is?

A blue-flowered plant with three queer, long, leaf-like appendages below the flower-buds. Some call it "spider wort," others "widow's tears." What is it?

British Columbia.

J. F. M.

\section{Send the Floral World to a Friend}

We desire the names and addresses of all persons who are interested in home flower growing. Send us the names of twenty-five of your friends whom you think would like to see a copy of THE FLORAL WORID, and promise us that you will write or speak to all of them about our little magazine, asking them to become subscribers, and we will give you absolutely free one year's subscription for any friend whom you may designate.

Address,

THE FLORAL WORLD, Springfield, Ohio.

\section{Make Your Money EARN MONEY}

Persons who have money to invest are invited to write us. We offer no extravagant profits, nor do we make improbable promises. Engaged in an established business, for the assuredly profitable extension of which additional capital is needed, we have for sale stock which bears a guaranteed dividend of

\section{SIX PER CENT}

PAYABLE SEMI=ANNUALIY

No higher dividends can be secured from any other investment of equal safety and character. Let us send you full particulars. Address

"INVESTMENT"

P. O. Drawer 755. Springfield, 0 . 


\section{SUGGESTIONS ALWAYS THANKFULLY RECEIVED.}

We are beginners in floriculture, and the experience of others, told in simple language, is what we require. ' 1 his The Floral World proposes to supply us for a small consideration, and we are glad to avail ourselves of the opportunity to increase its circulation in our community, knowing that it will increase the love of beauty and sense of order among our citizens, especially the young, and will finally result in much good to the community at large.

I would not favor having a children's department in the magazine, for the reason that all matter contained therein is simple enough to be understood by any child who can read or can listen with understandin $\gamma$ to the reading of others. If a child wishes to write, the idea of having her letter published beside those of "grown-ups," and read by them, would seem sufficient incentive. An editorial remark, as, Miss — is but ten years of age, yet she is quite entiusiastic, etc., would not come amiss.

A regular puzzle department often leads to the sacrifice of valuabie space to unworthy matter. An occasional puzzle of striking originality, however, under such a head as "For Nimble Wits," would interest many.

A special department of "Don'ts," or of "Things to Remember," would certainly be very useful if well edited.

Florida. Mrs. Lmlle Pleas.

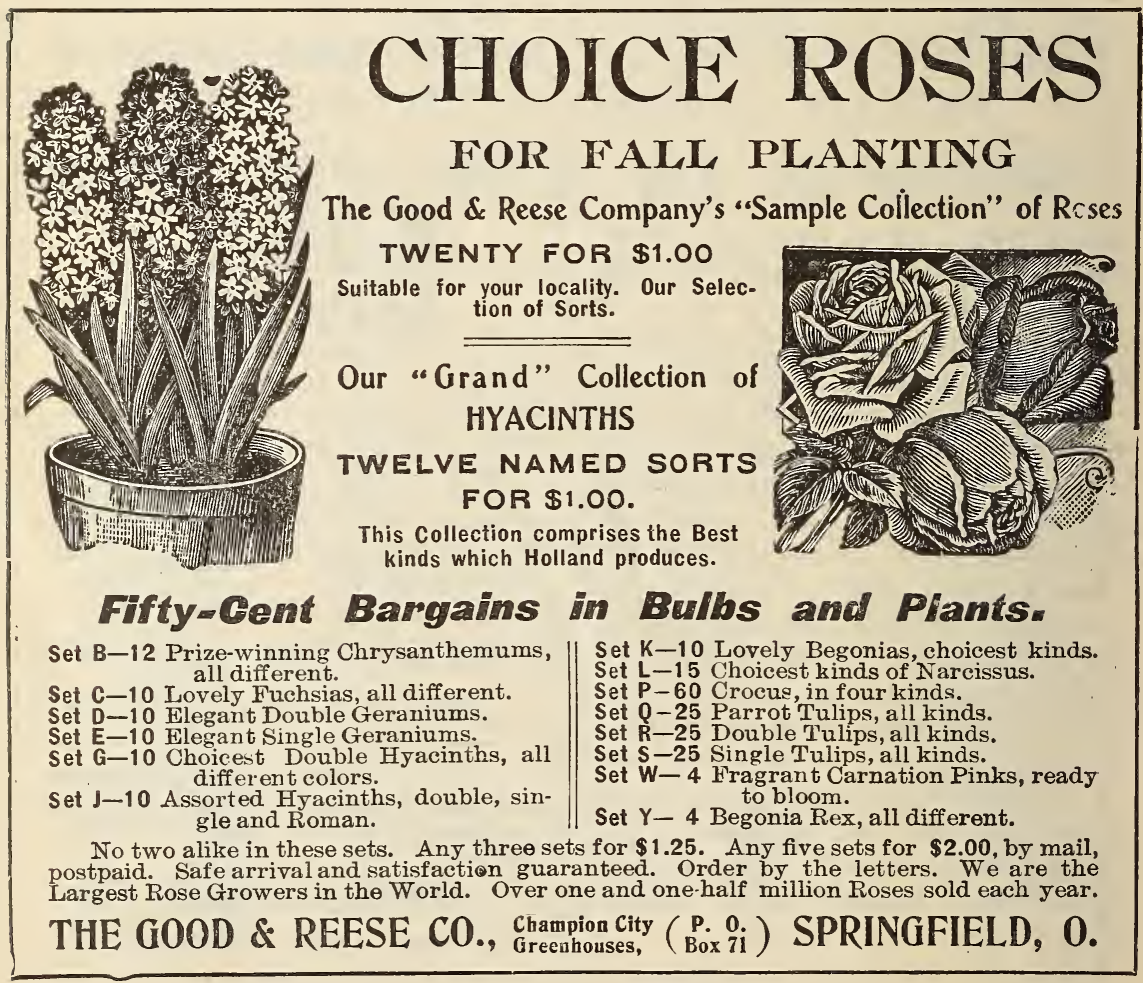


Sweet orange blossoms on the window shelf, pretty little green oranges in a prosperous state of growth, and several fat, ripe, rich, golden-yellow fruits, all of this on a little tree hardly measuring four inches in height, no more than four years old, and what is still more, blossoms, green and ripe fruits and plenty of buds-all of this at one and the same time-that ought to make every lover of plants feel like possessing one. How often have we looked at the picture of the Otaheite in the catalogues, read the description. shook our heads, turned a new leaf and spent the money for something else. Are they difficult to grow? Not if you know how! Give them such. soil as you give any other plant you wish to thrive well, and remember, the little tree can never be fed too highly. Give them all the sunlight you can, pick off the scales as soon as you discover them, and never let them get dust dry.

Wisconsin. Rev. F. P. Franke.

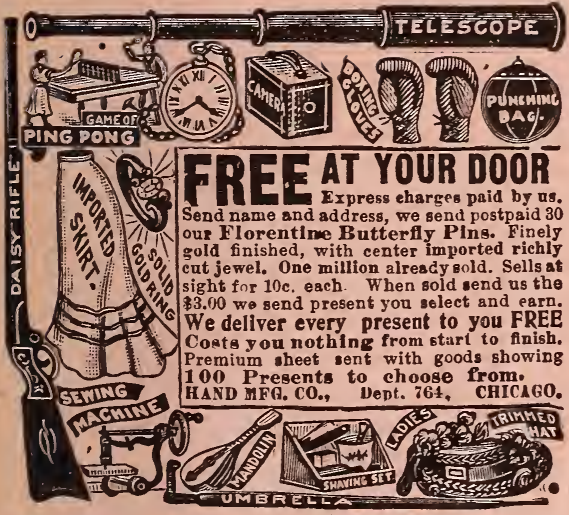

MADE \$105 THE FIRST MONTH

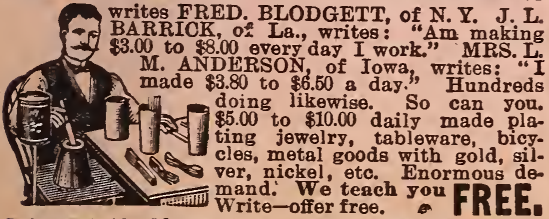

G. GRAY \& CO., Plating Works, A Miami Bldg. Cineinnati, 0 .

THE

Kola Plant CURES HAYYFEVER AND

ASTHMA.

FREE, The AfriRLE. can Kola Plant is nature's Positive Cure for Hay.

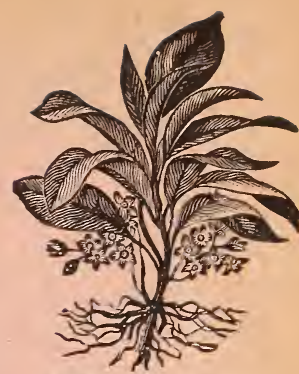

The Kola Plant.
Fever and Asthma. In the short time since its dis covery this remarkable botanical product has come into universal use in the Hospitals of Europe and America as an unfailing specific cure for Hay-Fever and Asthma in every form. Its cures are really marvelous. Dr. W. H. Vail, a prominent physician of St. Louis, Mo., writes March 8th, 1902, that he used Himalya on six different Hay-Fever patients last fall with satisfactory results in every case. Mrs. M. A. Scott, Crosby, Mich., writes March 6th, 1902, that Himalya completely cured her after fifteen years' persistent suffering of Hay-Fever and Asthma. Rev. J. L. Coombs, of Martinsburg, W. Va., wrote to the New York World, July 23rd, that Himalya cured him of Asthma of thirty years' standing. Mr. Alfred C. Lewis, editor of the Farmer's Magazine, Washington, D. C., was also cured, although he could not lie down for fear of choking, being always worse in Hay-Fever season. Hundreds of others send similar testimony proving Himalya truly a wonderful remedy. As the Kola Plant is a speciflc constitutional cure for the disease, HayFever sufferers should use it before the season of the attacks when practical, so as to give it time to act on the system. If you suffer from Hay-Fever or Asthma, in order to prove the power of this new botanical discovery, we will send you one trial case by mail entirely free. It costs you absolutely nothing. Write to-day to The Kola Importing Co., No. 1162 Broadway, New York.

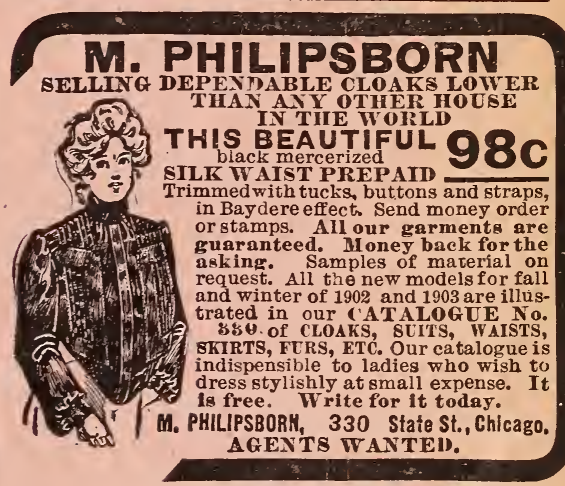

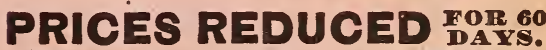

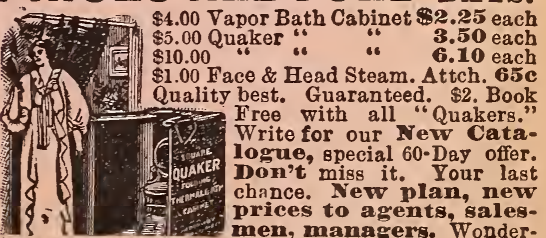
ful sellers. Hustlers getting rich. Plenty territory. World M'Pg Co., 97 World Bldg., Clncinnati, 0. 


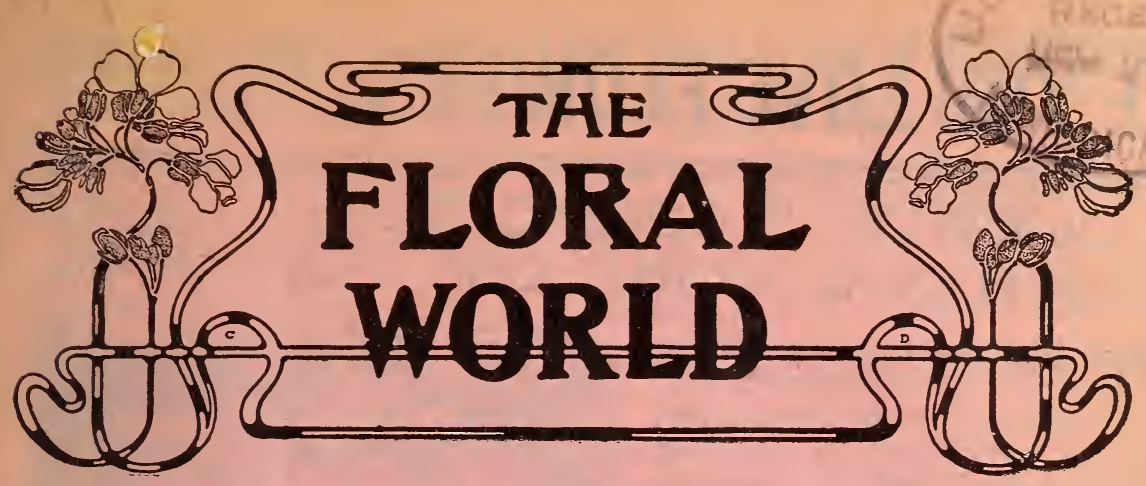

Vol. II. No. 2. Springfield, Ohio, October, 1902 25 Cents a Year

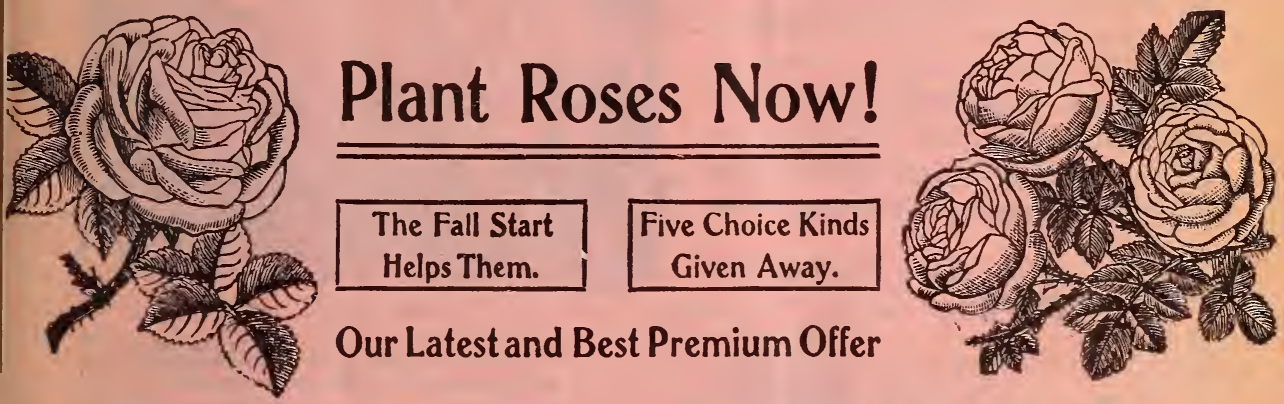

VOU may have THE Floral World one year and Five Choice Rose Plants, 1 assorted colors, for only 25 cents. . This is the regular subscription price of the journal, so you are getting the Roses $F \boldsymbol{R E} E$.

We wish to largely increase the subscription list of THE Floral World, and we wish to have our friends try fall planting of Roses. Many per $\mathbb{N}$, sons have found fall planting much better than spring

We recommend fall where the cold of the winter have never planted in the fall, on a small scale. Our splendid practically no cost. Remember:

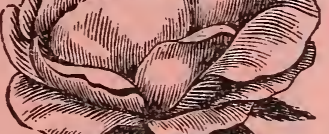
planting.

planting in all sections is not too severe. If you however, better make a trial offer enables you to do so at subscribe for THE FLORAL WORLD one year at 25 cents and we will give you Five Rose Plants FREE.

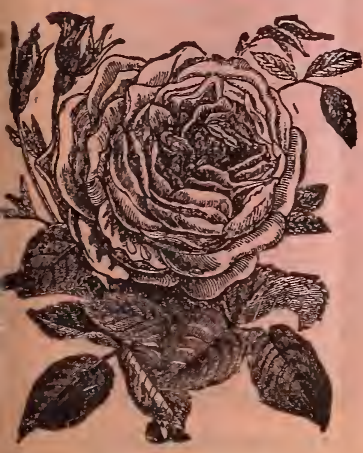

The Roses will be of assorted kinds and colors, especially selected to suit your locality. As far as possible we will send one white, one red, one yellow, one pink and one intermediate color. Five Choice Rose Plants and THE Floral WorLd a year for only 25 cents. Order at oncẹ.

\section{Address}

THE FLORAL WORLD, SPRINGFIELD, OHIO.

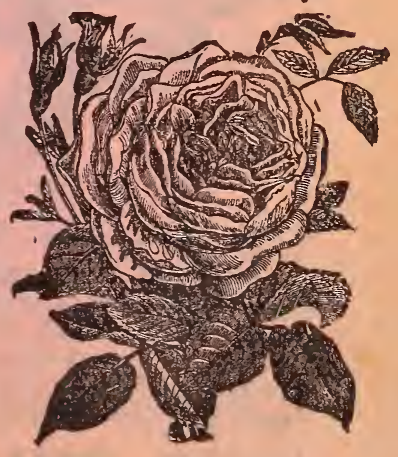




\section{IF YOU LOVE FLOWERS THIS OFFER IS FOR YOU.}

$* 20$ WINTER BLOOMING BULBS *
THE FLORAL WORLD ONE YEAR OIII 250 .

Eight Bermuda Buttercup Oxalis.

An unrivaled winter-flowering pot plant of easy culture. It is a strong and luxuriant grower with handsome foliage. The profusion of bloom produced in uninterrupted adundance for weeks is astonishing and delightful. The flowers are of the purest bright buttercup yellow. Properly treated the plants will flower in six weeks from the time the bulbs are set out. Well grown plants have produced as high as seventy flower stems at one time.

There are no finer flowers for window culture.
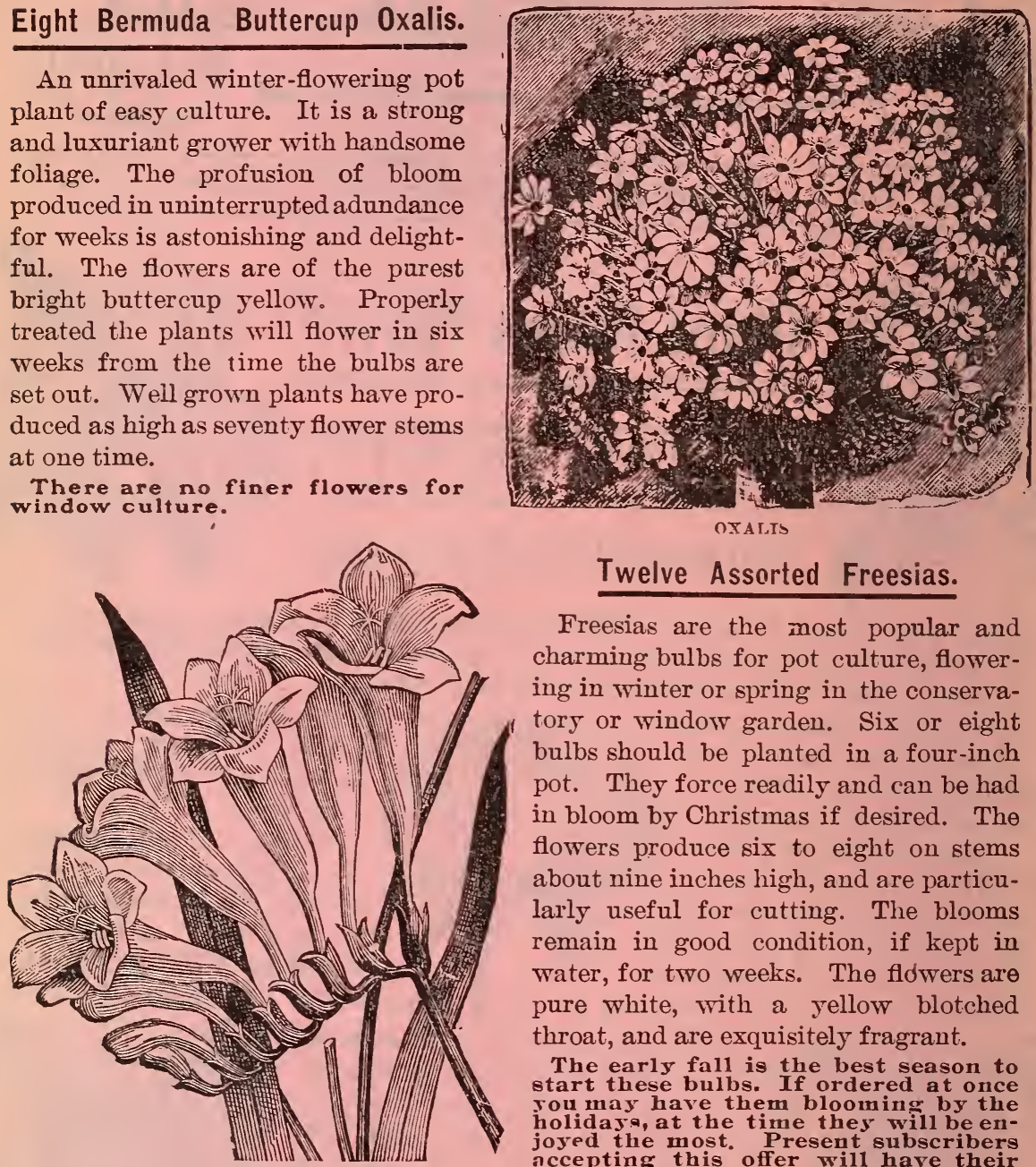

OXALIS

Twelve Assorted Freesias.

Freesias are the most popular and charming bulbs for pot culture, flowering in winter or spring in the conservatory or window garden. Six or eight bulbs should be planted in a four-inch pot. They force readily and can be had in bloom by Christmas if desired. The flowers produce six to eight on stems about nine inches high, and are particularly useful for cutting. The blooms remain in good condition, if kept in water, for two weeks. The fldwers are pure white, with a yellow blotched throat, and are exquisitely fragrant.

The early fall is the best season to start these bulbs. If ordered at once roumay have them bloomino by the holidaya, at the time they will be enjoyed the most. Present subscribers accepting this offer will have their time extended for one year.

\section{TWO MORE SUBSCRIBERS.}

We would like very much to have two more subscribers for Trie Floral WorLd from every one of our present subscribers, and there are thousands of them who could secure a club of two for us if they would only speak about it to their friends. If you will get two of your friends to accept this offer of The Floral World and Twenty Bulbs for $25 \mathrm{c}$., we will send you the collection of bulbs free, postage prepaid. A little effort will secure them. Order as Premium 1. 


\section{THE PRESS PUBLISHING ASSOCIATION OFFERS \$25,000 CASH PRIZES}

To be distributed among successful estimators of the total vote for Governor in the States of New York, Pennsylvania and Michigan on the 4th day of November, 1902.

The money, $\$ 25,000$, has already been deposited in the Central Savings Bank, Detroit.

\section{CONDITIONS OF THIS GREAT CONTEST.}

Any one sending us only 25 cents for THE FLORAL WORLD one year and an estimate of the total vote of Governor in New York, Pennsylvania and Michigan on November 4, 1902, will receive a certificate which will secure for him anj prizes his estimates entitle him to claim, provided no other premium is taken.

You may estimate as many times as you desire by sending us only 12 cents with each additional estimate. An investment of a few cents and careful study may bring you $\$ 10,000$.

The contest will close at midnight, November 3, 1902, and no estimate received after that hour will be allowed. The official certificates of the Secretaries of the three States, showing the total vote for Governor, will determine who are entitled to the prizes, and the awards will be made by a disinterested Committee of prominent judges, just as soon as the official figures can be obtained.

\section{HERE IS THE LIST OF PRIZES.}

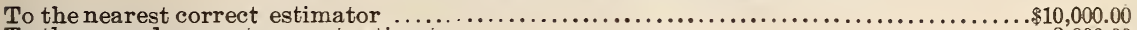

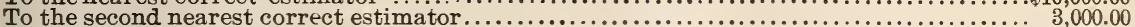

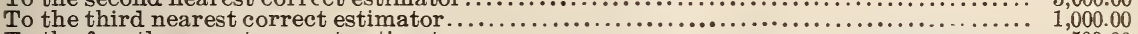

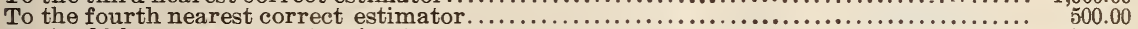

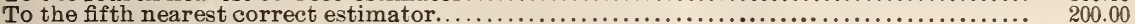

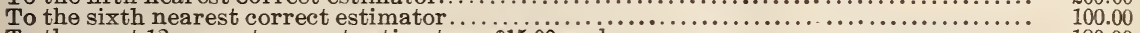

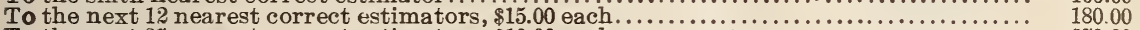

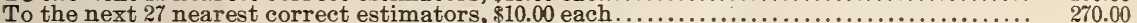

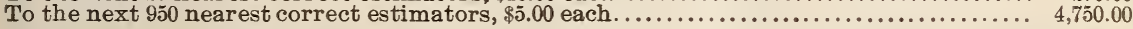

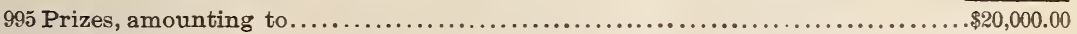

The following Special Prizes will Also be Paid:

For the nearest correct estimate received before August $1,1902 \ldots \ldots \ldots \ldots \ldots \ldots \ldots$ For the nearest correct estimate received on or after August 1, and before August $15 \ldots \ldots 1,000.00$ For the nearest correct estimate received on or after August 15, and before Sept. 1...... 1,000.00 For the nearest correct estimate received on or after Sept. 1, and before Sept. $15 \ldots \ldots \ldots .1,000.00$ For the nearest correct estimate received on or after Sept. 15, and before Oct. 1......... 1,000.00

Total 1,000 Prizes, amounting to.

$. \$ 25,000.00$ In case of a tie or that two or more estimators are equally correct, prizes will be divided equally between them

\section{VALUABLE INFORMATION.}

To aid in forming your estimates we furnish the following data:

Pennsylvania elects a Governor only once in four years. Michigan elects a Governor every two years, and since 1894 New York has elected a Governor every two Jears.

The total vote for Governor in New "York in 1891 was.
The
The

The total aggregate vote for Governor in these three states in 1894 and 1898, the Jears in which all three states elected Governors at the same time, was as follows:

In 1894 the aggregate unte for Governor in these three States was 2,645,616.

In 1898 the total aggregate vote for Governor in these three States was 2,752,091.

What will the total aggregate vote for Governor in these three States be on November 4 , 1902? Figure it out or guess at it, and send in your estimates. It may mean $\$ 10,000$ in cash to you. The official certificates of the Secretaries of the States of New York, Pennsylvania and Michigan, showing the combined total vote for Governor in these three States, will determine who are entitled to the priz $: s$, and the awards will be made by a Committee of prominent judges within twenty days after the official vote is known.

Be sure to include your estimate in plain figures when remitting. 


\section{SPLENDID COMBINATION OFFERS.}

5 ROSES,

20 BULBS,

FLORAL WORLD

for one year all for 40 cents. $\$$ sending us only 40 cents.

5 This offer is the combination of the Premium of 5 Roses described on first 9) cover and the premium of 20 bulbs described on second cover. These two pre.) miums and The Floral World for one year will be mailed postpaid to any one

5 ROSES,

20 BULBS, 10 PRIZE ESTIMATE, 5 on second cover and one estimate in the
ond FLORAL WORLD great contest explained on page one. for one year all for 50 cents. $\$$ sending us only 50 cents.

6 This offer is the combination of the 2) premium of 5 Roses described on the first 2) These three premiums and the Floral World for one year postpaid to anyone

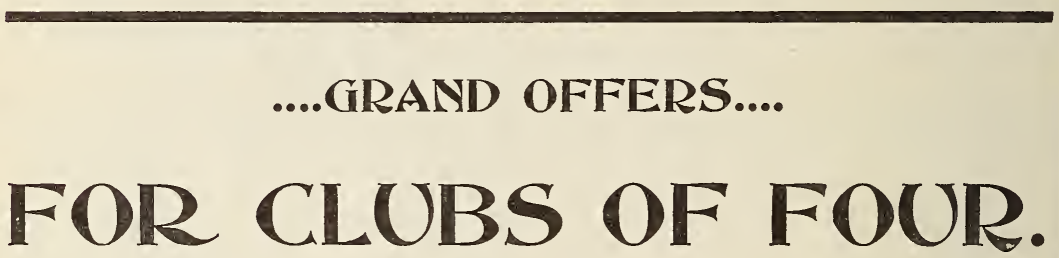

The next two pages are devoted to collections of plants and bulbs, any one of which will be sent postpaid to a person sending us a club of four subscribers for The Floral World. Persons accepting any of the preceding offers of the magazine and premium at 25 cents or the combination offer at 40 cents or the combina tion offer at 50 cents may be counted in a club. You will be surprised how easy it is to get up these clubs of four. We want thousands of these clubs of four, hence these liberal offers. Address,

THE FLORAL WORLD, Springfield, Ohio. 


\section{Premilum C'ollections for C'LUBS' OP FOUR}

Any Person Accepting Any of the Offers on the FIRST FOUR Pages of this Number may be Counted in a Club

\section{Premium No. 2.}

\section{LITTLE DAISY COLLECTION}

of 25 Bulbs for Winter Flowering

One Large Flowering Hyacinth.

Five Crocus, all different.

Two Beautiful Tritileas.

Three Lovely Tulips,
Four Freesias, delightfully fragrant. One Elegant Narcissus.

Four Snowdrops.

Five Beautiful Buttercups Oxalis.

\section{Premium No. 3. OXALIS-Mixed.}

25 Beautiful Winter.Blooming Oxalis

Mixed Colors, including Rose, Single Yellow, Pink, White, Double Yellow, and Bermuda Buttercup,

\section{Premium No. 4.}

Princess Royal.

Prince of Waterloo.

\section{Premium No. 5.}

Anna Carolina.

Alba Superbissima.

\section{Premium No. 6.}

Murillo.

Yellow Rose.

La Candeur.

Gloria Solis.

Count of Leicester.

Rose Blanche.

\section{Premium No. 7.}

Murillo.

Yellow Rose.

La Candeur.

Gloria Solis.
OUR SUPERB COLLECTION

of 4 Choige Named Double Hyacinths

Bloksberg.

Bouquet Royal.

OUR GRAND COLLECTION

of 4 Choice Named Single Hyacinths

La Peyrouse.

Gigantea.

DOUBLE TULIPS.

12 Choice Named Double Tulips.

Rosina.

Rex Rubrorum.

Agnes.

$\mathrm{Ma}$ Cousine.

Alba Maxima.

Queen Victoria.

\section{EARLY SINGLE FLOWERED TULIPS.}

Count of Leicester.

Rose Blanche.

Rosina.

Rex Rubrorum.
Agnes. $\mathrm{Ma}$ Cousine. Leonard de Vinci. Rose Gris de Lin. 


\section{Premium C'ollections for C'LUBS' OP FOUR}

Any Person Accepting Any of the Offers on the FIRST FOUR Pages of this Number may be Counted in a Club

\section{Premium No. 8. CARNATIONS.}

Mrs. Fisher.

Rose Queen.

Premium No. 9.

Glory of the Pacific.

Mrs. O. P. Bassett.

Ivory.

Mrs. J. Lewis Childs.
UP-TO-DATE SET OF CHRYSANTHEMUMS.

\author{
Golden Wedding. \\ Mrs. H. Weeks. \\ Mrs. Egan. \\ Eda Prass.
}

Genevieve Lord.

Armazinda.

\section{Premium No. 10. GERANIUMS FOR WINTER BLOOMING.}

White Swan.

Mrs. Hamilton.

General Grant.
Fire Brand.

Arbutus.

Crystal Palace Gem.
Galilee.

Bronze Bedder.

\section{Premium No. 11.}

Nephrolepsis Bostoniensis.

Weeping Lantana.

Jasmine.

Revolutum.

\section{Premium No. 12.}

White Maman Cochet. Cloth of Gold.

Pink Soupert.

\section{VARIETY OF PLANTS}

For the Window Garden.

New Single Violet, California. Lady Hume Campbell. Sanseviera Zeylanica. Alternanthera Aurea Nana.

\section{Premium No. 13. BEGONIAS AND FUCHSIAS.}

Marguerite.

Argentea Guttata.

\section{ROSES FOR FALL PLANTING.}

Frances E. Willard. Catherine Mermet.
Safrano.

Pink La France. White La France.

GIVE NUMBER OF COLLECTION WHEN ORDERING. Address, THE FLORAL WORLD, 


\section{The Floral World}

A Fournal of Home Floriculture

\section{COMPLIMENTARY.}

The September Floral World was decidedly the best number we have had.

Kentucky.

Miss Laura Jones.

We have been taking The Floral World for some time and have gained many valuable hints from it.

Ohio.

G. W. Porter.

We are much pleased with The Floral World. We take two copies, so we can hand one to the neighbors.

Illinois.

ANNIE J. PADDICK.

We are well pleased with your little monthly, because it is simple, practical and helpful, which is more than can be said of some floral journals. May it continue so.

Indiana.

\section{EMMA MEYER.}

I am glad to add my opinion to that of so many flower lovers, in expressing my approval of the conduct of The Floral World. I hope you will always keep it strictly floral, and that it may last as long as I do.

Kentucky. Mrs. A. F. Hurst.

\section{CLEMATIS PANICULATA.}

The clematis is the prettiest and sweetest vine I have. It is nearly fifteen feet high, tacked to the house. It blooms the first of September, and looks like a cream-tinted snowbank, and is sweet. I have counted hundreds of bees resting on its white, sweet flowers. It is nice for bouquets, funerals, weddings, churches, home and cemetery planting, easy to grow and very hardy.

I think it best planted in the fall; it then sets a few new roots and thereby starts earlier.

It is so pretty for fence drapery, and no insect bothers it. I give mine a bucket of water daily at its roots.

This fall flowering vine belongs to the Crawford family.

Illinois.

AnNie J. PADdICK.

\section{CLEMATIS ALL THE YEAR.}

Handsome clusters of bloom, of the large flowered variety, so seldom seen in our hot city yards, can be had by taking small roots and planting them in bottomles's corn cans, filled with rich soil, and then pressing the bottoms back again, to prevent the soil from falling out, and hanging them two or three feet from the ground to insure air to the plants. This spring I bought two roots of jackmani and planted them as described and hung them in wire baskets, on a brick wall, on stout spikes driven into the brick firmly, in an eastern exposure. The brick was covered with a fresh woodbine for a background. The plants grew rapidly up there and soon put out a budded vine two yards long. Although at first the small amount of soil was all the roots required for healthy growth, now to continue the vines on to perfection of bloom and later growth they must be refreshed with more, without being disturbed. So I took gallon cans and painted them 
green and filled them half full of the same rich soil and slipped the loose bottoms of the original cans out and set them on this new soil, without disturbing the plants in the least. They responded with a bound, so to speak, and rich clusters of twelve large purple flowers on each vine was the result of the experiment. In the late fall I will set the cans in a cool cellar for an early start next spring.

New York.

\section{A BULB BED.}

Along the foundation, at each side of our house, we have a long, narrow bed, slightly elevated. The soil is ordinarily good garden soil, mixed with sand. In it we grow white and pink tulips and light blue single hyacinths, with a border of white crocus. The tulips, cottage maid, rose luisante, l'immaculee, murillo and salvator rose, are the prettiest in this dainty bed. For the summer it was planted with mixed dianthus.

Both for beauty and as a mulch, mixed phlox would be good.

On the north side of the house we dug out a bed to the depth of sixteen inches, filled in first with broken crockery, tinware and old shoes; then ordinary soil; next, a two-inch layer of charcoal; after that, good garden soil well enriched with very old manure. In this bed we planted lilies, each bulb in a litle nest of sand.

Lilium auratum, spec. album and rubrum and L. longiflorum thrive and bloom beautifully. I have never succeeded with L. candidum, but shall try again.

A fine clump of funkia alba at one end, hemerocallis flava at the other, and ferns growing between the tall lilies make this bed very beautiful.

Last fall we invested in bulbs for winter blooming. We kept to the old reliable hyacinths, tulips and narcissus. We planted no mixtures; always three or five of a kind in a pot, except the Dutch hyacinths; they were potted singly.

The Roman hyacinthis were lovely; Dutch hyacinths very fine; of narcissus we wished we had more, especially Von Sion.

But oh, the tulips! Some were gorgeously, others exquisitely beautiful. Rose luisante was my favorite. Rosine is dainty and pretty; salvator rose beautiful, tournesol yellow extra good, fine flower, neat growth, Mon Tresor, very fine; Rembrandt and vermillion brilliant, very good scarlet sorts; Pottebaker white is almost as beautiful as a lily. Proserpine surprised us; the catalogue describes it as violet rose; ours was a rich color, almost a pure crimson. I must have them by the dozen this year.

They were so easy to grow. We simply potted them in rich, mellow garden soil, with an inch of charcoal for drainage. They were placed in the cellar in a box covered with a window screen to keep out mice, left in the cellar for six weeks or longer, and watered once a week. Friendis, try growing tulips!

Indiana.

EMMIA MEYeR.

\section{STOWING AWAY THE SUMMER FLOWERING BULBS.}

For a number of years I have tried several methods of keeping my summer flowering bulbs over winter, and find that the majority of them must be kept perfectly dry. The caladium, if kept moist, will rot every time. If placed in a box of dry sand and box raised above floor of pit or cellar, they will come out sound and healthy in the spring.

Last winter I kept my bulbs of spotted calla, gloxinia and tuberose in the self-sealing tin cans. I put a thick 
layer of perfectly dry sand in bottom, and covered up with sand, then pressed the tin top on tightly and set in a dark corner of pit. When ready to start into new growth in the spring, I found them perfectly sound, and they had not been disturbed by either rot or insects. The tuberous rooted begonia, I found, will winter best in dry sand.

The dahlia bulbs seldom decay, even when quite moist. My German neighbors who have neither cellar nor pit, bury their dahlia tubers with the potato, in the garden and they come out sound and plum, in the spring. The canna will keep best in dry sana.

Kentucky. Miss Laura Jones.

\section{AMARYLLIS JOHNSONII.}

Last winter we bousit an amaryllis bulb. When we unfrlded the package there was a large, mammoth bulb with one flower stalk visible. We soon potted it in grainy loam from an old, decomposed clover fifld. We used an inch of pulverized charcoal for drainage, planted it carefully with about a fourth above the surface, and not a root was severed. It never checked growth, but grew right on, and in six days it started another stalk on the other side of the bulb.

It grew 18 inches high, with eight large crimson flowers. We then placed it in a tolerably cool room to save the bloom longer.

After it bloomed we clipped off the pods. It then soon commenced to grow leaves.

We have kept it growing, and today it has twelve large leaves, and one of the lower ones is turning yellow. Do you know what that means? Rest, from now till nearly spring. Let it rest till it has had enough.

We will give it enough moisture to keep the bulb from shrinking, and no fertilizer.
This rest is just as natural as for you to sleep.

Never place amaryllis bulbs in a cold, damp cellar. Better place them upstairs through the winter.

While bulbs are growing they need a little plant food; it darkens and lengthens the leaves and builds up the future flowers.

Plant in October or November. They are very tender plants and they love sunshine and much water while growing.

IIl.

Axnie J. PADdicK.

\section{LUCK WITH FLOWERS.}

My friends' say, "You have such luck with flowers." If I depended on luck I would not be very successful. To grow flowers well you have to give them intelligent care. You must study them; for I find they are like children, with different tastes and disposition's.

These differences I have learned by experienca in some cases; but a less expensive and much quicker way is to read the experience of others, in a good floral magazine, such as The Floral World.

I have been taking it from the first number, and have learned many things from it.

Then I send for one or two reliable catalogues and study them. My friends ask, "How do you know all the names so well?" I learn them one by one. That is the only way.

I see a plant recommended in an article; I look it up in the catalogue; very often send for it, and by that time I have learned the name thoroughly.

Flowers also require systematic care. You cannot neglect them part of the time and make it up some other time.

$\mathrm{Pa}$.

Mrs. M. E. SHUFF. 


\section{The Floral World}

PUBLISHED MONTHLY BY THE

FL・RAL WORLD COMPANY, 12 to 14 South Limestone Street, SPRINGFIELD, OHIO.

Subscription Price, 25 Cents a Year.

Entered as second-class matter at the Postofice in pringfi eld, Ohio.

We will give $\$ 26.00$ in prizes for the five best articles for publication in the December number of The Floral World which may be submitted by subscribers.

The first prize will be $\$ 10.00$; the second, $\$ 7.50$; the third, $\$ 5.00$; the fourth, $\$ 2.50$; and the fifth, $\$ 1.00$. The awards will be announced in our December issue.

No article which contains more than two hundred words will be considered in the prize decision. All contributions entered in this prize contest. must reach uis not later than November 1.

The purpose of these prizes is to secure for publication in The Floral World matter which gives the actual experiences in flower growing of those who have subscribed for the journal. Prizes offered for articles published in the September number have been awarded as follows:

First Prize-Mrs. Mary McCants, Georgia.

Second Prize-E. C. Beebe, Connecticut.

Third Prize-Mary Kent Flint, California.

Fourth Prize-Mrs. W. G. Delashmutt, Illinois.

Fifth Prize-Mrs. L. A. Coolidge, Massachusetts.

\section{THE DIAMOND FLOWER.}

Indeed, a little plant, and, strange to say, little known. But no lover of flowers should be without some seed of this pretty, as the name indicates, little and so easily grown flower, at any time of the year. Those of The Floral World readers who cultivate bulbs for the winter window garden could greatly improve the looks of the hyacinths, tulips, narcissus, etc., by spraying a few seeds of the diamond flower on top of the soil of their pots, when they are taken out of the cellar, closet, or dark room, where the bulbs were stored to make roots, and by the time the bulbs are forced to bloom, the soil will be covered with numberless little diamonds, giving the whole a sweet effect.

It grows only a few inches high, spreads and buds rapidly, and it is hard to tell whether the leaves or the flowers, which it throws out abundantly and continually, are the prettier.

It is pretty anywhere, by itself in masses, with other plants as a groundwork, and last, but not least, for borders, carpet beds, etc., in the summer garden. I have also seen it largely used where it has one advantage over many rivals. It thrives and blooms regardless of ice and snow.

Wisconsin. REV. F. P. Franke.

\section{FAIRY LILIES.}

Some years ago I was the guest for a few hours of a young wife whose home was "over the hills and far away" from town life. She showed me, with pride, her well-made and well-stocked flower garden, and described in glowing terms the beauty of her fairy lilies. On my departure she presented to me a package of the precious lily bulbs. Mother planted them in her rich and well-prepared flower bed. Long slender leaves sprang up, but not a bud rewarded our search. One bright morning we found the pink lilies, fairy, indeed, for the flower stalk sprang directly from the dark earth, and it seemed they had blossomed in "a night." Their pink love- 


\section{"Let the GOLD DUST twins do your work"}

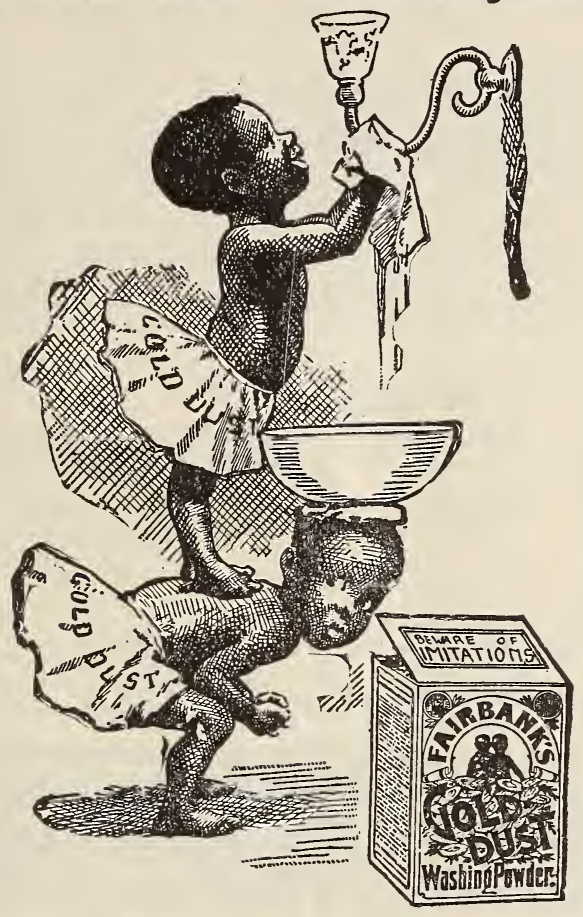

Are you a slave to housework?

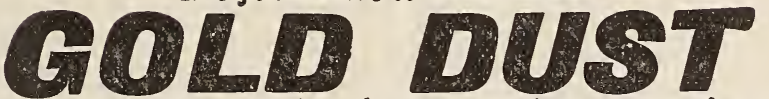

has done more than anything else to emancipate women from the back-breaking burdens of the household. It cleans everything about the house-pots, pans, dishes, clothes and woodwork. Saves time, money and worry.

Made only by THE N. K. FAIRBANK COMPANY,

Chicago. New York, Bosion, St. Louis, San Francisco, Montreal.-Makers of Oval Fairy Soap.

liness ever recalls the sweet, eager face of my young stranger-hostess as she described her cherished flowers.

When only a "memory" and a green mound was left of one inexpressibly dear to us, the suggestion was proffered that the sacred place be encircled by the fairy lilies in imitation of the beautiful act of the loving Undine, who caused a stream of silvery water to surround the green home where reposed all that was mortal of one she dearly loved.

New York. Linda L. KimbaLL.

\section{"Not a flower}

But shows some touch in freckle, streak or stain

Of God's unrivalled pencil."

-Cowper. 


\section{Nhe "Monte Carlo"}

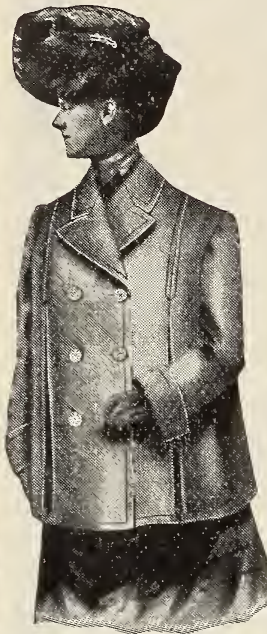

Fashion's latest and most stylish in $\mathrm{tr}$ od uction. Made 27 -inches long - from fine Wool Kersey, satin-lined across the shoulders-an exceedingly wellmade and stylish garment. Colors black, navy Castor and $\tan$

Price $\$ 7.75$

Same garment, 34 inches long,

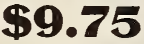

\section{Express Prepaid}

when money accompanies order. Absolute satisfaction guaranteed or money refunded.

NOW READY—OUR NEW FALLCATALOGUE No. 120-Send for It-It is Free.

American Cloak \& Fur Co., 176 State Street, CHICAGo.

\section{BE BEAUTIFUL}

Dr. Bidaman's Safe Arsenic Complexion Wafers remove pimples, freckles, blackheads, and all blemishes of the skin. Make the complexion clear, transparent, rosy, smootb and soft. Used by noted beauties and actresses. Sample box sent on receipt of $\mathbf{2 5}$ cents in stamps. Correspondence absolut 15 confidential.

DR. ISRAEL BIDAMAN,

Established over Thirty Years. NEWYORK.

$\$$

$\$ 2$ PROFIT

\section{FROM} HALF AN ACRE OF

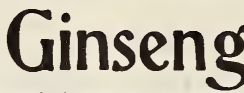

was made in one year. Demand is increasing. Easily grown and hardy everywhere in the United States and Canada. Can be grown in small gardens as well as on farms. Most profitable crop known. Cultivated roots and seeds for sale. Send four cents to help pay postage and get our complete book telling all about this wonderful GINSENG. CHINESE-AMERICAN GIN. SENG C0., Department N, JOPLIN, MO.

PAY 920 WERT AND EXPENSES to PAY $\$ 20$ A WEEK men with rigs to introduce our Poultry Compound. Send stp. JAVELLE MFG.CO.,Dept. 51, Parsons,Kans.

TAST WORK At home in spare Fither sex. No canvassing. Nours. \$3 per day. SOLAR Co., Providence, $\mathrm{R}$. I. $\$ 8$ PHID Per 100 for Distributing Samples of Washing
SELECTING BULBS.

In potting our bulbs for winter blooming, as many of us are now doing, it is to our interest to make a selection that will give us both quality and quantity. There is one plant answering both requirements that we seldom see-the buttercup oxalis. But to have it once is to have it always, for it is one of those little beauties you cannot help but love. The bulb looks just like the kernel of a hazelnut, but it will grow flowers and foliage enough to fill a five-inch pot, besides leaving enough bulbs for a dozen pots for the next autumn. It can be planted any time during the autumn, in ordinarily rich soil, and if given plenty of sunshine and water will grow luxuriously. The leaves are like a fourleaved clover, freckled over with dark brown spots, while the flowers reaching up over them in clusters are of that beautiful shade of yellow of the old Scotch rose, and as deliciously sweet scented. I like a lot of the bulbs planted together and a pan of them on a stand in a sunny window makes a very pretty sight, indeed.

New York. Mrs. Nelson PuFF, JR.

\section{THE CALADIUM.}

There is a good-natured rivalry in our town in regard' to growing the Caladium Esculentum. From the dominie, down to the dressmaker, each tries his hand, seeking to excel his neighbor in the size of this grand and stately plant. In a mound upon uur lawn, one superb specimen looks out upon his flowery kingdom as proudly as did King Edward during his coronation.

This monarch, like the other, is attended by "scarlet-coated pages"sometimes called geraniums - mor

(Concluded on page 11.) 


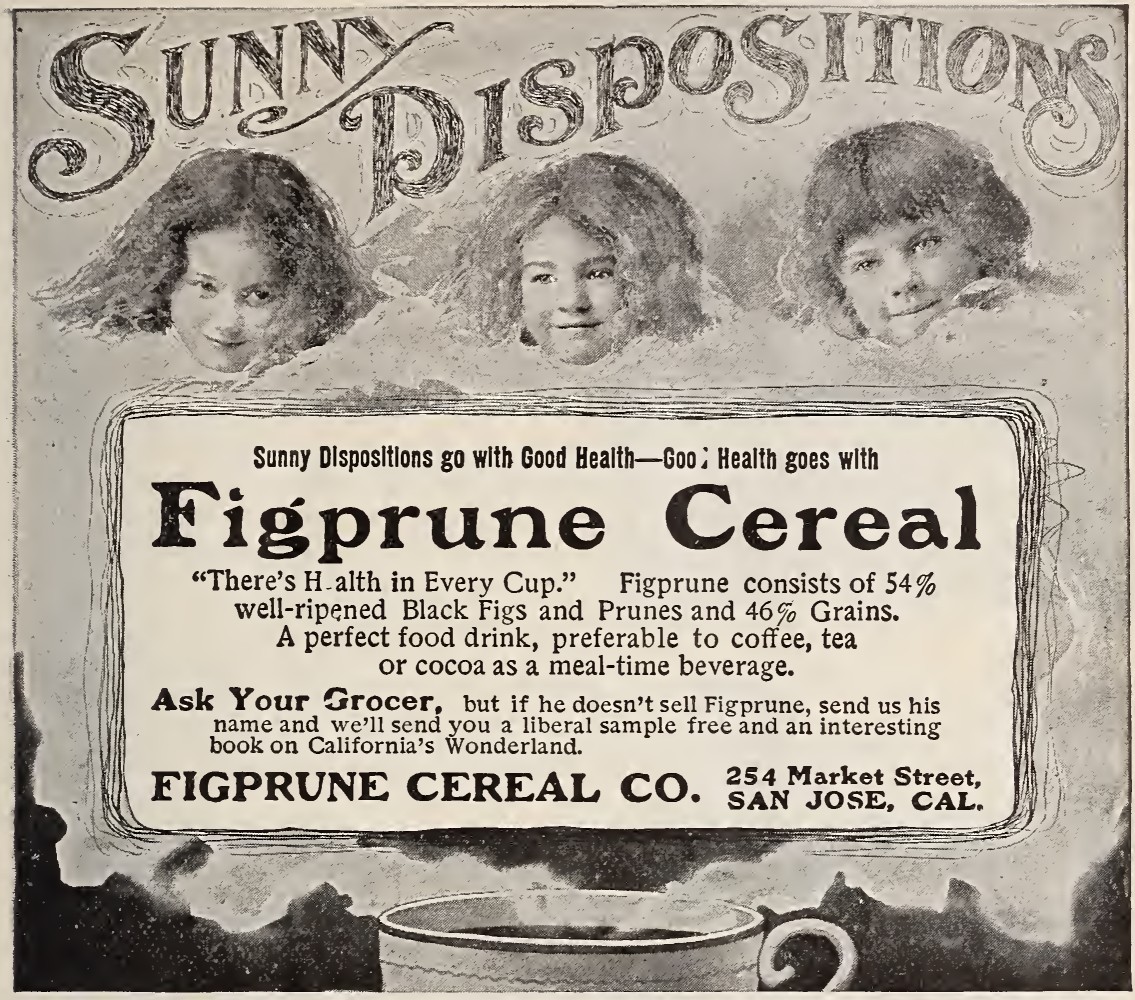

(Concluded from page 10.)

than twice six, daily standing around his throne, obedient to his every nod. Just beyond and around these scarletcoated pages, stands Madam Celeroi (a dainty silver leaf geranium), with her retinue of lords and ladies, spreading a perpetual cloth-of-silver canopy, in honor of their chieftain.

From the neighboring beds lordly dahlias and queenly asters bend their allegiance, carnations fairly prostrate themselves; while the common throng, petunias, antirrhimums, ageratums, phloxes, portulaccas, daisies and pansies turn red, then pale, then blue, then rosy by turns, with excitement, admiration and homage.

One specimen boasts several leaves
$28 \times 40$ inches in measurement, while those of smaller size fill gracefully in, preventing that sparse look so common in large specimens.

Indiana. Mrs. J. B. HowE.

\section{TREATMENT FOR TROPICAL PLANTS.}

Palms and ferns are two of the most beautiful plants. For soil use three parts woods soil, and one of grit, with a teaspoon of bonemeal well mixed. Place four inches of crock for drainage. Pot firmly. Water well each afternoon spraying foilage with clear water. Give morning sun till ten o'clock each morning. For palms, give soil three parts heavy garden soil and (Concluded on page 12.) 
DARKEN YOUR GRAY HAIR

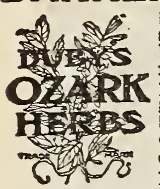

DUBY'S OZARK HERBS restore gray, streaked or faded hair to its natural color. beauty and softness. Prevents the hair from falling out, promotes its growth, cures and prevents dandruff, and gives the hair a soft, glossy and healthy appearance. IT WILL NOT STAIN THE SCALP, is not sticky or dirty, contains no sugar of lead, nitrate silver, copperas, or poisons or any kind, but is composed of roots, herbs, barks and flowers. It IS NOT A DYE, but a HAIR TONIC and cost ONLY 25 CENTS TO MAKE ONE PINT. It will produce the most luxuriant tresses from dry, coarse and wiry hair, and bring back the color it originally was before it turned gray. Tring back the color it originally was before it turned gray. There is more health to the hairin a single package of DUBY'S OZARK HERBS than in all the hair stains and dyes made.
Full size package sent by mail, postpaid, for 25 cents. Address OZARK HERB COMPANY, St. Louis, Mo.
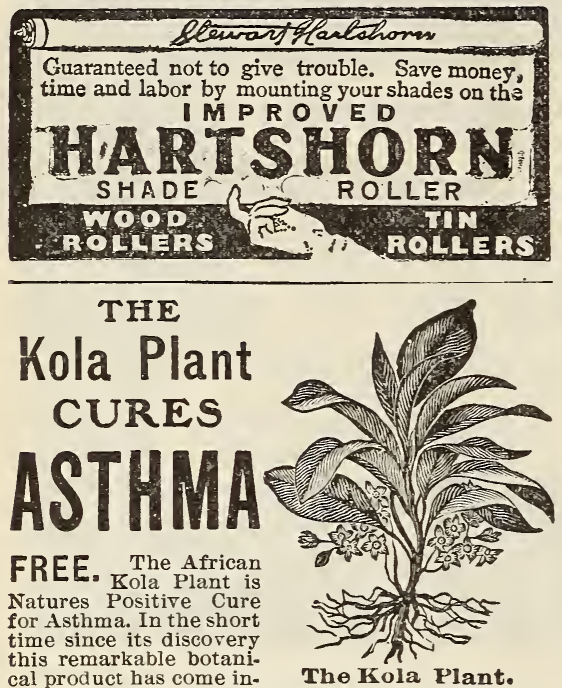
this remarkable botanical product has come in to universal use in the Hospitals of Europe and America as an unfailing specific cure for Asthma in every form. Its cures are really marvelous. Dr. W. H. Vail, a promin"nt physician of St. Louis, Mo. writes March 8, 1902, that he used Himalya on seven different Asthma patients with satisfactory results in every case. Mr. R. Johnson, Sr., Grand Forks, N Dak., writes Jan. 27, 1902, that he suffered with Asthma for flfty years, but Himalya cured him after twenty physicians and every change of climate failed. Miss Emaline Bolton, of 389 Conarroe St. Philadelphia, Pa., writes that Himalya is the only Asthma medicine of merit. It cured her after twenty years' suffering. Rev J. L. Coombs wrote to the New York World, July 23rd, that Himalya cured him of Asthma of thirty years' standing. Hundreds of others send similar testimony proving Himalya a wonderful remedy. If you suffer from Asthma in any form, in order to prove the power of this new botanical discovery, we will send you one trial case by mail entirely free. It costs you absolutely nothing. Write to-day to The Kola Importing Co., No. 1164 Broadway, New York.

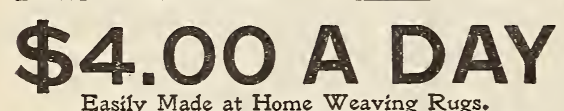

NO EXPERIENCE NEEDED.

If you are making $\$ 15.00$ a week or less, write for particulars at once.

REED MFG. CO., Box 12, Springfield, Ohio.
(Concluded from page 11.)

one of sand. Pot firmly and leave the bulb above ground. Water when needed, spraying once a week with sweet milk and twice with clear water. Give very little sun in summer, more in winter. When possible set all out in the rain. With the above treatment the following plants will be the pride and show of a neighborhood: Palms, kentias, barbcnica, areca, seaforthia, livistonia, phoenix, R. flabeliformis, P. Alexandrea; choice ferns, adiantums, N. doropteris, G. fartera, L.aristavarigata, L. scandens, $N$. carcifolia, IN. duvalloides-furcans, N. duffii, N. Bostoniensis, N. Washingtoniensis, $N$. refuscense-vripinnatifida, $P$, aureunn, P. capense, pteris argyrea, O. japanicum. Ornamental plants. arralia-filicifolia, paux-varigata-tahium, patens,varigata, ficus parcelli, varigatedsmooth-cayenne, alacasia illustris, alacasia-macrohirza, and the asparagus, of which there are two lovely new kinds. These plants have long names, but are of the easiest culture. These simple directions followed, and this collection wil be a pride to the most exclusive. All are rare and beautiful.

Louisiania. Mrs. Allan Mavile.

\section{LILIY BULB WORK IN OCTOBER.}

October is the month of all months for bulb planting, and is the month par excellence for lily bulb planting. Not all varieties of liles can be sent out now, some of them wil not be sent until after the 10 th of November but most of them should be planted now.

My bed has a naturally sloping situation and is particularly well drained. In making the bed I have a hole dug to the depth of three feet, all the old soil taken out, a few rocks in the bottom will help to secure good drainage. I then fill up with good garden soil,

(Concluded on page 13.) 
(Concluded from page 12.)

sand, leat mold and very old, wellrotted cow manure. For house culture I set bulbs just below the soil, but for bed's should go about nine inches or one foot in depth. Nothing will kill your lilies out sooner than shallow planting. In planting bulbs encase each bulb in a cushion of fine sand. In planting a bed of mixed lilies I so arrange them that the tallest varieties will be in the back ground and graduate them so the very lowest growing sorts will be in front.

Kentucky. Miss Laura Jones.

\section{THE GENTIANS BLOOM FOR ME.}

WE joy to find the first sweet flowers

That gem the fragrant spring;

Fair Flora smiling in her bower,

Blithe birds that ever sing.

Then the sad world forgets its cares

'Neath the sweet look that Nature wears-

Yet gentians bloom for me.

The spring is fair, oh very fair,

With sweet anemones:

With violets nestling everywhere

Beneath the forest trees;

With bluets here, with mayflowers there

I love these blossoms frail and fair-

When gentians bloom for me.

The passionate summer claims the rose,

Carnations, poppies, rue.

The fragrant lilies now unclose,

The honeysuckles too;

And meadows now are wondrous sweet

Where clover and wild daisies meet-

When gentians bloom for me.

Oh, beautiful are autumn days,

Crowned with the goldenrod.

Lovelilies glow through hush and haze

Above the browning sod.

Oh wondrous fair are Flora's bowers

That deck the fleeting autumn hours-

When gentians bloom for me.

Ohio. Annice Bodey Calland.

\section{THANK YOU.}

The Floral World is the best floral journal published. It is simply indispensable.

Missouri.

Mrs. F. Benton.

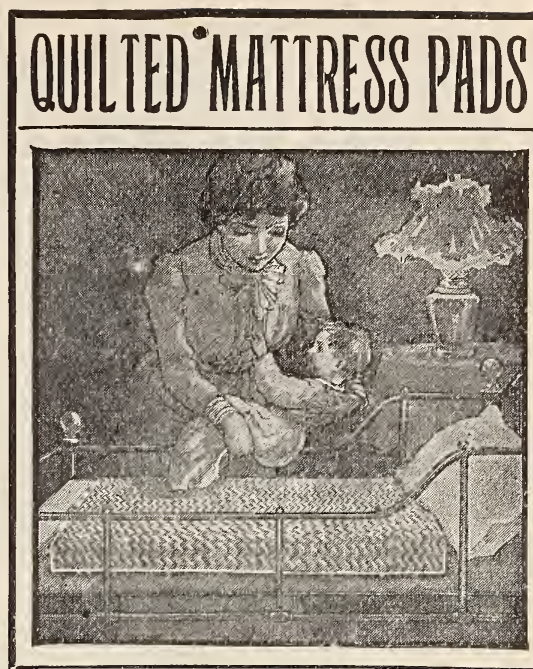

Fit your bed with a Quilted Mattress Pad and keep it in a cool and sanitary condition. A sound, refreshing sleep on hot nights will be made possible.

These pads are made of bleached muslin, both sides quilted, with pure white wadding of the best grade between. They wash perfectly.

Good as new after laundering, and the low cost places them within the reach of all. SEND FOR SAMPLE.

\section{The Excelsior Quilting Co.}

15 Laight st.

NEW YORE.

THE TRUTH Ladies and gentlemen, believe me, you need not suffer. I cure rheumatism, eczema, blood and skin diseases even when Hot Springs and others fail. Cure costs nothing. Rernedies cost but little sent to your homes. Now your fault if you suffer. Address,

Dr. W. H. ROSS, Grand Rapids, Mich.

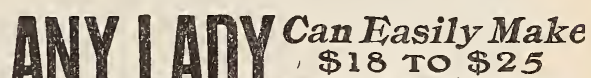

115 weekly by representing us in her lo. cality and as the position is pleasant and profitable the year round we will gladly send particulars free to all. Even your spare time is we will gladly send particulars free to all. Even your spare time is
valnable. This is no deception, and if you really want to make money address WOMAN'S MUTUAL BENEFIT CO., Bos \&1, JOLIET, ILL

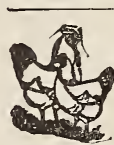

CIT RATES on all varieties EGGS and COI RALE POULTRY. Allvarieties Faney Pigeons and Belgium Hares Send for kates and for 60-Page Book, which one and all, each and everybody Bargains are included. All for 10c.

Address, J. A. BERGEY, Telford, Pa.

FREE Plans and suggestions for heautifying your home FREL or village improvment furnished free if I sup ply stock. Send measured sketch locating views, trees, buildings. etc.. with photos if possible. Visits if desired. W. H, Harrison, Landscape Architect, La Mott, Pa. and Tiquor Habit Cured with. out inconvenience or detention from business. Write THE DR. J. L. STEPH ENS Co., Dept. A-9, Lebanon, Ohio. 
CURES GOITRE.

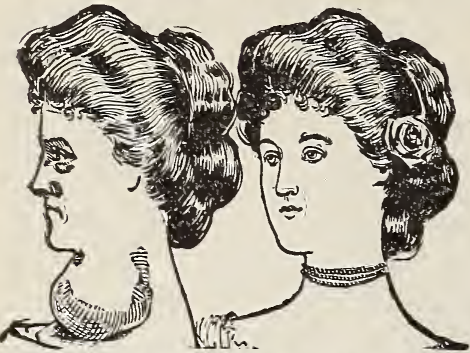

A well known Cincinnati physician has discovered a remedy that cures Goitre, or Thick Neck. And to prove this he sends a free trial package so that patients may try and know positively that Goitre can be cured. Send your name and address to Dr. John P. Haig, 3915 Glenn Bldg., Cincinnati, Ohio, tell him your age, the size and location of your goitre and how long you have had it, and he will be glad to send you free, a large trial package of his home cure, postage paid.

\section{BULBS AND PLANTS FOR WINTER}

* GiANT ROSE COLLECTION Our Selection, All Fine Sorts, For Your Locality, Named

TEN CHOICE KINDS ONLY 50 c. Three choice Hyacinths, different colors, 25 cents.

Twelve elegant Tulips, all colors, price 25 cents.

Thirty Crocus, assorted colors, price 25 cents.

Three large field-grown Carnations, price 25 cents.

Five elegant Geraniums for house culture, price 25 cents.

Five finest Chrysanthemums, best for winter blooming, price 25 cents.

Five Fuchsias, splendid for the winter window-garden, price 25 cents.

Five flowering Begonias, the best, price 25 cents.

Three Rex Begonias, choiceselection, price 25 cents.

Three Decorative Palms, price 25 cents.

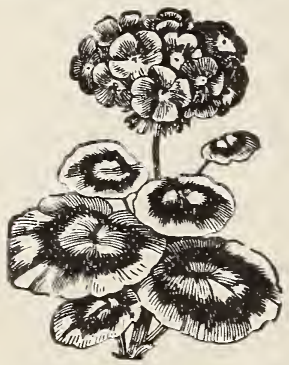

Send in your order to-day. Handsomely illustrated catalogue sent free. Address,

GREAT WESTERN PLANT CO.

Box 60 .

\section{SUCCESS WITH THE STOCK.}

I want to tell the readiers of The Floral World my experience with "stock." Last winter a neighbor gave me a large two-year-old plant. I potted it and the leaves dropped off, but it soon put out new leaves' and bloomed constantly all winter. I have it out in the garden now and it is still blooming. The way to get it is to plant seed early in the spring. Some will come single (those are the ones that have seed on them), others will come double, and they are the ones to take in for winter bloomers. Give plenty of water in winter and a sunny place.
Ohio.
Mrs. E. A. Rogers.

\section{A TRIBUTE TO THE FUCHSIA.}

One of the most beautiful plants I ever had was a fuchsia. I do not know its name. In August I received a slip from a friend, which I potted in onehalf garden soil, the remainder leaf mold with a good quantity of coarse sand, putting some stones in bollom of pot to insure good drainage. Do rot allow them to become dry during the growing period. I often gave mine a bath of soap suds, and was not much troubled with insects. Some use tobacco water, but I prefer the soap. Put one cup strong tobacco tea in one gallon water and sprinkle the plants with it. The last of October I withheld water. When the leaves were dead I cut off the top within two inches of the earth and set it in a cool room free from frost. The first of March I set it in the sun in a warm room, and watered sparingly at first, increasing the amount after growth began. The second summer mine was the admiration of all. I counted the flowers one day and there were forty-six, besides a multitude of buds.

Maine. Mrs. Albert F. Bean. 


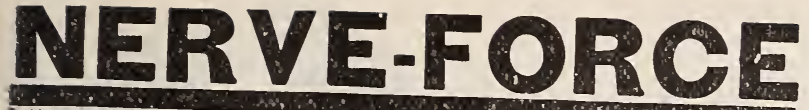

is a Home Remedy; a noble UNGUENT for external ap. plication. It is founded upom the principle that Suffering,

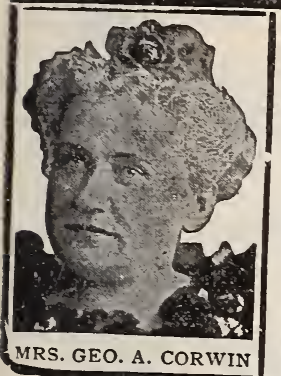
mature Death are the direct, and indirect, results of that rescue can only be assured by its re-establishment by directly
charging the controlling battery-cells with an element imitating the nerve force prepared for that purpose by Nature. This imitative element most sluggish CIRCULATIONE, and it will positively re-establish the Medals for life-saving in the to normal. It has won for us many Gold advertise it-but our NERVE-FORCEnty years. We do not, however. detail. We send this Publication dresses as you may send us.

We appeal especially to the "chronically ill" who are wearied and dissufferers threatened with cruel "operations of warfare against Disease; to spite of heroic efforts for cure, feel totions;' to men and women who, in and women who are victims of sedentaryselves steadily declining; to men exhaustion." and to those who have been east asident or excessive "brain MR. and MRS. GEO. A. CORWIN, 686 who have been cast aside as "incurable."

\section{SUMMER CLIMBERS.}

Plant vines and climbers! What would a garden be, with its wealth of bloom, without the graceful, summer climbers? I grow a variety of them. Wisteria is one of the most beautiful of climbers. I'he bloom s are lovely, with their long, pendulous racemes of blue, white and purple. The Belgian or monthly honeysuckle is a beautiful climber. Scarlet trumpet is another. Ipomea is a rapid climber, attractive in foliage and bloom. The balloon vine is a dainty arnual. There are many varieties of hardy ivies.

How few cultivate the cobea, yet how beautiful it is, with large bellshaped flowers. Plant the seed in moist earth, edge side down, in a hotbed, or in the house. The cobea is a native of Mexico, and was introduced in 1792. It was named for Bernardez, a Spanish priest and botanist. Give it rich, light soil and moisture. It makes a fine plant for rooms gas lighted and coal heaced, as it revels in heat.

Thunbergia laurifolia is a climber, admirable for winter blooming, with violet blue flowers. Rhyncospermum jasminoides is also a charming winter blooming climber, with white, fragrant, jasmine-like flowers.

Nebraska. Mrs. H. W. LeightoN.
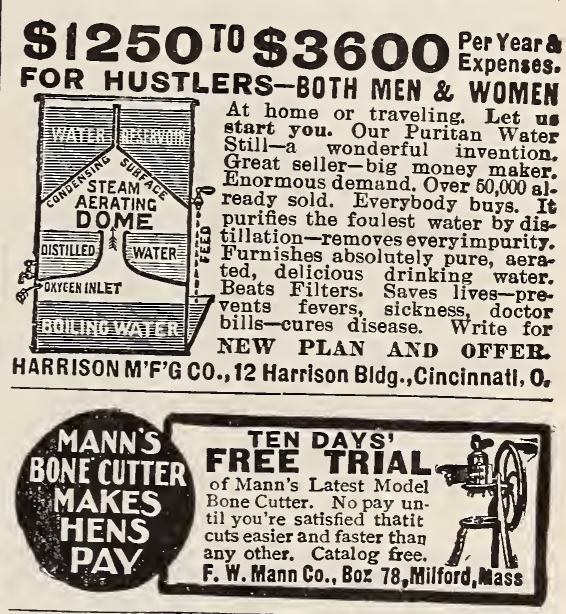

LADIES TO DO SEWING

and binding. Piece work; $\$ 4$ per 100; can make six an hour; material sent free prepaid; send addressed reply envelope for full particulars.

UNIVERSAL C0., Dept., 24 Walnut St., Philadelphia, Pa

LADIES TO DO PIECE WORK at their homes. $\$ 7$ to $\$ 12$ weekly. Experience furnish all material and pay from stamped envelope to ROYAL CO., DEPT. F, W. 34 Monroe St., Chicago.

SPECTACLES by mail guaranteed to suit. Easy method of fitting your eyes, and illustrated prices FREE. Fredrick Optical Co., Toledo, Ohio.

TO CA PIJ A T Required to work Por spare hours at home. Fither sex. No canvassing. SOLA I: Co., Providence, IR. I.

LADIES Your Bust enlarged permanently; cannot AD fail. Perfectly safe. Particulars free. MME. SADA WELLS, Box 282, Bloomington, III.

Big pay distributing samples, etc. Enclose stamp. Inter'l Dis. Bureau, 150 Nassau Street, New York. 


\section{HOW SO GROW CINERARIAS.}

Give your cinerarias a fibrous soil, composed of scrapings from off of sods, incorporate sand until you have it good and porous, then as they grow transplant to larger pots. And don't deluge with water while small, but give a little at a time when they require it. Then they become larger, and, of course, posisess more roots, they must be more liberally watered and showered every day to keep down the red spiders, and it is best to keep a supply of tobacco spread over the soil or the aphides will be likely to ruin your plants. The kind I use comes in packages already prepared.

$\mathrm{Pa}$. Mrs. Saituel M. Welsh.

\section{SICK MADE WELL WEAK MADE STRONG.}

\section{Marvelous Elixir of Life Discovered by Famous Doctor-Scientist That} Cures Every Known Ailment.

\section{Wonderful Cures Are Effected That Seem Like Miracles Performed -} The Secret of Long Life of Olden Times Revived.

\section{The Remedy Is Free to All Who Send} Name and Address.

After years of patient study, and delving into the dusty records of the past, as well as following modern experiments in the realms of medical science, Dr. James W. Kidd, 238 Baltes Block, Fort Wayne, Ind., makes the startling announcement that he has surely discovered the elixir of life. That he is able with the aid of a mysterious compound, known only to himself, produced as a result of the years he has spent in searching for this precious life-giving

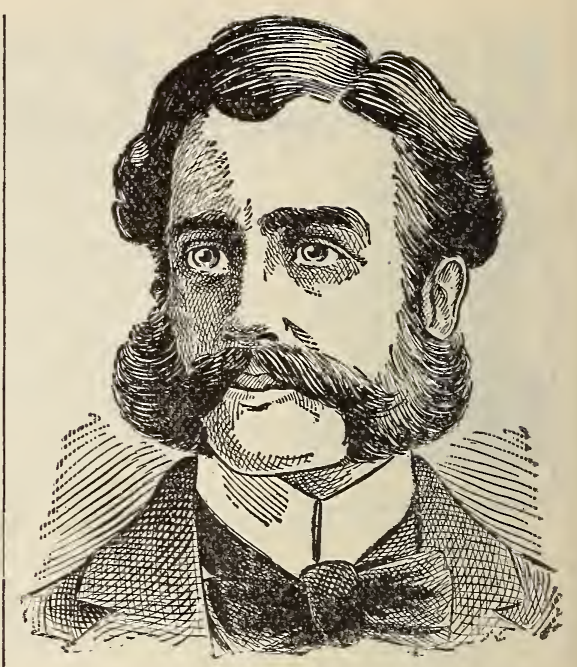

DR. JAMES WILLIAM KIDD.

boon, to cure any and every disease that is known to the human body. There is no doubt of the doctor's earnestness in making his claim and the remarkable cures that he is daily effecting seems to bear him out very strongly. His theory which he advances is one of reason and based on sound experience in a medical practice of many years. It costs nothing to try his remarkable "Elixir of Life," as he calls it, for he sends it free, to anyone who is a sufferer, in sufficient quantities to convince of its ability to cure, so there is absolutely no risk to run. Some of the cures cited are very remarkable, and but for reliable witnesses would hardly be credited. The lame have thrown away crutches and walked about after two or three trials of the remedy. The sick, given up by home doctors, have been restored to their families and friends in perfect health. Rheumatism, neuralgia, stomach, heart, liver, kidney, blood and skin diseases and bladder troubles disappear as by magic. Headaches, backaches, nervousness, fevers, consumption, coughs, colds, asthma, catarrh, bronchitis and all affections of the throat, lungs or any vital organs are easily overcome in a space of time that is simply marvelous.

Partial paralysis, locomotor ataxia, dropsy, gout, scrofula and piles are quickly and permanently removed. It purifies the entire system, blood and tissues, restores normal nerve power, circulation and a state of perfect health is produced at once. To the doctor all systems are alike and equally affected by this great "Elixir of Life." Send for the remedy today. It is free to every sufferer. State what you want to be cured of and the sure remedy for it will be sent you free by return mail. 
EXPERIENCE AND CONFESSION.

At twenty-one I married and went to a farm to live. Going from town to country life, I found I knew nothing and had everything to learn. Of course, I had many failures and few successes. My knowledge of flowers, which is quite small, is from experience and floral reading. I have an impatiens, one year old. It has never been out of bloom; measures 111/2 feet; is so full of bloom that it is a blaze of vivid color. It is under a tree where it has sun and shade. It is the admiration of passersby. I do not succeed with roses; with geraniums, heliotropes, jasmines, plumbago and hibiscus I have no trouble. I am very partial to bulbs and hard wooded' shrubs, have a lauristinus which is a beauty with its clusters of white bloom. Stephanotas and daphne are among my favorites, but could I have but one flower it would be the bright, beautiful, fragrant nasturtium, an allyear pleasure. I do not succeed with the umbrella plant, but have beautiful palms, ferns, lemons, oranges, pomegranates and hydrangeas. My garden is an old-fashioned wilderness with about fifty cosmos, and the grandest double

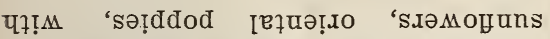
many handsome vines', cannas and' other plants in profusion.

Kentucky.

Mrs. A. T. HursT

\section{HIBISCUS IN "THE LAND OF FLOWERS."}

The hibiscuis does not get the praise that it deserves. On the east coast of Florida it is used for hedges, and its profusion of gorgeous blossoms is the attraction of winter tourists. The deep green bushes are always glittering with their gay colored flowers. In Florida they bloom all the year. The double pink and crimson are exquisite. They are easily grown from cuttings (Concluded on page 18.)

\section{WELTMERISM REVEALED.}

It Costs Nothing to Receive Full Information Re. garding the Greatest Curative Power Known to Civillzation.

Weltmerism the wonderful science of drug less healing is still the chief topic of conversa tion in scientific circles. Thousands have been cured of every known disease by it and the name

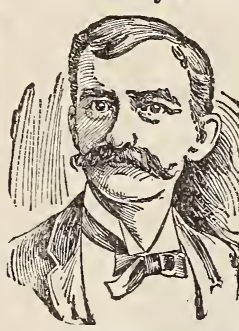
Weltmer has become a household word, yet most people know nothing of this grand science except that it cures when all else has failed. They look upon it as a mysterious power that cannot be un. derstood. Prof. Weltmer desires everyone to know just how his science cures and earnestly requests all who are afflicted in any way to write him, no matter how chronic their disease may be nor how many physicians have pronounced it incurable. Mrs F. M. Hall, of Rinaldo, Ky., was cured of Catarrh of the Stomach by Prof. Weltmer's Absent Treatment. Mrs. Emma Boehme of Belleville, Ill., was cured of Catarrh, Deafness and Head Noises by Absent Treatment. Mrs. C. E. Haddon of Tampa, Fla., was cured of Bright's Disease by Absent Treatment after physicians had failed to relieve her. No disease is too stubborn or of too long standing to be cured by this wonderful method. Send your name and address to Prof. S. A. Weltmer, Nevada, Mo., and he will send you absolutely free, full information as to how you may be cured and a beautiful 40 page illustrated magazine, containing matter of much interest and Hostimonials of

TEACHES HIS ART peoplewhowere TO OTHERS.

on the verybrink weres saved through Weltmerism. Prof. Weltmer has so perfected his method he can easily teach it to others either by mail or personal instruction. Many of his students are making from $\$ 10.00$ to $\$ 50.00$ a day. Full information sent free to those addressing Pros. S. A. Weltmer, Nevada, Missouri.

\section{PRICES REDUCED ToR 60}

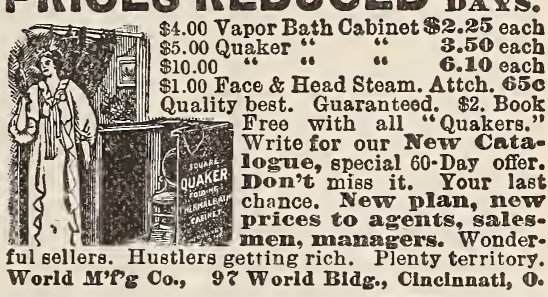

ONLY 65 CENTS FOR OUR SPECIAL WIDE Handsome Gilt Picture Frame.

Any size $10 \times 12,11 \times 14,14 \times 17,16 \times 20$ inside, suitable for any picture, guaranteed, less than one third of price others charge and much less than local dealers pay at wholesale. Cannot be bought elsewhere for three times the a mount. We sell direct to the people. For special bargain offer and INSIDE FACTORY PRICES on all styles and sizes of frames write for our FREE CATA LOCUE with large illustrations. We undersell everyo body, and can save you big money. Order at once.

Parwin Manufacturing Co., Frame Dept. L. Chicago, IIl. 


\section{Gures}

\section{Drumkards Secretly}

Free Package of the Only Successful Cure Known For Drunkenness Sent to

All Who Send Name and Address.

It Can Bo Put Secretly Into Food or Coffee and Quickly Cures the Drink Habit.

Few mell become drunkards from choice or inclination-all welcome release from the awful habit. Golden Specific will cure the worst habitual drunkard. This wonderful remedy can be administered by wife or daughter, in food, tea, coffee or milk, without causing the slightest

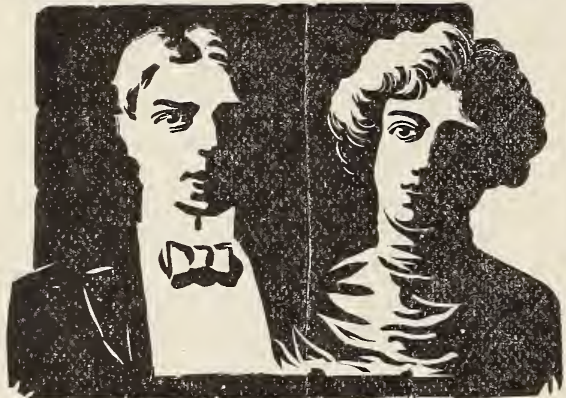

Mr. and Mrs. Harry Burnsides.

suspicion. Its cure is sure, without harmful results to the system. Many a home is now happy by the use of Golden Specific. "My husband got into a habit of taking a drink with the boys on his way home," says Mrs. Harry Burnside. "After a while he came home drunk frequently. He soon lost his position and I had to make a living for both of us and the little children. At times he tried to sober up, but the habit was too strong for him and then he would drink harder than ever. I heard of Golden Specific and sent for a free package. The treatment cured him. I put it in his coffee and he never knew it at all. He regained his old position and now we are happy in our little home again. I hope you will send Golden Specific to every woman that has suffered as I have, and save her loved ones from the drunkard's grave.

Send your name and address to Dr. J. W. Haines, 3649 Glenn Building, Cincinnati, Ohio, and he will mail you a free package of Golden Specific in a plain wrapper, accompanied by full directions how to useit. Enough of the remedy is sent in each free package to give you an op portunity to witness its marvelous effect on those who are slaves to drink.

Do not delay. You cannot tell what may happen to the man who drinks, and you would never forgive yourself for waiting.
(Concluded from page 17.)

and can be budded with great success. I have seen plants with eight or ten different colored flowers on at once. They attain the height of ten feet on the banks of the Indian River, where they are used as a fence in front of the beautiful homes. The single pink is most hardy, and is used more extensively than any other. They can't stand cold weather, so would have to be put in hot houses anywhere north of St. Augustine.

Florido.

Mrs. T. V. MOORE.

\section{MY OUTDOOR GARDEN.}

It is twelve by twenty-one feet, south of the house, consequently is exposed to the east, west and south; square on the west, it is rounded on the east, which is the front. Across the west end is a row of June roses, then a row of hybrid perpetuals. Between the latter some dahlias lift their gorgeous blooms above a row of sweet peas. In front of these are white and red double poppies, while nestling at their feet, protected by them from the hot sun, are pansies of wll colors. Sown in April, they began blooming in June, and their dainty faces have greeted me every day since. In front of the pansies runs a path. Then there is a triangular bed of asters, the buds just beginning to show color. In two small beds on the front sides of the triangle may be found phlox drummondi, pansies, and tea roses. Though young, the roses have grown finely and bloomed well.

On a bench between the house and garden are my chrysanthemums, single stems, standaras and bush plants, fifty strong, healthy plants. Not an insect so far. Have sprinkled thoroughly with hose when it did not rain.

Mich. Mrs. E. R. B. BARbER. 


\section{Why Be Fat}

When There Is a New Home Treatment That Quickly Reduces

Weight to Normal Without Diet or Medicine and is Absolutely Safe.

\section{A TRIAL PACKAGE FREE BY MAIL.}

Don't be too fat; don't puff and blow; don't endanger your life with a lot of excess fat; ard furthermore, don't ruin you stomach with a lot

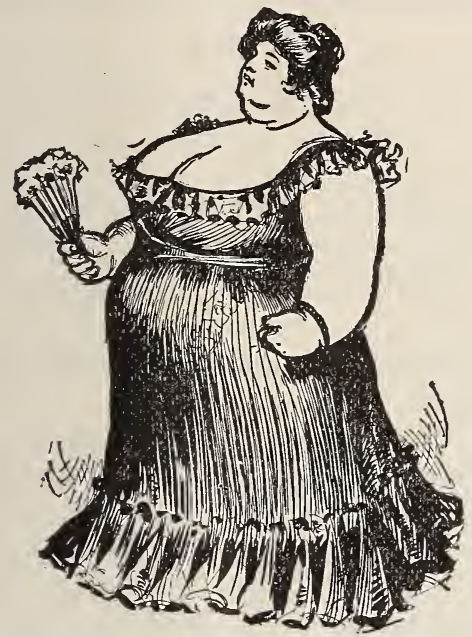

of useless drugs and patent medicines. Send your name and address to Prof. F. J. Kellogg, 964 W. Main St., Battle Creek, Mich., and he will send you free a trial package of his remarkable treatment that will reduce your weight to normal. Do not be afraid of evil consequences, the treatment is perfectly safe, is natural and scientific and gives such a degree of comfort as to astonish those who have panted and perspired, under the weight of excess fat. It takes off the big stomach, gives the heart freedom, enables the lungs to expand naturally and you will feel a hundred times better the first day you try this wonderful home treatment.

Send your name and address for a free trial package sent securely sealed in a plain wrapper with full directions how to use it, books and testimonials from hundreds who have been cured.

Send for the free trial package to-day. It will brighten the rest of your life.

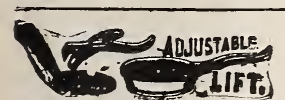

Ajustable Lift, for stew. ing pans, pie tins and stove lids. Holds pan firmly in any position.

Entirely new. Every housekeeper buys. Made of bright sheet steel. Sample postpaid, 15c;12 for $\$ 1.00$. Eureka Supply Co., Lamartine, Pa.
AS TO LIQUID MANURE.

Tell Mrs. Patterson that both old and fresh manure should be used in the drainage hopper for liquid manure. I have used an old barrel, set on an inclined platform for receptacle, and find this a good way. This season I am using an old, discarded ice box, zinc-lined, with a small pipe vent. When there is more liquid than I need I throw it back into the box and sava the waste, or pour it over soil in a box to be used for potting plants. My plants are the admiration of all who see them, especially my begonias. The secret is that I do not let them. starve. Feed them liberally and at: least once a week. By watching the effect you will soon learn what strength to use and how. often the plants require the food. It might be well to take two or three plants and experiment with them. I have never injured any plant and have redeemed many that were apparently dying.

Missouri.

HARL.

IN PRAISE OF THE OLEANDER.

I am of the opinion that few plants rival the oleander for beauty and wealth and sweetness of blostsoms. We have a pink one that is covered with an immense number of buds and blossoms every year. It is eleven years old, 5 feet 8 inches high and 25 feet in circumference! We are very proud of it.

The tree is placed upon the eastern lawn, in such a position that it receives the direct sunlight almost all day long. It requires an immense amount of water, which is given at all times during the day.

As soon as the frost becomes too severe, we allow the tree to "dry off," and then place it in the basement, where it is allowed to rest dur-

(Concluded on page 20.) 


\section{Consumption Now Curable}

By the Famous Doctor Yonkerman's Marvelous Discovery-State Officials and Great Medical Men Pronounce It the Only

Cure for Consumption, Throat and Lung Trouble.

\section{A Free Trial Package Will Be Sent by Mail} to All Who Write.

Consumption can at last be cured. Marvelous as it may seem after the many failures, a sure,

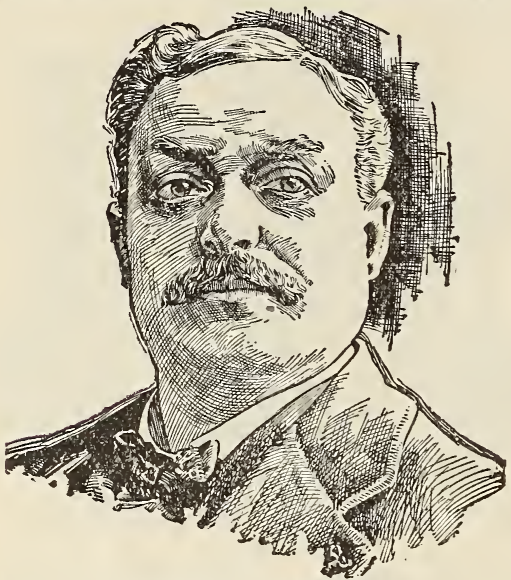

DR. DERK P. YONKERMAN.

positive and certain cure for the deadly consumption has at last been discovered. Cases given up to die and sent back from California hopeless and helpless, are now alive and well through this wonderful cure for consumption.

Free trial packages of the remedy and letters from grateful people-former consumptives rescued from the very jaws of death are sent free to all who write to Dr. Derk P. Yonker. man, 697 Shakespeare Building, Kalamazoo, Mich. Don't delay - there is not an hour to lose when you have consumption, throat or lung trouble. Send to-day for Free package.

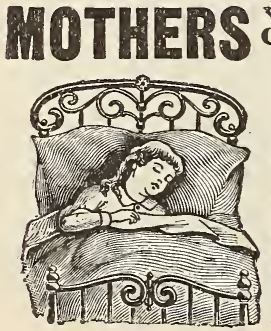

YOUR CHILDREN Cured of Bed-Wetting
SAMIPL EN-U-RE-SINE

cures Bed-Wetting, and in. continence of urine during the day-time, both in the old and young. It is the only cure prepared by a physician who guarantees it. Ladies troubled with a frequent de. sire to urinate and a burning sensation use it with perfect suecess. Send your address to DR. F. F. MAYY, Drawer 6 Bloomington, Ill., and re ceive sealed a free sample.
(Concluded from page 19.)

ing the winter months. No water is given it until about a month before we wish to place it out of doors again. Then we give it water once in a while -just enough to set the sap flowing.

During the early part of spring we protect it from frost by covering well with old rugs. Hardly any one passes our home without exclaiming: "What a lovely oleander! How sweet its blossoms smell."

Minnesota.

AnNa M. Kath.

\section{HARDINESS OF THE OLEANDER.}

Oleanders may be planted out of doors anywhere south of Mason and Dixon's line, except in a mountainous district, where the altitude does not suit them. In winter their tops will be killed, but the roots will not be injured.

I had a large growth of oleanders, at least ten feet high, shading the south windows of my bed-room. They bloomed profusely for years. One winter they were frozen stiff, and their long, leafless canes rattled in the wind like castanets, until I had them cut off level with the ground, and mourned over my dead beauties as hopelessly lost. But spring came-and so did the oleanders. From the buried root masses came the shoots with surprising rapidity, taking on size and strength, and leafage, until, at the appointed time, my windows were again shadowed with ten feet of greenery, enlivened with the lovely flowers all through the dry, hot summer.

Since that experience, I wrap and cover the roots carefully in the late fall, and have no further anxiety.

Has any other Floral World reader had a similar experience?

Texas.

GRETCHEN 
AN EXPERIENCE WITH A RUBBER PLANT.

I had a tall rubber plant that I was anxious should branch. So I cut the top off. The result was a sprout from one side, which gave it a crooked look. I cut it again, and then three shoots came, but all clustered around the top, leaving the lower part all bare. This did not suit me. I cut it right in two, sunk the pot in the ground on the north side of the house, and stuck the upper half in the ground near it, never thinking it would grow.

In about two weeks the lower part commenced to sprout out all over; I counted eleven places, and about a week later the top sprouted in six places. Now I have two rubber plants branched to my heart's content.
Pennsylvania.
M. E. SHUFF.

\section{ANNUALS FOR WINTER BLOOMING.}

Few amateurs seem to be aware that many of our common annuals are far more satisfactory for winter blooming in pots, than for the garden culture during summer.

Seed should be started in November and December. Young plants should be put in small pots and shifted' to larger size as the plants develop. Uise leaf loam mixed with sand in clean pots, with charcoal for drainage.

Schizanthi are novel, beautiful flowers, many of them resembling rare orchids. Shoo-fly plant is particularly pretty, the flowers being large and a pleasing shade of blue.

It is impossible to find a flower more floriferou $_{S}$ than alyssum, little gem. A single plant will cover a fifteen-inch pot, hanging over in such a graceful vine, like a mass of snow-white blossom's.

Cherianthus bears spikes of very bright crimson and lilac flowers. For
Ladies Cure

\section{Tobacco Habit}

Secretly at Home-Trial Package Free to All Who Send Name and Address.

Men who have tried time and again to quit tobacco have been instantly cured of the habit by a harmless compound discovered by a fam. ous Ohio chemist. It stops at once and forever

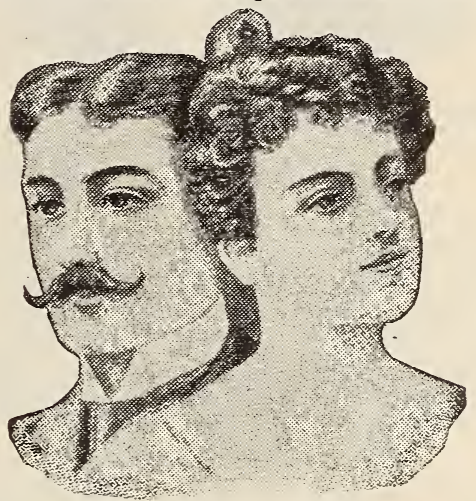

No More Smoke or Dirty Spittoons in the Home.

the craving for the weed and makes it impose sible for any man to chew or smoke. The marvelous part of the remedy is that it is odorless and tasteless. It is taken in milk, water, tea, coffee or food without any bad effects, and many women have already cured their husbands and sons of the toba cco habit without the slightest danger of detection. It is easy to quit tobacco and if you will write Rogers Drug and Chemical Co., 3498 Fifth \& Kace Sts., Cincinnati, Ohio, they will send a large trial package free, in a plain, sealed wrapper, and it will prove how easy it is to cure yourself or anyone else of using tobacco in any form.

MADE \$105 THE FIRST MONTH

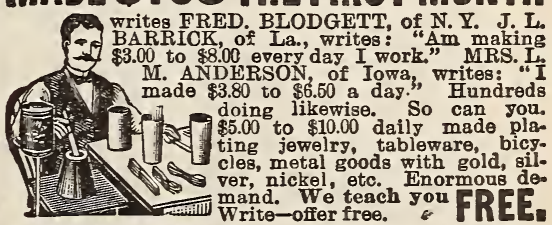
a. GRAY \& CO., Plating Worts, A Miami Bldg, Cinclnnati, 0 . prensed Air Sprayers, also large orchard sprayers. We have the best, and sell them under a gasrantee. 2c stamp will britig catalogue and terms. Ripoley Hardware $\mathrm{Co}, \mathrm{Box} 251$, Grafton, IIIinols.

(Concluded on page 22.) 


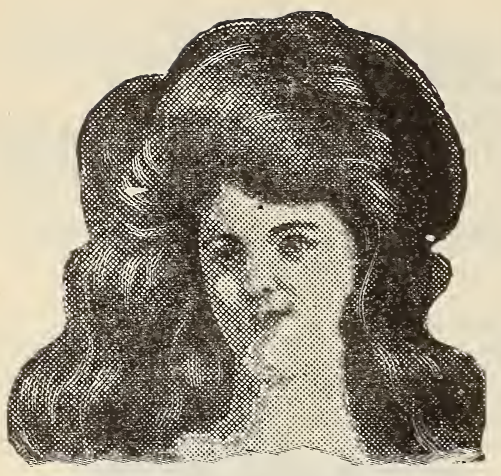

Her Marvelous

\section{Growth of Hair.}

All can have it by simply sending for a trial package of a new and wonderful remedy mailed free to convince people it actually grows hair, stops hair from falling out, removes dandruff and quickly restores luxuriant growth to shining scalps, eyebrows and eyelashes. Send your name and address to the Altenheim Medical Dispensary, 6602 Butterfield Building, Cincinnati, Ohio, for a free trial package enclosing a 2-cent stamp to cover postage. Write to-day.

\section{Send the Floral World to a Friend}

We desire the names and addresses of all persons who are interested in home flower growing. Send us the names of twenty-five of your friends whom you think would like to see a copy of THE FLORAL WORLD, and promise us that you will write or speak to all of them about our little magazine, asking them to become subscribers, and we will give you absolutely free one year's subscription for any friend whom you may designate. Address,

THE FLORAL WORLD, Springfield, Ohio.
(Concluded from page 21.)

a contrast of golden yellow and blue, try lobelia goldeise. Morning glories commence blooming in about thirty days, and are so pretty. Rhodanthe, petunia, mimulus, godetia, dwarf, are certain to bloom and should be included.

My experience in planting the above mentioned annualis for winter blooming was a surprising success, and I am more than pleased with the result.

Louisiana. MRs. W. N. WHITE.

\section{EXPERIMENTS WITH A ROSE BUSH.}

We wonder if the sisters know how easily they can transform just a common rose bush into a gorgeous thing of many bright colors. Even a coarse, old-fashioned rose can be made to give the beautiful bloom's of the ever-bloomers. Each month select a stem, hardwooded. Cut the top off, lower down make a slit with a sharp knife, then select the color wanted to put on this stem that has been left on its own roots. Cut a stem with an eye on it of the color wanted. Cut off on each side of the eye sharpened like a tooth pick at each end. Flatten the under side of the butt, then slip on under the bark of the slit on stem standing on its own roots. Draw the bark over the eye as much as possible and tie with a stout string. After three days loosen this string each morning till the bud has grown to the stem. This bud will grow if it takes, and mature perfect roses before frost. A rose buish with six or eight colors of perfect roses on it is a sight at once novel and very beautiful, and draws admiration from all that see it. If an old-fashioned rose is used, cut away all the bush but the budded stems and keep down all sprouts, for everbloomers are not necessary.

Georgia. Mrs. Mary McCants. 


\section{GERANIUM CULTURE BY AN AMATEUR.}

There is no plant so easy of culture, requiring less care than the geranium. It is seldom troubled with insects, and never fails to bloom if treated well. In the latter part of March, I take slips from my largest plants, rooting them in sand. They are well started to set out in garden in May. Then I take old plants, cut off tops (which I root), plunging the pots in a shady place in garden. In August I take them up, repot in well prepared soil, which has been well smoked with tobacco to kill insects. Use small pots. Then I put plants in a sunny place, keeping buds picked off. When it is time to take them indoors they are ready to bloom all winter. I have a fine bay window with sun nearly all day. I give plenty of fresh air. My plants do not lose leaves in changing from out doors to the house, as they are put in before the fire is started, and the air is so tempered that they do not feel the change.

New York. Mrs. D. C. KeYser.

\section{SUCCESS WITH THE HIBISCUS AND MANETTA VINE.}

When I ordered flowers in the spring I got a sub-violaceous hibiscus. I had never sten one before, but I planted it in a one-gallon pot, using one inch of charcoal in the bottom for drainage. I then filled the pot with well-rotted fertilizer from the barn, and garden soll. When the hibiscus was firmly rooted I gave liquid fertilizer twice a week. It is now three and a half feet high, and has a branch two and a half feet long and several shorter ones. In Augus it had fifteen blooms and eight buds, and is now full of buds and blossoms.

In the spring I obtained a cutting of manetta vine, which I placed in a pot filled with well-rotted soil from where

(Concluded on page 24.)

\section{FREE}

\section{A NEW CURE FOR}

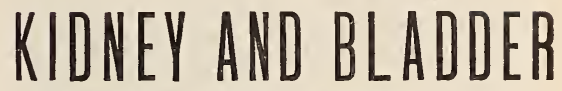

\section{Diseases, Rheumatism, Etc.}

Disorders of the Kidneys and Bladder cause Bright's Disease, Rheumatism, Gravel, pain in the Back, Bladder Disorders, difficult or too frequent passing water, Dropsy, etc. For these diseases a Positive Specific Cure is found in a new botanical discovery, the wonderful Kava-Kava Shrub, called by botanists, the PIPER METHYSTICUM, from the Ganges River, Wast India. It has the extraordinary record of 1,200 hospital cures in 30 days. It acts directly on the Kidneys, and cures by draining out of the Blood the poisonous Uric Acid, Lithates, etc., which cause the disease.

Rev. John H. Watson testifies in the "New York World" that it has saved him from the edge of the grave, when dying of Kidney distase and terrible suffering when passing water. Mr. Calvin G. Bliss, North Brookfield, Mass., testifies to his cure of long standing Rheumatism. Mr. Jos. Whitten, of Wolfboro, N. H., at the age of eighty-tive, writes of his cure of Dropsy and swelling of the feet, Kidney disorder and Urinary difficulty. Many ladies, including Mrs. C. C. Fowser, Locktown, N. J., and Mrs. Sarah Tharp, Montclair, Ind., also testify to its wonderful curative power in Kidney and allied disorders peculiar to womanhood.

'That you may test the value of this great discovery we will send you by mail Free, One Large Case and our book of 1000 testimonials, only asking that when cured yourself $y \cdot u$ will recommend this sure specific to others. Address, The Church Kidney Cure ciompany, 524 Fourth Avenue, New York City.

\section{Make Your Money EARN MONEY}

Persons who have money to invest are invited to write us. We offer no extravagant profits, nor do we make improbable promises. Engaged in an established business, for the assuredly profitable extension of which additional capital is needed, we have for sale stock which bears a guaranteed dividend of

\section{SIX PER CENT}

\section{PAYABIE SEMI=ANNUAIIY}

No higher dividends can be secured from any other investment of equal safety and character. Let us send you fuil particulars. Address

"INVESTMENT"

P. O. Drawer 755. Springfield, 0 . 
(Concluded from page 23.)

wood and chips had been piled, also a small quantity of sand.

I have kept the soil loose around the vine, using liquid fertilizer, as with the hibiscus. It is now eight feet long, the foliage is beautiful and is budding for fall blooming.

Mississippi. Mrs. W. R. PoPE.

THEY WANT TO KNOW.

How can I keep dahlias over winter? Mine have been grown from seed this year. Please tell me also about cannas from this year's seeds, and how I ought to treat my tuberoses to make them bloom. I have one two years old which has never yet bloomed.

Nebraska.
I had four large amaryllis plants last fall, but three of them were touched by frost and did not bloom. All were put out doors in seven-inch pots and have grown a wonderful display of foliage during the season, but have not bloomed, and I do not want them to bloom until winter.

Now, should I turn down these pots and let the bulbs rest, or would it be best to let them retain their foliage and bloom just when they will? Will some one who has had experience with amaryllis please answer at once.

Louisiana.

HART.

How shall I make my Egyptian lotus bloom? It is now three years old and has never bloomed. How shall I keep through the winter my ponderosa lemon, water lilies, and jasmine? Nebraska. Mrs. Clara WALlin.

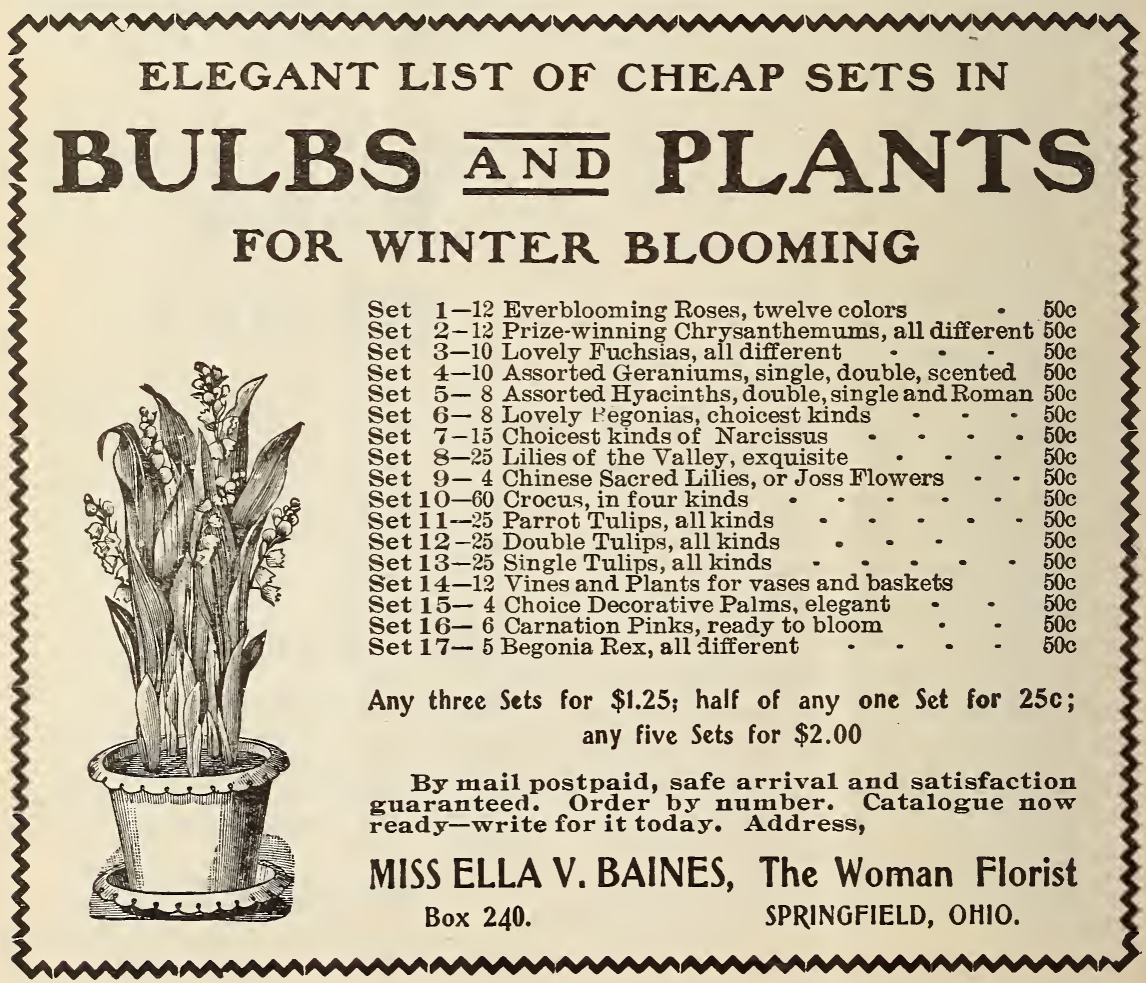




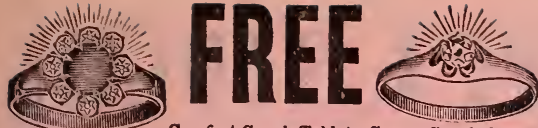

Comfort Cough Tablets Cure a Cough in one day. Sell 12 boxes at $10 \mathrm{c}$ s box. Send ug the money, we glve you any two of these Six Solid Gold laid Rings Free. No money wanted till Tablets are sold. We take back all not sold. Comfort II dedcine Co., Providence, R.I.
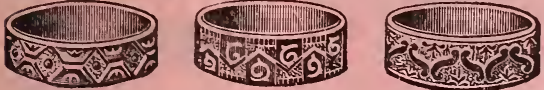

1 HYDRANGIA OTASKA.

1 JERUSALEM CHERRY.

1 WATER HYACINTH.

1 CHRISTMAS CHERRY.

1 MARANTA.

1 BERGONIA VERNON.

This Collection

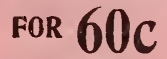

POSTPAID.

With every order for above I will give six bulbs of fine Freesias, also a due bill good for 25c. Worth of Plants FREE with next order selected from catalogue. Catalogue Free.

J. EDGAR TODD, Morris Park, L. I., N. Y. [RF[ Clairvoyance, If sick or ailing send now Dr. D. HinkIy, x-28, Grand Rapids, Mich.

EASY TUOWEY Made at home in sex. No canvassing. No capital required. $\$ 3$ per day. SOLAR Co., Providence, $R$. I.

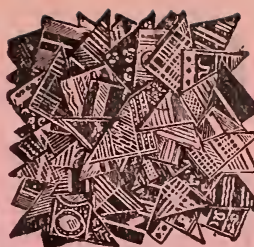

SILK REMNANTS 2 cents a pack. taving a lisge stuck we will reduce our price to move them. All new. bright pleces, corners and squares. Good size. Mos t beautiful designs. 15 choice pieces in each pack, also velvet and satin squares extra, I package, 2 cents; 3 pack: ages for 5 cents; 12 pack. ages for $15 \mathrm{c}$; 100 pack. ages for $\$ 1.00$, postpaid.

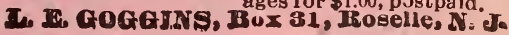

when for a 2 cent stamp 4 D $D$ Mrs. Louisa Lafarge, 43 TO $\mathrm{BE}=\mathrm{F}-$ Times Building. New York. scription took 20 to $120 \mathrm{lbs}$. of each of over 6.000 men and
women. Most effective \& least expensive treatment ever offered. Endorsed by United States Health Reports. ASTHMA CURED. I positively GUARANTEE my stop the longest, most desperate, discouraging case of ASTHMATIC TROUBLE at once without harm, disappointment or interference with rest. Immediate, Positive Cure assured. Price only $\$ 2.00$. Write,

Dr. Andresson, B 515 Main St., Kansas City, Mo.

LADIES, SUPERFLUOUS HAIR removed from the face, neck and arms. Harmless preparation positively guaranteed. Receipt and full instructions sent secure Iy sealed.One dime.Empire Nov.Co.,G.,Garrison, Tex Benuliful Chinese Primroses. We offer nice plants at 7c. each wiuter. Address Eastern Plant Co., Spring Mount, Pa.
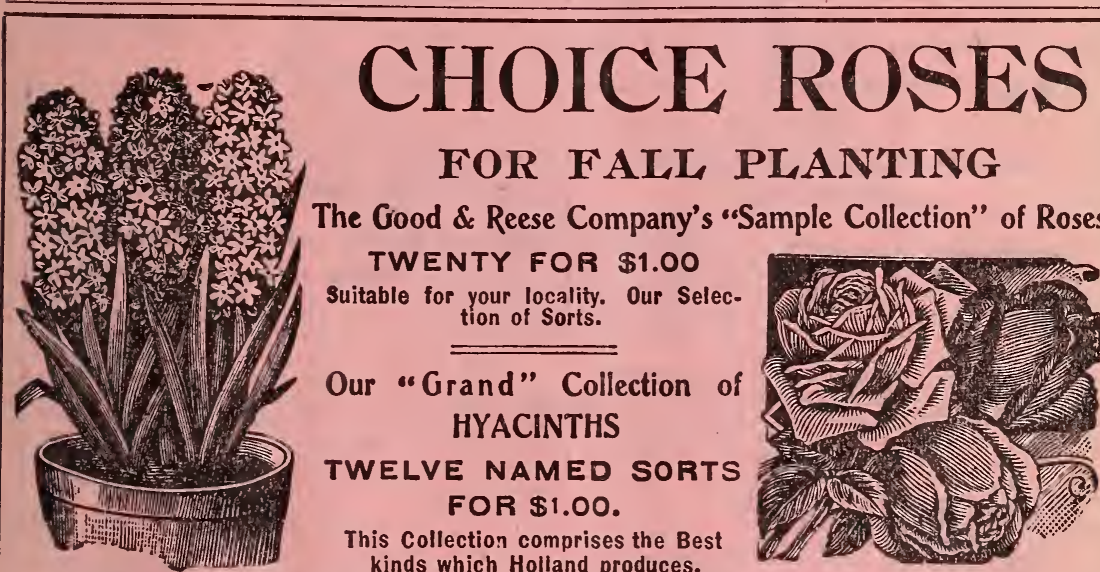

FOR FALL PLANTING

The Good \& Reese Company's "Sample Collection" of Roses

TWENTY FOR $\$ 1.00$

Suitable for your locality. Our Selection of Sorts.

Our "Grand" Collection of HYACINTHS

TWELVE NAMED SORTS FOR \$1.00.

This Collection comprises the Best kinds which Holland produces.

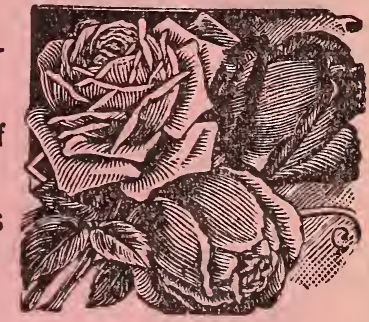

\section{Fifty-Gent Bargains in Bulbs and Plants.}

Set B-12 Prize-winning Chrysanthemums, || Set K-10 Lovely Begonias, choicest kinds all different.

Set C-10 Lovely Fuchsias, all different.

Set D-10 Elegant Double Geraniums.

Set E-10 Elegant Single Geraniums.

Set G-10 Choicest Double Hyacinths, all different colors.

Set J-10 Assorted Hyacinths, double, single and Roman.

Set $L-15$ Choicest kinds of Narcissus.

Set $\mathbf{P}-60$ Crocus, in four kinds.

Set $0-25$ Parrot Tulips, all kinds.

Set R-25 Double Tulips, all kinds.

Set S-25 Single Tulips, all kinds.

Set $W-4$ Fragrant Carnation Pinks, ready

Set $Y-4$ Begonia Rex, all different.

No two alike in these sets. Any three sets for \$1.25. Any five sets for \$2.00, by mail, postpaid. Safe arrival and satisfaction guaranteed. Order by the letters. We are the Largest Rose Growers in the World. Over one and one-half million Roses sold each year.

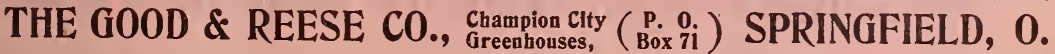




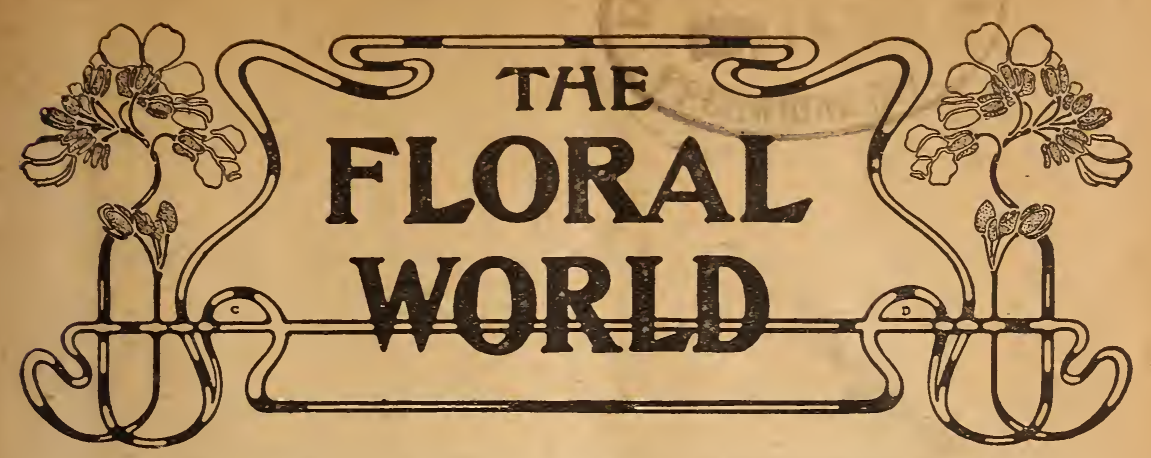

Vol. II. No. מै 々Springfield, Ohio, November $1902 \quad 25$ Cents a Year
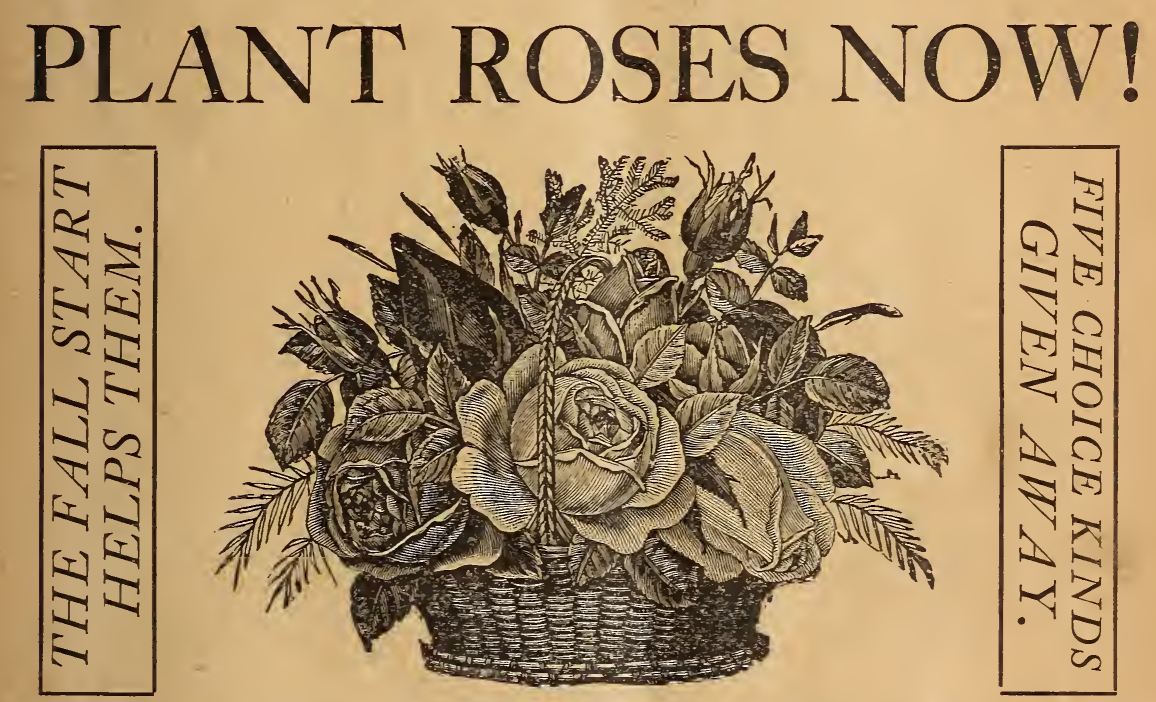

\section{Our Latest and Best Premium Offer}

TOU may have The Floral World one year and Five Choice Rose Plants, assorted colors, for only 25 cents. This is the regular subscription price of 1 the journal, so you are getting the Roses FREE.

We wish to largely increase the subscription list of THE FLORAL IVORLD, and we wish to have our friends try fall planting of Roses. Many persons have found fall planting much better than spring planting.

IVe recommend fall planting in all sections where the cold of winter is not too severe. If you have never planted in the fall, however, better make a trial on a small scale. Our splendid offer enables you to do so at practically no cost. Remember: Subscribe for THE FLORAL WORLD one year at 25 cents and we will give you Five Rose Plants Free.

The Roses will be of assorted kinds and colors, especially selected to suit your locality. As far as possible we will send one white, one red, one yellow, one pink, and one intermediate color. Five choice Rose plants and THE FLORAL WORLD a year for only 25 cents. Order at once. Address,

THE FLORAL WORLD, Springfield, Obio. 


\section{The Postal Revenue Awards}

The following matter, furnished by The Press Publishing Association, is self explanatory :

$\$ 121,848,047.26$ is the total revenue of the Post Office Department for the fiscal year ending June 30 th, 1902, as is shown by the following telegram from the Postmaster General :

Detroit, Mich., Oct. 21, 1902. Hon. H. C. Payne, Postmaster General, Washington, D. C.

Are total revenues of Postal Department for fiscal year, 1902, $\$ 121,848,047.26$ ? Please answer.

Press Publishing Association.

Washington, D. C., Oct. 21, 1902. Press Publishing Association, Detroit, Mich.

Replying to your telegram your figures are correct.

On receiving the above telegram, Mr. Henry Otis, an expert accountant, who had been previously appointed by the Committee on Awards, consisting of Hon. W'm. C. Maybury, Mayor of Detroit, the Hon. Jos. W. Donovan, Judge of the Wayne County Circuit Court, and the Rev. Chas. L. Arnold, Pastor of St. Peter's Episcopal Church of Detroit, commenced the work of choosing the winning numbers from the estimates which he had previously tabulated according to millions, thousands and hundreds. The following is Mr. Otis' report:

\section{Press Publishing Association, Detroit, Mich.:}

$$
\text { Detroit, Мich., Oct. 25, } 1902 .
$$

Gentlemen-Having been appointed by the Committee chosen by your Association to award the prizes in your recent Postal Revenue Contest, to tabulate the estimates and ascertain who should receive the prizes in that contest, I herewith submit a list of persons whose estimates show that they are entitled to the prizes and in the order named.

Respectfully submitted.

Press Publishing Association, Detroit, Mich.:

HENRY OTIS.

Oct. 25, 1902.

Gentlemen-The undersigned Committee, being satisfied that the list of estimates submitted by Mr. Otis is correct, hereby award the prizes in accordance with said list and in the order therein named.

Wh. C. Maybury,

Jos. W. Donovan,

Chas. L. ARNold.

Committe on Awards.

\section{Speoial}

The First Special Prize for the nearest correct estimate of the total revenue of Post Office Department for the fiscal year ending June 30,1902 , received before April 1st:

$\$ 1,000.00$. March 23-John H. Latture, Winchester, Tenn., Certificate No. 20115, Series D; Estimate $121,847,997$.

The Second Special Prize for the nearest correct estimate of the total revenue of Post Office Department for fiscal year ending June 30,1902 , received between April 1st and May 1st:

\section{Gerneral}

First Prize, $\$ 5,000.00$. E. Farquhar, To-

ronto, Ont., 9 Wilton Crest.... 77737G 121,848,047

Second Prize, $\$ 2,000.00$. E. L. Franey,

Farnam, Neb..............99634E 121,848,046

Third Prize, $\$ 1,000.00$. Frank P. Horn,

Easton, Pa., 914 Butler St.... 93103H 121,848,041

Fourth Prize, $\$ 500.00$. A. M. Allen, New-

town, Mo., Sullivan Co.........31688F 121,848,056

Fifth Prize, $\$ 300.00$. C. B. Johnson,

Palo, Mich................50171H 121,848,064
$\$ 1,000.00$. April 28-E. L. Franey, Farnam, Neb., Certificate No. 99634, Series E; Estimate, 121,848,046.

The Third Special Prize for the nearest correct estimate of the total revenue of Post Office Department for fiscal year ending June 30,1902 , received between May 1 st and June 1 st :

$\$ 700.00$. May 9-A. M. Allen, Newtown, Mo., Certificate No. 31688, Series F; Estimate, 121,818,056 .

\section{Prizes.}

Sixth Prize, $\$ 200.00$. Edith Roe, Detroit, Mich., 59 W. High..........63842H 121,848,023 Seventh Prize, $\$ 100.00$. R. L. Knabb, St. Louis, Mo.,3945 Cleveland Av.,76375H 121,848,006 Eighth Prize, $\$ 75.00$. P. La Due, Saginaw,E.S.,Mich, 516 Norman St. $43046 \mathrm{H}$ 121,848,001 Ninth Prize, $\$ 50.00$. Mrs. J. Capper,

Chandlersville, Ohio, R. F. D. No. 3

........................90774F $121,848,000$ Tenth Prize, $\$ 25.00$. John H. Latture,

Winchester, Tenn ..........20115D 121,847,997

In addition, ten prizes of $\$ 15$ each, 142 prizes of $\$ 5$ each, 160 prizes of $\$ 4$ each, 180 prizes of $\$ 3$ each, 200 prizes of $\$ 2$ each, and 260 prizes of $\$ 1$ each have been awarded on guesses ranging from $\$ 121,848,-$ 106 to $\$ 121,842,971$. Complete list of the prize winners will be furnished on application to the Press Publishing Association, Detroit, Michigan. 


\section{Premium Collections for CLUBS OF FOUR}

\section{Any Person Accepting the Offer on the FIRST COVER PAGE of this Number may be Counted in a Club.}

\section{Premium No. 2 LIT'TLE DAISY COLLECTION \\ Of 25 Bulbs for Winter Flowering}

One Large Flowering Hyacinth.

Five Crocus, all different.

Two Beautiful Tritileas.

Three Lovely Tulips.

Four Freesias, delightfully fragrant.

One Elegant Narcissus.

Four Snowdrops.

Five Beautiful Buttercup Oxalis.

\section{Premium No. 3 oxAlIS-Mixed.}

25 Beautiful Winter-Blooming Oxalis

Mixed Colors, including Rose, Single Yellow, Pink, White, Double Yellow, and Bermuda Buttercup.

\section{Premium No. 4 OUR SUPERB COLLECTION}

Of 4 Choice Named Double Hyacinths

Princess Royal.

Prince of Waterloo.

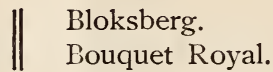

\section{Premium No. 5}

Anna Carolina.

Alba Superbissima.

\section{Premium No. 6}

Murrillo.

Yellow Rose.

La Candeur.

Gloria Solis.

Count of Leicester.

Rose Blanche.

\section{Premium No. 7}

Murrillo.

Yellow Rose.

La Candeur.

Gloria Solis.

\section{OUR GRAND COLLECTION}

Of 4 Choice Named Single Hyacinths

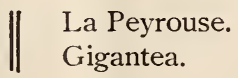

DOUBLE TULIPS.

12 Choice Named Double Tulips

Rosina.

Rex Rubrorum.

Agnes.

Ma Cousine.

Alba Maxima.

Queen Victoria.

\section{SINGLE TULIPS.}

12 Early Single Flowered Tulips

Count of Leicester

Rose Blanche.

Rosina.

Rex Rubrorum.
Agnes.

Ma Cousine.

Leonard de Vinci.

Rose Gris de Lin. 


\section{Premium Collections for CLUBS OF FOUR}

Any Person Accepting the Offer on the FIRST COVER PAGE of this Number may be Counted in a Club.

\section{Premium No. 8 CARNATIONS.}

Mrs. Fisher.

Rose Queen.

\section{Premium No. 9}

Glory of the Pacific.

Mrs. O. P. Bassett.

Ivory.

Mrs. J. Lewis Childs.

\section{Premium No. 10}

White Swan.

Mrs. Hamilton.

General Grant.

\section{Premium No. 11}

Nephrolepsis Bostoniensis.

Weeping Lantana.

Jasmine.

Revolutum.

\section{Premium No. 12}

White Maman Cochet.

Cloth of Gold.

Pink Soupert.

New Maroon Carnation, Gen. Gomez.

Genevieve Lord.
Armazinda.

UP-TO-DATE SET OF

CHRYSANTHEMUMS

Golden Wedding.

Mrs. H. Weeks.

Mrs. Egan.

Eda Prass.

\section{GERANIUMS}

FOR WINTER BLOOMING

Fire Brand.

Arbutus.

Crystal Palace Gem.
Galilee.

Bronze Bedder.

\section{VARIETY OF PLANTS}

For the Window Garden

New Single Violet, California.

Lady Hume Campbell.

Sanseviera Zeylanica.

Alternanthera Aurea Nana.

\section{ROSES FOR FALL PLANTING.}

Frances E. IVillard.

Catherine Mermet.
Safrano.

Pink La France.

White La France.

\section{Premium No. 13}

Marguerite.

Argentea Guttata.

Bertha De Chateaurocher.
Rosain's Patrie.

Monarch.

Black Prince.

GIVE NUMBER OF COLLECTION WHEN ORDERING. 


\section{The

\section{A JOURNAL OF HOME FLORICULTURE.}

Vol. II., No. 3

Springfield, Ohio, November, 1902

25 Cents a Year

\section{COMPLIMENTARY.}

I like the two issues which I have seen of THE FLORAL IVORLD very much. It is strictly floral and practical in its suggestions. I am glad to find something suitable for us who live in the South, which is generally lacking in such papers. Thanks to the two ladies from Georgia for their very timely advice, which I shall adopt when my premium bulbs arrive.

Florida.

Mrs. C. F. Fischer.

I am much interested in our little FLORAL WORLD and hope for its success.

Pennsylvania. Perle Heinyrater.

I like The Floral World ever so much and have found much help from its pages.

New York. Mrs. Irene M. Skiff.

\section{WHAT TO DO IN NOVEMBER.}

Time for early frosts; protect plants that are still in beds.

Have your pots well cleansed and soil mixed ready for potting.

Even the drainage should be collected to avoid hurrying.

Few plants with good nursing are better than many neglected ones.

Look over plants before bringing in, to see that there are no insects on them.

Order bulbs now and plant as soon as possible.

Remove faded leaves and cut back shaggly branches, with an eye to symmetry.

Accustom your plants to the change, before the time for fire in the room.

Lack of interest and energy among plants means a lack of flowers.
Water the foliage as well as the soil, to keep down the red spider.

One good sprayer is worth more than all insect powders.

Repot plants when roots cover ball o earth.

Little can be expected of plants watered too much or too little.

Don't forget to renew for THE FLORAL IVORLD.

Missouri. Mrs. Candace Powell.

\section{THE CHRISTMAS CHERRY OR CELES.} TIAL PEPPER.

There is no more pleasing sight to the eye than a well grown plant of the celestial pepper; and more especially so, as all winter long we have its flowers and beautiful fruit, which form such a striking contrast to the other plants.

It is readily raised from seed sown in the spring of the year. I generally use a small flat box filled with sifted garden loam and a small quantity of well-rotted stable manure. After packing the soil down firmly, sow the seeds by sprinkling on the top of the compost, then sift some more soil over the seeds and pack lightly again. Water well, taking care not to wash out the seeds, and place in window to germinate.

You will be rewarded in a few days by tiny shoots, which, in the course of a few weeks, after having made their second pair of leaves, you can begin to transplant into thumb pots. From tiny shoots, you will soon raise large plants which, as September advances, will begin to be loaded with the beautiful fruit. A wellgrown plant will show fruit in every stage 
of growth and in three or four different colors, creamy white, pink and vivid scarlet all on the same bush together-truly, a beautiful and most wonderful sight.

\section{Long Island. \\ J. EdGar TOdD. \\ CRASSULA CORDATA.}

There is a peculiar charm about the crassula cordata for me, and this charm is increased to a fascination when a fine specimen is displayed. As it is a plant greatly given to branching and graceful drooping, it should always be grown on brackets in the window or conservatory. For this purpose it is unexcelled and unequaled by any other plant of the same habit. It is impossible to understand why the crassula has failed to receive attention from the amateur florists, for it is of most wonderful adaptation. It will grow and do well in a shaded position, but does better in the sun.

While considered a strictly winter bloomer, it will bloom effectively any season, and the foliage remains perfect all the year. The crassula throws out roots at the joints, making it easy to propagate.

My strong and beautiful plant of crassula was grown in very rich sandy loam, with charcoal for drainage. Water freely in summer, but sparingly in winter, with frequent spraying when the temperature is dry. Every branch now is tipped with tall panicles of exquisite blooms, and it is really worthy of more praise.

\section{Louisiana. Mrs. W. N. White. \\ COME AND SEE MY PIAZZA.}

My south piazza, which is entirely screened, has shelves on each side of the door and on the walls, upon which are set galvanized pans filled with sand, for pots to stand in. Here about eighty plants (all raised from small up) do well the whole year round. Canvass curtains nailed outside are rolled down during cold nights, and if danger of frost a burning lantern stands on the floor all night.

In front of one window are Japanese climbing ferns, beautiful to look through. On the floor by the other window stands a handsome tall palm. Alba perfecta grandiflora begonia has, besides its old growth, one sprout over twelve feet long, reaching over the door across the roof. This, by pinching, has formed many branches, all covered with large bunches of white flowers.

My plants are different large begonias, palms, aralias, ferns, cactee, asparagus vine, caladiums, and a splendid pandanus veitchii. These, and about thirty plants in the house, (generally admired by all) are a great comfort and pleasure for me to take care of. Outside the piazza, the base is covered with blooming geraniums, and rosa de montana draped across the screen, makes this an attractive place.

Florida. Mrs. C. F. Fischer.

\section{PLANTS FOR WINTER BLOOMING.}

I have a large crab cactus, which blooms every Christmas. In spring I transplant, giving a good rich soil, and set aside to start growth, then I bring it into the sun, for summer sunshine makes winter flowers, and water frequently, but not too much, as they rot easily. Once a week I give a shower bath and a liquid manure. Do not allow them to become chilled in the fall. I bring them in early and keep them in a comfortable room.

In September transplant calla lillies, putting in a large pot. Use earth from woods, well mixed with hog manure and sand. To secure good drainage use charcoal and brick, pounded fine, for bottom.

Water occasionally and keep in condition for growing until frosts come, then remove to the house, placing where strong light and sunshine strikes them. Keep pot standing in a pan of water and every morning, after the plants are several inches in height, give water as hot as can be borne by the hands.

Bathe leaves to keep dust from closing pores. In a few months after transplanting they will bloom profusely. When done blooming set in a frost-proof place, and in summer turn pot on side to give a good rest. Perle Heitzenrater.

Pennsylvania. 


\section{PETUNIAS.}

If some of the flower lovers will try the petunia in their hot, dry rooms, they will have a plant that will not disappoint them, as it will bloom and bloom. One might get a paper of mixed seed and sow them in the spring and pot them in the fall. I have a pot full that I brought into the house in August, which were in bloom when I took them up, and they have bloomed ever since and are putting out new bloom all the time. To show you what rough treatment they will stand, I found the plants neglected but in bloom. After taking them up I wanted the pot for another plant, so reset them in the ground and again took them up and potted, and they are blooming now.

Mrs. Emma AnKney.

South Dakota.

WINTER CARE OF ROSES.

Last fall I had a few roses which I transplanted in small boxes, and after watering them well I put them in a shady place for a few days. I then put them on a table near a south window up-stairs, where there was no fire near, and by spring they had grown to be nice plants. I then put them out in the garden, where they have been blooming all summer, and are still full of buds and blossoms, (on the 23d of September). I think they are now large enough to remain out doors. I think all flower lovers should have a few Chinese primroses for winter blooming. Last winter I had five windows filled with them. They looked like one large bouquet from December to April, in different colors of pink, lilac, red, white and yellow center.

Pennsylvania.

Alice Fulmer.

Three years ago I bought eight rose bushes from a florist and potted them in soil made of three parts loam and one part manure, allowing a teaspoonful of bone-dust for each plant. I set them in a shaded place for a few days, then gradually brought them to the light, then all the sunshine they could get from a suoth window. They began to bloom in November and until the following June were never out of bloom-some bushes having fifteen roses at one time.

In June I put them in the garden to rest, or grow, keeping the buds pinched off. In September of each year I lift and repot in fresh soil as before, and they are ready and willing to begin their winter work. So much for the outline, but the "doing well" depends largely upon the care they receive during the winter. I shower mine once a week, or oftener, to keep down the little red spider that is so troublesome. After they begin to bud I give them manure water once a week, and feel well repaid for my trouble.
Michigan.
M. B. Воотн,

THE PEONY BANKSII.

A banksii peony growing in the open garden disappointed me in the size and quality of its flowers. I removed it to a light place where the house would shade it after ten o'clock. The top soil was rich loam, its feet penetrating stiff clay from the cellar. It made strong growth, but the stems were so crowded all its flowers could not reach out to the light. I filled in amongst them with rich earth, bending the outer ones as flatly as possible without breaking them, placing a stone on each to keep it in position, filling in more earth, and gave a heavy coat of manure every fall, covering the tops with evergreen branches through the winter and until danger of late spring freezing is past, as this sometimes injures the buds, which start into growth so early. The result was that every branch rooted freely and made strong upright growth with a large double flower on the tip of each branch, presenting a half-sphere of immense flowers - 160 by actual count-and literally carpeting the ground with their rosy petals when they faded.

Indiana.

Sarah A. Pleas. 


\section{THE FLORAL WORLD}

PUBLISHED MONTHLY BY THE

\author{
FLORAL WORLD COMPANY \\ 12 to 14 South Limestone Street \\ SPRINGFIELD, OHIO
}

\section{Subscription Price, 25 Cents a Year}

Entered as second-class matter at the Postoffice in Springfield, Ohio.

We will give $\$ 26.00$ in prizes for the best five articles for publication in the January number of THE FLORAL IVORLD, which may be submitted by subcribers.

The first prize will be $\$ 10.00$; the second $\$ 7.50$; the third, $\$ 5.00$; the fourth, $\$ 2.50$; and the fifth, $\$ 1.00$. The awards will be announced in our February issue.

No article which contains more than two hundred words will be considered in the prize decision. All contributions entered in this prize contest must reach us not later than December 1 .

The purpose of these prizes is to secure for publication in The Floral IYorLd matter which gives the actual experiences in flower growing of those who have subscribed for the journal. Prizes offered for articles published in the October number have been awarded as follows:

First Prize-Mrs. M. E. Shuff, Pennsylvania.

Second Prize-Mrs. A. T. Hurst, Kentucky.

Third Prize-Mrs. Nelson Puff, Jr., New York.

Fourth Prize- "Harl," Missouri.

Fifth Prize-Mrs. Margaret Styles, (Gretchen) Texas.

\section{SOME NEW IDEAS.}

The plant window should be a thing of beauty and not a plant hospital or Home for Aged Plants, It should suggest luxuriance, and this is oftener accomplished by one or two perfect specimens than by a confused jumble of even the most desirable plants. Sometimes a tropical effect can be obtained by "massing" several plants on a background of vines, but the best results are usually effected by giving each plant room to show its individuality. Plants are also healthier when the air circulates freely around them. You can keep a good many plants, however, if you will only plan a little. Chrysanthemums, asters, with the sun-loving plants, will monopolize the sunny windows during early winter. But your bulbs can bekept mostly in the dark closet and your begonias, primulas, cineraria, genisto, plumbago, etc., will do well in a north window or on a table back from the window if the light is good.

As the chrysanthemums and other plants finish their usefulness put them in the cellar or out of sight somewhere, for the yellow leaves of one plant "ripening off", will spoil an otherwise beautiful window. Replace them with your reserve spring blooming plants. With a little study and management you can have a continuous succession of plants that will please your artistic friends and be a pleasure to everybody-yourself included.

Iowa.

CORA I. GRIFFITH.

\section{A WORD TO THE FLOWER LOVERS OF NEBRASKA.}

Do you sometimes get discouraged? Let me advise you what to do-_"try, try again." In September send to some reliable florist an order for bulbs-crocus, hyacinths, tulips and narcissus. Then prepare beds by spading deeply, but do not raise your beds; leave them level to retain moisture. When your bulbs come, set them six inches deep. In December cover the beds with leaves or straw. In spring remove the covering and you will soon enjoy bud and blossom.

In February send to your seedsman for one packet each of verbena, phlox, petunia and portulacca. Plant in March in boxes of finely pulverized soil in the house, dampen them, then cover with a wet cloth and keep moist and warm until they germinate. By the time your bulbs are through blossoming your seedlings will 
be large enough to transplant to the beds, where they will soon begin to bloom, and will continue a mass of bloom all summer, not disturbing bulbs at all. In transplanting, water the seedlings well, thoroughly soaking the ground, then shade from the midday sun for a few days. Water thoroughly: once a week through dry weather.

Nebraska. Mrs. A. T. Converse.

TO THE FLORAL WORLD.

The bulbs you sent, received all right,

We've planted them with care,

And trust they'll make our home more bright,

With many blossoms fair;

And when the blossoms we may view

We'll think, dear FLORAL WORLD, of you.

This world would be a dreary place

Had God not made the flowers.

Their radiance we would not efface,

They cheer our lonely hours.

And when the lovely flowers we view

We'll recollect the giver too.

A. R. Perham.

\section{RAISING PANSIES.}

In April I sowed a-packet of seed and raised twenty-three plants. In May I prepared a bed on the north side of the house, set the plants in it, watered every evening when needed-and that was most all the time, as the soil dries out here so fast-and by the last of June they commenced blooming, and up to this writing I have picked a large dish full of the largest blossoms every morning. An artist could not paint any nicer pansies than I have had. Some say that spring-sown seed won't bloom through July, but I have found out that it is a mistake. It is the care they do not get that is the cause of their not blooming. Also I have one white petunia plant that measures three feet across the top and has bloomed ever since a tiny plant. It sets in one end of the pansy bed. My pansy stalks are eight inches high and have five and six branches on one single stalk. I hope this will encourage others to raise pansies, for I think there is no flower any nicer. Of course, they must have care, more so here than north or east, as the sun and wind is so hot. I hope to hear from other parts of Oklahoma, as I love to read experiences of others and to learn from their failures.
Oklahoma.
Molly Gilbert.

\section{GOOD WINTER-BLOOMING PLANTS.}

One of the best plants I have ever grown for winter blooming is impatiens sultana. I have a plant that I raised from seed last spring. It is now a fine large plant covered with light pink blossoms. Its culture is simple. A soil of leaf-mold and sand, water when the soil looks dry, and a thorough sprinkling with clear water twice a week, with good drainage seems to meet all its needs. It does well in sun or shade.

Another old but good plant is the petunia. The small-flowered varieties are pretty, but I consider the giant-flowered single the finest. The blossoms are very large and the colors beautiful. A soil of loam, leaf-mold and sand, with good drainage and a moderate amount of sunshine suits it well. The soil must not be allowed to become dust dry or the leaves will turn yellow. Sprinkle once a week.

Linum trigynum is a fine plant also. It has small green leaves and bright yellow flowers, shaped like a morning-glory only smaller. It needs a good-sized pot, soil of loam, leaf-mold and sand, good drainage and must be sprinkled twice a week to keep the red spider away. It does well with a little sun.

Another good yellow plant is oxalis, " Bermuda buttercup." It needs a soil composed largely of leaf-mold, plenty of sunshine and water. It will be covered with blossoms for months.

If you have plenty of room the abutilon is a good winter bloomer. With ordinary care they grow to be fine large plants and blossom freely.

All of the above plants are benefitted by admitting fresh air daily and keeping the air as moist as possible.

New York. Jennie M. Reynolds. 


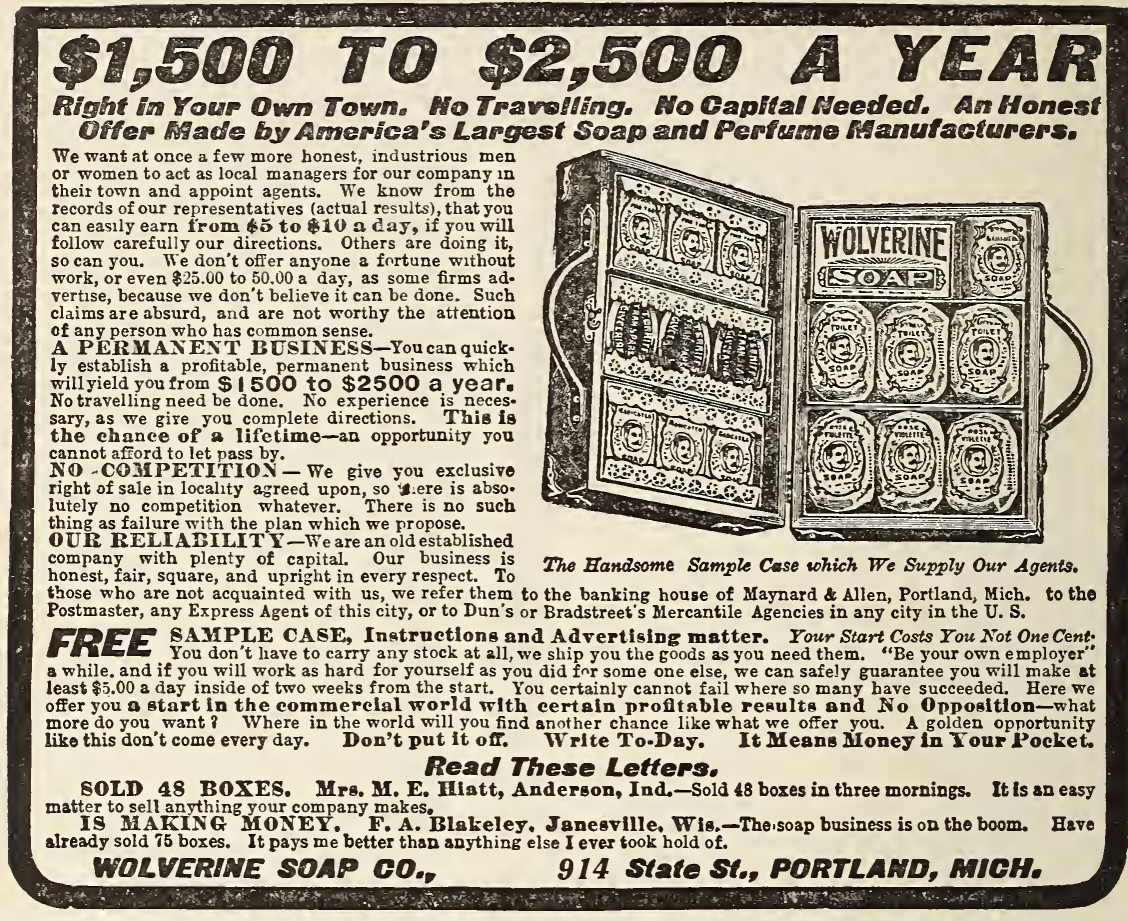

\section{BUDDING OF ROSES.}

I prefer the castilian rose as a foundation, as it is well adapted to our climate and is a strong grower. Our two springs, March and August, have been found to be the best times with us, as the bark of the stalk separates easily from the pith. In the bark of the growing castilian I cut a lengthwise gash about one inch in length, with a short cross cut at each end and slip a dull knife point between the bark and pith. If they separate easily, the time is right for budding.

At the base of every rose-leaf is a tiny bud. When this bud is about as large as half a grain of wheat, it is about the size required. With your knife slice off from the side of the choice stem the bud with enough bark to hold it well-perhaps a half inch above and below. Remove the pith and slip the bud into the gash in the castilian stalk; lay it smooth, allowing the main bark to cover all the slip except the bud itself. Wind tight with soft cord until growth commences, after which the cord should be loosened.

Mrs. Thos. D. Satterwhite. Arizona.

\section{THE CHINESE SACRED LILY.}

The Chinese Sacred lily will give more pleasure to the amateur in the ordinary window-garden than almost any other bulb. The growth is almost phenomenal. The rank, green foliage is beautiful in mid-winter, and each bulb sends up half a dozen spikes, crowned with the deliciously fragrant flowers.

When grown in water and pebbles and placed in a pretty cut-glass bowl, this is exceedingly ornamental. The Chinese lily is much more satisfactory in water than when grown in soil and blooms in three weeks after starting. I drain off water about twice a week and fill up with

(Concluded on page 9) 
(Concluded from page 8 )

fresh. I use a clear glass bowl, about eight inches around, and plant three large bulbs. When old growth over top of bulb is very dry and hard I turn bulb upside-down in water for a day or two, until it is softened, and then the growth is much more rapid.

When through blooming I throw old bulbs away and replace with fresh bulbs, and thus have a succession of these sweetly fragrant flowers during the whole winter.

Kentucky. Miss Laura Jones.

\section{THE HYACINTH IN GLASSES.}

The hyacinth is much prettier and more attractive grown in water than in soil, but it requires a little more care to grow them in glasses than in soil. The water must be kept sweet and changed regularly; if this is neglected the roots and bulbs are sure to rot. I find a bit of charcoal in water will help to keep it sweet, but the water should be changed twice a week. The tall, slim hyacinth glasses are the most attractive and I prefer the uncolored glasses, as it is as interesting to watch the root growth, as it is that of the foliage and flowers.

It is necessary to place in dark at start, for roots to form, and here one can see when roots are well formed, and know when to bring to light and sunshine. When buds are inclined to open low down in bulb, a dark paper cone placed over bulb will induce them to grow to the usual length.

Kentucky. Miss Laura Jones.

\section{YOU MUST LOVE YOUR PLANTS.}

In order to succeed with plants one must love them, use common sense and good judgment in their care. Have your jars perfectly clean. Scald those that have been used. Put charcoal in the bottom, as this keeps the soil sweet. Put a thin cloth or moss over charcoal, then good soil. Take small slips in July or August, firm the soil around them, water and set in shade until started, then bring into the light gradually. Water from the bottom. For soil I use earth from the henyard, some coarse sand and woods earth if I have it, if not a little phosphate. Do not fill jars too full of earth. Put in several kinds of geraniums, or begonias in a jar, taking care to get a good combination of colors. This gives more variety in less room.

New York.

MrS. I. M. SkIFF.

\section{TO WOMEN WHO DREAD MOTHERHOOD!}

\section{Information How They May Give Birth to Happy, Healthy Children Absolutely Without Pain-sent Free.}

No woman need any longer dread the pains of child-birth; or remain childless. Dr. J. H. Dye has devoted his life to relieving the sorrows of women. He has proved that all pain at childbirth may be entirely banished, and he will gladly tell you how it may be done absolutely free of charge. Send your name and address to Dr. J. H. Dye, Box 137 Buffalo, N. Y., and he will send you, postpaid, his wonderful book which tells how to give birth to happy, healthy children, absolutely without pain; also how to cure sterility. Do not delay but write to-day.

\section{Make Your Money}

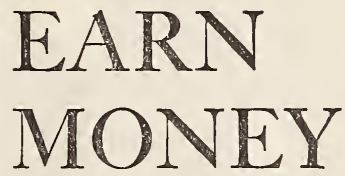

Persons who have money to invest are invited to write us. We offer no extravagant profits, nor do we make improbable promises. Engaged in an established business, for the assuredly profitable extension of which additional capital is needed, we have for sale stock which bears a guaranteed dividend of

\section{SIX PER CENT PAYABLE SEMI-ANNUALLY}

No higher dividends can be secured from any other investment of equal safety and character. Let us send you full particulars. Address

"INVESTMENT"

P. O. Drawer 755

STPRTERIIAID, O. 


\section{OUIR ITH \\ "Monte Carlo"}

The handsomest and best fitting $\mathrm{g}$ a rment in America for the money. No.685 -This sty $l$ is h garmen $\mathrm{t}$ made 30 inches from fine Wool Kersey, lined with guaranteed satin, beaut if ully made and elegantly finished.

Exactly as illustrated.

Price
only 10.00

Send for our Special Catalogue No. 200. It is Free. American Cloak \& Fur Co., 174 CHCAGO, ILiL

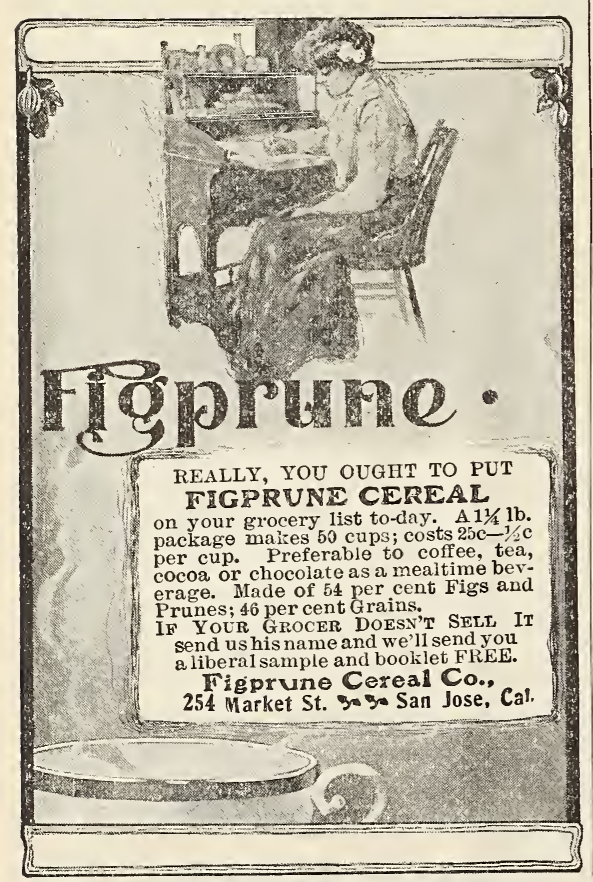

ABOUT OXALIS.

These will be found invaluable for the window garden during the winter months. As oxalis bulbs are small, six or ten, according to size, can be placed in a fiveinch pot. It is advisable to place the pot, after planting, in the cellar for a couple of weeks, or until growth commences. They do best in a moderate temperature, 60 to 70 degrees. Water should be given as required, and when plants are in bloom a little liquid manure twice a week will be found beneficial.

Let the soil be only moderately rich. These are lovely plants for hanging baskets or for brackets. They are constantly in bloom throughout the long dreary winter and give a cheery, springlike appearance, to even the humblest of windows. It is indeed a splendid offer made by THE FLORAL WORLD to obtain a start in these little beauties, leaving out the paper, also the other bulbs, we are getting more than our money's worth.

Iowa. - Mrs. L. C. Whitaker.

\section{SUCCESS ÚNDER DIFFICULTIES.}

To begin with, I have just a small room upstairs, for a sitting and dressmaking room. It has two common-sized windows, one east, one south. I use mostly tin cans, as they are cheaper, lighter to handle, and won't break when I move. The soil is clay and mixed garden soil, sand and rotted sawdust from where an icehouse had stood three or four years ago, mixed thoroughly. I made holes in the bottom of the cans, filled in an inch of pebbles for drainage, then set my slips, watered with warm water, set in the dark for a day or two, brought gradually to the light, showered once a week after they began to grow well, and watered when needed. When the weather began to get cool, I watered with warm soap suds once a week, and once every two weeks with soot tea, made from wood soot. My plants were the admiration of

(Concluded on page 11) 


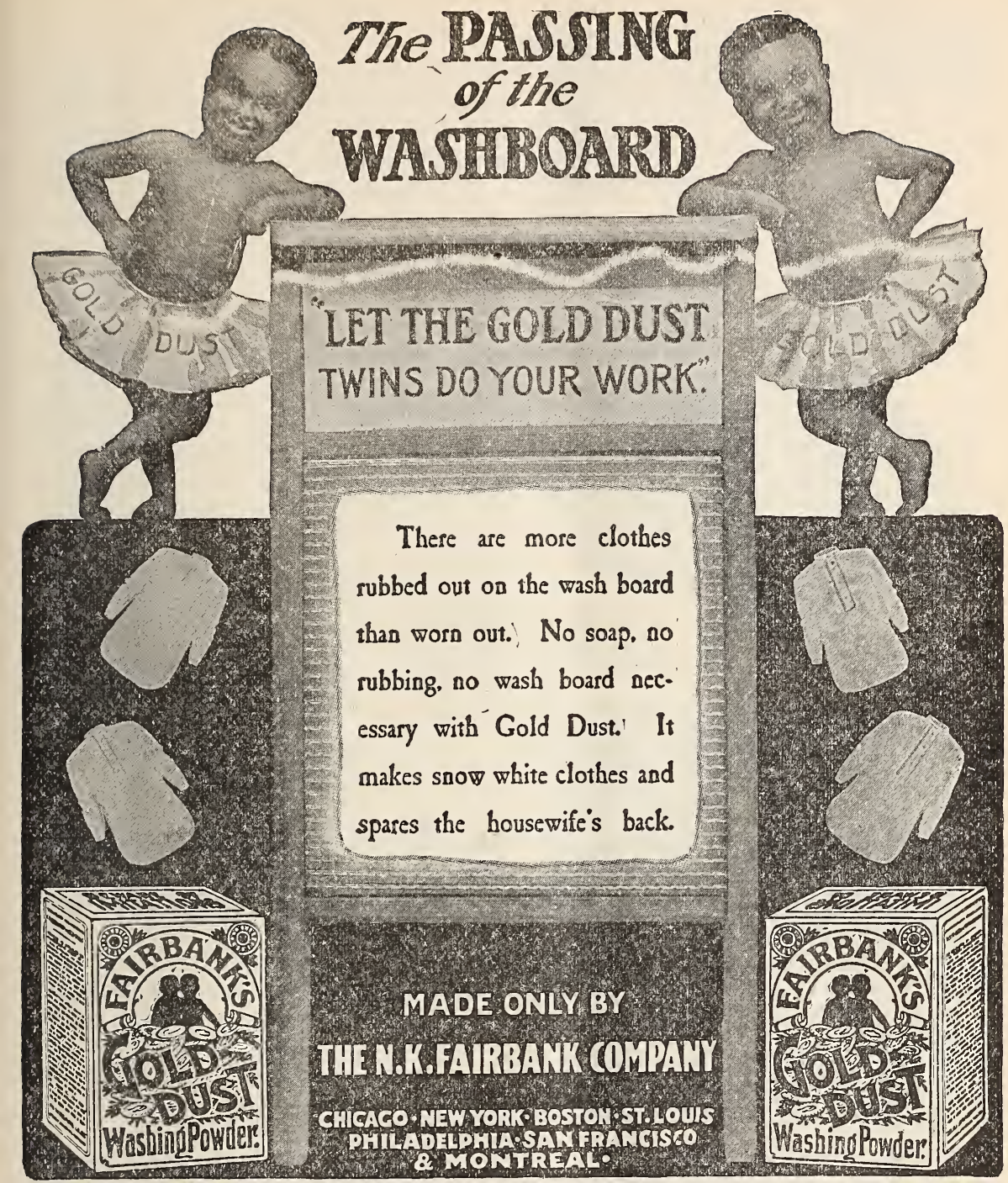

(Concluded from page 10)

all who saw them. While away from home a cold snap froze every one, twentysix in all, but, nothing daunted, I procured more seeds and bulbs and have my windows filled again with beautiful plants that will bloom this winter, I hope. Miss Ella Day. Missouri.
WANTED-A LEMON GERANIUM.

I have searched for several years for a geranium. It grows in tree form, has light green leaves similar to the nutmeg geranium, but a little thicker leaf. The fragrance is like that of a lemon. Have any of the readers of THE FLORAL WORLD a plant like it that I could get? New York. Mrs. Ione M. Skiff. 


\section{BULBSandPLANTS}

FOR WINTER

\section{GIANT ROSE COLLEGTION}

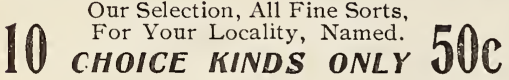

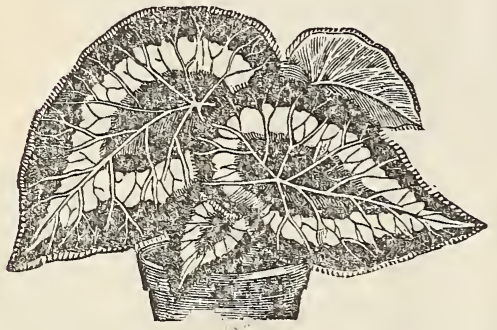

Three choice Hyacinths, different colors, price 25 cents.

Twelve elegant Tulips, all colors, price 25 cts. Thirty Crocus, assorted colors, price 25 cts.

Three large field-grown Carnations, price $25 \mathrm{cts}$.

Five elegant Geraniums for house culture, price 25 cents.

Five finest Chrysanthemums, best for winter blooming, price 25 cents.

Five Fuchsias, splendid for the winter window garden, price 25 cents.

Five flowering Begonias, the best, price 25 cts. Three Rex Begonias, choice selection, price 25 cents.

Three Decorative Palms, price 2.5 cents.

Send in your order to-day. Handsomely illustrated catalogue sent free. Address,

GREAT WESTERV PLANT CO., Box 60. SPRINGFIELD, OHIO.

\section{THE CYCLAMEN.}

How seldom we see this lovely plant, and yet how many go into raptures over a plant in bloom. This very beautiful, winter-flowering bulb has three-fold merit, for it combines neatness of habit, elegant foliage and a lovely flower. The bulbs can be bought of any florist. Plant in October or November in a five-inch pot, using light rich soil. When planted it should be at least one-third out of the ground, or the whole crown exposed. Many lose their fine bulbs by covering crown of bulbs. Water sparingly until it grows vigorously, then keep moist. If the plant never bloomed, the beauty. of its foliage alone would find it among choice collections. But bloom it will, if you only give it a chance. The dark-red and white blossoms make a lovely contrast to the silver and green foliage. The giantflowered type is the most popular and gives the best satisfaction.

Iowa. MIRs. L. C. IVhitaker.

\section{THE ROMAN HYACINTH.}

Last winter I had some beautiful Roman hyacinths. I put them in berry baskets. I put them away in the dark, like any other bulb, then I brought them in and put them in a north window back of the cook-stove for awhile. When they needed water I set them in a pan of warm water for about thirty or forty minutes; this will make the stens grow tall.

After the buds were nearly ready to open, I put them in a sunny window in the sitting-room. After they had opened I changed them to different places, still

(Concluded on page 13)

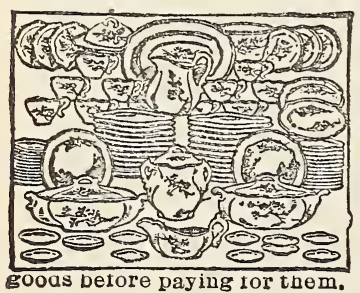

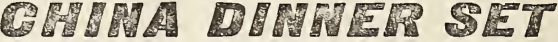
FOR SELING 15 POUNDS QUEEI BAKING POWDER

Our inducements are enormous. To every purchaser of a pound can of our Queen Baking Powder with a bottle of Vanilla Extract, box of Wash Blue, package of Pepper, cake of Toilet Suap and a box of Polishall, we give Fr:E a weautitul izoyal Biwo Pitcher and 6 classes to match. To the lady Who selis 15 pound cans Queen Baking Powder we wil make a present of a handsome 50-Pioco Dinnor set, fuil size tableware, handsomely deco. rated and gold traced. We also give Waists, Skirls, Jackets, Furniture, Sewing machines, and hundreds of other valuable premiums for selling our groceries. We also give cash commission. Write to-day and get our illustrated plans offering many premiums to customers; it will pay you. No money required. We pay freight and allow agents time to deliver 
(Concluded from page 12)

giving them the warm water, but not making them so wet. When they began to fade I cut the blossoms off, and set the bulbs out in the yard, allowing them to mature the same as any other bulb.

Oregon.

DORA LEAKE.

\section{THE AGERATUM.}

I consider the ageratum one of the best plants for house or garden, as it blossoms profusely and continues in bloom a long time. The very name, ageratum, suggests a continuance of fresh blossoms. It is easily obtained by rooting slips of the plant in water or common garden soil. I have tried several varieties. The light blue with white center is very delicate, but I have better success with the deep blue and consider it more hardy. It blossoms in the garden or in pots, out of doors all through the summer and fall till destroyed by late frost. I had a pot of it in the house last winter and it continued in blossom nearly all of the time and required no care except to be watered occasionally. Give rich soil and plenty of room for roots and use no liquid manure or prepared fertilizer. When root bound, transplant to a larger pot. Cut off the blossoms as soon as they begin to fade, and cut back the old stalks if necessary, to give the new ones a better chance.

A. R. P.

\section{THE QUEEN OF OUR GARDEN ROSES.}

Stately she stands in her queenly beauty,

The queen of our garden roses;

Like a sentinel keeping guard,

While each comrade soundly reposes.

The Summer breezes sigh around her,

The Autumn leares fall at her fect,

The dewdrops moisten her rosy cheeks,

And the humming-bird sups the honey sweet.

But WVinter is coming, fair garden rose,

The frost will burn your rosy face,

But all the frost and snow that come,

Cannot mar your stately grace.

Louisiana.

M. L. HLRLEY.
DARKEN YOUR GRAY HAIR

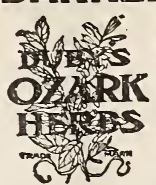

DUBY'S OZARK HERBS restoregray, treaked or faded hair to its natural color. beauty and softness. Prevents the hair from falling out, promotes its growth, cures and prevents dandruff, and gives the hair a soft, glossy and healthy appearance. IT WILL NOT STAIN THE SCALP, is not sticky or dirty, contaius no sugar of lead, nitrate silver, copperas, or poisons or any kind, but is comcopperas, or poisons or any kind, butis composed of roots, herbs, barks and flowers. It IS NOT A DYE, but a HAIR TONIC and cost ONLY 25 CENTS TO MAKE ONE PINT. It will produce the most luxuriant tresses from dry, coarse and wiry hair, and bring back the color it originally was before it turned gray. There is more health to the hairin a single package of DUGY's OAll OZARK HFRB CคMPANY, St. Louis, Mo.
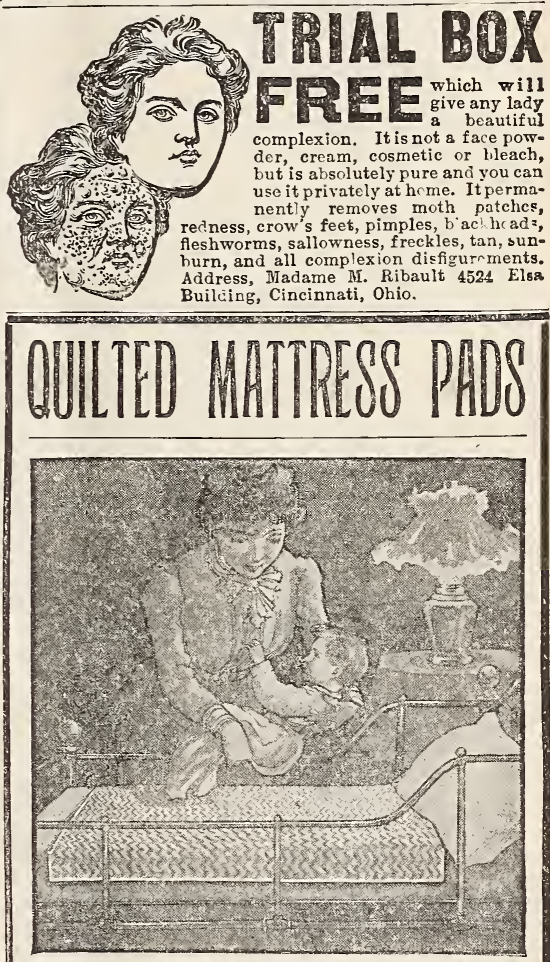

Fit 5our bed with a Ouilted Mattress Pad and keep it in a cool and sanitary condition. A sound, refreshing sleep on hot nights will be made possible.

These pads are made of bleacher muslin, both sides quilted, with pure white wadding of the best grade between. They wash perfectly.

Good as new after laundering, and the low cost places them within the reach of all.

SEND FOR SAMPLE.

The Excelsior Quilting Co.

15 Laight St. NET IORK.

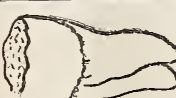

For 25e. K. \& S. Tooth Filier fills the teeth for 6 montls. Stops toothirhe instantly and prevents decay. Tanufacturer, GEO. $\mathrm{R}$, BAKER, fiemistered Pharmarist.

RANDOLPH and CLAIZK sT., CHICAGO. 

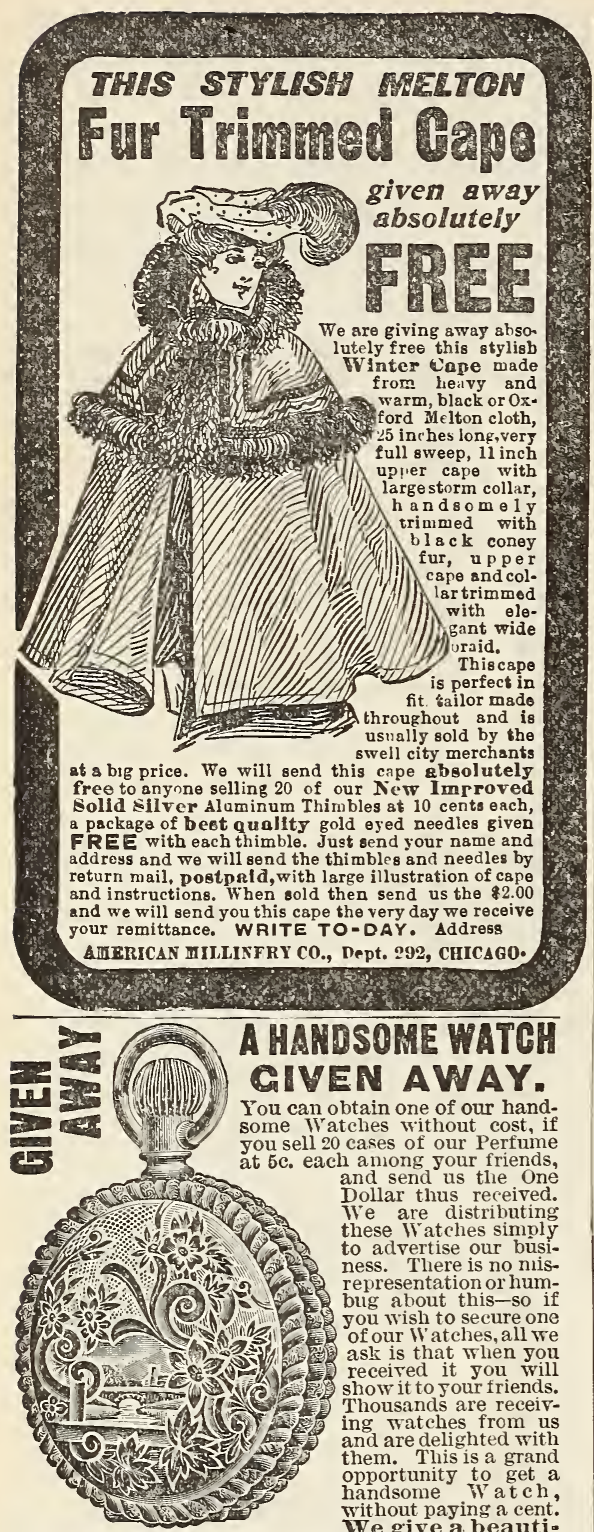
ful Watch as a present to anyone wlio sells 20 cases of our Perfume at $5 \mathrm{c}$. each and renits us $\$ 1.00$ for same. Send your name and address and we will mail you the Perfume postpaid the landsome Gold laid Wateh We trust you and take back all you cannot sell. No catch-words in this advertisement. We mean justwhat we say. You require no advertisement. Werking for us. Satisfaction (iuaranteed. capital while working for us. SERSIAN CO., Box 180, New York City.

\section{YOUP NAME PLEASE FOR OUR}

Register and receive your choice of any three pieces of Iusic from our list for only 10 Cents. MCSIC MAIL Co., 130 Lawn Str., Stamford, Conn.

\section{WE SHOULD STUDY THE "WHY."}

Hundreds of flower lovers read floral magazines and waste on bulbs that fail enough money for a bountiful supply of perfect blossoms from the greenhouses, yet seldom produce a flower. One reason is aptly expressed in the language of the king to Paul: "Much learning hath made thee mad."

For, one paragraph in "The Only True Guide to Successful Flower Growing" states that bulbs must be covered in a dark place, and in the same pamphlet a subscriber's experience advises light. Again, the amateur reads " use rich soil" and another "experienced grower" writes that it is immaterial. But as the former method seems most in favor, the puzzled beginner stuffs the earth with fertilizer and the rich soil process is settled-so is the fate of the bulb. The poor unfortunate reads on: "This plant requires plenty of water." He pours on the liquid, and the next step is accomplished. If the bulb survives the first step, this drenching performance is all needed for a finishing process.

The truth is, amateurs do not realize that successful flower culture requires study. In this "off month" of November is a good time to do a lot of thinking about the nature of a plant-how it generates and breathes like ourselves. Yes, and it will sulk, too, if not properly cared for.

Thoughtfully note how one loves the sun, while another prefers a cool, retired spot, and all will pine and droop away if we forget that all they ask is good food, pure air and water. And they love a bath. Wrap a cloth around the earth and immerse the tops in plenty of clean water - see how they strengthen up and thank you with their fresh glow. Quarantine your unhealthy plants, freely using the bath, and then you will not need insecticides.

I. M. Stacy MCLEOD.

New Jersey. 
A SIMPLE FERTILIZER.

It may benefit some readers of THE Floral IVORLd to learn of an experiment I have tried during the last two winters in feeding my pot plants with the rinsings of a milk pail or can. Perhaps many a farmer's wife or daughter before me has succeeded in producing excellent plants by this simple method, but here, at least, the practice has not been usual, for I had never heard of it until I began to apply it to my begonias, umbrella plant, fern, asparagus, eupatorium, verbenas and so on, all of which visibly improved under the treatment. Cyclamens, however, refused to thrive. Perhaps bulbous plants in general would object to the diet.

If diluted milk is a good food, why should not skimmed milk be even better, I reasoned. But one application of the stronger fluid was sufficient, for my nostrils, if not for the plants, and a disinfectant was promptly sprinkled upon the soil. Knowing-from Darwin's experiments with seedlings, if not from personal observation-that fatty substances do not agree with a root's digestion, I have not yet tried cream as a fertilizer. In this case the meaner product is the better.

Massachusetts. E. A. Josselyn.

\section{A NOVEL METHOD OF HEATING.}

I have a small house which is not very warm, and I cannot afford to keep fire at night, but must keep a few plants. One cold winter I moved my plant-table to the least exposed corner, put a two-gallon jug of boiling water, which I heated by the supper fire, beneath it and enclosed all with a bath cabinet, throwing a large blanket over that. I placed rugs around the bottom and stuffed something in the ventilator. Not a plant was injured and not more than ten minutes spent each day in thus caring for them, and was well repaid with blossoms.

Missouri.

H. O. Spickeriian.

\section{A GPEEN FRAIIE}

Th is new frame in green is flat and broad. It is made of wood and looks like Flemish Oak except it is a dull rich green instead of black. The frame, glass and picture, fitted complete and carefulıy packed, will be shipped and express charges prepaid cents. The picture is one of those new things people call artistic with broad lines and bright colors. It is suitable for a den and will look well in any room.

On Request Our Fall Catalogue will be Sent You

The prices will fit any pocketbook and the frames will fit your old and new pictures. When you see this green frame it will convince you of what we can do in other orders.

All orders promptly filled. We undersell eversbody and can save you big money.

'FARWIN MANEFACTCRING COMPANY Frame Dept. II Chicago, Ills.

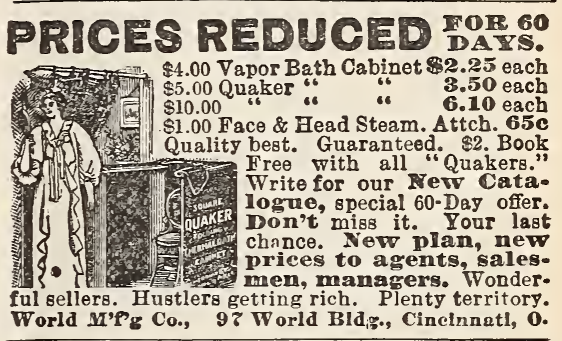

\section{MOTHEP YOUR OHILPEEN

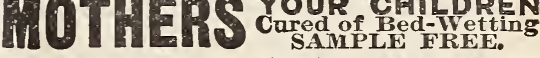

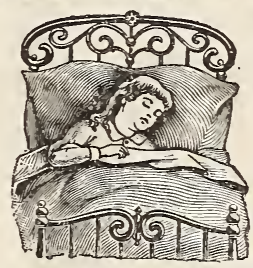
EN-U-RE-SINE cures Bed-Wetting, and incontinence of urine during the day-time, both in the old and young. It is the only cure prepared by a physician who guarantees it. Ladies. troubled with a frequent desire to urinate and a burning sensation use it with perfect success. Send your address to DR F. F Y Y to DR. F. F. MAY, Drawer 69 . ceive sealed a free sample.
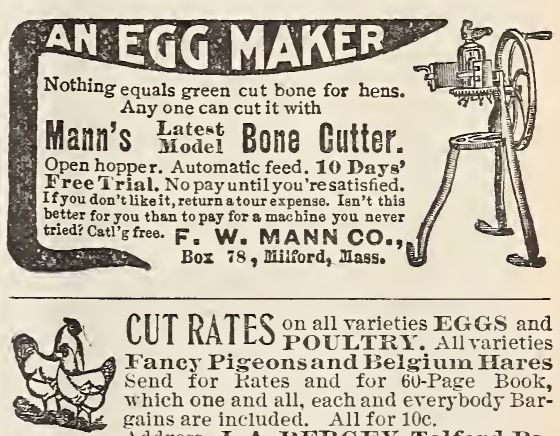

CIT DATES on all varieties EGGS and CUI RAIES POULTFY. All rarieties Fancy Pigeons and Helgium Hares send for Rates and for 6u-Page Book, which one and all, each and everybody Bargains are included. All for $10 \mathrm{c}$

Address, J. A. HERGEY, Telford,Pa.
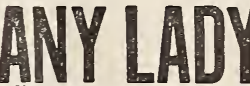

Can Easily Make $\$ 18$ To $\$ 25$

weekly by representing us in her locarity and as the prosition is pleasant and profite the year wo will gladiy send particulars free to all. Even your spare time is adross WOHAN'S MCTLAL BENEFIT CO., Box 21, JOLIET, ILL 


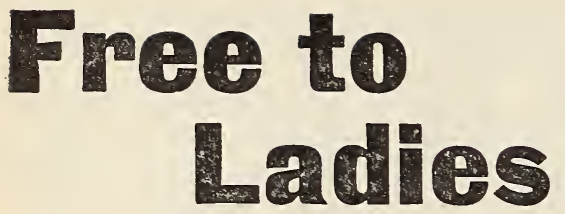

One Full \$5.00 Treatment of Dr. Mary Lock's Wonderful Home Remedy Mailed Free to Every Lady.

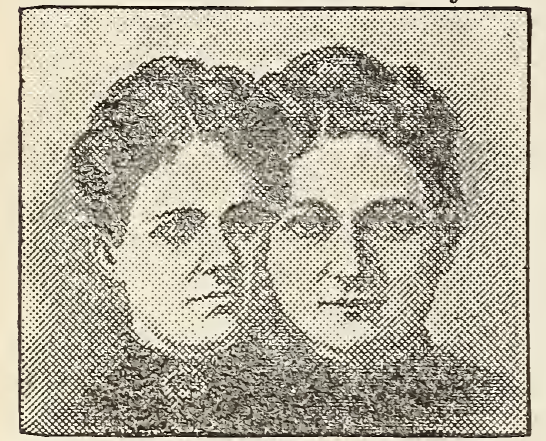

TWO OP AMERICA'S GREATEST LADY SPECIALISTS.

Cures every form of Piles, Female Weakness, Displacements, Leucorrhea, Suppressed or Painful placements, Leucorrhea, suppressed or Painful $\$ 5.00$ treatment free to every suffering $w:$ man in order to quickly introduce in every city, tow $n$ and hamlet in the U. S. Address Dr. Mary Lnck Co.,1131 Englewood Station, Chicago, Ill. - The above offer is genuine. We ask no questions or references of any kind. Every lady who writes, stating she is a sufferer from piles or female weaknesses, or both, will be sent by return mail free a full $\$ 5$. 00 treatment with special letter from the doctor. Write to-day. Remember this is not a patent medicine but a full three-course treatment.
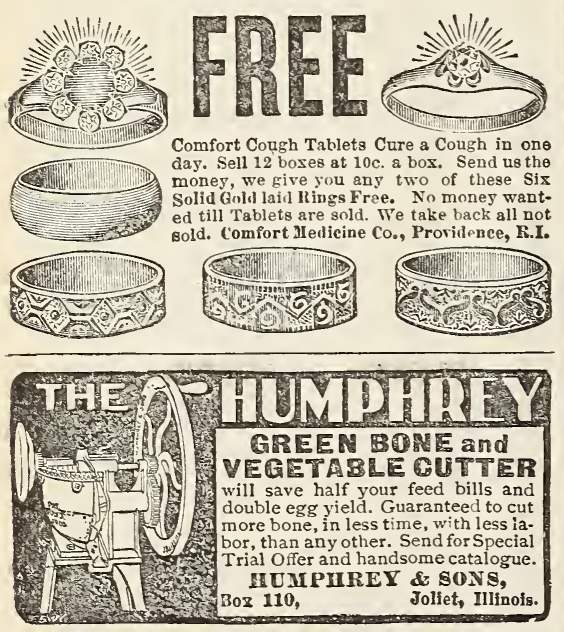

\section{A NOVEMBER SKETCH.}

The low winds are sighing,

The summer is gone,

And dreary old winter

Creeps steadily on.

With sad tears the dark cloud

For the lost summer grieres,

And autumn has robed

The dead flowers with her leaves.

Yet 'mid all this sadness

I cannot be sad,

There's so much to repay me

And make me feel glad.

Let me whisper a secret:

In the cellar below

My bulbs are all potted.

And waiting to grow.

When tempests outside

Their wild ravings begin,

Their moods shall be shamed

By the brightness within.

There's the hyacinth fragrant

And the tulip so fine,

Narcissus and jonquils

Made all of sunshine.

At yule-tide oxalis

So golden shall glow,

And the dear little snow-drop,

As pure as the snow.

And my flowers will bloom

While the winter winds blow,

And my life shall be happy

With watching them grow.

'Till spring brings the crocus,

And sweet lily bells

Recall the dear story

That glad Easter tells.

Penusylvania.

Nora IVAY.

\section{OUR WINDOW GARDEN.}

As the season approaches, when we must gather our floral treasures into winter quarters, our hearts ache over the many we must leave after every window is appropriated, and the good man declares he cannot see to read his paper.

Setting out to improve the situation, we had a box made four feet long, eighteen inches wide, fourteen deep, lined with zinc, set. on stout legs furnished with castors.

Set tallest plants in centre with moss or sand around to raise the smaller pots level

(Concluded on page 17) 
(Concluded from page 16)

with the larger and hold solid. IThen the plants are all in put a couple inches good soil all over, and plant slips of tradescantia, kenilworth ivy, or any trailing plant desired, around outer edge. Sweet allyssum or small bulbs are pretty between pots.

In this we have a thing of beauty, growing more beautiful every day. On very cold nights a lamp turned low set under the box will keep Jack Frost at a respectful distance, and supply bottom heat.

One winter a light frame attached to box, with cross pieces for shelves, a curtain around, made a cunning little conservatory, keeping dust out, and heat and moisture in.

Pennsylvania.

M. M. S.

\section{COREOPSIS LANCEOLATA.}

A more satisfactory plant for out-door planting would be hard to select. It grows thriftily in ordinary garden soil, if given a situation somewhat sunny. It blooms continuously and abundantly from June till frost, if only the flowers are picked freely enough to prevent the formation of seed-pods. This is, however, imperative. The long stemmed golden flowers are exceedingly graceful when used in large, loose bunches, unmixed with other flowers, except some feathery green. They also blend beautifully with any small, white flower. They are very hardy and come again year after year, without protection. One plant will grow to such a bunch in a summer that it may be divided into several the following spring. The best effect is obtained by planting in clumps about a foot apart, or by massing against a dense background of taller growing shrubs.

In considering this perennial, bear in mind that not a day throughout a long summer but will witness a harvest of bloom.

Nebraska.

Mrs. J. L. Neble.

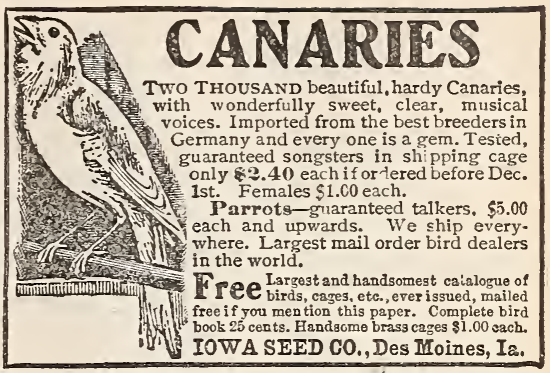

\section{Ping Pong Free}

Send us your name and address; we will send you ten pieces of regular fifty cent sheet music. Sell the music at 10 cents per copy, return us the dollar realized, and we will send you a complete set of Ping Pong, worth \$1.50. Free. Many other premiums; no money required.

UNIVERSAL MUSIC LIBRARY, Dept. $M$, 1178 Broadway, - New York City.

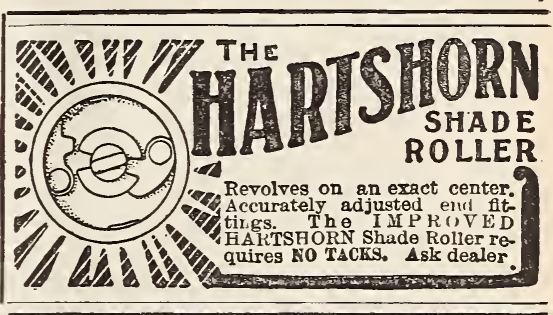

\section{BE BEAUTIFUL}

Dr. Bidaman's Safe Arsenic Complexion Wafers remove pimples, freckles, blackheads, and all blemishes of the skin. Make the complexion clear, transparent, rosy smooth and soft. Used by noted beauties and actresses. Sample box sent on receipt of 25 cents in stamps. Correspondence absolutely confidential.

DR. ISIAEL BIDAMIN,

Established over Thirty Years. NEW YORK.

MADE \$105 THE FIRST MONTH

Frites FRED. BLODGETT, of N. Y. J. L. \& BARRICK, of La., writes: "Am making - $\$ 3.00$ to $\$ 8.00$ every day I work." MRS. L. M. ANDERSON, of Iowa, writes: "I 3 made $\$ 3.80$ to $\$ 6.50$ a day." Hundreds 1. $\$ 5.00$ to $\$ 10.00$ daily made pla Ii. 5.2 ting jewelry, tableware, bicy1 . 1 cles, metal goods with gold, sil-

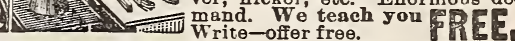
G. GRAY \& CO., Plating Works, $\Delta$ Yiami Bldg॰, Cineinnati, 0.

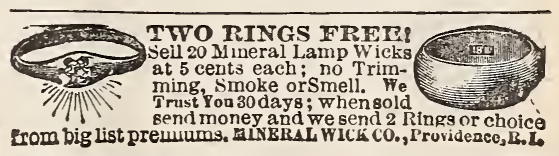




\section{ASTHMA}

CAN BE CURED BY

\section{THE \\ Kola Plant}

A New and Positive

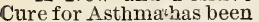
found in the Kola Plant, a rare botanic product of West African origin. So great are the powers of

this new remedy that in

the short time since its discovery it has come into almost universal use in the Hospitals of Europe and America for the cure of every form of Asthma. The cures wrought by it are really marvelous. Among others Mr. C. B. Slade, Los Angeles, Cal., writes March 8,1902 , that Himalya saved his life, and through his recommendation thirty-five or forty others have been cured by it. Mr. W. O. Coblentz, No. 7 La Salle St., Cleveland, O., writes that he suffered for years until Himalya cured him. Physicians and change of climate did him no good. Mrs. Lidelle Hodgkins, Old Town, Me, writes that Asthma was her worst enemy, but Himalya cured her completely. Mr. Alfred Lewis, editor of the Farmers' Magazine, Washington, D. C., testifies that after eight years continual suffering, especially in Hay-Fever season, Himalya completely cured him. Hundreds of others give similar testimony of their cures of Asthma of five to fifty years' suffering by this wonderful new remedy. If you suffer from Asthmain any form, in order to prove the power of this new botanical discovery, we will send you one trial case by mail entirely free. It cost you absolutely nothing. Write to-day to the Kola Importing Co., No. 1164 Broadway, New York.

\section{$\$ 1250^{10} \$ 3600^{\text {Per Year }}$ FOR HUSTLERS-BOTH Expenses.

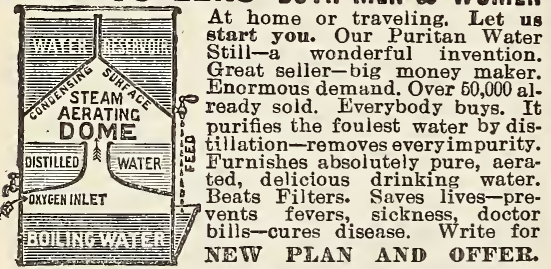

HARRISON M'F'G C0., 82 Harrison BIdg., Cincinnat, 0 .

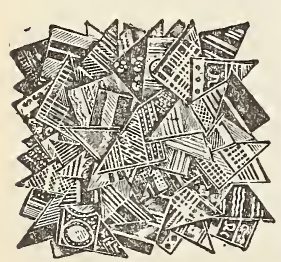

S!LK REMNANTS

Having a le rge stuck wo will reduce our price to move them. A lol new, bright pieces, corners and squares. Good size. Mos $t$ beautiful designs. 15 choice pieces in each pack, also velvet and satin squares extra, 1 package, 2 cents; 3 packages for 5 cents; 12 pack. ages for $15 \mathrm{c}$; 100 pack-

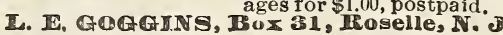

Silk Fringe Cards, Love, Transparent, Es. cort \& Acquaintance Cards, New Puzzles, New Games, Premium Articles, \&c. Finest 5 I 4.
ANSWER TO QUERY.

Let me suggest to M. O. P., Mfssouri, that the best way to care for those twentytwo roses would be to just bring them here, where they can live and bloom and grow all winter in the open ground. I have ever-blooming roses that have thrown up new stalks over seven feet tall and are full of blossoms all the time. I have over one hundred kinds and never any insect enemies. The La Marque is one of the best roses here as well as in Georgia. It blooms nearly all winter here on the east shore of Mobile Bay as also do many of the most tender varieties. I have a castor-bean over twelve feet tall, grown from seed this year,-they usually live over winter, but were killed last winter. I agree with Mrs. Wight on antigonum liptophus. Mine are lovely now, and so are the lantanas-in fact almost everything. The bathing is fine also, but all the summer people are gone and we are busy getting the cottages ready for people who come for winter.
Alabama.
Mrs. H. N. Brown.

\section{A SUCCESSFUL TROPICAL PLANT.}

Why a banana to be sure! Try it. Get a mailing plant from the florist, plant in a small pot in rich, loose soil and give plenty of water and sunshine. As it grows, shift it into a larger pot, finally landing it in a large tub or half-barrel, with soil which is about half well-rotted manure. Its growth is amazing-one year sufficing to change the tiny plant to a tree seven to nine feet high, with leaves three feet long and nearly half as broad. Never neglect to water plentifully till growth ceases about mid-winter, then water cautiously till spring. Keep watch for the red spider, sponging the leaves top and bottom about once a week. Use lime water for worms in the soil. Bananas may be bedded out in summer, in a sheltered place which has been deeply spaded and liberally enriched. Lift before the first frost, with ball of (Concluded on page 20) 


\section{THE MAN

\section{Prof. Weltmer, the Great Magnetic Healer, of Nevada, Mo., Causes Diseases to Dis= appear as if by Magic.}

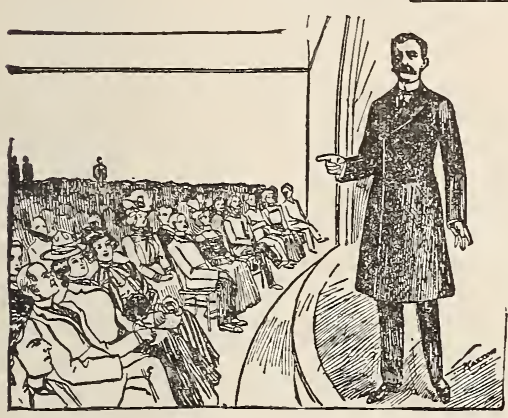

From the pulpit to the most eneviable position in the scientific world is the remarkable career of Prof. S. A. Weltmer, the renowned author and scientist of Nevada, Mo. By scientific researches this wonderful man has discovered a method which is now known on two continents as the Weltmer Method. He has so revolutionized the methods of healing, without the aid of medicine, that the medical profession stands aghast at the wonders he has performed. His cures are made rapidly and permanently, as if by magic, and for this reason the press throughout the country have named hin "The Great Magnetic Healer." This is indeed a great age. Just to think; right in our midst, a contemporary of ours, a man who can say to suffering, sad humanity, those who are afflicted, who suffer such misery and pain that they long and yet fear to die, "Come unto me, one and all, there is relief for you in the Weltmer Method."

When Weltmerism was first given to the world, scientists and medical men were skeptical, even refusing to investigate this great healing power. The newspapers gave so much space to it that practitioners of the old school, who imagined that strong and vile drugs were the only curative power, investigated more for the opportunity to ridicule than anything else, and in this connection we may use the words of the immortal Goldsmith, "They who came to scoff remained to pray," for after their investigatious they became firm believers in Weltmerism, and now so many physicians have taken the Weltmer Course it can almost be said it bears the indorsement of the medical profession.

The cures performed by this great benefactor of humanity have been of almost every disease imaginable, and for that reason it can be said, no matter what your disease, it is your duty to place yourself in communication with Prof. S. A. Welt- mer, of Nevada, Mo. By special request of grate ful ones, who are anxious to spread the glad tidings, we give below a few testimonials of some of the many who have been raised from the despair and sorrow of disease to the hope and happiness of perfect health.

Mr. John S. Small, Colfax, Ill., was deaf in his left ear for seven years. Was permanently cured in three days through Weltmerism. Mrs. M. E. Hawkins, Louisburg, Kan., was afflicted 20 years with prolapsus and enlargement of the womb, indigestion and perpetual headache. Tried everything in vain. In one week she was permanently restored to health through Weltmerism. A. A. Burris, of Fullerton, Neb., after being under treatment with the best doctors in the State, to whom he had paid $\$ 400$, without receiving any benefit, was cured of a tumor of the stomach in three weeks through Weltmerism. Mrs. F. M. Hall, of Rinaldo, Ky., suffered severely with the catarrh of the stomach. Was cured through Weltmer's Absent Treatment. Mrs. C. E. Haddon, of Tampa, Fla., was cured through the Absent Treatment of Bright's disease, after her family physician had pronounced her case hopelessly incurable.

Those who are unable to go to Nevada, Mo., can have the satisfaction of knowing that the Absent Treatment of Weltmerism will dispel disease in exactly the same wonderful way. Neither distance nor condition makes any difference to this great scientist. By writing Prof. S. A. Weltmer, Nevada, Mo., you will receive free of charge the Magnetic Journal, a 40-page, illustrated magazine, also much information on this science of healing that does away with both medicines and the surgeon's knife, and a long list of the most wonderful cures ever performed.

\section{TEACHES HIS METHOD TO OTHERS.}

Prof. S. A. Weltmer, the originator of this marvellous method, will teach the art to others how to cure every known disease without the aid of drugs or the surgeon's knife. Anyone who desires can learn this noble profession. Any one who learns can practice it. He has abundantly proven this by the large number who have been instructed by him and who are in the active practice of healing by his method. He will teach you in ten days, either by mail or personal instructions, his woncierful method, through which wealth and fame can be earned. Full information will be sent free of charge to anyone writing to Prof. S. A. Weltmer, Nevada, Mo. 

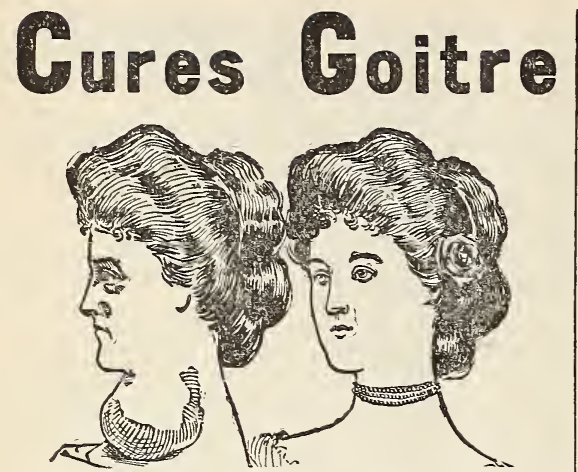

A well known Cincinnati physician has discovered a remedy that cures Goitre, or Thick Neck. And to prove this he sends a free trial package so that patients may try and know positively that Goitre can be cured, Send your name and address to Dr. John P. Haig, 4012 Glenn Bldg., Cincinnati, Ohio; tell him your age, the size and location of your goitre and how long you have had it and he will be glad to send you free, a large trial package of his home cure, postage paid.

THE TRUTH

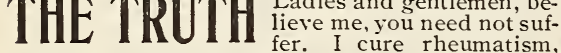
eczema, blood and skin diseases even when Hot Springs and others fail. Cure costs nothing. Remedies cost but little sent to your homes. Now your fault if you suffer. Address,

\section{Dr. W. H. ROSS, Grand Rapids, Mich.} greens, Shrubs, Fruit and other Trees, Roses, Water Lilies, etc. Prices low. Beautify your homes at small expense. E. S. Peterson \& Sons, Box 31, Montrose, N. Y.

112E RIPE FOR ALL STOMACH Q UhE GURE TROUBLES. FREE

I information and 32-page booklet sent at once. SIMARUBA, the greatest Stomich and Nerve Tonic, guaranteed to cure dyspepsia, indigestion, heartburn, etc., where all others fail. Write to-day. UTOPIA MEDICINE co., Cineinnati, Ohio. LADIES to do piecework at their homes. We furnish all to RoYaL Co., Dept. F. W., 34 Monroe St., Chieago.

CDFE Clairvoyance. If sick or ailing send now FRE nime, age sex, lock of hair and 2 stamps to Dr. D. Hinkly, $x-28$, Grand Rapids, Mich.

ADIES Your Bust enlarged permanently: cannot MIE. SADA WELLS, Box 282, Bloomington, Ili.

SPECTACLES by mail guaranteed to suit. Easy method of fitting your eyes, and illustrated prices FREE. Fredrick Optical Co., Toledo, Ohio.

RHEUMATISM CURED FREE!

Write to-day C. H. ROWAN, Milwaukee, Wis.

SOAP and WASH for CATS and Dofs; kills fleas; ma; soap $25 \mathrm{c}$, wash $25 \mathrm{c}$. Woodlawn Kennels, Louisville, Ky.

\$8 PAID Per 100 for Distributing Samples of Washing WORK at advertising business. Big pay. Enclose stamp. WORK at advertising business. Big pay. Enclose stamp.

\section{(Concluded from page 18)}

earth about the roots. If there is not room for it in the house, wrap a stout sack about the clump and carry to the cellar. It will winter as well as a canna. If kept in the house it must be placed in a frost-proof room.

Kansas. Melvina M. S. StopdARD.

\section{THE FLOWER OF THE HOUR.}

The aster is now the flower of great attraction. There are so many kinds that one hardly knows which to raise. My choice is the giant comet, which so resembles the chrysanthemum in its beauty, and is, I think, the queen of autumn annuals; and the Semple's marvel, a new and lovely sort, and Japanese aster, which are of immense size, and some actually measure five inches across, and grow about fifteen inches high. These are my favorites. From one packet of seed of each, one can have a yard full of beautiful blooming plants for early fall. I find that seed sown in boxes indoors in January give best results, taking enough rich soil in the house before winter comes on and kept in a dark place for a while after sown. Then, when the seed starts growing, put in the light and water moderately and transplant in May and you will have an unlooked for result. Buy seed from best florists known and you will not be disappointed. Among my house plants I have a beautiful singing canary and one does not know the worth of either until they put the two together in a window, where there is plenty of sunshine, and from the outside they are a most pleasant sight, when all without is so dreary. Flowers and birds are God's own gifts.

Ohio.

Mrs. M. WIOOdSON.

A good way to grow chrysanthemums is to start cuttings in May or June. First put a few pieces of charcoal in the bottom of the pot to keep the soil fresh and sweet. Fill with common garden earth mixed with a little sand and then put a thin layer

(Concluded on page 21) 
(Concluded from page 20)

of manure with a little dirt mixed in over the top. The sweepings from paved streets would be about right and are really better than the manure alone. Start the cuttings in the pots they are to be left in, so that they will not have to be changed after they are started. Water occasionally so as not to let them dry out. To have fine large blooms, cut off all the buds except two or three on the center stems. I have seen blooms as large as a saucer when all the buds but one were cut off.

Very frequently the plants are troubled with small black lice. Tobacco smoke will entirely destroy them. To destroy small worms in the soil stick matches, either burned or unburned, in the dirt around the plant. Rusty nails stuck in the dirt are good to brighten the color of the flowers.
Ohio.
G. IV. P.

The three leading varieties of chrysanthemums are Chinese, Japanese and Pompon. Their propagation and cultivation is quite easy, the plants being raised from cuttings or dividing the roots. Bring the old plants from their winter quarters in March and keep in a cool room. When of proper size break off cuttings and set to root. As soon as rooted pot in small pots, changing to larger pots as they become root bound. Use good rich soil and plenty of well rotted manure. After the last repotting, which should be the first of September, use liquid manure once a week. If chrysanthemums are raised in the garden, plant out the first of June, using plenty of well rotted manure; tie to stakes. Pinch out the top of the main stalk when twelve inches high, the side shoots when eight inches high. Don't pinch back after the first of September, "or the buds are set." Give water in abundance with liquid manure, and keep the earth loose so the water will penetrate the soil. Lift the plants in September and protect from sun and wind for a few days.

Kansas.

Lydia E. DuFFy.

\section{FREE}

\section{A xwew curas ros KIDNEY AND BLADDER}

\section{Diseases, Rheumatism, etc.}

Disorders of the Kidneys and Bladder cause Bright's Disease, Rheumatism, Gravel, Pain in the Back, Bladder Disorders, difficult or too frequent passing water, Dropsy, etc. For these diseases a Positive Specific Cure is found in a new botanical discovery, the wonderful Kava-Kava Shrub, called by botanists, the piper methysticum, from the Ganges Piver, East India. It has the extraordinary record of 1,200 hospital cures n 30 days.

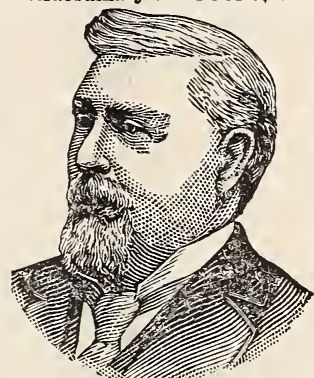

JAMES THOMAS, It acts directly on the Kidneys, and cures by draining out of the Blood the poisonous Uric Acid, Lithates,etc., which cause the disease. Rev. John H. Watson testifies in the $\mathrm{New}$ York World that it has saved him from the edge of the grave, when dying of Kidney disease and terrible suffering when passing water. Mr. James $T$ hom as, Esq. of the Board of Review Bureau of Pensions, Washington, D.C., writes: Was cured of a usually fatal Kidney Trouble after many physicians had failed No, 120 E. St. N. W. Washing- and he had given up all ton, D. C. hope of recovery. Hon. R. C. Wood, a prominent attorney of Lowell, Ind., was cured of Chronic Rheumatisin, Kidney and Bladder Disease of ten years" standing by Alkavis. Many ladies, includjng Mrs. E. R. Dinsmore, South Deerfield, Mass., and Mrs. James Young, Kent, Ohio, also testify to its wonderful curative power in Kidney and allied disorders peculiar to women,

That you may judge the value of this Great Discovery for yourself we wlll send you One Large Case by mail Free. It is a Sure Specific and can not fail. Address, The Church Kidney Cure Company, 524 Fourth Avenue, New York.

\section{FERN POTS}

Fern Pots, Solid copper hanging Fern Pots, full size, 19 inches in length, with chain and solid band near top. A very artistic English novelty guaranteed by manufacturer. Price One Dollar delivered any address.

F. E. WATTS \& C0., Room 804,

Monroe Building, 41 West 24th St., New York.

Self-Hypnotic Healing!

I have made a late discovery that enables all to induce the hypnotic sleep in themselves instantly, awaken at any desired time and thereby cure all known diseases and bad habits. Axyone can induce this sleep in themselves instantly at first trial, control their dreams, read the minds of friends and enemies, visit any part of the earth, solve hard questions and problems in this sleep and remember all when awake This so-called Mental-Vision Lesson will be sent to anyone ABsoloteso-called Mental-Vision Lesson will be sent to anyone ABSOLUTELY FReE, actually enabling him to do the above
whatever. Prof. R. E. DUTTON, Dept. F. W.

Lincoln, Neb., U. S. A.

WOMEN TO DO SEWING Binding Spec100. Can make six an hour. Material sent free prepaid. Send addressed reply envelope for full particulars. Universal Co., Dept. 214, Walnut St., Phila., Pa. 


\section{A A REAL TREAT FOR THE CHILDREN. \\ "Mr. Bunny-His Book," is one of the finest books for children ever printed-just such a book as the little men and women delight to study and ponder over for hours at a time. It is full from cover to cover, and on both covers-inside and out, of fascinating}

\section{Stories Told in Rhyme and Picture.}

Pictures, such as you have never seen before, in bright, attractive colors that are so pleasing to the little folks.

\section{EVERY PAGE IS ILLUSTRATED \\ EVERY PICTURE IS FUNNY \\ EVERY VERSE IS CATCHY \\ EVERY RHYME HAS ITS JINGLE}

Verses and Rhymes by Adah L. Sutton.

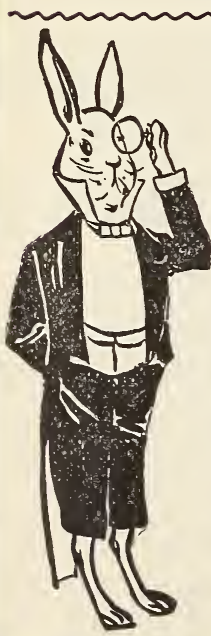

If we could put a copy of "Mr. Bunny-His Book" in the hands of each of our readers for examination we know the demand would be greater than we could supply. It is impossible to tell in a written description how attractive the book is to the children. Secure a copy and you will be more than pleased.

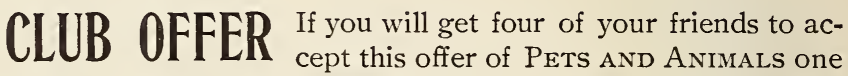
year and "Mr. Bunny-His Book," for 75 cents, remitting us $\$ 3$, we will send you a copy of "Mr. Bunny" free, charges prepaid. 


\section{"MR. BUNNY-}

HIS BOOK."

The price of the regular cloth-bound edition of "Mr. Bunny-His Book," is $\$ 1.25$. The book we send is exactly like the $\$ 1.25$ edition, except that it is bound in heavy leatherette to make it more easily mailed. It is printed from the same plates, in the same bright colors, and on the same heavy paper. It is only by having a large special edition printed that we can offer it to readers of PETS AND Animals at such a low price.

\section{NOT ONE OLD PICTURE \\ NOT ONE OLD RHYME \\ NOT ONE DULL PAGE \\ NOT ANOTHER BOOK LIKE IT}

Illustrations drawn by W. H. Fry.

\section{OUR OFFERS}

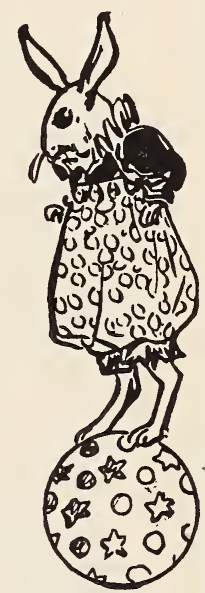

"Mr. Bunny-His Book" and Pets ANd Animals for one year will be sent, postpaid, to any one sending us only 75 cents.

Two copies of the book and one copy of Pets and Anrmals for one year will be sent to anyone sending us only $\$ 1.00$. This is the best offer of all.

Address, PETS AND ANIMALS,

Springfield, Ohio. 
POINTS WORTH KNOWING.

If a gloxinia leaf breaks off it can be rooted in water.

If a tuberous begonia stalk or any of the branches break, set in the earth and a new bulb will form.

New York.

I. M. SKIFF.

INQUIRIES.

My roses, which are supposed to bloom all summer, have never bloomed at all; instead, the lower leaves keep drying up and dropping off. Will some one kindly tell me how to care for them properly?

Michigan.

Mrs. J. D. Parent.

Will you please let me know how to set uut bulbs, as I never had any, and I am afraid that I would not have good luck with them, unless somebody told me how to plant them. I have quite a lot of house plants and hope that I shall get much valuable information in your paper as to the care of them.

Mass. Mrs. W. A. Graham.

May I have information on the three following points?

First-My dahlias are fairly well fed and watered, staked up, but bloom but little. One season I tried confining them to one shoot, and once I took them up in the fall and replanted later. The results have never been satisfactory as to bloom. In what am I deficient?

Second-I want to start a lily bed. Shall I locate it on the north, south, east or west of my home?

Third-Tell me something about time to plant, and the treatment to give gloxinias.

Georgia. Charles H. DorsetT.

\section{FREE TO EVERY LADY.}

A safe, simple home treatment that cured me after years of suffering with uterine troubles, displacements, lucorrhoea, etc.. sent free to ladies with full instructions how to use it. Address Mrs. L. Hudnut, South Bend, Ind.

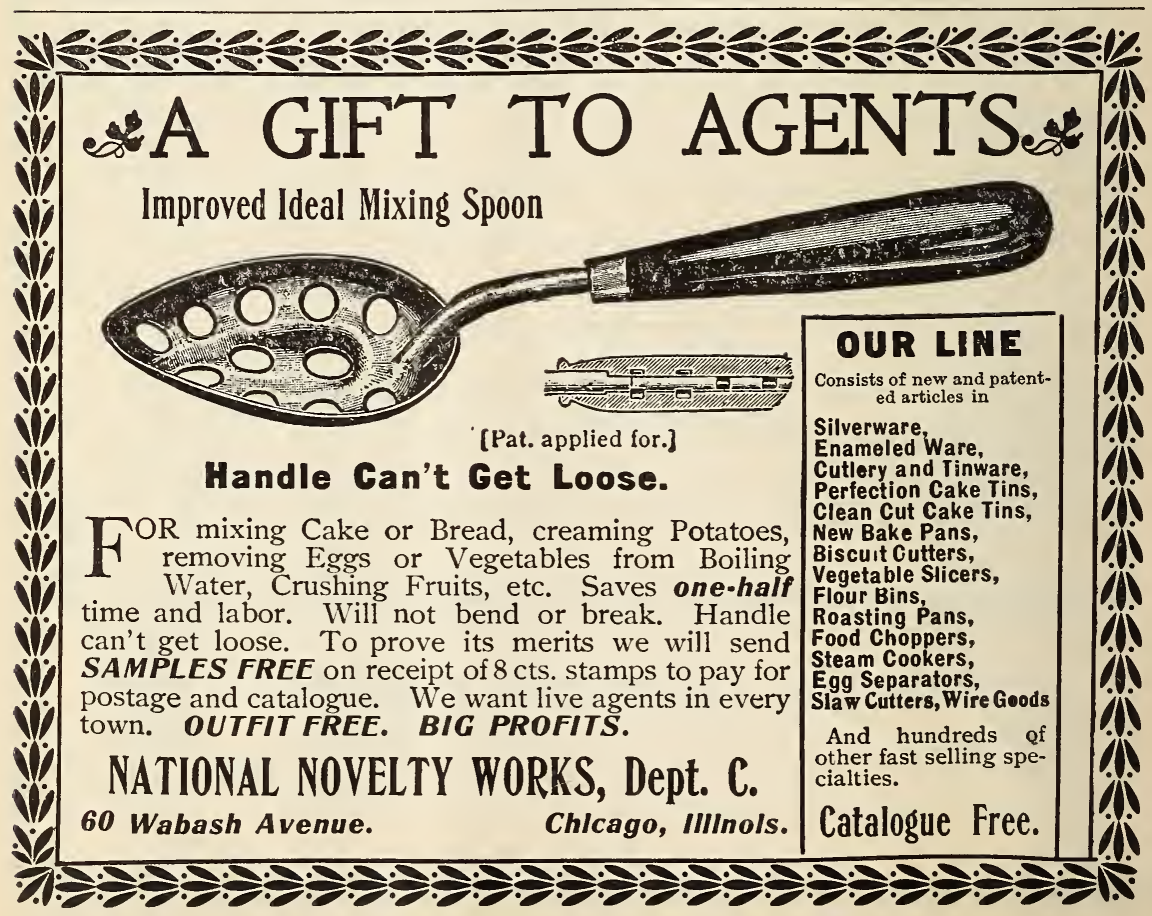




\section{Ohoice Hones FOR FALL PLANTING.}

The Good \& Reese Company's "Sample Collection" of Roses, Twenty for $\$ 1.00$

Suitable for your locality. Our selection of sorts.

Our "Grand" Collection of Hyacinths,

Twelve Named Sorts for \$1.00.

This Collection comprises the best kinds which Holland produces.

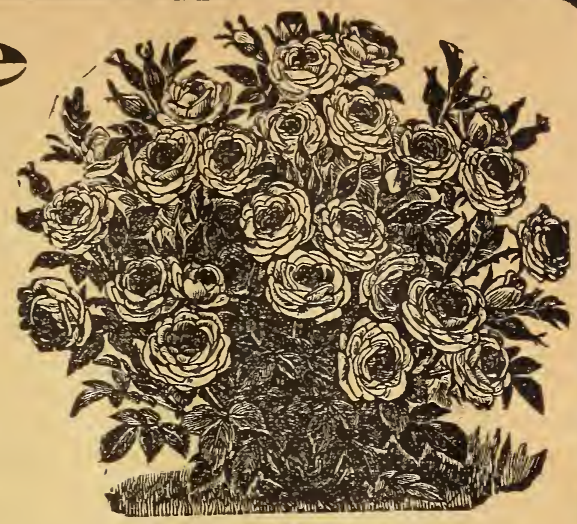

Fifty-Cent Bargains in Bulbs and Plants.

Set B-12 Prize-Winning Chrysanthemums, all Set K-10 Lovely Begonias, choicest kinds. different.

Set C-10 Lovely F uchsias, all different.

Set D-10 Elegant Double Geraniums.

Set E-10 Elegant Single Geraniums.

Set $G-10$ Choicest Double Hyacinths, all different colors.

Set J-10 Assorted Hyacinths, double, single and Roman.

set $\mathbf{L}-15$ Choicest kinds of Narcissus.

Set $\mathbf{P}-60$ Crocus, in four kinds.

set Q-25 Parrot Tulips, all kinds.

set $\mathbf{R}-25$ Double Tulips, all kinds.

Set $5-25$ Single Tulips, all kinds.

Set W-4 Fragrant Carnation. Pinks, ready to bloom.

Set $\mathbf{Y}-4$ Begonia Rex, all different.

No two alike in these sets. Any three sets for $\$ 1.25$. Any five sets for $\$ \mathbf{2 . 0 0}$, by mail, postpaid . Safe arrival and satisfaction guaranteed. Order by the letters. We are the Largest Rose Growers in the World. Over one and one-half million Roses sold each year.

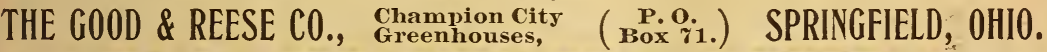




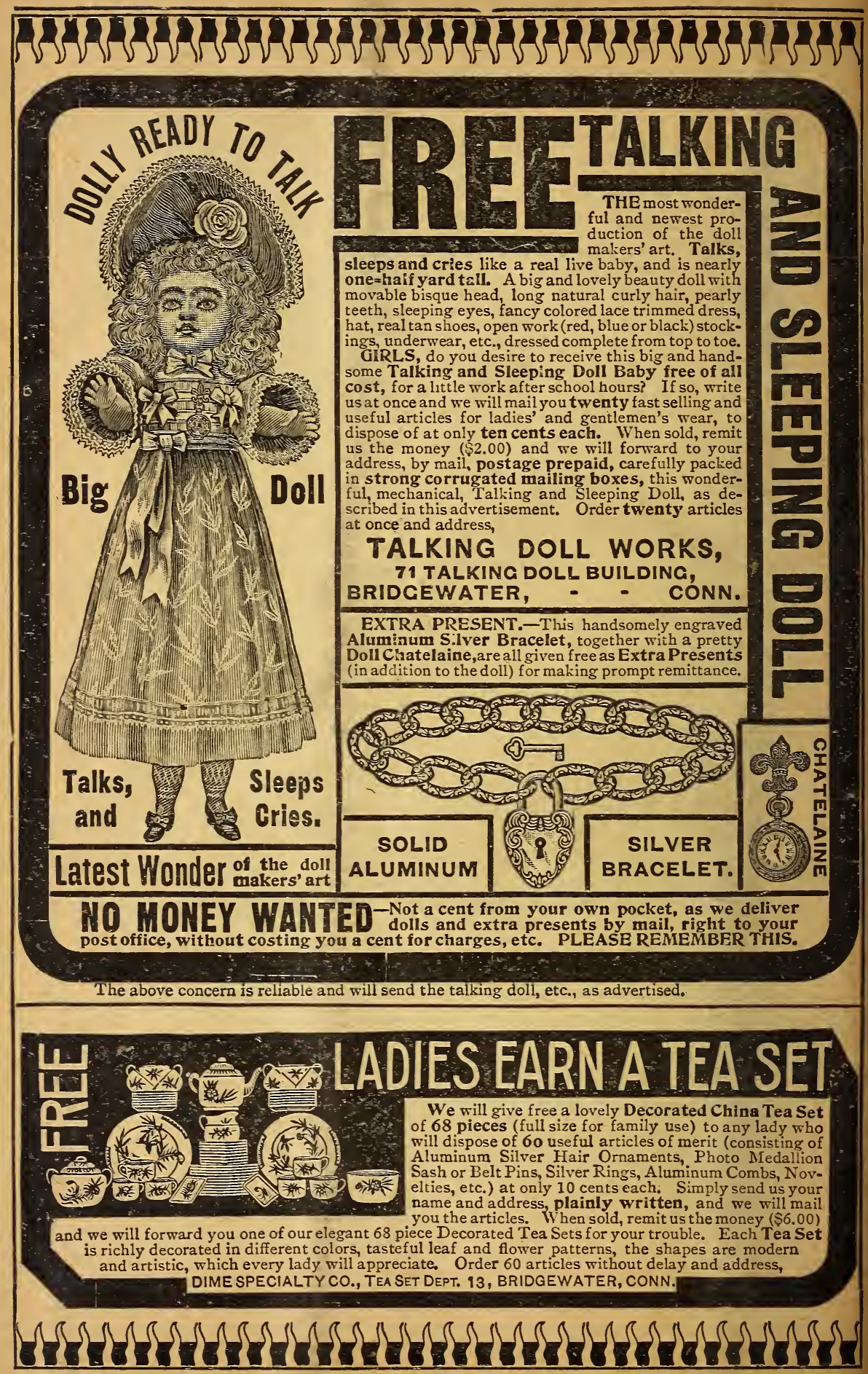




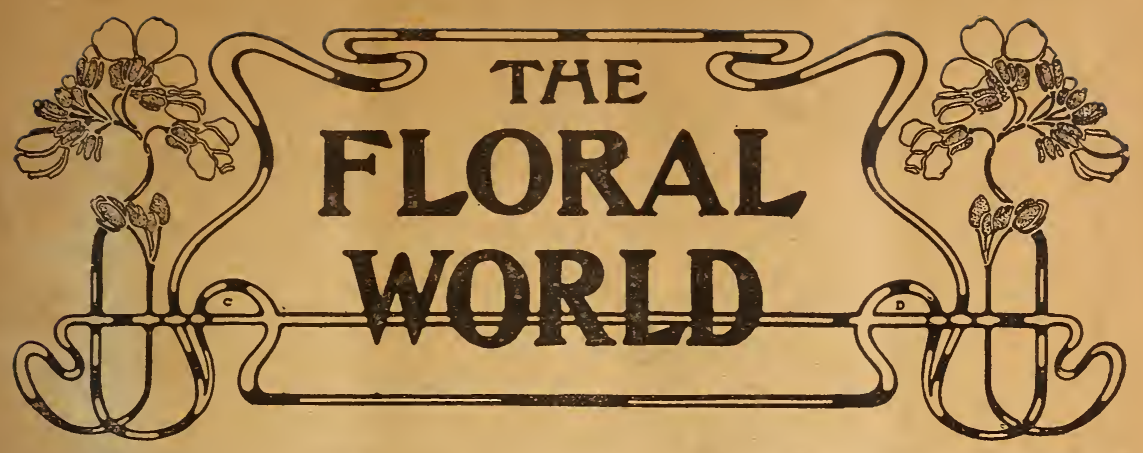

Vol. II. No. 3. Springfield, Ohio, December 190225 Cents a Year
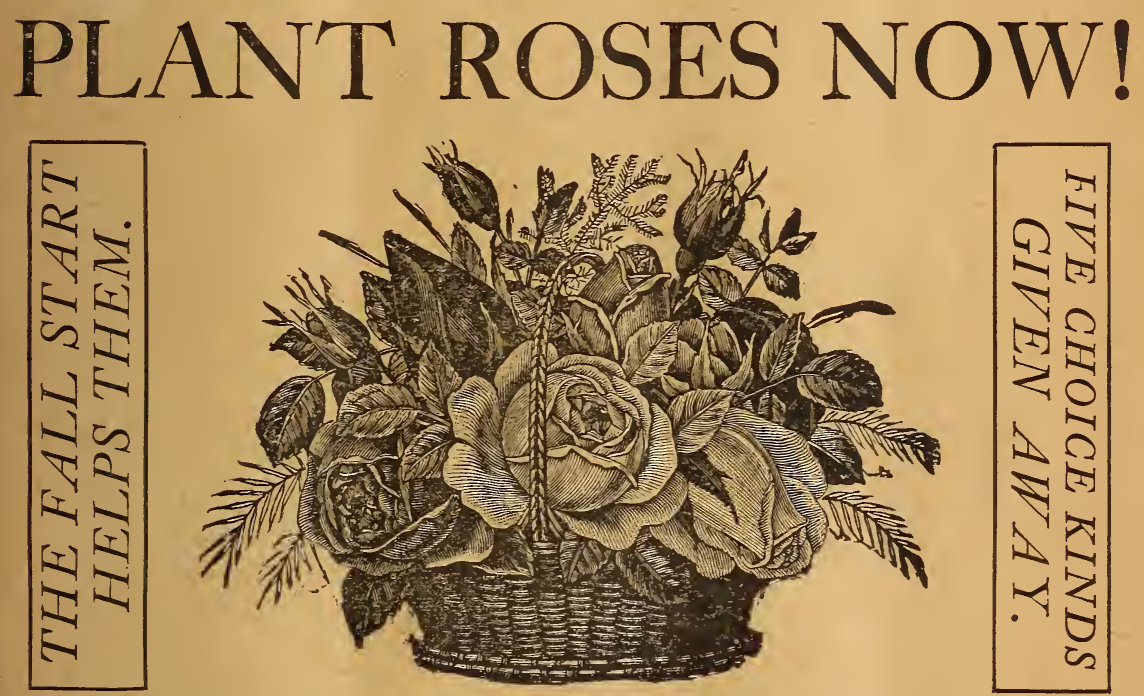

\section{Our Latest and Best Premium Offer}

TOU may have THE Floral WORLD one year and Five Choice Rose Plants, assorted colors, for only 25 cents. This is the regular subscription price of
the journal, so you are getting the Roses FREE.

We wish to largely increase the subscription list of THE FLORAL W'ORLD, and we wish to have our friends try fall planting of Roses. Many persons have found fall planting much better than spring planting.

We recommend fall planting in all sections where the cold of winter is not too severe. If you have never planted in the fall, however, better make a trial on a small scale. Our splendid offer enables you to do so at practically no cost. Remember: Subscribe for THE Floral WORLD one year at 25 cents and we will give you Five Rose Plants Free.

The Roses will be of assorted kinds and colors, especially selected to suit your locality. As far as possible we will send one white, one red, one yellow, one pink, and one intermediate color. Five choice Rose plants and THE FLORAL WORLD a year for only 25 cents. Order at once. Address, 


\section{A NEW $\$ 40,000.00$}

FIRST PRIZE, \$10,000; SECOND PRIZE $\$ 3,000 ;$ THIRD PRIZE, $\$ 1,000$

\section{It Costs You Nothing to Guess. You May Get a Prize}

Every subscriber to THE FLORAL WORLD will have an opportunity to share in these magnificent prizes if he wishes to participate in the Great Educational Contest in which these prizes are given.

The subject matter of this great contesi is the total vote cast for Governor in the States of Ohio, Massachusetts and lowa on the third day of November, 1903.

Every person interested in the science of Government should be interested in the election in these three States, as much valuable information can be gained by a study of the political conditions involved in these elections.

\section{CONDITIOHS OF THIS GREAT CONTEST;}

Every subscriber who remits 25 cents, the regular subscription price (a year's subscription) to THE FLORAL WORLD will receive a certificate that will secure for him any prize which his estimate entitles him to claim.

When you send in your subscription, also send your estimates of the total vote for Governor in the three States. Write your name, address and estimate in the subscription blank below and mail it to THE FLORAL WORLD, Springfield, Ohio.

The contest will close at midnight. November 2, 1903, and no estimate received after that hour will be allowed. The official certificates of the Secretaries of the three Siates, showing the total vote for Governor, will determine who are entitled to the prizes, and the awards will be made by a disinterested committee of prominent judges just as soon as the official figures can be obtained. Read the special prizes for those who guess early. It will pay you to guess now. The Press Publishing Association has already deposited the $\$ 40,000$ with the Central Savings Bank, Detroit, Mich., for the payment of the prizes.

CERTIFICATE OF BANK PRESIDENT

I hereby certify that the Press Publishing Association has deposited $\$ 40.000$ in the Central Savings Bank, Detroit, Mich., for the express purpose of paying the prizes to those making the nearest correct estimates of the total aggregate vote cast for the office of Governor in the States of Ohio, Massachusetts and Iowa, on the 3 rd day of November, 1903, and that this fund can be used for no other purpose.

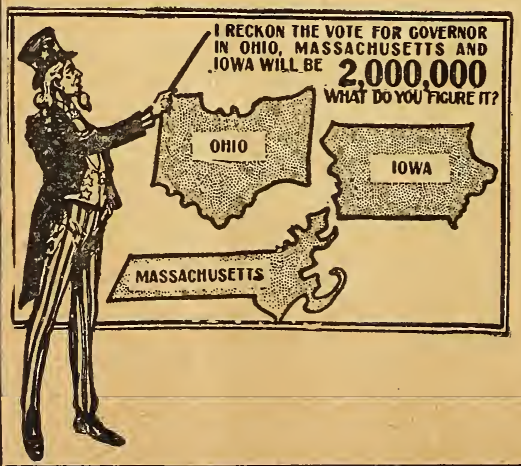

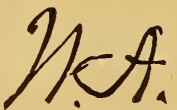

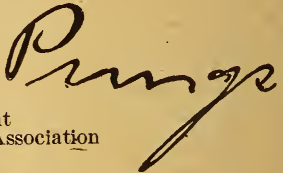

\section{VALUABLE INFORMATION.}

To aid in forming your estimate we furnish the official figures showing the vote for Governor in each of these States for the past ten years, as well as to give the total vote for the three States combined. The total vote for the th ree States is found in the right hand column.

Ohio Mass. Iowa Total 1801...795,629 $321,650 \quad 420,212 \quad 1,537,491$ $\begin{array}{llll}1893 \ldots 823,658 & 365,012 & 415,806 & 1,604,476\end{array}$ $1895 \ldots 837,466 \quad 328,121 \quad 401,345 \quad \mathbf{1 , 5 6 6 , 9 3 2}$ $\begin{array}{llll}1895 \ldots 8837,466 & 328,121 & 401,345 & 1,566,932 \\ 1897 \ldots 854,986 & 269,795 & 438,292 & 1,563, v i 3\end{array}$ $\begin{array}{llll}1899 . . .908,159 & 299,166 & 433,351 & 1,640,676\end{array}$ $1901 \ldots 827,566 \quad 324,526 \quad 390,489 \quad 1,542,581$

What will be the total vote for Governor in these three States combined on the third day of November, 1903? Figure it out and send in your cstinatis. it nar mean, $\$ 10,1100,00$ in cash to you. 


\section{Profit Sharing

TWENTY SPECIAL PRIZES OF $\$ 1,000.00$ EACH FOR EARLY ESTIMATES

\section{HERE IS THE LIST OF PRIZES.}

To the nearest correct estimator

$\$ 10,00000$

To the seeond nearest correct estimator.

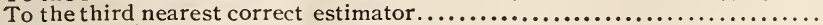

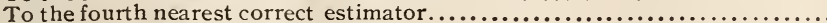

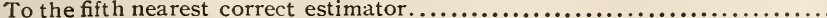

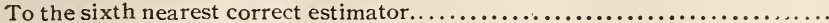

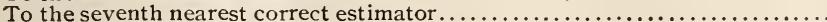

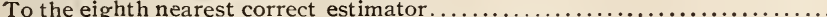

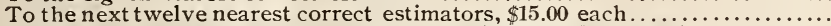

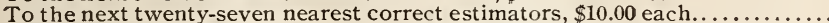

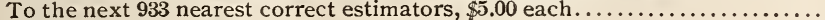

;,000 00

1,00000

50000

20000

10000

5000

3500

18000

27000

4,66500

980 prizes amounting to.

$\$ 20,00000$

\section{The Following Special Prizes will Also be Paid:}

For the nearest correct estimate received before Dec, 15, 1902.

$\$ 1,00000$

For the nearest correct estimate received on or after Dec. 15 and before Jan. $1,{ }^{\prime} 031,00000$

For the nearest correct estimate received on or after Jan. 1 and before Jan 15. 1,00000

For the nearest correct estimate received on or after Jan. 15 and before Feb. $1 . \quad 1,00000$

For the nea rest correct estimate received on or after Feb. 1 and before Feb. $15 \quad 1,00000$

For the nearest correct estimate received on or after Feb.15 and before Mar. $1 \quad 1,00000$

For the nearest correct estimate received on or after Mar. 1 and before Mar. $15 \quad 1,00000$

For the nearest correct estimate received on or after Mar. 15 and before April1 $\quad I, 00000$

For the nearest correct estimate received on orafter April1 a nd before April $15 \quad \mathbf{1 , 0 0 0} 00$

For the nearest correct estimate received on or after April 15 and before May $1 \quad$ 1,000 00

For the nearest correct estimate received on or after May $\mathbf{1}$ and before May $15 \quad 1,00000$

For the nearest correct estimate received on or after May 15 and before June $1 \quad$ 1,000 00

For the nearest correct estimate received on or after June 1 and before June $15 \quad 1,00000$

For the nearest correct estimate received on or after June 15 and before July $1 \quad 1,00000$

For the nea rest correct estimate received on or after July 1 and before July $15 . \quad 1,00000$

For the nearest correct estimate received on or after July 15 and before Aug. 1. $\quad 1,00000$

For the nearest correct estimate received on or after Aug. 1 and before Aug. 15 $\quad 1,00000$

For the nearest correct estimate received on or after Aug. 15 and before Sept. $1 \quad 1,00000$

For the nearest correct estimate received on or after Sept. 1 and before Sept. $15 \quad 1,00000$

For the nearest correct estimate received on or after Sept. 15 and before Oct. 1

1,00000

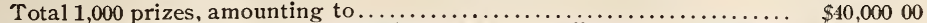

In case of a tie or that two or more estimators a re equally correct, prizes will be divided equally between them.

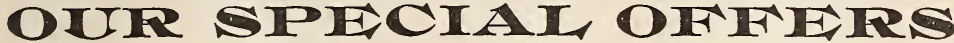

One year's subscription for THE FLORAL WORLD and one estimate only 25 cents. Send your estimate when you remit and you will promptly receive a certificate which will secure for you any prize your figures may win.

If you wish more than one estimate, remit us only 20 cents for each yearly subscription and estimate after your first one. Always include your estimates when remitting. Address,

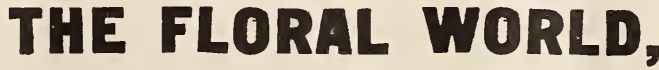




\section{Palms, Roses, \\ Chrysanthemums}

\section{Six Generous Collections of Plants GIVEN AWAY as Premiums}

We will give any of these valuable collections ABSOLUTELY FREE to any person who will send us a club of only four yearly subscribers to The Floral World, at 25 cents each. Two collections for a club of eight, and so on. The subscribers in your club may have their choice of Rose Collection described on first cover or the estimate in Profit-Sharing Contest advertised on second cover.

\section{Premium No. I4. The Rose Collection.}

1 Admiral Dewey.

1 Alliance France Russia.

1 Cornelia Cook.

1 Duchess De Brabant.
1 Enfant de Lyon.

1 Isabella Sprunt.

1 Lottie Bumgardner.

1 Silver King.

Premium No. I5. The Chrysantbemum Collection.

1 Fisher' sTorch.

1 Her Majesty.

1 Kioto.

1 Mrs. John Wanamaker.
1 Marie Louise.

1 Major Bonaffon.

1 Silver Wedding.

1 Vivan Morel.

\section{Premium No. I6. The Palm-Collection.}

1 Areca Lutescens. A majestic palm without a peer for elegance and grace.

1 Phoenix Canariensis. The true date palm.

1 Phoenix Reclinata. The hardiest of date palms, with dark green feathery foliage.

1 Latania Barbonica. The well-known Chinese Fan Palm. 


\section{Fuchsias, Ferns, and Basket Plants}

\section{The MOST LIBERAL OFFERS We have ever made to Club Raisers.}

Premium No. I7. The Basket Plant Collection.

1 Beautiful Fern. The Nephrolepsis.

1 Weeping Lantana. A new weeping plant of great beauty.

1 Manettia Bicolor. A beautiful climber that blooms both winter and summer.

1 Phrynium Variegatus. An ornamental plant for either pot culture or

1 Smilax. bedding out.

1 Russelia Multiflora. The "Scarlet Fountain" plant.

1 Saxafraga Sarmentosa. Fine for hanging baskets, vases, etc.

\section{Premium No. I8. The Jasmine Collection.}

2 Jasmines-Maid of Orleans. A fine grower, easily cultivated, and a good bloomer; and Grand Duke of Tuscany, a new one that is going to be very popular.

1 Lemon-Ponderosa, about which you hear so much.

1 Oleander-Lillian Henderson.

1 Stephanotis Floribunda. A hard-wooded vine, with thick lerthery leaves and bunches of pure white flowers that are deliciously fragrant.

\section{Premium No. I9. The Miscellaneous Collection.}

1 Abutilon, the Chinese Bell Flower, Souvenir de Bonne.

1 Asparagus Sprengeri.

1 Asparagus Plumosus Nanus.

1 Aloysia Ditriodora, the Lemon Verbena.

1 Cyperus Alternifolius, the Umbrella Plant.

1 Fuchsia-Duke of Aliany.

1 Grevillea Robusta. A splendid decorative plant, of quicker growth than the palm.

1 Chinese Hibiscus-The Double Crimson.

Any one collection for a club of only four subscribers to THE FLORAL WORLD at 25 cents a year. Order by number and write plainly. Give number of collection when ordering. Address,

\section{THE FLORAL WORLD, Springfield, Ohio.}


A JOURNAL OF HOME FLORICULTURE.

Vol. II., No. 3

Springfield, Ohio, December, 1902

25 Cents a Yeas

WORDS OF APPRECIATION.

May all success attend The Floral WORLD. Mrs. IV. D. Brown.

I have received my first copy of THE FLORAL TORLD, and like it very much. Missouri. G. E. LOCKer.

I like The Floral World very much. Although small, it contains a large amount of useful information.

Iowa. INDIA J. RUCH.

I have been benefited many times by the advice given in THE FLORAL WORLD. It is the most helpful and interesting magazine I have ever taken, and I wish it all the success it merits.

Massachusetts. M. N. H.

Some time ago I received sample copies of THE FLORAL WORLD which pleased me so much that now I am a well satisfied subscriber. I take three floral papers, all larger than yours, but I like the smallest one the best! Your articles are short and sensible.

Vivisconsin.

Delia Guhr.

I have been a subscriber to THE FLORAL WORLD for almost a year, and think it just splendid, as I learn a great deal from it. I think it a great deal cheaper to read and learn to tend flowers, than to buy them and learn how, as you will kill more plants by not knowing how to care for them, than a good many year's subscription will cost. The Floral WorLd is one of the best magazines. I love to read the letters, as it is just like talking to some flower-loving friend.

Missouri.

K. UNVERFERTH.
I received a sample number of THE Floral WORLD and liked it so much I subscribed at once, and have never missed a copy. I get several floral papers and like them all, and get a great deal of good from them, but THE FLORAL WORLD is unique. It has a "homey" air about it. When reading it one feels as though he were sitting talking to a flower-loving friend. THE FLORAL WORLD is handy in size, so generous in its premiums, and so entertaining to flowerlovers especially, it ought to have a million subscribers, and I shall try to prove my faith by works, and get up a club, at once. May The Floral World live long and prosper.

Georgia.

Mattie E. Green.

\section{AS TO COVERING BULBS.}

Never cover anything having top growth with leaves, when wet, as they are tight and will mildew green wood. I lost a fine lot of roses that way some years ago. I succeed well covering with corn stalks or evergreen boughs. Do not cover at all until the ground has frozen. The heat of the earth will start the buds and they are liable to die. We cover, not to keep warm, but to keep from thawing and freezing. For years I have used good surface soil, well screened and dried, to cover bulbs and tubers of all sorts, and I never lose any.

I plant cauliflower, celery and cabbage in same in a light cellar, and water when dry and have fine cauliflower in March.

So many recommend sand or leaves, but I believe they are both unsafe. Leaves may do for banking or covering bulb beds.

New York.

C. J. Pepper. 


\section{THE FLORAL WORLD}

PUBLISHED MONTHLY BY THE

\section{FLORAL WORLD COMPANY}

12 to 11 South Limestone Street SPRINGFIELD, OHIO

\section{Subscription Price, 25 Cents a Year}

Entered as second-class matter at the Postoffice in Springfield, Ohio.

We will give $\$ 26.00$ in prizes for the best five articles for publication in the February number of THE FLORAL ITORLD, which may be submitted by subscribers.

The first prize will be $\$ 10.00$; the second $\$ 7.50$; the third, $\$ 5.00$; the fourth, $\$ 2.50$; and the fifth, $\$ 1.00$. The awards will be announced in our March issue.

No article which contains more than two hundred words will be considered in the prize decision. All contributions entered in this prize contest must reach us not later than January 1.

The purpose of these prizes is to secure for publication in THE FLORAL ITORLD matter which gives the actual experiences in flower growing of those who have subscribed for the journal. Prizes offered for articles published in the November number have been awarded as follows:

First Prize-Miss Ella Day, Missouri.

Second Prize-Lydia E. Duffy, Kansas.

Third Prize-Mrs. C. F. Fisher, Florida. Fourth Prize-Molly Gilbert, Oklahoma. Fifth Prize-E. A. Josselyn, Massachusetts.

\section{DO FLOWERS TALK?}

We are told that flowers are the "illumined scriptures of the prairies." And we feel that their influence for good is omnipotent.

IVe meet the snowdrop, the violet and the fair, frail windflower while the snow still lingers, and they whisper of leafy trees and fields of golden grain; and we are gladdened to know that chilly winds must fall back before the warmth of spring.
Later the trees deck themselves in fragrant blossoms and we hearken to the promise of a bounteous fruitage.

A man, long deaf to the appeals of humanity, morose, sullen and bent upon revenge, makes his way towards the object of his fury.

Then, he pauses beside a row of oldfashioned flowers, growing round a deserted cottage, uncared for and unkept, but, for all that, they plead until his better self is master.

His eyes-so long dry-are overflowing; their petals are bathed in tears. The morning sun kisses these all away. But he does not forget the words of these flowers, that are like those his sainted mother tended, and he is saved.

Tell me, did they speak, or how did they stay the hand that was raised against it's brother?

Iowa. Alberta M. KEPPER.

INQUIRIES.

Can you tell me something that will destroy black ants? They have very nearly ruined all of my roses and chrysanthemums.

\section{Alabama. Mrs. C. E. MCConnell}

Please tell me how to care for a palm. I have a beautiful one but the tips of its leaves turn brown.

Illinois.

Beulah P. Gilliatt.

I cannot find the "Diamond Flower" in any catalogue. Has it another name and where can I get it?

Florida. Mrs. C. F. Fischer.

I have some choice tender roses that I am anxious to keep through the winter. IVill someone tell me how to protect tea roses in the ground, to bring them through the winter all right?

Illinois.

Mrs. Haskell.

Will Rev. F. P. Franke, or some othe $\mathrm{r}_{\mathrm{r}}$ reader of THE FLORAL ITORLD, tell me where to get seeds of the diamond flower?

Ohio. 
BRANCHING RUBBER PLANTS.

I never liked the tall "sticky" specimens of the rubber plant, so when I was given a healthy young plant last Christmas I was advised to "branch it" as follows :

Wherever I wished a new sprout to appear I tied a small sponge where the leaf joined the main stem and kept it moist all the time. I have a superb evenly-branched specimen at this time which is the wonder of all my visitors. Wipe off the leaves once in two weeks with milk and water.

Another hint that may be of use to some one. I have a cycas revoluta or saro palm. It had been in the parlor all summer, where there was an awning over the window before which it was placed. The leaves beran to turn yellow and spotted as you gazed through them, when held up to the light. I transferred it to a room upstairs, where it had plenty. of light, but no sun and withheld water for two weeks. Much to my satisfaction, the spots disappeared and it gradually regained its healthy appearance.

One great mistake with the "woody" palms is over-watering. On the contrary, rubber plants, caladium sand sanseveriaa swordlike leaved plant, beautifully blotched in green and white-can hardly have too much water.

\section{Mrs. Minnie N. Hinds.}

Massachusetîs.

ENVELOPES Printed to order, only $\$ 1.00$ per 1000. HOWARD COMPANY, 563 Masonic Temple, Chicago.

\section{FOR CHRISTMAS GIFTS, THE PERRY PICTURES \\ The World's Great Paintings. Gold Medal, Paris Exposition}

The one-cent pictures are six to eight times the size of this picture. Order today. You will wish to order again when you see how beautiful they are for Holiday Gifts.

Send 25 Cents for

25 Art Subjects,

Or 25 Madonnas

Or 25 of Life of Christ, 7

Or 25 Landscapes,

Or 25 Dogs, Kittens and

Horses,

Or 25 Authors and Poets,

Or 25 for Children,

A choice Holiday Gift,

Or 13 Pictures in colors,

Or 5 extra size (10x12),

Or Art Booklet, Madonnas,
Each set in a portfolio.

Or 50 cents for any two sets in first column, or 11 Perry Pictures, extra size, or Portfolio 25 pictures, New York edition $7 \times 9$, Gems of Art.

Or $\$ 1$ for any four $25 \mathrm{c} \mathrm{sets,} \mathrm{or}$ our beautiful 1902 Christmas set, No. 1, 120 pictures, no two alike, or Christmas Set, No. 2, 120 pictures, all in the new Boston edition, no two alike, or 120 Periy Pictures, your own selection from 2000 subjects.

Or these pictures, $5 \frac{1}{2} \times 8$, may be assorted as desired at ONE CENT EACH, for 25 or more, postpaid, 129 for $\$ 1.60$.

Send three two-cent stamps for Catalogue with 1000 miniature illustrations and two sample pictures.

THE PERRY PICTURES COMPANY, Box 666, Malden, Mass.

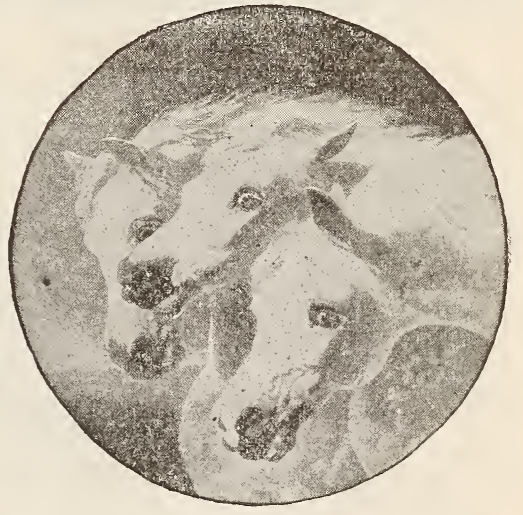

\section{$33 \%$ DIVIDEND}

paid by the Mexican Plantation Asso. ciation, 1602 Title and Trust Building, Chicago, Ill, Oldest of its zind in Mexico. ESTABLISHED 1897. Has 6,000 shares, or acres, planted to permanent crops, rubber, coffee and va. nilla. The Association's contract is like an insurance policy-in case of death the money is refunded. 38 deaths have occured since 1897. These shares will now be resold. For iull particulars, address as above.
40 To do piece work at their homes. We furnish all perience unnecessary. Send stamped envelope to ROYAL Co., Dept. F. W., 34 Monroe Street, Chicago.

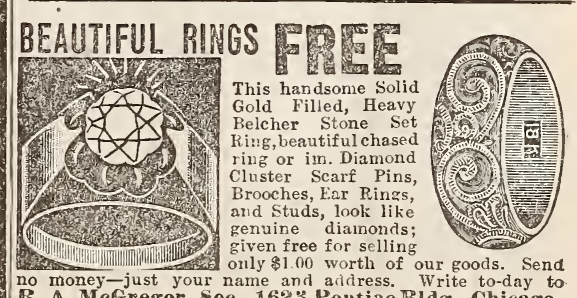

B. A. McGregor, See., 16 '3 Pontiae Bldg., Chicago 

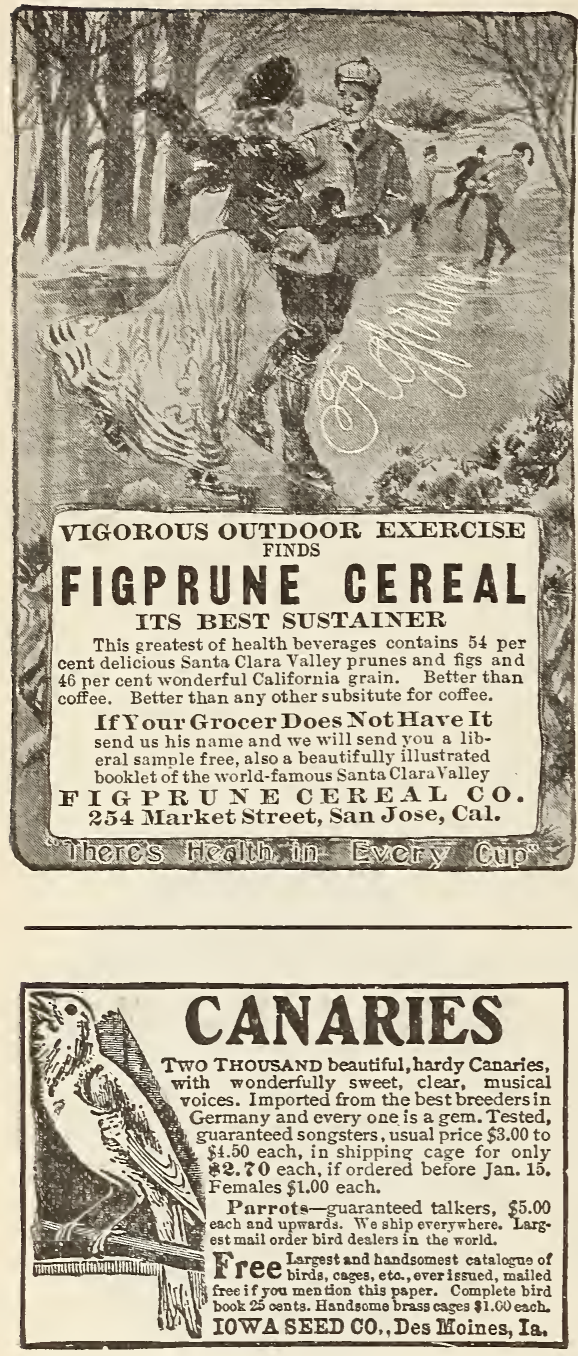

\section{A GRAND INVENTION!}

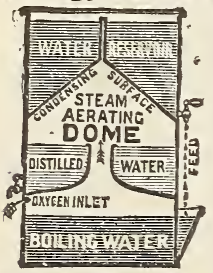

Famous Puritan Water Still. Over 72,000 already sold. Placed over the kitchen store, it purifies the foulest water. Re. moves every impurity. Furnishes delicious distilled Pure Wister. Beats filters. Saves lives and Dr. bills. Prevents Typhoid Malaria, other fevers, sickness. Only safe water for children. Cures disease. Write for Booklet and testimonials free. Agents Wanted-Men andi Women-Big Wages. Harrison Mfg. Co., i4 Harrison Bidg., Cincinnatl, 0 .

\section{FALL PLANTING OF ROSES.}

I find from experience that the fall of the year is the best time for planting roses, both monthly and hybrid perpetual. First spade the bed deep and put in manure from the barn, old, well pulverized from the cow barn being best, as it does not fire them, causing them to die the first summer, as that from the horse barn will sometimes do. Spade the manure well into the soil and plant the roses when the ground is not too wet, mulching well on top of ground with dry grass or leaves to keep the ground from freezing around the roots. I have the following which I find very good for out door planting: monthly; Princess Bonnie, the queen, Etoil de Lyonaise, Francisca Kruger, pink la France and Catherine Mermet, polyantha roses, little white pet, very profuse bloomer; Pink Soupert, Clotilde Soupert and Perle de Ore are good bloomers with me. Running roses, Marechal Neil and meteor planted together to mingle their pretty blooms of yellow and crimson in the rambling over the piazza. Hybrid perpetuals, General Jacqueminot and Madam Plantier I had also.

South Carolina Mrs. M. R. L. PEDEN.

\section{AN EXPERIENCE WITH OLEANDERS.}

I should like to tell you what I know about the oleander, which grows very luxuriantly in this city. It is a very hardy plant and requires but little care. It grows abundantly on Sullivan's island, both the pink and white varieties, and requires no attention. About four years ago my daughter put a few branches in a jar of water and at the end of two months they had long roots on them. We planted them in the yard and now the tree is over eight feet in height and about twenty-seven feet in circumference, and has been covered with double pink flowers since May. At first the flowers were a light pink, but now they are a deep rose color. We live in the western part of the city, and when the tide is very high the salt water comes up through the drains, but it does not 
injure the oleander. The cold in this climate does not hurt it unless very severe. Last winter my tree did not lose its leaves and they remained green and glossy.

Can any one tell me of any other plant that tide water does not injure?

Mrs. F. A. E. Sirth.

South Carolina.

\section{CARNATIONS FROM SEED.}

Last year I had over two hundred fine plants. I worked the ground mellow, mixing with rotted manure and planted the seeds in rows just covering them with soil. In two weeks they were up, and when large enough, I loosened the soil around them and transplanted them about a foot apart.

During the warm weather I watered them in the early morning, as they needed it.

By fall I had strong plants, some as large as a ten quart pail.

By Thanksgiving one had fifteen large blossoms of a bright red color.

All were double and some the size of a silver dollar. They paid me well and are a great deal better than plants raised from cuttings. Everyone admired them.

Mass. Mrs. Mary F. Moody.

\section{DECORATING A LOG CABIN IN THE $\mathrm{CHURCH}$.}

Last Christmas eve we had a real " log cabin," $4 \times 5$ feet, of the old W. H. H. type, neatly made from hewed poles. I, being one of the committee on decoration, proposed to the others to place an evergreen tree at the back of the cabin, (the door faced the audience,) which gave it an "old pioneer" look.

We placed bunches of cotton on the tree and sprinkled it with powdered mica to represent a snowy winter scene, and one side of the roof also, was white and sparkling.

We used cedar over the front of the cabin to represent a vine reaching to the comb, and many bunches of ammobium and helichrysum (grown for the purpose),

(Concluded on page 10)
"Let the GOLD DUST twins do your work."

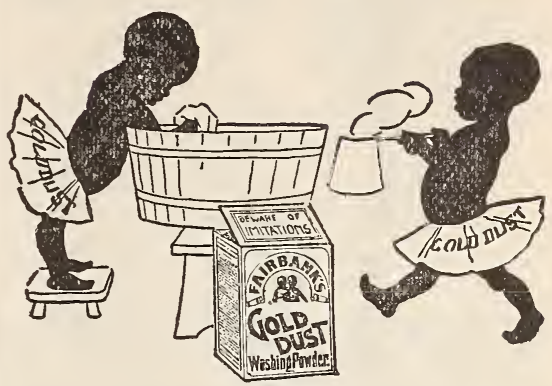

More clothes are rubbed out than worn out.

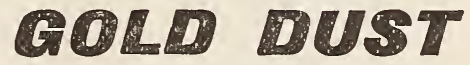

Will spare your back and save your clothes. Better and far more economical than soap and other Washing Powders.

Made only by the N. K. FAIRBANK COMPANY, Chicago, New York, Boston, St. Louis.

New Orleans, San Francisco, Montreal

Makers of OVAL FAIRY SOAP.

\section{BE BEAUTIFUL}

Dr. Bidaman's Safe Arsenic Complexion Wafers remove pimples, freckles, blackheads, and all blemishes of the skin. Make the complexion clear, transparent, rosy smooth and soft. Used by noted beauties and actresses. Sample box sent on receipt of $\mathbf{2 5}$ cents in stamps. Correspondence absolutely confidential.

DR. ISRAEL BIDAMAN,

Established over Thirty Years.

NEW YORK.

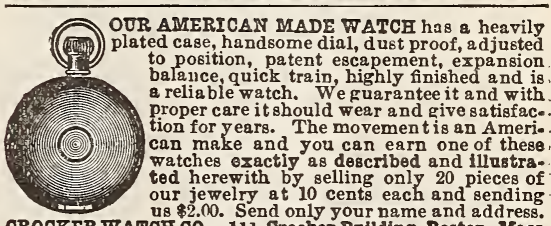

CBOCKER W us $\$ 2.00$. Send only your name and add ress.

RHE U MATIS M

ANYONE CAN CURE IT

When the attack is mild. We positively cure all aggravated chronic cases of long standing, when

\section{ALL OTHERS FAIL}

We charge for the medicine only. Address

EBERHOLD CO., T145 22d St, Chicago,III.

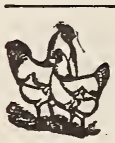

CUT RATFS on all varieties Egos and GU RAIES POULTRY. All varieties Fancy Pigeonsand Belgium Hares Send for rates and for 60-page book, which one and all, each and everybody bargains a re tucluded. All for $10 \mathrm{c}$.

Address, J.A.BERGEY, Telford, Pa.

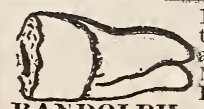

For 25c. K. \& S. Tooth Filier fills the teeth for 6 months. Stops toothache instantly and prevents decay. Manufacturer, GEO. R, BAKER. Pegistered Pharmacist

RANDOLPH \& CLARK ST, CHICAGO. 


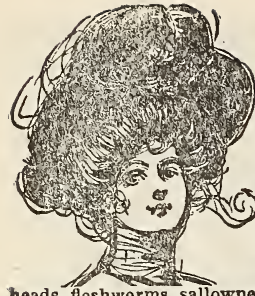

\section{Lovely Comploxion FREE.}

A Trial Box Mailed FREE which will give any lady a beautiful complexion. It is not a face powder, cream, cosmetic or bleach, but is absolutely pure and you can use it privately at home. It perma. nently removes moth patches. redness, crow's feet, pimiles, black heads, fleshworms, sallowness, freckles, tan, sunburn, and all complexion disfigurements. Address,

MADAME M. KIBAULT, 4012 Elsa Bldg., Cincinnati, 0.

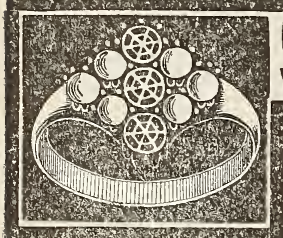

George Clark WILL GIVE YOU THIS RINC Solid Gold finished, set with Rubies and Pearls, F R E E for selling 4 of $\mathrm{my}$ large Ar Pictures at the reduced pric of 25 cents. All different. No trouble to sell these pictures, they are handsome art productions, done in 10 to 17 colors, originals costing 200 to 500 dollars. The first four you meet will gladly take them at 25 cents to help you win the premium. The Ring guaranteed worth many times this small service, but want to introduce my pictures at once. Send No Money in advance. I trust you and will send the picture gepresenting 4 different and heaut ful scenes, all charces paid, immediately on hearing from you. GEO. T CLARE, IIgr. 323 Dearoorn St., Chicago.

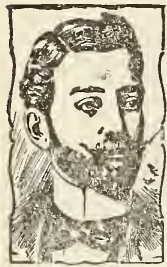

LEARM TO HYPHOTIZE!

Instruction Free! You csn become a Hypotist in a few hours time without leaving your home. You can sway the minds of others, control friendship and affection, oure disease and bad habits, gratify your ambitions and produce amusement hy the hour. My mammotb Illustrated Lesson or Key to Hypnotism which I send free of charge and postage paid, will tellyou all about this marvelous science. It contains hundreds of besutiful and artistic engravings, and shows you just what Hypnotism is and what 1 will accomplish. Send for it and learn to Eypnotize. Remember, this wonderful book costs you nothing. A postal card

tion this paper, I will also include a large packsge

of other valuable, interesting and profusely il-

lustrated literature, without charge. A chance

lustrated literature, without charge. A chance
of a lifetime. Write to-day. Address, PROF.
L. A. HARRADEN, Jaekson, Michigan.
(Concluded from page 9 )

also frosted with mica. The door was small, but after a short program, "Santa" came out of the cabin and served the children.

Cedar, evergreen, shrubbery and flowers are standard trimmings. Use only enough to make it picturesque, as too much decoration 'produces a "cluttery" effect. ANNIE J. PADDICK.

Illinois.

\section{PELARGONIUMS.}

In April buy small plants and pot in three-inch pots. Use of old barnyard dressing and soil, two-thirds; sharp sand, one-third; wood ashes, two trowelsful to a pail of earth. Set outside in some cool spot where they get the sun part of the day. Water only when they seem dry, occasionally with liquid dressing. Pinch back until January, when they should be large enough for eight-inch pots. In October take into an unheated south room, open the window every day through the winter when possible, avoiding a direct draught. Give full sunshine, a temperature of sixty-five, and you will have no aphides on them.

In May, when beginning to bloom, they require more water as the sun gets hotter,

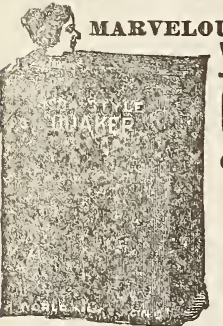
AIE SCRI

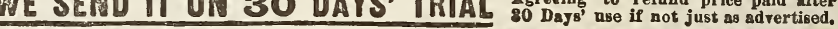
79. TOLNING

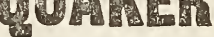
HOT AIR BATH

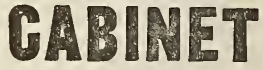

OVER 1,000,000 SOLD. A Regular Hot Springs Treatment at Home* PRODUCES CLEANLINESS, HEALTH, VIGOR AND $\triangle$ BKACTIFCL COHPLEXION.

Every family, doctor, hospital should have our Cabinet for bathing purposes. A nnishing are resulis. It opens the $5,000,000$ pores of the skin, sweats out all the impure ? poisonous matier of the blood, which causes disease, equalizes the circulation, and keeps 1 rong and vigorons. You enjoy at home or when traveling for $3 \mathrm{c}$, each all the marvelous, invi rn: sing and parifying effects of the famous Tnrkish, hot air or medicated baths. Whim . Invention tones every organ and nerve in the system, makes your blood pure, you ep sound. Prevents disease. Cures the worst cold, and breaks up all symptows of fevers, or La Grippe often with one bath. Reduces obesity. Cures rheumatim. neuralgis, In grippe, malaria, dropsy, bronchitis, female complalnts, blood, skin, nerve and kidney troubles. Immediate rellep surrnteed in worst eases. Our head steaming attachnent b-autifies complexion,

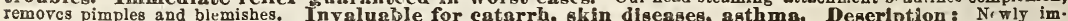
proved. at $\$ 5.00$ each, reduced to $\$ \mathbf{B . 5 0}$ complete. Style $1904-0$ ur finest and best $\$ 10.00$ double walled Cabinet, reduced to $\$ 6.10$ complete. Best heater, mcdicine and vanorizing pan, 100 page $\$ 2.00$ Health and Beauty Book, directions, receipts etc.; Iurnished FREE with each Cabinet. \$1.00 Head Steamer Artachm nt only 65c. Write us. Order today. You won't be disappointed. Guaranteed as represented or money refunded. We are rcsponsible, capital $\$ 100,000.00$. Largest manufacturers in the world. DON'T FAIL TO WRITE FOR 
but, like other plants, resent too much. Give dressing more often now. After blooming remove to east side of house, cut back one-half, water sparingly until September first, then cut the roots back, put into the same pots with new earth, shading from the sun for a time. By the second spring they should measure three yards in circumference, stand two and a half feet high, and be loaded with large beautiful flowers.

L. IV.

\section{Massachusetts.}

\section{SUGGESTIONS AS TO CACTI.}

I have three large plants of phyllo-cactus and one of cereus speciosissimus, which blossomed at the same time last spring, having from ten to twenty flowers on each plant. They were considered magnificent by all who saw them, and a traveled visitor pronounced the cereus speciosissimus as fine as an orchid.

I have had these plants seven years, age being one of the requisites for profuse blooming, but in that time they have been shifted and given new soil but twice. They were grown in tin cans, seven inches deep, and completely root-bound, another requisite. The rust from the cans in which they had been so long, proved a valuable fertilizer. When budding in early spring I gave ammonia in water once a week, but I warn phyllo-cactus growers against manure in any form as it is sure to disease the plants. I find occasional applications of lime water beneficial to all cacti. In summer I keep them on an open porch shaded by trees, for the hot sun blisters the leaves. They winter in a warm, dry cellar and need no water unless they shrivel. A large plant will continue to unfold blossoms for three weeks.

Washington.

\section{FREE TO EVERY LADY}

A safe, simple home treatment that cured me after years of suffering with uterine troubles, displacements, lucorrhoea, etc., sent free to ladies with full instructions how to useit. Address Mrs.A.L.Hudnut, South Bend, Ind

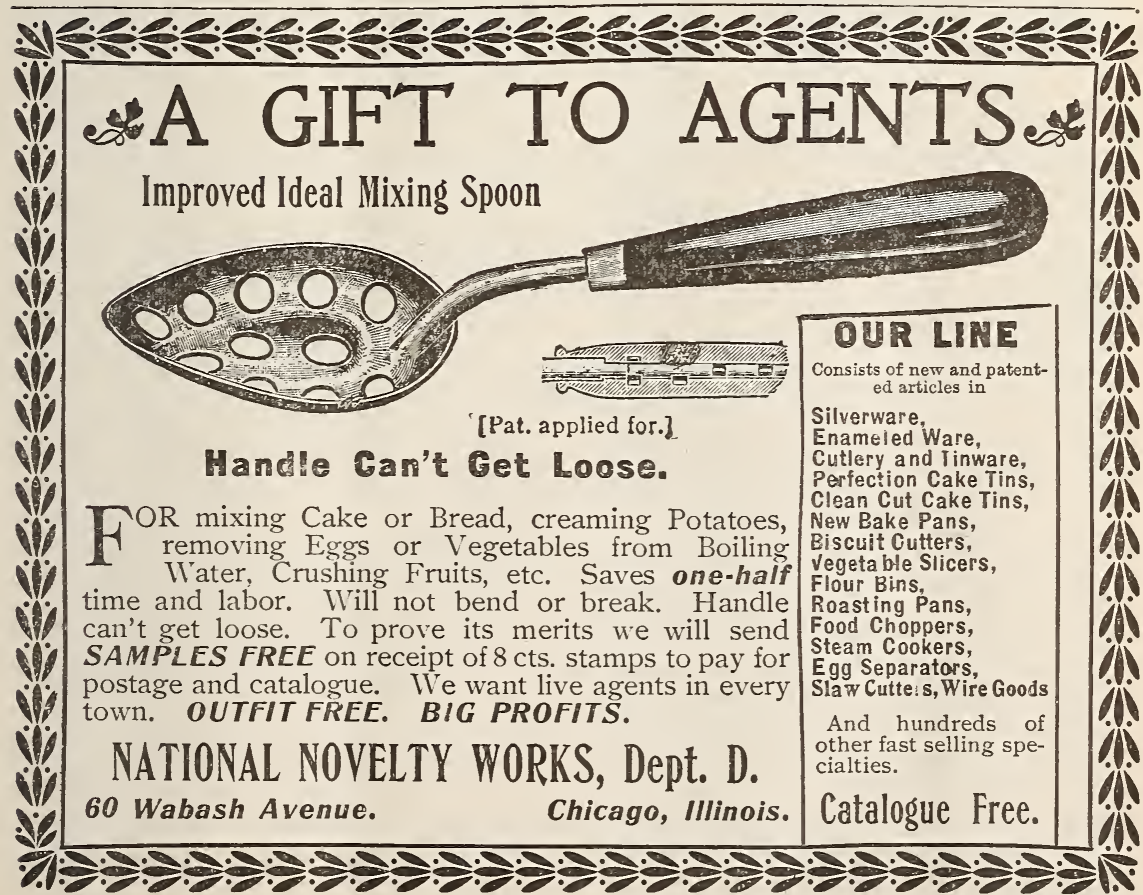




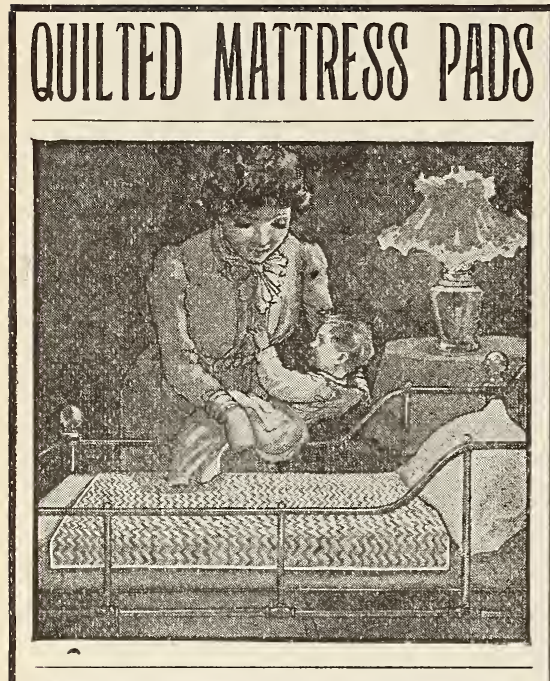

Fit your bed with a Quilted Mattress Pad and keep it in a cool and sanitary condition. A sound, refreshing sleep on hot nights will be made possible.

These nads are made of bleached muslin, hoth sides quilted, with pure white wadding of the best grade between. They wash perfectly.

Good as new after laundering, and the low cost places them within the reach of all.

\section{SEND FOR SAMPLE.}

\section{The Excelsior Quilting Co.}

MADE \$ 105 THE FIRST MONTH

(3. writes FRED. BLODGETT, of N. Y. J. L. BA BARIOK, of La., writes : "Am making \$7 $\$ 3.00$ to $\$ 8.00$ every day I work." MRS. IL. M. ANDWRSON, of Iowa, writes: "I
made $\$ 3.80$ to $\$ 6.50$ a day." Hundreds
doing likewise. So can jou. 1. 55.00 to $\$ 10.00$ daily made pla ting jewelry, tableware, bicycles, metal goods with gold, sil.

(1) ver, nickel, etc. Enormous de-

ver, nickel, etc. Enormous de-
mand. We tesch you
Write-offer free.

\section{Q. GRAT \& CO., Plating Works, A Minmi Bidg, Cincinnati, 0.}

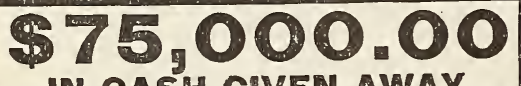

IN CASH CIVEN AWAY.

F To arouse interest in, and to advertise the CREAT ST. LOUIS WORLD this enormous sum will be distributed. Full information will be sent you absolutely free. Just send your name and address on a postal card and we will eend you full particulars. Address,

WORLD'S FAIR CONTEST CO., St. Louis. LADIES Your Bust enlarged permanently; cannot MME. SADA WELLS, Box 282, Bloomington, Ili. FREE Clairvoyance. If sick or alling send now Dr. D. Hinkly, $x-28$, Grand Rapids, Mich.

ANGORA CATS WHTTE SILK FRENCH POODLES
DAY-LILY CULTURE.

I want to give my experience with a funkia or day-lily_or "August-lily " as it is called here-a small root of which was given me by a friend about ten years ago, together with half dozen geranium cuttings, all of which I set in a leaky tin foottub. They grew together the first two seasons; the third they were so crowded I removed all but the lily and one or two others. Next season I removed everything but the lily, which I loosened and slipped to the middle of the tub. Each spring I take off one or two plants, for neighbors. The soil has never been emptied and refilled since the flowers were planted

Each fall, after cutting off dead flowers, stalks and leaves, I cover with stable manure, and set out of the weather; in pit when I have room, (though that is not necessary here, ) or under the house or porch. Last winter I set in an unused room, with no more attention till spring, when I slightly sprinkled the soil, which was dust-dry, with soapsuds once or twice before bringing out of doors, when it was to remain. Each summer I top-dress with hen-manure, and keep renewing the soil which the rains wash out. It grows finer every year, and is a thing of beauty, with or without flowers. Last year it measured twelve feet around; the leaves were $10 \times 12$ inches. It sent up six flower stalks, four of which must have had forty or fifty blooms each. This year it was quite as fine, though not measured, with eight immense flower stalks. My plant is the finest in the country; in fact, the finest I have ever seen. I nearly always water with soapsuds, but it doesn't need as much watering as other pot plants.

Georgia. Miss Mattie E. Green.

\section{AN EXPERIENCE WITH THE CALLA.}

The calla lily is a very desirable winter plant, both as a foliage plant and also for its handsome blossoms. It is quite interesting to watch it grow. One can almost see the leaves unfold, and ere long the 
buds appear, giving promise of a most beautiful plant. The calla loves a rich soil, free from worms, and a warm, moist atmosphere, with plenty of warm water; the roots do not want to be crowded; it also loves fresh air, if not too cold, and a shower bath to keep the plant clean.

I had one near a south window, which was seldom closed. The room opened into the sitting-room, and on the sittingroom stove water was kept most of the time. At times the moisture was so great that drops of water would hang on the leaves.

My plant grew very large, and was very beautiful. It had two sets of blossoms, six in all, some very large, with long stems, others not so large, but ail of them were taller than the leaves.

$$
\text { Oregon. DORA LEAKE. }
$$

\section{UTILIZING THE BACK YARD.}

The tide of civic betterment has struck Texas, and the especial wave reaching Temple has brought with it inspiration which we feel will result in much practical good in the line of home gardening and town improvement.

In developing the hitherto unknown resources of my back yard, I find your helpful publication a daily guide. On the rear of our lot we have erected a hothouse, 16x24, and beside anticipating great pleasure in our work, we hope, in time, to derive some profit. As a start we have ninety callas, 2 to $21 / 2$ feet high, in pots, (bulbs brought from California recently). These are in fine condition, and will soon bloom.

We have also set out one hundred carnation plants, which promise much. For mid-winter blooming we have two hundred pots of hyacinths, freesias, etc., set out successively through October.

Our growing plants stand on wide shelves, in damp sand. The bulbs rest in a "dark room" until time for forcing. We are also planting pansy and cosmos seed for spring transplanting.

Texas.

Gussie A. Young.

\section{CURES}

\section{DRUNKARDS \\ SEGRETLY}

\section{Free Package of the Only Successful Cure Known for Drunkenness Sent to All Who Send. Name and Address.}

\section{It Can Be Put Secretly into Food or Coffee and Quickly Cures the Drimk Habit}

Few men become drunkards from choice or inclination-all welcome release from the awful habit. Golden Specific will cure the worst habitual drunkard. This wonderful remedy call be administered by wife or daughter, in food, tea, cuffee or milk, without causing the slightest sus-

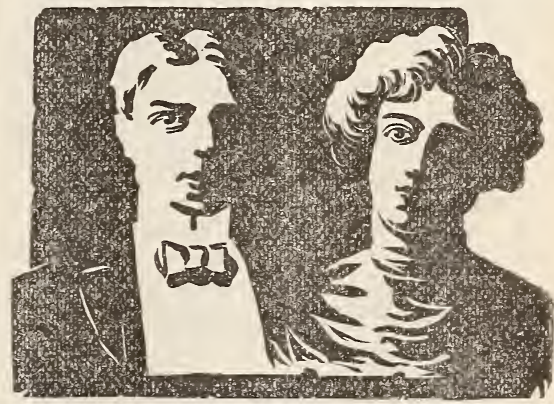

MR. AND MRS. HARKY BURNSIDE,

picion. Its cure is sure, without harmful results to the system. Many a home is now happy by the use of Golden Specific. "My husband got into t'?e habit of taking a drink with the boys on his way home," says Mrs. Harry Burnside. "After a while he came home drunk frequently. He soon lost his position and $I$ had to make $a_{2}$ living for both of us and the little children. At times he tried to sober up, but the habit was too strolig for him and then he would drink harder than ever. I heard of Golden Specific and sent for a free package. The treatment cured him. I put it in his coffee and he never knew it at all. He regained his old position and now we are happy in our little home again. I hope you will send Golden Specific to every woman that has siffered as I have, and save her loved ones from the drunkard's grave.

Selld your name and address to Dr. J. W. Haines, 4105 Glenn Building, Cincinnati, Ohio, and he will mail you a free package of Golden Specific in a plain wrapper, accompanied by full directions how to use it. Enough of the remedy is sent in each free package to give you all opportunity to witness its marvelous effect on those who are slaves to drink.

Do not delay. You cannot tell what may happen to the man who drinks, and you would never furgive yourself for waiting. 


\section{DARIEN YOUR CRAY HAIR}

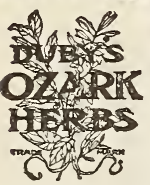

DUBY'S OZARK BIERBS restoregray, streaked or faded hair to its natural color beauty and softness. Prevents the hair from falling out, promotes its growth, cures and prevents dandruff, and gives the hair a soft. glossy and healthy appearance. IT WUL NOT STAIN THE SCALP, is not sticky or dirty, contains no sugar of lead, nit rate silver, copperas, or poisons of any kind, but is composed of roots, herbs and flowers. It cost ONLY 25 CENTS TO MAKE ONE PENT It will produce the most luxuriant tresses from dry, coarse and wiry hair, and bring back the color it originally was before it turned gray. Full size package sent by mail for 25 cents. CRARE HEBB COMPANY, St. Louis, Mo.
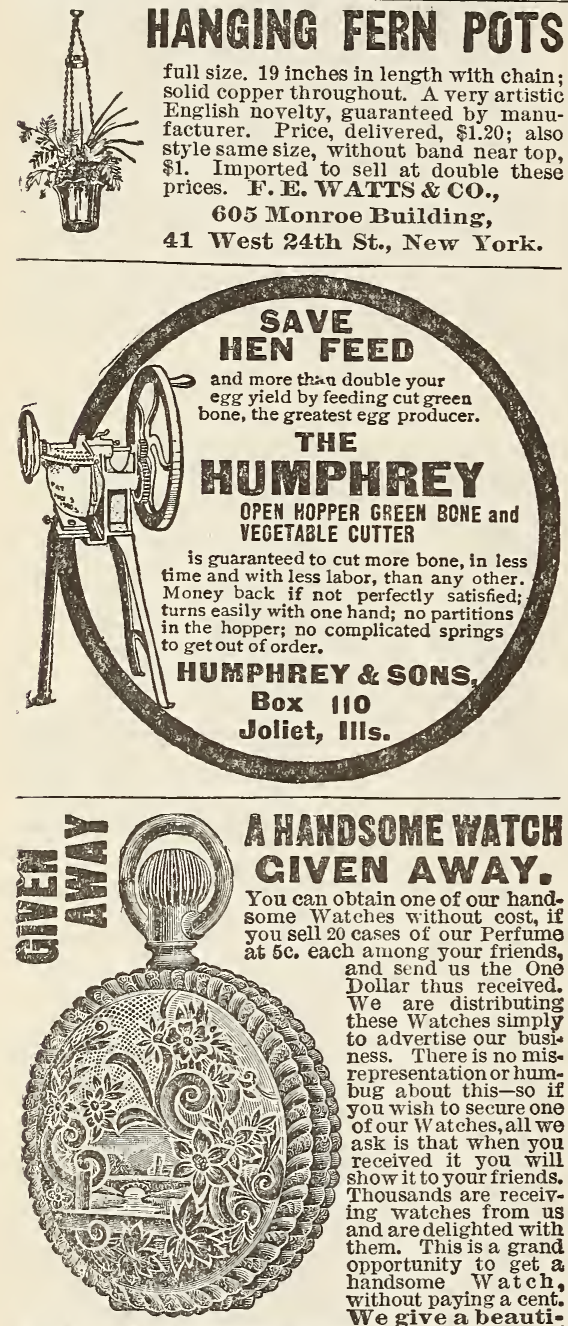

\section{A HAMDSOME WATCH} CIVEN AWAY.

You can obtain one of our hand. some Watches without cost, if you sell 20 cases of our Perfume 5 . each among your friends, and send us the One Dollar thus received. We are distributing these Watches simply to advertise our busi ness. There is no mis. representation or hum. bug about this-so if you wish to secure one of our W atches, all we ask is that when you received it you will Show it to your friends. Thousands are receiving watches from us and are delighted with them. This is a grand opportunity to get a handsome Watch, without paying a cent: We give a beautiful Wasch as a present to anyone who sells 20 cases of our Perfume at 5c. each and remits us $\$ 1.00$ for same. Send. your zame and address and we will mail you the Perfume postpaid. When sold, send us the $\$ 1.00$, and we will for ward you the handsome Gol d laid Watch. We trust you and take back all you cannot sell. No catch-words in this adrertisement. We mean justwhat we say. You require no advertisement. Working for us. Satisfaction Guaranteed. capital while working for us. Satistaction Guaranteed.

\section{CITRUS FRUITS.}

I pot citrus trees in sandy soil from the woods, with burned bone pounded fine for drainage. The bone is not so heavy and cold as gravel.

I bought a two-foot ponderosa lemon tree and planted it in a bucket. Some of the neighbors said, "Your lemon will never bear fruit in a bucket." "Well," said I, "when it does fruit I will snap my finger and you may come and see it."

It has proved itself true, bearing lemons which are now as large as goose eggs, and foliage prettier than my orange tree. You see the proved fact is what convinces. I never have to treat it for scale as I do my orange tree.

For the scale I take a half gallon of warm water, with three tablespoonfuls of coal oil and sprinkly it thoroughly. Sometimes three applications are necessary to cleanse it, but several days apart. The scale drops off and the tree takes on a clean look. During the winter the soil for the citrus trees should be kept rather dry, just moistened, as too much water will decay the roots. When new growth commences in the spring, water more freely and give manure water once a week.

Illinois.

Annie J. Paddick.

\section{TAKING CARE OF PLANTS IN WINTER.}

As I have no bay window I have frames of boards made inside the window frames, with one-sided buttons screwed to the inner edge so as to turn round the window casing to hold the frame in place. Along the sides of the frame as many cleats are nailed as are wanted for shelves. Nails are driven into the top edge for hanging baskets, etc. Besides, I have stands made with the tops even with the window sill, somewhat longer than the window is wide and two or three feet wide as best suits the room. Cactus does all right set in any warm, dry place till the buds start. Plants having hard wood can be wintered in the cellar. Mrs. IdA E. Cozins.

Pennsylvania. 
HOW TO GROW GERANIUMS FROM

\section{CUTTINGS.}

Make your boxes of planed boards four inches wide by a half inch thick, any size desired to fit on your window ledges. Make perfect drainage by boring several holes in the bottom of your boxes. Then fill in your boxes with a mixture of equal parts of nice sharp sand and clay loam thorpughly mixed. In September take cuttings with three or four joints, making the cut close to the joint, and strip off all the leaves but two. Plant your cuttings one inch apart each way, water thoroughly and set them in the shade for two days, then expose them to the full sunlight. Don't water again till very dry. You can keep them outside in a cold frame until the middle of November. Pinch the center out and they will make nice bushy plants for spring bedding. They don't take so much room this way and they root readily.

J. Chicken.

Ohio.

\section{GERANIUMS FROM SEED.}

Did any reader ever try raising auriole geraniums from seed? Two years ago I bought a packet of the best, (sixteen seeds for twenty-five cents) of which I raised nine. Those nine geraniums more than repaid the time and money spent for them. When not quite a year old they began to bloom, and have been blooming ever since. I keep them in the window through the winter and set them in a bed in summer, and they are seldom out of bud; if so, but for a few weeks.

My window of aurioles attracts more attention than any of my other plants, and I have quite a variety. Everyone takes them for pelargoniums, which they greatly resemble as they are zoned and striped.

I have quite a collection of nice double geraniums, among them being Souv. de
Mirande, Gertrude and New Life. If you can have but one geranium, by all means let it be an auriole.

DeLIA GuHr.

IVisconsin.

\section{TO WOMEN WHO DREAD MOTHERHOOD!}

Information How They May Give Birth to Happy, Healthy Children Absolutely ivithout Pain-sent Free.

No woman need any longer dread the pains of child-birth; or remain childless. Dr. J. H. Dye has devoted his life to relieving the sorrows of women. He has proved that all pain at childbirth may be entirely banished, and he will gladly tell you how it may be done absolutely free of charge. Send your name and address to Dr. J. H. Dye, Box 137 Buffalo, N. Y., and he will send you, postpaid, his wonderful book which tells how to give birth to happy, healthy children, absolutely without pain; also how to cure sterility. Do not delay but write to-day.

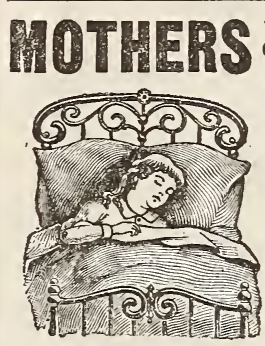

YOUR CHILDREN Cured of Bed-Wetting SAMPLE FREE。 EN-U-RE-3IRE cures Bed-Wetting, and in. continence of urine during the day-time, both in the old and young. It is the only cure prepared by a physician who guarantees it. Ladies troubled with a frequent desire to urinate and a burning sensation use it with perfect success. Send your address to DR F. F. IIAY Drawer 69 Bloming. Na , Drawer 60 ceive sealed a free sample.

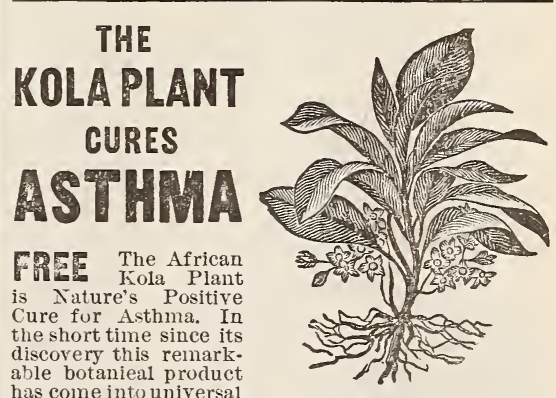
has eorreinto universal use in the Hospitals of Europe and America as

The Kola Plant.

an unfailing specific cure for Asthma in cvery form. Its cures are really marvellous. Dr. W. H. Vail, a prominent physician of St. Louis, Mo., writes March 8,1902 , that he used Himalya on seven different Asthma patients with satisfactory results in every case. Irr. R. Johnson, Sr., Grand Forks, N. Dak., writes Jan. 27, 1902, that lie suffered with Asthma for fifty yea $: s$, but Himalya cured him after twenty physicians and every change of climate failed. Miss Emaline B Iton, of 389 Conarroe St., Philadelphia, Pa., writes that Himalya is the only asthma medicine of merit. It cured her after twenty years suffering. Rer. J. L. Coombs wrote to the New York World, July 23rd, that Himalya cured him of Asthma of thirty years standing. Hundreds of others send similar testimony proving Himalya a wonderful remedy. If you suffer from Asthmain any form, in order to prove the power of this new botanical discovery, we will send you olie trial case by mail entirely free. It costs you absolutely nothing. Write to-day to the Kola Importing Co., No. 1164 Broadway, New York. 


\section{NEW CURE FOR KIDNEYS: BLADDER}

Bright's Disease, Rheumatism, Gravel, Pain in the Back, Dropsy, Diabetes, Etc.

a large Trial Case Free

For these diseases a Positive Specific Cure is found in a new botanical discovery, the wonderful Kava Kava Shrub, called by botanists the piper methysticum, from the Ganges River, East India. It has the extraordinary record of 1,200 hospital cures in 30 days. It acts directly on the kidneys, and cures by draining out of the Blood the poisonous Uric Acid, $\mathrm{L}$ it h a t e s, etc., which cause disease.

James Thomas, Esq., of the Board of Review Bureau of Pensions, Washington, D. C., was cured after many physicians had failed and he had given up all hope of recovery. Nathan- Miss; Viola Dearing, Petersburg, Ind. Esq. of Greenwood,

S. C., writcs: "Was a sufferer of Kidney and Bladder troubles, which caused two hemorhages of the Kidneys; had to urinate every few minntes; physicians told me my case was incurable, but was completely cured by Alkavis." Alvin D. Lane, Auburn, Me., writes: "Was cured of Rheumatism, which was so severe as to cause him to use crutches." Many ladies, including Miss Viola Dearing, Petersburg, Ind., Mrs. E. R. Dinsmore, South Deerfield, Mass., also testify as to its wonderful curative powers in Kidney diseases and other disorders peculiar to women.

That you may judge of the value of this Great Discovery for yourself, we will send you one Large Case by mail Free. It is a Sure Specific and cannot fail. Address, The Church Kidney Cure Company, No. 524 Fourth Avenue, New York City.

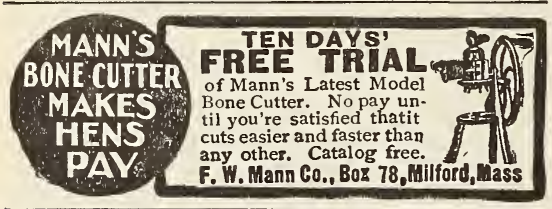

THE TPUTH Latis and gentitume, be

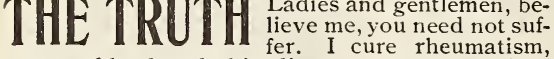
eczema, blood and skin diseases even when Hot Springs and others fail. Cure costs nothing. Remedies cost but little sent to your homes. Now your fault if you suffer. Address,

Dr. M. H. ROSS, Grand Rapids, Wich.

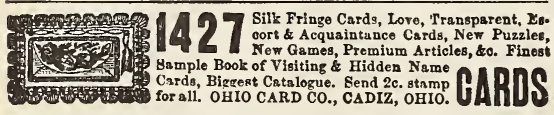

\section{GRAFTING CACTI.}

Sisters, who love cactus, do you know that one can have the oddest, most interesting and beautiful of all plants in the cactus? Get a cereus colubrinus, which is easily grown, and as it grows cut off in different lengths, laying up in your greenhouse to dry off the end. After some days put these cuttings in a pot just a size larger than the cutting, in almost dry sand, giving sun and the least little moisture. When the sides begin to fill out, put in a larger pot. Give moisture once a week, in winter and summer, spraying moderately while in full growth, except queen and king cactus, which require much water while blooming.

Take cuttings of flageltiformis, cristata, mamalariaus, ophipliylumus and rat-tail cactus, cut wedge shape, slip in the slit made in the cereus plant for it, pin through with a thorn and cultivate as above described, never giving too much water, and watch the beautiful, strange shapes. All that see them will be charmed and delighted with their beauty. They are also very valuable and costly.
Georgia.
Mrs. Allan Wamble.

\section{CONVENIENT HOUSES FOR PLANTS.}

A friend of mine built a square house with the corners cut off so a window could be put in, which, with a window on each side, made three windows together. Think of it; eight bay windows, four above and four below. The porch runs entirely round the house. It is a pretty house and their house plants are very fine. My own house is made very warm with siding, tarred paper, rough lined with boards, and plastered, and ventilators in the ceiling, so, with fire below, the upper rooms are warm enough for plants. The house sets at an angle with the points of the compass so the sun shines on every side sometime during the day. A large cellarway on the southeast side makes a nice place to set plants till nearly Christmas. A large porch in front and wide eaves. allow me to set plants anywhere.

Penna. Mrs. IdA E. Cozins. 


\section{SUCCESS WITH OTAHEITE ORANG}

Putting all theories aside, I followed treatment all my own. Proving such a grand success, I deem it my imperative duty to give my method to those having experienced disappointments.

Four years ago I received gratis a plant of the Otaheite orange. Not knowing its requirements, it received about the same care as geraniums. The leaves turned yellow, the fruit dropped off. The plant became infested with ants and scale.

In October I turned it out and found a ball of roots woven into a mass of network. which were cut away, leaving the main tap root. After pruning the top branches in the same severe manner, it was planted in rich soil, put in the pit and let alone.

In January, the new growth started. In May it was put out, and in two months had twenty fine oranges. I continued my experiment with copious watering, an occasional feeding with liquid fertilizer, washing the leaves and stems with soap and water, picking off every ant and scale, tying up the fruited limbs, and cutting back the superfluous growth. Now I have as fine a specimen of the Otaheite orange as it is possible to produce.

Louisiana. Mrs. W. N. WhITE.

\section{FERNS FOR TABLE DECORATION.}

If you are too far from the woods to get ferns, buy these little ones the florist sells at five cents each, take from their pots and place in a pretty cut-glass dish, which can be procured at the department stores for ten cents, fill in with any good garden loam or leaf mold if you have it. Sprinkle the foliage every day or two, and turn out the water that settles in the dish, as too much water at the roots is not good for the plants. Keep in a north or west window until wanted for the center of the dining table, when it should be placed in the center of a white linen doily with maiden-hair ferns embroidered upon it.

Connecticut.

Miss E. C. Beebe.

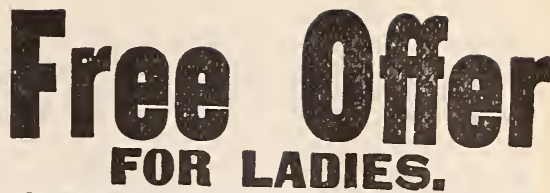

Cures every form of Plles, Female Weakness, Dis placements, Leucorrhea, Suppressed or Painful Periods, etc. We have decided to send one grand $\$ 5.00$ treatment free to every suffering woman in order to quickly introduce in every city, town and hamlet in the U. S. Address Dr. Mary Lock Co.,1165 Englowood Station, Chicago, IIl. The above offer is genuine. We ask no questions or references of any kind. Every lady who writes, stating she is a sufferer from piles or female weaknesses, or both, will be sent tre日 a full $\$ 5.00$ treatment with special letter from the doctor. Write to-day Rememer leter from patent medicine but a full thre日-coure treatment.

\section{Model Dandruff Cure and} Hair Tonic

$I^{s}$

FREE from alcohol and poisonous drugs which are injurious to both hair and scalp. It is prepared by a man with 20 years' experience in hair dressing. He has made the hair and scalp a special study, and we guarantee the Model to cure Dandruff, Falling Hair, Itching Scalp, Eczema and all scalp diseases. To convince you of its merits we will send you a full pint prepaid for 25 cents, and if it don't do you more good than all the tonic you ever used, we will refund your money. Agents wanted. Address

NODEL TOILET CO.

Box 340, Springfield, Ohio.

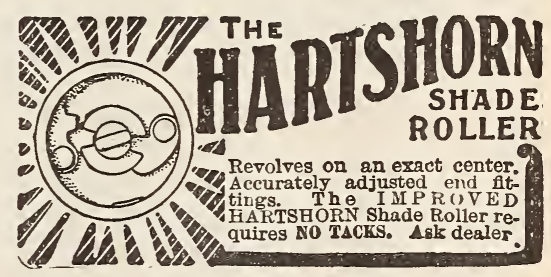

1V A T Can Fasily Make 11 , \$18 10 \$ 25

cality and as the position is pleasanty by representing us in her lowo will gladly send particulars free to all. valusble. This is no deception, and if you really want to make money address WOMAN'S IIUTUAL BENEFIT CO., BOX 21, JOLIET, ILI

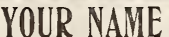

PLEASE FOR OUR

Register and receivirectory pieces of Music from our list for only 10 Cents. MU8IC MAIL CO., 130 Lawn Str., Stamford, Conn.

WOMEN TO DO SEWING Binding Spec. UMEN $U$ DU SEWIIG ialties. \&4 per 100. Can make six an hour. Material sent free prepaid. Send addressed reply envelope for full particulars. Universal Co., Dept. 214, Walnut St., Phila., Pa.

Rubber Complexion Bulb for massage treał ment; Victoria Protectors and other goods for ladies, circulars, H. D. Dettra, Room 5, $3471 / 2$ High, Columbus, O. $\$ 8 P A D \begin{aligned} & \text { Per } 100 \text { for Distributing Samples of Washing } \\ & \text { fluid. Send 6c. stamp. A.W. Sco'T', Cohoes, N.Y }\end{aligned}$ 


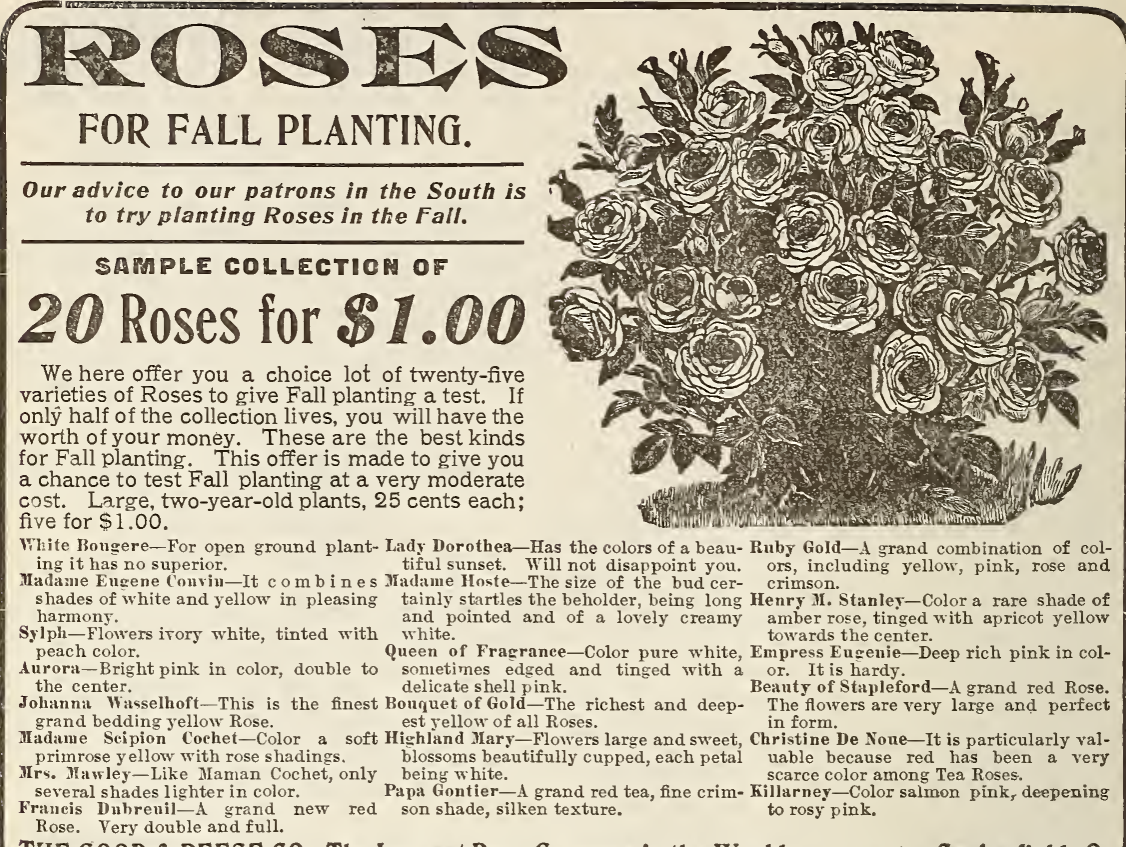

THE G00D \& REESE C0., The Largest Rose Growers in the World, P. 0. Box 71, Springfield, 0.

\section{HOW TO ARRANGE FLOWER BEDS.}

For small yards it is best to plant the flowers along the fence and around the house, and leave the rest of the yard in grass, as a small yard cut up in beds will not show to advantage. Make a border of about three or four feet and plant with roses and hardy plants, and put hyacinths and tulips along the edge of the border and you will be pleased with the result. Climbing roses and vines around the porch or portico will be splendid. Clematis is a good vine for shade on the porch, for, by giving it plenty of water, it will bloom almost all summer. Clematis can be rooted the same as roses, by taking cuttinss in the fall and putting them under ginss cans. K. UNverferth.

Missouri.

E MEXICAN FN!MROSE.

"Our common primrose," is the contemptuou:s remark of the Texas amateur when first she receives a Mexican primrose from the florist. Then she tucks it away where she hopes it will die, for our roadsides and creeks are bordered with them, and they creep with riotous profusion through the palings into our country gardens. And though you could never call them intrusive, they are common-in the summer.

Our primrose, though as delicate in texture and as pinky white as any of the florist's, is rather hard to domesticate and does not at first understand how to blossom in winter. The one from the florist won't die and generally begins blooming at once, though it be mid-winter, if put in rich soil and given plenty of water.

The Mexican primrose is desirable as a winter plant, not only because of the graceful beauty and wanten profusion of its "buttercups" and the ease with which it is grown, but an occasional freeze does it no harm. LOUISE VARNELL.

Texas. 
SAVED BY THE LILIES.

"We'll have to take these lilies with us anyway, mother," said Mrs. Carey.

"What on earth do you want to take them away out west for? Ten to one, they'll up and die afore you get there. I sortor thought you were going to raise cattle instead of house plants. Now, Elvirey, I do wish you'd give up this notion of going to live out there with them wild Inguns. They'll have you scalped afore you've been there a week." A!1 this from Mrs. Carey's mother.

"It is settled between John and myself that we go," said Mirs. Carey quietly.

Accordingly they started with twenty other wagons for the west. They met with few adventures during their many days' travel until one night they camped about a mile behind the rest of the train of wagons, thinking that the savage would not dare to attack them when only such a short distance from the others. Towards midnight they were awakened by the howl of a dog. They rushed out in time to see half a dozen Sioux riding away. "What could have frightened them off," said Mr. Carey. Then he broke into a hearty laugh. There stood his wife wrapped in a white blanket, holding her lilies. She had waked up in the night and thought of her lilies she left in the wagon and had gone to get them to keep them from freezing. The Indians, naturally superstitious, became alarmed at the figure in white, and thus ended what might have been a general massacre.

Washington. Mrs. Luxi FIsk.

ROSES IN THE SOUTH.

My best success came with roses planted, in December. I had the ground spadedone foot deep and a liberal supply of well decayed cow manure thoroughly mixed in. I then set the plants, carefully spread ing the roots in their natural position filling the holes two-thirds full of soil and

(Concluded on page 20)

\section{Big Bargain Bulb Collection!}

\section{A GRAND CLEARANCE SALE OF CHOICE SURPLUS STOCK}

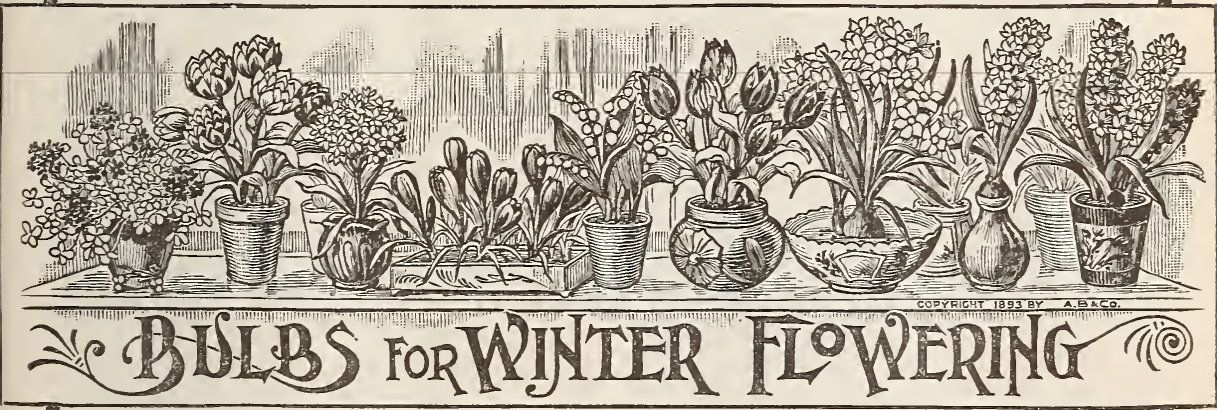

IN handling my enormous bulb trade, it is necessary to grow and import an extensive stock of all varieties in order to be in position to supply the demand of my customers. It nearly always happens that I have a surplus stock of most kinds. This season I have decided to dispose of this surplus stock at cost or less than cost, and in order to do this, I now offer my patrons

FOUR OR FIVE DOLLARS' WORTH OF BULBS FOR \$1.00

Send me One Dollar and I will forward, charres prepaid, a magnificent collection of bulbs, for which you would have to pay four or five dollars at the usual price.

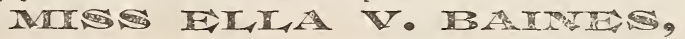

P. O. $80 \times 240$,

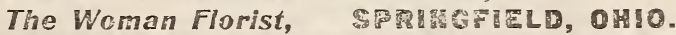




\section{Pain and Sickness}

\section{CURED LIKE IMAGIC.}

\section{The Marvelous Skill of a Noted Indi- ana Doctor in Curing Every Sort of Disease Has Made Him World-Famous.}

\section{Sends Free Trial Packages by Mail to All Who Write-Gives Instant Relief.}

There is no question that all disease can be cured by his marvelous discovery after having talked with people whom he has cured quickly and

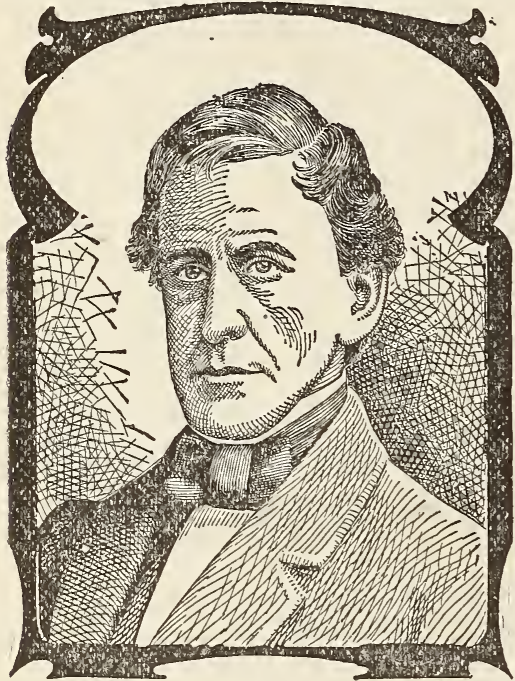

No Man is Lost-There is a Sure Cure For Every Sick and Ailing Man or Woman-Dr. Ferris.

safely of Rheumatism, Catarrh, Paralysis, Diabetes, Lost Vitality, Nervous Debility, Female Weakness and Ailments, Kidney and Liver Disease, Lung ahd Stomach Trouble, Syphilis, Consumption, Constipation, Neuralgia, Bronchitis, Insomnia, Blood Poison, Anemia, Eczema or Salt Rheum, Locomotor Ataxia Asthma, Epilepsy, Piles, Varicocele, Stricture, Chronic Diarrhea’ All Skin Diseases, Heart Disease. It matters not what the disease, nor of how long standing, nor how many doctors or remedies have failed. To weak, weary women he has brought the light and happiness of health. For worn-out men he has relighted the sparkling vitality of youth. He has cured the crippled and healed the sick.

The doctor sends free trial treatment to every sick or ailing person who sends him their name and address, telling him what they wish to be cured of. Every sick and suffering person should avail themselves of the marvelous skill he gives them absolutely free. Thousands have saved a sick friend's life by sending him their name. For the benefit of any who wish to address him personally, we give his private address, Dr. C. Sargent Ferris, 2332 Elektron Building, Fort Wayne, Ind., for although the demands on his time are something enormous he gives his personal attention to every letter.
(Concluded from page 19)

watering to settle. The holes were then filled with soil, and the bed given a topdressing of rotted manure, then a mulch of pine straw about four inches thick. The roses all lived.

I planted seventy-five more in the same way last April, but eight of them died during the summer's heat, in spite of all nursing.

Many fine roses are utterly worthless in the South unless budded or grafted on a thrifty stock. The crimson rambler makes an excellent stock.

Florists are not always to blame for roses not being true to name. There is a great difference in soils, and such chemical ingredient as an abundance of iron will often effect the colors of flowers. Roses may also change in the sandy soils of the South, which lack certain necessary ingredients.

For mulching, any straw or dry grass will do as well as pine-straw, the idea being to protect the roots from heat, and to prevent the evaporation of moisture.

Florida. Mrs. Lillie Pleas.

THE CHINESE SACRED LILY.

I obtained the bulb late in October and potted it the first of November in a candy jar half filled with nice, white sand, pebbles and water, just enough to come up to the neck of the bulb. I set it in the cellar until Thanksgiving day and then brought it to the sitting-room, and found the jar filled with pretty white roots and the top covered with nice, green sprouts. I gave it plenty of light and by Christmas day it was a thing of beauty, having thirty-nine full-blown lilies and any number of bucs.

If you could have seen the joy that lily brought. First, it went to a mission school, to make so many children happy; then it spent several days with a sick bcy and helped to brighten his lonely hours; from there it went to the home of a neighbor who was suffering great pain, and oh! the pleasure it gave him; and then we enjoyed it greatly at our own home. Ire would not be without one again.

Illinois. Mrs. IV. R. Stillwell. 


\section{SPECIMEN PLANTS FOR HOUSE DECORATION.}

Many persons, loving plants, refrain from having any, as it is generally known that gas is injurious to vegetation.

In our home gas is used both for lighting and cooking, yet I have grown beautiful specimens plants of sanseveria zeylanica, asparagus tenuissimus, Boston fern, and asparagus sprengeri without difficulty. As each of these makes a large plant they suffice for indoor decorative effects in most homes. Every warm, pleasant morning I set them out on a sheltered porch and shower likerally with lukewarm water. Leaving them out till dry, serves for an airing. If more than a week elapses without favorable weather, I shower in the kitchen. Also, I never fail to water them every morning, and occasionally add a few drops of ammonia to the water.

Nebraska. Mrs. John Neble.

\section{A LAMARQUE ROSE.}

I have a Lamarque rose three years old. For the first two years I grew it as a shrub-that is, I kept it pinched back and root-bound, but the third spring I repotted it in a very large pot and gave it the very richest soil possible, mixing in a large portion of well rotted cow manure. This has grown to the height of ten or twelve feet, has sent out numerous sicle branches from the main half dozen branches, and when in full bloom is exquisite. The large creamy white roses are perfectly double to the center and the fragrance is delightful. This takes up a large portion of any pit but is well worth all the care given it. I have never seen this recommended as a pot plant, but this with my Marechal Neil, are two of the best blooming and most exquisite roses I have.

I keep soil well stirred, now and then put in a top dressing of rich earth, and twice a week give liquid fertilizer.

Kentucky. MIss Latra Jones.

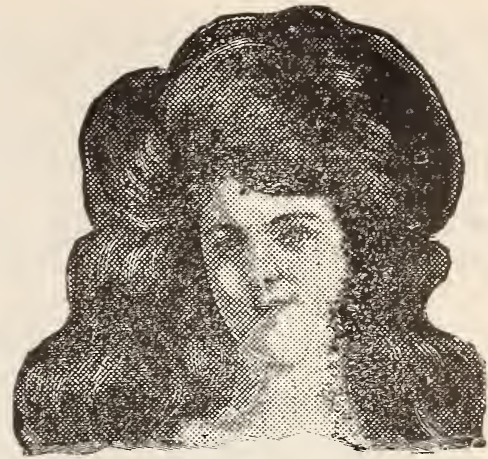

\section{Her Marvelous}

\section{Growth of Hair}

\section{FREE TO ALL}

a trial package of a new and wonderful remedy mailed free to convince people it actually grows hair, stops hair falling out, removes dandruff, and quickly restores luxuriant growth to shining scalps, eyebrows and eyelashes. Send your name and address to the Alienheim Medical Dispensary, 7217 Foso Building, Cincinatti, Ohio, for a flee trial package, enclosing \& 2-cent stamp to cover postage. Write today.

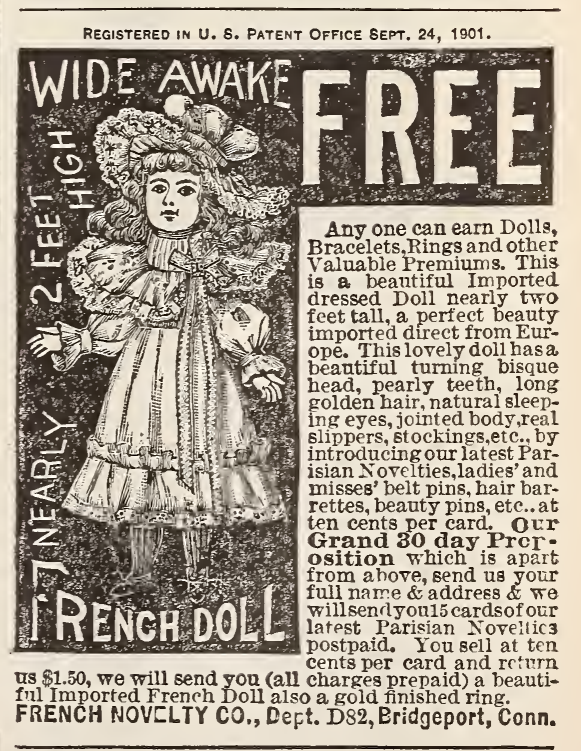

X.1. BOS BOKS New plans, new prices, new per cent commission on fine bools selling at $22 \mathrm{c}, 37 \mathrm{c}$, $73 \mathrm{c}$, and $\mathrm{you}$ can sell 2 to 6 at every horre. Address, quickly. Howard Co, $8 \odot 3$ I.Fasonic Temple, Chicago. 


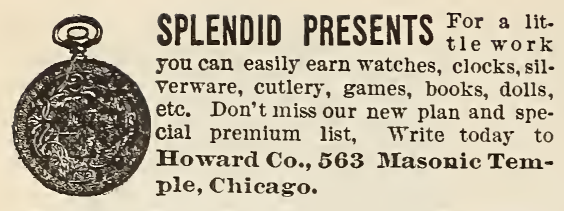

Don't Die of

\section{Consumption}

\section{A Positive Gure Found by a Celebrated michigan Physician-He Sends a Large Trial Package Free by Mail To All Who Write.}

At last a cure has been found. Increditable as it may seem, after the centuries of failure, a a posiiive and certain cure for the deadly con-

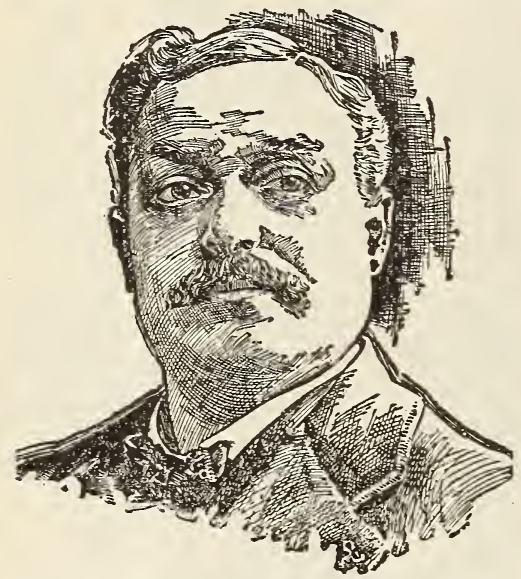

DR. D. P. YONKERMAN, The Discoverer of

Tuberculozyne-Endorsed by State Officials and Greatest Medical Men of the World as the only Cure for Consumption.

sumption has at last been discovered. It re. mained for a great physician of Hichigan to find the only known cure for consumption, after clmost a life's work spent in experimenting and study.

Consumptives who have returned from the west-come home to die because they thought nothing could be done for them-bave tried this new discovery and are now well and strong.

If you are afflicted do not fail to send at once to Dr. Derk P. Yonkerman, 1147 Shakespeare Blug., Kalamazoo, Mich., for a free trial packa.ge of this remedy, prools and testimonials from hendreds of cured patients, it costs nothing. The Doctor does not ask anyone to take his W ird or anyone else's, as he sends a trial packs. fe free, and a few day's use will show you how easily and quick!y you can be cured. Delay is dangerous. There is no time to inse when the death hand of conanmption is tightening its clutch upon you. 17 rite today.
THE RUBRA BEGONIA.

No prettier or more ornamental display of plants for wintea decoration can be found than a collection of begonias.

Such a collection affords great variety of foliage, and its pleasing effect excites admiration. But of all the begonias with which I have had experience or have seen, my favorite is the rubra. Its dark green leaves and clusters of red flowers are prettily contrasted. This begonia is well known and it is hardly necessary to give a description of its appearance; but, perhaps all may not know the full extent of its beauty if they have not kept it for several years at a time.

IVe, in our home, have had large plants that have afforded great pleasure, both in summer and winter.

When transplanted to beds in the yard in the summer, they flourish best and grow to be strong and vigorous; but it is always necessary to tie them firmly to a stake driven in the ground securely in order that the wind may not break them.

We would advise all who love flowers and admire ornamental foliage to try the rubra begonia this winter.

Missouri. Sophie P. IVatson.

\section{LILIUM AURATUM VATTATUM RUB.}

\section{RUM.}

About the first of November of last year I purchased a lilium auratum vattatum rubrum. I planted it in the center of a circular bed-the bed being highest in the center, and partially shaded by large trees. I dug a hole a foot deep and filled in several inches of good soil, composed of leaf mould, well rotted manure and garden soil; all thoroughly mixed, and on that a light covering of sand on which I placed the bulb-about 8 inches deep. I covered the bulb with a thin layer of sand and filled up with the prepared soil. I added a top dressing of well decayed manure, over which I placed a few boards.

In April I removed the boards, and socn two green shoots apyeared, which 


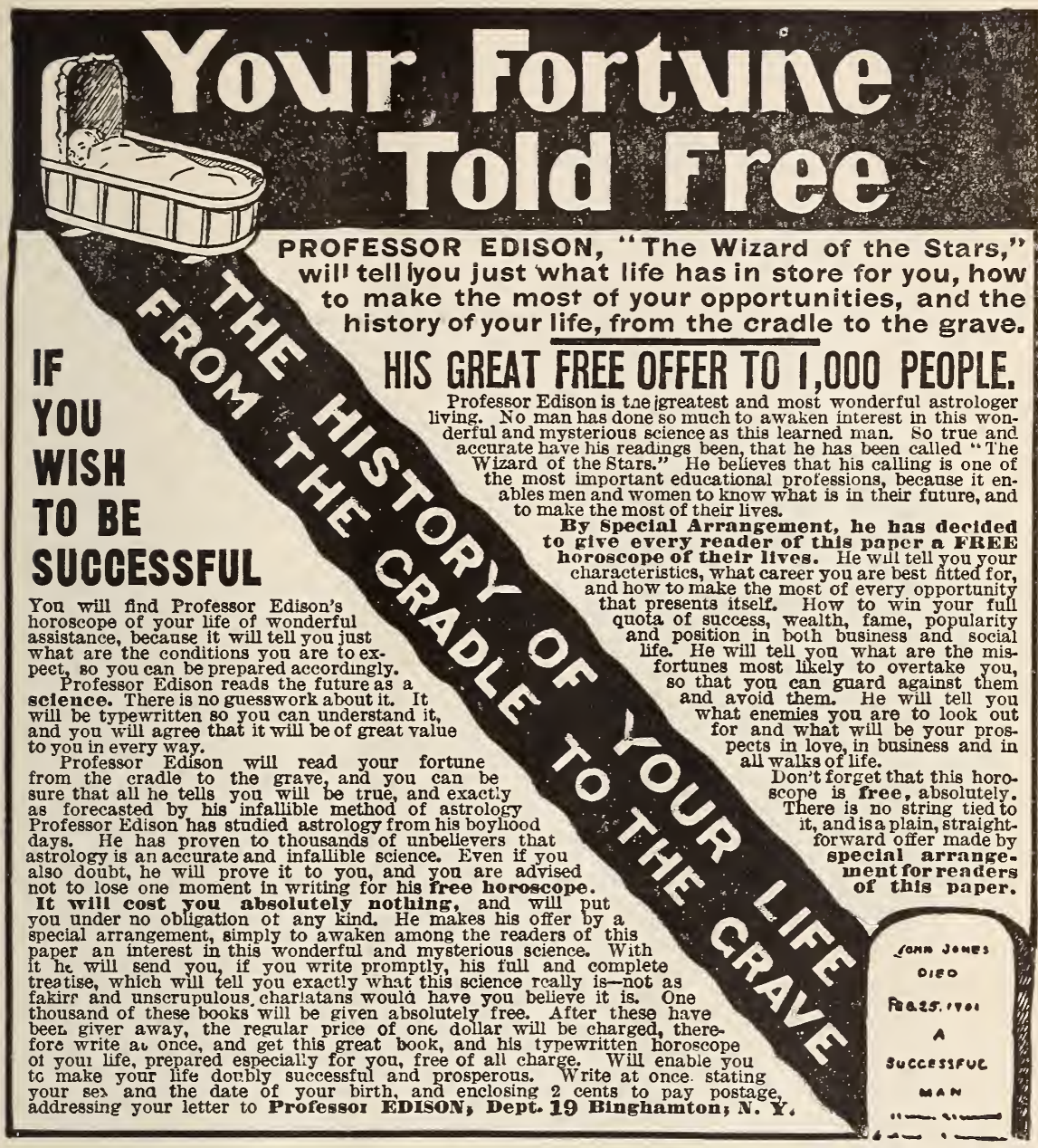

really seemed to run a race with each other. They grew three or four feet high, and one stem had three, the other four magnificent lilies about ten inches across. - color clear waxy white, spotted crimson and a crimson stripe, half an inch wide through the center of each petal.

When put in a bouquet, their fragrance pervaded the entire room.

They were exqusitely beautiful, and attracted great attention from the flower lovers.

Maryland.

Mrs. F. H. SeIss.
CULTURE OF PANSIES.

For autumn, winter and spring flowers, sow the pansy seeds in July or August, in sifted soil composed of leaf mold and loam, and cover with soil one-eighth of an inch deep. Water moderately until the plants appear, which will be in about a week after sowing the seeds. When

(Concluded on page 24)

\section{Dil Cure for Cancer}

The Dr. D. M. Bye Co., of Indianapolis, Ind., report the discovery of a combination of soothing and balmy oils which readily cure all forms of cancer and tumor. They have cured many very bad cases without pain or disfigurement. Their new books with full report sent free to the afflicted. 


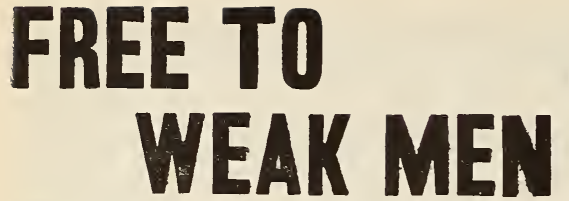

A Discovery of a Remedy Has Been Made That Restores Lost Manhood and Gives Man the Vitality of a Lion

\section{One Week's Trial Package Sent} Free to All Men who Write for it

Regenerative Tablets is the only recognized permanent cure for Lost Manhood in any form. It is scientifically prepared by some of the best

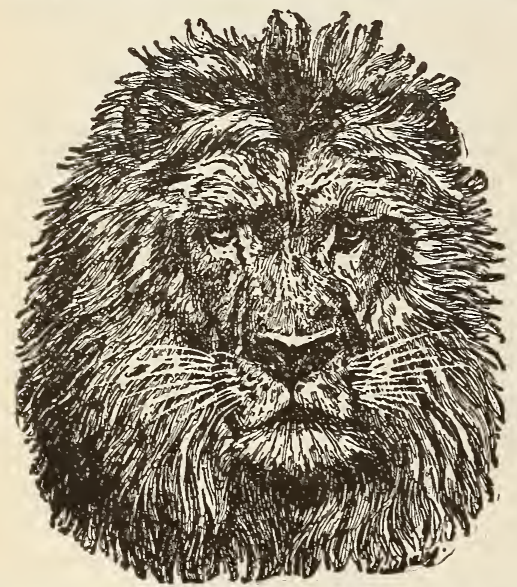

chemists in the world. This firm gives a legal guarantee that Regenerative Tablets will cure every case of Lost Manhood, Spermatorrhea, Varicocele or weakness of any nature of the nerve or sexual organs. There is but one test of a genuine medicine, and that is the results which are obtained byits use; if it cures the disease for which it is prepared it is a true remedy. This is the test by which the Fallopia Lynn Co. wish their remedy to be tried, therefore they give one week's treatment free. After using it the sufferer will find new vigor in his organs; new force in his muscles; new blood in his veins; new ambition; a new man in vitality, health and appearance. Regenerative Tablets has a peculiarly grateful effect and the patient feels the benefit after its first day's use. It goes direct to the seat of the trouble, no matter the age of the sufferer nor of how long standing his affiction, unless Epilepsy or Insanity has been reached, giving strength and development where it is needed. This marvellous remedy banishes all feelings of bashfulness or blushing; cures all the ills and troubles that come from early abuse, excess, or overwork and business cares, all of which result in premature loss of strength and memory, emissions, impotency and varicocele. Fallopia Lynn Co. makes no restrictions, every person who writes will be sent postpaid a week's treatment absolutely free, carefully wrapped in a plain package with no advertising on it to indicate what it contains. Write today to the Fallopia Lynn Co., 428 Pozzoni Building, St. Louis, Mo., and receive the week's treatment absolutely free, also their book which is free and sent with the free treatment which explains how to take the treatment in private and cure yourself at home.
(Concluded from page 23.)

the plants begin to crowd each other in the seed box transplant them to other boxes. When large enough for bedding out plant them where you wish them to bloom, setting one foot apart each way. Partially shaded beds, as the north side of the picket fence, the west or east end of the house, where the plants get a good strong indirect light during the day and a touch of the morning sun, will produce perfect plants. Never allow the soil to dry out so as to wilt the plants. With this simple treatment and a first-class variety of seeds, the finest pansies may be grown by anyone. The summer flowers are rather small, but as the weather turns cool they will increase in size. A sash placed over the bed will often prolong the blooms throughout the winter season.

JANE Young.

Illinois.

\section{FLOWERS, LIKE PEOPLE, REQUIRE} CARE.

To grow nice nasturtiums one has to understand their requirements and simply grow them in poor or clay soil, in a sun. ny location, to have best results.

My rubber tree has leaves more than a half yard in length, is a rapid grower, needing only rich earth and a sponging of the leaves when dusty. When a leaf or limb falls off, tie a cloth around the fresh spot, to keep it from bleeding on other leaves, as it turns them black.

To grow nice chrysanthemums take new shoots from winter plants, set in small pots in March, transplant to open ground in early May, pinch off all buds until the first of August, leaving just one bud on each bush if a large single flower is desired. Transplant to good sized pots middle of September and water once a week with liquid (cow) manure water.

For a beautiful hedge plant rudbeckia (or golden glow). Should the red spider infect this plant sprinkle with a weak solution of kerosene oil, soap and water.

Iowa. 
You, Dear Reader, Threatened with Consumption, try this Complete, Philosophical and SUCCESSFUL CURE. It may save your life as it has Thousands of others.-DR. SLOCUM.

\section{Are Your Lungs Weak?}

\section{The Consumptive Can be Cured!}

\section{HERE IS}

Have you dry, hacking cough?

Doyou have pains in lungs, chest or back?

Do you raise phlegm?

Is your throat sore and inflamed?

Does your head ache?

Is your appetite poor?

Do you have night sweats?

Are you losing flesh?

Do you have ringing in ears?

\section{HEALTH.}

Are you pale, thin, weak and worn out?

Do you have hot or cold flushes?

Is there dropping in throat?

Is the nose dry and stuffy?

Have you a coated tongue?

Have you catarrh?

Have you stomach trouble?

Have you kidney trouble?

Any or all of the above symptoms are relieved and cured by the Slocum System of Treatment.

The System consists of four preparations.

The many ailments of women and delicate children are speedily relieved and cured.

By the timely use of these Remedies thousands of apparently hopeless cases have been permanently cured.

All FOUR, or any THREE, or TWO, or any ONE, may be used singly or in combination, according to the needs of the case. Our readers are urged to take advantage of Dr. Slocum's generous offer.

\section{Write for Four Free Samples.}

Please send your name and full address to DR. T. A. SLOCUM, 98 Pine STREET, New York, and the Four Free Remedies will be at once forwarded to you with full directions for use. When writing please mention reading this in THE FLORAL WORLD.

Editor's Note.-The New Slocum System of Treatment for the cure of Tuberculosis, Consumption, Lung troubles, Bronchitis, Catarrh, General Debility, a Rundown System, and nearly all the ills of life, is medicine reduced to an exact science by the world's foremost specialist. 


\section{THIS HANDSOME

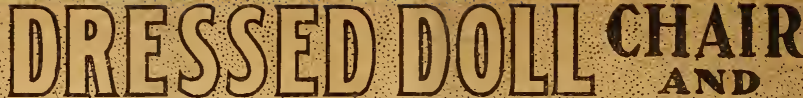

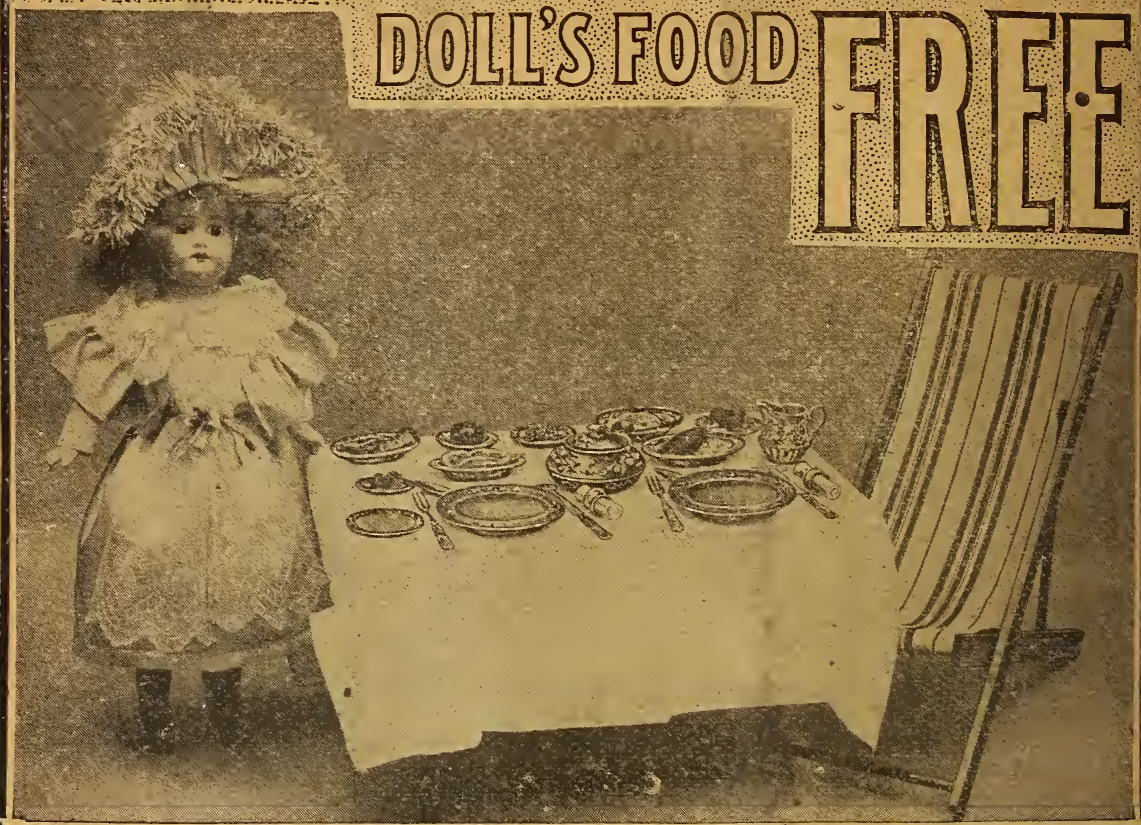

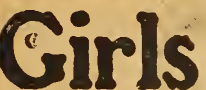

send us your name and address and we will mail you 26 pieces of Art Jewelry to sell at only 10 cents each. No trash. Every one you offer it to When sold send us the 2.60 and we will send you at once, by express, this

\section{Handsome Dressed Doll.}

Nearly one and one-half feet in height, imported directly from Europe for us. This doll has a beautigolden curly ringlets, hat, dainty shoes and stock. ings that can be taken off, lace trimmed underwear, elegantly and stylishly dressed. A magnificent creature of dolldoun, sweet and pretty as a picture, and will be a source of endless pleasure and amusement to the little ones.

This illustration is very much smaller than the doll and chair, but it gives an absolutely correct idea of how they look. It is from a photograph just taken and shows the doll all dressed (just as we give it) and the reclining chair, both of which we give $\mathbf{F} \mathbf{I E}$. A drawing could be niade so as to lonk better than the doll itself, but this is direct from the photograph,

\section{Photographs Tell the Truth.}

Understand this is no printed cloth or rag doll that has to be made up and stuffed, or a cheap paper doll snch as some concerns give, but a real Dressed With dill we also send this handsome and which we a re confident will please you. In a ddi-
tion we will also give y'n entirely free and send in the same shipment, with the I)oll and Chair, eight pieces of Indestructible Doll's Food; it comes mounted on Imi. China plates two inches in diameter, and we send the following assortment: one plate each of Roast Chicken, Cold Ham, Lobster, Blue Fish, Pickles, Plum Pudding, Grapes and Oranges. The food is colored perfectly natural and we know it will delight you. It is something entirely new and novel and will be wanted by all your playmates as soon as they see it.

Our Patrons are Extremely Well Pleased with Our Premiums as the Following Letters Show.

Iola B. Mills, Rochester, N. Y., writes: 'Doll received this p. m. all right. I think it is lovely. Well paid me for my work."

Mrs. F. Cousin, Jacoby, La., writes: "Doll received and we are more than delighted with it. It surely surprised my little girl and she is delighted."

Mrs. Charles Gray, Paines Point, Jll., writes: "Re ceived doll all right yesterday. It was all right many thanks.

Rosa Fehrenbach, East Bottoms, Mo., writes: "Re ceived my doll from you and was very much pleased with it. I thank you.

Mrs. J. W. Hallard, Easton, Pa., writes: "Received doll for selling goods and was very much pleased with it. Will answer any question any one may ask concerning it."

Lulie Richmond, Harrisburgh, Pa., writes: "I re ceived my doll and was very much pleased with it."
Katie Ilvingstone, Yulan, N. Y writes . "I received the doll Friday all right and it was just as nire as I expected, "Thank you kindly for sending it so promptly."

Miss G. E. Folger, North Foxboro, Mass., writes : "The doll received $\mathrm{O}$. $\mathrm{K}$. and was very much pleased with it. It was perfectly satisfactory and I must thank you for your kindness."

Mary Welch,"Millis, Mass.. writes: "I am very much pleased with my doll. My mother would like to know how much you would sell a doll for without elling any goods."

Francis Colston, Wakefield, R.I., writes: "I received my doll in due time and am very much pleased with her. She is beautiful."

Elizabeth Hill, Philadelphia, Pa., writes; "I received the doll with great pleasure and it is ver nice. Many thanks for promptness in sending it."

C 100 is hereby of fered to any person who can prove that our Testimonial letters are not Genuine. We have thousands of similar letters on file. Write today. Address, STANDARD DOLL CO., P.0.Box $530^{8}$. Boston, Máss. 


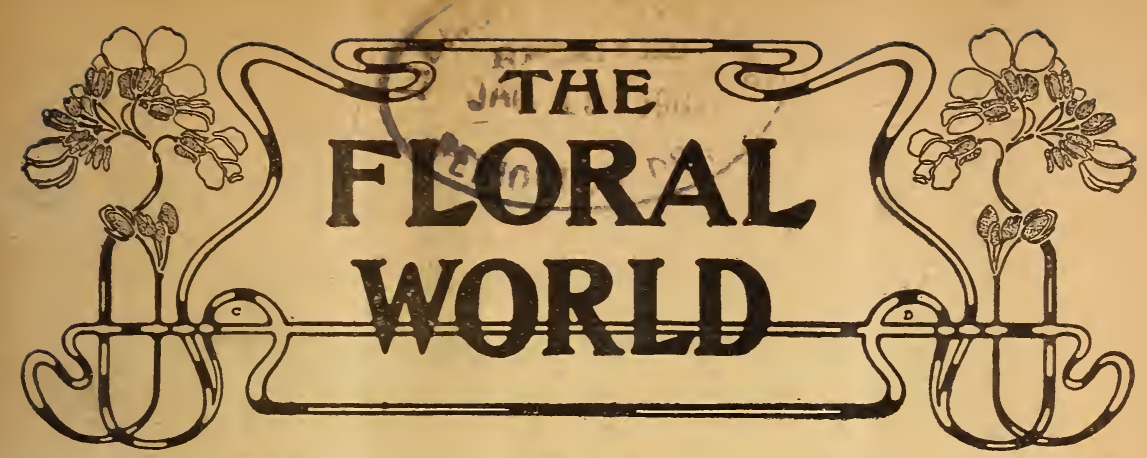

Vol. II. No. 4. Springfield, Ohio, January 190325 Cents a Year

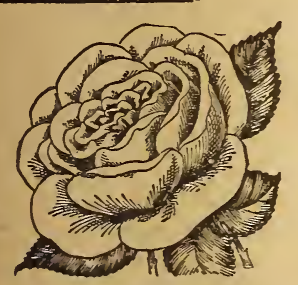

\section{FOUR CHOICE ROSES

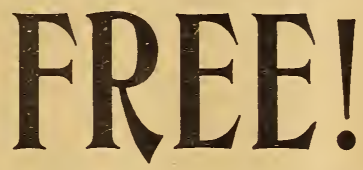

THE FLORAL WORLD

For One Year
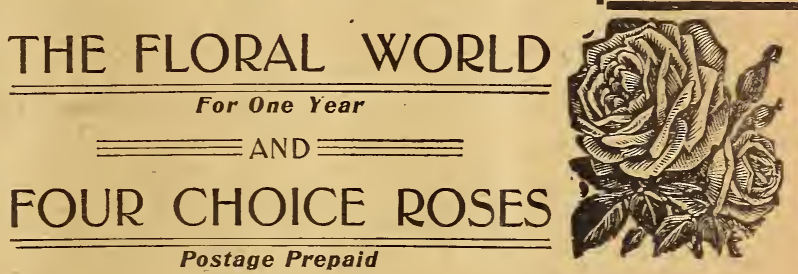

Will be Sent to Anyone Remitting us Only 25 Cents-the Regular Subscription Price-for The Floral World.

We believe this offer is so attractive and liberal that everyone of our present readers will bring it to the attention of his friends. "The Floral World" is a magazine that makes friends wherever it is read, but there are thousands of flower lovers who do not know of its existence. Many of your friends, perhaps, do not. Tell them about it. Show them this offer. They will thank you for doing so.

The Roses Will be the Following Varieties: $\equiv$

GRUSS AN TEPLITZ-A Great New Red Rose.

It is a superior Rose for general planting. A perfect sheet of richest crimson-scarlet all summer. We know of no Rose that has such bright colors in it as this variety, with its rich velvety-crimson overlaid with the brightest penetrating scarlet. It is very free in bloom and a strong, vigorous grower.

\section{IVORY-Ivory White.}

A most beautiful Rose, pure ivory white in color. A strong grower, excellent for general planting and a great favorite.
ISABELLA SPRUNT-Canary Yellow.

A very free bloomer, literally lavishing its large, beautiful buds. Very fragrant, a strong grower requiring little attention.

MAMAN COCHET-Rich Pink.

The color is a deep, rosy pink, the inner side of the petals being a silver-rose, shaded and touched with golden-yellow. We pronounce this the finest Rose by far that has been introduced from France in the past five years.

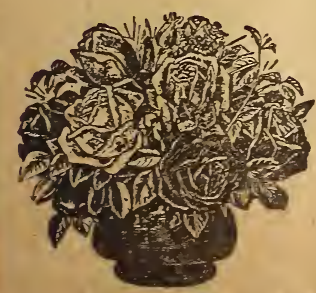

Twenty-five cents is the regular subscription price of THE FLORAL WORLD, so by accepting this offer you get the Roses absolutely FREE. If you take the Roses you will not be entitled to any other premium for the same subscription.

\section{OFFER FOR A CLUB OF FOUR}

Get three friends to accept this Rose offer, which, with you r subscription will make a club of four. Send us a dollar and we will mail THE FLORAL WORLD one year and the premium chosen, to each member of the club and send you an extra set of the Roses. Address

THE FLORAL WORLD, SPRINGFIELD, OHIO.

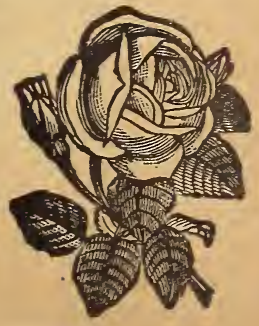




\section{A NEW $\$ 40,000.00$}

FIRST PRIZE, \$10,000; SECOND PRIZE $\$ 3,000 ;$ THIRD PRIZE, \$1,000

\section{It Costs You Nothing to Guess. You May Get a Prize}

Every subscriber to THE FLORAL WORLD will have an opportunity to share in these magnificent prizes if he wishes to participate in the Great Educational Contest in which these prizes are given.

The subject matter of this great contesi is the total vote cast for Governor in the States of Ohio, Massachusetts and lowa on the othird day of November, 1903.

Every person interested in the science of Government should be interested in the election in these three States, as much valuable information can be gained by a study of the political conditions involved in these elections.

\section{CONDITIOHS OF THIS GREAT GONTEST:}

Every subscriber who remits 25 cents, the regular subscription price (a year's subscription) to THE FLORAL WORLD will receive a certificate that will secure for him any prize which his estimate entitles him to claim.

When you send in your subscription, also send your estimates of the total vote for Governor in the three States. Write your name, address and estimate in the subscription blank below and mail it to THE FLORAL WORLD, Springfield, Ohio.

The contest will close at midnight. November 2, 1903, and no estimate received after that hour will be allowed. The official certificates of the Secretaries of the three Siates, showing the total vote for Governor, will determine who are entitled to the prizes, and the awards will be made by a disinterested committee of prominent judges just as soon as the official figures can be obtained. Read the special prizes for those who guess early. It will pay you to guess now. The Press Publishing Association has already deposited the $\$ 40,000$ with the Central Savings Bank, Detroit, Mich., for the payment of the prizes.

\section{CERTIFICATE OF BANK PRESIDENT}

I hereby certify that the Press Publishing Association has deposited $\$ 40,000$ in the Central Savings Bank, Detroit, Mich., for the express purpose of paying the prizes to those making the nearest correct estimates of the total aggregate vote cast for the office of Governor in the States of Ohio, Massachusetts and Iowa, on the 3 rd day of November, 1903 , and that this fund can be used for no other purpose.

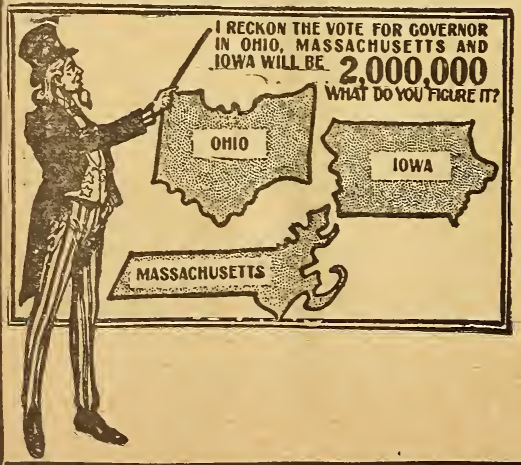

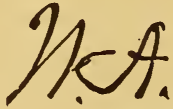

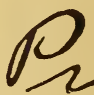

President

Central Savings Association

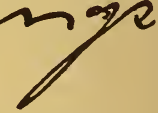

\section{VALUABLE INFORMATION.}

Tu aid in forming your estimate we furnish the official figures showing the vote for Governor in each of these States for the past ten years, as well as to give the total vote for the three States combined. The total vote for the three States is found in the right hand column. Ohio Mass. Iowa Total $1801 . .795,629 \quad 321,650 \quad 420,212 \quad 1,537,491$ $1893 \ldots 823,658 \quad 365,012 \quad 415,806 \quad 1,604,476$ $1895 \ldots 837,466 \quad 328,121.401,345 \quad 1,566,932$ $\begin{array}{llll}1897 . .854,986 & 269,795 & 438,292 & 1,563,073\end{array}$ $\begin{array}{llll}1897 \ldots 854,986 & 269,795 & 438,292 & 1,563,073 \\ 1899 . .908,159 & 299,166 & 433,351 & 1,640,676\end{array}$ $1901 \ldots 827,566 \quad 324,526 \quad 390,489 \quad 1,542,581$

What will be the total vote for Governor in these three States combined on the third day of November, 1903? Figure it out and send in your estimates. It may mean $\$ 10,000.00$ in cash to you. 


\section{Profit Sharing Contest}

\section{TWENTY SPECIAL PRIZES OF $\$ 1,000.00$ EACH FOR EARLY ESTIMATES}

\section{HERE IS THE LIST OF PRIZES.}

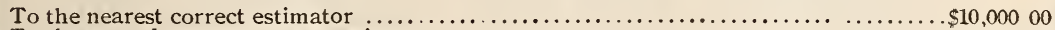

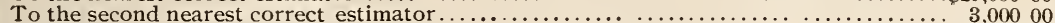

To the third nearest correct estimator $\ldots \ldots \ldots \ldots \ldots \ldots \ldots \ldots \ldots \ldots \ldots \ldots \ldots \ldots \ldots \ldots \ldots \ldots, 1,00000$

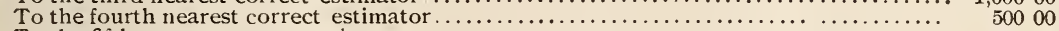

To the fifth nearest correct estimator $\ldots \ldots \ldots \ldots \ldots \ldots \ldots \ldots \ldots \ldots \ldots \ldots \ldots \ldots \ldots \ldots \ldots \ldots \ldots \ldots \ldots, 200,00$

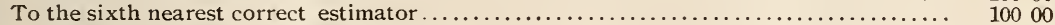

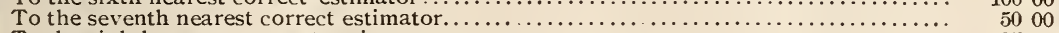

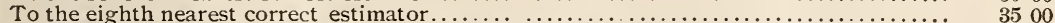

To the next twelve nearest correct estimators, $\$ 15.00$ each $\ldots \ldots \ldots \ldots \ldots \ldots \ldots \ldots \ldots \ldots \ldots . \ldots \ldots$

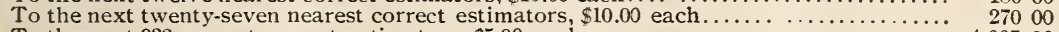

To the next 933 nearest correct estimators, $\$ 5.00$ each $\ldots \ldots \ldots \ldots \ldots \ldots \ldots \ldots \ldots \ldots \ldots \ldots, 4,66500$

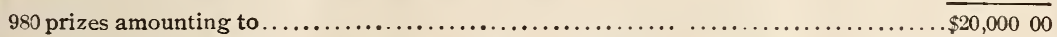

\section{The Following Special Prizes Will Also be Paid:}

For the nearest correct estimate received before Dec. $15,1902 \ldots \ldots \ldots \ldots \ldots \ldots \ldots \ldots \ldots \ldots 1,00000$

For the nearest correct estimate received on or after Dec. 15 and before Jan. 1, '03 .... 1,000 00

For the nearest correct estimate received on or after January 1 and before January $15 . \ldots 1,00000$

For the nearest correct estimate received on or after Jan. 15 and before Feb. $1 \ldots \ldots \ldots \ldots, 000$

For the nearest correct estimate received on or after Feb. 1 and before Feb. 15... . 1,00000

For the next nearest correct estimate received on or after Feb. 15 and before March $1 \ldots . .1,00000$ For the next nearest correct estimate received on or after March 1 and before March 15. 1,000 00

For the nearest correct estimate received on or after March 15 and before April $1 \ldots \ldots \ldots 1,00000$

For the nearest correct estimate received on or after April 1 and before April $15 \ldots \ldots \ldots \ldots, 000,09$

For the nearest correct estimate received on or after April 15 and before May $1 \ldots \ldots \ldots .1,00000$

For the nearest correct estimate received on or after May 1 and before May 15........ 1,000 00

For the nearest correct estimtae received on or after May 15 and before June $1 \ldots \ldots \ldots \ldots 1,00009$

For the nearest correct estimate received on or after June 1 and before June $15 \ldots \ldots \ldots \ldots 1,00000$

Eor the nearest correct estimate received on or after June 15 and before July $1 \ldots \ldots \ldots \ldots 1,000$ l

For the nearest correct estimate received on or after July 1 and before July $15 \ldots \ldots \ldots \ldots, 1,00000$

For the nearest correct estimate received on or after July 15 and before August $1 \ldots \ldots \ldots, 1,00000$

For the nearest correct estimate received on or after August 1 and before August $15 . . \quad \ldots \quad 1,00000$

For the nearest correct estimate received on or after August 15 and before September $1 \ldots 1,00000$

For the nearest correct estimate received on or after Sept. 1 and before Sept. 15 ....... 1,000 00

For the nearest correct estimate received on or after Sept. 15 and before Oct. $1 \ldots \ldots \ldots \ldots, 000$

Total 1,000 prizes, amounting to ...................... $\$ 10,00000$

In case of tie or that two or more estimators are equally correct, prizes wili be divided equally between them.

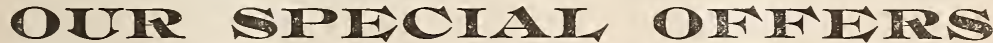

One year's subscription for THE FLORAL WORLD and one estimate only 25 cents, provided no other premium is taken. Send your estimate when you remit and you will promptly receive a certificate which will secure for you any prize your figures may win.

If you wish more than one estimate, remit us only 20 cents for each yearly subscription and estimate after your first one. The extra subscription may be for yourself or for any of your friends. Always include your estimate when remitting. Address,

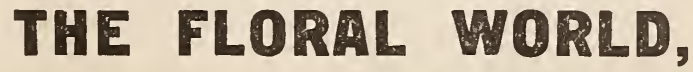




\section{Palms, Roses,}

\section{Chrysanthemums}

\section{Six Generous Collections of Plants GIVEN AWAY as Premiums}

We will give any of these valuable collections ABSOLUTELY FREE to any person who will send us a club of only four yearly subscribers to The Floral World, at 25 cents each. Two collections for a club of eight, and so on. The subscribers in your club may have their choice of Rose Collection described on first cover or the estimate in Profit-Sharing Contest advertised on second cover.

\section{Premium No. I4. The Rose Collection.}

1 Admiral Dewey.

1 Alliance France Russia.

1 Cornelia Cook.

1 Duchess De Brabant.
1 Enfant de Lyon.

1 Isabella Sprunt.

1 Lottie Bumgardner.

1 Silver King.

Premium No. 15. The Chrysantbemum Collection.

1 Fisher's Torch.

1 Her Majesty.

1 Kioto.

1 Mrs. John Wanamaker.
1 Marie Louise.

1 Major Bonaffon.

1 Silver Wedding.

1 Vivan Morel.

\section{Premium No. I6. The Palm Collection.}

1 Areca Lutescens. A majestic palm without a peer for elegance and grace.

1 Phoenix Canariensis. The true date palm.

1 Phoenix Reclinata. The hardiest of date palms, with dark green feathery foliage.

1 Latania Barbonica. The well-known Chinese Fan Palm. 


\section{Fuchsias, Ferns, and Basket Plants}

\section{The MOST LIBERAL OFFERS We have ever made to Club Raisers.}

Premium No. I7. The Basket Plant Collection.

1 Beautiful Fern. The Nephrolepsis.

1 Weeping Lantana. A new weeping plant of great beauty.

1 Manettia Bicolor. A beautiful climber that blooms both winter and summer.

1 Phrynium Variegatus. An ornamental plant for either pot culture or

1 Smilax. bedding out.

1 Russelia Multiflora. The "Scarlet Fountain" plant.

1 Saxafraga Sarmentosa. Fine for hanging baskets, vases, etc.

\section{Premium No. I8. The Jasmine Collection.}

2 Jasmines-Maid of Orleans. A fine grower, easily cultivated, and a good bloomer; and Grand Duke of Tuscany, a new one that is going to be very popular.

1 Lemon-Ponderosa, about which you hear so much.

1 Oleander-Lillian Henderson.

1 Stephanotis Floribunda. A hard-wooded vine, with thick leathery leaves and bunches of pure white flowers that are deliciously fragrant.

Premium No. 19. The Miscellaneous Collection.

1 Abutilon, the Chinese Bell Flower, Souvenir de Bonne.

1 Asparagus Sprengeri.

1 Asparagus Plumosus Nanus.

1 Aloysia Ditriodora, the Lemon Verbena.

1 Cyperus Alternifolius, the Umbrella Plant.

1 Fuchsia-Duke of Albany.

1 Grevillea Robusta. A splendid decorative plant, of quicker growth than the palm.

1 Chinese Hibiscus-The Double Crimson.

Any one collection for a club of only four subscribers to THE FLORAL WORLD at 25 cents a year. Order by number and write plainly. Give number of collection when ordering. Address,

THE FLORAL WORLD, Springfield, Ohio. 


\section{DON'T TAKE OUR WORD FOR IT-YOURSELF}

WIITE TO.DA bath and their marvelons results, you will never part with it, that

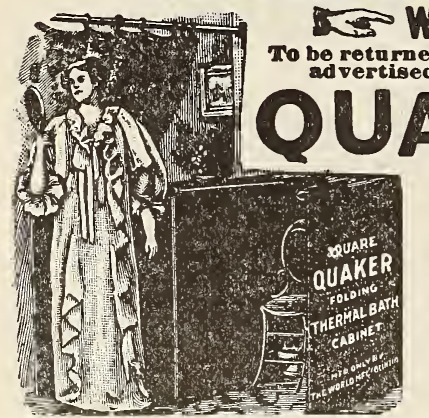

THIS $\$ 5$ QUaKER CABinet COMPLETE, REDUCED TO $\$ 3.60$ THOUSANDS OF PROMINENT PEOPLE PRABSE IT.

John W. Pricchard, Editor "Chriatian Nation," Now York City. writes: This Cabinet Bath is refreshing and invigorating to a degree aurprising, and is in lact, "Tired Netures woet Restorer

WV. L, Browz, Oxford, Ohio, sayg: My father wes down in bed for montho with rheumatiom; thi Cabinet did bim more good than $\$ 50.00$ worth of medicines.

Forat1o Page, M'g'r "Now York Weekly Witnese," witea: I must beartily endorse your Quaker Cabinet. It cured a bad case of rheumatiom with whicb 1 had been afflicted for gears. It paid for itself in week. Should be in every home,

Simon Tompkins, a retired capitaliat of Columbus, 0 , 1031 E Brond Street, eays: I am eatisfied it eaved my life. $\checkmark$ was dowa with a dangeroue case of pneumonia and its uee promptly cured me.

Wm. J. C. Dalaney, No. 8 E. Baltimore St., Baltlmore, Md. Publisher "Methodiet Protestant." writes: For Lagrippe, rheumatiem, kidney troubles, dropey, okin dieesees and bad colle. I believe the Quaker to be the best thing yet and bad colle, I believe the Quaker to be the best thing yet
diecovered. I use it weekly. Know many others who do and diecovered. I use it weekly. Know mung others who do and have yet to bear of one who does not praise ite virte

D. C. Smith, Clerk Board of Health, Mount Healthy, O.. eaye : Since using this Cabin et my catarrb, asthme and other troubles with which I have been afflicted for 20 years bave not retirned. Worth $\$ 1,00000$ to $\mathrm{me}$. I have oold $120 \mathrm{Ca}$ inets and many of my customers have cured Lagrippe, measles, croup, kidney troubles. ecze ma, blood and skin diseases, dia. beles in fact, slmost every ailment, and all are delighted with
the Cabinet. My wife findo it excelient for ailments peculiar to ber oex and invaluable for our children.

Rev. Fred. D. II amllton, of Buffalo, 6ryo: This Cavinet did my wife more good in five weeks than three years of doctoring and a fortnne spent at Hot Springe and beaith reserts Cured her of female weaknese, nervoueness, as well as kidney tronbles and dropay, with which sbo had long suffered, It is a God sent blesing to bumanity.

John Curtis Matone. N Y. says: The doctore told coe I had the workt case of eczema ever eeen. Mig kidneys, liver and heart were bad and blood was in awful obape-your Quaker Cabinet bas done wonders for me. Beats medicina. My friende are ourprised at my cure-I want the agency.

Julian F. Tanner, La Fayecto, La, writes:- Your Quaker Cabinet has cured mo of a troke of earalygts when the best doctors failed to do me any good.

Prof. Alden. Ft Thomas. Kg.. 8ay a: No man witb 3.50 in his pocket, can afford to be without this grand invention. He owes it to bis family and children.

SPECIAL-Select the Cabinet you wisb, eend us $\$ 1.00$, and to examination. If perfectly satisfied, pay exprese agent the balance. We carry 10.000 Cabinets in otock and ship by exprese sameday your order is received. Remit by Bank Draft. Exprese Money Order, P. O. Mones Order, Certified Cbeck or Registered Letter.

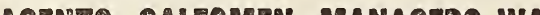

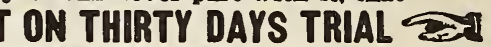

ense, and your money rerunded, if not just as

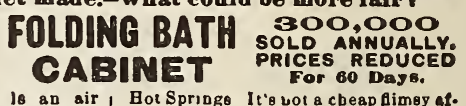
Hot Springe It's wot a cbeap Alimsy af-
fair, but a genuine Cabinet, onboian. tial and durable Finest goods, hand. oomely faisbed. bas every improve; ment, real door on hinges beavy steel frame. galvanized. beol antiseptic covering, rubber lined obly lablnet large and roomy inside plenty of room for hot foot bath and to eponge and towel the body while ineide Folde flat il in. apace Easily carried. Neigbe 10 lbs. "Eoliness Advacete;" Congress.

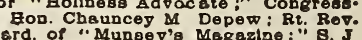
derd, of "Muneey"s Megaztre:" R. J use and recommend it ?

THE PREVIKNT Colds, Fovers, L agrippe and Dlsease, Mako clear skim, pure blood, strong nerves, creas brain. healthy bodies. Whike you sieep bound. Beatiry complexion.

WE POSITIVELY CUARANTEE RESULTS.

1,000,000 users. 27,000 physiclans recommend the Quaker, and it will cure Nervous Troubles, and Debility. Sleeplessmess. Obesity, Lagr ippe, Neuralgla.

Jean din 5 years a standing reward of 850.00 for a case not relieved.) Curses Woman's Troubles, Illead. ache, Gout. Plles, D ropsy, Disbetes, Blood and Skin Diseabes, Liver and Eidney Tromblea.

SO SIMPLE TO OPERATE.

Before retiring. light otove, otep in Cabinet, close and fasten door, ait down and you enjoy a temperature of $100^{\circ}$ to otove. All dome in one mimnte. Stay in from 15 to 30 minutes-open top Stay in from 15 to 30 minutes - open top curtains, cool of gradually while you sponge and towel the body. Imposeible
to catch cold or weaken the aystem. Per to catch cold or weaken $t$

foctly afe and harmle日s.
SOAP and WATER simply washe the eurface of the skin, while Vapo bathe opens the $5,000,000$ pores all over the body, otimulating the oweat glande. washing out all the poisons in the blood. and the impure acide, oslta, etc. which if retained overwork and weaken the heart. kidneys, lungs, liver, causing dis. ease debility and sluggishness. with one bath, and prevent Lagrippe,

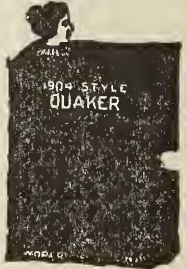

This 10.00 Doublo Walled Quaker. Oabinet complete. REDUCED to 6.10 ma. Is really a bousehold necessity With the Cabipet if de. cired, is a FTEAD AND COMPLEXION STEAMINE ATTACEMTENT.

(the beot ever offered) In which the head, face and neck is given (the beet over ofiered) In which the head, face and neck is given the eame vapor treatment as the body. Makes clear skin, beautiful complezion, cures and prevente pimples, blotches,
blackheads, okin eruptions and diseases. Invaluable for blackheads, skin eruptions and diseases. Invaluable for sthma, Catarrh and Broncbiti

We're an old frm, responeible, Captial oroo,000.00, do just as we agree, are the large st and olde日t manufacturers of Batb Cabinete in the World.

PRIBES REDUCED For 60 Style 1903, onr 86.00 plete with best Heater. Medicine and Vaporizing Pan and 100 page \$2.00 "Health and Beanty" book, only 88.50.

age Stole 1904 our \$10.60-finest and begt double walled Cabinet comnlete, only \$6.10. \$1.00 Head Steamer attuch. ment, only 65 cents.

MYTE TO. AY for full information and our valaa. L ble book free. Also testimoniale from thousands of users. Or, better still, order a Cabinet. You won't be disappointed as we guarantee every one and re fund price paid after 30 days use, if not just as represented.

DOEF DON'T FAIL TO SEND FOR BOOKLET AHY WAY.

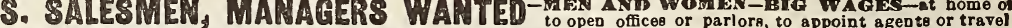
A wonderful seller. Enormous demand right in your locality. You oupply it. Most liberal terme and commiseione. Plent good territory. Be your own bnes. Anv energetic man or poman can make \$5 00 to $\$ 10.00 \mathrm{clear}$ daily.

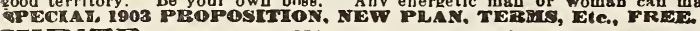

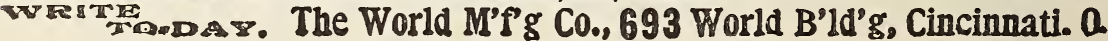




\section{SWEET PEAS.}

One of the most beautiful of annuals for summer blooming is the sweet pea with its many shades of red, pink, white, purple and variegated flowers. Mine are planted in the middle of April. Dig a small trench several inches deep and in this plant the seeds about an inch apart and cover about an inch and a half deep. As they grow the earth should be filled in around them to keep the earth moist; but if the weather is very dry they should be watered, as the plants require much water. If late bloomers are wanted the seeds may be planted later in the season. The flowers must be picked every day if they are expected to bloom all season.

\section{Ohio.}

\section{Katie M. Roads.}

[Early planting and filling in the trench as you do contribute largely to your success with this flower. If you would enrich the soil in the fall and throw it up into a rough ridge over winter it would probably enable you to plant much earlier in the spring than otherwise].

\section{BACKYARD ON THANKSGIVING DAY.}

Never can I remember the garden more beautiful. Fragrant pinks nodding over sweet alyssum scattered here and there, immaculate white all summer and sweetest of all in late autumn. By its side behold the roses, Clotilde Souperts are trying to unfold their buds before frost comes. Madame Camille has a beautiful full blown rose-it will surely be the last rose of summer. Larkspurs that in midsummer were pink, blue and white, have left the dark blue ones with me still; they seem to cheer me with their simple sweetness. In the center of the yard, on a pile of rocks, is a geranium, so large that its branches cover the stones, displaying its colors, pink and white. Beautiful chrys- anthemums! The tops that I nipped off from older plants I rooted in midsummer, and now this late autumn day no garden is more beautiful in yellow, pink and darkest of reds. There by the side of the chrysanthemums, as if to beautify their leafy stems, seeds of early corn flowers have found their resting place, pink and blue, they are treasures in their simple beauty.

What a sweet remembrance until spring time comes again.

\section{New Jersey. Mrs. Dan'l Hauser.}

[It is pleasing to note the increasing popularity of making the back yard a place for floral display. Here it is possible to satisfy one's own taste in the way of ornamental gardening without having it subjected to the varying criticisms of the public ].

\section{FLOWERS ARE SYMBOLS OF THOUGHTS.}

I wonder if every woman who reads or hears of the experience of others with flowers realizes that the simplest home can be beautifully adorned. No need of costly bulbs or plants when a few cents will purchase seed that will yield abundant bloom a whole season. No yard so small but there is room for a few beauties. Flowers are educators of the highest order, from the tiny shoot to the vigorous blooming plant. If parents would encourage their children to have their little flower bed or even one plant all their very own to care for, the influence would be elevating. It is said that in beginning the education of the child, first cultivate attention. What more likely to attract and interest than a beautiful growing plant or bed of flowers? To me it seems there is nothing more refining than floral culture. It makes neighbors more neighborly. Love offers flowers as tokens, 
and they seem to be the purest emblems expressive of sympathy, either of grief or joy-they voice our best feelings.

\section{Indian Territory. Mrs. Lou Hall.}

[ Kindergarten workers in the lower districts o our large cities find most excellent use for plants, flowers and seeds in seeking just the results you mention ].

\section{SOME ADVICE FROM EXPERIENCE.}

Last summer I thought I would try salpiglossis as I had read so much about their beauty. I procured a packet of mixed seed and sowed them in a box in the house. They came up nicely and I had a quantity of healthy plants to set out when the weather became settled.

In due time they burst forth into bloom. Such marvels of coloring I never saw. ITe were enraptured by them. But, alas! One wet soggy night I was passing by the border and an offensive odor rose to meet me which I had never noticed before. On investigating I found that it issued from the hearts of those lovely salpiglossis.

I was commanded to root them out, which I did after a succession of rainy days made them an unbearable nuisance. Wet weather renders them positively malodorous, for in dry weather they are practically scentless. Put them out of the way of your nostrils if you wish to enjoy their beauty. Mrs. IV. J. Doughertr.

\section{Minnesota.}

[Numbers of otherwise beautiful flowers have this undesirable feature. The arum draconculus, a gorgeous purple-flowered calla, has a most unbearable odor, while the flower of the well-known stapelia is farfrom pleasant in this respect ].

\section{BATHE THE FLOWERS.}

I have some three hundred window plants which do nicely for me in a soil one part good garden soil, one part leaf mold, and one part sand-clay for cacti. Ferns and begonias fill the north windows, fuchsias and palms the east, geraniums, .. abutilons, primroses and amaryllises the south, while to the west are roses and bulbs. I water them when they seem dry, and every two weeks I fill a bath-tub nearly full of water as warm as would be comfortable to bathe in, and lay my plants in this, allowing them to stay about one hour, then refill until all are washed. I know of no one else doing this, but the plants like it and the parasites do not. I have given this treatment for three years and have hardly seen a red spider or any other pest. Once a week I give liquid fertilizer. I think plants could not do better. They bloom winter and summer.

Vermont.

Mrs. E. J. PECK.

[Your collection is really unusually large, and the methods employed in their carearequite practical, though the time you keep the plants submerged seems rather long. The "red-spider," however, would certainly be destroyed ].

\section{MY HOUSE PLANTS.}

How gloriously the sun shines through my plants. What delight it brings. There are eucharis, poinsettia, palms, fuchsias, oxalis, begonias, geraniums, coleus, roses, ferns, calocasias cacti, amaryllis and others, the tropic and temperate zones blended in one gorgeous mass of beauty. Problems of soil; heat, moisture, sunshine, light and air have been mastered. They feed upon me and I upon them, for the poison I exhale they use, and I need the oxygen they yield.

The water used upon them makes the house air wholesomely humid and health increases. Those who come and go need no spur to conversation, for the grace and variety and beauty and thrift of the flowers overflows, and the words that we speak are of things that elevate and spiritualize the body and mind. How many blossoms have been sent to place in hands whose work on earth is ended, and by their sweet perfume and beauty to comfort those who mourn. When I meditate upon the mysteries of their life and growth and lovliness, my soul is lifted up and I praise Him who created them and me.
Illinois.
AdA H. Kepley.

[One of the plants that you mention, the poinsettia, attracts quite a little attention at this season of the year, many of them being displayed in the windows of the florists' stores in the cities. The brilliancy of the poinsettia reminds one of the lobelia cardinalis ]. 


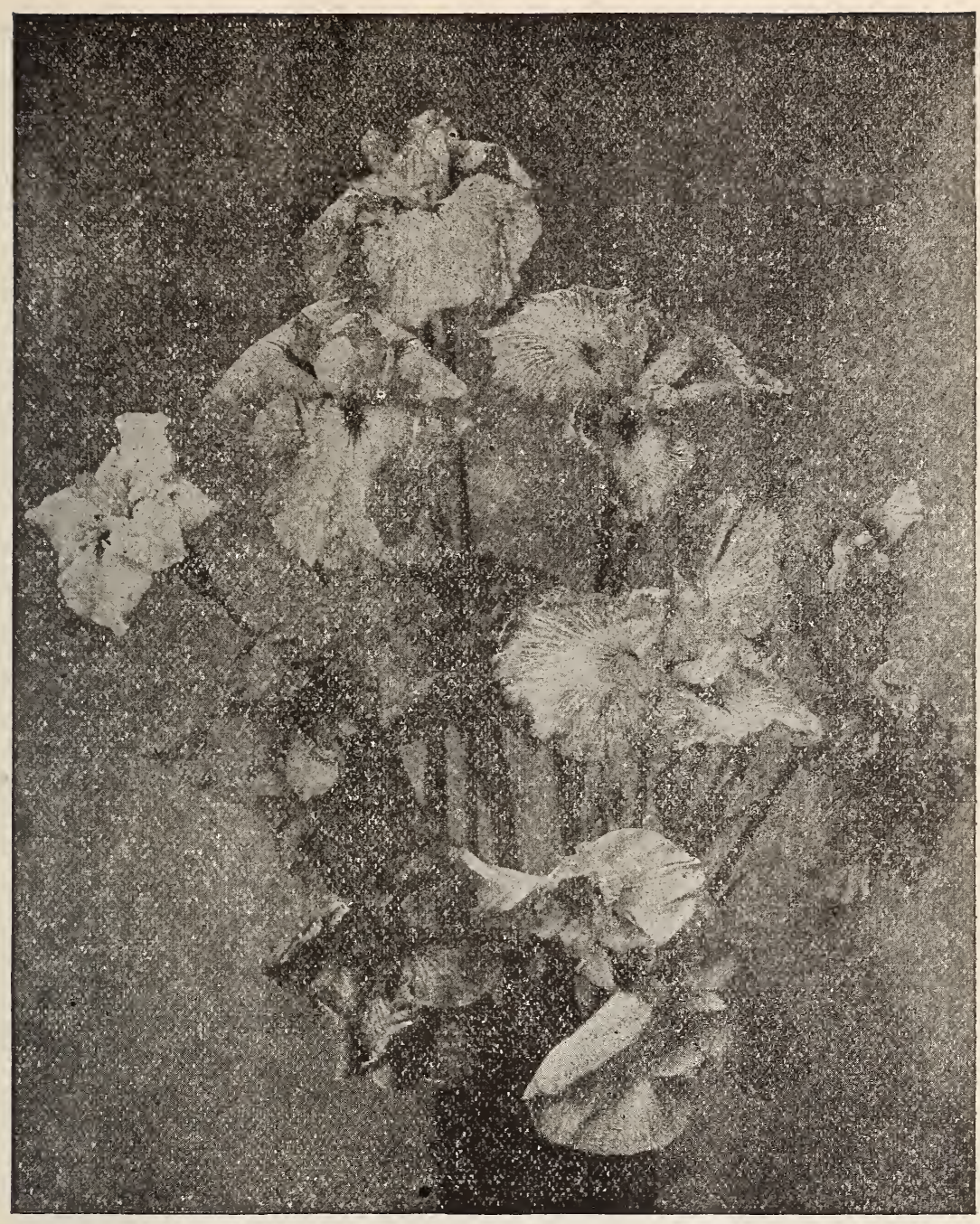

A BIT OF SUMMER.

\section{SWORD FERNS.}

Readers of The Floral World, do you have success in growing sword ferns? If so, perhaps I may also tell you of mine. Last spring I repotted them in soil gathered from the woods, composed of leaf mold, well rotted cow manure and sandy soil from near a creek, watered them well, then placed them on a bench on the north side of the house, giving each pot plenty of room. Every day I watered them well with a watering pot (not the hose, as it is too cold), and my ferns this fall have been the admiration of every one who has seen them.

Iowa.

INDIA J. RUCH.

[ Unless there was too much of the cow manure used-and very little would suffice-the mixture of soil you used for the ferns was of the best. Watch your specimens carefully now for the appearance of scale insects ]. 


\section{THE FLORAL WORLD}

PUBLISHED MONTHLY BY THE

\section{FLORAL WORLD COMPANY}

12 to 14 South Limestone Street

SPRINGFIELD, OHIO

\section{Subscription Price, 25 Cents a Year}

Entered as second-class matter at the Postoffice in Springfield, Ohio.

The editor of The Floral World takes great pleasure in announcing that, beginning with this number, each letter from its readers will receive such special attention as it requires. An experienced authority on floriculture will answer any questions you may care to ask, and make suggestions as to how you may have greater success in your flower growing. The editor hopes every reader will take full advantage of this feature of the magazine and tell all his or her friends about it.

The regular prize offer is continued. The magazine will give $\$ 26.00$ in prizes for the best five articles for publication in the March number of THE FLORAL WorLd, which may be submitted by subscribers.

The first prize will be $\$ 10.00$; the second, $\$ 7.50$; the third, $\$ 5.00$; the fourth, $\$ 2.50$; and the fifth, $\$ 1.00$. The awards will be announced in our April issue.

No article which contains more than two hundred words will be considered in the prize decision. All contributions entered in this prize contest must reach us not later than February 1.

The purpose of these prizes is to secure for publication in THE FLORAL IVORLD matter which gives the actual experiences in flower growing of those who have subscribed for the journal. Prizes offered for articles published in the December number have been awarded as follows:

First Prize-C. J. Peffer, New York.

Second Prize-Gussie A. Young, Texas.

Third Prize-Mrs. Minnie N. Hinds, Massachusetts.

Fourth Prize-India J. Ruch, Iowa.
Fifth Prize-Mrs. F. A. E. Smith, South Carolina.

During the year just past the relation between the publishers and the readers of THE FlORAL WORLD have been most cordial and helpful. Can we not be even more helpful to one another in 1903? A very happy New Year to you all.

\section{DORMANT ROSES.}

The winters here are too severe to safely leave the teas and other tender roses out of doors, and I have not the space to keep them in the living rooms, but as I must have them I grow them as pot shrubbery, keeping them dormant all winter in a frost-proof cellar, along with my oleanders, etc. And to my mind it is the most successful way of growing them in the north, as you can always have your soil, drainage and location just about perfect in the summer, and in the winter they are safe from freezes and green lice. I use good, well fertilized garden soil, and put the plants in pots that will hold the roots comfortably, and still leave space for them to start into growth. In the spring I plunge the roots in a sunny location and keep well watered, repotting as often as the roots fill the pots, and I keep the top pruned into shape until they are strong, bushy plants. I find their principal requisites are sunshine and plenty of water, and with these wants attended to they will bloom abundantly all summer, providing, of course, that they are kept free from insect pests. In the fall I lift the pots out and let them dry out somewhat, and ripen up, in a sunny, sheltered location, before I put them away in the cellar. Once in winter quarters they are no trouble, save an occasional watering, while every year's growth adds to their value and beauty.

\section{New York. Mrs. Nelson Puff, Jr.}

[ Have you ever tried protecting your roses out of doors with forest leaves. In Ohio, where the temperature drops away below zero and with less snow to protect them than in your state, tea roses can be wintered over out of doors by a heavy protection of leaves ]. 

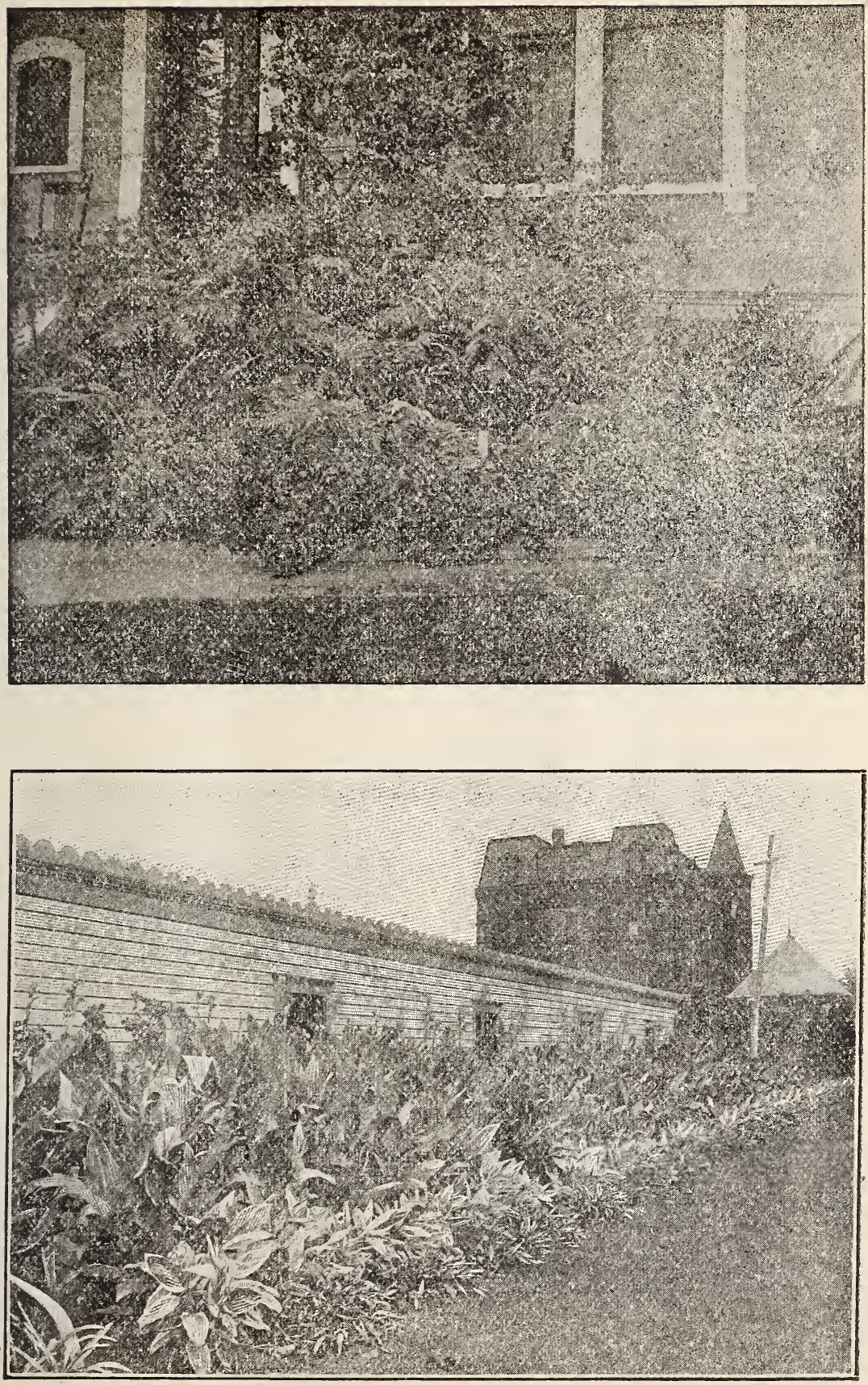

EXAMPLES OF FLORAL WALL DECORATION, 


\section{WORDS OF APPRECIATION.}

We have been subscribers to The Floral World since its first issue, and love it dearly as our very own, as none but flower-loving people are allowed to write for it. May our little plant magazine live and flourish for many years.

Georgia. Mrs. Allan Wamble.

The Floral WORLD is the best floral magazine I have ever subscribed for. I hope its present standard will be continued.

Mrs. Abbie J. Douglas.

Ohio.

I have received THE FLORAL WORLD and name it a "Daisy." Everything in it is practical. Mrs. E. M. HASKell.

Illinois.

I have subscribed for THE FLORAL WORLD and am very well pleased with it.

Pennsylvania. Mrs. Silvannia Linn.

I like The Floral WorLd very much. It has many useful hints and suggestions. "West Texas."

The little Floral World is just about right.

Mrs. Nelson Puff, Jr.

New York.

I like the little Floral WORLD better than ever. Mrs. Sara A. Pleas.

Indiana.

I greatly appreciate THE FLORAL WORLD. Mrs. Abbie J. Layman.

Indiana.

I like The Floral World very much and hope to remain a subscriber.

Delaware. MRs. L. W. BALDWIN.

I am delighted with THE FLORAL WORLD and feel that I could not do without it.

North Carolina.

Long live THE FLORAL WORLD! It is practical and to the point. I intend to try and get some subscribers for this, my favorite paper.

Oklahoma. Mrs. Alice Thompson.
I like The Floral World very much indeed. It is helpful, interesting and attractive.

"HAyseed."

Maine.

I am a subscriber and reader of other floral magazines, but I get more practical information from THE FLORAL WORLD.

Michigan. Mrs. Emma S. Wood.

The Floral WORLD is a monthly treat. MrS. Florence M. WALKer.

Louisiana.

I find The Floral World a very interesting magazine. What I like about it is it tells all about flowers and nothing but flowers. Miss CARrIE A. LARUE.

West Virginia.

THE Floral WORLD is full of good things for the flower lovers of the South.

Louisiana. Mrs. G. E. Pearce.

I am very much delighted with the flower talks in THE FLORAL WORLD.

Iowa. Mrs. F. E. Millken.

\section{DAHLIAS.}

The finest thing in my old garden is an imperial dahlia. The main stem is over twelve feet high, with branching top having fully fifty great bell-shaped flowers, each one being eight inches across. They are pearly white with faint lines of mauve pink deepening to the center, which is just a big bunch of yellow stamens. I have cut and counted a hundred and forty-three flowers and there are still buds and flowers. Some plants, in twentypound tin buckets have just as large blossoms, but the plants have been pinched and are dwarf. These dahlias will bloom all winter in a warm, sunny window, but in the garden they die off like other dahlias and are left in the ground all winter.
Louisiana.
M. E. C. Pearce.

[ Hardly less astonishing have been the results obtained from the high cultivation of the dahlia than with the chrysanthemum. Some of the later introductions in dahlias are decidedly novel and beautiful]. 


\section{HELPFUL HINTS.}

Geraniums. - When your geranium leaves become yellow or look like dropping, remove them and tuck them down into the earth. They will enrich the soil and you will be well paid for the little trouble.

CALLA LiLies. - I have found that nothing is better than to put a tablespoonful of castor oil in a gutter around the plant once a week.

Slugs.-Any choice plants may be preserved from the ravages of slugs by placing a few pieces of garlic near them. No slugs will approach the smell of garlic.

Amaryllis.-If anyone has an amaryllis she will find it will blossom more freely if the soil is kept away from the top of the bulb. It should be watered freely.

\section{Ohio.}

\section{Christina Hug.}

[Instead of doses of castor oil, why not imitate nature more closely and provide food in the form of humus (decayed vegetable matter) for your callas? Garlic certainly should keep slugs away. Has it any effect on cut worms? Have you ever seen an amaryllis bulb grow and bloom without water, soil or planting in any way? Theysometimes do it ].

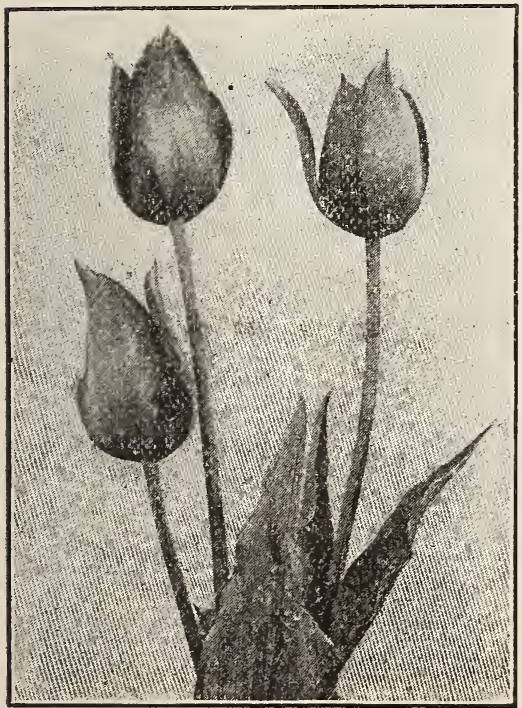

\section{TO OKLAHOMA FLOWER LOVERS.}

Two years ago I sowed a packet of midget or fairy rose seed. Thirty came up and five survived and blossomed within sixty days from the time of sowing. They were dainty little pot plants, some were double and some were semi-double. At the same time I sowed a packet of baby primrose which was truly a thing of beauty and fragrance. I have an otaheite orange with seven oranges on it. I put it in the open ground in the summer then lift it and bring it in the house in the winter.

Molly Gilbert, try moss verbenia and sweet alyssum. They flourish in our hot sun and winds. For two winters I have grown the Bermuda buttercup oxalis, and it is indeed a continual bloomer. My weeping latana is loaded with buds. Let us hear from other Oklahoma flower lovers. Mrs. Alice Thompson.

Oklahoma.

[Two of the plants you mention, the "baby primrose" and the "Bermuda buttercup" oxalis, are old plants, which fortunately, were not allowed to sink into oblivion, but recently brought out and pushed as novelties. They are well worth cultivating'].

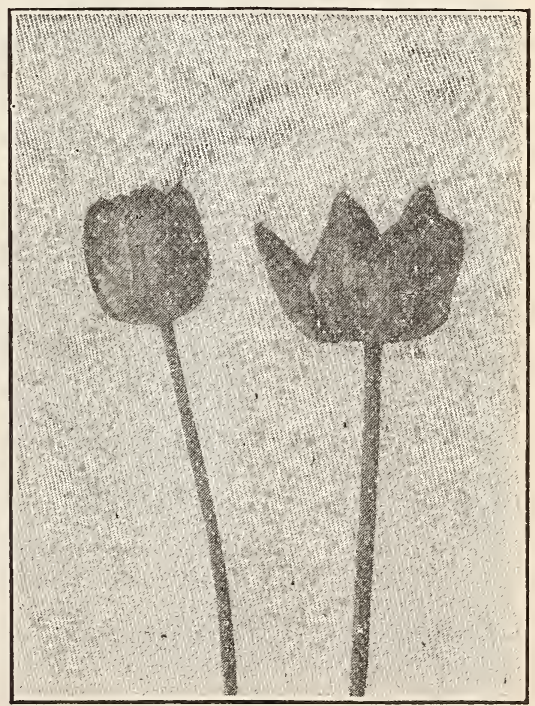


COSTS NOTHING TO INVESTIGATE. WRITE US FOR OUR PROPOSITION ANYWAY. S20 TO \$35 AND EXPENSES WEEKLY. \$1000 to \$1500Annual Income

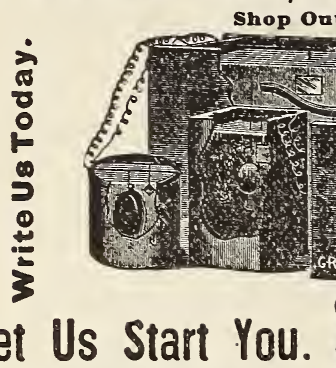

\section{BIG PROFITS.}

\section{Don't Be Hard Up. New, Quick Process}

No Humbug, Fake or Toy Proposition. An Honest, Legitimate Enterprise, Backed by an Old, Reliable, Responsible Firm. Capitai $\$ \mathbf{1 0 0 , 0 0 0 . ~ W e ~ M a n u f a c t u r e ~}$ Complete Outfits. All Sizes.

What is the Use of Your Slaving Longer for Someene Else.

Why not start a business for yourself, reap all the profits and get a stunding in your locality.

If you are in some one's employ, remember he will not continue to pay you a salary only so long as he can make profit out of sour labor.

In this era every bright man and woman is looking to own a business, to employ nelp, and to make money.

It is just as easy to muke money for vourself as it is to coin money for some grasping employer, who pays you a small sulary each week.

If you are making less than $\$ 30$ weekly it will pay you to read this unnouncement, for it will not appear ugain in this paper.

If you read it and take advantage of the opportunity

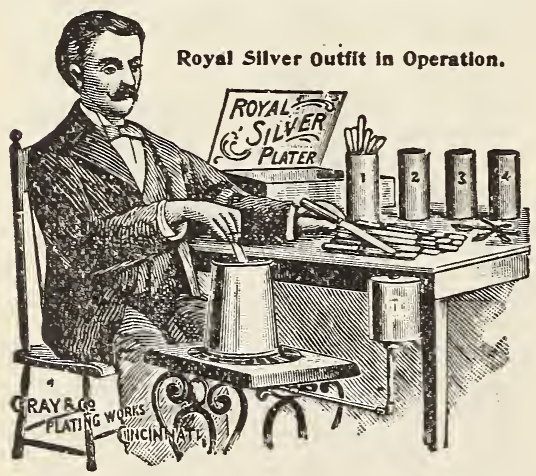

offered, you will never regret it. To own a business yourself is certainly your ambition.

We start you in a protituble business. Teach you absolutely freo how to conduct it.

$\$ 20$ to $\$ 35$ weekly can be made at home or traveling. taking orders, using, selling and appointing agents for PROFESSOR GRAY'S Latest Improved, Guaranteed Plating Macbines and Outfits. NO FAKE OR TOYS, but genuine, practical, complete, scientific outfits, for doing the finest of plating on WATCHES, JEWELRY, KNIVES, FORKS, SPOONS, CASTORS, TABLEWARE,

of all kinds, B T CYCLES SEWING MACHINES. REVOLVER S, $S$ W O R D H A R N E S S a n d BUGGY TR I MMINGS; me tal special. ties: in fact all

kinds of methl goods. HEAVY, THICK PLATE. GUARANTEED TO WEAR FOR YEARS. No experience necessiry.

WHAT OTHERS ARE DOING.

H. F BALLOW of MHss, writes: "MADE \$17.00 FIRST 5 DAYS." H. BULLOCK, of Pt., writes: "HAVE MADE $\$ 10$ to $\$ 20$ A DAY." FRED BLODGETT, of N. Y., writes: "MADE \$105 FIRST MONTH." I. T. CONKLIN, of Ohin writes: "Am teacbing school, double my income by doing plating." J. L. BARRETT, of La.. says: "Am mrking $\$ 300$ to $\$ 8.00$ every day I work." J. A. DEEDS. of W Ve suys: "Directions so plain I did first-cluss work first day. Your business no humbug, but just what you cluim." GEO.AD ANS, of Mass.. writes: "Huve made as hig $\mathrm{b}$ ( $\$ 9.00$ a duy." A ABERT ABRA HAM, of Minn. writes: "Must write you of $\mathrm{my}$ success in the plating business. Made as high as $\$ 9.25$ a duy. Have more plating than I can do. Plating gives splendid sutisfaction." MRS. L M. ANDERSON, of IOwa, writes: "I have made $\$ 3.80$ to $\$ 6.50$ a day with the ROYAL SILVER PLATER. Gray \& Co., have been very kind to me." J. P. A.NDERSON, of Minn,, says: "Have made $\$ 2.50$ to $\$ 3.00$ a day for past year plating. Big demand for plating." Hundreds of others are muking money. Why not you?

$$
\text { ENORMOU'S DEMAND. }
$$

There is really a wonderful demand for re-plating. You can do business at nearly every house, store, office or factory. Almost every family has from $\$ 2$ to $\$ 10$ worth of tableware to be plated, besides watches, jewelry, bicycles, etc.

Every boarding house. hotel, restaurant, college or public institution has from $\$ 5$ to 875 worth of work to be plated. Every jeweler, repair or bicycle shon, every dentist. doctor and surgeon, every man, woman and child you meet has either a watch. some jewelry, bicycles, instruments, or some articles needing plating.

Besides the above there are bundreds of patentees and manufacturers of metal goods, bicyles, serving machines and typew riter repair shops who want their goods plated. or to whom you can sell a plating out6t, furnishing them supplies for doing their own plating.

pelal ware and plated or metal goods all need a plating and polishing outfit for refinishing goods that become worn soiled, rusty or tarnished. 
Every Undertaker requires a plating outfit for repairing and finishing coffin and bearse trimmings, which are solled, tarnished or worn.

Manufacturers are making and selling tons of new tableware, jewelry, bicycles and various kinds of metal goods every month which has only a very thin plate, which in a few weeks wears off, making the goods un. sightly, unfit for future use unless plated.

Manufacturers of new goods do no replating of old goods whatever, but try to torce the public to throw a way the old and buy new at high prices, but this only makes the plating business better.

The more new thinly plated goods sold the greater will be the demand- for plating. Plate some article for your friends and neighbors by Professor Gray's Process, and it quickly proves to them its genuineness and merit and that your plating is much thicker, will wear better and longer than a large percentuge of the new goods. Your trade is then established, and within a short time you will have all the goods you can plate.

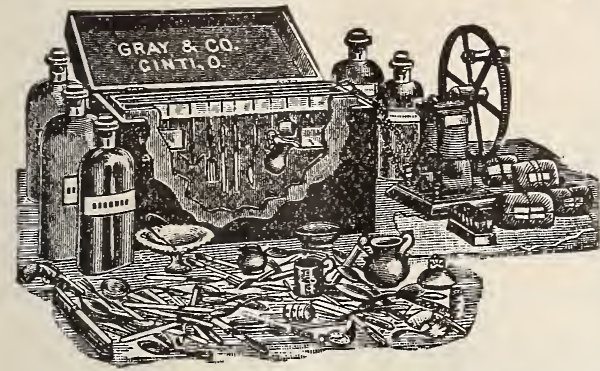

We allow rou to set your own price for plating. Get as much as you can. You will have no competition. You know what it costs to plate the goods, and all you get over cost is profit. Some agents charge much more than the above prices, while others do the work for half and still make money.

Let us start you in Business for yourself at once, don't delay a single day. Be your own boss. Be a money maker. We do all linds of plating orraclves, have had years of experience, and are headquarters for plating supplies. We munufacture our own sizes, and send them out complete, with all tools, lathes, wheels and materials; everything reudy for use.

We teach you everything, furnigh all recetpts, formulas and Trade secrets free, so that failure should be impossible, and any one who follows our directions and teachings can do fine plating with a little practice, and become a money maker.

\section{THE ROYAL SILVER OUTFIT.}

\section{Prof. Gray's Famous Discovery.}

THE NEW DIPPING PROCESS is the latest. quickest, easiest method known. Tableware plated by simply dipping in melted metal, taken out in. stantly, with fine, brilliant, beautiful plate deposited. All ready to deliver to customers. MAKES THICK ALATE EVERY TIME. GUARANTEED TO WEAR 5 to 10 YEARS. A BOY CAN PLATE 100 to $300^{\circ}$ pleces tableware a day, from $\$ 10$ to $\$ 30$ worth of work, protits almost 1000 per cent. Goods come out of plater finely finished. No poltshing, grinding or work necessary, elther lohing, grinding or wo

You will not need to canvas. Agents write they have all the goods they can plate. People bring it for milesaround. You can hire boys cheap to do your plating, the same as we do, and solicitors to gather work for a small per cent. Put a small advertisement or two in your locul paper and you will have all the plating you can do. The plating busiTraveling Outfit for Gold, Sllver and Nickel Plat!ng.

Plate a few articles for your friends, call a few weeks, a few months, or five yeurs later, and you will find the plate satistactory, and they will give you every urticle they have needing to be plated.

When you deliver the goods plated to customers they will be well pleased, in tact,delighted with the work. will pay for it promptly, and you will be given on an averuge twice us much work to be plated as they gave you the first time you called.

\section{YOU CAN DO PLATING SO CHEAP}

that every person cun afford to have their goods plated. Notidy housekeeper will allow worn and rusty tableware to go before a guest when it can be restored and made equal to new.

No person will wear jewelry or a watch, or ride a bicycle, or use a typewriter, sewing machine, or any machine made of metal from which the plate is worn off when they see sumples of your work and hear jour prices. People in this-day and generation are too sensible and economical to throw away their old goods and buy new when they can have their old goods replated for so small a cost, making them in many cases better than when new.

The best part of the plating business is that it increases fast and is permanent.

Put out your sign, secure your outfit, do a little work. and quickly you will be fuvored with orders. If you do not wish to do the plating yourself you can hire boys for \$3 to 84 g week to do the work the same we do und solicitors to gather up.goods to be plated on commission.

It is not hard work, but pleasant; and especially so when your business is netting you $\$ 20$ to $\$ 35$ a week for 5 or 6 hours' work a day.

\section{TREMENDOUS PROFITS.}

The profits realized from plating are tremendous.

To plate a set of teaspoons requires only about $3 \mathrm{c}$ worth of metal and chemicals; a set of knives, forks or tablespoons about 5c worth. The balance of the price received for the work is for the agent's time and profit.

Agents usually charge from $25 \mathrm{c}$. to $50 \mathrm{c}$. per set for plating teasponns, from $50 \mathrm{c}$. $1075 \mathrm{c}$. for tablespoons and forks, and from $60 \mathrm{c}$. to $\$ 1.00$ for knives. ness is honest and legitimate. Plating on our muchines gives good satisfaction. Wears.for years; customers are delighted und recommend you and your work

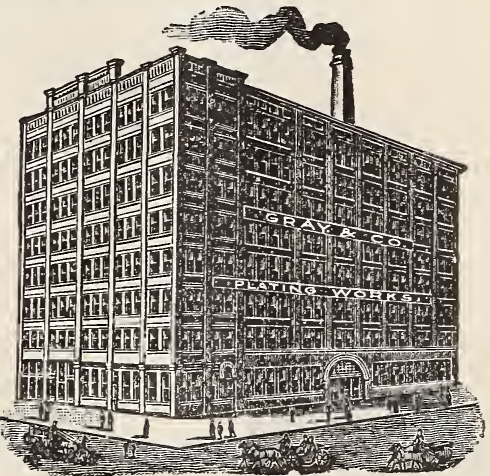

Factory and Warehouse of Gray \& Co, Cincinnatl,Ohlo. Capltal $\$ 100,000$. Employ 200 to 300 people dally.

We are an old established firm, have been in business for years, know exactly what is required furnish complete outfits and materials, the same as we ourselves use, and customers always have the benefit of our experience. We are responsible and guaramsee everything. Reader, here is a chance of a life time to go in business for yourself. We start you. Now is the time to make money

\section{FREE-WRITE US TODAY}

for ournew plan and proposition; also valuable in forma. tion how the plating is done. Sit down and write now, sowe can start you without delay. If you wish to see sample of plating by our outfits. send $2 c$ postage. Send your address anyway. 

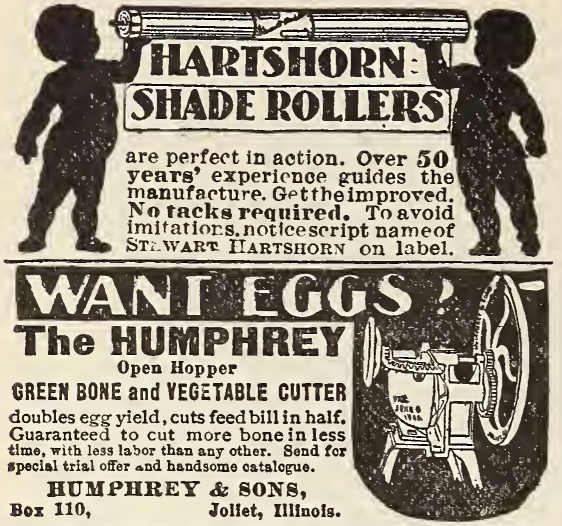

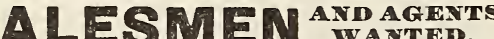

8I INAES Har-

Blue Flame, Wickless,

Fuel Oil Stove for cook.

ing and heating. New,

Wonderful Invention.

Enormous demand. Ev-

errody busg

Generates its own fuel gas from kerosene oil. A spoonful oil makes hogshead fuel gas. Oheapest, safest fuel. No dirt, ashes or big coal bills. All sizes. Prices $\$ 3$ up. Write for speclal offer, new plan. Catalogue Free. WORLD MFG. C0., 6236 World BIdg., CINCINNATI, 0.

\section{Paper Jardinieres Wanted in Every Home.}

\section{Pretty, Pleasing,}

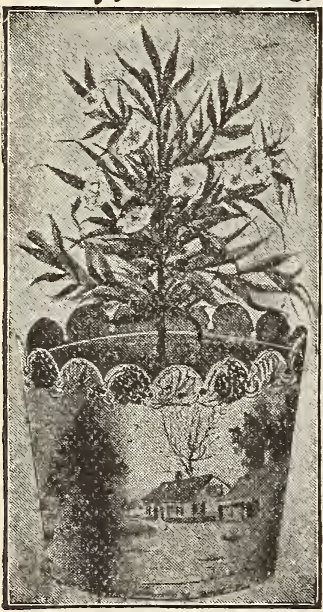

Ornamental.

This engraving illustrates our new Paper Jardiniere placed over a common flower pot. A charming decoration for wind ow plants or cut flowers.

Made of flexible cardboard A child can adjust them to any flower pot. Will protect your window plants from frost. Will hide the unsightly appearance of the common flower pot. Will lend to your flowers and plants additional grace and beauty.

Price 25 Cents Per Dozen, Postpaid 30 Cents. Assorted colors, packed one dozen in neat folding box, convenient for mailing.

Stronghurst Manufacturing Co., STRONGHURST, ILLINOIS .

\section{ANSWERS TO INQUIRIES.}

To Slip Rubber Plants-Cut off a branch and place in a jar of water until roots are formed. M. M. Conner.

Pennsylvania.

Keeping Dahlias and Cannas Dahlias and cannas will keep wherever potatoes will keep. Allow the soil to dry on the bulbs.

To Mrs. Graham - Set out hardy bulbs any time before the ground freezes. A well drained, sandy soil is best, as the bulbs are not so apt to decay in sand.

Illinois. Mrs. E. M. HAskell.

\section{INQUIRIES.}

I have a number of small geraniums and other plants which I wish to force to greater growth and bloom. My windows are light and sunny and my soil is good. What plant food, besides liquid manure, shall I use? Would bone meal be good? If so, tell me how to use it, and the price of it.

Mrs. C. J. HunT.

New Jersey.

Have any of the readers of THE FLORAL WORLD a plant called "othonna?" It is sometimes called " pickle plant," and is used for hanging baskets. I should be glad to purchase one if any of the readers have one which they care to dispose of.

Ohio. Mrs. Abbie J. Douglas.

I have a four-year-old orange tree which blooms and bears fruit every year, but the leaves and fruit drop off. Shall I keep it very wet and fertilize frequently? Please tell me how to care for it.

Pennsylvania. Mrs. Silvania Linn.

Will some one tell me how to care for a pineapple geranium? I have one which grew four feet last summer, but the leaves are curling and turning yellow. What is the trouble? Mrs. M. A. G.

Washington.

I once saw a plant which was called a strawberry geranium. It was in a hang-

(Concluded on page 15) 


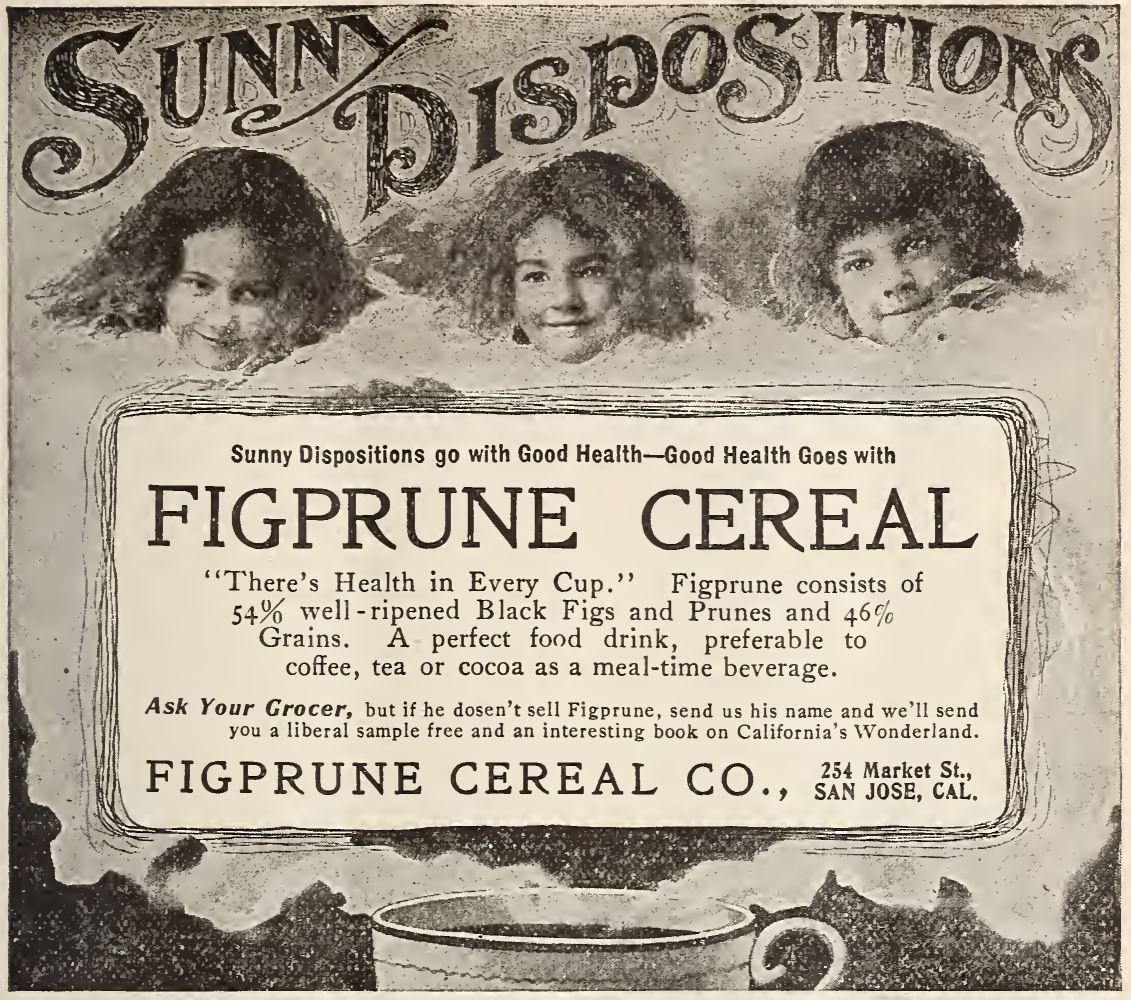

(Concluded from page 14)

ing basket and sent down runners with tiny plantlets just as the strawberry plants do. The leaves are round and of a pleasing red color. Is that the proper name and where can it be had? I have never seen it listed in any catalogue.

Minnesota. Eleanor R. Bartlett.

[Possibly fragaria indica-probably the apple geranium ].

Have any of you tried the peppermint geranium? The foliage is beautiful, soft and velvety, and the odor is very refreshing. A single plant will soon fill an entire window. Eleanor R. Bartlett.

Minnesota.

\section{SUCCESS WITH WINTER PLANTS.}

I will tell the lovers of THE FLORAL WORLD how I manage my winter plants, such as geraniums, foliages, primroses and umbrella plants. I have all my flowers at a south window where they get the most sun all day. I have them arranged on a table two and a half feet across, and on one side I fastened a stout wire with nails and bent it over the top of the table to the height of three feet and fastened it to the other side of the table, then set some pretty vine at one side and let it run over to the other side. I will tell you how I succeed with my umbrella plant. I filled a china pot with good rich soil to within three inches of the top, and placed my plant, putting a layer of little rock on on the roots, then filled the pot with water. I can almost see the plant grow. Give your plants a bath with warm water once a week and then you will hear your friends say, "O my, your plants look so (Concluded on page 16) 
"Let the GOLD DUST twins do your work."

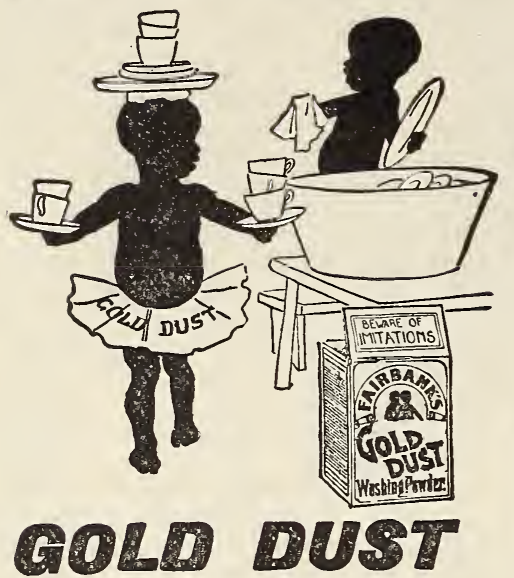

solves the problem of easy dish washing. It cuts grease and cleans dishes better than anything else. Does its work quickly, well and economical.

Made only by THE N. K. FAIRBANK COMPANY,

Chicago, New York, Boston, St. Louis, San Francisco, Baltimore, Montreal.

Makers of OVAL FAIRY SOAP.

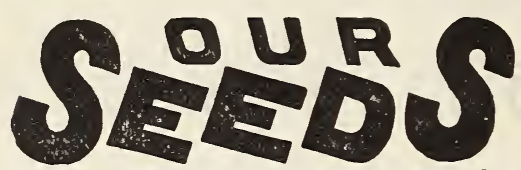

Frait and Ornamental Trees, Eto., have been the standard of excellence for nearly half a century. We send by mail postpaid, Seeds, Plants, IRoses, Bulbs, Vines and Smali Trees and guaranteesafe arrival and satisfaction, larger by express or freight. Direct deal will insure you the best and save you money. Try us. Your address on a postal will bring you our elegant 168 page catalogue free. 49 years, 44 greenhouses, 1,000 acres.

THE STOLIRS AE HA R RISON CO., Box 99 , PAINESVILLE, OHIO.
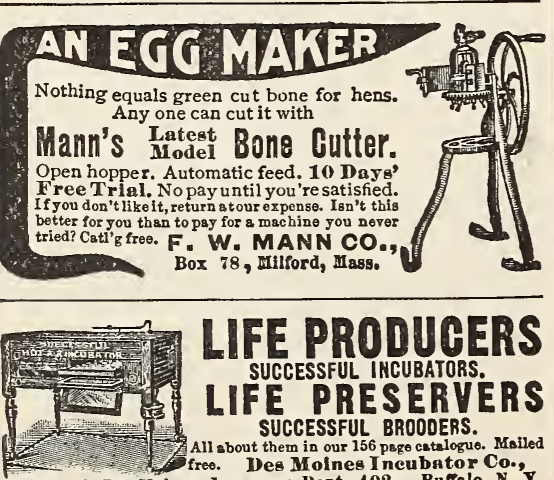

Dopt. 402, Des IIulnes, Iora, or Dept. 402, Bufralo, N.'X.
(Concluded from page 15)

fresh." Care for your plants and they will grow. Mrs. DaIsy STUDDARD.

Kansas.

[The umbrella plant (cyperus alternifolius) is an exceedingly satisfactory house plant. About all it requires is, water, water, water. Have no fear of water-logging it. It is well to go over it occasionally to see that no "mealy-bugs" have found lodgement about the center of its leaves].

Do not be discouraged because you have no south window for your plants. The sunshine is good for them, but many plants can be grown in east windows, or even in west windows, where they get the sunshine only for a short time, but no one need expect to have good plants without giving them the proper care.

Plants kept in the kitchen or living room should be washed at least twice a week in warm soap-suds, which will prevent lice. Place the pot in the dish of suds while washing the plant and you will be sure the roots are well watered. I give them liquid manure about once a week.

Plants cannot thrive without good air, and when it is too cold to ventilate from the window, they can be aired by opening a door in the room and fanning the air about them. If you wish bushy plants, cut them back occasionally. If necessary to protect on cold nights cover with newspapers.

A. R. P.

New Hampshire.

[General suggestions as to the care of house plants, or rather plants in the house, are always of value. The specimens found in windows often excel those of the professional florist, just because the owner may have more real talent in that line or is keener to note the demands of her pets ].

One plant that should claim our attention at this season of the year, when we are selecting plants for winter blooming is epiphyllum russellianum (lobster cactus). It is an excellent house plant, and, with ordinary care, will do well in almost any situation that is above freezing point.

Its flowering period lasts from November until February. A well-grown plant will bloom nearly as abundantly as a

(Concluded on page 17) 
(Concluded from page 16)

fuchsia. The flowers are a brilliant rose color with white throats, have good lasting qualities, usually remaining open three days. It likes a rich soil. After the buds appear give plenty of moisture and fresh air. It is easily propagated from cuttings, grows rapidly and is very satisfactory in every respect.

California. Mrs. M. E. Patterson.

[ To obtain a fine specimen of the lobster cactus it should be grafted upon the stem of some other stiffer-growing sort. The variety mentioned is hardly strong enough to support itself when grown to large proportions ].

HOW TO GROW ROSES FROM SLIPS.

Doubtless every flower lover has experimented with rose slips. I have, and have been successful in starting them under jars and in hot-beds. I have also grown roses during all season of the year - even the American Beauty, which florists claim will root only in the winter. In planting a slip under a jar mix some sand with the soil and after the jar is perfectly placed over it fill around with soil or ashes to half the height of the jar.

A hot-bed composed of a layer of manure, and one of soil, and two inches of sand is sufficient for starting rose slips. Plant them two inches apart, and during the hot mid-day sunshine, cover with a cloth, while the weather is warm. Now I think the most important point is how to cut the slip and what kind to cut. The growth of the slip does not depend upon the size of the slip. People seem to think the larger the slip the better, and often times when I give slips to some they say, "Oh, how small!" Cut a three joint slip -not the new growth, nor the old woody -but the part between. I have rooted two-joint slips, but prefer the three. Always take a joint with a good eye, as it is called, to place beneath the soil.

$$
\text { Kentucky. IRENe Hall. }
$$

[ Amateurs will often succeed in obtaining good results from prospects so hopeless that the professional florist could not afford to risk his time and money upon. Let us suggest that you show your floral friends how high you have risen in the pro:fession by using the word "cutting" for slip].

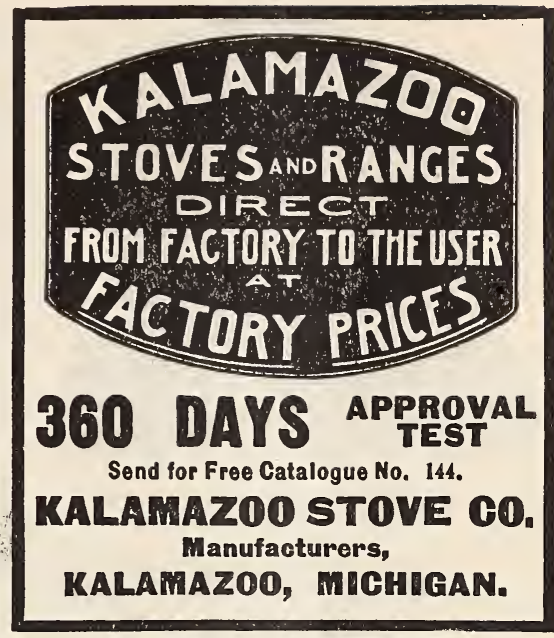

GREAT CROPS OF

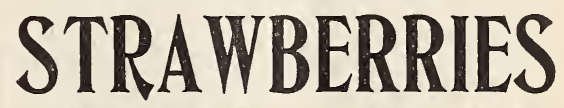

AND HOW TO GROW THEM

The best book on strawberry growing ever written. It tells how to grow the biggest crops of big berries ever produced. The book is a treatise on Plant Physiology and explains how to make plants bear Big Berries and Lots of Them. The only thorough-bred scientifically grown Strawberry Plants to be had for spring planting. One of them is worth a dozen common scrub plants. They grow BIG RED BERRIES. The book is sent free to all readers of THE FLORAL WORLD. Send your address to IR. M. IK IEII, IG THREE RIVERS, WICHIGAN.

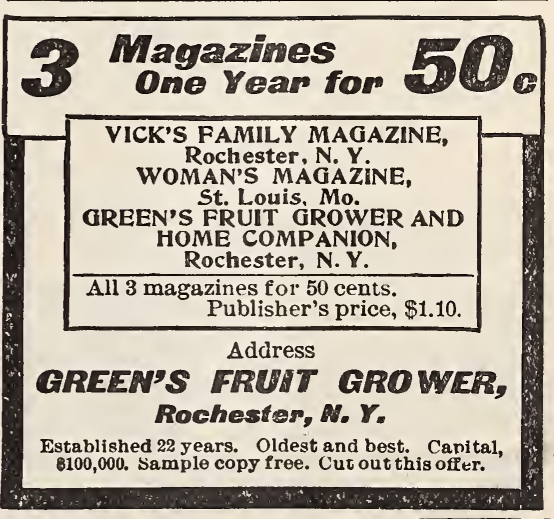

The Greider Strains, flfty of them, are bred to make prize winners. Very low prices on birds and eggs, considering quality. Elegant 1903 catalogue sent postpaid for 10 cents. Write to-day.

B. H. GREIDER, RHEEMS, PA. 


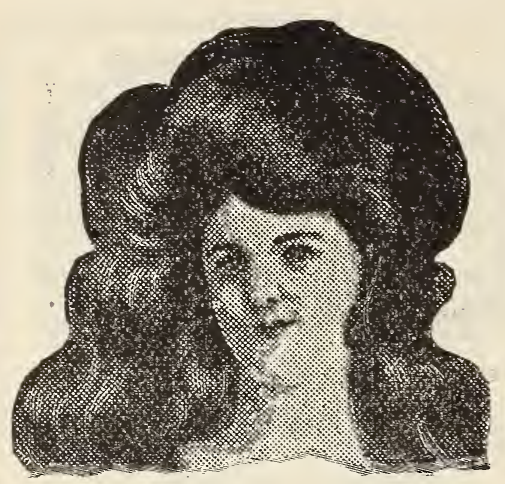

\section{Her Marvelous}

\section{Growth of Hair.}

\section{FREE TO ALL}

a trial package of a new and wonderful remedy mailed free to convince people it actually grows hair, stops hair falling out, removes dandruff and quickly restores luxuriant growth to shining scalps, eyebrows and eyelashes. Send your name and address to the Altenheim Medical Dispensary, 7616 Foso Building, Cincinnati, Ohio, for a free trial package, enclosing a 2-cent stamp to cover postage. Wiite to-day.

\section{Model Dandruff Cure and Hair Tonic}

I

S FREE from alcohol and poisonous drugs which are injurious to both hair and scalp. It is prepared by a man with 20 years' experience in hair dressing. He has made the hair and scalp a special study, and we guarantee the Model to cure Dandruff, Falling Hair, Itching Scalp, Eczema and all scalp diseases. To convince you of its merits we will send jou a full pint prepaid for 25 cents, and if it don't do you more good than all the tonic you ever used, we will refund your money. Agents wanted. Address

MODEL TOILE'T CO.

Box 340, springfield, Ohio.

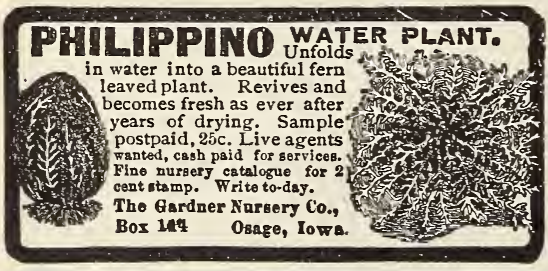

THE FLORAL WORLD is positively the best floral magazine ever published. I am an amateur but I know what I am talking about.

CARRIE LARUE.

West Virginia.
PALMS FROM SEED.

A few years ago I sent for the seed of five different varieties of palms. When the seed arrived I soaked them in warm water for forty-eight hours. In the meantime I prepared a box with soil composed of one half sand, the other half good, rich, garden soil. I planted my seed in rows and kept the ground moist. Every morning I. would look for some sign of life, but six weeks or more passed before my labor was rewarded: Then a filifera seed sent up a green sprig. Months passed and then the seeds in two other rows sprouted forth, but picture my dismay -they all appeared alike. Yet I had patience and transplanted them into separate pots and always kept the soil moist. It was nearly two years when the true characteristic leaves showed themselves. Today I have three varieties of palms, filifera, pheonix and the latana borbonica. These plants are beautiful, and seldom, if ever, are seen more splendid specimens of these varieties.

"SChUBERT."

Ohio.

[Palms can easily be grown from seed in the manner which you describe. The difficulty is generally to obtain fresh seed that will germinate. Many persons have experienced your disappointment in confusing the embry and character leaves ].

\section{KEEPING UP A SUCCESSION OF BLOOM.}

Wishing to stimulate a clump of peonies to produce the largest flowers possible next spring, I covered the earth thickly with stable manure, watering thoroughly through August and September, thinking the liquid would be utilized in time to produce extra strong crown buds before freezing weather. On opposite sides grew white perennial phlox and larkspur. These received full benefit of the manure and watering. The phlox being four feet

(Concluded on page 19)

Cancer Cured by Anointing with Oil.

A combination of soothing and balmy oils has been discovered which readily cures all forms of cancer and tumor. It is safe and sure and may be used at home without pain or disfigurement. Readers should write for free book to the originators, whose Home Office address is Dr. D. M. Bye Co., Drawer 505 Indianapolis, Ind. 
(Concluded from page 18)

high had immense bloom panicles which continued to push fresh flowers and formed long-stemmed panicles below the first. I broke out the older ones to prevent their seeding. The side shoots bloomed even prettier than the first, and many of them were used for cut flowers. New foliage and branches of bloom formed down the entire length of the stalk, continuing full until frost.

The larkspur had already bloomed twice and was not permitted to form seed, now put up new growth stronger than before, with larger flowers, and now, November fifteenth, is three feet high, full of bloom, with still another set of younger stalks crowding up full of unopened buds. There are many other plants, both annuals and perennials, which may be made to bloom continuously by this same treatment.

\section{Indiana.}

Sarah A. Pleas.

[You speak of larkspur in bloom November 15 th, but it was a stranger sight to see in Ohio, late in November, geraniums, salvias, cosmos and other equally tender plants in bloom and weighted down with snow].

\section{CINERARIAS-A LOVELY WINTER FLOWER.}

I like to try something new every spring. Last winter I saw the beautiful Cinerarias and made up my mind I would try some. I was told they could not be raised except in a hothouse, but I got a package of seed, sowed them in on top of some fine soil, in a shallow cigar box, covered it every morning for an hour with a wet cloth and set it in the morning sun on the window sill. They soon came up and when they had two or three leaves I transplanted them into a larger box, and later transplanted them into pots, keeping them in a shady place during the summer. I raised fourteen nice thrifty plants, some of which are now in bloom, others budding. I think I will have a continuous bloom through the winter. I feel that they are repaying me fully for their care, with their beautiful flowers of white and rose, purple and blue, with dark cen-

\section{Catarrh, \\ Foul Breath.}

If You Continually K'hawk and Spit And There is a Constant Dripping

From"the Nose into the Throat, If You Have Foul, Sickening Breath, That is Catarrh.

\section{Large Trial Package Free-Quickly Cures.}

Any person having catarrh always has a bad breath. The sense of smell and taste are nearly always totally destroyed in time so that the person who has catarrh does not realize how loathsome their disease is. They continue their K'hawking$\mathrm{K}$ 'hawking and spitting and spitting about promiscuously until they are shunned by everyone, and the sight of them is enough to make a well person sick.

Gauss' Catarrh Cure gives wonderful relief, especially in those chronic cases where the mucus drops down the throat and lungs, sickening the stomach, and leads to many diseases, including Consumption.

Catarrh is a deep-seated disease, and local applications, inhalations, sprays, ointments or salves will do no good. A large trial package mailed free that will convince you. Send name and address at once to C. E. Gauss, 797 Main St., Marshall, Mich.

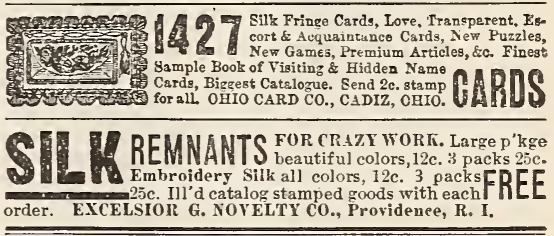

ter. Try some Cinerarias, dear sisters, they are lovely flowers.

Ohio.

Mrs. Marie Dykema.

[Your success with cinerarias in the house is rather unusual, as the conditions in the average house is not usually of the best for the plant. The kitchen, with its humid atmosphere, is probably the best place to start plants of this natnre].

\section{TO WOMEN WHO DREAD MOTHERHOOD!}

\section{Information How They May Give Birth to Happy, Healthy Children Absolutely} Without Pain-sent Free.

No woman need any longer dread the pains of child-birth; or remain childles.i. Dr. J. H. Dye has devoted his life to relieving the sorrows of women. He has proved that all pain at childbirth may be entirely banished, and he will gladly tell you how it may be done absolutely free of charge. Send your name and address to Dr. J. H. Dye, Box 137*Buffalo, N. Y., and he will send you, postpaid, his wonderful book which tells how to give birth to happy, healthy children, absolutely without pain; also how to cure sterility. Do not delay but write to-day. 


\section{ASTHMA} CAN BE CURED BY

\section{THE Kola Plant}

A New and Positive Cure for Asthma has been found in the Kola Plant, $\mathbf{a}$ rare botanic product of West African origin. So great are the powers of this now remedy that in

the short time since its discovery it has come into almost universal use in the Hospitals of Europe and America for the cure of every form of Asthma. The cures wrought by it are really marvelous: Among others Mr. C. B. Slade, Los Angeles, Cal., writes March 8, 1902, that Himalya saved his life, and through his recommendation thirty-five or forty others have been cured by it. Mr. W. O. Coblentz, No. 7 La Salle St. Cleveland, O., writes that he suffered for years until Himalya cured him. Physicians and change of climate did him no good. Mrs. Lidelle Hodgkins, Old Town, Me., writes that Asthma was her worst enemy, but Himalya cured her completely. Mr. Alfred Lewis, editor of the Farmers' Magazine, Washington, D. C., testifies that after eight years continual suffering, especially in Hay-Fever season, Himalya completely cured him. Hundreds of others give similar testimony of their cures of Asthma of five to fifty years' suffering by this wonderful new remedy. If you suffer from Asthmain any form, in order to prove the power of this new botanical discovery, we will send you one trial case by mail entirely free. It cost you absolutely noth1ng. Write to-day to the Kola Importing Co., No. 1164 Broadway, New Fork.

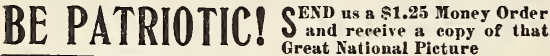

OUR PRESIDENTS, Size, I8x24 inches, and Success or Woman's Home Companion, one year. Should be in every Patriotic Home in the land. Seud $2 c$ stamp and list of papers you take, or intend to get and we will show you how you can get this Beautiful Photogravure FREE! Picture at once, only 50c, postpaid. We furnish any periodical. Write us. The E. E. Shuirr Periodical A geney, Springfield, Ohio

\section{A DUTCH PICTURE}

Artistic and beautiful with broad lines and bright colors. IN A GREEN FRAMI

of wood, resembling flemish oak, dull finish, 10x12 inches. SENT FREE

to all who will send us $75 \mathrm{c}$, to pay for packing, delivery and express charges. Our Home art Catalogue free to all for the asking.

FARWIN MANUFACTURING CO.

Dept. I. Chicaso, Illinois.

\section{Free Rupture Cure}

If ruptured write to Dr. W. A. Rice, 1556 Main St., Adams, N. Y., and he will send free a trial of his wonderful method. Whether skeptical or not get this free method and try the remarkable invention that cures work. Write to-day. Don't wait.
DRAINAGE-RUST.

Nearly two-thirds of the trouble with plants may be traced to bad drainage. Plants taken from out doors shed all their leaves during the winter, so if you get a dust-pan of leaves now and then don't be alarmed. If new buds and shoots dry up, the air is too dry, which may be remedied by placing a small dish of water on the stove.

When you have a plant, the soil of which is sour, give better drainage and water sparingly. Tin cans may be drained by punching holes around the bottom of can and setting in saucer. I have heard people say that cold water would not kill lice, but it will. Don't take an infected plant and shower it once, but keep it up. My advice is to shower all of your plants frequently.

Rust is the worst enemy of the begonia, which may be remedied by cutting it back, leaving but two or three buds. When a rusty leaf appears, pinch it off. In this manner it will be made presentable, at least, whereas it would have been dead if you had let it alone.

$$
\text { "HAyseed." }
$$

[ Why not discard tin cans altogether, and use regular flower pots? Their porous nature will do much toward preventing soggy, sour soil, and a hole for drainage is already provided, Pots cost comparatively little now, and certainly far excel cans in point of attractiveness ].

\section{ARTIFICIALLY COLORED FLOWERS.}

To color scarlet or pink, dissolve red aniline in water to about the transparency of claret and place the stems of lilies of the valley, narcissi, daffodils, hyacinths, tulips and lilies in it and let them remain until the required depth of shade has been obtained. To color blue, use indigo carmine; combine the two and a beautiful mixture in mottled effects is the result. By leaving the stems in the red for some time, then setting in clear water for a while, then placing in the blue dye, a large.white lily with a long stem may

(Concluded on page 21) 


\section{(Concluded from page 20)}

easily be made to display the national colors. By very careful manipulation several colors may be induced to stripe the petals. To secure a more lasting coloring, raise some flowers very carefully from the earth, put the roots and part of the stems in the dye and when colored replant in a pot and keep from direct sunshine.

Abbie J. Fayman.

\section{Indiana.}

[ The experiment referred to is, we must admit, quite interesting, especially so with the coarsestemmed calla, but it seems almost a pity to spoil the natural beauty of the flower, for the color is not so diffused as to look really natural].

\section{HOW TO SELECT HYACINTHS.}

Most novices at bulb culture are at a loss to know which varieties to choose out of the many hyacinths offered.

I have adopted the following plan. First, I decide how much money I propose to spend and what colors I desire, then I take my bulb catalogue and study the various kinds.

For light pink, Horma is my choice, and for light blue, Regulus, both of which have large spikes and bells, and a delightful fragrance. I consider Regulus the finest hyacinth I grow.

Gertrude is my choice for dark pink and is a free and early bloomer.

When I have no preference in white, yellow and dark blue, I select those marked "early" and "medium" and described as having large spikes and large bells. I do not like those so well that have compact spikes.

The different kinds of Roman hyacinth are all good, but I prefer the white. I always order several white and plant three in a six-inch pot, or more in a small grape basket. Either way is very satisfactory, those in the basket, of course, producing a greater mass of bloom.

\section{Michigan. Miss CorA B. GibBs.}

[The varieties of hyacinths you mention are a.11 first-class. Fortunately the better sorts are easier for the importer to obtain generally than the poorer ones. The colored Roman hyacinths are really small Dutch hyacinths, or "Dutch Romans"].

\section{To Cure Drunkards.}

\section{A Simple Way to Cure any Drunkard Against His Will.}

By using the new odorless and tasteless remedy which is placed in the coffee or food any drunkard can be cured. Anyone can use it without the drunkard ever knowing it. It does its work so

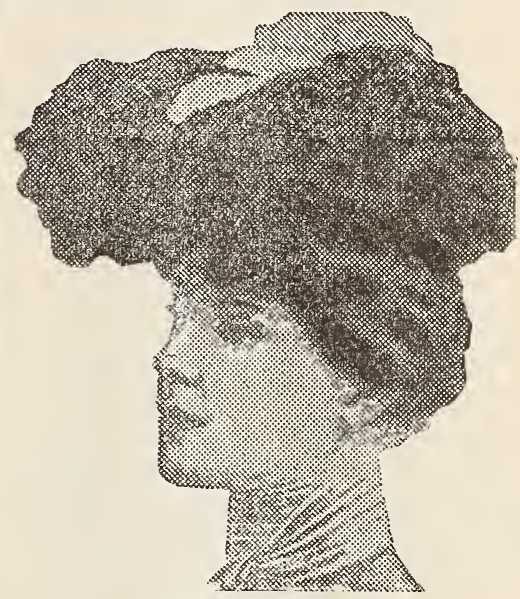

MRS. SAMTEL BOYD.

silently and surely that while the devoted wife, sister, daughter or mother looks on, the drunkard is cured even against his will.

Every person who has a loved one who is a slave to drink ought to give them this remedy at once.

Mrs. Samuel Boyd says: "With Golden Specific I cured my husband of drinking. I put it in his coffee and after that he could not drink liquor or bear to be where he could smell it."

Write to Dr. J. W. Haines, 4262 Glenn Building, Cincinnati, Ohio, and he will send you a free trial package which will show you how simple it is to use and how positive is its cure.

\section{Self = Hypmotic Healing}

I have made a late discovery that enables all to induce the hypnotic sleep in themselves instantly at first trial, awaken at any desired time and thereby cure all known diseases and bad habits, control their dreams, read the minds of friends and enemies, visit any part of the earth, solve hard questions and problems in this sleep and remember all when awake. This so-called Mental Vision Lesson will be sent to anyone for only 10 (silver). Sold on credit, Actually enabling you to do the above before any charge whatever.

Prof. R. E. DUTTON, Dept P W., Lincoln, Neb., U. S. A.

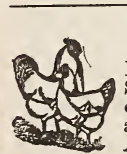

CIIT RATES on all varieties Eggs and UUT RATES POULTRY. All varieties Fancy Pigeons and Belgium Hares Send for rates and for 60-page book, which one and all; each and everybody bargains are included. All for $10 \mathrm{c}$. Address, J.A.HERGEY, Telford, Pa. 


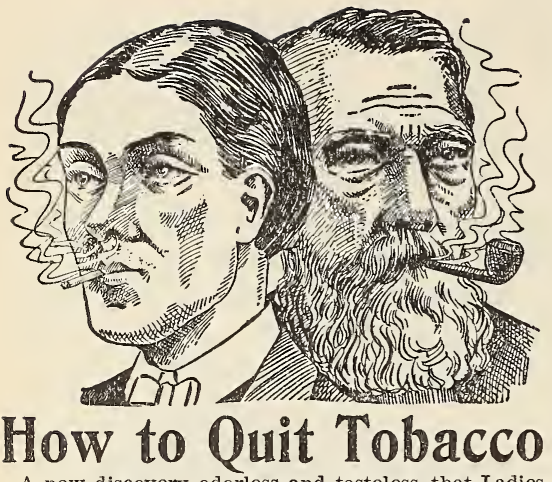

A new discovery odorless and tasteless, that Ladies can give in coffee or any kind of food, quickly curing the patient without his knowledge. Anyone can have a free trial package by addressing Rogers Drug \& Chemical Co., 3789 Fifth and Race Streets, Cincinnati, ohio, and easily drive foul tobacco smoke and dirty spittoons from the home.

\section{BE BEAUTIFUL}

Dr. Bidaman's Safe Arsenic Complexion Wafers remove pimples, freckles, blackheads, and all blemishes of the skin. Make the complexion clear, transparent, rosy smooth and soft. Used by noted beauties and actresses. Sample box sent on receipt of 25 cents in stamps. Correspondence absolutely confidential.

DR. ISRAEL BIDAMAN,

Established over Thirty Years. NEW YORK.

ANY LADY Can Fasily Make weekly by representing us in her 10 colly and as the position is pleasant and profitabie the year round wo will gladly send particulars free to all. Even your spare time is

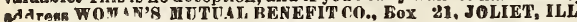

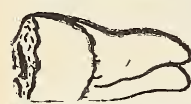

For 25c. K. \& S. Tooth Filler fills the teeth for 6 months. Stops toothache instantly and prevents decay. Manufacturer, GEO. R, BAKER, Registered Pharmacist.

RANDOLPH \& CIARK ST., CHICAGO.

WOMEN TO DO SEWING Binding Spec100. Can paid. Send addressed reply envelope for full particulars. Universal Co., Dept. 214, Walnut St., Phila., Pa. and Liquor Habit Cured without inconvenience or detention from business. Write THEDR.J.L. STEPHENS CO., Dept. A.9, Lebanon, Ohio.

YATED Ladies to embroider doilies and centerpieces at WATED home; steady work; all materials furnished; highest prices paid; no canvassing. Send stamped envelope to ELY NOVELTY CO,, Dept. A. D., ELY B'LD'G, CHICAGO, ILI.

DIN to do piecework at their homes. We furnish all $2 A D C S$ material and pay from $\$ 7$ to $\$ 12$ weekly. Experience unnecessary. Send stamped envelope to ROYムL CO., Dept. F. W., 34 Monroe St., Chicago.

CDEC Clairvoyance. If sick or ailing send now FREE name, age, sex, lock of hair and 2 stamps to Dr. D. Hinkly, $x-28$, Grand Rapids, Mich.

F0R CALE Sewing Machine Needles, Shuttles and parts.

\section{BEGONIAS FOR THE WINDOW GARDEN.}

In my opinion begonias excel all other plants for the window garden. The rex are so gorgeous in size and coloring that flowers are not needed to enhance their beauty, yet must of them bloom well. I have had flowers on rubella for a full month without fading.

The fibrous sort show an infinite variety of leaf in shape, color and size. Multifloree has a tiny, glossy leaf, scarcely a half inch long; vershafeldtii has enormous leaves a foot in length by nine inches wide on strong panicles eight inches long, with a stem five inches in circumference. The shapes are variousheart shaped, round, toothed, plain, spotted, red lined. Such diversity cannot fail to be pleasing. Pictaviensis has red leaves with a texture like plush. Beside it in my window rubra's smooth green leaves look severely plain. But a wellgrown plant of rubra in bloom is worth seeing. Try to make everyone a specimen plant. Good drainage, ample root room, leaf mould, frequent turning to the light to secure uniformity of contour will accomplish it. The long-stemmed sorts look well on brackets each side of the window. The light filters through the lovely leaves, bringing out their rich tints.

Delaware. MRs. L. W. BALdwin.

[ Is it possible that your collection of begonias does not contain the beautiful variety, manicata aurea, the one having the large green leaves with golden blotches similar to the farfigium grande? You do not mention it. How does that other magnificently colored sort, Louise Closson, do in your window?].

\section{EXTEND THE SWEET PEA SEASON.}

Do the lovers of sweet peas know how to have an abundance of the fragrant blossoms for the longest time possible? As soon as I can work the ground I dig a trench 18 inches wide by 18 inches deep and as long as wanted, and fill it in with loose (not too rich) soil and do not use soil that will pack, for if too rich, in hot weather it will cook the vines, unless you are fixed to give plenty of good soft

(Concluded on page 23 ) 
(Concluded from page 22)

water. Then open row in center $1 \frac{1}{2}$ inches deep, plant good mixed seeds and cover loosely, not trying to pack. Now lay an 8-inch board along each side of row, with a 2-inch space left open for the plants to come up and grow through. As soon as the plants are up, set posts at the ends of the row, get galvanized netting with 2-inch meshes and 60 inches wide, and stretch tight over the row of sweet peas. At first they have to be trained some but later they take care of themselves and all they need is to have some one keep the blossoms cut, as they bloom best when the blossoms are cut frequently. My row this year was 30 feet long and bloomed from May 1st to October 1st, five months of perpetual sweetness, which I gave to all comers, and on seeing the row, one and all exclaimed: "Oh! what a beautiful sight."

\section{Missouri.}

G. E. Locker.

[ We have few annuals that give so much pleasure to such a large number of people each year as the Sweet Pea. So much time has been spent in the selection of the best varietiesaand the culling out of undesirable ones that much of the mixed seed now sold is really very fine].

\section{FOR ADMIRERS OF OLEANDERS, HI- BISCUS AND PLUMBAGOS.}

Without the slightest care they grow here in Florida to become large trees. Beginning to bloom in March, they are literally covered with flowers all summer. I have white and pink. This month they commence resting, but stay green all winter. I agree with Mrs. Moore about the beauty of hibiscus. I have a tall one by my kitchen, and how I enjoy looking at it when I stand by my sink washing dishes three times a day. It never fails to have some flowers open every day, nodding their handsome faces at me and making me forget so-called drudgery.

In my front yard are two magnificent plumbagos. They also love sunshine every day the whole year round, and as they pretty near have their own way about

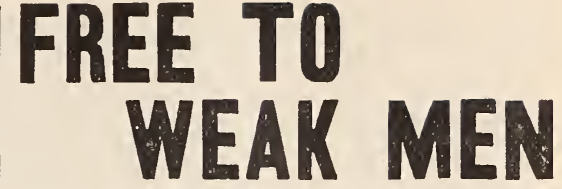

A Discovery of a Remedy Has Been Made That Restores Lost Manhood and Gives Man the Vitality of a Lion.

\section{One Week's Trial Package Sent Free to All Plen who Write for it.}

Regenerative Tablets is the only recognized permanent cure for Lost Manhood in any form. It is scientifically prepared by some of the best chemists in the world. This firm gives a legal guarantee that Regenerative

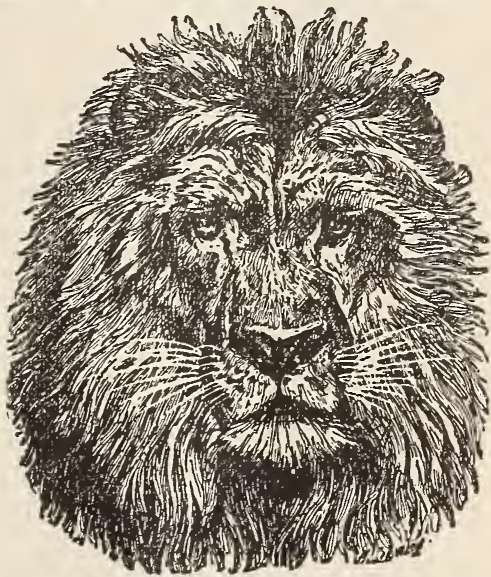

Tablets will cure every case of Lost Manhood, Spermatorrhœa, Varicocele or weakness of any nature of the nerve or sexual organs. There is but one test of a genuine medicine and that is the results which are obtained by its use; if it cures the disease for which it is prepared it is a true remedy. This is the test by which the Fallopia Lynn Co. wish their remedy to be tried, therefore they give one week's treatment free. After using it the sufferer will find new vigor in his organs; new force in his muscles; new blood in his veins; new ambition; a new man in vitality, health and appearance. Regenerative Tablets has a peculiarly grateful effect and the patient feels the benefit afterits first day's use. It goes direct to the seat of the trouble, no matter the age of the sufferer nor of how long standing his affliction, unless Epilepsy or Insanity has been reached, giving strength and development where $1 \mathrm{t}$ is needed. This marvelous remedy banishes all feelings of bashfulness or blushing; cures all the ills and troubles that come from early abuse, excess or overwork and business cares, all of which result in premature loss of strength and memory, emissions, impotency and varicocele. Fallopia Lynn Co. makes no restrictions, every person who writes will be sent postpaid a week's treatment absolutely free, carefully wrapped in a plain package with no advertising on it to indicate what it contains. Write today to the Fallopia Lynn Co., 428 Pozzonl Building, St. Louis, Mo., and recelve the week's treatmen $t$ absolutely $f$ ree, also their book which is free and sent with the free treatment which explains how to take the treatment in private and cure yourself at home. 
DARKEN YOUR CRAY HAIR

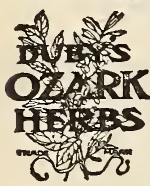

DUBY'S OZARK FERBS restoregray, streaked or faded hair to its natural color beauty and softness. Prevents the hair from falling out, promotes its growth, cures and glossy and healthy appearance. IT WILL. NOT STAIN THE SCALP, is not sticky or dirty, contains no sugar of lead, nitrate silver copperas, or poisons of any kind, but is comONLY 25 CENTS TO MAKE ONE PINT will produce the mL 2 CENTS TO MAKE ONE PINT wiry hair, and bring back the color it originally was before it turned gray. Fuli size package sent by mail for 25 cents. OZARK HERB COMPANY, St. Louis, Mo,

\section{A GRAND INVENTION!}

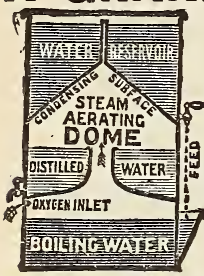

Famous Puritan Water Still. Over 72,000 already sold. Placed over the kitchen stove, it purifies the foulest water. Re. moves every impurity. Furnishes delicious distilled Pure Water. Beats filters. Saves lives and Dr. bills. Prevents Typhoid Malaria, other fevers, sickness. Only safe water for children. Cures disease. Write for Booklet and testimonials free. Agents Wanted-Men and Women-Big Wages. Harrison Mfg. Co., 14 Harrison Bldg., Cincinnatl, 0 .

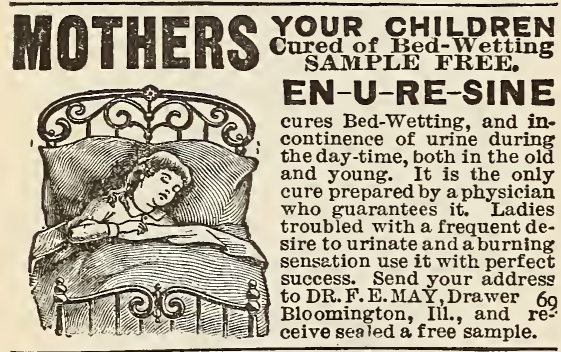

\section{$33 \%$ DIVIDEND}

paid by the Mexican Plantation Association, 1602 Title and Trust Building, Chicago, Ill, Oldest of its kind in Mexico. ESTABLISHED 1897. HaS 6,000 shares, or acres, planted to permanent crops, rubber, coffee and $\nabla$. nilla. The Association's contract is like an insurance policy-in case of death the money is refunded. 38 deaths have occured since 1897. These shares will now be resold. For full particulars, address as above.

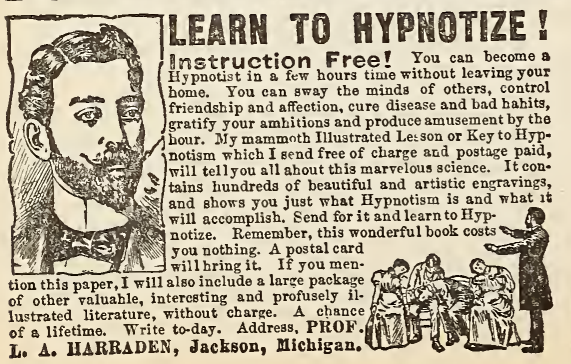

(Concluded from page 23)

that, they are perfectly beautiful, always covered with their sweet blue flowers. On rainy days their lovely heads are drooping, only to look more bright and beautiful as soon as the sun strikes them again. Their measure this summer was twelve feet in circumference. To trim them symmetrical twice a year is all the care I give them.
Florida.
Mrs. C. F. Fischer.

[It is strange how few grow the Hibiscus as a tub plant. It is well worth more extensive cultivation than is now given it. A well-grown specimen in a tub, when in flower, presents a magnificent appearance].

\section{SCARLET SAGE AND NASTURTIUMS.}

This summer I had a box of scarlet sage in full bloom when the first cold nights came, and truly it was a thing of beauty but not likely to prove a joy forever if left to the tender mercies of Jack Frost. Grandma proposed "covering it with her apron," but we carried it in and gave it the place of honor in a large east window. The box looking bare on top, I transplanted two large hybrid nasturtiums in it that had bloomed finely on the lawn all summer. The result was a perfect bank of rich nasturtium blooms, nearly reaching the lowest blooms of the sage. After the sage seeded, I broke off the dry blossoms, and now it is coming into bloom again. The nasturtiums, not to be out-done, are also full of bloom and buds after two weeks' rest. I also tried cuttings of each, just sticking them into pots containing other plants and both are in bloom.

\section{Missouri. Mrs. E. C. Curtis.}

[ If you are an admirer of the salvia or scarlet sage (and everyone is), you will be interested in a new dwarf variety growing about half the height of splendens, the common variety, and really even more profuse in its flowering].

\section{EVERY LADY READ THIS.}

Years ago when I was a sufferer, an old nurse told me of a wonderful cure for Leucorrhea, Displacements, Painful Periods, Lterine and Ovarian troubles. It cured me in one month. It is a simple harmless lotion that can be prepared by any one having the recipe. I will send it Free to every suffering sister who writes to me. Address Mrs. A. L. Hudnut, South Bend, Ind. 


\section{VEAK MAN}

\section{A Wide-Open Letter to that Great Army of Weak Men Who Have Been Hoodwinked and Defrauded by the Infamous Rascals Who Disgrace the Medicine Business.}

MY DEAR BRothers: - More than 260,000 permanent cures during the past four years prove that my "Wonder-Workers" are a Godsend to weak men everywhere. There is not a case of Men's Weakness or Nervous Troubles of any kind anywhere on earth (no matter whether caused by overwork, abuse or worry; and no matter whet her the man be old or young) that "Wonder-Workers" will fail to cure quicker and at less expense than any other remedy made anywhere in the world, if simply used (at home, at your work) one tablet at a dose three times a day. They cured me.in less than one month's time, at the age of forty-four years, when I, like you, lacked that vitality without which a person is a man only in name, and after I had been nearly ruined by the frauds and

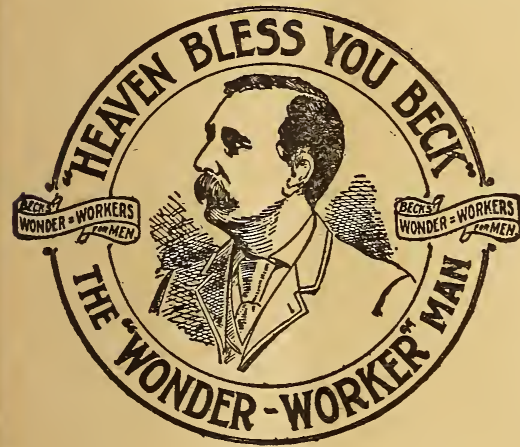

fakirs who disgrace the medicine business. Bear in mind that I am the only man in the world in the business who has solemnly sworn that the medicine he sells cured himself, and that the names of all who buy it will be held sacred forever. Cures Varicocele.

I am the same Geo. S. Beck, who is hated by every Free Sample schemer, Free Prescription fakir and C. O. D. fraud in America, because of the manner in which I have exposed their infamous schemes. Their only object in making "Free" offers is to get the names of men who are vitally weak, so that they may harass them with their impudent letters and lying, filthy circulars; and I now again challenge all of these poison distributors to thoroughly sift and test my charges of villainy and fraud in any court they may select. If you have had any dealings with them you know that my charges are true.

I beg to assure you on my honor as a man that no matter whether you are married or single, old, young or middle-aged; or no matter whether your weakness or nervousness is caused by overwork, too frequent indulgence in legitimate pleasures, the practice of secret vice or the excessive use of strong drink or tobacco, the use of my "Wonder-Workers" will search every nerve center of your body, renew every tissue, develop every organ, strengthen every muscle, invigorate every function, and bring to you a perfect and permanent restoration of nerve strength and manly vigor. The reason why "Wonder-Workers" do this is because they are a Pure Nerve Food and Tonic, and because they do not contain any phosphorus, or Spanish Fly, or any other of the poisons that make the vile nostrums sent out by the frauds and quacks so dangerous to human life. It is perfectly safe to use them at any time or under any circumstances, and their use will not fail to restore natural strength and vigor without stimulation in old or young.

Because of the wonderful merit of my "Wonder-Workers" medicine, I have built up the largest mail-order medicine business in the world in less than four years, and have been compelled to remove from my old quarters at 420 South Market St., this city, to 44 and 46 East Main Street, the largest business building in Springfield, in order to properly conduct my enormous business. If you order "Wonder-Workers,"mention this paper, the publisher of which is hereby authorized to publish me as a fraud and scoundrel if I fail to do exactly as I agree with any of its readers.

The price of "Wonder-Workers" is only One Dollar per box, always cash with order; by express at your expense. It will cost 25 cents to lift them from express office. If you send $\$ 1.15$ to pay packing and postage, I send them by mail prepaid, thus saving you ten cents. If you have any doubt about me, write to any Commercial Agency, the First National Bank of this city, (the bank of which Hon. Asa S. Bushnell, Ex-Gov. of Ohio, is President,) or to any of Your friends in Springfield.

\section{GEO.S. BECK, $\begin{gathered}44 \text { and } \\ \text { Main Street, }\end{gathered}$ Springfield, Ohio.}




\section{HEALTH}

\section{STRENGTH}

A N

BODILY

VIGOR

FOR

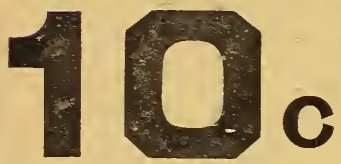

TRADE

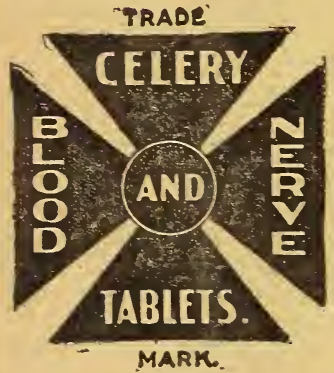

SLEEPLESS NIGHTS VANISH

NO MORE DULL DAYS

BE WELL FOR
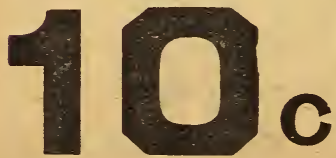

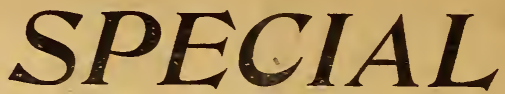

JANUARY

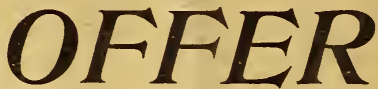

50 Cents Worth for 10 Cents

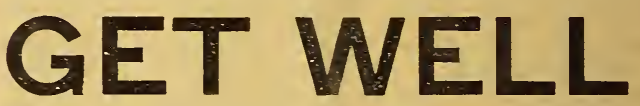

AND STAY WELL. OUR

\section{CELERY, BLOOD}

\section{and NERVE TABLETS}

are not a cure-a11. They are purely vegetable. They are GUARANTEED to Purify the Blood and CURE all forms of disease arising from a poor and unhealthy condition of the blood, such as Pale and Sallow Complexion, Loss of Appetite, Lack of Ambition, Sleeplessness, Muscular Weakness, Neuralgia, Partial Paralysis and Nervous Affections of every description.

Celery Blood and Nerve Tablets are an infallible remedy and cure quicker and at less expense than any other remedy on earth.

This introductory offer is only good until the first of February. Ten cents only covers the cost of packing and postage. Can you afford to be sick when such an unprecedented opportunity to get well, or prepare for the dangerous consequences of cold weather, overwork, worry, indiscretions, etc. is offered jou for the trifling sum of ten cents? Address,

Dational Drug and Chemical @ SPRINGFIELD, OHIO. 


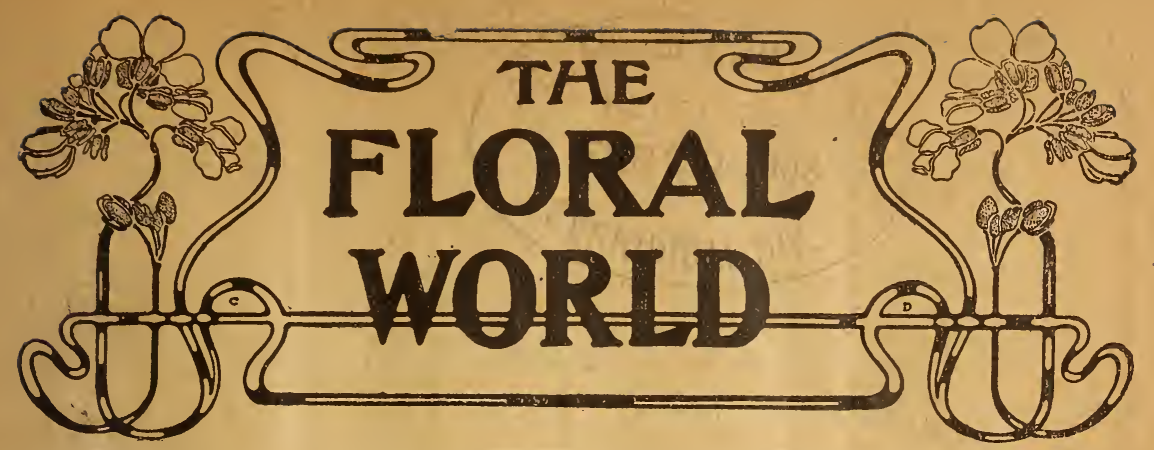

Vol. II. No. 5. Springfield, Ohio, February, 1903. 25 Cents a Year
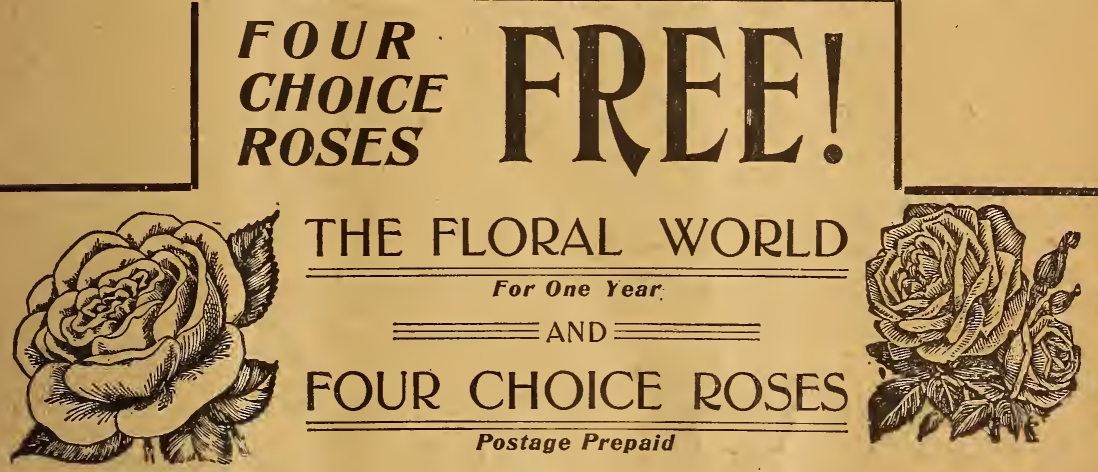

Will be Sent to Anyone Remitting us Only 25 Cents-the Regular Subscription Price-for The Floral World.

We believe this offer is so attractive and liberal that everyone of our present readers will bring it to the attention of his friends. "The Floral World" is a magazine that makes friends wherever it is read, but there are thousands of flower lovers who do not know of its existence. Many of your friends, perhaps, do not. Tell them about it. Show them this offer. They will thank you for doing so.

\section{$\overline{\bar{\equiv}}$ The Roses Will be the Following Varieties: $\bar{\equiv}$}

GRUSS AN TEPLITZ-A Great New Red Rose.

It is a superior Rose for general planting. A perfect sheet of richest crimson-scarlet all summer. We know of no Rose that has such bright colors in it as this variety, with its rich velvety-crimson overlaid with the brightest penetrating scarlet. It is very free in bloom and a strong, vigorous grower. IVORY-Ivory White.

A most beautiful Rose, pure ivory white in color. A strong grower, excellent for general planting and a great favorite.
ISABELLA SPRUNT-Canary Yellow.

A very free bloomer, literally lavishing its large, beautiful buds. Very fragrant, a strong grower requiring little attention.

\section{MAMAN COCHET-Rich Pink.}

The color is a deep, rosy pink, the inner side of the petals being a silver-rose, shaded and touched with golden-yellow. We pronounce this the finest Rose by far that has been introduced from France in the past five years.

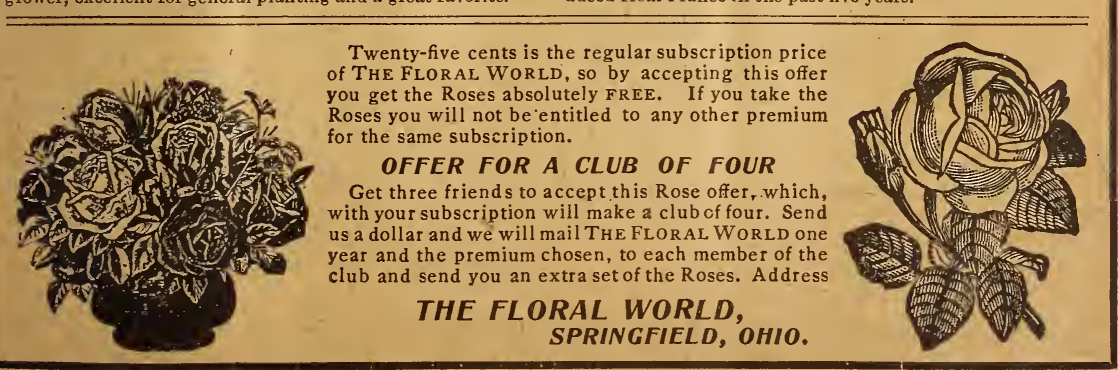




\section{A NEW

FIRST PRIZE, \$10,000; SECOND PRIZE $\$ 3,000 ;$ THIRD PRIZE, \$1,000

\section{It Costs You Nothing to Guess. You May Get a Prize}

Every subscriber to THE FLORAL WORLD will have an opportunity to share in these magnificent prizes if he wishes to participate in the Great Educational Contest in which these prizes are given.

The subject matter of this great contest is the total vote cast for Governor in the States of Ohio, Massachusetts and lowa on the third day of November, 1903.

Every person interested in the science of Government should be interested in the election in these three States, as much valuable information can be gained by a study of the political conditions involved in these elections.

\section{GONDITIONS OF THIS GREAT GONTEST:}

Every subscriber who remits 25 cents, the regular subscription price (a year's subscription) to THE FLORAL WORLD will receive a certificate that will secure for him any prize which his estimate entitles him to claim.

When you send in your subscription, also send your estimates of the total vote for Governor in the three States. Write your name, address and estimate in the subscription blank. below and mail it to THE FLORAL WORLD, Springfield, Ohio.

The contest will close at midnight. November 2, 1903, and no estimate received after that hour will be allowed. The official certificates of the Secretaries of the three Siates, showing the total vote for Governor, will determine who are entitled to the prizes, and the awards will be made by a disinterested committee of prominent judges just as soon as the official figures can be obtained. Read the special prizes for those who guess early. It will pay you to guess now. The Press Publishing Association has already deposited the $\$ 40,000$. with the Central Savings Bank, Detroit, Mich., for the payment of the prizes.

CERTIFICATE OF BANK PRESIDENT

I hereby certify that the Press Publishing Association has deposited $\$ 40,000$ in the Central Savings Bank, Detroit, Mich., for the express purpose of paying the prizes to those making the nearest correct estimates of the total aggregate vote cast for the office of Governor in the States of Ohio, Massachusetts and Iowa, on the 3rd day of November, 1903, and that this fund can be used for no other purpose.

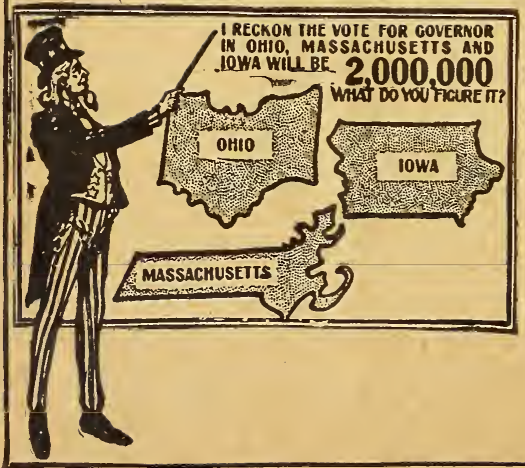

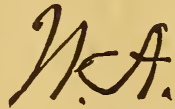

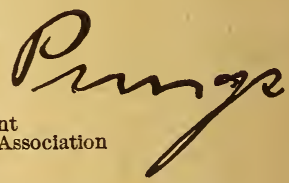

\section{VALUABLE INFORMATION.}

To aid in forming your estimate we furnish the official figures showing the vote for Governor in each of these States for the past ten years, as well as to give the total vote for the three States combined. The total vote for the three States is found in the right hand column.

Ohio Mass, Iowa Total 1801...795,629 $\quad 321,650 \quad 420,212 \quad 1,537,491$ $1893 \ldots 823,658 \quad 365,012 \quad 415,806 \quad 1,604,476$ $1895 \ldots 837,466 \quad 328,121 \quad 401,345 \quad 1,566,932$ $1897 \ldots 854,986 \quad 269,795 \quad 438,292 \quad 1,563, v 13$ $\begin{array}{llll}1897 \ldots 854,986 & 269,790 & 438,292 & 1,563,073\end{array}$ $1901 \ldots 827,566 \quad 324,526 \quad 390,489 \quad 1,542,581$

What will be the total vote for Governor in these three States combined on the third day of November, 1903? Figure it out and send in your estimates. It may mean $\$ 10,000.00$ in cash to you. 


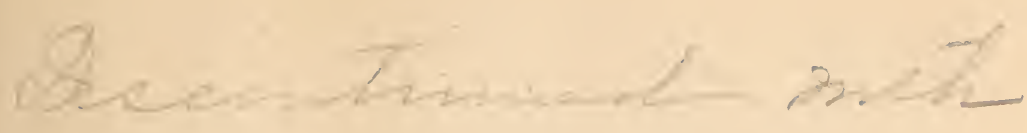

Hel- asene

Ongana flee $x \frac{1}{4}$ 



\section{Profit Sharing

\section{TWENTY SPECIAL PRIZES OF $\$ 1,000.00$ EACH FOR EARLY ESTIMATES}

\section{HERE IS THE LIST OF PRIZES.}

To the nearest correct estimator $\ldots \ldots \ldots \ldots \ldots \ldots \ldots \ldots \ldots \ldots \ldots \ldots \ldots \ldots \ldots \ldots \ldots \ldots \ldots, \ldots \ldots 00, \ldots \ldots \ldots$

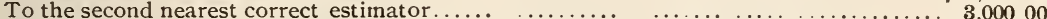

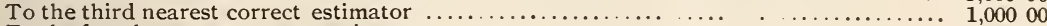

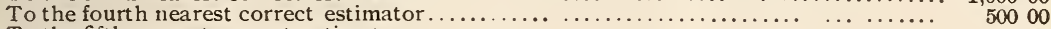

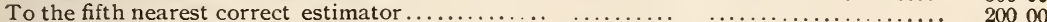

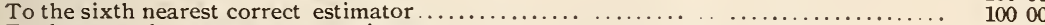

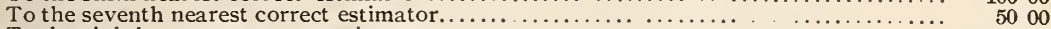

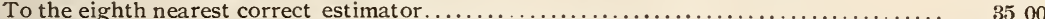

To the next twelve nearest correct estimators, $\$ 15.00$ each $\ldots \ldots \ldots \ldots \ldots \ldots \ldots \ldots \ldots \ldots \ldots . \quad 18000$

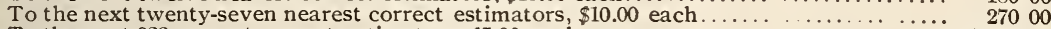

To the next 933 nearest correct estimators, $\$ 5.00$ each... . . . . . . . . . . . . . . 4,66500

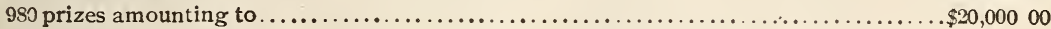

\section{The Following Special Prizes Will Also be Paid:}

For the nearest correct estimate received before Dec. $15,1902 \ldots \ldots \ldots \ldots \ldots \ldots \ldots \ldots \ldots \ldots 1,00000$

For the nearest correct estimate received on or after Dec. 15 and before Jan. 1, $03 \ldots \ldots, 1,00000$

For the nearest correct estimate received on or after January 1 and before January $15 \ldots .1,00000$

For the nearest correct estimate received on or after Jan. 15 and before Feb. $1 \ldots \ldots \ldots \ldots, 000,00$

For the nearest correct estimate received on or after Feb. 1 and before Feb. 15...... 1,000 00

For the next nearest correct estimate received on or after Feb. 15 and before March $1 . \ldots 1,00000$ For the next nearest correct estimate received on or after March 1 and before March 15. 1,000 00 For the nearest correct estimate received on or after March 15 and before April 1...... 1,000 00

For the nearest correct estimate received on or after April 1 and before April $15 \ldots \ldots \ldots \ldots, 00000$ For the nearest correct estimate received on or after April 15 and before May 1......., 1,000 00

For the nearest correct estimate received on or after May 1 and before May 15........ 1,000 00 For the nearest correct estimtae received on or after May 15 and before June $1 . \ldots \ldots \ldots . \ldots 1,00000$ For the nearest correct estimate received on or after June 1 and before June $15 \ldots \ldots \ldots, 1,00000$

Eor the nearest correct estimate received on or after June 15 and before July $1 \ldots \ldots \ldots \quad \ldots 1,00000$

For the nearest correct estimate received on or after July 1 and before July $15 \ldots \ldots \ldots \ldots 1,00000$ For the nearest correct estimate received on or after July 15 and before August $1.1,00000$

For the nearest correct estimate received on or after August 1 and before August 15. . . . 1,000 00 For the nearest correct estimate received on or after August 15 and before September $1 . .1,00000$ For the nearest correct estimate received on or after Sept. 1 and before Sept. 15....... 1,000 00 For the nearest correct estimate received on or after Sept. 15 and before Oct. 1...... 1,000 00

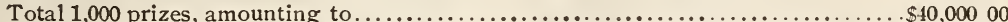

In case of tie or that two or more estimators are equally correct, prizes will be divided equally between them.

\section{OUIR SPECIAT OAREIRS}

One year's subscription for THE FLORAL WORLD and one estimate only 25 cents, provided no other premium is taken. Send your estimate when you remit and you will promptly receive a certificate which will secure for you any prize your figures may win.

If you wish more than one estimate, remit us only 20 cents for each yearly subscription and estimate after your first one. The extra subscription may be for yourself or for any of your friends. Always include your estimate when remittting. Address,

\section{THE FLORAL WORLD,}




\section{PREMIUMS FOR CLUB RAISERS Fine Collections of Roses}

The following offers of plant collections to club raisers are the most liberal we have ever made. The selections were made from catalogues of thoroughly reliable florists who will fill all our orders from regular stock. We guarantee safe delivery, with plants in good condition.

Any person accepting any of our combination offers of THE FLORAL WORLD and a premium may be counted in a club.

Premium 21

\section{Seven Fine Rose Plants}

\section{Given for a Club of Four Yearly Subscribers for THE FLORAL WORLD}

Marie Guillot - White; tinged with delicate shade of lemon; large, full and beautifully imbricated in form. One of the finest Tea Roses.

Pink Soupert-It is a cross between Clothilde Soupert and Lucullus, and may be said to be exactly identical with Clothilde Soupert, its progenitor, with the exception of foliage and color of flower.

Clothilde Soupert-This lorely Rose comes from tie Garden of Luxembonrg, France, and is undoubtedly the finest Rose of its class. The flowers are borne in clnsters, and are of large, round, flat form, with beautifully imbricated petals; perfectly full and double and deliciously sweet; color, beautiful pinkish amber or pale creamy yellow.

Climbing Marie Guillot-It is one of the most rapid growing and vigorous Climbing Roses; small plants making a growth of 10 to 20 feet in five months. It blooms continuously throughout the season, the first and every year.

Helen Gould-The strongest growing, freest blooming and hardiest Hybrid Tea Rose now known. The color is nnique, a very soft, intense carmine-crimson, with deeper shades in the depths of the petals. The profusion of bloom is truly marvelous, every shoot producing a flower.

Duchesse de Brabant-Few Roses equal this in freedom of flowering; fragrance or vigor; the flowers are rich and peculiarly flavored. Color, rose, heavily shaded with amber and salmon.

Mile. Francisca Kruger-One of the finest Roses in habit, color and general character. The flowers are large, full and fragrant, and the buds of elegant shape; color, rich, coppery-yellow. with shadings of perch-pink.

\section{Twelve Choice Rose Plants}

\section{Given for a Club of Six Yearly Subscribers for THE FLORAL WORLD}

Queen Olga of Greece-This Rose comes to us very highly praised. The color is light pink, shading deeper toward the center of the flower. The flower is very double, fnll and deep. Fine free bloomer and strong grower.

White Le France-Here we have a beauty-indeed. Identical with La France except in color. Pearly white, sometimes tinted with fawn.

Madame Joseph Schwartz-A lovely Tea Rose; extra large globular fiower, very full and sweet; color pnre white, tinged and shaded with pale yellow and rosy blush.

Johanna Wessenhoff-This is the finest grand bedding Rose. It is a deep, golden-yellow, and is snch a good bedding Rose that it is already called by some the "Bedding Perle." It", is certainly flne.

Mary Washington-The original Rose bush was planted by George Washington. It is a lovely Rose and usnally comes in large clusters of the pnrest white and very fragrant.

Golden Gate-A magnificent Rose, with large, full, finely - formed flowers. Bnds long and besntiful. Color, rich, cresmy-white, tinged with golden-yellow and clear rose.

Climbing Meteop-Is the acme of all red Climbing Roses. It is a free, persistent bloomer, and will make a growth of from ten to fifteen feet in a single season; in bloom all the time, as it is a true ever-bloomer.

Coquette de Lyon-Vigorous rapid grower and constant bloomer. Pnre canary yellow.

David Pradle-The flowers are prodnced in wonderful profusiun on long, straight shoots, deliciously fragrant and of the largest size, double to the center, and of most beautifnl form. The color is an exqnisite blending of lilac and rose, with a delicate, rich crimson center.

Empress of China-Here we have a Rose that blooms continuonsly for over seven months in the year. When it flrst opens the flowers are a beautifnl red, but soon; turn to a lovely light pink.

Gruss an Teplitz-One of the brightest colored Roses grown, when first opened it is dark rich crimson, quickly changing to bright scarlet shading to velvety, fiery red. Blooms continually.

Maman Cochet-This is a trnly grand Rose. It is a vigorous grower, with rich, healthy foliage. The flowers are extra large, very double, full and sweet; borne on long stems:-nice for cntting. Color, doep corsl-pink, delicately tiuted with silver-rose. Makes exquisite buds. 


\section{GRAND COLLECION}

\section{Sixteen Selected Rose Plants}

\section{Given for a Club of Only Eight Yearly Subscribers for THE FLORAL WORLD.}

Premium 29.

Mosella-The center is deep orange-jellow, shading to lighter lemon-yellow on edge of petals. It is a remarkably free bloomer; flowers of the largest size.

Laevigata-A new, hardy, evergreen Japanese Rose with the most beautiful, heavy, dark, glossy-green foliage that is as bright and showy in Winter out of doors as it is in Summer. The plant trails over the ground, the runners growing six to ten feet in a season.

Climbing Bridesmaid-The fiowers are simply beautiful (identical with Bridesmaid). A clear, dark pink. In bud they are superb beyond that of any other Climbing Rose. Bridesmaid is considered the most beautiful of all pink Roses, and in Climbing Bridesmaid you have all this beauty coupled with a rampant climber.

Norma-Is a Rose at once unique and valuable, having the vigor, strength and hardiness of a Hybrid Perennial, an enormous flower like the American Beauty, and the perpetual blooming qualities of Tea Rose. From our experience with it we are satisfied that it is the grandest Rose ever introduced.

Bridesmaid-This Rose is fast superseding Catherine Mermet. Identical with it in growth and shape of flower, differing only in its color, which is the most charming pink imaginable.

New Climbing Red Rose, Climbing Souvenir De Wooton-It is a very strong, rapid grower, throwing out thick canes and bearing large clusters of deep violet-crimson flowers. Is a freeblooming red climber has always been in great demand.

Antoine Rivoire - A handsome new Rose of vigorous growth, with large, full, Camelliashaped flowers. Color, rosy flesh, on a yellow ground, shaded with a border of carmine; flowers five inches in diameter. A remarkable variety of great worth

Beaute Inconstant-(The Rose of many colors.) A single plant will bear flowers ranging in color from coppery-yellow, blush pink, carmine and apricot to light crimson. The bud is especially fine, keeping a coppery-orange-scarlet, all the variations of color are to be found in the open flower.

Crown Princess Victoria - (Bourbon.) "White Malmaison." The bud, which is slightly tinte.l yellow, opens out into a fine double pure white flower. Very fragrant.

White Maman Cochet-The finest Rose of the year. Like its parent the growth is vigorous, with rich, healthy foliage, introducing large, fine flowers of the purest white.

Kaiserin Augusta Victoria - Color, delicate creamy-white, deliciously fragrant. The plant is a strong healthy grower and constant bloomer. The flowers are on strong, stiff stems, with rich, glossy foliage, making it one of the finest Roses for corsage wear.

Helena Gambier-Of medium size, very full and of varying colors, from salmon-rose to copperyrose, often of a handsome saffron hue, becoming lighter as the flowers open. A fine sort.

Red Marechal Niel-The Yellow Marechal $\mathrm{Niel}$ has been known from time immemorial as one of the most fragrant and delightful of all Roses. The red one is a cross between the old Marechal Niel and the equally well-known and desirable Rose, Gen. Jacqueminot. Color a bright carmine-red, shading to pink.

Triumphe de Pernet Pere-The flowers are extra large, having broad, thick petals and long tapering buds; color, fine, clear magenta red.

Papa Gontier-A grand red Tea Rose of fine crimson shade and silken texture. The bud is fine size and graceful form.

Psyche, The New Rambler Rose-A cross between Crimson Rambler and the Polyanthe Rose, Golden Fairy. In growth and habit it much resembles the Rambler. The flowers are produced in clusters of eight to thirty-five, and are two to two and une-half inches across when fully expanded. 


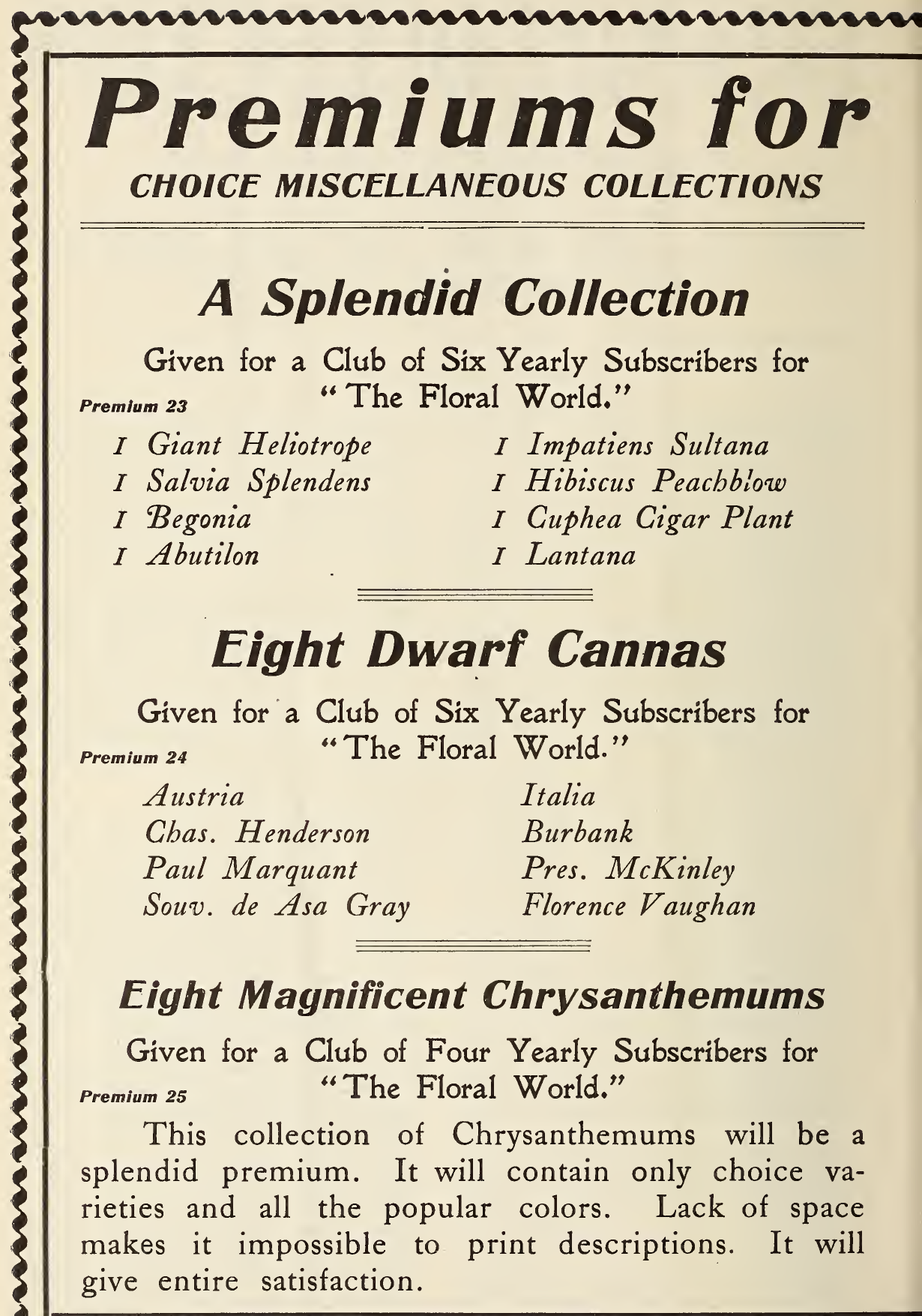




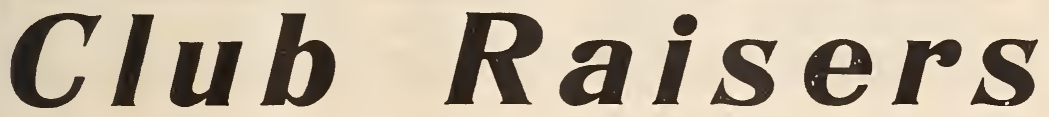

\section{CHOICE MISCELLANEOUS COLLECTIONS}

\section{Collection of Verbenas}

Given for a Club of Four Yearly Subscribers for

Premium 26 "The Floral World."

This choice collection of Six Verbenas will be carefully selected the day they are shipped so as to contain the best possible variety of nice, strong plants. We will guarantee their safe arrival in good condition.

\section{A Pansy Collection 10 PRETTY VARIETIES}

Given for a Club of Four Yearly Subscribers for Premium 27 "The Floral World."

Plants of the varieties in the best condition for shipping will always be selected for this collection. Care being taken to include all the favorite colorings.

\section{A Favorite Collection}

Given for a Club of Four Yearly Subscribers for Premium 28 "The Floral World."
6 Oxalis, different colors 4 Gladioli
2 Tuberoses
I Caladium (Elephant Ear)

Collections of Plants offered in this number will be sent by mail, postage prepaid and safe delivery guaranteed. Subscribers accepting any of our offers of "The Floral World" one year with a premium, whether an old or a new subscriber, may be counted in these clubs. Order by Premium Number, and address THE FLORAL WORLD, Springfield, Ohio 


\section{A Premium With Every Subscription}

In other pages of this number we make some very attractive offers to subscribers for THE FLORAL WORLD. There are three of these offers:

1. Four Choice Roses and "The Floral World," one year, for 25 cents.

2. One estimate in the $\$ 40,000.00$ Profit Sharing Contest and "The Floral World," one year, for 25 cents.

3. Linen and Lace Materials (774 square inches), and "The Floral World," one year, for 30 cents.

These offers are made to both present and new subscribers. An old subscriber sending his or her renewal is entitled to a premium the same as a new subscriber. Everyone now on our subscription list will, of course, see and read these offers. But we want to bring THE FLORAL WORLD and these generous premium offers to the attention of thousands of other people, new people who have never read or heard of THE FLORAL WORLD. To interest present readers in this work we have selected some of the

\section{MOST LIBERAL AND ATTRACTIVE CLUB PREMIUMS}

\section{To Offer Our Readers for Raising Small CIubs}

You know some of the thousands whom we want to reach. They are your relatives, friends and neighbors -people you see every day. They will thank you for bringing these offers to their attention and be glad to subscribe through you. We want you to get some of the fine collections of plants offered in this number for small clubs of four, six, or eight subscribers to "The Floral World." A little effort will secure you enough choice plants so you will not have to buy any others for your spring planting. 


\section{The Floral World.}

A JOURNAL OF HOME FLORICULTURE.

Vol. II., No. 5

Springfield, Ohio, February, 1903

25 Cents a Year

THE LAST SNOW STORM.

Just as we thought that spring had come With birds and bees and sunshine warm,

The wind blew cold, the sky grew dark,

And soon began a wintry storm.

Old mother earth was warm at first

The flakes they melted as they fell ;

But when all else was covered o'er

She was mantled in white as well.

The stately tree, the budding bush,

The tiny little blade of grass,

And every kind of plant that lives !

Drew nectar from the melting mass.

The crocus held its head as high

As it did in pleasant weather;

The robins sang their sweetest songs

As they built their nests together.

All nature seemed to understand

'Twas winter's last caressing ;

Before he left for colder climes

He would give to each his blessing.

Colorado.

I. M. B. K.

\section{WINTER WORK.}

Now is the time to prepare for next summer's blossoms. It takes extra effort, but when springtime comes we should have a plentiful supply of rooted cuttings for open ground planting. As I have a large shady yard I plant begonias, fuchsias, sultanas, etc., with success. By wintering last year's nicotianas and planting in open ground I have an abundance of blossoms throughout the summer. For the sunniest beds I have geraniums. I also plant some annuals in boxes and have them large enough for spring setting, but for busy housewives I find they require too much time and care. Last year I kept a large double red and white petunia in the south sitting-room window until May, when I prepared a bed (on the south side of the house) with leaf mold, garden soil and a little sand. I broke my petunia into small limbs and planted them two joints deep. I shaded them (for the bed had the morning sunshine) a week " and they grew and they grew, " and I had hundreds of blossoms lasting until frost. Truly it was a thing of beauty,

\section{Indiana.}

\section{ANNA BRICKERT.}

[ Let us suggest that in making cuttings for the purpose of rooting, you use a very sharp knife and cut them off. The commercial florists always see to it that their cutting knives are quite sharpso as to make as smooth a cut as possible, thereby promoting the chances of the end of the cutting callousing.]

\section{GROWING ANNUALS.}

February is the month to plan for the preparation of our annual floral beauties. While the seedsman has a full store and plenty of nice fresh seed is the time to make up our orders for spring planting. During the open balmy days of February we must saunter over the lawn and make our plans for the various flower beds. The very tiny seeds should be sown in finely sifted soil in boxes, the surface being covered with muslin and sprinkled lightly with tepid water. Remove the cover when the tiny sprouts appear. Some of the seed may be sown in the hotbed later on and transplanted; still others may be sown in the flower beds. To grow annual bloomers successfully we must study their nature, and not crowd the plants too closely, nor crowd weak growing plants in among those of more sturdy growth, lest they lose their strength and beauty.

Ohio.

George W. Brown.

[ To prevent weak, drawn seedlings, allow them plenty of air, not too much heat and a good light location. The success of annuals depends quite a little on obtaining strong, sturdy seedlings. Frequent transplanting helps materially.] 


\section{THE FLORAL WORLD}

PUBLISHED MONTHLY BY THE

\section{FLORAL WORLD COMPANY}

12 to 14 South Limestone Street

SPRINGFIELD, OHIO

\section{Subscription Price, 25 Cents a Year}

Entered as second-class matter at the Postoffice in Springfield, Ohio.

The editor of THE FLORAL WORLD takes great pleasure in announcing that hereafter each letter from its readers will receive such special attention as it requires. An experienced authority on floriculture will answer any questions you may care to ask, and make suggestions as to how you may have greater success in your flower growing. The editor hopes every reader will take full advantage of this feature of the magazine and tell all his or her friends about it.

The regular prize offer is continued. The magazine will give $\$ 26.00$ in prizes for the best five articles for publication in the April number of THE FLORAL WORLD, which may be submitted by subscribers.

The first prize will be $\$ 10.00$; the second, $\$ 7.50$; the third, $\$ 5.00$; the fourth, $\$ 2.50$; and the fifth, $\$ 1.00$. The awards will be announced in our May issue.

No article which contains more than two hundred words will be considered in the prize decision. All contributions entered in this prize contest must reach us not later than March 1.

The purpose of these prizes is to secure for publication in THE FLORAL WORLD matter which gives the actual experiences in flower growing of those who have subscribed for the journal. Prizes offered for articles published in the January number have been awarded as follows :

First Prize-Irene Hall, Kentucky.

Second Prize-“'Hayseed."

Third Prize-G. E. Locker, Missouri. Fourth Prize-Mrs. L. W. Baldwin, Delaware.

Fifth Prize-Mrs. E. J. Peck, Vermont.

\section{LILAC BLOOMS IN WINTER.}

From earliest childhood I have been a lover of flowers, delighting in their cultivation, petting and nursing them in summer and coddling them in winter. I tried many kinds with success and finally fancied the notion of having "May in January "; more plainly speaking, lilac blooms in February. So, late one November, from a self-sown grove I selected young bloom-budded trees. With a spike I made three holes each in the bottoms of tobacco pails and alongside the holes I tacked inch-thick blocks to raise the pails off the floor. I first placed in the pails bits of broken flower pots, charcoal and gravel. Then using rich soil for my rose bed I planted in each pail three trees, leaving on what soil clung to the roots, watered well and set in a dark cellar where they remained until the middle of January, when they were brought to a warm sunny window. The sun laughed here and gentle dews (from the sprinkling pot) blessed them. Oh, how the lilacs flourished! I had forty large, purple-pink panicles, beautiful to the eye and sense, for the air was "balmy May" with the sweet perfume of the lilacs.

\section{Wisconsin. L. B. E. WADLEIGH.}

[ This is certainly an interesting experiment and well worth while. White varieties are more frequently used for forcing than the purple, and are more beautiful. Have you heard of the new ether process used in connection with forcing lilacs? If any of our readers are familiar with it we would be glad to have a detailed explanation of the method employed.]

\section{AS TO THE DIAMOND FLOWER.}

In reply to a number of inquiries as to where the diamond flower can be purchased, The Floral World will be glad to forward to florists who sell this plant, any letters or communications received from its readers.

\section{PUBLICATIONS RECEIVED.}

Templin's Catalogue for 1903, of the "Ideal" Seeds, Bulbs, Plants-copiously illustrated. 
THE NEW YEAR IN THE FLOWER GARDEN.

In flower growing, as in everything, there is a starting point, and to succeed one must begin at the beginning. One must learn to make haste slowly and not go beyond his present knowledge, and to avoid extravagance. Begin with plants of easy culture and learn from them how to succeed with other and more difficult plants. The secret of success in flower growing is selection-a knowledge of flowers and their requirements before ordering them. Many plants will succeed well in one locality while in another locality the same plants will prove an utter failure. Start slowly but with success firmly rooted in your mind and success is assured. Some people spend annually hundreds of dollars on plants but they are not necessarily the most successful or the best gardeners, but the best is he who produces the best plants at the least expense. The soil should be made rich and worked deep at first, then keep the flower garden always clean, for it is necessary to success. One's taste and means should always govern the extent of his flower growing.

\section{Ohio. Annice Bodey Calland.}

[ Our correspondent has certainly struck the key-note of success. Observation is everything in flower culture. It is possible that it is by sticking to their old adage, "Make haste slowly," that the Germans are such successful gardeners.]

\section{EARLY BLOOMING PLANTS.}

In February or March we dig from the woods the roots of bloodroot, spring beauties, dutchman's breeches, isopyoums and other early plants, and set them out in shallow boxes where they will bloom very soon if placed in a sunny window. They bloom in the woods early in April and we enjoy having them a month or two ahead of time. They are particularly nice for people who can not take care of houseplants during the winter. We have also taken up small roots of the old-fashioned bleeding heart from the garden and had it bloom in the window long before its time of blooming out of doors. It is a beauti$\mathrm{f}_{\mathrm{ul}}$ plant for this use. So, also, is the lily of the valley. Apple, peach, pear and cherry twigs can be brought in a month or six weeks before their time of blooming. and if placed in a jar of water in a sunny window will bloom very quickly. Such foretastes of spring are very cheering when the weather is drear out of doors.

Illinois. Mary ANDrews.

[ We imagine there would be some difficulty in: locating the bulbs of these plants at the time you suggest unless one marked them during the summer previous. Have you tried trillium grandiflora? This is one of the prettiest of native bulbous plants, and should do as well as those you suggest.]

\section{TAKING TIME BY THE FORELOCK.}

Those who wait until bedding time to start seed and bulbs are usually behind time the whole season and frost nips many plants before they are ready to bloom. Seed of the cosmos and dahlia should be started in February. I start mine about the fifteenth in shallow boxes of rich soil-usually finely sifted woods earth-and water well at the start and then keep moist, but not wet, until well up. I find it as injurious to young seedlings to become very dry as to keep them very wet. Germination of the cosmos takes place in from three to five days and of the dahlia in from five to seven days. Some of the prettiest dahlias I had last year were grown from seed started in February. I have gotten a good start of a number of greenhouse seed started in this way and only the finest of seed are very difficult. to manage. For the very fine seed I sift the soil, press it down, sifting the seed finely over the soil and then sift a fine layer of soil over the seed. For very hard. coarse seed I either file or soak a few hours before planting.

\section{Kentucky. Miss Laura Jones.}

[ Have you tried some of the newer varieties of dwarf early blooming cosmos. It is rather discouraging, even when one does start them early to have: plants cut down by the frost before blooming ] 


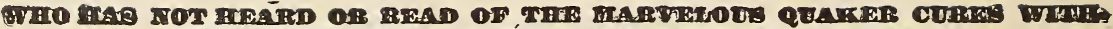

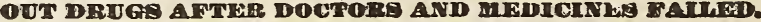

A GRAND INVEUTION-Plwsiolans astonished and Thouaands of Grate-

ful Users Testlfy To The Marvelous Resulte Obtained From The

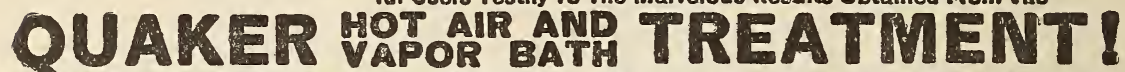

MARY L. WILLIS. of Cloverdale, Alr., testifie日 that it wavid her 11 re, cured her or aropey and hidney troubles after doctore and medicines failed to bezeft her. JUDGE J. 0 EUTOBINS. Hey.wards, Calif., tastifies that at rescued him from the grave. Waa a confirmed in Fslid for 15 years. Baffled best doetore. Thanke God the mar. relous power of the Quaker cured him of weak hart, sieeploes: nese dropey, catarrb, piles, rbeumatism, kidney troubles end partisi paralysis. Is todsy well and vigorous.

L. MOBRISON, Peilivilie, Ky afficted 30 years. anable to watk, ras cured of $\mathrm{kidney}$ disesse. Fheumation. cehorai dobiuty after oversthing else failed.

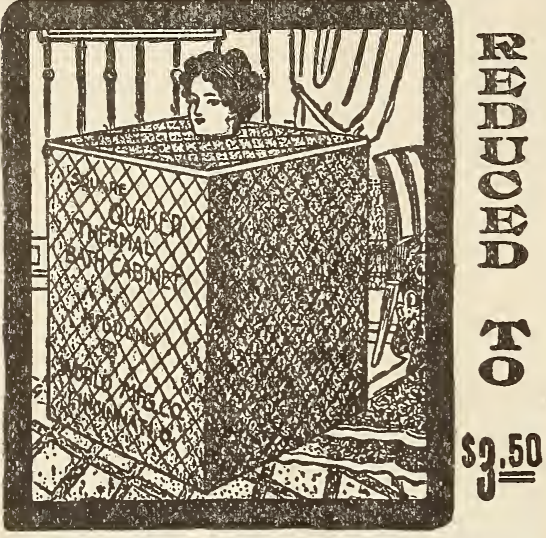

JOER P. PERBI, Elorfolk, W. Fin, wasted awey untll he Fas a mere szeleton on crutches. Aficted with worat caes of blood poison and rhon matiom on record. Was completely curedpiter doctors modicines ander fres trial

Qusker Treatment. Improved after tires trial. I doctod and coctored witt no beneat. Phy lclans at Long Branch Hospltal coctored with no beneti. Phy tclans as Long Branch Hosplal told me foug joars ego I bad that deadly dieease, Loco-nutor Alusia and Wonld aever fo wend commenced at once to grow cnres of the Qugker sent for lt and commenced at once to

trong and well. heed to ton with frightful ézema, also bad kidneys, impare poed to tont with frightful ecrema, also bad kldneys, mpare Hid dapil red of iifo.

Had danpilred of iifo. FMAN, Bokosho, I. T. teatleses that her doctor told ber two years agn she bad deedi, Bright's and fildnoy droave. Conda noe mendad the Qnaker Treatment. She writes it saved her life. Nuw weil and atrons Does her own bonsework.

BEV. J. W. HEN DERSON, Weaton, Le., writes: That pls son is years nld the doctors had glven up to die. BadlJ

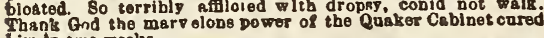
bim to iwo wegks.

D. P. SMITH. Greenebarg, Kan. An old Eoldier. Jever W Will day since 1862. A mere wreck. 63 yearo old. After most eminans dootore falled to beneft, Fas cured of heart failure, kidney troubles, rhenmstlem and воге еjes. Today is bale and bearty.

MBS AVY WOODRUM. Thurman, Iowa, afficted for geare teatifles thas ghe was cured of nervope prostratlon, bead. nobe, Indigentlon, kidney and female 111 with the Quaker Treatment aftes doctora and medioines failed. Fes aince many Oablnets tn friopds and saye pveryone is deilghted. MrRS. L CORN, of Maysvliie, Mn. Fra relieved of patns, congestions, otc. rind racomme.

MaS W. BLACE WELL. BIrmingham, Miss., Friteo: "I hope that old ehronio canea like mine that bave been doptored hair to hram will not give no hus take courage ae I did, and ery the wonderfni Qurtrer Bath Cabinet Trearment. I had muscular paral, raio a joarn. Was helpleas. Boctora caid was a hmpeleze casen After three of the fsmoun Quaker Treatmonts moy improvement whe Fonderial. and no

A M
No disease can resist its marvelous power. Benefits every Man, Woman and Child.

WM. CORNET, Smithrille, Miss. 72 yeare old. Terribls efillcted pith lang trouble 16 years. Hardly able to walk. Teetifies that $t$ did him wore good can ail medicines and and rheumatim. After three treatments throw away his cang. Walked 7 miles.

REV. BRED. D. BAMILTON, Buffalo, says: "This Quaker Trenment did my wito mose good in 5 weelso than 3 jears doctoriag nd a, fortune spent at Hot Springs and Heulth Resorts. Cared hes of cemake weukness. at is a God-Spnt blessing to humanits

JULIAN F. TAN NER, LaFryette, La., afficted, testifles that this marvelous Tresiment cared him of a sirolie of paraly bis when the beat doctors failed 10 benefit.

MISS M. SPARKS, Hatleg. Mise , afficted two yeare with acuse indigestion. had wot eaten solid food for 3 months, After ols treatments could eat what ohowanted. In a few monthe was completely well.

THE ATHENS SANITARIUM, Athene. Pa., writes: Ther 6nd the Qualser Cabinet Treatment Eplendidi for curing viorphine, Cocante, Opinim, Cigaretto, Tobacco and Liquor Habits. Hundredo of prominent people have bean cured there.

Thourands of other sufferers testify to the marvelone re. DX. GOVERNOR ATKINSON, of W.Va., D.8. SENATOB OBAUACEY M. DEPEW, CONGRESSMAN JOE J J. LENTZ. RT. RIV. BISHOP J. O. HARTZELL and bosts of othes prominent people endoreo it.

OROWINO RICH ARE MEN AND WOMEN SELLING THIS GRAND INVENTION.

MR. VAN TASSEL cDred himself and made over 1, 600.00 Arst five months seiling these Cobiuets. IRA

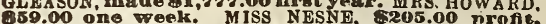
MRS. TLORA BEARD, A400.00 proft. RUBERT PrART, gold ol Any honest lady of gentleman having spare time can get a good position at BIG WAGAS by writing us at omce.

Lef us send you a Quaker on 30 days' trial

To be retnrned at our expenee and yonr money refunded, If not as repreeented. Costs you nothing to try te. Ons Quaker Cabinete jave a National repntation for durability. cosvenience and healling propertles. Over 300,000 Cebinets cold laet joar. Lverybody boodn lt, mob, women and children. Our Cabinets are handsomely made, beat materlgle, sbonld last 20 years guaran teed best on the market. Anyone oan operges. Sested within the Cabinet. clouds of Hot Air Alr and Vapor Bath, which opens the millions of ekin pores. drawing ont of the eystem all impure acids, sslts and poisonous matter of the biood and in ternal organs which, If retinined. overwork the vital organs and canse disease, debility and sluggishnese. Keeps the body aboolutely clean, inwardly and outwardly-vigorously and healthy withont medicine. Clear the akln, besutifies the complexion. Sfer than druge. Cheeper than doctore and medlcines. Wonderful blood puifier. Pre. vents dieesse. you enjoy at home ror 3 cents each all the cleansing purifying and invigorating hesing effets of the famone Turlsish. Huasian, of taking cold afterward or weakening the syotem.

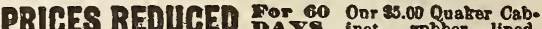
complete with medicine and vaporizing pan, best falcohol complete wlth medicine and raporizing pan, best falcohol heater, directlons end 100 page " Hesith and Beanty Book" reduced to Qpaker cahinet complete with fixtures ae described above, roo Attach. excellent for beantifying the complexion, curing caterrb, astbra, bronchltis and throat tronbles, reduced to 65 cents.

DAN'T FAIL TO WRITE TPDAY FOR VAL. FPES Also tentimonials from bundreds of usero-Sent IPIIE. or. better atill, order a Cablnes. Don't wait. You won't be dis: appointed or deceived, for Fe guarantee every Cablnes and cheerfully refnud yonr money affer 30 dag $\theta^{\circ}$ use. If not just as reprobented. We're reliable old Firm. Largeet Mfgre. Capital 100.000 .00 . Ship immodiately npon receipt of remittanco.

T.

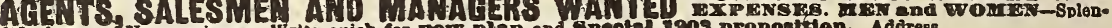

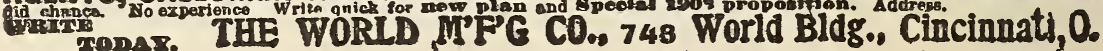


A FEW EARLY FLOWERS.

The snowdrop is the earliest of all spring flowers. Its drooping white blossoms flecked with green are exceedingly pretty and graceful and make a beautiful contrast planted with the lovely blue scilla in beds or in the grass on the lawn. Following the snowdrop is the crocus. Its flowers are lovely in form and of the brightest and freshest colors, pure white, golden yellow, purple, pink and variegated. The crocus is entirely hardy and likes a rich dry soil and sunny location. The bulbs should be planted two inches deep and two or three inches apart. Then follows the hyacinth which is esteemed among the most beautiful of all spring flowering bulbs. The flower spikes are regular in form and the colors are very. bright and distinct. The bulbs are set so that the tops will be three or four inches under the surface and six inches apart. Give a light covering of leaves or litter during the winter. All of these flowers are highly valued for their beauty and fragrance.

\section{Ohio.}

KAtie M. RoAds.

ᄂ The bulbous plants that you mention are all fine, but do you overlook the tulips? Is there any plant that gives more for the time, labor, and money invested than the single tulip? We refer to the single earlier varieties.]

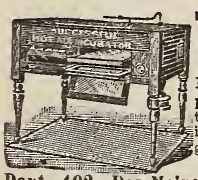

\section{THE SUCCESSFUL} Incubator and Erooder Made for folks who succeed. Perfect regulation, perfect hatches. Don't experiment, geta machine that you can know about. Send for our large incubator book, 156 pages. Books in fire lam uges. Write for the one you want.

Des Moines Incubator Co..;

Dept. 402, Des Jloines, Iowa, or Dept. 402 , Buffalo, N. Y.

\section{GREAT_POULTRY BOOK}

My 1903 catalogue. Elegant in illustration, full of practical hints, describes 56 breeds of prize winners. Low prices for birds and eggs. Book postpaid, 10 cents. Calendar for 1903 on cover. B. H, GREIDER, REEEMS, PA.

- $=$ BUY SEEDS THAT WILL GROW

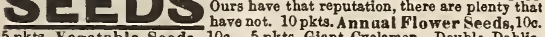
5 pkt3. Vegetable Seeds, 10c. 5 pkts. Giant Cyclamen, Double Dahlia, 6 Roses, 25c; 4 Polargoniums, 25c; 6 Geraniums, 25c; 6 Pegontas, 25 : Catalogue free. A. C. ANDERSON, COLUMB'S, NKBKASKA.

A.Y AYE can have Beautiful Plants and Flowers by usA. Un 5 ing my famous receipt for Plant Food. Easily month only for 10c. A. C. Merser, Florist, New Bedferd, Mass.

"RALIFORNIA BEAUTIFS" Send Six 2-cent stamps Soeds, to SCCCESS SUPPLY CO., F. W. 23., Santa Rosa, Calif.
DARKEN YOUR GRAY HAIR

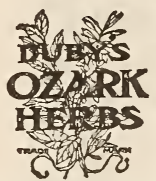

DUBY'S OZARK KERBS restoregray, streaked or faded hair to its natural color, beauty and softness. Prevents the hair from falling out, promotes its growth, cures and prevents dandruff, and gives the hair a soft, glossy and healthy appearance. IT WIL NOT STAIN THE SCALP, is not sticky or dirty, contains no sugar of lead, nitrate silver. copperas, or poisons of any kind, but is composed of roots, herbs and flowers. It cost ONLY 25 CENTS TO MAKE ONE PINT It will produce the most luxuriant tresses from dry, coarse and wiry hair, and bring back the color it originally was before it turned gray. Full size package sent by mail for 25 cents. OZARIE HERB COMPANY, St. Louis, Mo,
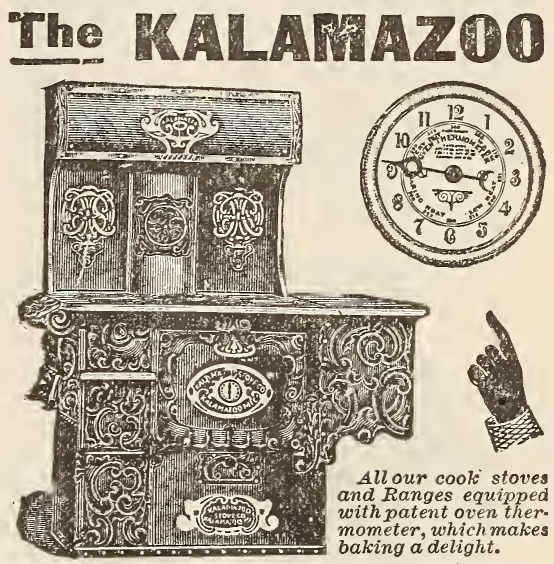

The only strictly high grade stoves and ranges sold direct from factory to user at factory prices. 360 Dht TS Approval Don't buy until you have investigated our special proposition. Send for FREE catalogue No.145 KALAMAZOO STOYE BO. manufacturers, Kalamazoo, Wich.

\section{An Asthma Cure at Last.}

It gives us great pleasure to announce the discovery of a positive cure for Asthma, in the wonderful Kolo Plant, a new botanic product found on the Congo River, West Africa. The cures wrought by it in the worst cases, are really marvelous. Sufferers of twenty to fifty years' standing have been at once restored to health by the Kolo Plant. Among others, many ministers of the gospel testify to its wonderful powers. Rev. J. L. Combs, of Martinsburg, West Va., was perhaps the worst case, and was cured by the Kolo Plant after fifty years' suffering. Mr. Alfred C. Lewis, Washington, D. C., Editor of the Farmer's Magazine, gives similar testimolly, as do many others. To prove to you beyond doubt its wonderful curative power. the Kolo Importing Co., No. 1164 Broadway, New York, will send a large case of the Kolo Compound free by mail to every reader of THE FLORAL WORLD who suffers from any form of Asthma. They only ask in return that when cured yourself you will tell your neighbors about it. You should surely try it, as it costs you nothing.

WOMEN TO DO SEWING Binding Spec100. Can make six an hour. Material sent free pre paid. Send addressed reply envelope for full particulars. Universal Co., Dept. 214, Walnut St., Phila., Pa. 


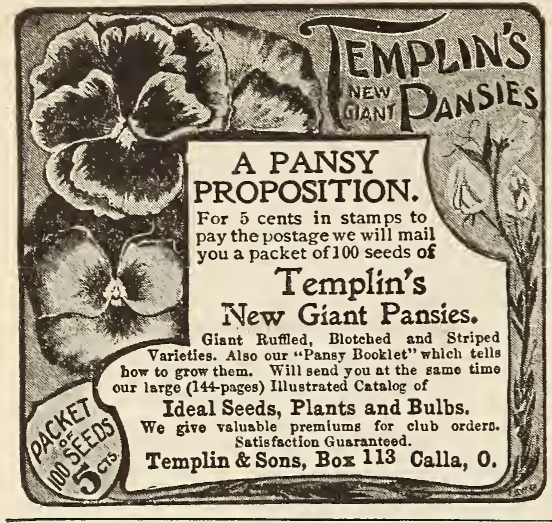

"Let the GOLD DUST twins do your work."

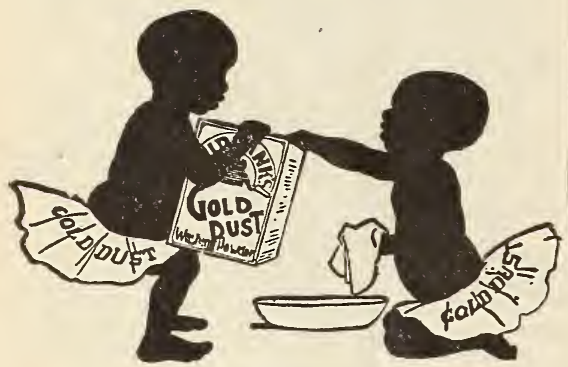

No Soap, Borax, Soda or Ammonia is needed with

\section{GOLD DUST}

With little water and less effort you can clean any thing about the house better, easier and cheaper than with soap or any other cleanser. Once try it, you'll always buy it.

Made only by THE N. K. FAIRBANK COMPANY,

Chicago, New York, Boston, St. Louis, San Francisco, Baltimore, Montreal.

Makers of OVAL FAIRY SOAP.

"A BRIGHT LITTLE PAPER."

The Floral World (December number, 1902) comes to us bright and interesting in pen-pictures, actual experiences of its numerous subscribers. So real are they that we can see the snowdrop, the violet, and the frail wind flower, and hear the zephyrs whisper as they play among the leaves and branches in the numerous gardens. We see the tall rubber plant, the woody palms; we almost help at the fall planting of roses. We are there with the oleanders on Sullivan's Island, and help at planting carnations and in the decorating of the log-cabin in the church. The pelargoniums, cacti, day-lily, and calla and numerous others, we see them all. We stand beneath the lilies and gaze in rapt, wondering admiration into the deep corolla of the lilium auratum vattatum rubrum. As we look long into the heart of those clear, waxy, white bells, spotted and striped with crimson, our admiration turns from idle curiosity and our hearts fill with prayer and praise of the great Creator, who hath given us so bountifully of all things good; and we stoop in our worshipping to caress the deep-eyed, pleading pansy, modestly groping at our feet. Long live THE FLORAL IVORLD. It will ever be a welcome visitor in our home.

Wisconsin. L. B. E. WADLEIGH.

\section{CHRYSANTHEMUMS AND POMPONS.}

May I tell how I succeeded with chrysanthemums? In one bed six feet by three, made on the south side of the porch, I planted a background of tallgrowing white chrysanthemums and bordered them with very dark and red pompons.

On the east side of the porch steps I made a bed which curved past the end of the porch, taking in the angle between the house and the porch. In this I planted one pink cosmos and two white ones, with tall yellow, white and pale pink chrysanthemums in the foreground. I bordered this bed with pale pink pompons fading into white. Across the porch ran a vine of cobea scandens which I raised from seed.

The soil is clay, to which I added leaf mold and old decayed manure from the cow stable. I plant my tall-growing bed(Concluded on page 13)

HOME TREATMENT FOR CANCER.

All forms of Cancer and Tumor cured by soothing, balmy oils, Doctors, lawyers and ministers endorse it. Write for free book to the Home Office, Dr. D. M BYE CO., Orawer 505, Indianapolis, Ind. 
(Concluded from page 12)

ding chrysanthemums two and one-half feet apart and the pompons eighteen inches each way. I remove one-third of the buds from the tall chrysanthemums but none from the pompons. As these varieties are all perfectly hardy they are taken up only on May first, the best sprouts removed, throwing away old roots, and the soil is renewed and spaded. The new slips are planted and hoed once a week, until July or August, according to the growth they make.

The tall ones grow to a height of four and one-half feet, the pompons two feet. The display of bloom was bcautiful and called forth much admiration.

\section{Indiana.}

EMila PERRY.

[Those who grow large chrysanthemums for market prune the plants severely, allowing only one or two stems to grow and pinching off all others. With some varieties the terminal bud on the sten is retained, removing all others; while other varietics give best results from a side bud].

\section{MIDWINTER NUTRIMENT.}

It is not possible for plants to maintain steady growth and produce an abundance of blossoms unless we give them the proper treatment, thus helping them to meet the changed conditions that obtain between our windows in midwinter and their native homes, so full of life-giving air, so rich in plant food, so bathed in sunshine. They are prisoners. The rootlets strike out boldly in fresh soil, but after a little time they come to an impenetrable wall, then they turn back and (Concluded on page 14)

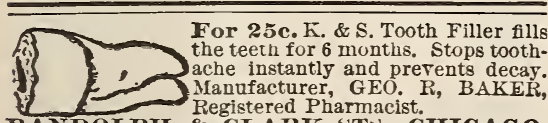

RANDOLPH \& CLARK ST's., CHICAGO.

\section{NY LADY Can Easily Make 11 , $\$ 1810 \$ 25$}

weekly by representing us in her lo ality and as the position is pleasant and profitsble the year ronnd we will gladly send particulars free to all. Even your spare time is aleble. This is no deception, and if you really want to make money

IIZ are manufacturers of a line of useful Household Articles of consumption and have an exceptionally attractive proposition to offer energetic ladies who will act as local managers for our products. The character of service you will have to render will be of both a profitable and congenial nature. It will not necessarily require all your time at the beginning but can be attended to in connection with other duties. For further information address,

ELI CITY CHEI. LABORATORY, Finsted, Conn.

\section{\$10 DRESSES AHY WOMAK IN LATEST STYLE.}

Fra: Saniples

and Measurement Blanks.

To Introduce Direct to the Wearer our Ladies' Custom Tailoring we will make suits absolutely to measure sent us for only 810 and give the following com. plete FREE Actually 828 value for only 810 aud nothing to pay till after you receive the suit and free outfit and find jt just as represented. Send us your name and post. office address, and we will send you RREE SAMPLES OF CLOTH, 5-ft. tape line and measurement blank for size of Suit, Shirtwaist \& Shoes. A gennine wool mixed repellant latrst etyle, Tailor Hade Blouse Sult, for ach ladies' tailors charge............... \$20.00 at 2.56 Pair Stylish Shoes....... 2.5 Flanneletto Sbirtwalst.. 1.50 Pair Lisle Thread Hose. Lsce Bordered H'ndk'rch'? Handsome Loather Be't. Ladies' psy deily for this $\$ 28.00$ DON'T DELAY-After havinf filled 10,000 orders our prices for these suits will be 820.00 and No Free Articles. GENTS' COMPLETE OUTFITTING CO.,

Ladies' Tailoring, Dept. 424

\section{Adams Street}

Beforence: First Fat'l Bank

Chicago. Capitsl $\$ 12,000,002$.
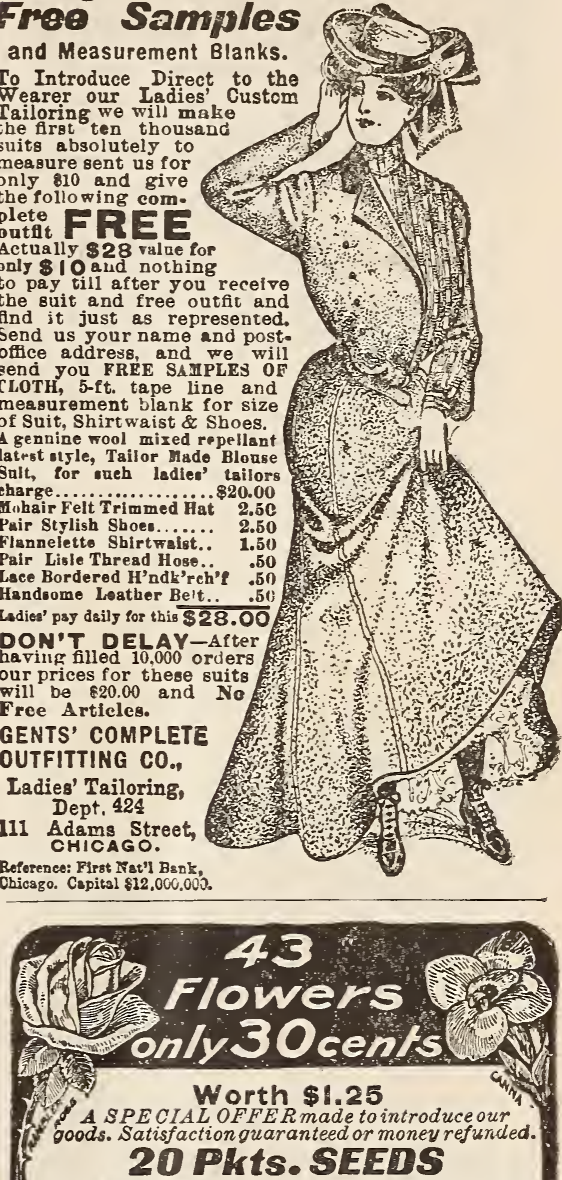

1 Pkt. Rambler Rose 3 col's msd. 1 Pkt. Diamond Flower. "Pansies, 10 colors mixed. "California Sweet Peas. “Washington Weeping Palm. "Donble Chinese Pink. “ MarySemple A sters, 4 colors." Carnation Margnerite. "Alyssum. Little Gem, mixed." Heliotrope mixed. “ Bouquet Chrysanthemum. "Poppy-New Shirley. “ Forget-me-not Victoria. "Umbrella Plant. ¿ Hibiscns Crimson Eye. “ Giant Verbena, mixed. “ Lovely Bntterfly Flower. “ Japan Morning Glors. “ Phlox Drummondii. "Petunia Hybrid,mixed 23 BUL" BS

1 New Red Calla Lily, 1 Summer Flowering Hyacinth, 1 Double Pearl Tuberose, 2 Butterfly and 2 Hybrid Gladiolus, 8 Fine Mixed Oxalis, 2 Rainbow Lilies, Hardy Wind Flowers, 2 Lovely Cinnamon Vines, Splendid New Canna Lilies-1 crimson, 1 golden.

A Return Check Good for 25 Cents New Floral Gulde, all above postpaid, only 30 c. THE COMARD \& JOHES CO. Growers of the "Best Roses in America." BOX E, WEST GROVE, PA. 


\section{7. (2) HARTSHORNS SHADERROLilips:}

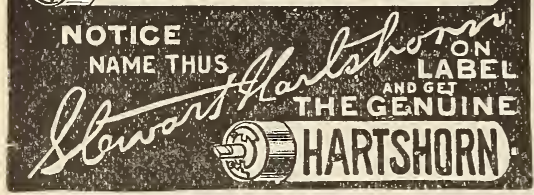

\section{GRERT CROPS OF \\ STRAWBERRIES \\ AMD HOW TO GROW THEM}

The best book on strawberry growing ever written. It tells how to grow the biggest crops of big berries ever produced. The book is a treatise on Plant Physiology and explains how to make plants bear Big Berries and Lots of Them. The only thorough-bred scientifically grown Strawberry Plants to be had for spring planting. One of them is worth a dozen common scrub plants. They grow BIG RED BERRIES. The book is sent free to all readers of THE FLORAL WORLD. Send your address to IR. MI. IX $\mathbb{E}, \mathbf{I}, \mathbf{I}, \mathrm{O} \in \mathrm{G}$, THREE RJUERS, MICHBCAN.

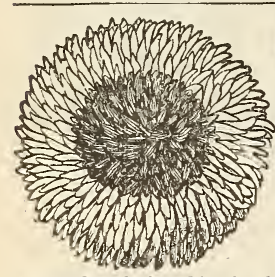

\section{GOLIO}

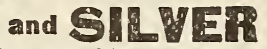

The wonderful new Cold and SIlver Flower is the best floral novelty for 1903. Never before offered in the U.S. and cannot be obtained elsewhere. Large silvery white, intensely double fower with center of gold. Must be seen to be appreciated. Price 25 cents per packet, but if you will send us before March 15, the addresses of three persons who cultivate flowers, and two 2 cent stamps, we will send you a full sized packet to pay you for your trouble. Also a copy of our large,beautiful catalog, con taining hundreds ofillustrations, many choice novelties and bargain prices many choice novel ties and bargain prices on seeds, plants and bulbs,
you mention this paper.

HOWA SEED BO. DES RUINES, IONA.

\section{A GRAND INVENTION!}

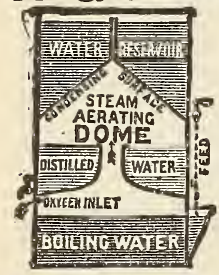

F'amous Puritan Water Still. Over 72,000 already sold. Placed over the kitchen stove, it purifies the foulest water. Removes every impurity. Furnishes delicious distilled Pure Water. Beats filters. Saves lives and Dr. bills. Prevents Typhoid Malaria, other fevers, sickness. Only safe water for children. Cures disease. Write for Booklet and testimonials free. Azents Wanted-Men and Women-Biz Wagew. Harrison Mffg. Co.. i4 Harrlson Bidg., Cincinnatl, 0.

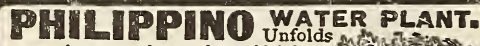

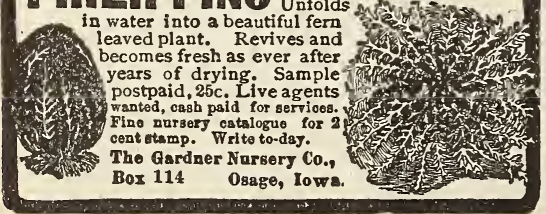

(Concluded from page 13 )

draw such nourishment as they can find in the little unoccupied soil remaining. This occurs so often in midwinter when the negligent plant owner has no fertilizer stored upon which to carry them safely through. An easily obtainable plant food for winter is beef broth. When cooking beef remove a little unsalted broth; let it cool and remove fat. Once a week water with this ; or, each day, as you boil beef take a little for a few of the plants. Where beef is not much used in the home a few bones obtained weekly from the butcher would yield sufficient food for many plants.

\section{Iowa. \\ Alberta M. Kepper.}

[ The fertilizer that you mention would contain some of the elements of a good fertilizer but would lack others equally important. Why not use well rotted manure, the cheapest and best? It contains all the elements of a perfect nutriment for plants besides having the humus to keep the soil porous and friable.]

\section{CARNATION CULTURE.}

Many varieties and colors of carnations may be grown from seed. Seed should be sown early in the spring so as to produce large plants by fall. Carnations may also be grown from cuttings which are taken from the old plants in three or four inch lengths and inserted in moist sand. Carnations require a heavy soil. They do not thrive well in leaf mold alone, but

(Concluded on page 15)

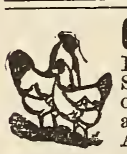

CUT RATES on all varieties Eggs and POULTRY. All varieties Fancy Pigeons and Belgium Hares Send for rates and for 60-page book, whicl one and all, each and everybody bargains are included. All for $10 \mathrm{c}$.

Address, J.A.BERGEY, Telford, Pa.

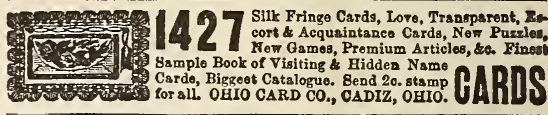

RIC R R 4-inch Doilies, 15c. Best BIG BARGAIN! Embroidery Silk, 15 skeins, date, Catalogue, all postpaid, 25c. Everybody should take advantage of this offer, W.T. S. KELLY, Franklin, Neb.

I I material and pay from $\$ 7$ to $\$ 12$ weekly. Experience unnecessary. Send stampod envelope to ROYLL CO., Dept. F. W., 34 Monroe St., Chicago.

FD CL Clairvoyance. If sick or ailing send now name, age, sex, lock of hair and 2 stamps to Dr. D. Hinkly, x-28, Grand Rapids, Mich. 


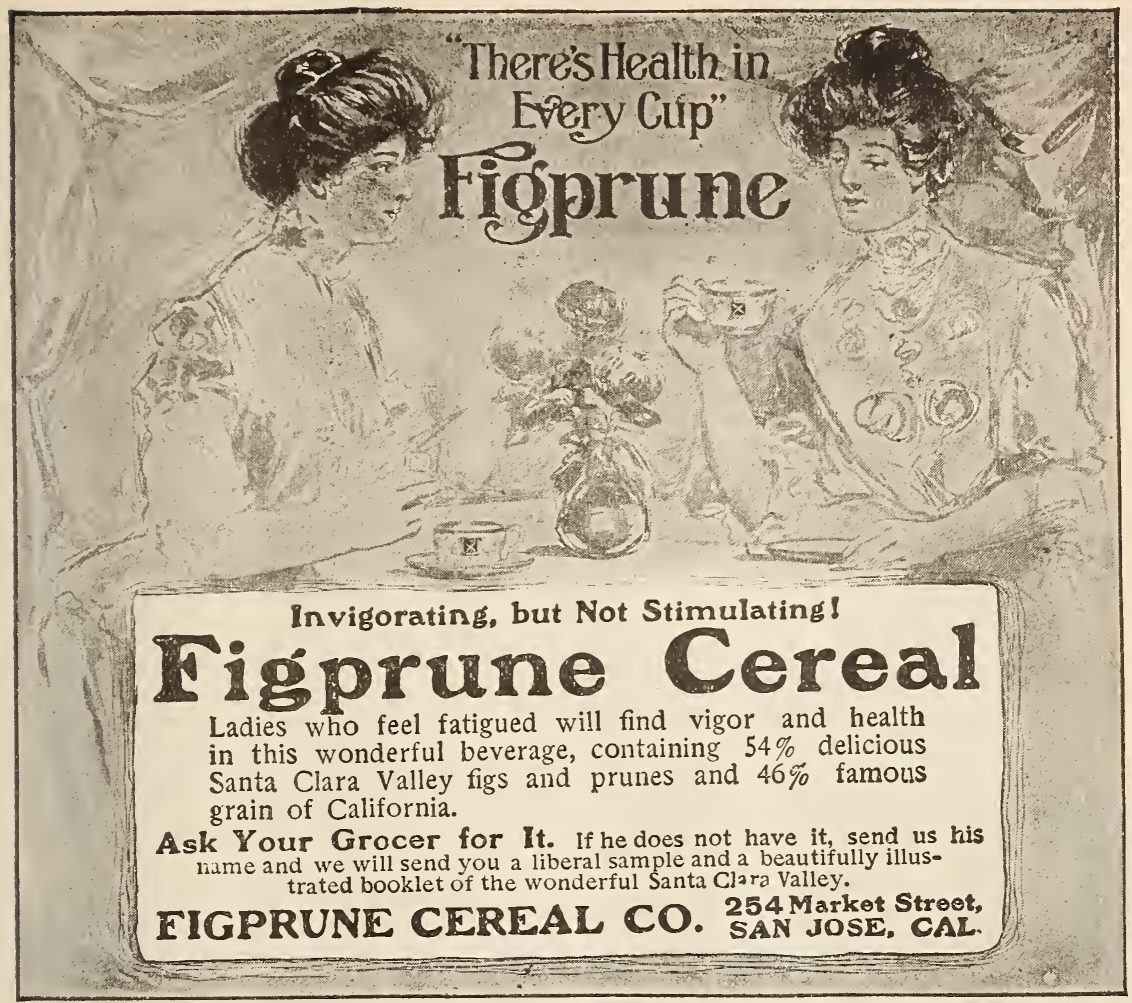

(Concluded from page 14)

garden soil with a mixture of sand and leaf mold is very good. The pots should be well drained and kept in a sunny location. After the plants begin to send up shoots they should be pinched back and all buds kept off if they are intended for winter blooming. In October plants should be brought into the house and set in a cool sunny window. Apply liquid manure at intervals of two weeks to help produce fine large flowers throughout the whole winter.

\section{Pennsylvania. A. W. Newconer.}

[Few plants have taken such rapid strides toward perfection as has the carnation during the last few years. The newer varieties of today are simply magnificent as compared with what were considered fine only a short time ago. It is a beautiful flower and when grown along the lines you mention is not difficult to handle.]

\section{PRUNING ROSES.}

Much of the success with roses depends upon the manner in which the plants are pruned. The most necessary pruning of the year is in the spring. All roses of whatever class should then pass under the pruning knife. The work must not be done too early in the season, however, otherwise some of the blooming branches of the summer roses might be unwisely removed. The development of new branches and new buds will then be permitted and the blooming will continue until autumn frosts.

\section{Kentucky. Mrs. L. A. McDonald.}

[ How few seem to think that a rose should be pruned, if the appearance of the majority of rose bushes may be taken as evidence. The rose responds most readily to careful pruning and those who have not tried it should commence this spring.] 


\section{ARsSH \\ IOWA SEEDS \\ For 25c.}

We will send, postpaid, 10 packets Flower Seeds and 10 packets Garden Seeds.

2 Crimson Rambler Roses, 20c., prepaid

Carnations, per dozen, mixed, 70c.

Clematis, each 35c., 3 for $\$ \mathbf{\$ 1 . 0 0}$.

Red, White and Purple Sweet Peas, fancy mixed, per oz. 7c.: $1 / 4$ lb., $15 c . ; 1 / 2$ lb., $25 c$.

Geranium Ruyblas and Extra Double Pink, each 15 c.; 2 for $25 c$.

Our 1903 Catalogue Free.

Address F. C. GRAVES SEED COMPANY, 627 East Walnut St. DE MOINES, IOWA

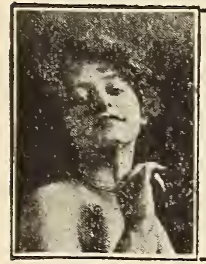

\section{BE BEAUTIFUL.}

Dr. Bidaman's Safe Arsenic Complex. lon Walers make complextion clear, smooth and velvety. Remove all skin blemishes. Used by noted beauties and actresses. Sample box sent for twentyconfidential. Circular free.

DR. ISRAEL BIDAMAN,

New York.
APPRECIATIVE WORDS.

THE Floral IVorld has my best wishes for success. I always look forward with delight to its monthly visits. It is so bright and cheery.

Kansas. Mrs. J. B. Koontz.

I prize THE Floral WORLD.

Indiana. Mrs. ANNA Brickert.

I have taken THE FLORAL IVORLD for several months and have been much benefited by it.

Kentucky. Mrs. L. A. McDonald.

I find The Floral IVorld very useful in keeping my plants.

New York. Mrs. Molineatx.

I must send twenty-five cents for one year more of the "much in little" FLORAL WORLD, as I find it is freighted from cover to cover with practical knowledge for the flower lover.

Massachusetts. Mrs. O. J. Putray.

The Floral IVORLD is too valuable a magazine to miss one number.

Pennsylvania.
M. Perle.

\section{WONDERFULLY PROFITABLE BUSINESS,}

FOR MEN and WOMEN. At home or traveling, all or only spare time. Easily lesrned. No Fake, Humbug or Toy scheme. Costs nothing to investigate. Write Todar. Dave Crawiord, of W. Va, writes: Made 42.75 first week. D. Caston, of Texas, 15. a daj. A. W. Bush, of IIl., is high as 11.50 a day. Sam'l Brown, of Me., 8 8. one week, only part time. A. Johnson, of Minn., plating I did 10 Jears ago ls firing perfect satisfaction. Mr. Reed, of 0 888. fret week. Mrs. L. M Anderson, 8.80 to $6.50 \mathrm{~g}$ day, hundreds of others mak. ing money - go ye and do likewise. Let us start you in the Gold, SHver, Nickel and Metal Plating Business. New, Qulck Process. The profits will amaze you. Metal Plating Businesa New,

You can positively make 5 to 15 a day, st home or traveling, taking orders, nsing and selling Prof. Oray's new Ilne of guaranteed Plating Machines. Unequalled for plating warches, jewelery, tableware, bicycles, all metal goods. Heary plate. Warranted. No experlenco necessary.

We do plating onrselves. Have years of experience. Mannfacture the only practical ontfits, inclnding all tools, lathes and materials. All sizes complete. Ready for work when received. Guaranteed. WE TEACH

Yod the art, furnish recipes, formulas and trade secrets THE ROYAL, Prof. Gray'ses, formulas and trade secrets FREE. method. Goods dipped in melted metal, taken out instantly with fine, brilliant, beautiful plate, resdy to deliver. Thick plate every time. Guaranteed 5 to 10 jears. A boy plates from 200 to 800 pleces tableware dally, 10 to 80 worth of coods. No pollehing, erinding or electrlclty necessary.

DIMAND FOR PLATING IS IENORMOUS. Every family, hotel and restanrant, have coods plated instead of buying new. It's cheaper and better. Every store, jeweler, shop, factory, have goods needing plating. You will not need to can rass. Onr agents have all the work they can do. People bring it. You can hire boys cheap to do your plating, the same as we, snd solloitors to gather work for small per cent. Replating is homest and legitimate. Cnstomers delighted. WE ARE AN OLD ESTA BLISHED FIRM. Been in brainess for Jears. Capitsl $\$ 100.000 .00$. Know what is required. Our eustomers hnve the benefit of our experienee, so that fallure is next to impossible. WE ARE RESPONSIBLE and Guarantee Everything. Reader, here Is a chanc of a lifetime to go in business for yonrself. We start jou. Now is the tlme to make monej. WRITE TODAY. Our New Plan. Samples Tentimonials and Cireulars FRE. Don't veft. Send

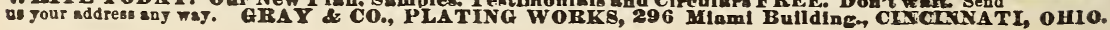




\section{ROSES GROWN FROM SEED.}

Last April I planted a packet of rose seed in a five-inch pot filled with rich soil and broken rock for drainage. In about two weeks five tiny rose plants appeared which, when they had the fourth and fifth leaves, I transplanted to thumb pots and covered with tumblers. When they became root-bound I transferred them to larger pots. In July three of them had tiny cream colored bloomers. One is now about eighteen inches high and they are all doing well. When spring comes I will plant them in the yard and leave them out next winter.

Missouri.

Mrs. C. Cunningham.

[ There must be a certain amount of fascination about growing roses from seed. You probably know that the common roses offered for sale, such as teas, everbloomers and hybrids, are raised from cuttings exclusively. Roses from seed are generally grown to obtain new varieties only.]

\section{THE BOSTON FERN.}

The Boston fern is so easily grown, I wonder every person does not have one. In May I bought a small plant in a fourinch pot and about eight inches high. I repotted it in a ten-inch pot in good, rich, porous soil with good drainage, I kept it in a cool, shady place with plenty of water, it grew very fast during the sum-

(Concluded on page 18)

M. De will send a Needleworkers' a a Complete Beginner's Stamping Outfit with ink, ready for use, for $75 \mathrm{c}$. If bought separately, this entire outfit could not be had for less than $\$ 4.00$. With this outfit you can learn to do all kinds of Needlework. Just the thing for beginners. The Design Book and Instruetor should be on every needleworker's table, as they are indispens. able. They will be mailed separately (without stamping outfit) for $35 \bar{c}$. Order at once from

\section{Standard Stamping Pattern Co.,}

o. VICTOR, Manager. MILWAUKEE, WIS.

Hardy sorts, Nursery grown, for wind.
breaks, ornament and hedges. Prepaid, $\$ 1$
to $\$ 10$ per 100-50 Great Bargains to select
from. Write at once for free Catalogue

IV I I Ladies to embroider doilies and centerpieces at $1 \mathrm{AL}=1$ home; steady work; all materials furnished; highest prices paid; no canvassing. Send stamped envelope to

A NGORA CATS WHTE SIIK FRENCH POODLES Woodlawn Kennels, Louisville, Ky.

\section{THE "|900" FAMILY WASHER FREE,}

Greatest Invention of the Age. Labor and Expense of Washing Clothes Cut In Two.

Wo More Stooping, Rubbing or Boiling of Clothes.

\section{Every Household Heods One.}

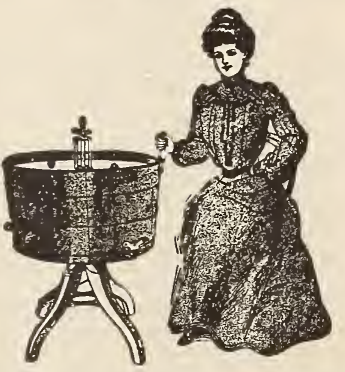

\section{THE "1900" BALL-BEARIIG FAMILY WASHER}

will be sent absolutely free to anyone answering this advertisement, without deposit or advance payment of any kind, freight paid, on 30 days trial. The 1900 Ball-Bearing Washer is unquestionably the greatest labor-saving machine ever invented for family use. Entirely New Principle. It is simplicity itself. There are no wheels, paddles, rockers, cranks or complicated There are no wheels, paddles, rockers, cranks or complicated
machinery. It revolves on bieycle ball-bearings, making it by far the easiest running washer on the market. No strength required, a child can operate it.

No more stooping, rubbing, boiling of clothes. Hot water and soap all that is needed. It will wash large quantities of elothes (no matter how soiled) perfeetly elean in 6 minutes. Impossible to injure the most delicate fabrics.

\section{MACHINEFULS IN 4 HOURS.}

Chicago, July $13,1900$.

Last week I started to wash with your 1900 Ball-Bearing Washer. A neighbor saw me wasl wy little boys' waists (which were terribly dirty) and we were both surprised to see there was not a spot left. On Mnnday we did a bic wash of 15 machinefuls and the work was done in 4 hours. It is the best machine I ever saw (and I have tried many.) It works so easy that my little boy can run it. Mrs. A. H. Centrer, 636 Diversey Boulevard,

\section{WASHING EASY AT 81 YEARS OLD.}

Wherler, S. Dak., Aug. 30, '99.

I am more than pleased with the 1900 washer. Last week ny mother, an old lady 81 years helped ine do my washing. She sat on a chair and did a large 2 weeks wash with ease, and as she said, without even perspiring and it was 90 in the shade. Mrs. B. F. REYNolds.

\section{NO LONGER PREJUDICED.}

North Hudson, Wis., Jan. 27, 1900.

Enclosed please find P. O. order. My wife is very much pleased with the washer. This speaks volumes for it, owing to her being PREJUDICED against all washers. All who have seen it think it the best and easiest washing machine they have ever seen.

C. Williams.

Write at once for catalogue and full particulars.

"I900" WASHER CO. 315 G State St., BINGHAMTON, N. Y. 


\section{A NEW INVENTION! Big Money}

BIG WAGES musTi

Write for Special offer to Men and Women, at home or trav. agents for HA RRISON's BLU, all or part time, showing, taking orders and appointing without Radiator attachment for heating. Wonderful invention. Just out. Noth. ing elee like it. Splendid for Cooking and Heating We want Agents, Salesmen and Managers in every State. Biggest || 1 Write for catalogue-Most Wonderful Stove ever Invented. SL

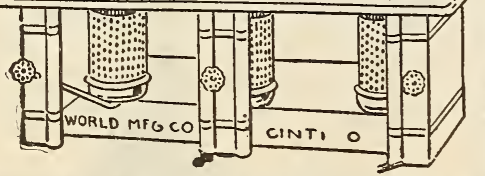
common coal oil. No wick, dirt, smoke, kindling, ashes. Splendid for cooking. Makes fine Heating Stove for rooms, stores, offices, with Radiator attachment.

BHEAPEST AND SAEEST FUE 10 to 20 o week ohould furnich Fuel Gas for amall famils for ing. A gallon of Kerosene oil costing $8 \mathrm{c}$ to $10 \mathrm{c}$ will furnish Fuel Gas for a constant blue flame, hottest fire, for about eighteen hours.

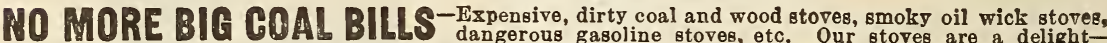
Dill not explode, simple, easilgerous gasoline stoves, etc. Our stoves are a delight-last for years. All sizes. PRICES, $\$ 3.00$ UP.

Write to-day for Catalogue FREN. ALSO FOIR S PECHAL OFIER, NBW PLAN, ETC. Address, WORLD MANUFACTURINC CO., 5267 WORLD BUILDING, CINGINNATI, OHIO:

\section{SEEDS, PLANTS, ROSES,}

Bulbs, Vines, Shrubs, Fruit and Ornamental Trees

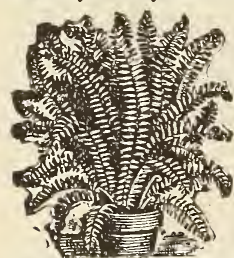

The best by 49 years test, 1,000 acres, 40 in hardy roses. 44 greenhouses of Palms, Ferns, Ficus, Geraniums, Everblooming Roses and other things too numerous to mention, Seeds, Plants, Roses, Etc., by mail postpaid, safe ar. rival and satisfaction guaranteed. Elegant 168 page catalogne free send for it and see what values we give for a little money: a number of cheap collections of Seeds, Plants, Trees, Etc., offered which will interest you.

\section{THE STORRS \& HARRISON CO., BOX 100 . PAINESVILLE, OHIO.}

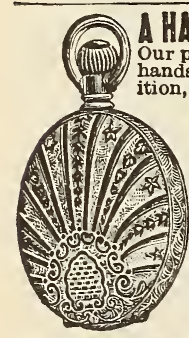
AHANOSOME WATCH GVER AVAY premium watch has a GOLD laid case, prol, dust proor, adjusted to pospatent escapement, expansion balance quick train, and is a highly finished and remarkable watch. We guarantee it, and with proper care it should wear and give satisfaction for 20 years. The movement is an American make, and you can rely upon it that when you own one of these truly handsome watches you will always have the correct time in your possession. Do you want g your possession. Do you want a it Free as a premium to anyone for sell. ing 20 cases of our everlasting Perfum. ery at 5c, each. Simply send your name and address and we will send you the Perfumery postpaid. When sold send us the One Dollar. and we will forward you the handsome watch. We trust you and will take back all you cannot sell. We purpose to give away these watches simply to advertise our business. give away these watches simply to advertise our business.
dddress, W. S. SIMPSON, NEW YORK CITY.

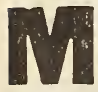
painless home treatment, endorsed and used by sufficient to convince you, sent FREE, with book of testr. monia s sealed. Correspondence Confidential.

OPA SPECIAL'Y CO., Dept. 59, San Antonio, Teras.
(Concluded from page 17 )

mer, this fall I brought it in the house, set it in a window in a warm room where it gets a few rays of morning sun. It is a fine healthy plant, the leaves are fifteen inches tall and three inches wide and it begins to droop in a graceful shape over the pot. The pretty green color of the leaves is refreshing to look at and it presents a beautiful sight when watered, the water standing on the leaves like dew drops on the grass on a summer morning.

CARRIE A. LARUE.

Vest Virginia.

[ The Boston fern is certainly one of the most valuable and welcome acquisitions of recent years. Watch it carefully, as it becomes large and the center dense and thick, that it harbors no scale insects, for they soon ruin the best specimens ].

FIGHTING THE SCALE.

Perhaps there is no one who grow's plants as I do. From the middle of June until the middle of September I keep all the buds picked off the geranium and water just enough to keep them living. In September I remove the top soil, replacing it with fresh soil, and they grow and bloom through the winter and spring.

(Concluded on page 19) 
(Concluded from page 18)

My plants are full of bloom at this time. Let me give my experience with the scale. I fought scale all one summer on my oleander. The next spring I was discouraged to find it as full as ever. I placed it in the open ground where the sun could shine on it all day and it did not take long to scorch off the leaves. I took it up, gave it fresh soil and put it in the shade. It soon began to grow and I have never seen a scale since.

\section{Texas.}

\section{L. Eichelberger.}

[ It is to be admitted that scale insects are most pernicious foes to plant life. The treatment accorded your oleander seems rather severe and almost as hard on the plant as the insects. Why not try scrubbing the plant with whale-oil soap? ]

\section{ANSWERS TO INQUIRIES.}

Mrs. C. E. MCCONNELl-A friend tells me that "insect powder" will destroy black ants on roses and chrysanthemums. I have never tried it for ants, but I have used it for lice on my tuberose and it will not hurt the plants.

\section{Miss Eliza Day.}

Mrs. McConnell-Try common granulated red pepper spread around your (Concluded on page 20)

\section{$33 \%$ DIVIDEND}

paid by the Mexican Plantation Association, 1602 Title and Trust Building, Chicago, Ill, Oldest of its kind in Mexico. ESTABLISHED 1897. Has 6,000 shares, or acres, planted to permanent crops, rubber, coffee and va. nilla. The Association's contract is like an insurance policy-in case of death the money is refunded. 38 deaths have occured since 1897. These shares will now be resold. For full particulars, address as above.

\section{MAKES RENS LAY \\ Tegive 10 days' free trial, no money in adrance, on Mann's New Model Bone Cutter. You prove on your own premises that it turns easier and F. W. Outs faster than any other. Catalogue free.

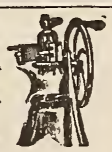
Our handsome Garden Annual and Seod Catalogue. Send your address on a postal to-day, or for $4 c$. in stamps and the names of 3 neighbors who are actual seed buyers we will send our catalogue and packet of the Clant Rod, Madam Porrot PANS COIE'S SEED STORE, Pella, Iowa.

\section{Drunkards}

\section{Cured Secretly.}

\section{A Home Gure Which Any Lady Can Give Secretly That Will Posi- tively Stop Driaking,}

\section{TRIAL PACKAGE MAILED FREE.}

An odorless and tasteless remedy when put in the drunkard's coffee or food will destroy all desire for drink. This remedy is so simple that

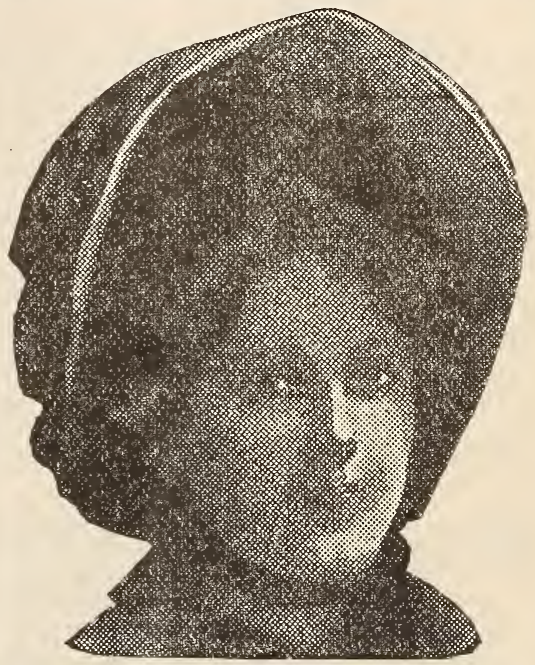

The Noted Salvation Army Worker Says: I

Think the World Owes a Debt of Gratitude to Dr. Haines, the Discoverer of Golden Specific.

anyone can use it and the drunkard need nerer know why he quit drinking in toxicating liquors.

It is a physical impossibility for anyone to drink intoxicating liquors and take this medicine.

If anyone desires to try this marvelous remedy, Dr. J. W. Haines, 297 Glenn Building. Cincinnati, Ohio, will gladly send a free trial package that they may see how easily it can be used and how positive its effect is.

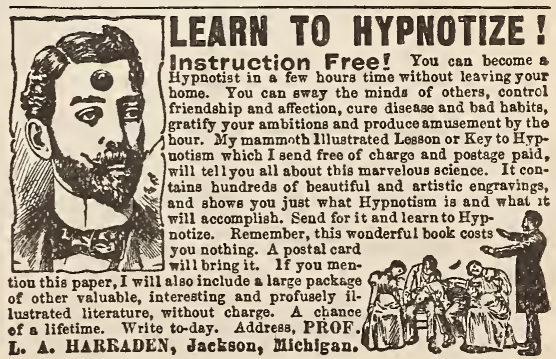




\section{Catarrh, \\ Foul Breath.}

If You Continuaily K'hawk and Spit And There is a Constant Dripping

From the Nose into the Throat, If You Have Foul, Sickening Breath, That is Catarrh.

\section{Large Trial Package Free-Quickly Cures.}

Any person having catarrh always has a bad breath. The sense of smell and taste are nearly always totally destroyed in time so that the person who has catarrh does not realize how loathsome their disease is. They continue theil. K'hawking-K'haw kıng and spittıng and spitting about promiscuously until they are shunned by everyone, and the sight of them is enough to make a well person sick.

Gauss' Catarrh Cure gives wonder'iul relief, especially in those chronic cases where the mucus drops down the throat and lungs, sicken ing the stomach, and leads to many diseases, including Consumption.

Catarrh is a deep-seated disease, and local applications, inhalations, sprays, ointments or salves will do no good. A large trial package mailed free that will convince you. Send name and address at once to C. F. Gauss, 926 Main St., Marshall, Mich.

\section{OTHEPS YOUR, CHㅐLDREN MOTHERS

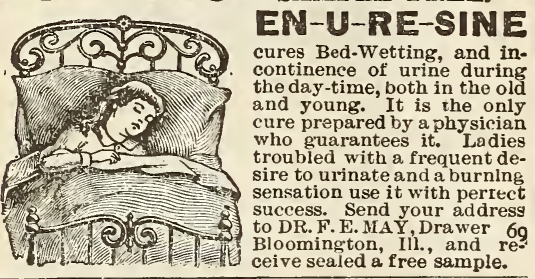

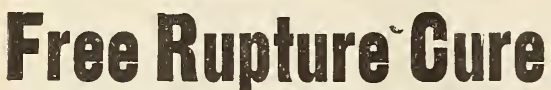

If ruptured write to Dr. W. S. Rice, 1556 Main St., Adams, N. Y., and he will send free a trial of his wonderful method. Whether skeptical or not get this free method and try the remarkable invention that cures without pain, danger. operation or detention from work. Write to-day. Don't wait.

50,000 TRIAL BOXES FREE CHAMBARD'S TEA ours Constipation

Biliousness, Sick Head-Ache, Eczemas. It cleanses the Bowels, regulates the Liver, the Bladder and the Kidneys, clears the Complexion and restores Health. Strength and Vigor. Palatable, no atter-effects, no fatigue of the Stomach. I'on't delay, write to-day for a free trial box. Legoll's Pharmacy, 286 Seventh Ave., New York.

COMPLEXION BULBS removes wrinkles. Victoria Protectors and other rubber goods for ladies; stain? for circulars, H. D. Dettra, $3471 / 2$ S. High St., Columbus, O
(Concluded from page 19)

'mums and roses and the black ants will trouble you no more.

B. P. Gilliate-Avoid transplanting your palm too much, give it good drainage, keep clean of scale, wash the leaves with a little sweet milk added to warm, soft water, place it where it gets a little sun and much light.

Mrs. HASKEL-You can winter tender roses in a cold frame covered with evergreen boughs and a light straw covering placed on these, the cold frame, of course, has to be covered with a glass sash, giving on warm sunny days an occasional airing.

DiAmond Flower-Ionopsidium, better known as diamond flower, can be had from any good seed house. I will gladly give more information about it to those readers of THE FLOR.L WORLD who enclose a stamp for an answer.

Wisconsin. Rev. F. P. Franke.

INQUIRIES.

Will you tell me how to rid soil of little white worms and flies?

Pennsylvania.

M. PERLE.

[ IVe suppose that you refer to wire worms in the soil and to plant-lice or possibly manure-flies. Better dump out the affected soil and repot the plants, or drench the soil with lime-water. Manure-flies will do no harm. If it is the aphis or plant-lice dust the plants well with snuff or tobacco dust, when the foliage is moist. Keep the plants out of the sun while the snuff is on the foliage.]

I want a hedge of something which is a rapid grower and will be green winter and summer. What shall I get and where shall I get it ? Mrs. Thos. Hester.

South Carolina.

[ The best and prettiest plant for this purpose would be the California privet. This may be obtained of any nurseryman.]

How shall I make my tuberose bloom? I obtained a blooming-size bulb but it has never bloomed.

\section{Missouri. \\ Miss Eliza Day.}

[ Better try a new bulb. Tuberoses are sometimes stubborn, or have bloomed before being sold.] 


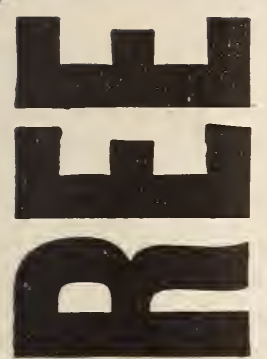

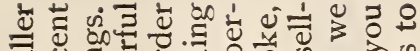
을. 可

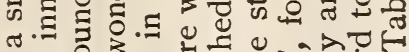

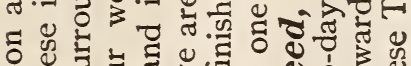

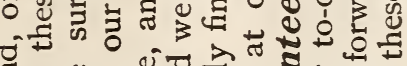

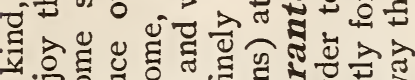

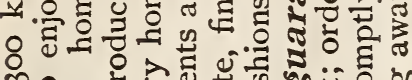

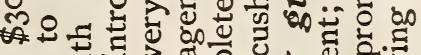
ช 곡 인 웜. สี

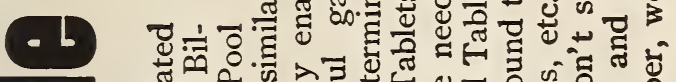

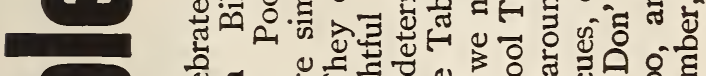

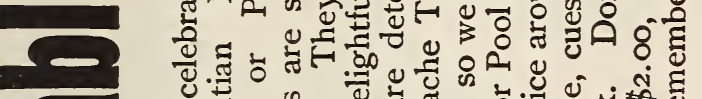

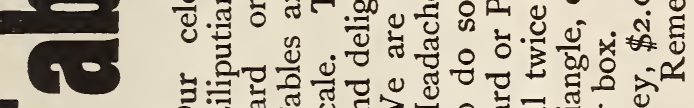

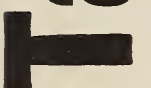

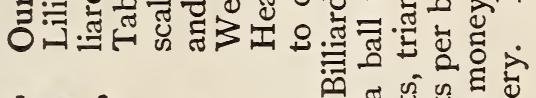
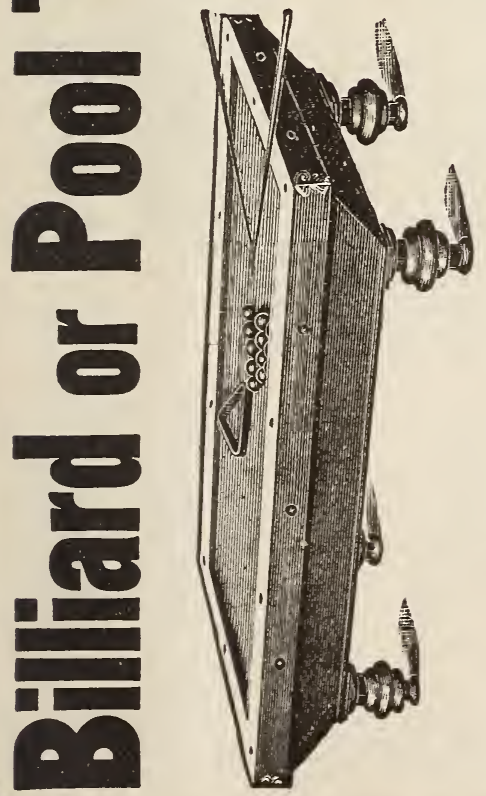

a

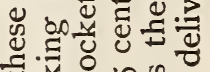

$\therefore$ 늘

ฮี่

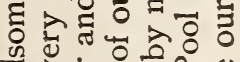

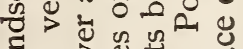

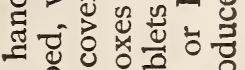

द्व

赵

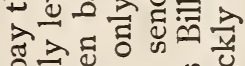

월

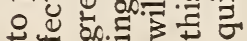

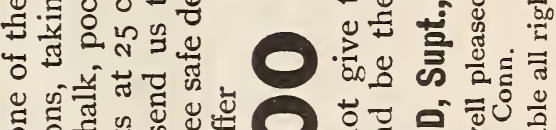

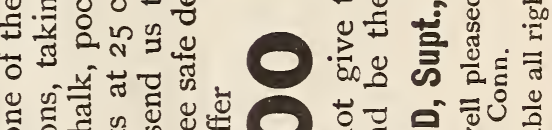

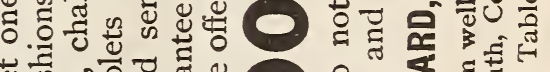

๘

ส

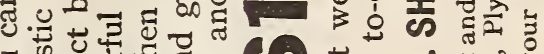

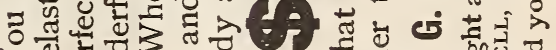

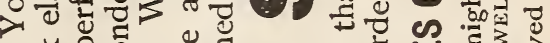

ว

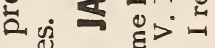

ปี

ชู่ \&ै \&

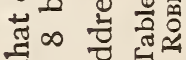

령

तo

క.

윰 


\section{Man's Mission on Earth}

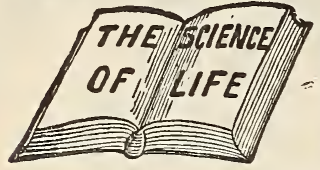

\section{KNOW THYSELF!}

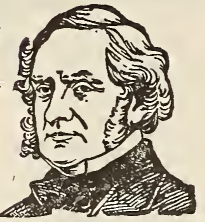

Do you wish to know the Physiology and Morale of Marriage and healthy offspring?

Do you wish to be successful in All Undertakings in life?

Do you wish to know the history, cause and cure of the most insidious diseases that sitp the citadel of life?

Do you wish to recover from Exhausted

Vitality, Nervous and Physical Debility?

Do you wish to be powerful, healthy, happy and respected by both sexes?

Do you wish to know the most Vital Truths concerning the Physical and Mental acumen of perfect Manhood?

If so, inclose $\$ 1$ for the Best Medical Work of this or any age, the Gold Medal Prize Treatise, entitled

The Science of Life, or Self Preservation, $370 \mathrm{pp}$.; cloth, full gilt, with engravings and prescriptions; by mail sealed in plain package. More than a Million copies gold! Write for it to-day. It is the secret key to Health and Happiness. Send 6 cents now for Know Thyself Manual, a Vade Mecum Brochure, sealed, to men only. Address

\section{THE PEABODY MEDICAL INSTITUTE,}

No. 4 Bulfinch St., opposite Revere House, Boston, Mass., the oldest and best in this country, established in 1860. Skill and experience. Fxpert Treatment and Positive Cure are the lasting attributes that have made this institute famous throughout this country and Europe. Consultation by letter or in person, 9 to 6 . Sundays, 10 to 1, with the author and samous Nervo specialist, graduate of Harvard Medical College, clasw 1864.

FDITOR'S NOTE For 40 years the Peabody LITh $N$ IL. Medical Institute has been a fixed fact, and it will remain so. It is as standard as American Gold.

MT The Peabody Medical Institute has many imitators, but no equals.-Boston Herald.

\section{TO WOMEN WHO DREAD MOTHERHOOD!}

\section{Information How They May Give Birth to Happy, Healthy Children Absolutely} Without Pain-sent Free.

No woman need any longer dread the pains of child-birth; or remain childless. Dr. J. H. Dye has devoted his life to relieving the sorrows of women. He has proved that all pain at childbirth may be entirely banished, and he will gladly tell you how it may be done absolutely free of charge. Send your name and address to Dr. J H. Dye, Box 137 Buffalo, N. Y., and he will send you, postpaid, his wonderful book which tells how to give birth to happy, healthy children, absolutely without pain; also how to cure sterility. Do not delay but write to-day.

\section{SOME SUCCESSFUL EXPERIMENTS}

Late in February the past year some dahlia tubers were sent me unexpectedly, so the only thing to do was to immediately plant them in the open ground. The bed was spaded about twenty inches and a good layer of manure from the horse stable put in ; over this some soil and then the tubers which were covered with soil, then a layer of the manure, then soil to the top. That was all that was done for them except staking in the summer. They grew five feet high and blossomed from July sixth until frost came. A good way to protect seeds sown in the open ground or plants just set out is to make several frames of lath any size desired and cover with newspapers or cheap muslin; newspapers can be renewed often and the frames last for years. To keep track of each plant I write the name or initial letters in insignificant letters on the pot of each plant or bulb. For outdoor labels I use short surips of tin, marking the name deeply. They are everlasting, or nearly so.

\section{Ohio.}

Annice Bodey Calland.

[ The most durable out-door labels that you could use would be strips of zinc. Write plainly the name of the plant with lead pencil. Try a few of these and see how lon\& hey will last.]

\section{RAISE YOUR OWN PLANTS.}

In March I sowed seeds for chrysanthemums, heliotropes, cineraria, carnations and geraniums. I took my soil from beneath my currant bushes, sifted it in a shallow box and smoothed it nicely, then sowed my seeds and sprinkled a very little soil over them. I laid a piece of cloth over them, sprinkled it with water and kept the soil moist and in a warm

(Concluded on page 24)

\section{EVERY LADY READ THIS.}

Years ago when I was suffering, an old nurse told me of a wonderful cure for Leucorrhea, Displacements, Painful Periods, Uterine and Ovarian troubles. It cured me in one month. It is a simple harmless lotion that can be prepared by any one having the recipe. I will send it Feee to every suffering sister who writes to me. Address Mrs. A. L. Hudnut, South Bend, Ind. 


\section{FREE TO WEAK MEN}

\section{A Discovery of a Remedy has been made that Restores Lest Man- hood and Gives Man the Vitality of a Lion.}

\section{One Week's Trial Package Sent Free To All Men Who Write For It.}

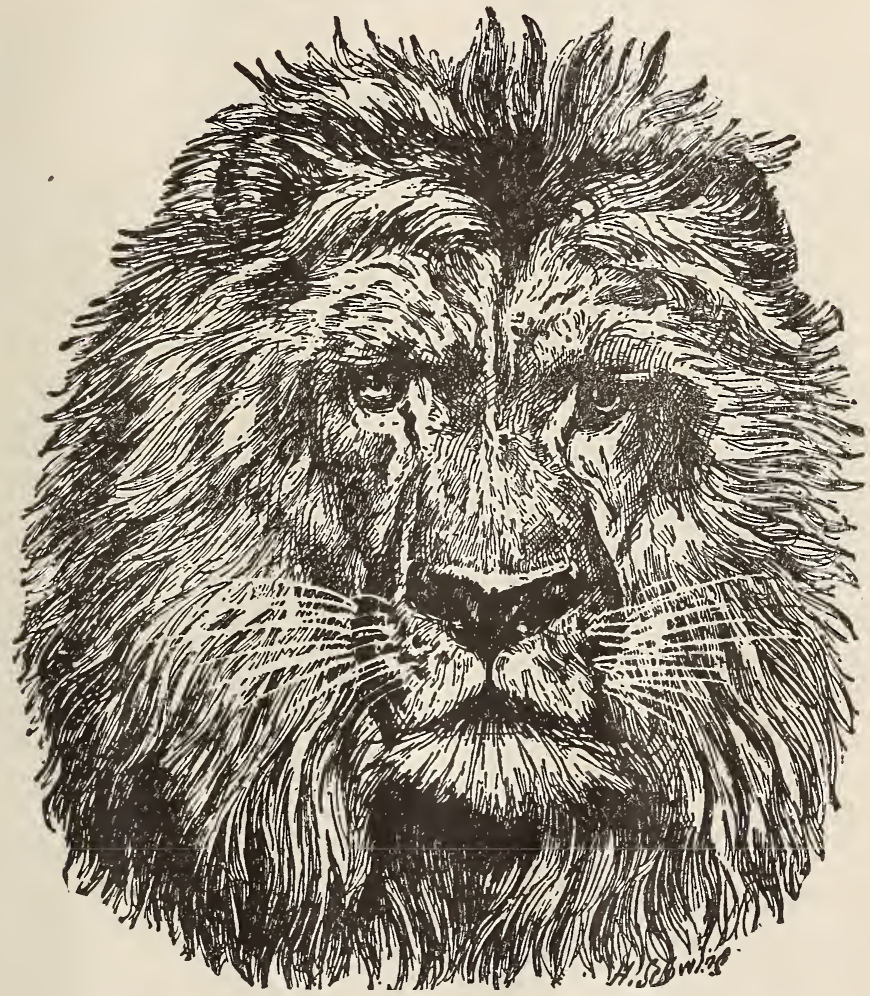

Regenerative Tablets is the only recognized positive and permanent cure for Lost Manhood in all its forms and stages.

It is scientifically prepared by the best chemists in the world. The reputation of the institution is such, that all physicians know when they stand sponsor for a remedy, that remedy must be exaculy as represented. And when upon their reputation they make the statement that Regenerative Tablets will cure all cases of Lost Manhood, Spermatorrhœa, Varicocele or weakness of any nature of the nerve or sexual organs, a cure must be positive and permanent. This Company will send every person who is suffering from nervous dis. eases a week's treatment absolutely free. There is but one test of a genuine medicine and that is the results which are obtained by its use; if it cures the disease for which it is prepared it is a true remedy. This is the test by which the Fallopia Lynn Co. wish their one week free treatment to be tried, After using Regenerative Tablets one week the sufferer will find new vigor in his organs; new force in his muscles; new blood in his veins; new ambition; a new man in vitality, health and appearance. Regenerative Tablets has a peculiarly grateful effect and the patient feels the beneflt after its flrst day's use. It goes direct to the seat of the trouble, no matter of how long standing giving strength and development where it is needed. This marvelous remedy banishes all feellngs of bashfulness toward the opposite sex; cures all the ills and troubles that come from early abuse, excess or overwork and business cares, all of which result in premature loss of strength and memory, emissions, impotency and varicocele. Regenerative Tablets will effect a cure at any age, there is no case that it will not cure permanently except where epilepsy or insanity has already been reached. Fallopia Lynn Co. makes no restrictions, very person who writes will be sent a week's treat ment absolutely free and postpaid, carefully wrapped in a plain package with no advertising on it to indicate what it contains. They have recelved thousands of letters from people all over the country telling of the most astonishing cures made by Regenerative Tablets. Their one week free offer is genuine, and no embarrassing questions asked. Write today to the Fallopia Lynn Co.,428 Pozzon I Building, St. Louis, Mo, and receive the week's treatment free; their book which is aleo free and sent $w i t h$ the free treatment will explain how to take the treatmentin private and cure yourself at home. 


\section{APOWERFUL HEALER}

Sick Made Well. Weak Made Strong.

\section{Heals the Sick by the Marvelous Curative Power of His World- Famous Magnetic Remedies.}

\section{Asks No Pay For His Medicines Until You Are Satisfied. No.Cure, No Pay.}

If you are sick and in need of help here it is. There is no question but that all manner of Chronic Diseases can be cured by these truly marvelous remedies ana the beauty of it is, you do not need to pay on cent for the medicine until you are satistied with results.

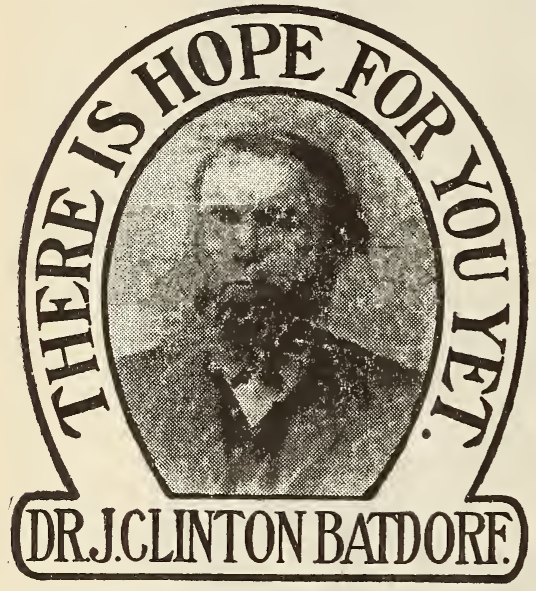

We find that, by the use of his Magnetic Remedies, Dr. Batdorf is absolutely curing all forms and kinds of Rheumatism, Dyspepsia, Catarrh, Dropsy, Liver trouble, Constipation, Kidney disease, Bladder troubles, Lost Vitality, Nervous Exhaustion, Nervous Spells or Fits, Asthma, Coughs, Bronchitis and first stages of Consumption, Neuraliga of the Nerves or Muscles, Paralysis, chronic or periodical Headaches, Blood Poison, Eczema, or Salt Rlieum, Old Sores, Ulcers. etc. All Skin Disease, Heart Disease, Female Troubles, Nervous Debility, etc. It matters not what the disease is or of how long standing, or who or what may have failed to cure. If the disease is there, it is quite evident that the Magnetic Remedies have never been used Do not waste time on "trial treatments" that last but a few days, fail to cure and tell nothing; but write at once to Dr. Batdorf, tell him just how you suffer and get a FULL MONTH'S TREATMENT of his wonderful Magnetic Remedies and pay when satisfied. They are truly wonderful remedies that can stand a test like this, but Dr. Batdorf has had 30 years' experience in the medical fields and knows what he is about. He has cured thousands who failed to find relief elsewhere and SAVED hundreds of others from PAINFUL OPERATIONS, after being told that the knife was the only cure. Those who wish to try a month's treatment should write the Dr. through his medical institute as follows: Address your letter to Magnetic Medical Institute, 36 Porter, Grand Rapids, Mich., and he will give you his personal attention. All communications are held in strictest confidence. WRITE TO-DAY.
(Concluded from page 22.)

place until the plants were up. I then removed them to a window where they could get sun and light. I watched carefully that they did not dry out. I did not sow all kinds in the same box, for some come up sooner than others. When the plants were large enough I transplanted them into another box. Cigar boxes are excellent as they are handy and take but little room. When the plants were an inch high I put them in tin cans, the size used for cove oysters, which are large enough and much better than the earthen pots, as they do not dry out so soon. Sprinkle the plants daily to keep them healthy and prevent the red spiders attacking them.

Iowa.

Mrs. S. SurLs.

\section{VIOLET CULTURE.}

I have beautiful house plants which make my home cheerful and pretty, but my chief pleasure is in my "violet bed." In our back yard I have a hot-bed about six feet long and two feet wide filled with these little plants. Violets are very little trouble and can be planted in moderately rich soil, either in the spring or fall. Spring is the best time for planting, for, if well watered through the summer, they will spread and give one a very full bed by fall. The hot-bed once made and your trouble is over. They need no water through the winter, but should have sun for half the day. The frame can easily be made of boards, or a box with the bottom removed, and covered with glass. A covering of some kind should be banked around the box to protect the plants. from frost. When the winter is not too severe blossoms may be picked on Christmas day. In February and March they will bloom profusely. Thin them out in the spring. Lillie E. Schapker.

Indiana.

[One of the main points to keep in mind in violet culture is to obtain only perfectly healthy plants. The newer single sorts such as the Prince of Wales, California, etc., will give better satisfaction than the older double ones 7 . 


\section{ONITY \\ 174 SQUARE INCHES LIMEN

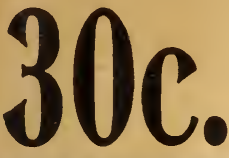 \\ AND LAGE MATFRIALS AND \\ THE FLORAL WORLD OHE YEAR}

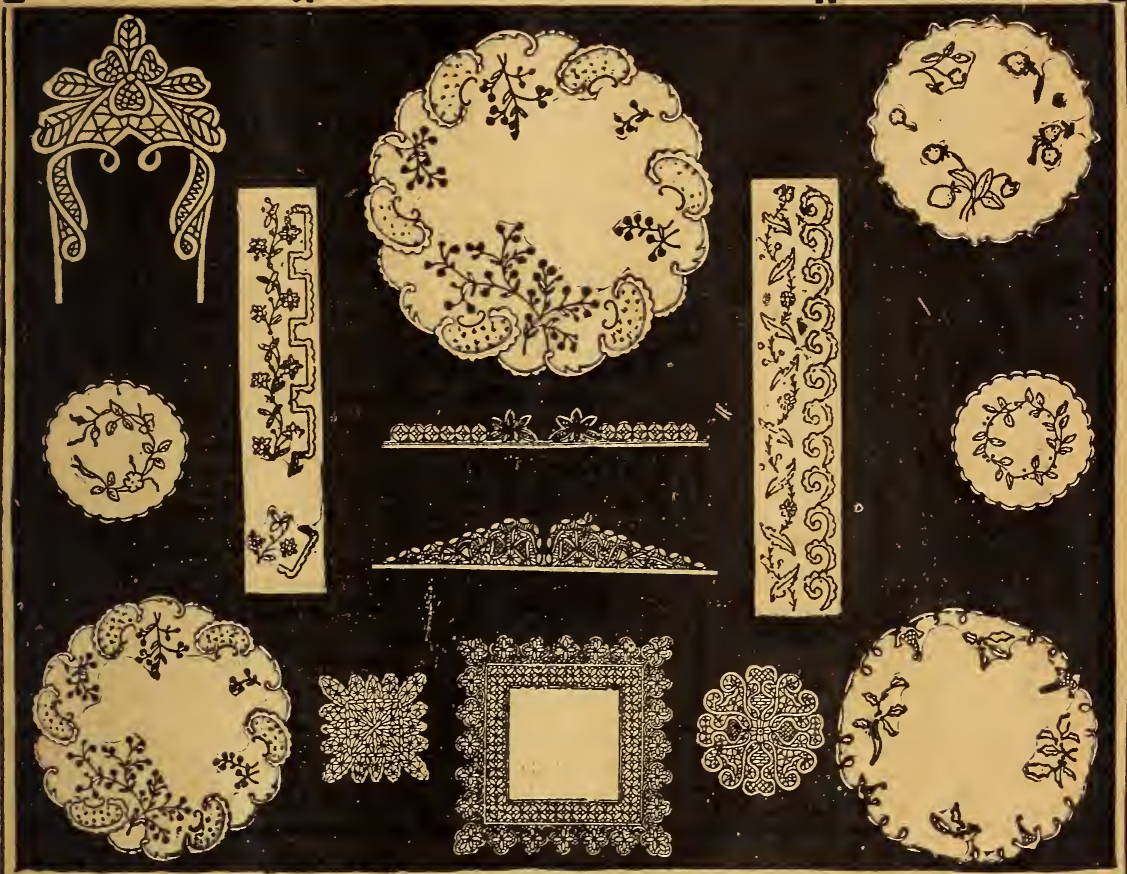

\section{Beautiful}

\section{This Colleotion of $\equiv$}

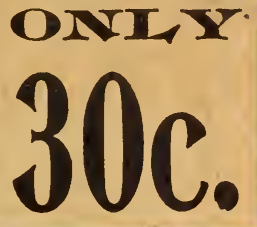

And contains the following articles, every one of which is plainly stamped on a good quality of material. Equal in every way to the material for which you pay a much higher price at the stores
I Holly-berry Centerpiece
I Forget-Me-Not Centerpiece
I Strawberry Doilie
I Rose Doilie
I Forgot-Me-Not Doilie
I Maiden-Hair Doilie
I Linen Collar
I Linen Collar, different design

Battenberg Designs as Follows:
I Lace Handkerchief
I Tie End
2 Latest turn-over Collars
2 Large Doilies

\section{Pieces in all-774 Square Inches}

This beautiful combination of designs and material and THE FLORAL WorLD for a whole year will be mailed, postpaid, to anyone remitting us only 30 cents. Or send us a club of three subscribers who accept the above offer and we will mail you the complete combination as your reward. Order by Premium Number and address

\section{Publishers THE FLORAL WORLD, SPRINGFIELD, OHIO.}




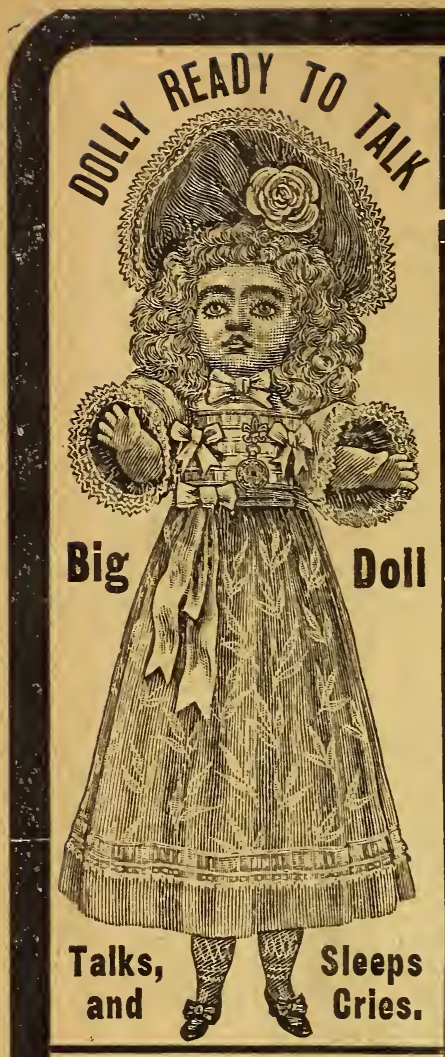

Latest Wonder makers' art

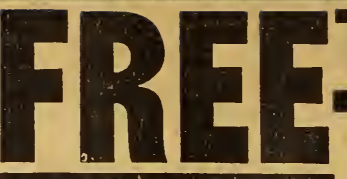
TALKING

THE most wonderful and newest production of the doll

sleeps and cries like a real live bakers art. Talks, one=half yard tall. A big and lovely beauty doll with movable bisque head, long natural curly hair, pearly teeth, sleeping eyes, fancy colored lace trimmed dress, hat, real tan shoes, open work (red, blue or black) stockings, underwear, etc., dressed complete from top to toe.

GIRLS, do you desire to receive this big and handsome Talking and Sleeping Doll Baby free of all cost, for a little work after school hours? If so, write us at once and we will mail you twenty fast selling and useful articles for ladies' and gentlemen's wear, to dispose of at only ten cents each. When sold, remit us the money $(\$ 2.00)$ and we will forward to your address, by mail, postage prepaid, carefully packed in strong corrugated mailing boxes, this wonderful, mechanical, Talking and Sleeping Doll, as described in this advertisement. Order twenty articles at once and address,

TALKING DOLL WORKS, 92 TALKING DOLL BUILDING, BRIDGEWATER, - - CONN.

EXTRA PRESENT.-This handsomely engraved Aluminum Silver Bracelet, together with a pretty Doll Chatelaine, are all given free as Extra Presents (in addition to the doll) for making prompt remittance.

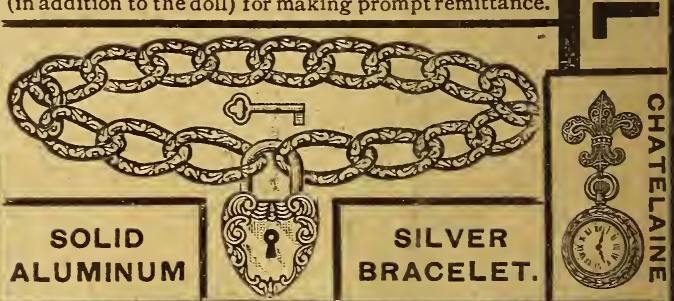

ONE-HALF
YARD TALL

Gentlemen: I received the Talking and Sleeping Doll, and found it to be as you said. It talks, sleeps and cries. I thank you also for the Extra Presents, which surprised me.

All who have seen the doll think she is a perfect beauty. I hope I will be able to help you introduce your goods again. I am,

Respectfully yours,

INEZ JOHNSON,

HANDSOMELY DRESSED

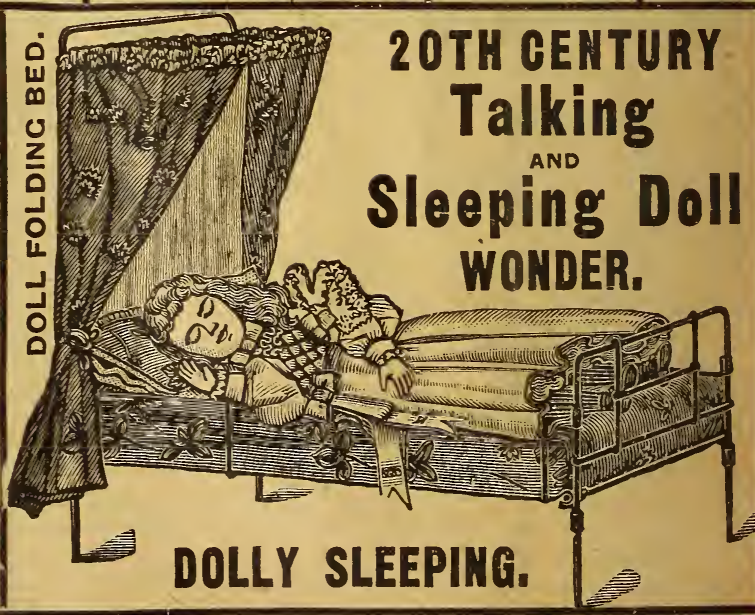

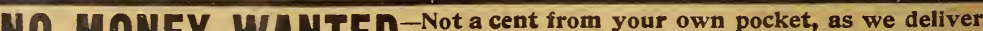

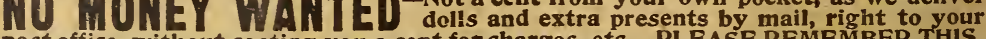
post office, without costing you a cent for charges, etc. PLEASE REMEMBER THIS. 




LINDERY 1903

$$
1903
$$




\section{LIBRARY OF CONGRESS}

||||||||||||||||||||||||||||||||||||||||||||||||||||||||||||||||||||

00014588681 